

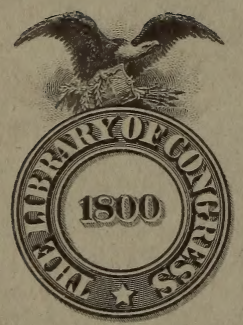




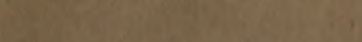

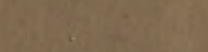
B.

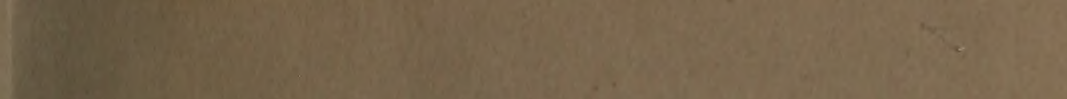

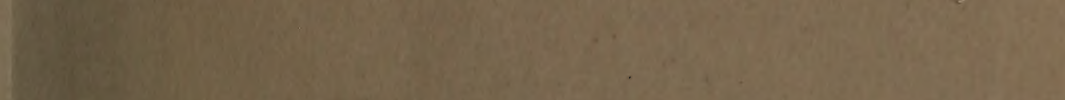

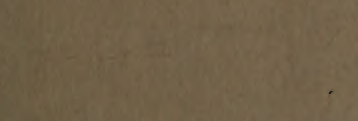

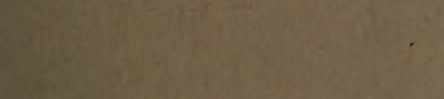

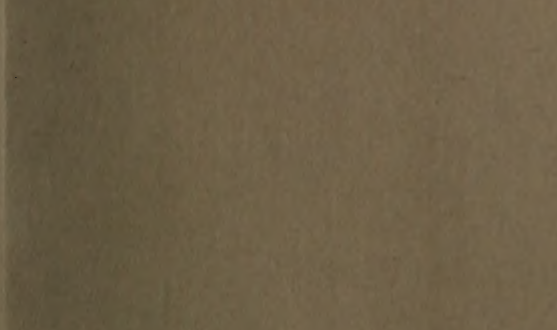

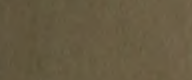

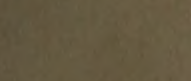

$3 x^{2}+y^{3}=$

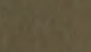

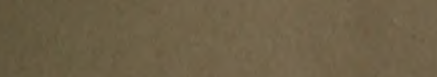

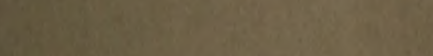

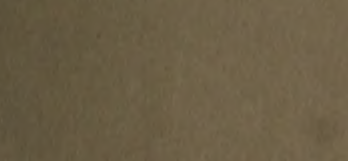

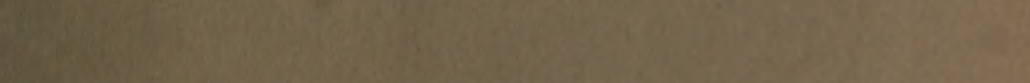

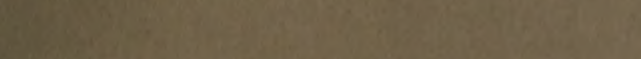

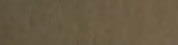

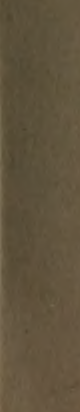
63

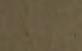

withy

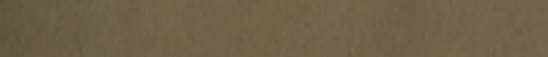

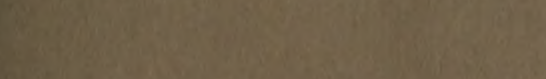

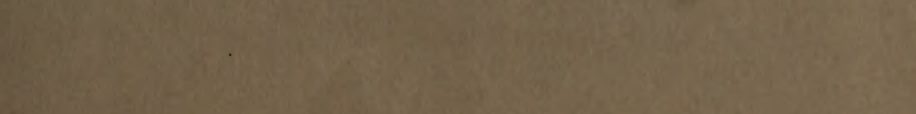

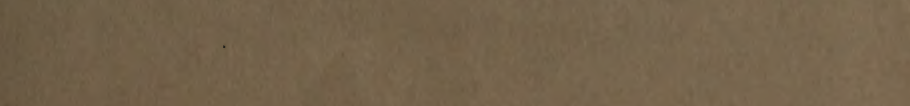

16. 



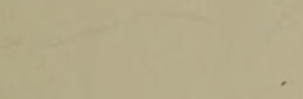






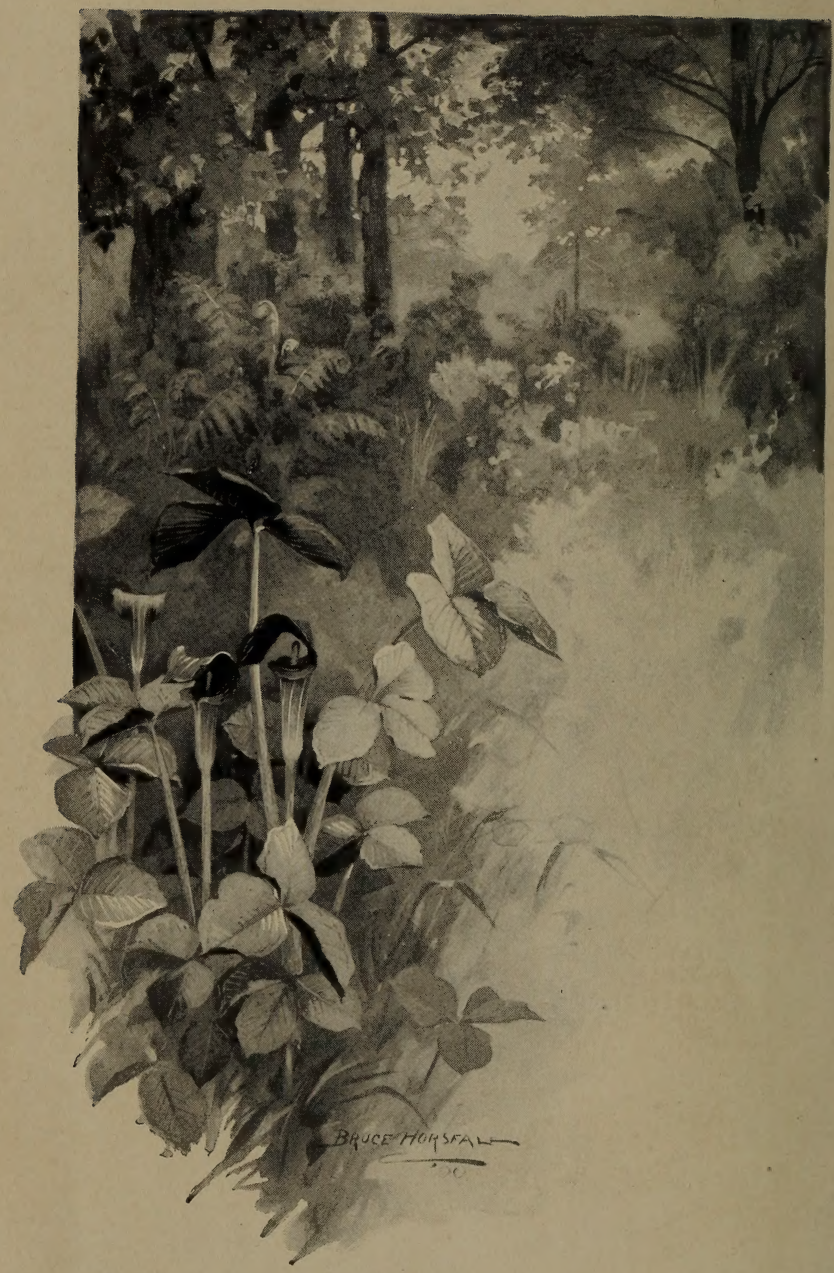

Frontispiece. - A Shade Plant, Jack-in-the-Pulpit 


\section{FOUNDATIONS OF BOTANY}

BY

JOSEPH Y. BERGEN, A.M.

Instructor in Biology, English High School, Boston

BOSTON, U.S.A.

GINN \& COMPANY, PUBLISHERS

Tbe Atbenæum press

1901 


\section{6}

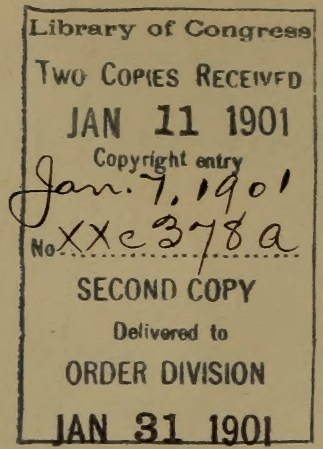

COPYRIGHT, 1901, BY JOSEPH Y. BERGEN

ALL RIGHTS RESERVED 


\section{PRE F A E}

THIs book is written upon the same plan as the author's Elements of Botany. A few chapters stand here but little altered from the former work, but most of them have been rewritten and considerably enlarged, and many new ones have been added. The principal changes in the book as a whole are these :

1. Most of the discussion of ecological topics is put by itself, in Part II.

2. The amount of laboratory work on the anatomy and physiology of seed-plants is considerably increased and additional experiments are introduced.

3. The treatment of spore-plants is greatly extended, so as to include laboratory work on the most important groups.

4. The meagre Flora which accompanied the earlier book has been replaced by one which contains fairly full descriptions of nearly seven hundred species of plants. Most of these are wild, but a considerable number of cultivated species have been included, mainly for the convenience of schools in large cities.

Ample material is offered for a year's course, four or five periods per week. The author is well aware that most schools devote but half a year to botany, but the tendency sets strongly toward allowing more time for this subject. Even in schools where the minimum time allowance is devoted to botany, there is a distinct advantage in being provided with a book which allows the teacher considerable option as regards the kind and amount of work which he shall offer to his classes. 
Suggestions are made in the teacher's Handbook, which accompanies this volume, in regard to shaping half-year courses.

The latest authorities in the various departments of botany have been consulted on all doubtful points, and the attempt has been to make the book scientifically accurate throughout, yet not unduly difficult.

Most of the illustrations have been redrawn from those in standard German works of an advanced character, or drawn from nature or from photographs, expressly for this book. Besides the sources of drawings acknowledged in the author's Elements, many cuts have been taken from the botanies of Frank, Prantl, Detmer, Murray, and Bennett and Murray, as well as from Schimper's Pflanzengeographie.

Of the drawings from nature or from photographs, some figures, and Plates I, VII, and VIII, are by Mr. Edmund Garrett of Boston; several figures, the Frontispiece, and Plates II, IV, X, XI, are by Mr. Bruce Horsfall of New York ; several figures are by Mr. F. Schuyler Mathews of Boston; a large number of figures and Plate $\mathrm{V}$ are by Mr. E. N. Fischer of Boston; several figures are by Mr. E. R. Kingsbury of Boston and Dr. J. W. Folsom of the University of Illinois.

Thanks for the use of photographs are due to Mr. H. G. Peabody of Boston (Fig. 234), to Mr. J. H. White of Boston (Figs. 32, 75, 222), to Professor Conway MacMillan of the University of Minnesota (Frontispiece), and to Professor F. V. Coville of Washington (Plate VII). Figs. 28 and 275 are taken by permission from the Primer of Forestry, issued by the Division of Forestry, U. S. Department of Agriculture. Figs. 263, 264, 276 are copied by permission from Professor W. J. Beal's Seed Dispersal, and Figs. 226, 229, 233 from Professor W. M. Davis's Physical Geography. Fig. 269 is from a photograph by Professor C. F. Millspaugh of the Field Columbian Museum, Chicago. 
Most of the redrawn illustrations (not microscopical) from various European sources are by Mr. Fischer. Most of the microscopical ones (and a number of figures from nature) are by Dr. J. W. Folsom of the University of Illinois, and many of both classes are by Mr. Mathews. Thanks are due to Professor J. M. Holzinger of the Winona (Minn.) State Normal School, to Professor L. Murbach of the Detroit High School, and to Mr. I. S. Cutter of Lincoln, Nebraska, for their many discriminating criticisms of the proof of Parts I and II. Mr. Samuel F. Tower of the Boston English High School, Professor Charles V. Piper of the Washington State Agricultural College, and Dr. Rodney H. True, Lecturer on Botany at Harvard University, have all read the whole or large portions of Part I and given valuable suggestions. Professor IV. F. Ganong, of Smith College, has read and criticised Part II.

The chapters on spore-plants, excepting a small amount of matter retained from the Elements of Botany, are entirely the work of Mr. A. B. Seymour of the Cryptogamic Herbarium of Harvard University.

The author has attempted to steer a middle course between the advocates of the out-of-door school and of the histological school of botany teaching. He has endeavored never to use a technical term where he could dispense with it, and on the other hand, not to become inexact by shunning necessary terms. In deciding questions of this sort, a priori reasoning is of little value; one must ascertain by repeated trials how much of a technical vocabulary the average beginner in botany can profitably master. The teacher who has discovered that not one of the boys in a division of thirty-six pupils knows that his own desk-top is of cherry wood may well hesitate about beginning his botany teaching with a discourse on centrospheres and karyokinesis. It has been assumed throughout this book that, other things being equal, the knowledge is of 
most worth which touches the pupil's daily life at the most points, and therefore best enables him to understand his own environment. On the other hand, the author has no sympathy with those who decry the use of apparatus in botany teaching in secondary schools and who would confine the work of their pupils mainly within the limits of what can be seen with the unaided eye. If the compound microscope plainly reveals things shown only imperfectly by a magnifier and not seen at all with the naked eye, - use the microscope! If iodine solution or other easily prepared reagents make evident the existence of structures or substances not to be detected without them, - then use the reagents ! No one thinks of denying a boy the use of a spyglass or a compass for his tramps afield or his outings in a boat because he has not studied physics. No one would refuse to let an intelligent boy or girl use a camera because the would-be photographer had not mastered the chemical reactions that follow upon the exposure of a sensitized plate. Yet it is equally illogical to defer some of the most fascinating portions of botanical study until the college course, to which most never attain. When the university professor tells the teacher that he ought not to employ the ordinary appliances of elementary biological investigation in the school laboratory because the pupils cannot intelligently use them, the teacher is forced to reply that the professor himself cannot intelligently discuss a subject of which he has no personal knowledge. The pupils are deeply interested; they prove by their drawings and their recitations that they have seen a good way into plant structures and plant functions; then why not let them study botany in earnest?

$$
\text { J. Y. B. }
$$

CAmbridge, January, 1901. 


\section{CONTENTS}

\section{PART I}

STRUCTURE, FUNCTIONS, AND CLASSIFICATION OF PLANTS

CHAPTER I

PAGES

The Seed and its Germination . . . . . . 5-13

CHAPTER II

Storage of Food in the Seed . . . . . . 14-24

CHAPTER III

Moreyents, Detelopyent, And Morphology of the Seedlivg 25-35

CHAPTER IV

Rоотs . . . . . . . . . 36-61

CHAPTER V

Stems . . . . . . . . . $62-82$

CHAPTER VI

Structure of the Stem . . . . . . . . 83-102

CHAPTER VII

Livivg Parts of the Stem, Work of the SteM . . . 104-118

CHAPTER VIII

Beds 
LEAVES

\section{CHAPTER $\mathrm{X}$}

Leaf-Arrangement for Exposure to Sun and Air; Movements of Leaves aNd Shoots . . . . . . . 140-149

\section{CHAPTER XI}

Minute Structure of Leaves; Functions of Leaves. . 150-177

$$
\text { CHAPTER XII }
$$

Protoplasm and its Properties . . . . . . . . 178-185

\section{CHAPTER XIII}

Inflorescence, or Arrangement of Flowers on the Stem 186-191

$$
\text { CHAPTER XIV }
$$

The Study of Typical Flowers . . . . . . . 192-196

\section{CHAPTER XV}

Plan and Structure of the Flower and its Organs

\section{CHAPTER XVI}

True Nature of Floral Organs; Details of their Structure; Fertilization . . . . . . . . . 208-216

\section{CHAPTER XVII}

The Study of Typical Fruits

CHAPTER XVIII

The Fruit

CHAPTER XIX 
Types of Cryptogais; Thallophytes . . . . . 235-276

\section{CHAPTER XXI}

Types of Cryptogays; Bryophytes

\section{CHAPTER XXII}

Types of Cryptogans; Pteridophytes . 286-297

CHAPTER XXIII

The Evolutionary History of Plants . . 298-305

\section{PART II}

ECOLOGY, OR RELATIONS OF PLANTS TO THE WORLD ABOUT THEM

CHAPTER XXIV

Plant Societies . $307-323$

CHAPTER XXV

Botanical Geography . . . . . . . . 324-335 CHAPTER XXVI

Parasites, Enslaved Plants, Messuates, Carnivorous Plants 336-344

\section{CHAPTER XXVII}

How Plants Protect themselves from Animals . . 345-352 
CHAPTER XXVIII

Ecology of Flowers
PAGES

. $3532-372$

\section{CHAPTER XXIX}

How Plants are Scattered and Propagated . . . . 373-386

\section{CHAPTER XXX}

The Struggle for Existence and the Survival of the Fittest 


\section{LIST OF PLATES}

Frontispiece. Jack-in-the-pulpit, a typical shade-plant, with large, thin leaves.

Plate I. Sand-dunes with sea rye grass. Deep-rooted, with extensively running rootstocks .

Plate II. Pollarded willows, showing growth of slender twigs from adventitious buds . . . . . . . . .

Plate III. Japanese ivy, a tendril-climber growing on face of a building, showing leaves all exposed to sunlight at the most

- advantageous angle . . . . . . . . .

Plate IV. Cypress swamp, showing "Spanish moss" (Tillandsia), a phanerogamic epiphyte practically leafless, the work ordinarily done by leaves devolving on the slender stems. The cypress trees are furnished with "knees" or projections from the roots, which are thought by some to absorb air . . . . . .

Plate V. Indian pipe, a saprophytic seed-plant, wholly destitute of chlorophyll and with scales instead of foliage leaves . . 168

Plate VI. Fan palms, showing general habit of the tree, and large projecting bases of old petioles left after the decay of the leaves 176

Plate VII. A tree yucca in the Mohave Desert, a characteristic xerophytic tree. Other sparse desert vegetation is also shown . 316

Plate VIII. Belt of trees along a Nebraskan river, showing dependence of forest on water supply . . . . . . . . . . 334

Plate IX. Cottonwood. Tree largely overgrown with American mistletoe, near Mesilla, New Mexico. The photograph was taken in winter, when the tree was leafless, so that all the foliage shown is that of the mistletoe

Plate X. Humming-bird visiting flowers of the trumpet creeper. This is one of the best North American examples of a flower mainly pollinated by birds .

Plate XI. Asters and golden-rods, Compositæ, illustrating the principle of grouping many small flowers into heads (and in the golden-rod the heads into rather close clusters) to facilitate the visits of insects. 



\section{FOUNDATIONS OF BOTANY}

\section{INTRODUCTION}

"Botany is the science which endeavors to answer every reasonable question about plants." 1

ThE plant is a living being, provided generally with many parts, called organs, which it uses for taking in nourishment, for breathing, for protection against its enemies, and for reproducing itself and so keeping up the numbers of its own kind. The study of the individual plant therefore embraces a variety of topics, and the examination of its relation to others introduces many more subjects.

Morphology, or the science of form, structure, and so on, deals with the plant without much regard to its character as a living thing. Under this head are studied the forms of plants and the various shapes or disguises which the same sort of organ may take in different kinds of plants, their gross structure, their microscopical structure, their classification, and the successive stages in the development of the individual plant.

Plant Physiology treats of the plant in action, how it lives, breathes, feeds, grows, and produces others like itself.

Geographical Distribution, or botanical geography, discusses the range of the various kinds of plants over the

1 Professor George L. Goodale. 
earth's surface. Another subdivision of botany, usually studied along with geology, describes the history of plant life on the earth from the appearance of the first plants until the present time.

Systematic Botany, or the classification of plants, should naturally follow the examination of the groups of seedplants and spore-plants.

Plant Ecology treats of the relations of the plant to the conditions under which it lives. Under this division of the science are studied the effects of soil, climate, and friendly or hostile animals and plants on the external form, the internal structure, and the habits of plants. This is in many respects the most interesting department of botany, but it has to be studied for the most part out of doors.

Many of the topies suggested in the above outline cannot well be studied in the high school. There is not usually time to take up more than the merest outline of botanical geography, or to do much more than mention the important subject of Economic Botany - the study of the uses of plants to man. It ought, however, to be possible for the student to learn in his high-school course a good deal about the simpler facts of morphology and of vegetable physiology. One does not become a botanist - not even much of an amateur in the subject - by reading books about botany. It is necessary to study plants themselves, to take them to pieces and make out the connection of their parts, to examine with the microscope small portions of the exterior surface and thin slices of all the variously built materials or tissues of which the plant consists. All this can be done with living specimens or with those taken 
from dead parts of plants that have been preserved in any suitable way, as by drying or by placing in alcohol or other fluids which prevent decay. Living plants must be studied in order to ascertain what kinds of food they take, what kinds of waste substances they excrete, how and where their growth takes place and what circumstances favor it, how they move, and indeed to get as complete an idea as possible of what has been called the behavior of plants.

Since the most familiar and most interesting plants spring from seeds, the beginner in botany can hardly do better than to examine at the outset the structure of a few familiar seeds, then sprout them and watch the growth of the seedlings which spring from them. Afterwards he may study in a few typical examples the organs, structure, and functions of seed-plants, trace their life history, and so, step by step, follow the process by which a new crop of seeds at last results from the growth and development of such a seed as that with which he began.

After he has come to know in a general way about the structure and functions of seed-plants, the student may become acquainted with some typical cryptogams or sporeplants. There are so many groups of these that only a few representative ones can be chosen for study. 



\section{PART I}

\section{STRUCTURE, FUNCTIONS, AND CLASSIFI- CATION OF PLANTS}

\section{CHAPTER I}

\section{THE SEED AND ITS GERMINATION}

1. Germination of the Squash Seed. - Soak some squash seeds in tepid water for twelve hours or more. Plant these about an inch deep in damp sand or pine sawdust or peat-moss in a wooden box which has had holes enough bored through the bottom so that it will not hold water. Put the box in a warm place (not at any time over $70^{\circ}$ or $80^{\circ}$ Fahrenheit), ${ }^{1}$ and cover it loosely with a board or a pane of glass. Keep the sand or sawdust moist, but not wet, and the seeds will germinate. As soon as any of the seeds, on being dug up, are found to have burst open, sketch one in this condition, ${ }^{2}$ noting the manner in which the outer seed-coat is split, and continue to examine the seedlings at intervals of two days, until at least eight stages in the growth of the plantlet have been noted. ${ }^{3}$

${ }^{1}$ Here and elsewhere throughout the book temperatures are expressed in Fahrenheit degrees, since with us, unfortunately, the Centigrade scale is not the familiar one, outside of physical and chemical laboratories.

2 The student need not feel that he is expected to make finished drawings to record what he sees, but some kind of careful sketch, if only the merest outline, is indispensable. Practice and study of the illustrations hereafter given will soon impart some facility even to those who have had little or no instruction in drawing. Consult here Figs. 9 and 89.

${ }^{3}$ The class is not to wait for the completion of this work (which may, if desirable, be done by each pupil at home), but is to proceed at once with the examination of the squash seed and of other seeds, as directed in the following sections, and to set some beans, peas, and corn to sprouting, so that they may be studied at the same time with the germinating squashes. 
Observe particularly how the sand is pushed aside by the rise of the young seedlings. Suggest some reason for the manner in which

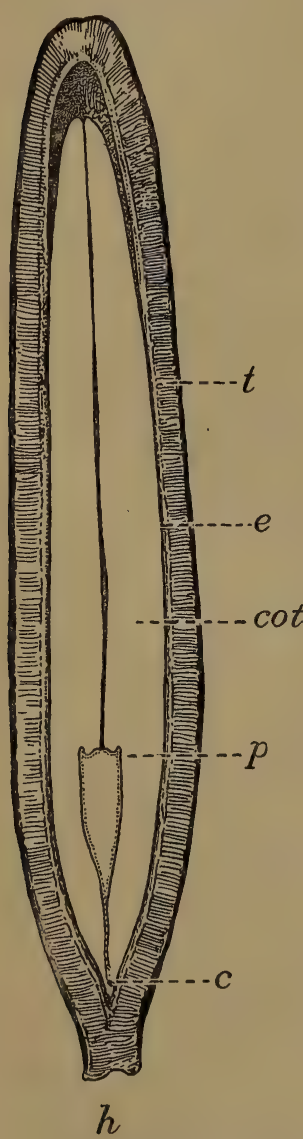

FIG. 1. - Lengthwise Section of a Squash Seed. (Magnified about five times.) the sand is penetrated by the rising stem.

2. Examination of the Squash Seed. Make a sketch of the dry seed, natural size. Note the little scar at the pointed end of the seed where the latter was attached to its place of growth in the squash. Label this hilum.

Note the little hole in the hilum; it is the micropyle, seen most plainly in a soaked seed. (If there are two depressions on the hilum the deeper one is the micropyle.)

Describe the color and texture of the outer coating of the seed. With a scalpel or a very sharp knife cut across near the middle a seed that has been soaked in water for twentyfour hours. Squeeze one of the portions, held edgewise between the thumb and finger, in such a way as to separate slightly the halves into which the contents of the seed is naturally divided. Examine with the magnifying glass the section thus treated, make a sketch of it, and, label the shell or covering of the seed and the kernel within this.

Taking another soaked seed, chip away the white outer shell, called the testa, and observe the thin, greenish inner skin (Fig. $1, e)$, with which the kernel of the seed is closely covered. ${ }^{1}$

Strip this off and sketch the uncovered kernel or embryo. Note that at one end it tapers to a point. This pointed portion, known as the hypocotyl, will develop after the seed sprouts into the stem of the plantlet, like that shown at $c$ in Fig. 2. Split the halves of the kernel entirely apart from each other, 
noticing that they are only attached for a very little way next to the hypocotyl, and observe the thickness of the halves and the slight unevenness of the inner surfaces. These halves are called seed-leaves or cotyledons.

Have ready some seeds which have been soaked for twenty-four hours and then left in a loosely covered jar on damp blotting paper at a temperature of $70^{\circ}$ or over until they have begun to sprout.

Split one of these seeds apart, separating the cotyledons, and observe, at the junction of these, two very slender pointed objects, the rudimentary leaves of the plumule or first bud (Fig. 1, p).

3. Examination of the Bean. - Study the seed, both dry and after twelve hours' soaking, in the same general way in which the squash seed has just been examined. ${ }^{1}$

Notice the presence of a distinct plumule, consisting of a pair of rudimentary leaves between the cotyledons, just where they are joined to the top of the hypocotyl. In many seeds (as the pea) the plumule does not show distinct leaves. But in all cases the plumule contains the growing point, the tip of the stem from which all the upward growth of the plant is to proceed.

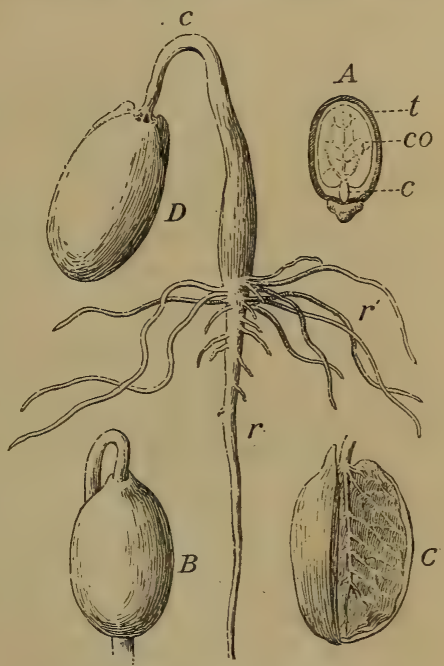

FIG. 2. - The Castor Bean and its Germination.

$A$, longitudinal section of ripe seed : $t$, testa ; $c o$, cotyledon ; $c$, hypocotyl; $B$, sprouting seed covered with endosperm; $C$, same, with half of endosperm removed; $D$, seedling; $r$, primary root; $r$, secondary roots; $c$, arch of hypocotyl.

Make a sketch of these leaves as they lie in place on one of the cotyledons, after the bean has been split open.

1 The larger the variety of bean chosen, the easier it will be to see and sketch the several parts. The large red kidney bean, the horticultural bean, or the lima bean will do well for this examination. 
Note the cavity in each cotyledon caused by the pressure of the plumule and of the hypocotyl.

4. Examination of the Pea. - There are no very important points of difference between the bean and pea, so far as the structure of the seed is concerned, but the student should rapidly dissect a few soaked peas to get an idea of the appearance of the parts, since he is to study the germination of peas in some detail.

Make only one sketch, that of the hypocotyl as seen in position after the removal of the seed-coats. ${ }^{1}$

5. Germination of the Bean or the White Lupine, the Pea, and the Grain of Corn. - Soak some beans or lupine seeds as directed in Section 3 , plant them, ${ }^{2}$ and make a series of sketches on the same general plan as those in Fig. 9.

Follow the same directions with some peas and some corn. In the case of the corn, make six or more sketches at various stages to illustrate the growth of the plumule and the formation of roots; first a main root from the base of the hypocotyl, then others more slender from the same region, and later on still others from points higher up on the stem (see Fig. 15). The student may be able to discover what becomes of the large outer part of the embryo. This is really the single cotyledon of the corn (Fig. 6). It does not as a whole rise above ground, but most of it remains in the buried grain, and acts as a digesting and absorbing organ through which the endosperm or food stored outside of the embryo is transferred into the growing plant, as fast as it can be made liquid for that purpose.

6. Germination of the Horse-Chestnut. - Plant some seeds of the horse-chestnut or the buckeye, study their mode of germination, and observe the nature and peculiar modifications of the parts.

Consult Gray's Structural Botany, Vol. I, pp. 19, 20.

\section{Conditions Requisite for Germination. - When we} try to enumerate the external conditions which can affect

1 The teacher will find excellent sketches of most of the germinating seeds described in the present chapter in Miss Newell's Outlines of Lessons in Botany, Part I.

2 The pupil may economize space by planting the new seeds in boxes from which part of the earlier planted seeds have been dug up for use in sketching, etc. 
germination; we find that the principal ones are heat, moisture, and presence of air. A few simple experiments will show what influence these conditions exert.

8. Temperature. - Common observation shows that a moderate amount of warmth is necessary for the sprouting of seeds. Every farmer or gardener knows that during a cold spring many seeds, if planted, will rot in the ground. But a somewhat exact experiment is necessary to show what is the best temperature for seeds to grow in, and whether variations in the temperature make more difference in the quickness with which they begin to germinate or in the total per cent which finally succeed.

\section{EXPERIMENT I}

Relation of Temperature to Germination. - Prepare at least four teacups or tumblers, each with wet soft paper packed in the bottom to a depth of nearly an inch. Have a tightly fitting cover over each. Put in each vessel the same number of soaked peas. Stand the vessels with their contents in places where they will be exposed to different, but fairly constant, temperatures, and observe the several temperatures carefully with a therrmometer. Take pains to keep the tumblers in the warm places from drying out, so that their contents will not be less moist than that of the others. The following series is merely suggested, - other values may be found more convenient. Note the rate of germination in each place and record in tabular form as follows:

No. of seeds sprouted in 24 hrs. $48 \mathrm{hrs} .72 \mathrm{hrs} .96 \mathrm{hrs}$. etc.

At $32^{\circ}$,
At $50^{\circ}$,
At $70^{\circ}$,
At $90^{\circ}$,

1 For the exact regulation of the temperatures a thermostat (see Handbook) is desirable. If one is available, a maximum temperature of $100^{\circ}$ or over should be tried. 
9. Moisture. - What was said in the preceding section in regard to temperature applies also to the question of the best conditions for germination as regards the supply of moisture. The soil in which seeds grow out of doors is always moist; it rests with the experimenter to find out approximately what is the best amount of moisture.

\section{EXPERIMENT II $^{1}$}

Relation of Water to Germination. - Arrange seeds in several vessels as follows:

In the first put blotting paper that is barely moistened; on this put some dry seeds.

In the second put blotting paper that has been barely moistened; on this put seeds that have been soaked for twenty-four hours.

In the third put

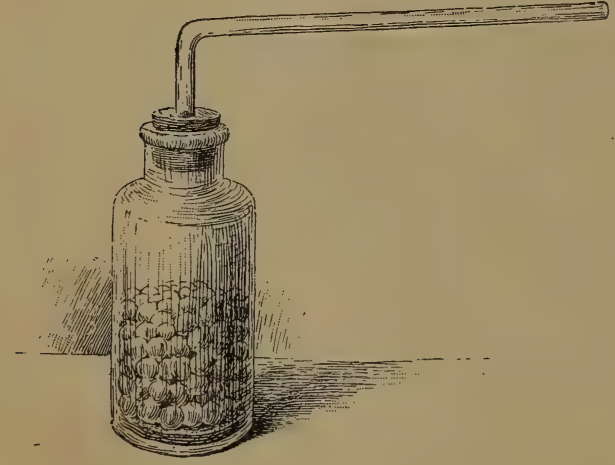

FrG. 3. - Soaked Peas in Stoppered Bottle, ready for Exhaustion of Air. water enough to soak the paper thoroughly; use soaked seeds.

In the fourth put water enough to half cover the seeds.

Place the vessels where they will have same temperature and note the time of germination.

Tabulate your results as in the previous experiment.

10. Relation of the Air Supply to Germination. - If we wish to see how soaked seeds will behave with hardly any air supply, it is necessary to place them in a bottle arranged

1 This may be made a home experiment. 
as shown in Fig. 3, exhaust the air by connecting the glass tube with an air-pump, which is then pumped vigorously, and seal the tube while the exhaustion is going on. The sealing is best done by holding a Bunsen flame under the middle of the horizontal part of the tube. A much easier experiment, which is nearly as satisfactory, can, however, be performed without the air-pump.

\section{EXPERIMENT III}

Will Seeds Germinate well without a Good Supply of Air?Place some soaked seeds on damp blotting paper in the bottom of a bottle, using seeds enough to fill it three-quarters full, and close tightly with a rubber stopper.

Place a few other seeds of the same kind in a second bottle; cover loosely.

Place the bottles side by side, so that they will have the same conditions of light and heat. Watch for results, and tabulate as in previous experiments.

Most seeds will not germinate under water, but those of the sunflower will do so, and therefore Exp. III may be varied in the following manner:

Remove the shells carefully from a considerable number of sunflower seeds. ${ }^{1}$ Try to germinate one lot of these in water which has been boiled in a flask to remove the air, and then cooled in the same flask. Over the water, with the seeds in.it, a layer of cottonseed oil about a half inch deep is poured, to keep the water from contact with air. In this bottle then there will be only seeds and air-free water. Try to germinate another lot of seeds in a bottle half filled with ordinary water, also covered with cotton-seed oil. Results?

11. Germination involves Chemical Changes. - If a thermometer is inserted into a jar of sprouting seeds, for

1 These are really fruits, but the distinction is not an important one at this time. 
instance peas, in a room at the ordinary temperature, the peas will be found to be warmer than the surrounding air. This rise of temperature is at least partly due to the absorption from the air of that substance in it which supports the life of animals and maintains the burning of fires, namely, oxygen.

The union of oxygen with substances with which it can combine, that is with those which will burn, is called oxidation. This kind of chemical change is universal in plants and animals while they are in an active condition, and the energy which they manifest in their growth and movements is as directly the result of the oxidation going on inside them as the energy of a steam engine is the result of the burning of coal or other fuel under its boiler. In the sprouting seed much of the energy produced by the action of oxygen upon oxidizable portions of its contents is expended in producing growth, but some of this energy is wasted by being transformed into heat which escapes into the surrounding soil. It is this escaping heat which is detected by a thermometer thrust into a quantity of germinating seeds.

\section{EXPERIMENT IV}

Effect of Germinating Seeds upon the Surrounding Air. - When Exp. III has been finished, remove a little of the air from above the peas in the first bottle. This can easily be done with a rubber bulb attached to a short glass tube. Then bubble this air through some clear, filtered limewater. Also blow the breath through some limewater by aid of a short glass tube. Explain any similarity in results obtained. (Carbon dioxide turns limewater milky.) Afterwards insert into the air above the peas in the same bottle a lighted pine splinter, and note the effect upon its flame. 
12. Other Proofs of Chemical Action. - Besides the proof of chemical changes in germinating seeds just described, there are other kinds of evidence to the same effect.

Malt, which is merely sprouted barley with its germination permanently stopped at the desired point by the application of heat, tastes differently from the unsprouted grain, and can be shown by chemical tests to have suffered a variety of changes. If you can get unsprouted barley and malt, taste both and see if you can decide what substance is more abundant in the malt.

Germinating kernels of corn undergo great alterations in their structure; the starch grains are gradually eaten away until they are ragged and full of holes and finally disappear.

13. The Embryo and its Development. - The miniature plant, as it exists ready formed and alive but inactive in the seed, is called the embryo. In the seeds so far examined, practically the entire contents of the seed-coats consist of the embryo, but this is not the case with the great majority of seeds, as will be shown in the following chapter. 


\section{CHAPTER II}

\section{STORAGE OF FOOD IN THE SEED}

14. Food in the Embryo. - Squash seeds are not much used for human food, though both these and melon seeds are occasionally eaten in parts of Europe; but beans and peas are important articles of food. Whether the material accumulated in the cotyledons is an aid to the growth of the young plant may be learned from a simple experiment.

15. Mutilated and Perfect Seedlings. - One of the best ways in which to find out the importance and the special

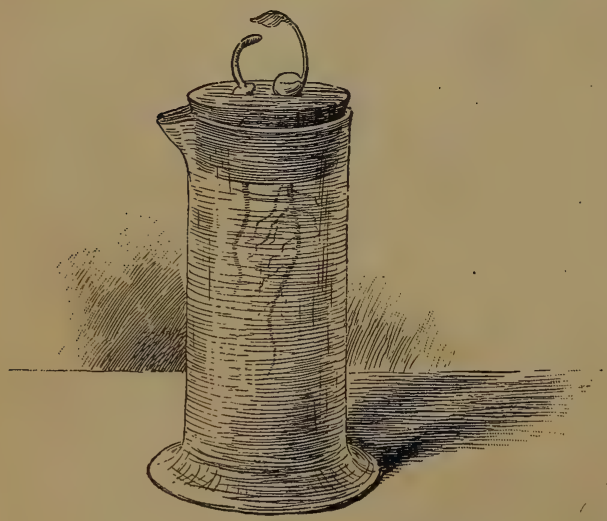

FrG. 4. - Germinating Peas, growing in Water, one deprived of its Cotyledons. use of any part of a plant is to remove the part in question and see how the plant behaves afterward.

\section{EXPERIMENT V 1}

Are the Cotyledons of a Pea of any Use to the Seedling? Sprout several peas on blotting paper. When the plumules appear, carefully cut away the cotyledons from some of the seeds. Place on a perforated cork, as shown in Fig. 4, one or two seedlings from 1 May be a home experiment. 
which the cotyledons have been cut, and as many which have not been mutilated, and allow the roots to extend into the water. Let them grow for some days, or even weeks, and note results.

16. Food stored in Seeds in Relation to Growth after Germination. - If two kinds of seeds of somewhat similar character, one kind large and the other small, are allowed to germinate and grow side by side, some important inferences may be drawn from their relative rate of growth.

\section{EXPERIMENT VI ${ }^{1}$}

Does the Amount of Material in the Seed have anything to do with the Rate of Growth of the Seedling ? - Germinate ten or more clover seeds, and about the same number of peas, on moist blotting paper under a bell-jar. After they are well sprouted, transfer both kinds of seeds to fine cotton netting, stretched across wide-mouthed jars nearly full of water. The roots should dip into the water, but the seeds must not do so. Allow the plants to grow until the peas are from four to six inches high.

Some of the growth in each case depends on material gathered from the air and water, but most of it, during the very early life of the plant, is due to the reserve material stored in the seed. Where is it in the seeds so far studied? Proof?

17. Storage of Food outside of the Embryo. - In very many cases the cotyledons contain little food, but there is a supply of it stored in the seed beside or around them (Figs. 2, 5, and 6).

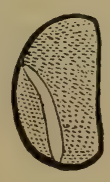

I

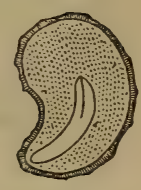

II

Fig. 5. - Seeds with Endosperm, Longitudinal Sections. I, asparagus (magnified). II, poppy (magnified).

18. Examination of the Four-o'clock Seed. - Examine the external surface of a seed ${ }^{2}$ of the four-o'clock, and try the hardness of 1 May be a home experiment. $\quad{ }^{2}$ Strictly speaking, a fruit. 
the outer coat by cutting it with a knife. From seeds which have been soaked in water at least twenty-four hours peel off the coatings and sketch the kernel. Make a cross-section of one of the soaked seeds which has not been stripped of its coatings, and sketch the section as seen with the magnifying glass, to show the parts, especially the two cotyledons, lying in close contact and encircling the white, starchy-looking endosperm. ${ }^{1}$

The name endosperm is applied to food stored in parts of the seed other than the embryo. ${ }^{2}$ With a mounted needle pick out the little almost spherical mass of endosperm from inside the cotyledons

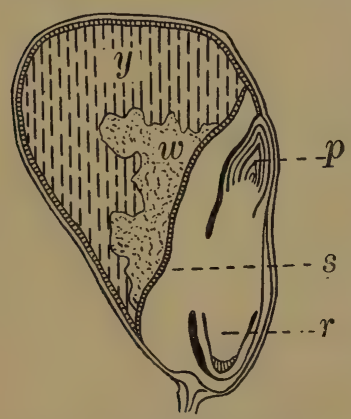

Fig. 6. - Lengthwise Section of Grain of Corn. (Magnified about three times.) $w$, white, starchy part of endosperm ; $p$, plumule ; $s$, the shield (cotyledon), in contact with the endosperm for absorption of food from it; $r$, the primary root. $y$, yellow, oily part of endosperm;

of a seed which has been deprived of its coats, and sketch the embryo, noting how it is curved so as to enclose the endosperm almost completely.

19. Examination of the Kernel of Indian Corn. - Soak some grains of large yellow field corn ${ }^{3}$ for about three days.

Sketch an unsoaked kernel, so as to show the grooved side, where the germ lies. Observe how this groove has become partially filled up in the soaked kernels.

Remove the thin, tough skin from one of the latter, and notice its transparency. This skin - the bran of unsifted corn meal — does not exactly correspond to the testa and inner coat of ordinary seeds, since the kernel of corn, like all other grains (and like the seed of the four-o'clock), represents not merely the seed, but also the seed-vessel in which it was formed and grew, and is therefore a fruit.

1 Buckwheat furnishes another excellent study in seeds with endosperm. Like that of the four-o'clock, it is, strictly speaking, a fruit; so also is a grain of corn.

2 In the squash seed the green layer which covered the embryo represents the remains of the endosperm.

${ }^{3}$ The varieties with long, flat kernels, raised in the Middle and Southern States under the name of "dent corn," are the best. 
Cut sections of the soaked kernels, some transverse, some lengthwise and parallel to the flat surfaces, some lengthwise and at right angles to the flat surfaces. Try the effect of staining some of these sections with iodine solution.

Make a sketch of one section of each of the three kinds, and label the dirty white portion, of cheesy consistency, embryo; and the yellow portions, and those which are white and floury, endosperm.

Chip off the endosperm from one kernel so as to remore the embryo free from other parts. ${ }^{1}$ Notice its form, somewhat triangular in outline, sometimes nearly the shape of a beechnut, in other specimens nearly like an almond.

Estimate what proportion of the entire bulk of the soaked kernel is embryo.

Split the embryo lengthwise so as to show the slender, somewhat conical plumule. ${ }^{2}$

20. Corn Seedlings deprived of Endosperm. - An experiment parallel to No. V serves to show the function and the importance of the endosperm of Indian corn.

\section{EXPERIMENT VII}

Of how much Use to the Corn Seedling is the Endosperm ? - Sprout kernels of corn on blotting paper. When they get fairly started, cut away the endosperm carefully from several of the seeds. Suspend on mosquito netting on the surface of water in the same jar two or three seedlings which have had their endosperm remored, and as many which have not been mutilated. Let them grow for some weeks, and note results.

21. Starch. - Most common seeds contain starch. Every one knows something about the appearance of ordi-

1 The embryo may be removed with great ease from kernels of rather mature green corn. Boil the corn for about twenty minutes on the cob, then pick the kernels off one by one with the point of a knife. They may be preserved indefinitely in alcohol of 50 or $75 \%$.

${ }^{2}$ The teacher may well consult Figs. 56-61, inclusive, in Gray's Structural Botany. 
nary commercial starch as used in the laundry, and as sold for food in packages of cornstarch. When pure it is characterized not only by its lustre, but also by its peculiar velvety feeling when rubbed between the fingers.

22. The Starch Test. - It is not always easy to recognize at sight the presence of starch as it occurs in seeds, but it may be detected by a very simple chemical test, namely, the addition of a solution of iodine. ${ }^{1}$

\section{EXPERIMENT VIII ${ }^{2}$}

Examination of Familiar Seeds with Iodine. - Cut in two with a sharp knife the seeds to be experimented on, then pour on each, drop by drop, some of the iodine solution. Only a little is necessary; sometimes the first drop is enough.

If starch is present, a blue color (sometimes almost black) will appear. If no color is obtained in this way, boil the pulverized seeds for a moment in a few drops of water, and try again.

Test in this manner corn, wheat (in the shape of flour), oats (in oatmeal), barley, rice, buckwheat, flax, rye, sunflower, four-o'clock, morning-glory, mustard seed, beans, peanuts, Brazil-nuts, hazelnuts, and any other seeds that you can get. Report your results in tabular form as follows :

MUCH StaRch

Color : blackish or

dark blue.
Little Starch

Color: pale blue or greenish.
No STARCH

Color : brown, orange, or yellowish.

23. Microscopical Examination of Starch. ${ }^{3}$ - Examine starch in water with a rather high power of the microscope (not less than 200 diameters).

1 The tincture of iodine sold at the drug-stores will do, but the solution prepared as directed in the Handbook answers better. This may be made up in quantity, and issued to the pupils in drachm vials, to be taken home and used there, if the experimenting must be done outside of the laboratory or the schoolroom.

2 May be a home experiment.

${ }^{3}$ At this point the teacher should give a brief illustrated talk on the construction and theory of the compound microscope. 
Pulp scraped from a potato, that from a canna rootstock, wheat flour, the finely powdered starch sold under the commercial name of "cornstarch" for cooking, oatmeal, and buckwheat finely powdered in a mortar, will furnish excellent examples of the shape and markings of starch grains. Sketch all of the kinds examined, taking pains to bring out the markings. ${ }^{1}$ Compare the sketches with Figs. 7 and 8.

With a medicine-dropper or a very small pipette run in a drop of iodine solution under one edge
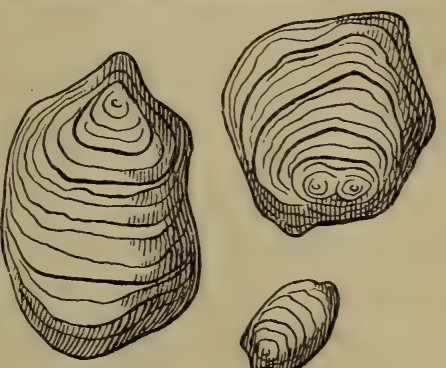

FIG. 7. - Canna Starch. (Magnified 300 diameters.) of the cover-glass, at the same time withdrawing a little water from the margin opposite by touching to it a bit of blotting paper.

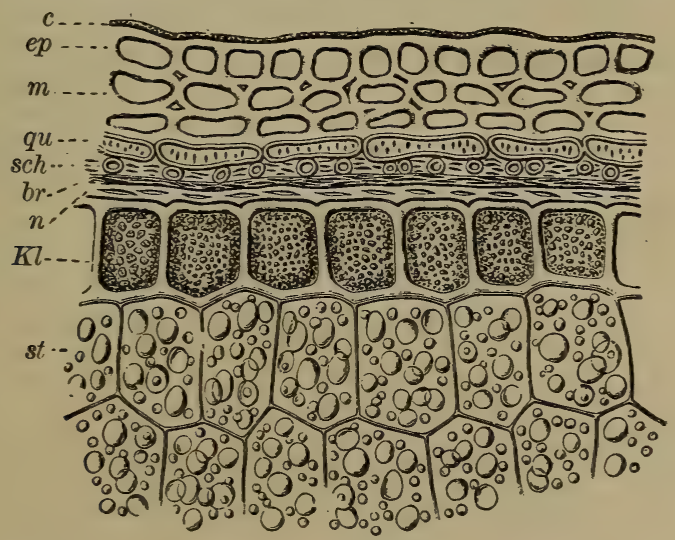

FIG. 8. - Section through Exterior Part of a Grain of Wheat.

$c$, cuticle or outer layer of bran ; ep, epidermis ; $m$, layer beneath epidermis ; $q u$, $s c h$, layers of hull next to seed-coats; $b r, n$, seed-coats ; $K l$, layer containing proteid grains ; st, cells of the endosperm filled with starch. (Greatly magnified.)

1 The markings will be seen more distinctly if care is taken not to admit too much light to the object. Rotate the diaphragm beneath the stage of the microscope, or otherwise regulate the supply of light, until the opening is found which gives the best effect. 
Examine again and note the blue coloration of the starch grains and the unstained or yellow appearance of other substances in the field. Cut very thin slices from beans, peas, or kernels of corn; mount in water, stain as above directed, and draw as seen under the microscope. Compare with Figs. 7 and $8 .^{1}$ Note the fact that the starch is not packed away in the seeds in bulk, but that it is enclosed in little chambers or cells.

24. Plant-Cells. - Almost all the parts of the higher plants are built up of little separate portions called cells. The cell is the unit of plant-structure, and bears something the same relation to the plant of which it is a part that one cell of a honeycomb does to the whole comb. But this comparison is not a perfect one, for neither the waxen wall of the honeycomb-cell nor the honey within it is alive, while every plant-cell is or has been alive. And even the largest ordinary honeycomb consists of only a few hundred cells, while a large tree is made up of very many millions of cells. The student must not conceive of the cell as merely a little chamber or enclosure. The living, more or less liquid, or mucilage-like, or jelly-like substance known as protoplasm, which forms a large portion of the bulk of living and growing cells, is the all-important part of such a cell. Professor Huxley has well called this substance "the physical basis of life." Cells are of all shapes and sizes, from little spheres a ten-thousandth of an inch or less in diameter to slender tubes, such as fibers of cotton, several inches long. To get an idea of the appearance of some rather large cells, scrape a little pulp from a ripe, mealy apple, and examine it first with

1 The differentiation between the starch grains, the other cell-contents, and the cell-walls will appear better in the drawings if the starch grains are sketched with blue ink. 
a strong magnifying glass, then with a moderate power of the compound microscope. To see how dead, dry cellwalls, with nothing inside them, look, examine (as before) a very thin slice of elder pith, sunflower pith, or pith from a dead cornstalk. Look also at the figures in Chapter VI of this book. Notice that the simplest plants (Chapter XX) consist of a single cell each. The study of the structure of plants is the study of the forms which cells and groups of cells assume, and the study of plant physiology is the study of what cells and cell combinations do.

25. Absorption of Starch from the Cotyledons. - Examine with the microscope, using a medium power, soaked beans and the cotyledons from seedlings that have been growing for three or four weeks. Stain the sections with iodine solution, and notice how completely the clusters of starch grains that filled most of the cells of the unsprouted cotyledons have disappeared from the shriveled cotyledons of the seedlings. A few grains may be left, but they have lost their sharpness of outline.

26. 0il. - The presence of oil in any considerable quantity in seeds is not as general as is the presence of starch, though in many common seeds there is a good deal of it.

Sometimes the oil is sufficiently abundant to make it worth while to extract it by pressure, as is done with flaxseed, cotton-seed, the seeds of some plants of the cress family, the "castor bean," and other seeds.

27. Dissolving Oil from Ground Seeds. - It is not possible easily to show a class how oil is extracted from seeds by pressure; but there are several liquids which readily dissolve oils and yet have no effect on starch and most of the other constituents of seeds. 


\section{EXPERIMENT IX}

Extraction of Oil by Ether or Benzine. - To a few ounces of ground flaxseed add an equal volume of ether or benzine. Let it stand ten or fifteen minutes and then filter. Let the liquid stand in a saucer or evaporating dish in a good draught till it has lost the odor of the ether or benzine.

Describe the oil which you have obtained.

Of what use would it have been to the plant?

If the student wishes to do this experiment at home for himself, he should bear in mind the following:

Caution. - Never handle benzine or ether near a flame or stove.

A much simpler experiment to find oil in seeds may readily be performed by the pupil at home. Put the material to be studied, e.g., flaxseed meal, corn meal, wheat flour, cotton-seed meal, buckwheat flour, oatmeal, and so on, upon little labeled pieces of white paper, one kind of flour or meal on each bit of paper. Place all the papers, with their contents, on a perfectly clean plate, free from cracks, or on a clean sheet of iron, and put this in an oven hot enough nearly (but not quite) to scorch the paper. After half an hour remove the plate from the oven, shake off the flour or meal from each paper, and note the results, a more or less distinct grease spot showing the presence of oil, or the absence of any stain that there was little or no oil in the seed examined.

28. Albuminous Substances. - Albuminous substances or proteids occur in all seeds, though often only in small quantities. They have nearly the same chemical composition as white of egg and the curd of milk among animal substances, and are essential to the plant, since the living and growing parts of all plants contain large quantities of proteid material.

Sometimes the albuminous constituents of the seed occur in more or less regular grains (Fig. 8, at $K l$ ).

But much of the proteid material of seeds is not in any 
form in which it can be recognized under the microscope. One test for its presence is the peculiar smell which it produces in burning. Hair, wool, feathers, leather, and lean meat all produce a well-known sickening smell when scorched or burned, and the similarity of the proteid material in such seeds as the bean and pea to these substances is shown by the fact that scorching beans and similar seeds give off the familiar smell of burnt feathers.

29. Chemical Tests for Proteids. - All proteids (and very few other substances) are turned yellow by nitric acid, and this yellow color becomes deeper or even orange when the yellowish substance is moistened with ammonia. They are also turned yellow by iodine solution. Most proteids are turned more or less red by the solution of nitrate of mercury known as Millon's reagent. ${ }^{1}$

\section{EXPERIMENT $\mathrm{X}$}

Detection of Proteids in Seeds. - Extract the germs from some soaked kernels of corn and bruise them; soak some wheat-germ meal for a few hours in warm water, or wash the starch out of wheatflour dough; reserving the latter for use, place it in a white saucer or porcelain evaporating dish, and moisten well with Millon's reagent or with nitric acid; examine after fifteen minutes.

30. The Brazil-Nut as a Typical Oily Seed. - Not many familiar seeds are as oily as the Brazil-nut. Its large size makes it convenient for examination, and the fact that this nut is good for human food makes it the more interesting to investigate the kinds of plant-food which it contains.

1 See Handbook. 


\section{EXPERIMENT XI ${ }^{1}$}

Testing Brazil-Nuts for Plant-Foods. - Crack fifteen or twenty Brazil-nuts, peel off the brown coating from the kernel of each, and then grind the kernels to a pulp in a mortar. Shake up this pulp with ether, pour upon a paper filter, and wash with ether until the washings when evaporated are nearly free from oil. The funnel containing the filter should be kept covered as much as possible until the washing is finished. Evaporate the filtrate to procure the oil, which may afterwards be kept in a glass-stoppered bottle. Dry the powder which remains on the filter and keep it in a widemouthed bottle. Test portions of this powder for proteids and for starch. Explain the results obtained.

31. Other Constituents of Seeds. - Besides the substances above suggested, others occur in different seeds. Some of these are of use in feeding the seedling, others are of value in protecting the seed itself from being eaten by animals or in rendering it less liable to decay. In such seeds as that of the nutmeg, the essential oil which gives it its characteristic flavor probably makes it unpalatable to animals and at the same time preserves it from decay.

Date seeds are so hard and tough that they cannot be eaten and do not readily decay. Lemon, orange, horsechestnut and buckeye seeds are too bitter to be eaten, and the seeds of the apple, cherry, peach, and plum are somewhat bitter.

The seeds of larkspur, thorn-apple, ${ }^{1}$ croton, the castoroil plant, nux vomica, and many other kinds of plants contain active poisons.

1 Datura, commonly called " Jimpson weed." 


\section{CHAPTER III}

\section{MOVEMENTS, DEVELOPMENT, AND MORPHOLOGY OF THE SEEDLING}

32. How the Seedling breaks Ground. - As the student has already learned by his own observations, the seedling does not always push its way straight out of the ground. Corn, like all the other grains and grasses, it is true, sends a tightly rolled, pointed leaf vertically upward into the air. But the other seedlings examined usually will not be found to do anything of the sort. The squash seedling is a good one in which to study what may be called the arched hypocotyl type of germination. If the seed when planted is laid hori-

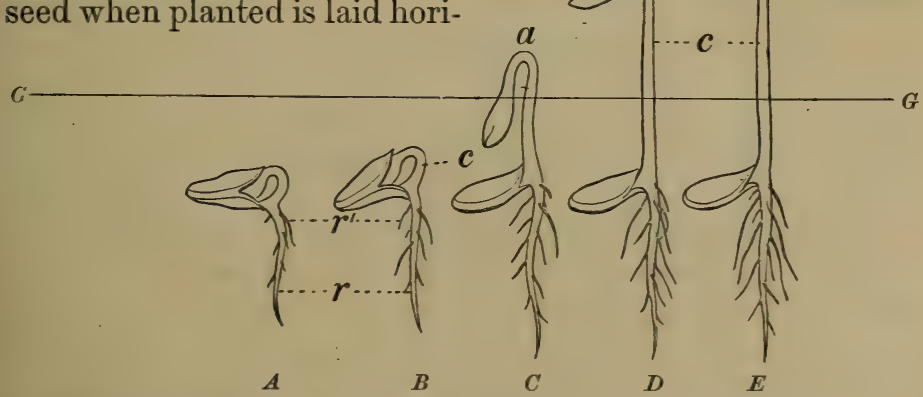

Fig. 9.-Successive Stages in the Life History of the Squash Seedling.

$G G$, the surface of the ground; $r$, primary root; $r^{\prime}$, secondary root; $c$, hypocotyl; $a$, arch of hypocotyl; co, cotyledons.

zontally on one of its broad surfaces, it usually goes through some such changes of position as are shown in Fig. 9. 
The seed is gradually tilted until, at the time of their emergence from the ground (at $C$ ), the cotyledons are almost vertical. The only part above the ground-line $G, G$, at this period, is the arched hypocotyl. Once out of ground, the cotyledons soon rise, until (at $E$ ) they are again vertical, but with the other end up from that which stood highest in $C$. Then the two cotyledons separate until they once more lie horizontal, pointing away from each other.

Can you suggest any advantage which the plant derives from having the cotyledons dragged out of the ground rather than having them pushed out, tips first?

33. Cause of the Arch. - It is evident that a flexible object like the hypocotyl, when pushed upward through the earth, might easily be bent into an arch or loop. Whether the shape which the hypocotyl assumes is wholly caused by the resistance of the soil can best be ascertained by an experiment.

\section{EXPERIMENT XII}

Is the Arch of the Hypocotyl due to the Pressure of the Soil on the Rising Cotyledons? - Sprout some squash seeds on wet paper under a bell-glass, and when the root is an inch or more long, hang several of the seedlings, roots down, in little stirrups made of soft twine, attached by beeswax and rosin mixture to the inside of the upper part of a bell-glass. Put the bell-glass on a large plate or a sheet of glass on which lies wet paper to keep the air moist. Note whether the seedlings form hypocotyl arches at all and, if so, whether the arch is more or less perfect than that formed by seedlings growing in earth, sand, or sawdust.

34. What pushes the Cotyledons up? - A very little study of any set of squash seedlings, or even of Fig. 9, is 
sufficient to show that the portion of the plant where roots and hypocotyl are joined neither rises nor sinks, but that the plant grows both ways from this part (a little above $r^{\prime}$ in Fig. 9, $A$ and $B$ ). It is evident that as soon as the hypocotyl begins to lengthen much it must do one of two things : either push the cotyledons out into the air or else force the root down into the ground as one might push a stake down. What changes does the plantlet undergo, in passing from the stage shown at $A$ to that of $B$ and of $C$, making it harder and harder for the root to be thrust downward?

35. Use of the Peg. - Squash seedlings usually (though not always) form a sort of knob on the hypocotyl. This is known as the peg. Study a good many seedlings and try to find out what the lengthening of the hypocotyl, between the peg and the bases of the cotyledons, does for the little plant. Set a lot of squash seeds, hilum down, in moist sand or sawdust and see whether the peg is more or less developed than in seeds sprouted lying on their sides, and whether the cotyledons in the case of the vertically planted seeds usually come out of the ground in the same condition as do those shown in Fig. 9 .

36. Discrimination between Root and Hypocotyl. - It is not always easy to decide by their appearance and behavior what part of the seedling is root and what part is hypocotyl. In a seedling visibly beginning to germinate, the sprout, as it is commonly called, which projects from the seed might be either root or hypocotyl or might consist of both together, so far as its appearance is concerned. A microscopic study of the cross-section of a root, compared with one of the hypocotyl, would show decided differences 
of structure between the two. Their mode of growth is also different, as the pupil may infer after he has tried Exp. XIV.

37. Discrimination by Staining. - For some reason, perhaps because the skin or epidermis of the young root is not so water-proof as that of the stem, the former stains more easily than the latter does.

\section{EXPERIMENT XIII}

The Permanganate Test. - Make a solution of potassium permanganate in water, by adding about four parts, by weight, of the crystallized permanganate to 100 parts of water. Drop into the solution seedlings, e.g., of all the kinds that have been so far studied, each in its earliest stage of germination (that is, when the root or hypocotyl has pushed out of the seed half an inch or less), and also at one or two subsequent stages. After the seedlings bave been in the solution from three to five minutes, or as soon as the roots are considerably stained, pour off (and save) the solution and rinse the plants with plenty of clear water. Sketch one specimen of each kind, coloring the brown-stained part, which is root, in some way so as to distinguish it from the unstained hypocotyl. Note particularly how much difference there is in the amount of lengthening in the several kinds of hypocotyl examined. Decide whether the peg of the squash seedling is an outgrowth of hypocotyl or of root.

38. Disposition made of the Cotyledons. - As soon as the young plants of squash, bean, and pea. have reached a height of three or four inches above the ground it is easy to recognize important differences in the way in which they set out in life.

The cotyledons of the squash increase greatly in surface, acquire a green color and a generally leaf-like appearance, and, in fact, do the work of ordinary leaves. In 
such a case as this the appropriateness of the name seedleaf is evident enough, - one recognizes at sight the fact that the cotyledons are actually the plant's first leaves. In the bean the leaf-like nature of the cotyledons is not so clear. They rise out of the ground like the squash cotyledons, but then gradually shrivel away, though they may first turn green and somewhat leaf-like for a time.

In the pea (as in the acorn, the horse-chestnut, and many other seeds) we have quite another plan, the underground type of germination. Here the thick cotyledons no longer rise above ground at all, because they are so gorged with food that they could never become leaves; but the young stem pushes rapidly up from the surface of the soil.

The development of the plumule seems to depend somewhat on that of the cotyledons. The squash seed has cotyledons which are not too thick to become useful leaves, and so the plant is in no special haste to get ready any other leaves. The plumule, therefore, cannot be found with the magnifying glass in the unsprouted seed, and is almost microscopic in size at the time when the hypocotyl begins to show outside of the seed-coats.

In the bean and pea, on the other hand, since the cotyledons cannot serve as foliage leaves, the later leaves must be pushed forward rapidly. In the bean the first pair are already well formed in the seed. In the pea they cannot be clearly made out, since the young plant forms several scales on its stem before it produces any full-sized leaves, and the embryo contains only hypocotyl, cotyledons, and a sort of knobbed plumule, well developed in point of size, representing the lower scaly part of the stem. 
39. Root, Stem, and Leaf. - By the time the seedling is well out of the ground it, in most cases, possesses the three kinds of vegetative organs, or parts essential to growth, of ordinary flowering plants, i.e., the root, stem, and leaf, or, as they are sometimes classified, root and shoot. All of these organs may multiply and increase in size as the plant grows older, and their mature structure will be studied in later chapters, but some facts concerning them can best be learned by watching their growth from the outset.

40. Young Roots grown for Examination. - Roots growing in sand or ordinary soil cling to its particles so tenaciously that they cannot easily be studied, and those grown in water have not quite the same form as soil-roots. Roots grown in damp air are best adapted for careful study.

41. Elongation of the Root. - We know that the roots of seedlings grow pretty rapidly from the fact that each day finds them reaching visibly farther down into the water or other medium in which they are planted. A sprouted Windsor bean in a vertical thistle-tube will send its root downward fast enough so that ten minutes' watching through the microscope will suffice to show growth. To find out just where the growth goes on requires a special experiment.

\section{EXPERIMENT 'XIV}

In what Portions of the Root does its Increase in Length take Place? - Sprout some peas on moist blotting paper in a loosely covered tumbler. When the roots are one and a half inches or more long, mark them along the whole length with little dots made with a bristle dipped in water-proof India ink, or a fine inked thread stretched on a little bow of whalebone or brass wire. 
Transfer the plants to moist blotting paper under a beil-glass or an inverted battery jar and examine the roots at the end of twentyfour hours to see along what portions their length has increased; continue observations on them for several days.

42. Root-Hairs. - Barley, oats, wheat, red clover, or buckwheat seeds soaked and then sprouted on moist blotting paper afford convenient material for studying root-hairs. The seeds may be kept covered with a watchglass or a clock-glass while sprouting. After they have begun to germinate well, care must be taken not to have them kept in too moist an atmosphere, or very few root-hairs will be formed. Examine with the magnifying glass those parts of the root which have these appendages.

Try to find out whether all the portions of the root are equally covered with hairs and, if not, where they are most abundant. (See also Sect. 53.)

The root-hairs in plants growing under ordinary conditions are surrounded by the moist soil and wrap themselves around microscopical particles of earth (Fig. 11). Thus they are able rapidly to absorb through their thin walls the soil-water, with whatever mineral substances it has dissolved in it.

43. The Young Stem. - The hypocotyl, or portion of the stem which lies below the cotyledons, is the earliest formed portion of the stem. Sometimes this lengthens but little; often, however, as the student knows from his own observations, the hypocotyl lengthens enough to raise the cotyledons well above ground, as in Fig. 10.

The later portions of the stem are considered to be divided into successive nodes, - places at which a leaf (or 
a scale which represents a leaf) appears; and internodes,portions between the leaves.

The student should watch the growth of a seedling bean or pea and ascertain by actual measurements whether the internodes lengthen after they have once been formed, and if so, for how long a time the increase continues.

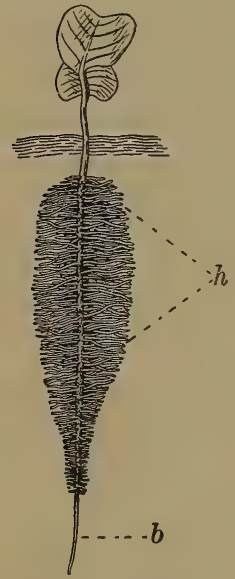

Fig. 10.

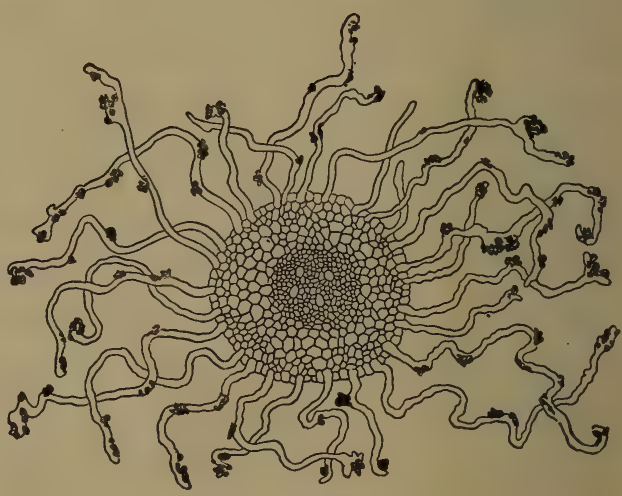

FIG. 11.

FIG. 10. - A Turnip Seedling, with the Cotyledons developed into Temporary Leaves.

$h$, root-hairs from the primary root; $b$, bare portion of the root, on which no hairs have as yet been produced.

Frg. 11. - Cross-Section of a Root, a good deal magnified, showing root-hairs attached to particles of soil, and sometimes enwrapping these particles.

44. The First Leaves. - The cotyledons are, as already explained, the first leaves which the seedling possesses, even if a plumule is found well developed in the seed, it was formed after the cotyledons. In those plants which have so much food stored in the cotyledons as to render these unfit ever to become useful foliage leaves, there is little or nothing in the color, shape, or general appearance 
of the cotyledon to make one think it really a leaf, and it is only by studying many cases that the botanist is enabled to class all cotyledons as leaves in their nature, even if they are quite unable to do the ordinary work of leaves. The study of the various forms which the parts or organs of a plant may assume is called morphology; it traces the relationship of parts which are really akin to each other, though dissimilar in appearance and often in function. In seeds which have endosperm, or food stored outside of the embryo, the cotyledons usually become green and leaf-like, as they do, for example, in the four-o'clock, the morning-glory, and the buckwheat; but in the seeds of the grains (which contain endosperm) a large portion of the single cotyledon remains throughout as a thickish mass buried in the seed. In a few cases, as in the pea, there are scales instead of true leaves formed on the first nodes above the cotyledons, and it is only at about the third node above that leaves of the ordinary kind appear. In the bean and some other plants which in general bear one leaf at a node along the stem, there is a pair produced at the first node above the cotyledons, and the leaves of this pair differ in shape from those which arise from the succeeding portions of the stem.

45. Classification of Plants by the Number of their Cotyledons. - In the pine family the germinating seed often displays more than two cotyledons, as shown in Fig. 12; in the

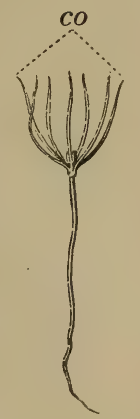

FIG. 12. - Germinating Pine. co, cotyledons. majority of common flowering plants the seed contains two cotyledons, while in the lilies, the rushes, the 
sedges, the grasses, and some other plants, there is but one cotyledon. Upon these facts is based the division of most flowering plants into two great groups: the dicotyledonous plants, which have two seed-leaves, and the monocotyledonous plants, which have one seed-leaf. Other important differences nearly always accompany the difference in number of cotyledons, as will be seen later.

46. Tabular Review of Experiments. - Make out a table containing a very brief summary of the experiments thus far performed, as follows:

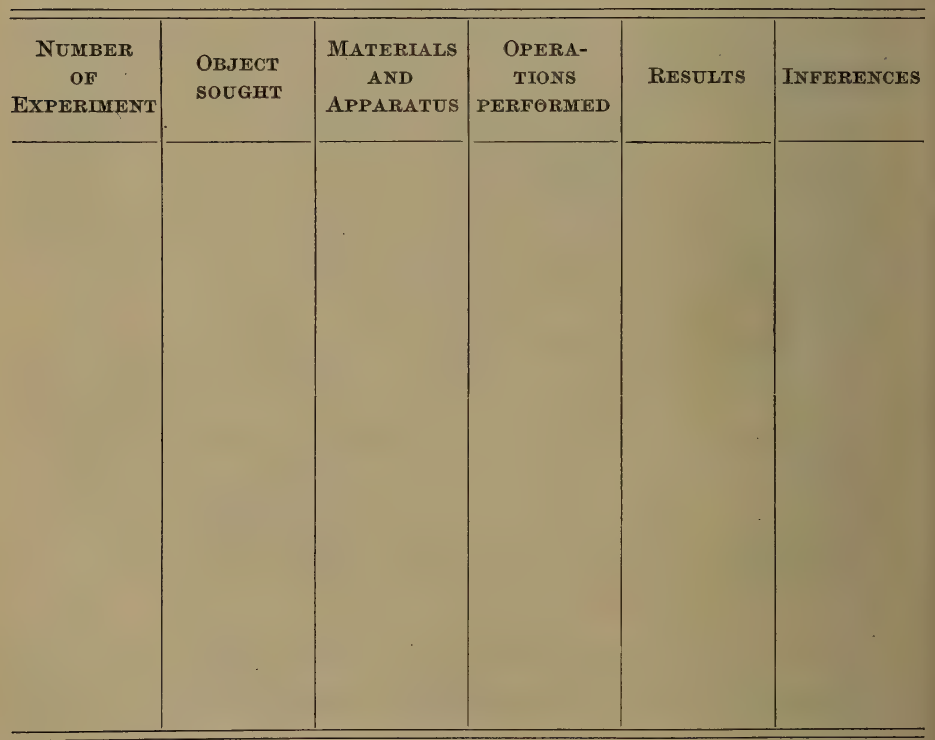

47. Review Sketches. - Make out a comparison of the early life histories of all the other seedlings studied, by arranging in parallel columns a series of drawings of each, 
like those of Fig. 9, but in vertical series, the youngest of each at the top, thus :

\begin{tabular}{|c|c|c|c|}
\hline & BeAN & Pea & Corn \\
\hline First Stage & & & \\
\hline Second Stage & & & \\
\hline Third Stage & & & \\
\hline Fourth Stage & & & \\
\hline $\begin{array}{c}\text { Fifth StaGe } \\
\text { etc. }\end{array}$ & & & \\
\hline
\end{tabular}




\section{CHAPTER IV}

\section{R00TS ${ }^{1}$}

48. Origin of Roots. - The primary root originates from the lower end of the hypocotyl, as the student learned from his own observations on sprouting seeds. The branches of the primary root are called secondary roots, and the branches of these are known as tertiary roots. Those roots which occur on the stem or in other unusual places are known as adventitious roots. The roots which form so readily on cuttings of willow, southernwood, tropæolum, French marigold, geranium (pelargonium), tradescantia, and many other plants, when placed in damp earth or water, are adventitious.

49. Aerial Roots. - While the roots of most familiar plants grow in the earth and are known as soil-roots, there are others which are formed in the air, called aerial roots. They serve various purposes: in some tropical air-plants (Fig. 13) they serve to fasten the plant to the tree on which it establishes itself, as well as to take in water which drips from branches and trunks above them, so that these plants require no soil and grow in mid-air suspended from trees, which serve them merely as supports $;^{2}$ many such

1 To the plant the root is more important than the stem. The author has, however, treated the structure of the latter more fully than that of the root, mainly because the tissues are more varied in the stem and a moderate knowledge of the more complex anatomy of the stem will serve every purpose.

2 If it can be conveniently managed, the class will find it highly interesting and profitable to visit any greenhouse of considerable size, in which the aerial roots of orchids and aroids may be examined. 
air-plants are grown in greenhouses. In such plants as the ivy (Fig. 15) the aerial roots (which are also adventitious) hold the plant to the wall or other surface up which it climbs.

In the Indian corn (Fig. 14) roots are sent out from nodes at some distance above the ground and finally descend until they enter the ground. They serve both to anchor the cornstalk so as to enable it to resist the wind and to supply additional water to the plant. ${ }^{1}$ They often produce no rootlets until they reach the ground.

50. Water-Roots. plants, such as the willow, readily adapt their roots to live either in earth or in water, and some, like the little floating duckweed, regularly produce roots which are adapted to live in water only. These water-roots often show large and

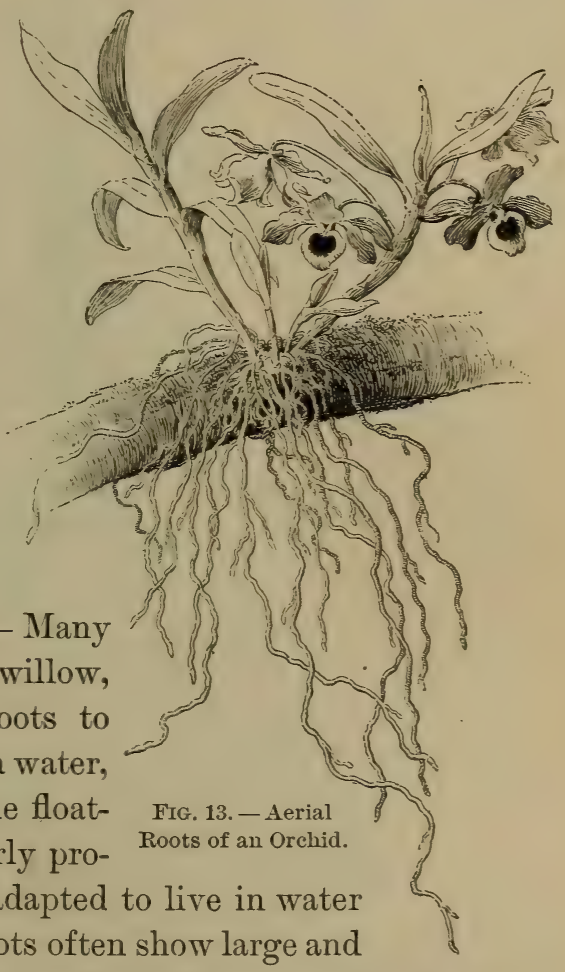
distinct sheaths on the ends of the roots, as, for instance, in the so-called water-hyacinth. This plant is especially interesting for laboratory cultivation from the fact that

1 Specimens of the lower part of the cornstalk, with ordinary roots and aerial roots, should be dried and kept for class study. 


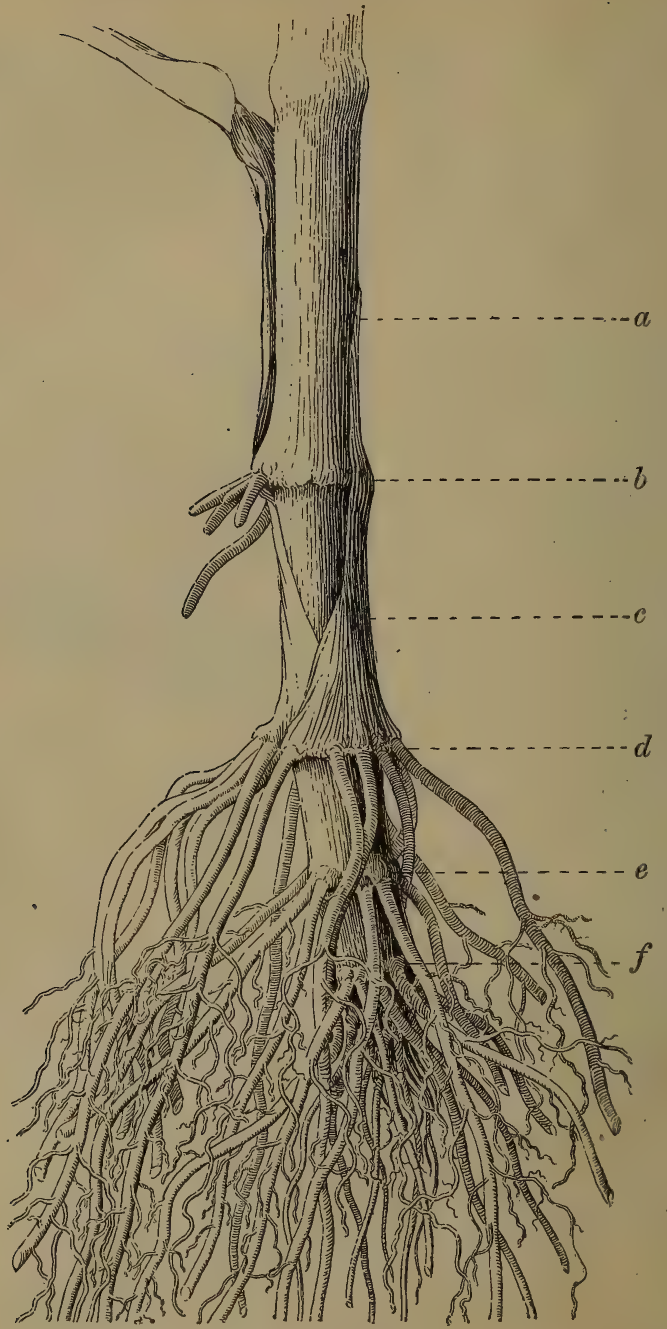

Fig. 14. - Lower Part of Stem and Roots of Indian Corn, showing Aerial Roots ("Brace-Roots").

$a, c$, internodes of the stem ; $b, d, e, f$, nodes of various age bearing roots. Most of these started as aerial roots, but all except those from $b$ have now reached the earth. 
it may readily be transferred to moderately damp soil, and that the whole plant presents curious modifications when made to grow in earth instead of water.

51. Parasitic Roots. ${ }^{1}$ - The dodder, the mistletoe, and a good many other parasites, live upon nourishment which they steal from other plants, called hosts. The parasitic

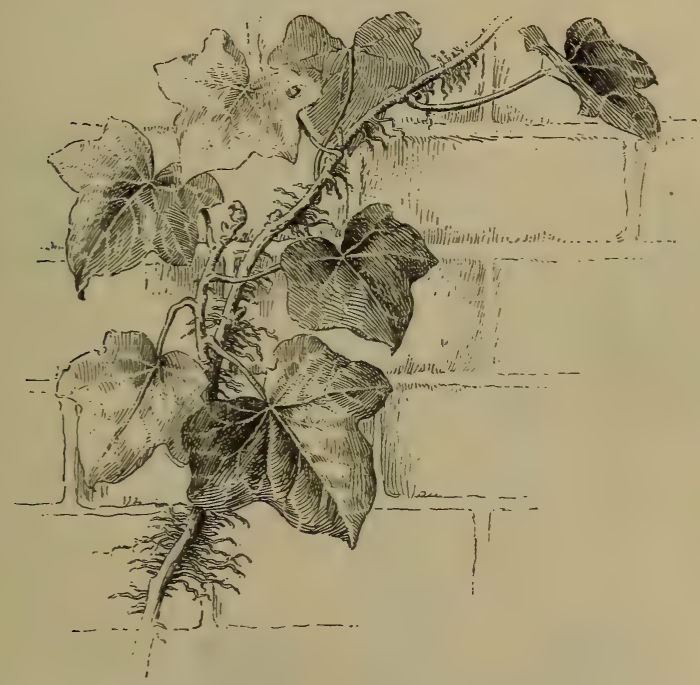

Fig. 15. - Aerial Adventitious Roots of the Ivy.

roots, or haustoria, form the most intimate connections with the interior portions of the stem or the root, as the case may be, of the host-plant on which the parasite fastens itself.

In the dodder, as is shown in Fig. 16, it is most interesting to notice how admirably the seedling parasite is adapted to the conditions under which it is to live. Rooted

${ }^{1}$ See Kerner and Oliver's Natural History of Plants, Vol. I, pp. 171-213. 
at first in the ground, it develops a slender, leafless stem, which, leaning this way and that, no sooner comes into

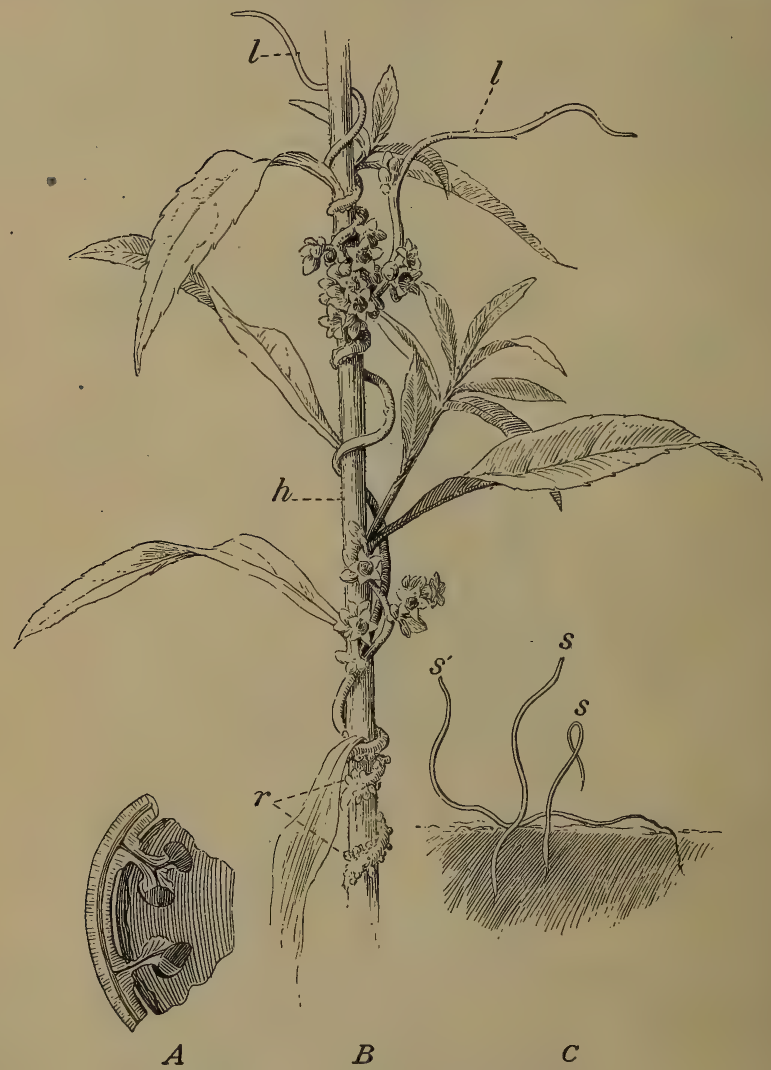

Fig. 16. - Dodder, growing upon a Golden-Rod Stem.

$s$, seedling dodder plants, growing in earth; $h$, stem of host; $r$, haustoria or parasitic roots of dodder ; $l$, scale-like leaves. $A$, magnified section of a portion of willow stem, showing penetration of haustoria.

permanent contact with a congenial host than it produces haustoria at many points, gives up further growth in its 
soil-roots, and grows rapidly on the strength of the supplies of ready-made sap which it obtains from the host.

52. Forms of Roots. - The primary root is that which proceeds like a downward prolongation directly from the lower end of the hypocotyl. In many cases the mature rootsystem of the plant contains one main root much larger than any of its branches. This is called a taproot (Fig. 17).

Such a root, if much thickened, would assume the form

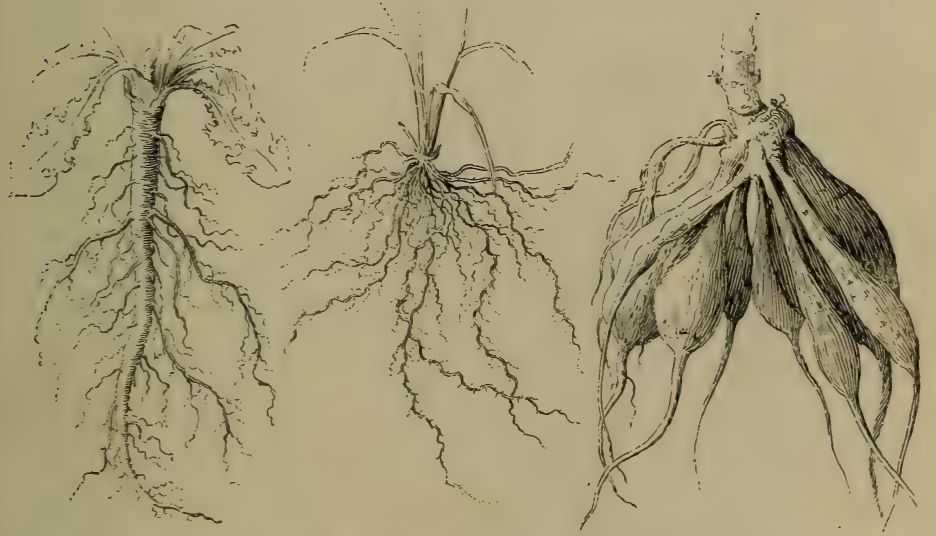

FIG. 17. - A Taproot. FIG. 18. - Fibrous Roots. Fig. 19.-Fascicled Roots.

shown in the carrot, parsnip, beet, turnip, salsify, or radish, and is called a fleshy root. Some plants produce multiple primary roots, that is, a cluster proceeding from the lower end of the hypocotyl at the outset. If such roots become thickened, like those of the sweet potato and the dahlia (Fig. 19), they are known as fascicled roots.

Roots of grasses, etc., are thread-like, and known as fibrous roots (Fig. 18).

53. General Structure of Roots. - The structure of the very young root can be partially made out by examining 
the entire root with a moderate magnifying power, since the whole is sufficiently translucent to allow the interior as well as the exterior portion to be studied while the root is still alive and growing.

Place some vigorous cuttings of tradescantia or Zebrina, which can usually be obtained of a gardener or florist, in a beaker or jar of

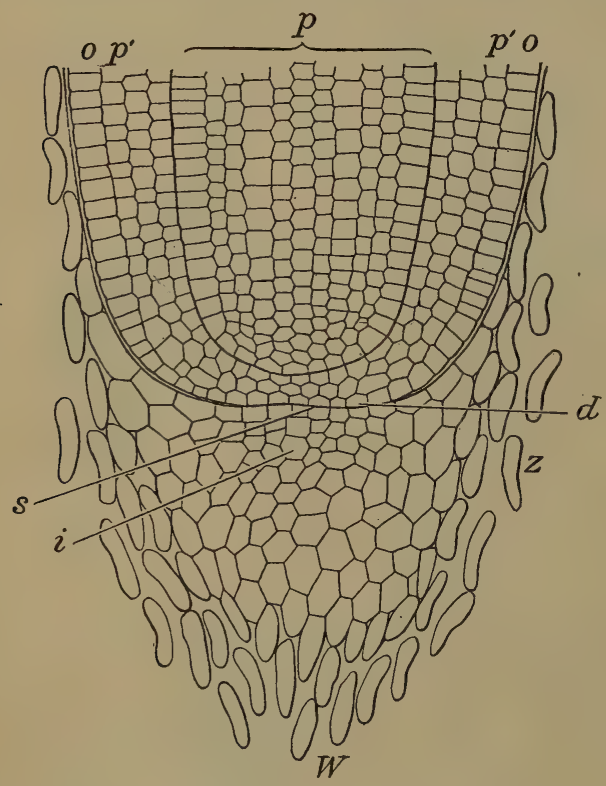

FIG. 20. - Lengthwise Section (somewhat diagrammatic) through Root-Tip of Indian Corn. $\times$ about 130.

$W$, root-cap ; $i$, younger part of cap ; $z$, dead cells separating from cap ; $s$, growing point ; $o$, epiderm:s; $p^{\prime}$, intermediate layer between epidermis and central cylinder; $p$, central cylinder; $d$, layer from which the root-cap originates. water. ${ }^{1}$ The jar should be as thin and transparent as possible, and it is well to get a flatsided rather than a cylindrical one. Leave the jar of cuttings in a sunny, warm place. As soon as roots have developed at the nodes and reached the length of three-quarters of an inch or more, arrange a microscope in a horizontal position (see Handbook), and examine the tip and adjacent . portion of one of the young roots with a power of from twelve to twenty diameters.

Note:
(a) The root-cap, of loosely attached cells.
(b) The central cylinder.

1 If the tradescantia or Zebrina cannot be obtained, roots of seedlings of oats, wheat, or barley, or of red-clover seedlings raised in a large covered cell on a microscope slide, may be used. 
(c) The cortical portion, a tubular part enclosing the solid central cylinder.

(d) The root-hairs, which cover some parts of the outer layer of the cortical portion very thickly. Observe particularly how far toward the tip of the root the root-hairs extend, and where the youngest ones are found.

Make a drawing to illustrate all the points above suggested $(a, b, c, d)$. Compare your drawing with Fig. 20. Make a careful study of longitudinal sections through the centers of the tips of very young roots of the hyacinth or the Chinese sacred lily. Sketch one section and compare the sketch with Fig. 20.

Make a study of the roots of any of the common duckweeds, growing in nutrient solution in a jar of water under a bell-glass, and note the curious root-pockets which here take the place of root-caps.

54. Details of Root-Structure. - The plan on which the young root is built has been outlined in Sect. 53. A few further particulars are necessary to an understanding of how the root does its work. On examining Fig. 21 the cylinders of which the root is made up are easily distinguished, and the main constituent parts of each can be made out without much trouble. The epidermis-cells are seen to be somewhat brick-shaped, many of them provided with extensions into root-hairs. Inside the epidermis lie several layers of rather globular, thin-walled cells, and inside these a boundary layer between the cortical or bark portion of the root and the central cylinder. This latter region is especially marked by the presence of certain groups of cells, shown at $w$ and $d$ and at $b$, the two former serving as channels for air and water, the latter (and $w$ also) giving toughness to the root.

Roots of shrubs and trees more than a year old will be found to have increased in thickness by the process 
described in Sect. 106, and a section may look quite unlike the young root-section shown in Fig. 21.

55. Examination of the Root of a Shrub or Tree. - Cut thin transverse sections of large and small roots of any hardwood tree ${ }^{1}$ and examine them first with a low power of the microscope, as a two-inch objective, to get the general disposition of the parts, then

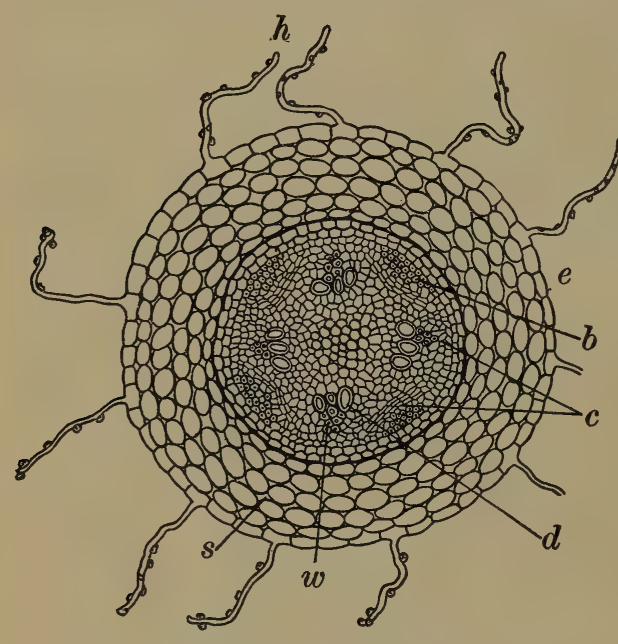

Fig. 21. - Much Magnified Cross-Section of a

Very Young Dicotyledonous Root.

$h$, root-hairs with adhering bits of sand; $e$, epidermis ; $s$, thin-walled, nearly globular cells of bark; $b$, hard bast ; $c$, cambium ; $w$, wood-cells ; $d$, ducts. with a higher power, as the half-inch or quarter-inch, for details. With the low power, note:

(a) The brown layer of outer bark.

(b) The paler layer within this.

(c) The woody cylinder which forms the central portion of the root.

The distinction between $(b)$ and $(c)$ is more evident when the section has been exposed to the air for a few minutes and changed somewhat in color. It is a good plan to look with the low power first at a thick section, viewed as an opaque object, and then at a very thin one mounted in water or glycerine, and viewed as a transparent object.

Observe the cut-off ends of the ducts, or vessels, which serve as passages for air and water to travel through; these appear as holes in the section, and are much more abundant relatively in the young

1 Young suckers of cherry, apple, etc., which may be pulled up by the roots, will afford excellent material. 
than in the older and larger portions of the root. Sketch one section of each kind.

Examine with a higher power (100 to 200 diameters), and note the ends of the thick-walled wood-cells. Compare these with Fig. 72 .

Notice the many thinner-walled cells composing stripes radiating away from the center of the root. These bands are the medullary rays, whose mode of origin is shown in Fig. 68. Moisten some of the sections with iodine solution, ${ }^{1}$ and note where the blue color shows the presence of starch. Split some portions of the root through the middle, cut thin sections from the split surface, and examine with the high power some unstained and some stained with iodine.

Notice the appearance of the wood-cells and the ducts as seen in these sections, and compare with Fig. 58.2

56. Structure and Contents of a Fleshy Root. - In some fleshy roots, such as the beet, the morphology of the parts is rather puzzling, since they form many layers of tissue in a single season, showing on the cross-section of the root a series of layers which look a little like the annual rings of trees.

The structure of the turnip, radish, carrot, and parsnip is simpler.

Cut a parsnip across a good deal below the middle, and stand the cut end in eosin solution for twenty-four hours.

Then examine by slicing off successive portions from the upper end. Sketch some of the sections thus made. Cut one parsnip lengthwise and sketch the section obtained. In what portion of the root did the colored liquid rise most readily? The ring of red marks the boundary between the cortical portion and the central cylinder. To which does the main bulk of the parsnip belong? Cut thin transverse sections from an ink-stained parsnip and notice how the medullary rays run out into the cortical portion, and in those sections

1 If the roots are in their winter condition.

2 The examination of the minute structure of the root is purposely made very hasty, since the detailed study of the structural elements can be made to better advantage in the stem. 
that show it, find out where the secondary roots arise. If possible, peel off the cortical portion from one stained root and leave the central cylinder with the secondary roots attached. Stain one section with iodine, and sketch it. Where is the starch of this root mainly stored?

Test some bits of parsnip for proteids, by boiling them for a minute or two with strong nitric acid.

What kind of plant-food does the taste of cooked parsnips show them to contain? [On no account taste the bits which have been boiled in the poisonous nitric acid.]

57. Storage in Other Roots. - The parsnip is by no means a remarkable plant in its capacity for root-storage. The roots of the yam and the sweet potato contain a good deal of sugar and much more starch than is found in the parsnip. Beet-roots contain so much sugar that a large part of the sugar supply of Europe and an increasing portion of our own supply is obtained from them. Oftentimes the bulk of a fleshy root is exceedingly large as compared with that of the parts of the plant above ground.

The South African plant (Harpagophytum, Chapter XXIV) is a good example of this, and another instance is that of a plant, ${ }^{1}$ related to the morning-glory and the sweet potato, found in the southeastern United States, which has a root of forty or fifty pounds weight.

Not infrequently roots have a bitter or nauseous taste, as in the case of the chicory, the dandelion, and the rhubarb, and a good many, like the monkshood, the yellow jasmine, and the pinkroot, are poisonous. Can you give any reason why the plant may be benefited by the disgusting taste or poisonous nature of its roots?

1 Ipomøa Jalapa. 
58. Use of the Food stored in Fleshy Roots. - The parsnip, beet, carrot, and turnip are biennial plants; that is, they do not produce seed until the second summer or fall after they are planted.

The first season's work consists mainly in producing the food which is stored in the roots. To such storage is due their characteristic fleshy appearance. If this root is planted in the following spring, it feeds the rapidly growing stem which proceeds from the bud at its summit, and an abundant crop of flowers and seed soon follows; while the root, if examined in late summer, will be found to be withered, with its store of reserve material quite exhausted.

The roots of the rhubarb (Fig. 22), the sweet potato, and of a multitude of other perennials, or plants which live for many years, contain much stored plant-food. Many such plants die to the ground at the beginning of winter,

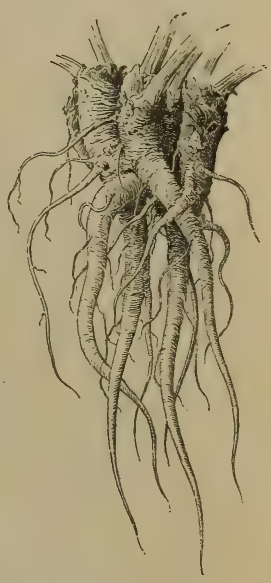

FiG. 22.-Flesliy Roots of Garden lhubarb. (About one-fifteenth natural size.) and in spring make a rapid growth from the materials laid up in the roots.

59. Extent of the Root-System. - The total length of the roots of ordinary plants is much greater than is usually supposed. They are so closely packed in the earth that only a few of the roots are seen at a time during the process of transplanting, and when a plant is pulled or dug up in the ordinary way, a large part of the whole mass of roots is broken off and left behind. A few plants have 
been carefully studied to ascertain the total weight and length of the roots. Those of winter wheat have been found to extend to a depth of seven feet. By weighing the whole root-system of a plant and then weighing a known length of a root of average diameter, the total length of the roots may be estimated. In this way the roots of an oat plant have been calculated to measure about 154 feet; that is, all the roots, if cut off and strung together end to end, would reach that distance.

Single roots of large trees often extend horizontally to great distances, but it is not often possible readily to trace the entire depth to which they extend. One of the most notable examples of an enormously developed root-system is found in the mesquite of the far Southwest and Mexico. When this plant grows as a shrub, reaching the height, even in old age, of only two or three feet, it is because the water supply in the soil is very scanty. In such cases the roots extend down to a depth of sixty feet or more, until they reach water, and the Mexican farmers in digging wells follow these roots as guides. Where water is more plenty, the mesquite forms a good-sized tree, with much less remarkably developed roots.

60. The Absorbing Surface of Roots. - Such aerial roots as are shown in Fig. 13 are usually covered with a spongy absorbent layer, by means of which they retain large quantities of the water which trickles down them during rain-storms. This water they afterwards gradually give up to the plant. Most water-roots (not however those of tradescantia) have no special arrangement for absorbing water except through the general surface of their epidermis. But some water-roots and most soil-roots take in water 
mainly through the root-hairs. These are delicate, hairlike outgrowths from the epidermis of the root. They. are, as seen in Fig. 11, thin-walled tubes, of nearly uniform diameter, closed at the outer end and opening at the inner end into the epidermis-cell from which they spring. The relation of each hair to the epidermis-cell is still better shown in Fig. 23 , which represents a very young roothair and a considerably older one.

\section{Absorption of Water by Roots. -} Many experiments on the cultivation of corn, wheat, oats, beans, peas, and other familiar plants in water have proved that some plants, at any rate, can thrive very well on ordinary lake, river, or well water, together with the food which they absorb from the air (Chapter XII). Just how much water some kinds of plants give off (and therefore absorb) per day will be discussed when the uses of the leaf are studied. For the present it is suffcient to state that even an

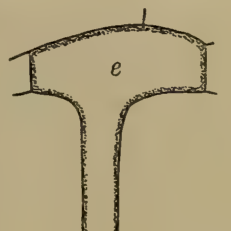
annual plant during its lifetime absorbs through the roots very many times its own weight of water. Grasses have been known to take in their weight of water in every twentyfour hours of warm, dry weather. This absorption takes 
place mainly through the root-hairs, which the student has examined as they occur in the seedling plant, and which are found thickly clothing the younger and more rapidly growing parts of the roots of mature plants. Some idea of their abundance may be gathered from the fact that on a rootlet of corn grown in a damp atmosphere, and about one-seventeenth of an inch in diameter, 480 root-hairs have been counted on each hundredth of an inch of root. The walls of the root-hairs are extremely thin, and they have no holes or pores visible under even the highest power of the microscope, yet the water of the soil penetrates very rapidly to the interior of the root-hairs. The soil-water brings with it all the substances which it can dissolve from the earth about the plant; and the closeness with which the root-hairs cling to the particles of soil, as shown in Figs. 11 and 21, must cause the water which is absorbed to contain more foreign matter than underground water in general does, particularly since the roots give off enough weak acid from their surface to corrode the surface of stones which they enfold or cover.

62. Osmosis. - The process by which two liquids separated by membranes pass through the latter and mingle, as soil-water does with the liquid contents of root-hairs, is called osmosis.

It is readily demonstrated by experiments with thin animal or vegetable membranes.

\section{EXPERIMENT XV}

Osmosis as shown in an Egg. - Cement to the smaller end of an egg a bit of glass tubing about six inches long and about three-sixteenths of an inch inside diameter. Sealing-wax or a mixture of equal parts of beeswax and resin melted together will serve for a cement. 
Chip away part of the shell from the larger end of the egg, place it in a wide-mouthed bottle or a small beaker full of water, as shown in Fig. 24, then very cautiously pierce a hole through the upper end of the eggshell by pushing a knitting-needle or wire down through the glass tube.

Watch the apparatus for some hours and note any change in the contents of the tube. ${ }^{1}$ Explain.

The rise of liquid in the tube is evidently due to water making: its way through the thin membrane which lines the eggshell, although this membrane contains no pores visible even under the microscope.

\section{EXPERIMENT XVI}

Result of placing Sugar on a Begonia Leaf. - Place a little powdered sugar on the upper surface of a thick begonia leaf under a small bell-glass. Put another por= tion of sugar or a bit of paper alongside the leaf. Watch for several days. Explain results. The upper surface of this leaf contains no pores, even of microscopic size.

63. Inequality of 0 smotic Exchange. - The nature of the two liquids separated by any given membrane determines in which direction the greater flow shall take place.

If one of the liquids is pure water and the other

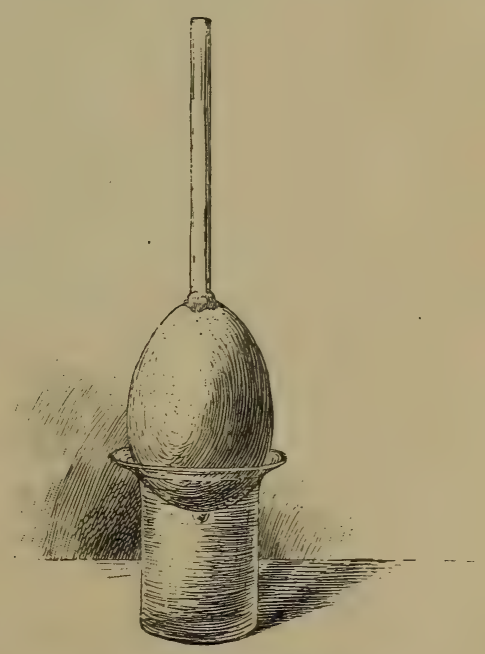

Fig. 24, - Egg on Beaker of Water, to show Osmosis.

1 Testing the contents of the beaker with nitrate of silver solution will then show the presence of more common salt than is found in ordinary water. Explain. 
is water containing solid substances dissolved in it, the greater flow of liquid will be away from the pure water into the solution, and the stronger or denser the latter, the more unequal will be the flow. This principle is well illustrated by the egg-osmosis experiment. Another important principle is that substances which readily crystallize and are easily soluble, like salt or sugar, pass rapidly through membranes, while jelly-like substances, like white of egg, can hardly pass through them at all.

64. Study of Osmotic Action of Living Protoplasm; Plasmolysis. - The obvious parts of most living and growing plant-cells are a cell-wall, which is a skin or enclosure made of cellulose, and the living, active cell-contents or protoplasm. Every one is familiar with cellulose in various forms, one of the best examples being that afforded by clean cotton. It is a tough, white or colorless substance, chemically rather inactive. Protoplasm is a substance which differs greatly in its appearance and properties under different circumstances. It is of a very complex nature, so far as its chemical composition is concerned, belonging to the group of proteids and therefore containing not only the elements carbon, hydrogen, and oxygen, common to most organic substances, but nitrogen in addition. The protoplasm in a living cell often consists of several kinds of material; for instance, a rather opaque portion called the nucleus, and a more or less liquid portion lining the cell-walls and extending inward in strands to the nucleus (Fig. 126). Often, in living and active cells, the spaces left between strands and lining are filled with a watery liquid called the cell-sap.

The action of the protoplasm in controlling osmosis is well shown by the process known as plasmolysis. 
Put some living threads of pond-scum (Spirogyra) (Chapter XX) into a 4 per cent solution of glycerine in water, a 16 per cent solution of cane sugar, or (for quick results) a 2 per cent solution of common salt. ${ }^{1}$ Any one of these solutions is much denser than the cell-sap inside the cells of the pond-scum, and therefore the watery part of the cell-contents will be drawn out of the interior of the cell and the protoplasmic lining will collapse, receding from the cell-wall. The cell-contents are then said to be plasmolyzed. Sketch several cells in this condition. Remove the filaments of Spirogyra and place them in fresh water. How do they now behave? Explain. Repeat the plasmolyzing operation with another set of cells which have first been killed by soaking them for five minutes in a mixture of equal quantities of acetic acid, three parts to 1000 of water, and chromic acid, seven parts to 1000 of water. The pond-scum threads before being transferred from the killing solution into the plasmolyzing solution should be rinsed with a little clear water. Note how the cells now behave. How is it shown that they have lost their power of causing a liquid to be transferred mainly or wholly in one direction? Why do frozen or boiled slices of a red beet color water in which they are placed, while fresh slices do not?

65. Osmosis in Root-Hairs. - The soil-water (practically identical with ordinary spring or well water) is separated from the more or less sugary or mucilaginous sap inside of the root-hairs only by their delicate cell-walls, lined with a thin layer of protoplasm. This soil-water will pass rapidly into the plant, while very little of the sap will come out. The selective action, which causes the flow of liquid through the root-hairs to be almost wholly inward, is due to the living layer of protoplasm (Chapter XII), which covers the inner surface of the cell-wall of the roothair. When the student has learned how active a substance protoplasm often shows itself to be, he will not be astonished to find it behaving almost as though it were

1 This should be done as a demonstration by the teacher. 
possessed of intelligence and will. Plants of two different species, both growing in the same soil, usually take from it very various amounts or kinds of mineral matter. For instance, barley plants in flower and red-clover plants in flower contain about the same proportion of mineral matter (left as ashes after burning).. But the clover contains $5 \frac{2}{3}$ times as much lime as the barley, and the latter contains about eighteen times as much silica as the clover. This difference must be due to the selective action of the protoplasm in the absorbing cells of the roots. Traveling by osmotic action from cell to cell, a current of water derived from the root-hairs is forced up through the roots and into the stem, just as the contents of the egg _was forced up into the tube shown in Fig. 24.

66. Root-Pressure. - The force with which the upwardflowing current of water presses may be estimated by attaching a mercury gauge to the root of a tree or the stem of a small sapling. This is best done in early spring after the thawing of the ground, but before the leaves have appeared. The experiment may also be performed indoors upon almost any plant with a moderately firm stem, through which the water from the soil rises freely. A dahlia plant or a tomato plant answers well, though the root-pressure from one of these will not be nearly as great as that from a larger shrub or a tree growing out of doors. In Fig. 25 the apparatus is shown attached to the stem of a dahlia. The difference of level of the merculy in the bent tube serves to measure the root-pressure. For every foot of difference in level there must be a pressure of nearly six pounds per square inch on the stump at the base of the tube $T .^{1}$

1 See Handbook. 
A black-birch root tested in this way at the end of April has given a root-pressure of thirty-seven pounds to the square inch. This would sustain a column of water about eighty-six feet high.

67. Root-Absorption and Temperature of Soil. - It would not be remarkable if the temperature of roots and the earth about them had something to do with the rate at which they absorb water, since this absorption depends on the living protoplasm of the root-hairs (see Sects. 64, 65). An experiment will serve to throw some light on this question.

\section{EXPERIMENT XVII}

Effect of Temperature on Absorption of Water by Roots. - Transplant a tobacco seedling about four inches high into rich earth contained in a narrow, tall beaker or very large test-tube (not less than

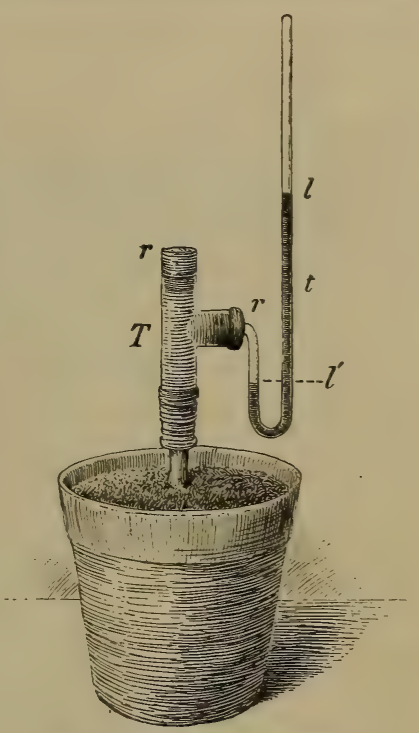

Fig. 25. - Apparatus to Measure Root-Pressure.

$T$, large tube fastened to the stump of the dahlia stem by a rubber tube; $r r$, rubber stoppers; $t$, bent tube containing mercury; $l l$, upper and lower level of mercury in $T$. $1 \frac{1}{4}$ inch in diameter and six inches high). When the plant has begun to grow again freely, in a warm, sunny room, insert a chemical thermometer into the earth, best by making a hole with a sharp round stick, pushed nearly to the bottom of the tube, and then putting the thermometer in the place of the stick. Water the plant well, then set the tube in a jar of pounded ice which reaches nearly to the top of the tube. Note the temperature of the earth just before placing it in the ice. Observe whether the leaves of the seedling wilt, 
and, if so, at what temperature the wilting begins. Finally, remove the tube from the ice and place it in warm water (about $80^{\circ}$ ). Observe the effect and note the temperature at which the plant, if wilted, begins to revive. Find an average between the wilting temperature and the reviving temperature. For what does this average stand?

68. Movements of Young Roots. - The fact that roots usually grow downward is so familiar that we do not generally think of it as a thing that needs discussion or explanation. Since they are pretty flexible, it may seem as though young and slender roots merely hung down by their own weight, like so many bits of wet cotton twine. But a very little experimenting will answer the question whether this is really the case.

\section{EXPERIMENT XVIII}

Do all Parts of the Root of the Windsor Bean Seedling bend downward alike? - Fasten some sprouting Windsor beans with roots about an inch in length to the edges of a disk of pine wood or other soft wood in a soup-plate nearly full of water and cover them with a low bell-jar. Pins run through the cotyledons, as in Fig. 26, will hold the beans in place. When the roots have begun to point downward strongly, turn most of the beans upside down and pin them in the reversed position. If you choose, after a few days reverse them again. Make sketches of the various forms that the roots assume and discuss these.

\section{EXPERIMENT XIX}

Does the Windsor Bean Root-Tip press downward with a Force greater than its 0wn Weight? - Arrange a sprouted bean as shown in Fig. 26, selecting one that has a root about twice as long as the diameter of the bean and that has grown out horizontally, having been sprouted on a sheet of wet blotting paper. The bean is pinned 
to a cork that is fastened with beeswax and resin mixture to the side of a little trough or pan of glass or glazed earthenware. The pan is filled half an inch or more with mercury, and on top of the mercury is a layer of water. The whole is closely covered by a large tumbler or a bell-glass. Allow the apparatus to stand until the root has forced its way down into the mercury. Then run a slender needle into the root where it enters the mercury (to mark

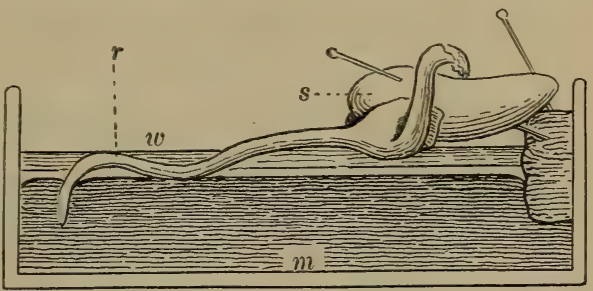

Frg. 26. - A Sprouting Windsor Bean pushing its Root-Tip into Mercury. $s$, seed ; $r$, root ; $w$, layer of water ; $m$, mercury. the exact level), withdraw the root, and measure the length of the part submerged in mercury. To see whether this part would have stayed under by virtue of its own weight, cut it off and lay it on the mercury. Push it under with a pair of steel forceps and then let go of it. What does it do?

69. Discussion of Exp. XIX. - By comparing the weights of equal bulks of mercury and Windsor bean roots, it is found that the mercury is about fourteen times as heavy as the substance of the roots. Evidently, then, the submerged part of the root must have been held under by a force about fourteen times its own weight. Making fine equidistant cross-marks with ink along the upper and the lower surface of a root that is about to bend downward at the tip, readily shows that those of the upper series soon come to be farther apart, — in other words, that the root is forced to bend downward by the more rapid growth of its upper as compared with its under surface.

70. Geotropism. - The property which plants or their organs manifest, of assuming a definite direction with 
reference to gravity, ${ }^{1}$ is called geotropism. When, as in the case of the primary root, the effect of gravity is to make the part if unobstructed turn or move downward, we say that the geotropism is positive. If the tendency is to produce upward movement, we say that the geotropism is negative; if horizontal movement, that it is lateral. It was stated in the preceding section that the direct cause of the downward extension of roots is unequal growth. We might easily suppose that this unequal growth is not due to gravity, but to some other cause. To test this supposition, the simplest plan (if it could be carried out) would be to remove the plants studied to some distant region where gravity does not exist. This of course cannot be

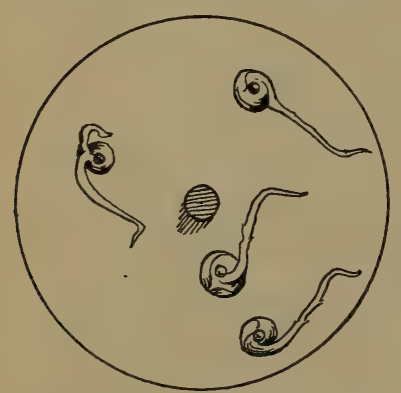

Frg. 27.-Sprouting Peas, on the Disk of a rapidjy Whirling Clinostat.

The youngest portions of the roots all point directly away from the axis about which they were revolved.

done, but we can easily turn a young seedling over and over so that gravity will act on it now in one direction, now in another, and so leave no more impression than if it did not act at all (Exp. XX). Or we can whirl a plant so fast that not only is gravity done away with, but another force is introduced in its place. If a vertical wheel, like a carriage wheel, were provided with a few loosely fitting iron rings strung on the spokes, when the wheel was revolved rapidly the rings would all fly out to the rim of the wheel. So in Fig. 27 it will be

1 Gravity means the pull which the earth exerts upon all objects on or near its surface. 
noticed that the growing tips of the roots of the sprouting peas point almost directly outward from the center of the disk on which the seedlings are fastened. Explain the difference between this result and that obtained in Exp. XX.

\section{EXPERIMENT XX}

How do Primary Roots point when uninfluenced by Gravity? Pin some soaked Windsor beans to a large flat cork, cover them with thoroughly moistened chopped peat-moss, and cover this with a thin glass crystallizing dish. Set the cork on edge. Prepare another cork in the same way, attach it to a clinostat, and keep it slowly revolving in a vertical position for from three to five days. Compare the directions taken by the roots on the stationary and on the revolving cork. ${ }^{1}$

71. Direction taken by Secondary Roots. - As the student has already noticed in the seedlings which he has studied, the branches of the primary root usually make a considerable angle with it (Fig. 2). Often they run out for long distances almost horizontally. This is especially common in the roots of forest trees, above all in conebearing trees, such as pines and hemlocks. This horizontal or nearly horizontal position of large secondary roots is the most advantageous arrangement to make them useful in staying or guying the stem above, to prevent it from being blown over by the wind.

72. Fitness of the Root for its Position and Work. - The distribution of material in the woody roots of trees and shrubs and their behavior in the soil show many adaptations to the conditions by which the roots are surrounded.

1 See Ganong's Teaching Rotanist, pp. 182-186, for complete directions. The brief statement above given is abstracted from that of Professor Ganong. 
The growing tip of the root, as it pushes its way through the soil, is exposed to bruises; but these are largely warded off by the root-cap. The tip also shows a remarkable sensitiveness to contact with hard objects, so that when touched by one it swerves aside and thus finds its way downward by the easiest path. Roots with an unequal water supply on either side grow toward the moister soil. Roots are very tough, because they need to resist strong

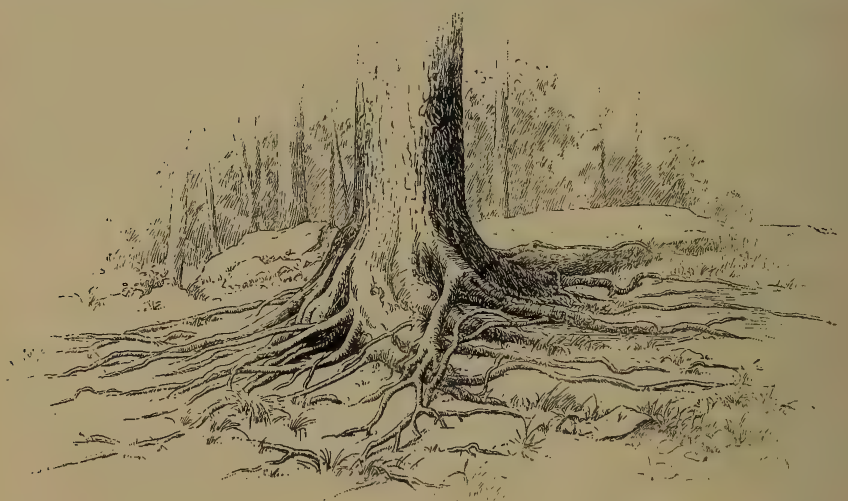

FrG. 28. - Roots of a Western Hemlock exposed by having most of the Leaf-Mould about them burned away by Forest Fires.

pulls, but not as stiff as stems and branches of the same size, because they do not need to withstand sildewise pressure, acting from one side only. The corky layer which covers the outsides of roots is remarkable for its power of preventing evaporation. It must be of use in retaining in the root the moisture which otherwise might be lost on its way from the deeper rootlets (which are buried in damp soil), through the upper portions of the root-system, about which the soil is often very dry. 
73. Propagation by Means of Roots. - Some familiar plants, such as rose bushes, are usually grown from roots or root-cuttings.

Bury a sweet potato or a dahlia root in damp sand, and watch the development of sprouts from adventitious buds. One sweet potato will produce several such crops of sprouts, and every sprout may be made to grow into a new plant. It is in this way that the crop is started wherever the sweet potato is grown for the market.

\section{Tabular Review of Experiments.}

[Continue the table begun at end of Chapter III.]

\section{Review Summary of Roots.}

Kinds of roots as regards origin ..... \{

Kinds as regards medium in which they grow . \{

Structure of root of a tree.

'Storage in roots . . . . . . . . . . . . $\begin{aligned} & \text { materials. } \\ & \text { location. } \\ & \text { uses. }\end{aligned}$

Absorption of water by roots . . . . . $\left\{\begin{array}{l}\text { apparatus. } \\ \text { amount. } \\ \text { proofs. } \\ \text { causes. }\end{array}\right.$

Movements of roots . . . . . . . $\left\{\begin{array}{l}\text { nature. } \\ \text { causes. } \\ \text { uses. }\end{array}\right.$ 


\section{CHAPTER V}

\section{STEMS}

76. What the Stem is. - The work of taking in the raw materials which the plant makes into its own food is done mainly by the roots and the leaves. These raw materials are taken from earth, from water, and from the air (see Chapter XI). The stem is that part or organ of the plant which serves to bring roots and leaves into communication with each other. In most flowering plants the stem also serves the important purpose of lifting the leaves up into the sunlight, where alone they best can do their special work.

The student has already, in Chapter III, learned something of the development of the stem and the seedling; he has now to study the external appearance and internal structure of the mature stem. Much in regard to this structure can conveniently be learned from the examination of twigs and branches of our common forest trees in their winter condition.

77. The Horse-Chestnut Twig. ${ }^{1}$ - Procure a twig of horse-chestnut eighteen inches or more in length. Make a careful sketch of it, trying to bring out the following points:

(1) The general character of the bark.

1 Where the buckeye is more readily obtained it will do very well. Hickory twigs answer the same purpose, and the latter is a more typical form, having alternate buds. The magnolia or the tulip tree will do. The student should (sooner or later) examine at least one opposite- and one alternate-leaved twig. 
(2) The large horseshoe-shaped scars and the number and position of the dots on these scars. Compare a scar with the base of a leaf-stalk furnished by the teacher.

(3) The ring of narrow scars around the stem in one or more places, ${ }^{1}$ and the different appearance of the bark above and below such a ring. Compare these scars with those left after removing the scales of a terminal bud and then see Fig. 29, $b s c$.

(t) The buds at the upper margin of each leafscar and the strong terminal bud at the end of the twig.

(5) The flower-bud scar, a concave impression, to be found in the angle produced by the forking of two twigs, which form, with the branch from which they spring, a Y-shaped figure (see Fig. 36).

(6) (On a branch larger than the twig handed round for individual study) the place of origin of the twigs on the branch; - make a separate sketch of this.

The portion of stem which originally bore any pair of leaves is called a node, and the portions of stem between nodes are called internodes.

Describe briefly in writing alongside the sketches any observed facts which the drawings do not show.

If your twig was a crooked, rough-barked, and slow-growing one, exchange it for a smooth, vigorous one, and note the differences. Or if you sketched a quickly grown shoot, exchange for one of the other kind.

Answer the following questions :

(a) How many inches did your twig grow during the last summer?

How many in the summer before?

How do you know?

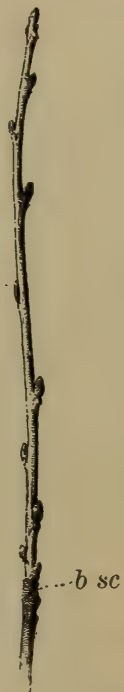

FIG. 29. - A quickly grown $\mathrm{Tw}$ ig of Cherry, with Lateral and Terminal Buds in October.

b sc, bud-scale scars.

All above these scars is the growth of the spring and $\mathrm{summer}$ of $\mathrm{the}$ same year.

How many years old is the whole twig given you?

(b) How were the leaves arranged on the twig?

${ }^{1}$ A very vigorous shoot may not show any such ring. 
How many leaves were there?

Were they all of the same size?

(c) What has the mode of branching to do with the arrangement of the leaves? with the flower-bud scars?

(d) The dots on the leaf-scars mark the position of the bundles of ducts and wood-cells which run from the wood of the branch through the leaf-stalk up into the leaf.

78. Twig of Beech. - Sketch a vigorous young twig of beech (or of hickory, magnolia, tulip tree) in its winter condition, noting particularly the respects in which it differs from the horse-chestnut. Describe in writing any facts not shown in the sketch. Notice that the buds are not opposite, nor is the next one above any given bud found directly above it, but part way round the stem from the position of the first one. Ascertain, by studying several twigs and counting around, which bud is above the first and how many turns round the stem are made in passing from the first to the one directly above it.

Observe with especial care the difference between the beech and the horse-chestnut in mode of branching, as shown in a large branch provided for the study of this feature.

79. Relation of Leaf-Arrangement to Branching. ${ }^{1}$ - This difference, referred to in Sect. 78, depends on the fact that the leaves of the horse-chestnut were arranged in pairs, on opposite sides of the stem, while those of the beech were not in pairs. Since the buds are found at the upper edges of the leaf-scars, and since most of the buds of the horsechestnut and the beech are leaf-buds and destined to form branches, the mode of branching and ultimately the form

1 The teacher in the Eastern and Middle States will do well to make constant use, in the study of branches and buds, of Miss Newell's Outlines of Lessons in Botany, Part I. The student can observe for himself, with a little guidance from the teacher, most of the points which Miss Newell suggests. If the supply of material is abundant, the twigs employed in the lessons above described need not be used further, but if material is scanty, the study of buds may at once be taken up. (See also Bailey's Lessons with Plants, Part I.) 
of the tree must depend largely on the arrangement of leaves along the stem.

80. Opposite Branching. - In trees the leaves and buds of which are opposite, the tendency will be to form twigs in four rows about at right angles to each other along the sides of the branch, as shown in Fig. 30 .

This arrangement will not usually be perfectly carried out, since some of the buds may never grow,

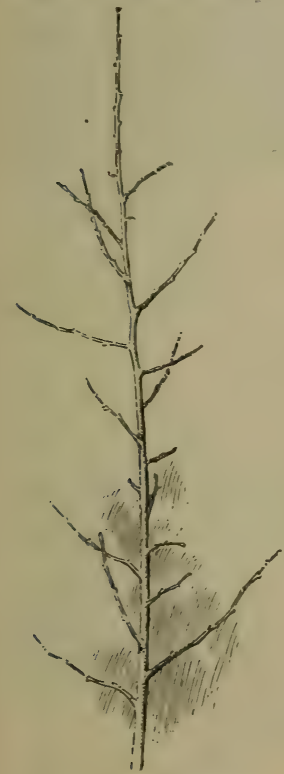

FIG. 31. - Alternate Branching in a very Young Apple Tree. or some may grow $\mathrm{much}$ faster than others and so make the plan of branching less evident than it would be if all grew alike.

81. Alternate Branching. - In

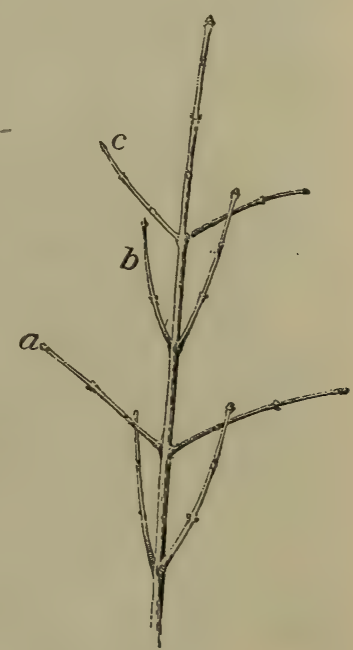

Frg. 30.- Opposite Branching in a very Young Sapling of Ash. trees like the beech the twigs will be found to be arranged in a more or less regular spiral line about the branch. This, which is known as the alternate arrangement (Fig. 31), is more commonly met with in trees and shrubs than the opposite arrangement. It admits of many varieties, since the spiral may wind more or less rapidly round the stem. In the apple, pear, cherry, poplar, oak, and walnut, one passes 


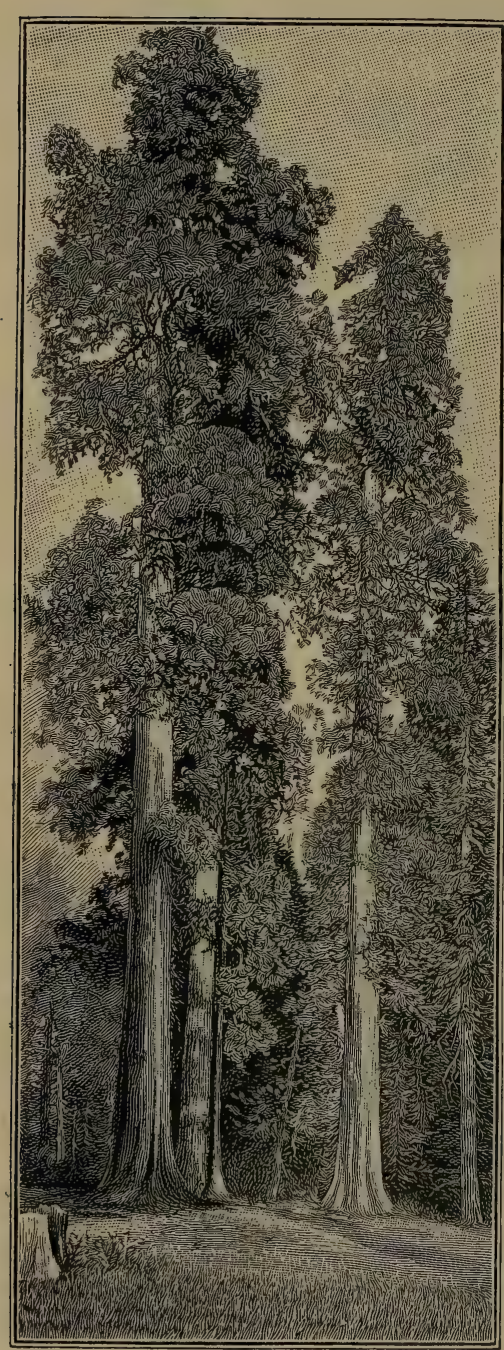

Fig. 32. - Excurrent Trunks of Big Trees (Sequoias). over five spaces before coming to a leaf which is over the first, and in doing this it is necessary to make two complete turns round the stem (Fig. 105).

82. Growth of the Terminal Bud. - In some trees the terminal bud from the very outset keeps the leading place, and the result of this mode of growth is to produce a slender, upright tree, with an excurrent trunk like that of Fig. 32.

In such trees as the apple and many oaks the terminal bud has no preeminence over others, and the form of the tree is round-topped and spreading, deliquescent like that in Fig. 33.

Most of the larger forest trees are intermediate between these extremes.

Branches get their characteristics to a 


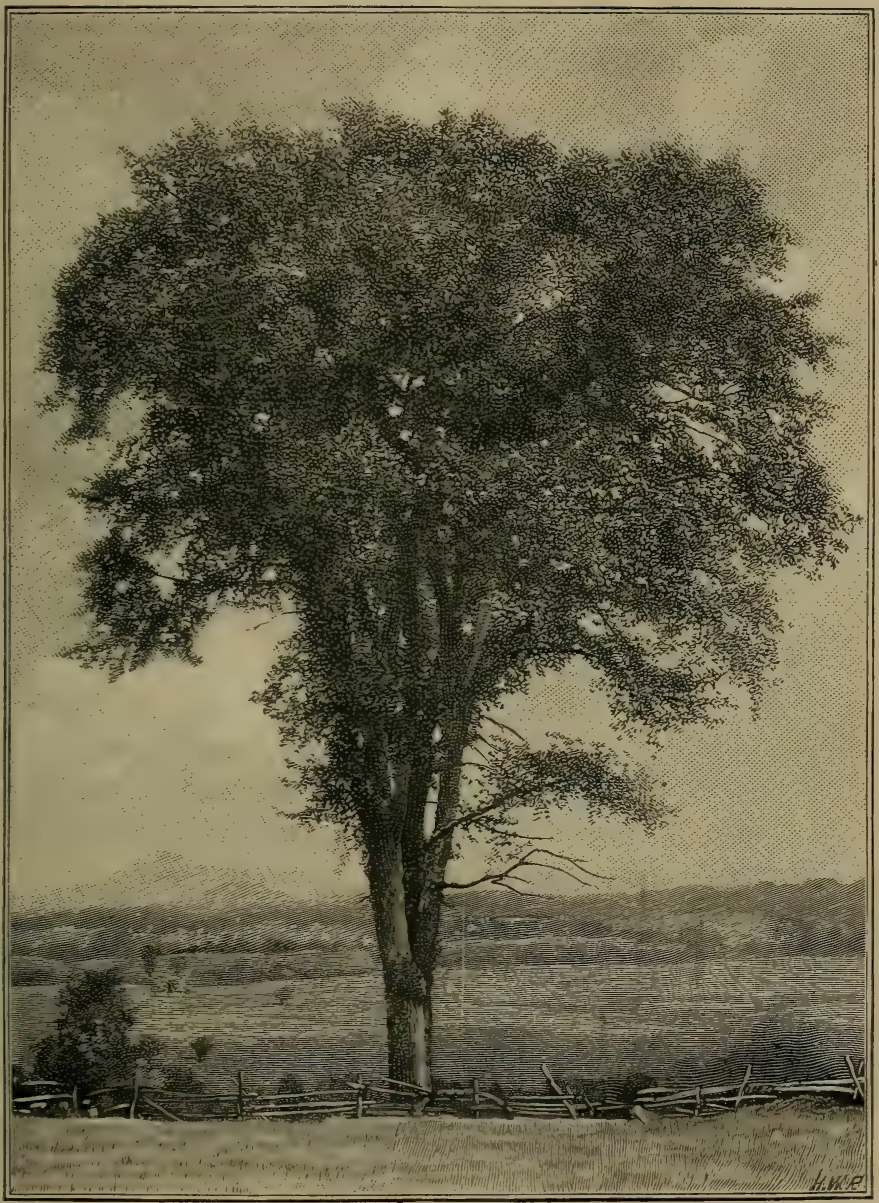

FIG. 33. - An American Elm, with Deliquescent Trunk.

considerable degree from the relative importance of their terminal buds. If these are mainly flower-buds, as is the case in the horse-chestnut and some magnolias (Figs. 35, 36), 
the tree is characterized by frequent forking, and has no long horizontal branches.

If the terminal bud keeps the lead of the lateral ones, but the latter are numerous and most of them grow into slender twigs, the delicate spray of the elm and many birches is produced (Fig. 37).

The general effect of the branching depends much upon the angle which each branch or twig forms with that one from which it springs. The angle may be quite acute, as in the birch; or more nearly a right angle, as in the ash (Fig. 30). The inclination of lateral branches is due to geotropism, just as is that of the branches of primary roots. The vertically upward direction of the shoot which grows from the terminal bud is also due to geotropism.

This is really only a brief way of saying that the growing tip of the main stem of the tree or of any branch is made to take and keep its proper direction, whether vertically upward or at whatever angle is desirable for the tree, by the steering action of gravity. After growth has ceased this steering action can no longer be exerted, and so a tree that has been bent over (as, for instance, by a heavy load of snow) cannot right itself, unless it is elastic enough to spring back when the load is removed. The tip of the trunk and of each branch can grow and thus become vertical, but the old wood cannot do so.

83. Thorns as Branches. - In many trees some branches show a tendency to remain dwarfish and incompletely developed. Such imperfect branches forming thorns are familiar in wild crab-apple trees and in the pear trees which occur in old pastures in the Northeastern States. In the honey locust very formidable branching spines spring 
from adventitious or dormant buds on the trunk or limbs. Such spines sometimes show their true nature as branches by bearing leaves (Fig. 34).

84. Indefinite Annual Growth. - In most of the forest trees, and in the larger shrubs, the wood of young branches is matured and fully developed during the summer. Protected buds are formed on the twigs of these branches to their very tips. In other shrubs - for example, in the sumac, the raspberry, and blackberry - the shoots continue to grow until their soft and immature tips are killed by the frost.

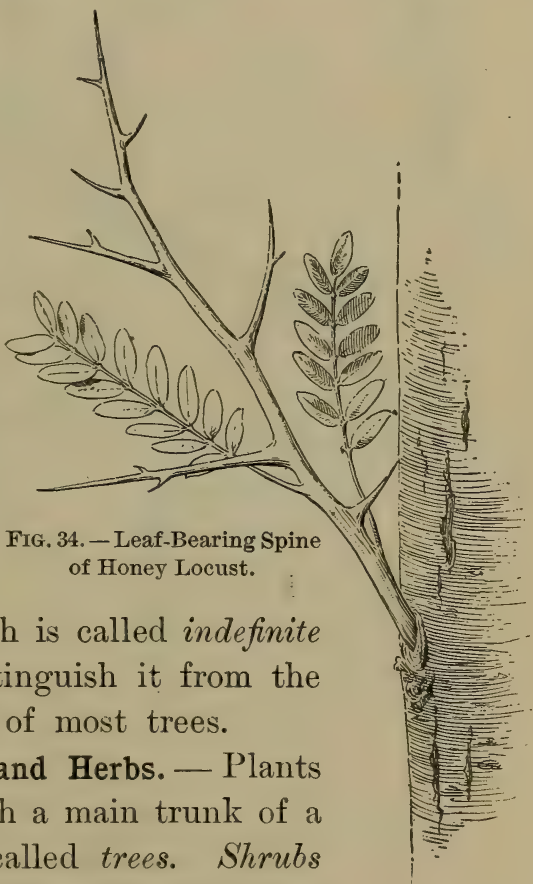
Such a mode of growth is called indefinite annual growth, to distinguish it from the definite annual growth of most trees.

85. Trees, Shrubs, and Herbs. - Plants of the largest size with a main trunk of a woody structure are called trees. Shrubs differ from trees in their smaller size, and generally in having several stems which proceed from the ground or near it or in having much-forked stems. The witch-hazel, the dogwoods, and the alders, for instance, are most of them classed as shrubs for this reason, though in height some of them equal the smaller trees. Some of 
the smallest shrubby plants, like the dwarf blueberry, the wintergreen, and the trailing arbutus, are only a few inches

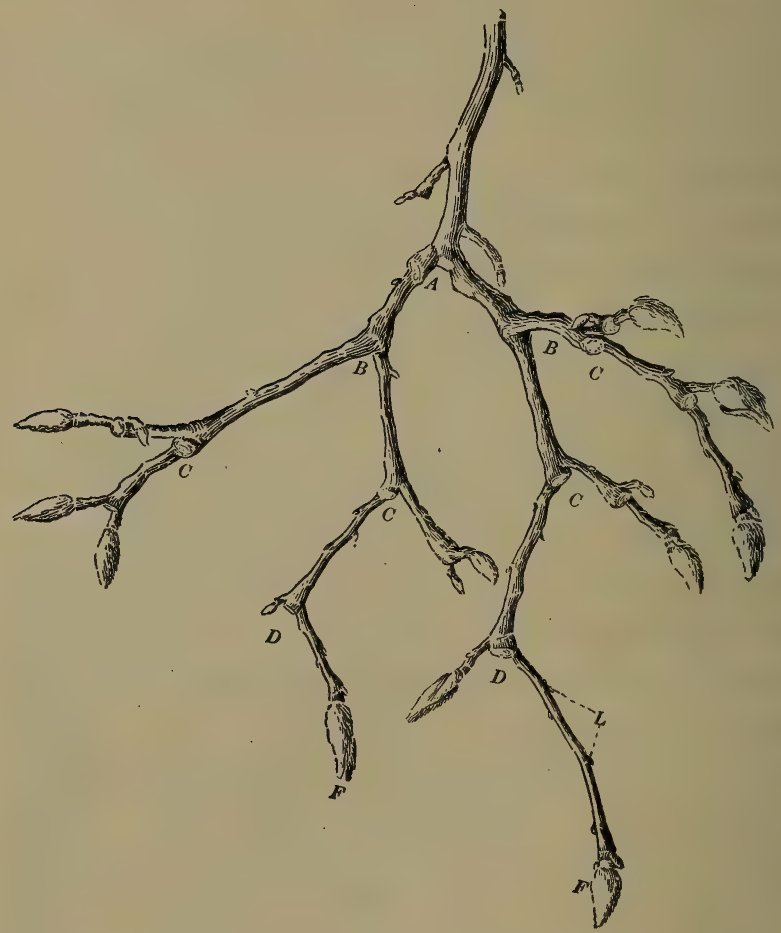

Fig. 35. - Tip of a Branch of Magnolia, illustrating Forking due to Terminal Flower-Buds.

$A$, oldest flower-bud scar ; $B, C, D$, scars of successive seasons after $A ; L$, leafbuds; $F$, flower-buds.

in height, but are ranked as shrubs because their woody stems do not die quite to the ground in winter.

Herbs are plants whose stems above ground die every winter. 
86. Annual, Biennial, and Perennial Plants. - Annual plants are those which live but one year, biennials those which live two years or nearly so.

Some annual plants may be made to live over winter, flowering in their second summer. This is true of winter wheat and rye among cultivated plants.

Perennial plants live for a series of years. Many kinds of trees last for

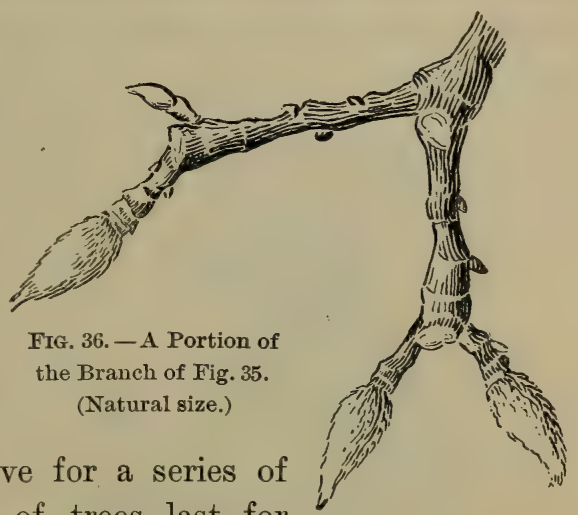
centuries. The Californian giant redwoods, or Sequoias (Fig. 32), which reach a height of over 300 feet under favorable circumstances, live nearly 2000 years ; and some

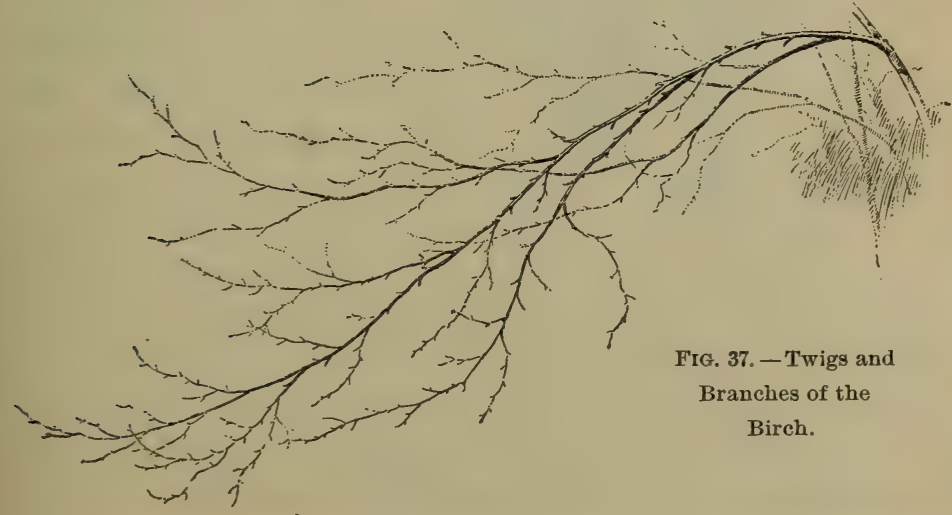

monstrous cypress trees found in Mexico were thought by Professor Asa Gray to be from 4000 to 5000 years old. 
87. Stemless Plants. - As will be shown later (Chapter XXX), plants live subject to a very' fierce competition among themselves and exposed to almost constant attacks from animals.

While plants with long stems find it to their advantage to reach up as far as possible into the sunlight, the cinque-

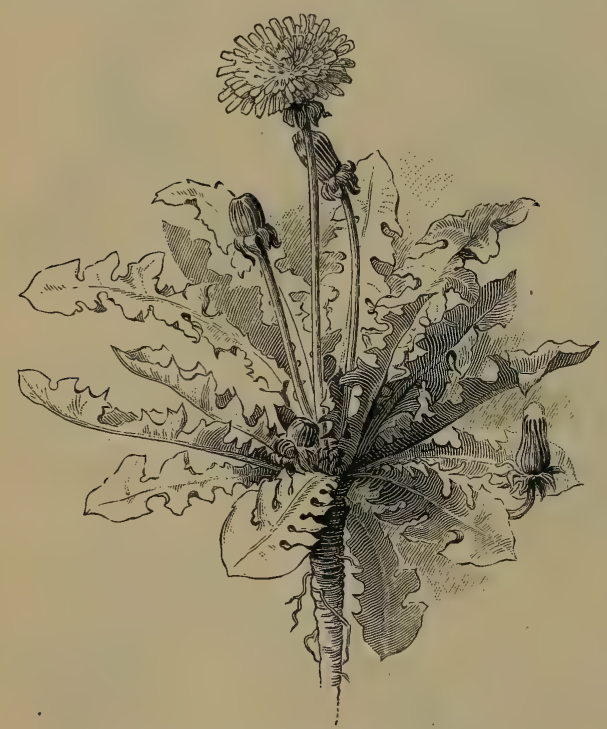

FrG. 38. - The Dandelion ; a so-called Stemless Plant. foil, the white clover, the dandelion, some spurges, the knotgrass, and hundreds of other kinds of plants have found safety in hugging the ground.

Any plant which can grow in safety under the very feet of grazing animals will be especially likely to make its way in the world, since there are many places where it can flourish while ordinary plants would be destroyed. The bitter, stemless dandelion, which is almost uneatable for most animals, unless cooked, which lies too near the earth to be fed upon by grazing animals, and which bears being trodden on with impunity, is a type of a large class of hardy weeds.

The so-called stemless plants, like the dandelion (Fig. 38), and some violets, are not really stemless at all, but send 
out their leaves and flowers from a very short stem, which hardly rises above the surface of the ground.

88. Climbing and Twining Stems. ${ }^{1}$ - Since it is essential to the health and rapid growth of most plants that they should have free access to the sun and air, it is not strange that many should resort to special devices for lifting themselves above their neighbors. In tropical forests, where the darkness of the shade anywhere beneath the tree-tops is so great that few flowering plants can thrive in it, the climbing plants or lianas often run like great cables for hundreds of feet before they can emerge into the sunshine above. In temperate climates no such remarkable climbers are found, but many plants raise themselves for considerable distances. The

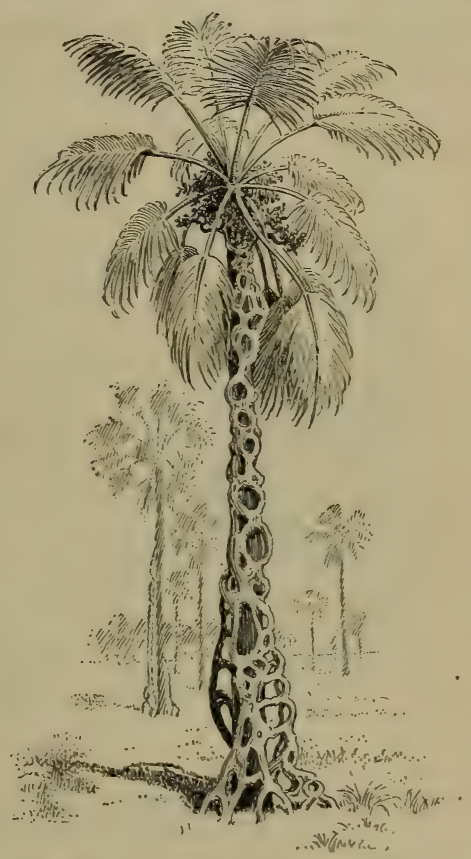

Frg. 39. - Lianas strangling a Palm. principal means to which they resort for this purpose are :

(1) Producing roots at many points along the stem above ground and climbing on suitable objects by means of these, as in the English ivy (Fig. 15).

(2) Laying hold of objects by means of tendrils or twining branches or leaf-stalks, as shown in Figs. 40, 41.

${ }_{1}^{1}$ See Kerner and Oliver's Natural History of Plants, Vol. I, p. 669. 
(3) Twining about any slender upright support, as shown in Fig. 42.

89. Tendril-Climbers. - The plants which climb by means of tendrils are important subjects for study, but they cannot usually be managed very well in the schoolroom. Continued observation soon shows that the tips of

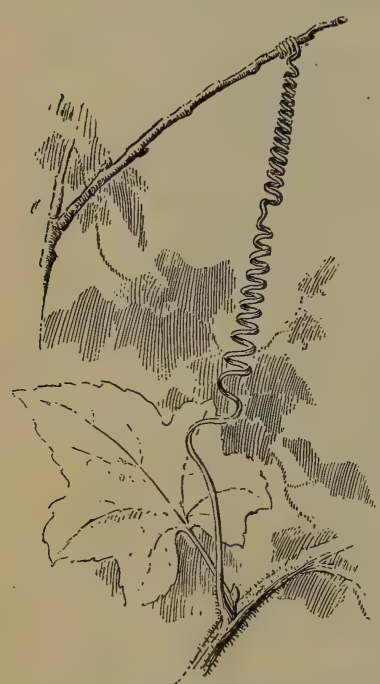

Frg 40.-Coiling of a Tendril of Bryony. tendrils sweep slowly about in the air until they come in contact with some object about which they can coil themselves. After the tendril has taken a few turns about its support, the free part of the tendril coils into a spiral and thus draws the whole stem toward the point of attachment, as shown in Fig. 40. Some tendrils are modified leaves or stipules, as shown in Fig. 104; others are modified stems.

90. Twiners. - Only a few of the upper internodes of the stem of a twiner are concerned in producing the movements of the tip of the stem. This is kept revolving in an elliptical or circular path until it encounters some roughish and not too stout object, about which it then proceeds to coil itself.

The movements of the younger internodes of the stems of twiners are among the most extensive of all the movements made by plants. A hop-vine which has climbed to the top of its stake may sweep its tip continually around the circumference of a circle two feet in diameter, and the 
common wax-plant of the greenhouses sometimes describes a five-foot circle, the tip moving at the rate of thirty-two inches per hour. ${ }^{1}$ This circular motion results from some cause not yet fully understood by botanists. ${ }^{2}$

The direction in which twiners coil about a supporting object is almost always the same for each species of plant, but not the same for all species. In the hop it is as

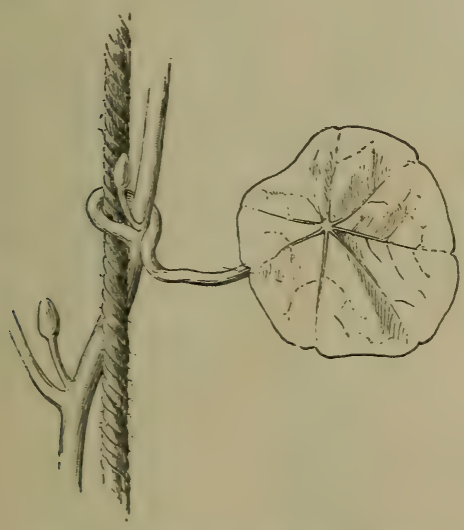

Fig. 41. - Coiling of Petiole of Dwarf Tropæolum.

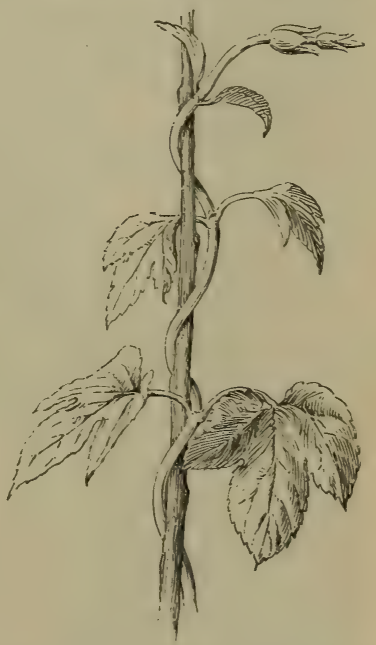

Frg. 42. - Twining Stem of Hop.

shown in Fig. 42. Is it the same as in the bean? in the morning-glory?

91. Underground Stems. - Stems which lie mainly or wholly underground are of frequent occurrence and of many kinds.

In the simplest form of rootstock (Fig. 43), such as is

1 See article on Climbing Plants, by Dr. W. J. Beal, in the American Naturalist, Vol. IV, pp. 405-415.

2 See Strasburger, Noll, Schenk, and Schimper, Text-Book, pp. 258-262 ; also Vines, Students' Text-Book of Botany, London and New York, 1894, pp. 759,760 . 
found in some mints and in many grasses and sedges, the real nature of the creeping underground stem is shown by

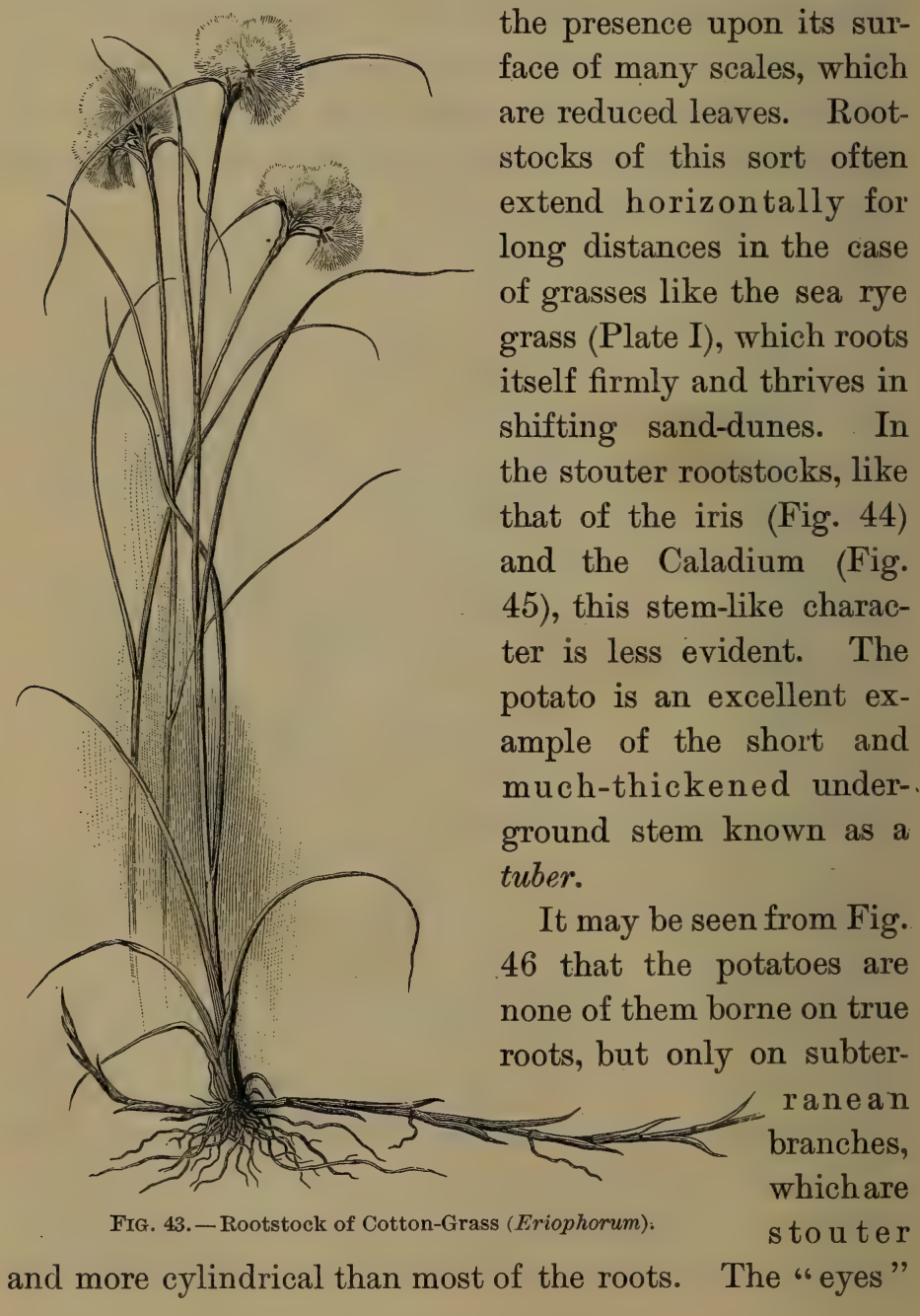




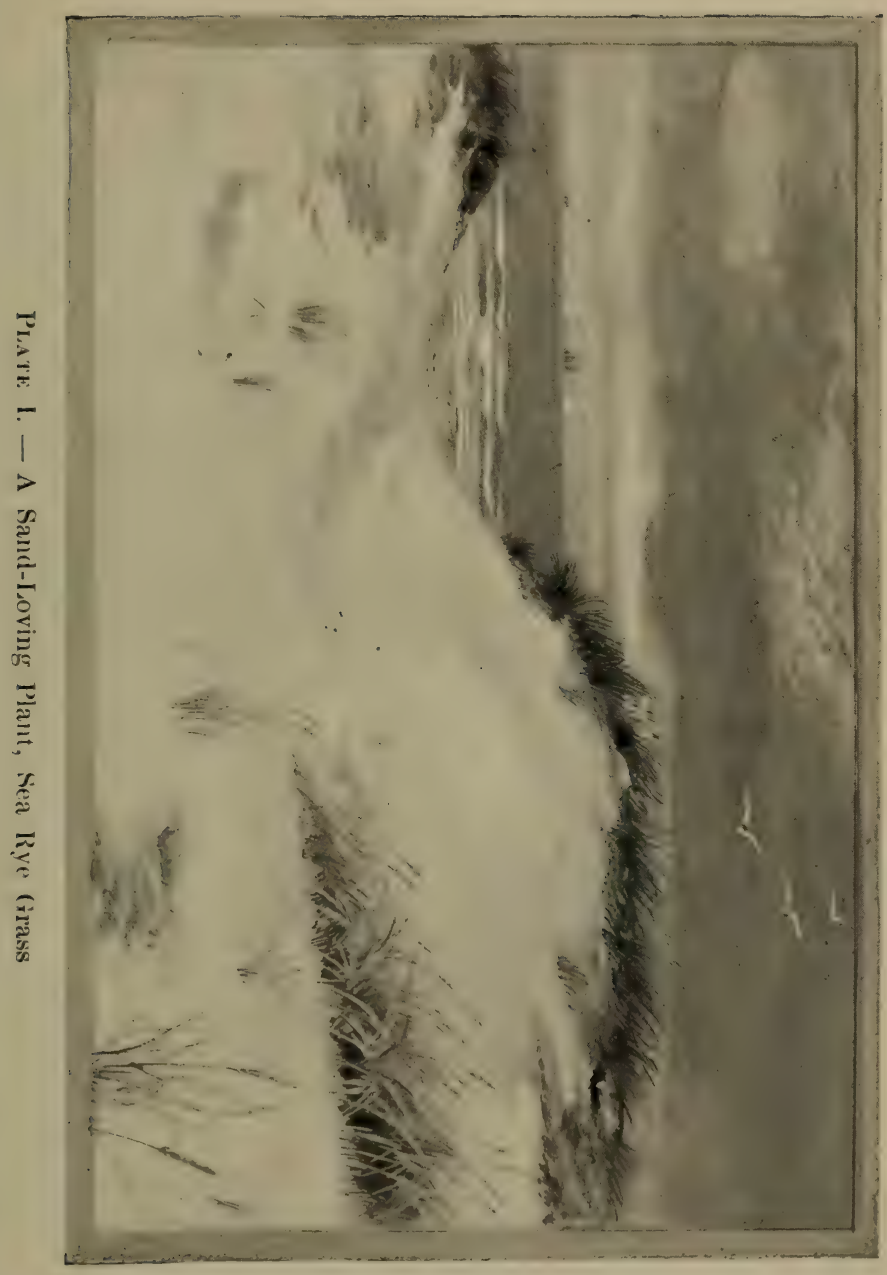





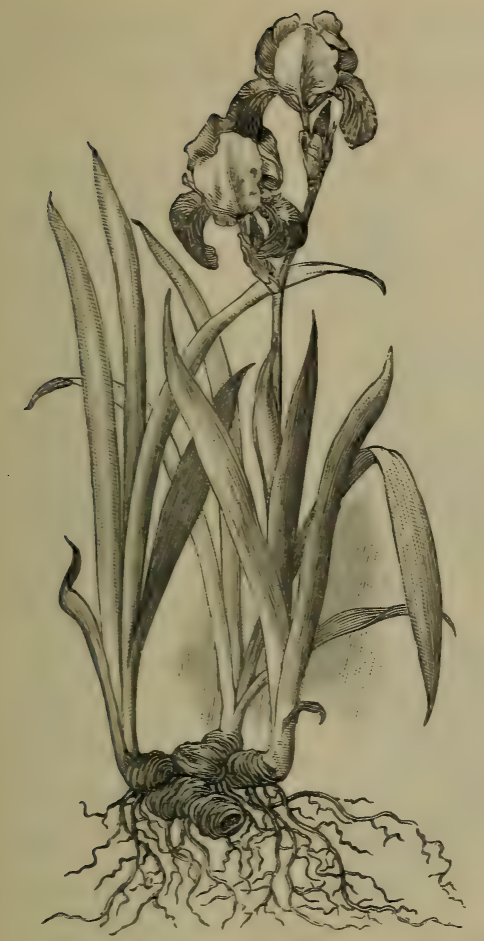

FIG. 44.-Roots, Rootstocks, and Leaves of Iris.

trate in a marked way the storage of nourishment during the winter (or the rainless season, as the case may be) to secure rapid growth during the active season. It is interesting to notice that nearly all of the early-flowering herbs in temperate climates, like the crocus, the snowdrop, the spring-beauty, the which they bear are rudimentary leaves and buds.

Bulbs, whether coated like those of the onion or the hyacinth (Fig. 47), or scaly like those of the lily, are merely very short and stout underground stems, covered with closely crowded scales or layers which represent leaves or the bases of leaves (Fig. 48).

The variously modified forms of underground stems just discussed, illus-

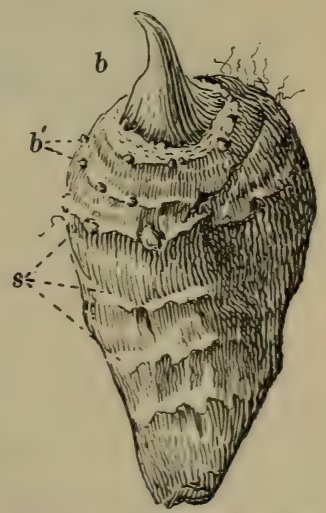

FIG. 45. - Rootstock of Caladium (Colocasia).

$b$, terminal bud; $b^{\prime}$, buds arranged in circles where bases of leares were attached; $s$, scars left by sheathing bases of leaves. 
tulip, and the skunk-cabbage, owe their early-blooming habit to richly stored underground stems of some kind, or to thick, fleshy roots.

92. Condensed Stems. - The plants of desert regions require, above all, protection from the extreme dryness of the surrounding air, and, usually, from the excessive heat

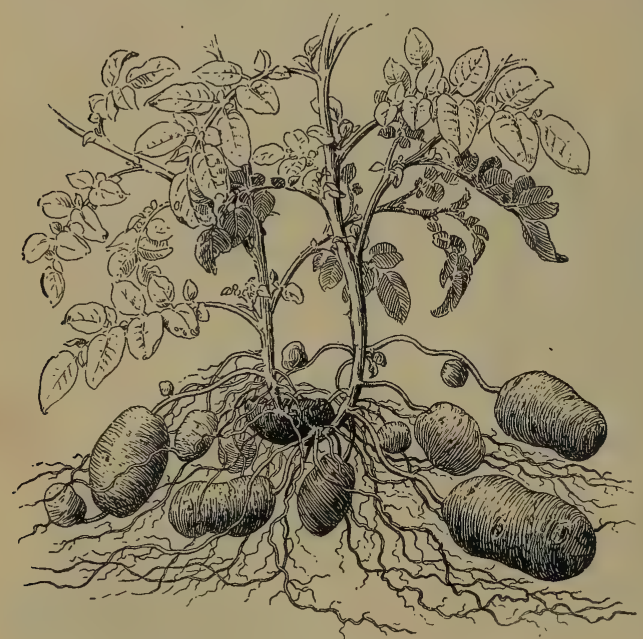

Fig. 46. - Part of a Potato Plant.

The dark tuber in the middle is the one from which the plant has grown. of the sun. Accordingly, many desert plants are found quite destitute of ordinary foliage, exposing to the air only a small surface. In the melon-cactuses (Fig. 49) the stem appears reduced to the shape in which the least possible surface is presented by a plant of given bulk, - that is, in

a globular form. Other cactuses are more or less cylindrical or prismatic, while still others consist of flattened joints ; but all agree in offering much less area to the sun and air than is exposed by an ordinary leafy plant.

93. Leaf-Like Stems. - The flattened stems of some kinds of cactus (especially the common, showy Phyllocactus) are sufficiently like fleshy leaves, with their dark green color and imitation of a midrib, to pass for leaves. There are, 
however, a good many cases in which the stem takes on a more strikingly leaf-like form. The common asparagus
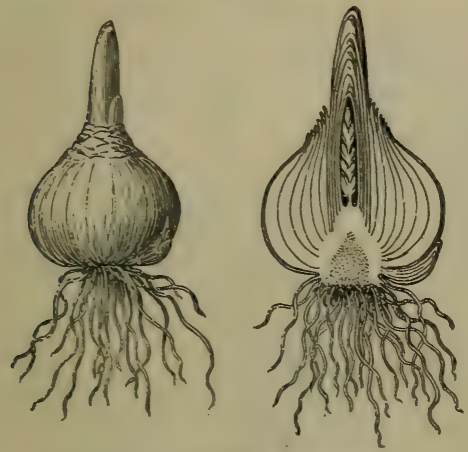

FiG. 47. - Bulb of Hyacinth.

(Exterior view and split lengthwise.) sends up in spring shoots that bear large scales which are really reduced leaves. Later in the season, what seem like thread-like leaves cover the much-branched mature plant, but these green threads are actually minute branches, which perform the work of leaves (Fig. 50). The familiar greenhouse climber, wrongly known as smilax (properly called Myrsiphyllum), bears a profusion of what appear to be delicate green leaves (Fig. 51). Close study, however, shows that these are really short, flattened branches, and that each little branch springs from the axil of a true leaf, $l$, in the form of a minute scale. Sometimes a flower and a leaf-like branch spring from the axil of the same scale.

Branches which, like those of Myrsiphyllum, so closely resemble leaves as to be almost indistinguishable from them are called cladophylls.

94. Modifiability of the Stem. - The stem may, as in the tallest trees, in the great lianas of South American forests, 


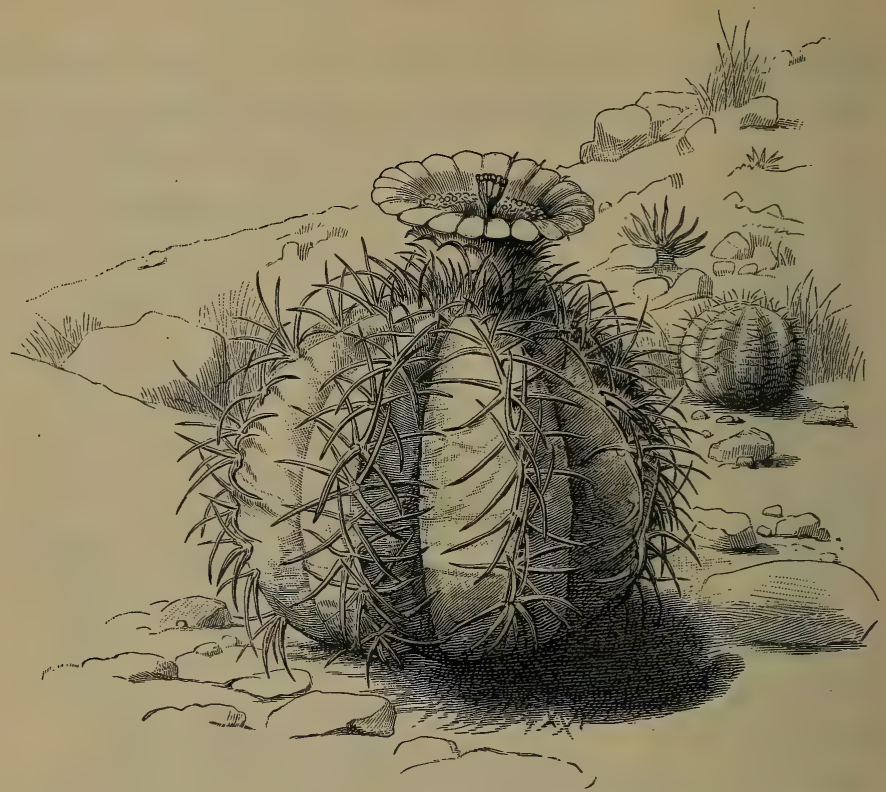

Fig. 49. -A Melon-Cactus.

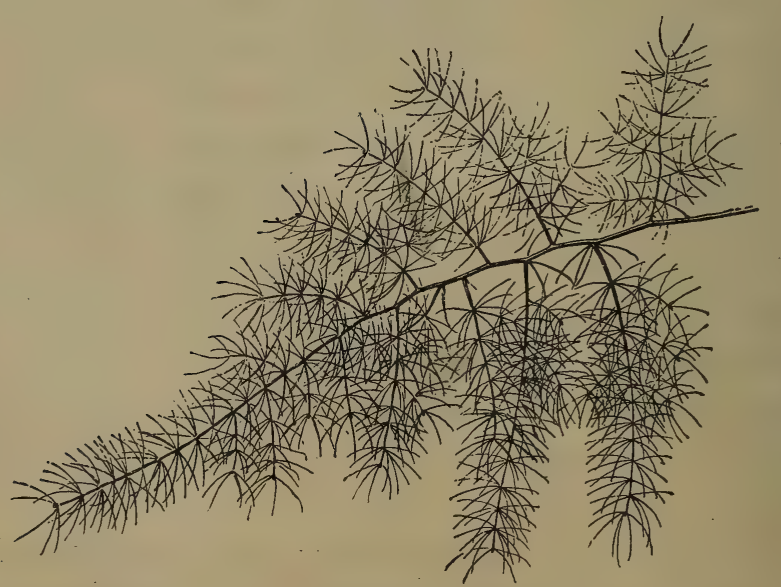

FIG. 50. - A Spray of a Common Asparagus (not the edible species). 
or the rattan of Indian jungles, reach a length of many hundred feet. On the other hand, in such "stemless" plants as the primrose and the dandelion, the stem may be reduced to a fraction of an inch in length. It may take

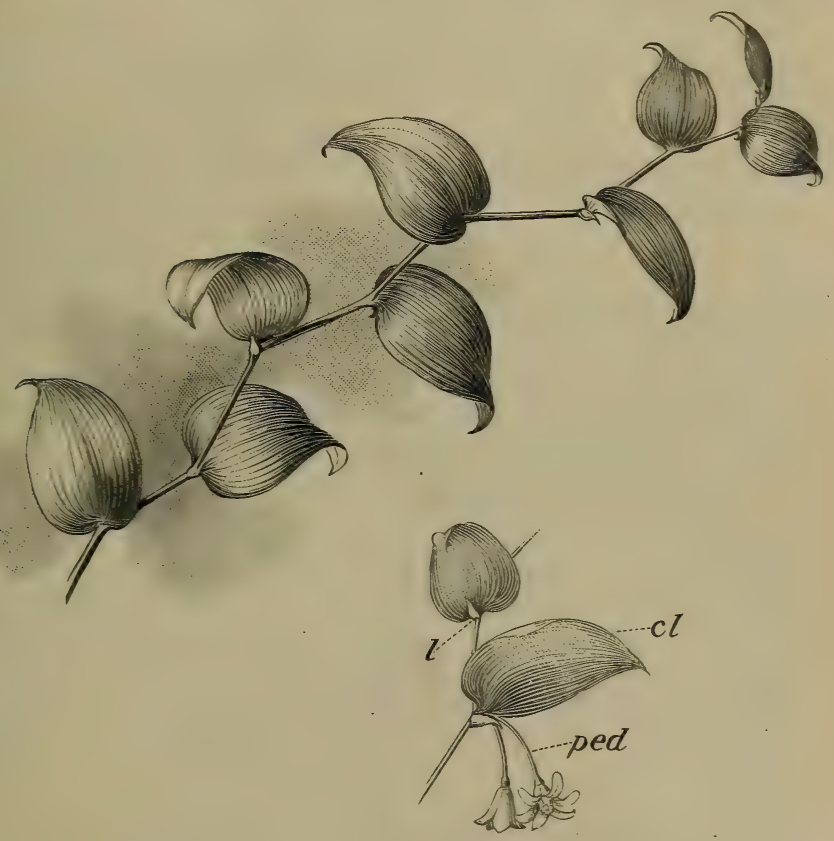

Fig. 51. - Stem of "Smilax" (Myrsiphyllum).

$l$, scale-like leaves; $c l$, cladophyll, or leaf-like branch, growing in the axil of the leaf ; ped, flower-stalk, growing in the axil of a leaf.

on apparently root-like forms, as in many grasses and sedges, or become thickened by underground deposits of starch and other plant-food, as in the iris, the potato, and the crocus. Condensed forms of stem may exist above ground, or, on the other hand, branches may be flat and 
thin enough closely to imitate leaves. In short, the stem manifests great readiness in adapting itself to the most varied conditions of existence.

\section{Review Summary of Stems. ${ }^{1}$}

Kinds of branching due to leaf arrangement ... $\left\{\begin{array}{l}1 . \bullet \\ 2 .\end{array}\right.$

Kinds of tree-trunk due to greater or less predominance $\{1$ of terminal bud . . . . . . . . . . . . . . . . $\left\{\begin{array}{l}1 \\ 2 .\end{array}\right.$

Classes of plants based on amount of woody stem . $\left\{\begin{array}{l}1 . \\ 2 . \\ 3 .\end{array}\right.$

Classes of plants based on duration of life .... $\left\{\begin{array}{l}1 . \\ 2 . \\ 3 .\end{array}\right.$

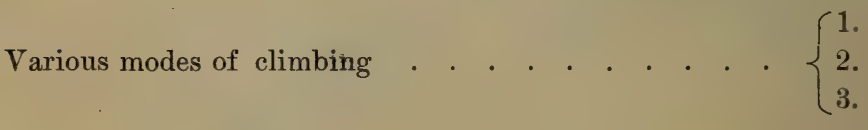

Kinds of underground stem . . . . . . . . . . . $\left\{\begin{array}{l}1 . \\ 2 . \\ 3 .\end{array}\right.$

Condensed stems above ground . . . . . . . . : \{

Leaf-like stems

1 Where it is possible to do so, make sketches; where this is not possible, give examples of plants to illustrate the various kinds or classes of plants in the summary. 


\section{CHAPTER VI}

\section{STRUCTURE OF THE STEM}

\section{STEM OF MONOCOTYLEDONOUS PLANTS}

96. Gross Structure. - Refer back to the sketches of the cornseedling, to recall something of the early history of the corn-stem. Study the external appearance of a piece of corn-stem or bamboo two feet or more in length. Note the character of the outer surface. Sketch the whole piece and label the enlarged nodes and the nearly cylindrical internodes. Cut across a corn-stem and examine the cut surface with the magnifying glass. Make some sections as thin as they can be cut and examine with the magnifying glass (holding them up to the light) or with a dissecting microscope. Note the firm rind, composed of the epidermis and underlying tissue, the large mass of pith composing the main bulk of the stem, and the many little harder and more opaque spots, which are the cut-off ends of the woody threads known as fibrovascular bundles (Fig. 52).

Split a portion of the stem lengthwise into thin translucent slices and notice whether the

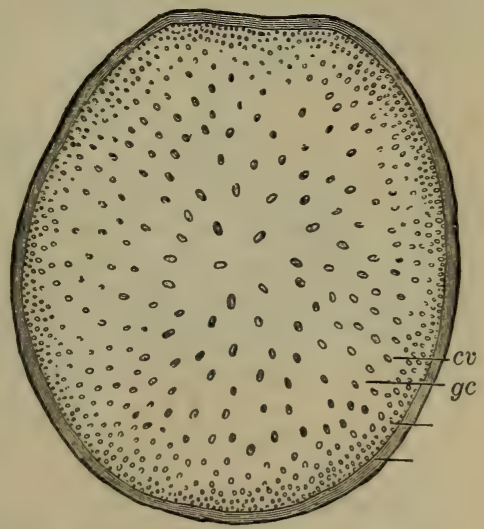

FIG. 52. - Diagrammatic Cross-Section of Stem of Indian Corn.

$c v$, fibro-vascular bundles; gc, pithy material between bundles.

bundles seem to run straight up and down its length; sketch the entire section $\times 2$. Every fibro-vascular bundle of the stem passes outward through some node in order to connect with some fibro-vascular 
bundle of a leaf. This fact being known to the student would lead him to expect to find the bundles bending out of a vertical position more at the nodes than elsewhere. Can this be seen in the stem examined?

Observe the enlargement and thickening at the nodes, and split one of these lengthwise to show the tissue within it.

Compare with the corn-stem a piece of palmetto and a piece of cat-brier (Smilax rotundifolia, S. hispida, etc.), and notice the similarity of structure, except for the fact that the tissue in the palmetto and the cat-brier which answers to the pith of the corn-stem is much darker colored and harder than corn-stem pith. Compare also a piece of rattan and of bamboo.

97. Minute Structure. - Cut a thin cross-section of the corn-stem, examine with a low power of the microscope, and note:

(a) The rind (not true bark), composed largely of hard, thickwalled dead cells, known as sclerenchyma fibers.

(b) The fibro-vascular bundles. Where are they most abundant? least abundant?

(c) The pith, occupying the intervals between the fibro-vascular bundles.

Study the bundles in various portions of the section and notice particularly whether some are more porous than others. Explain.

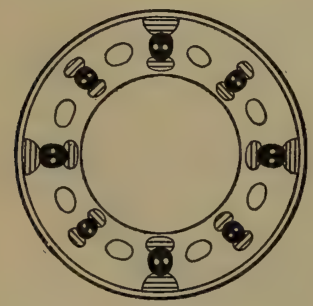

FIG. 53. - Diagrammatic Cross-Section of Stem of Bulrush (Scirpus), a Hollow Cylinder with Strengthening Fibers. Sketch some of the outer and some of the inner ones.

A more coinplicated kind of monocotyledonous stem-structure can be studied to advantage in the surgeons' splints cut from yucca-stems and sold by dealers in surgical supplies.

98. Mechanical Function of the Manner of Distribution of Material in Monocotyledonous Stems. - The well-known strength and lightness of the straw of our smaller grains and of rods of cane or bamboo are due to their form. It can readily be shown 
by experiment that an iron or steel tube of moderate thickness, like a piece of gas-pipe, or of bicycle-tubing, is much stiffer than a solid rod of the same weight per foot. The oat straw, the stems of bulrushes (Fig. 53), the cane (of our southern canebrakes), and the bamboo are hollow cylinders; the cornstalk is a solid cylinder, but filled with a very light pith. The flinty outer layer of the stalk, together with the closely packed sclerenchyma fibers of the outer rind and the frequent fibro-vascular bundles just within this, are arranged in the best way to secure stiffness. In a general

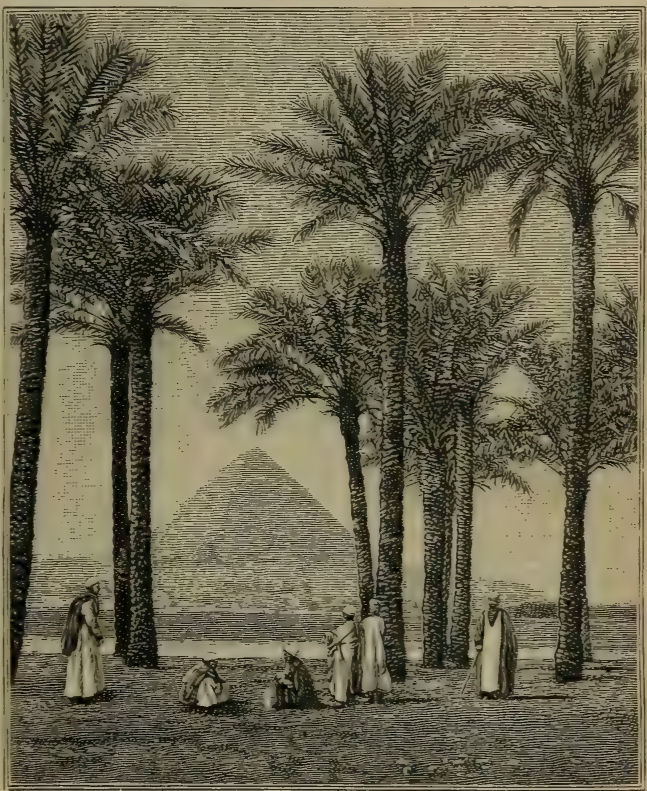

FIG. 54. - Group of Date-Palms. way, then, we may say that the pith, the bundles, and the sclerenchymatous rind are what they are and where they are to serve important mechanical purposes. But they have other uses fully as important (Fig. 78).

99. Growth of Monocotyledonous Stems in Thickness. In most woody monocotyledonous stems, for a reason 
which will be explained later in this chapter, the increase in thickness is strictly limited. Such stems, therefore, as in many palms (Fig. 54) and in rattans, are less conical and more cylindrical than the trunks of ordinary trees and are also more slender in proportion to their height.

\section{STEM OF DICOTYLEDONOUS PLANTS}

100. Gross Structure of an Annual Dicotyledonous Stem. - Study the external appearance of a piece of sunflower-stem several inches long. If it shows distinct nodes, sketch it. Examine the crosssection and sketch it as seen with the magnifying glass or the dissecting microscope. After your sketch is finished, compare it with Fig. 55, which probably shows more details than your drawing, and label the parts shown as they are labeled in that figure. Split a short piece of the stem lengthwise through the center and study the split surface with the magnifying glass. Take a sharp knife or a scalpel and carefully slice and then scrape away the bark until you come to the outer surface of a bundle.

Examine a vegetable sponge ( $L u f f a)$, sold by druggists, and notice that it is simply a network of fibro-vascular bundles. It is the skeleton of a tropical seed-vessel or fruit, very much like that of the wild cucumber, common in the Central States, but a great deal larger.

The different layers of the bark cannot all be well recognized in the examination of a single kind of stem. Examine ( $a$ ) the cork which constitutes the outer layers of the bark of cherry or birch branches two or more years old. Sketch the roundish or oval spongy lenticels on the outer surface of the bark. How far in do they extend? Examine $(b)$ the green layer of bark as shown in twigs or branches of Forsythia, cherry, alder, box-elder, wahoo, or willow. Examine (c) the white, fibrous inner layer, known as hard bast, of the bark of elm, leatherwood, pawpaw, or basswood.

101. Minute Structure of the Dicotyledonous Stem. — Study, first with a low and then with a medium power of the compound microscope, thin cross-sections of clematis-stem cut just before the end of 
the first season's growth. ${ }^{1}$ Sketch the whole section without much detail, and then make a detailed drawing of a sector running from center to circumference and just wide enough to include one of the large bundles. Label these drawings in general like Figs. 55, 56.

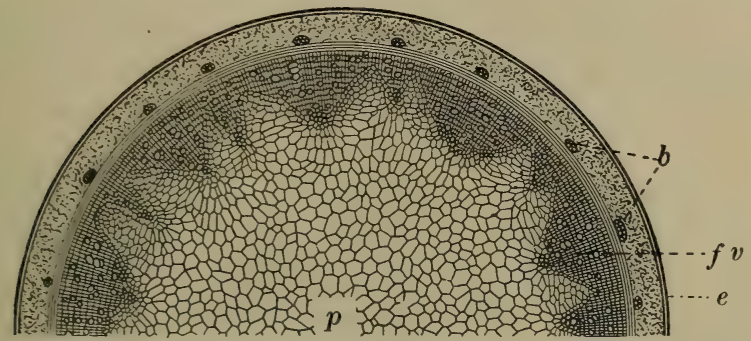

Fig. 55. - Diagrammatic Cross-Section of an Annual Dicotyledonous Stem. (Somewhat magnified.)

$p$, pith ; $f v$, woody or fibro-vascular bundles; $e$, epidermis; $b$, bundles of hard bast fibers of the bark.

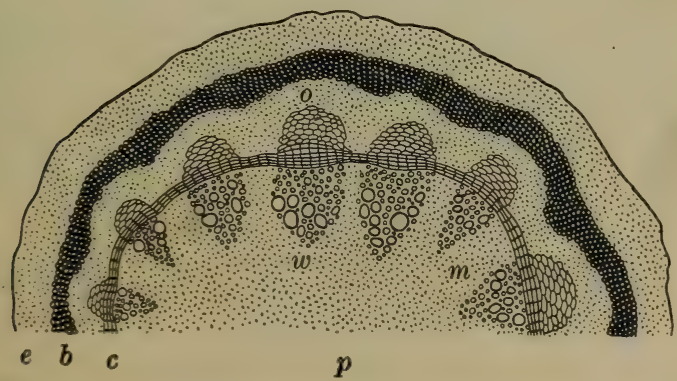

FiG. 56. - Diagrammatic Cross-Section of One-Year-Old Aristolochia Stem.

(Considerably magnified.)

$e$, region of epidermis; $b$, hard bast; $o$, outer or bark part of a bundle (the cellular portion under the letter) ; $w$, inner or woody part of bundle ; $c$, cambium layer; $p$, region of pith ; $m$, a medullary ray.

The space between the hard bast and the bundles is occupied by thin-walled, somewhat cubical cells of the bark.

1 Clematis virginiana is simpler in structure than some of the other woody species. Aristolochia sections will do very well. 
Note :

(a) The general outline of the section.

(b) The number and arrangement of the bundles. (How many kinds of bundles are there?)

(c) The comparative areas occupied by the woody part of the bundle and by the part which belongs to the bark.

(d) The way in which the pith and the outer bark are connected (and the bundles separated) by the medullary rays.

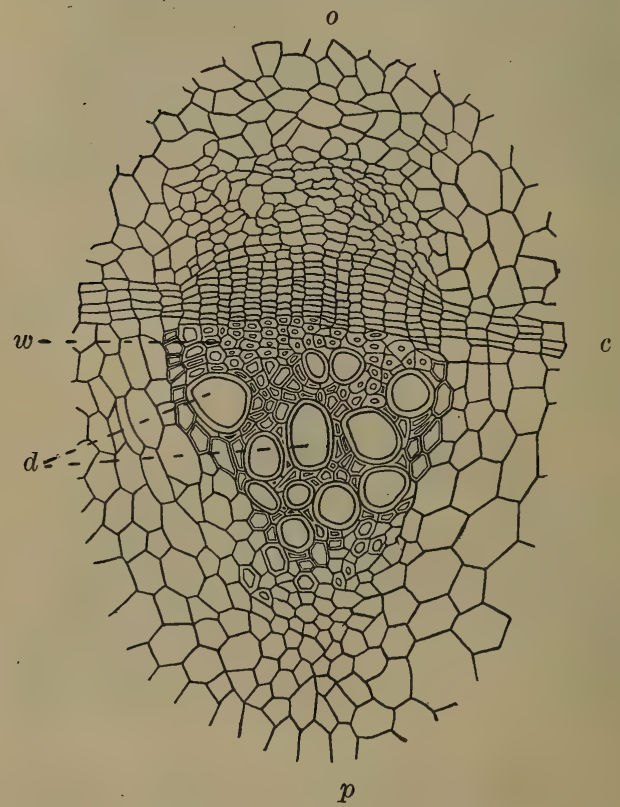

Fig. 57. - One Bundle from the Preceding Figure. ( $x$ 100.)

$w$, wood-cells ; $d$, ducts. The other letters are as in Fig. 56. Many sieve-cells occur in the region just outside of the cambium of the bundle.

Examine a longitudinal section of the same kind of stem, to find out more accurately of what kinds of cells the pith, the bundles, and the outer bark are built. Which portion has cells that are nearly equal in shape, as seen in both sections? 


\section{Mechanical Importance of Distribution of Material} in the Dicotyledonous Stem. - It is easy to see that those tissues which are tough, like hard bast, and those which are both tough and stiff, like wood fibers, are arranged in a tubular fashion in young dicotyledonous stems as they are in some monocotyledonous ones (Fig. 53). Sometimes the interior of the stem is quite hollow, as, for example,

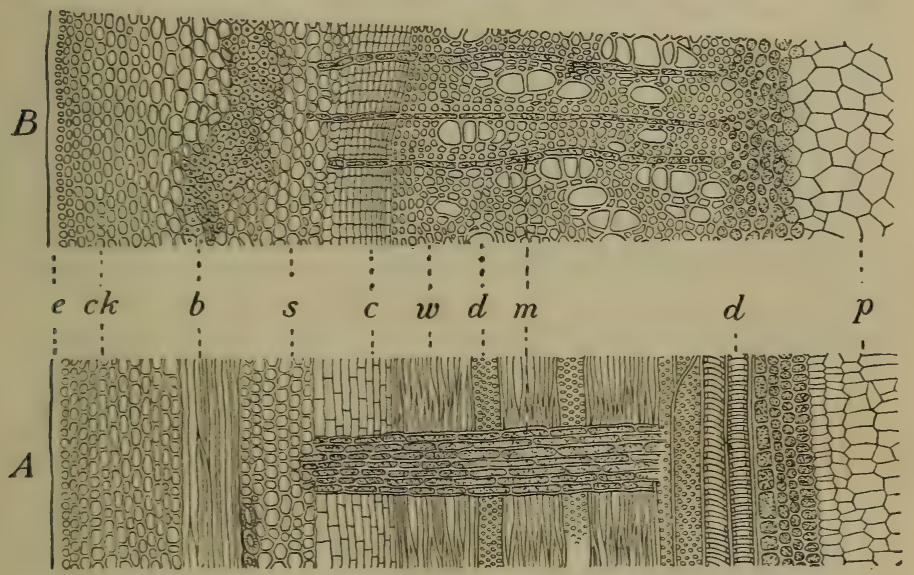

Fig. 58. - Stem of Box-Elder One Year Old. (Much magnified.)

$A$, lengthwise (radial) section ; $B$, cross-section ; $e$, epidermis ; $c k$, cork ; $b$, hard bast ; $s$, sieve-cells ; $c$, cambium ; $w$, wood-cells ; $m$, medullary rays ; $d$, ducts ; $p$, pith.

in the stems of balsams, melons, cucumbers, and squashes, and in the flower-stalks of the dandelion. In older stems, such as the trunks of trees, the wood forms a pretty nearly solid cylinder.

Stiffness in dicotyledonous stems is secured mainly in two ways: (1) by hard bast fibers, (2) by wood fibers. Which of these types does the stem (Fig. 55) represent? Which does the flax-stem (Fig. 60) represent? 
Notice that in both types bast fibers and wood fibers are present, but the proportions in (1) and (2) vary greatly.

103. Kinds of Cells which compose Stems. - The student has already seen something of cells in the seed, in the roots of seedlings and mature plants, and in several kinds of stems. But he will need to become acquainted with a much larger variety of cells in the stem. The following materials will serve to illustrate some of the most important forms. ${ }^{1}$

Examine with a half-inch objective and one-inch eyepiece (or higher power) these preparations (1-9 below):

Study very carefully each of the sections described, find in it the kind of cell referred to in the corresponding number (1-9) of the following section (104), and make a good sketch of a group of cells of each kind as actually seen under the microscope. ${ }^{2}$

(1) Very thin sections of the epidermis of a potato, some cut parallel to the surface (tangential), others cut at right angles to the epidermis.

(2) Thin sections of the green layer of the bark of Forsythia, spindle tree (Euonymus), or box-elder (Negundo).

(3) Thin cross-sections and longitudinal sections of the inner bark of linden twigs, or of full-grown stems of flax.

(4) Longitudinal sections of the stem of squash or cucumber plants.

(5) Thin cross-sections of young twigs of pine or oak, cut in late summer.

(6) Thin cross-sections and longitudinal sections, cut from pith toward bark (radial) of young wood of sycamore, of sassafras, or of box-elder.

(7) Thin longitudinal sections of the stem of castor-oil plant (Ricinus) or of the stalk (peduncle) on which the fruit of the banana is supported.

1 These studies may be made from sections cut by the pupil, by the teacher, or by a professional hand, as circumstances may dictate. The soft bast (No. 4, see p. 91) can best be studied in good prepared sections obtained of the dealers.

2 Nothing can do so much to make these studies valuable as for the teacher to correct in class the errors of most frequent occurrence in the drawings, by aid of his own camera lucida drawings of the same objects. 
(8) Thin longitudinal radial sections of sycamore, of sassafras, maple, or box-elder wood.

(9) Thin sections of elder pith, sunflower-stem pith, or of so-called Japanese "rice-paper."

\section{Names of the Cells of Bark, Wood, and Pith. - No} two varieties of stems will be found to consist of just the

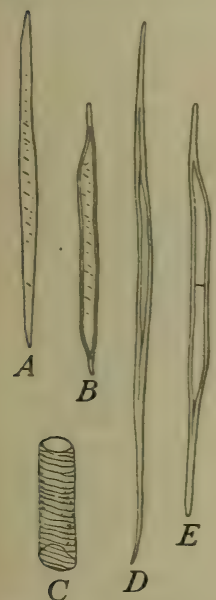

Fig. 59. $-A, B, C$,

$D$, Isolated Wood-

Cells and BastCells of Linden.

$A, B$, wood fibers ; $C$, piece of a vessel; $D$, bast fiber ; $E$, a partitioned, woody fiber from European iry. Much magnified.)

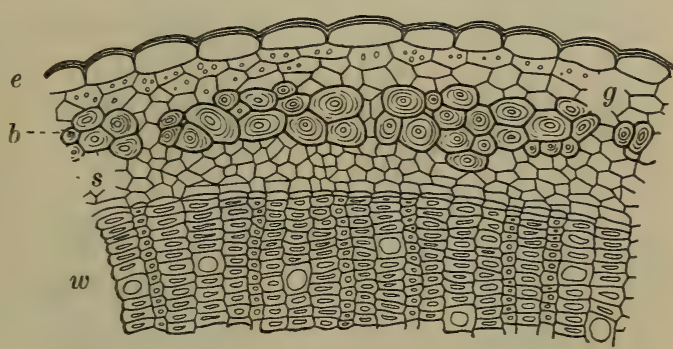

FIG. 60. - Part of Cross-Section of Stem of Flax. (Much magnified.)

$e$, epidermis ; $b$, hard bast ; $s$, sieve-cells ; $v$, wood.

same kinds of cells, present in the same proportions, but it is easy to refer to illustrations which will serve to identify the kinds of cells found in the studies of the preceding section. They are :

(1) Cork-cells of the epidermis (e.g., flax, Fig. $60, e)$.

(2) Cells of the green bark (e.g., flax, Fig. 60), between $b$ and $e$.

(3) Hard bast (Fig. 60).

(4) Soft bast (e.g., flax, Fig. 60, $s$, for the cross-section and (very greatly magnified) Figs. 63, 64, for the lengthwise section). ${ }^{1}$

1 The sieve-tubes shown in these figures are only one of several kinds of cell found in soft bast, but they are the most peculiar and characteristic ones. (See Strasburger, Noll, Schenk, and Schimper's Text-Book, pp. 102-104.) 
(5) Cambium (e.g., Fig. 57, c).

(6) Wood-cells (e.g., Figs. 58, 72-73).

(7) Vessels or ducts (e.g., Figs. 58 and 62).

(8) Wood parenchyma (e.g., Figs. 58 and 72 in the medullary rays).

(9) Pith (e.g., Figs. 55, 57).

105. Structure of Coniferous Wood. - In the wood of the cone-bearing trees of the pine family regular ducts or

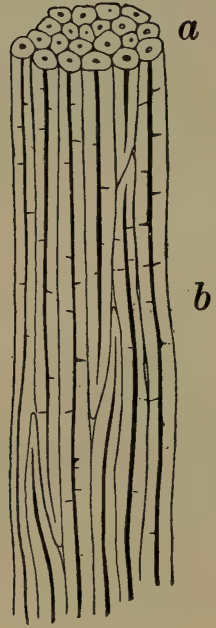

FIG. 61.

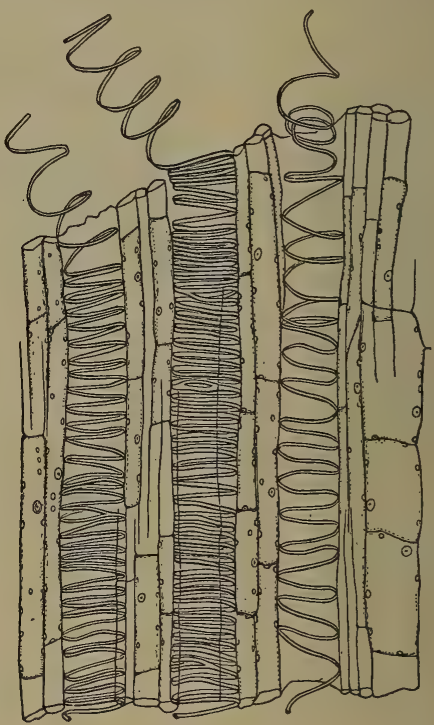

FIG. 62.

FIG. 61. - A Group of Hard Bast Fibers. (Greatly magnified.) $a$, cut-off ends ; $b$, lengthwise section of fibers.

FiG. 62. - A Lengthwise Section (greatly magnified) of a Group of Spiral Vessels from the Stem of Sunflower. At the top of the figure some of the spiral threads which line the vessels are seen partly uncoiled.

vessels are lacking. The main bulk of the wood is composed of long cells (often called tracheids), marked with 
peculiar pits. These pits, when young, are shaped much like two perforated watch-glasses, placed against a piece of cardboard, with their concave sides toward each other

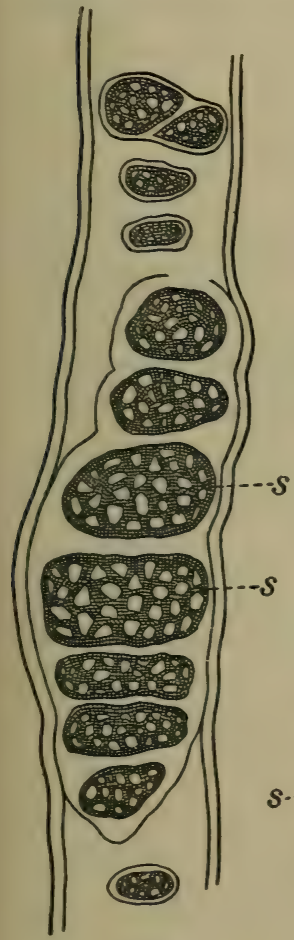

FIG. 63.
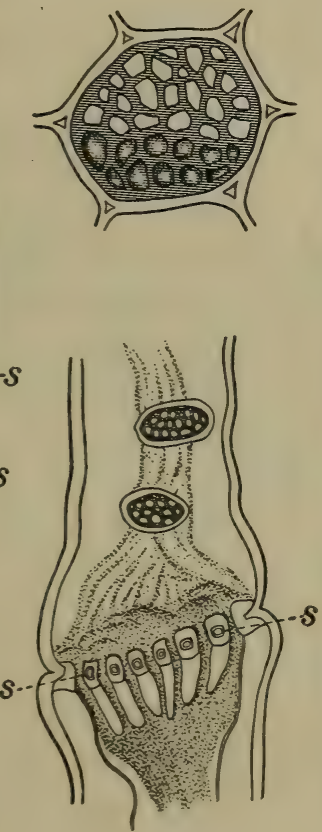

FIG. 64.

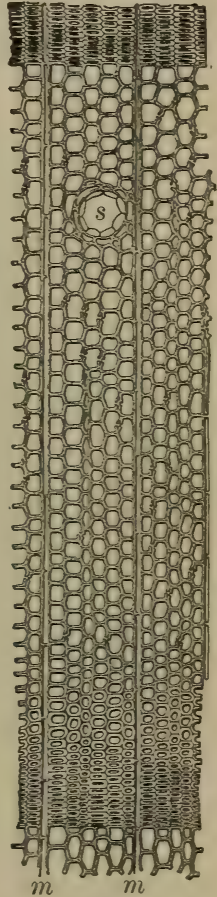

Fig. 65.

FrG. 63. - Part of a Sieve-Tube from Linden.

$s$, sieve-plates on the cell-wall. ( $\times$ about 900.)

Fig. 64. - Parts of Sieve-Tubes as found in Plants of the Gourd Family.

(Greatly magnified.)

$s, s$, a sieve-plate seen edgewise ; above it a similar one, surface view.

FIG. 65. - Cross-Section of Fir Wood.

$s$, a resin passage; $m$, medullary rays. (Much magnified.) 
(see Fig. 66, $\mathrm{t}^{\prime \prime}$ ). The cardboard represents a part of the cell-wall common to two adjacent cells, and the watchglasses are like the convex border bulging into each cell.

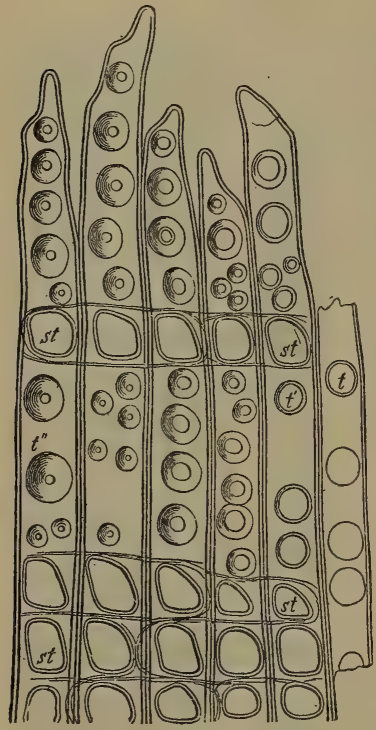

FIG. 66. - Longitudinal Radial Section through a Rapidly Growing Young Branch of Pine.

$t, t^{\prime}, t^{\prime \prime}$, bordered pits on wood-cells ; st, large pits where medullary rays lie against wood-cells. (Much magnified.)

When the cells grow old the partition in each pit very commonly breaks away and leaves a hole in the cell-wall.

106. Tissues. - A mass of similar coöperating cells is called a tissue. ${ }^{1}$ Two of the principal classes which occur in the stem are parenchymatous tissue and prosenchymatous tissue. Parenchyma is well illustrated by the green layer of the bark, by wood parenchyma, and by pith. Its cells are usually somewhat roundish or cubical, at any rate not many times longer than wide, and at first pretty full of protoplasm. Their walls are not generally very thick. ${ }^{2}$ Prosenchyma, illustrated by hard bast and masses of wood-cells, consists of thick-walled cells many times longer than wide, containing little protoplasm and often having little or no cell-cavity.

As a rule the stems of the most highly developed plants owe their toughness and their stiffness mainly to prosen-

1 See Vines' Students' Text-Book of Botany, London, 1894, pp. 131-144.

2 Excepting when they are dead and emptied, like those of old pith. 


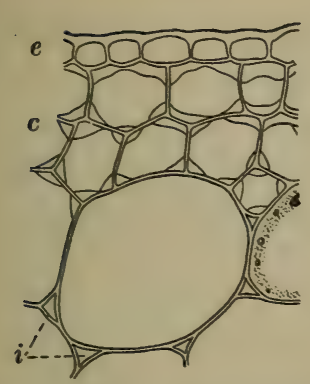

Fig. 67.-Collenchymatous and Other Tissue from Stem of Balsam (Impatiens).

e, epidermis ; $c$, collenchyma; $i$, intercellular spaces between large parenchymacells.

chymatous tissue. In some (particularly in fleshy) stems the stiffness is, however, largely due to collenchyma, a kind of parenchyma in which the cells are thickened or reinforced at their angles, as shown in Fig. 67.

107. Early History of Stem-Structure. - In the very young parts of stems, such, for instance, as the growing point between the two rudimentary leaves of a bean-plumule, the cells are all of thin-walled formative tissue and look a good deal alike. This condition of things is quickly succeeded by one in which there is a cylinder (appearing in cross-sections of the stem as a ring) of actively growing tissue $x$ (Fig. 68, $A$ ), lying between the cortex $r$ and the pith $m$. Soon the cylinder $x$ develops into a series of separate fibro-vascular bundles arranged as shown in Fig. $68, B$, and these again in a short time unite, as shown at $C$. A comparison of this last portion of the figure with that of the

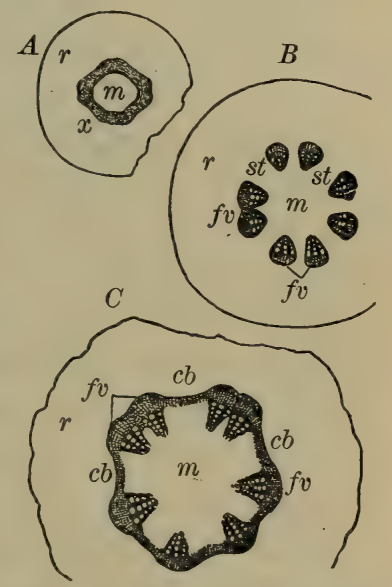

FIG. 68. - Transverse Section through the Hypocotyl of the Castor-Oil Plant at Various Stages.

$A$, after the root has just appeared outside the testa of the seed; $B$, after the hypocotyl is nearly an inch long; $C$, at the end of germination; $r$, cortex (undeveloped bark); $m$, pith; $s t$, medullary rays; $f v$, fibrovascular bundles; $c b$, layer of tissue which is to develop into cambium. (Considerably magnified.) 
one-year-old Aristolochia-stem (Fig. 56) shows a decided similarity between the two. In both cases we have the central pith, the regularly grouped bundles, and cambium (or in Fig. 68, $C$, a tissue which will grow into cambium), - part of it in the bundles and part of it between them.

In the young monocotyledonous stem the grouping of the bundles is less regular than that just explained. This is shown by Fig. 52. A much more important difference consists in the fact that the monocotyledonous stem has usually no permanent living cambium ring. Annual dicotyledons, however, are also destitute of permanent cambium.

108. Secondary Growth. - From the inside of the cambium layer the wood-cells and ducts of the mature stem are produced, while from its outer circumference proceed the new layers of the inner bark, composed largely of sievecells and hard bast. From this mode of increase the stems of dicotyledonous plants are called exogenous, that is, outside-growing. The presence of the cambium layer on the outside of the wood in early spring is a fact well known to the schoolboy, who pounds the cylinder cut from an elder, willow, or hickory branch until the bark will slip off and so enable him to make a whistle. The sweet taste of this pulpy layer, as found in the white pine, the slippery elm, and the basswood, is a familiar evidence of the nourishment which the cambium layer contains.

With the increase of the fibro-vascular bundles of the wood the space between them, which appears relatively large in Fig. 68, becomes less and less, and the pith, which at first extended freely out toward the circumference of the stem, is at length only represented by thin plates, the medullary rays. 
These are of use in storing the food which the plant in cold and temperate climates lays up in the summer and fall for use in the following spring, and in the very young stem they serve as an important channel for the transference of fluids across the stem from bark to pith, or in the

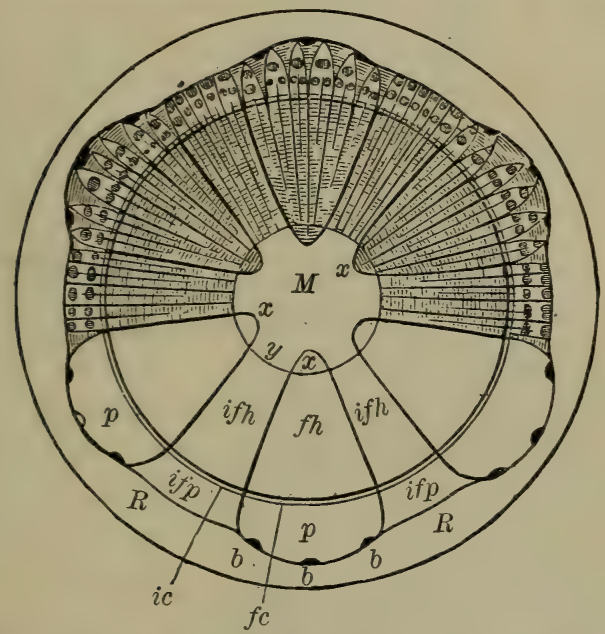

Fig. 69. - Diagram to illustrate Secondary Growth in a Dicotyledonous Stem.

$R$, the first-formed bark ; $p$, mass of sieve-cells ; if $p$, mass of sieve-cells between the original wedges of wood; $f c$, cambium of wedges of wood; $i c$, cambium hetween wedges ; $b$, groups of bast-cells ; $f h$, wood of the original wedges ; ifh, wood formed between wedges ; $x$, earliest wood formed; $M$, pith.

reverse direction. On account, perhaps, of their importance to the plants, the cells of the medullary rays are among the longest lived of all plant-cells, retaining their vitality in the beech tree sometimes, it is said, for more than a hundred years.

After the interspaces between the first fibro-vascular bundles have become filled up with wood, the subsequent 
growth must take place in the manner shown in Fig. 69. All the cambium, both that of the original wedges of wood, $f c$, and that, $i c$, formed later between these wedges, continues to grow from its inner and from its outer face, and thus causes a permanent increase in the diameter of the stem and a thickening of the bark, which, however, usually at an early period begins to peel off from the outside and thus soon attains a pretty constant thickness. ${ }^{1}$ It will be noticed, in the study of dicotyledonous stems more than a year old, that there are no longer any separate fibro-vascular bundles. The process just described has covered the original ring of bundles with layer after layer of later formed wood-cells, and the wood at length is arranged in a hollow cylinder.

It is the lack of any such ring. of cambium as is found in dicotyledonous plants, or even of permanent cambium in the separate bundles, that makes it impossible for the trunks of most palm trees (Fig. 54) to grow indefinitely in thickness, like that of an oak or an elm. ${ }^{2}$

109. Grafting. - When the cambium layer of any vigorously growing stem is brought in contact with this layer in another stem of the same kind or a closely similar kind of plant, the two may grow together to form a single stem or branch. This process is called grafting, and is much resorted to in order to secure apples, pears, etc., of any desired kind. A twig from a tree of the chosen variety is grafted on to any kind of tree of the same species (or sometimes a related species), and the resulting stems will bear the wished-for kind of fruit. Sometimes grafting comes

1 See Vines' Students' Text-Book of Botany, London, 1894, pp. 211, 212.

2 See, however, Strasburger, Noll, Schenk and Schimper's Text-Book, pp. 138, 139. 
about naturally by the branches of a tree chafing against one another until the bark is worn away and the cambium layer of each is in contact with that of the other, or two separate trees may be joined by natural grafting, as is shown in Fig. 70.

110. Stem-Structure of Climbing Shrubs. Some of the most remarkable kinds of dicotyledonous stems are found in climbing shrubs. The structure of many of these is too complicated to be discussed in a botany for beginners, but one point in regard to them is of much interest. The bundles (as seen in the clematis and shown in Fig. 56) are much more distinct than in most other woody stems. Even after several years of growth the wood is often found to be arranged in a number of flattish twisted strands.

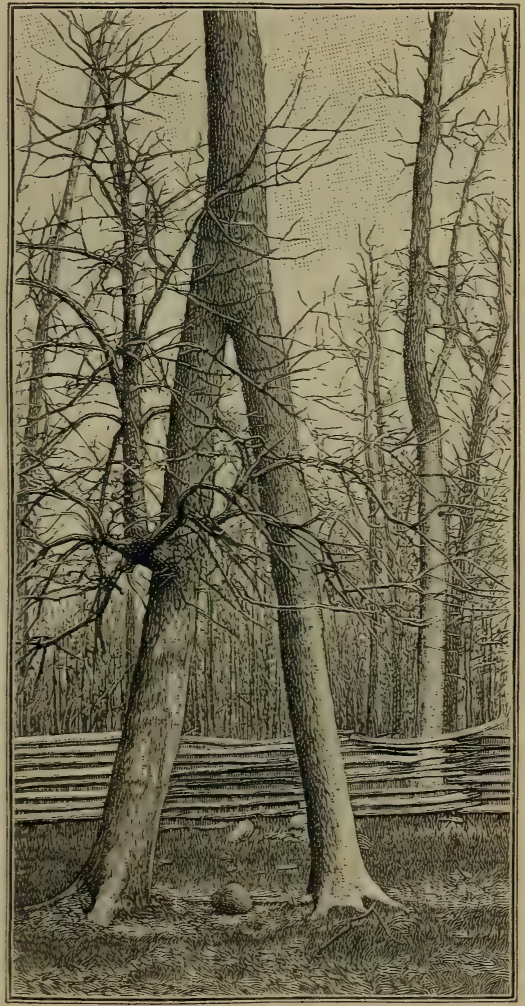

Fig. 70. - Two Ash Trees naturally grafted together.

It is evident that this is for the sake of leaving the stem flexible for twining purposes, just as a wire cable is adapted to be wound about posts or other supports, while L. of C. 
a solid steel or iron rod of the same size would be too stiff for this use.

111. The Dicotyledonous Stem, thickened by Secondary Growth. Cut off, as smoothly as possible, a small branch of hickory and one of white oak above and below each of the rings of scars already mentioned

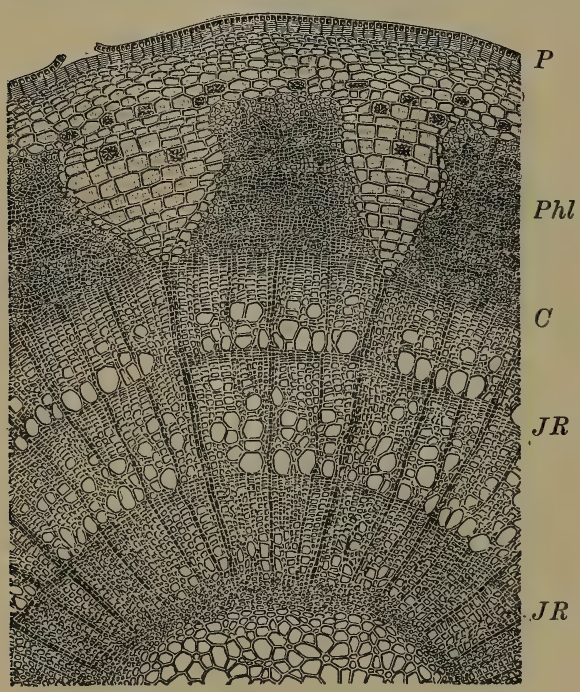

FIG. 71. - Cross-Section of a Three-Year-Old

Linden Twig. (Much magnified.)

$P$, epidermis and corky layer of the bark ; $P h l$, bast ;

$C$, cambium layer; $J R$, annual rings of wood.

(Sect. 77), and count the rings of wood above and below each ring of scars.

How do the numbers correspond? What does Phl this indicate?

Count the rings of wood on the cut-off ends of large billets of some of the following woods: locust, chestnut, sycamore, oak, hickory.

Do the successive rings of the same tree agree in thickness?

Why? or why not?

Does the thickness of the rings appear uniform all the way round the stick of wood? If not, the reason in the case of an upright stem (trunk) is perhaps that there was a greater spread of leaves on the side where the rings are thickest ${ }^{1}$ or because there was unequal pressure, caused by bending before the wind.

Do the rings of any one kind of tree agree in thickness with those of all the other kinds? What does this show?

In all the woods examined look for:

(a) Contrasts in color between the heartwood and the sapwood. ${ }^{2}$

1 See Sect. 118.

2 This is admirably shown in red cedar, black walnut, barberry, black locust and osage orange. 
(b) The narrow lines running in very young stems pretty straight from pith to bark, in older wood extending only a little of the way from center to bark, the medullary rays, shown in Fig. 72.1

(c) The wedge-shaped masses of wood between these.

(d) The pores which are so grouped as to mark the divisions between successive rings. These pores indicate the cross-sections of vessels or ducts. Note the dis-

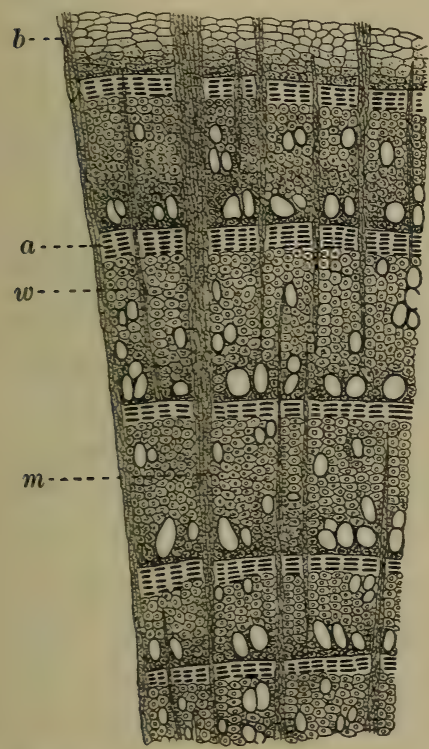

FrG. 72. - Cross-Section of Beech-Wood.

$b$, bark ; $a$, flattened cells formed near end of each year's growth; $w$, regular wood-cells ; $m$, medullary ray. tribution of the vessels in the rings to which they belong, com-

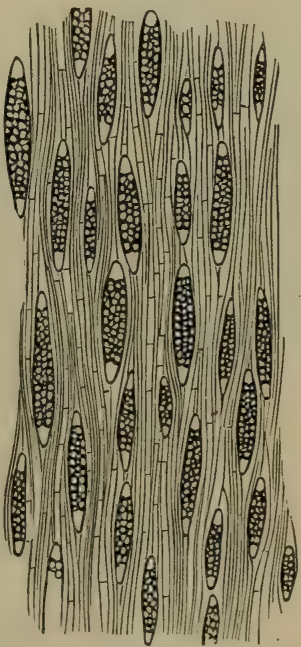

FiG. 73. - Longitudinal Section of Mahogany at Right Angles to Medullary Rays, showing Cutoff Ends. (Much magnified.)

pare this with Figs. 58, 72, and decide at what season of the year the largest ducts are mainly produced. Make a careful drawing of the end-section of one billet of wood, natural size.

Cut off a grapevine several years old and notice the great size of

1 These and many other important things are admirably shown in the thin wood-sections furnished for $\$ 4$ per set of 24 by R. B. Hough, Lowville, N. Y. 
the vessels. Examine the smoothly planed surface of a billet of red oak that has been split through the middle of the tree (quartered

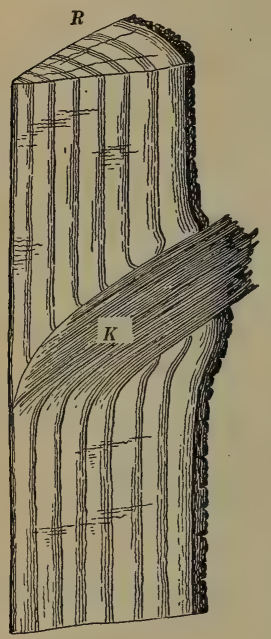

FIG. 74. - Formation of a Knot in a TreeTrunk.

$R$, cut-off end of stick, showing annual rings ; $K$, knot, formed by growth of a branch. oak), and note the large shining plates formed by the medullary rays.

Look at another stick that has been planed away from the outside until a good-sized flat surface is shown, and see how the medullary rays are here represented only by their edges.

\section{Interruption of Annual Rings by} Branches ; Knots. - When a leaf-bud is formed on the trunk or branch of a dicotyledonous tree, it is connected with the wood by fibro-vascular bundles. As the bud develops into a branch, the few bundles which it originally possessed increase greatly in number, and at length, as the branch grows, form a cylinder of wood which cuts across the annual rings, as shown in Fig. 74 . This interruption to the rings is a knot, such as one often sees in boards and planks. If the branch dies long before the tree does, the knot may be buried under many rings of wood. What is known as clear lumber is obtained from trees that have grown in a dense forest, so that the lower branches of the larger trees were killed by the shade many years before the tree was felled.

In pruning fruit trees or shade trees the branches which are removed should be cut close to the trunk. If this is done, the growth of the trunk will bury the scar before decay sets in. 
113. Comparison of the Monocotyledonous and the Dicotyledonous Stem. ${ }^{1}$

MoNocotyledonous

SteM

General Structure.

Structure of

Bundles.

Growth in Thickness. manent cambium.
Dicotyledonous

STEM

A complex bark, usually on young shoots consisting of a corky layer, a green layer, and a layer of bast. Wood in annual rings. Pith in a cylinder at the center.

Bundles closed, Bundles open, with that is, without per- permanent cambium.

Cells of mature New wood-cells parts of stem expand formed throughout somewhat, but (in growing season from most palms) new ones cambium ring. are not found.

\section{Review Sketches and Diagrams.}

(1) Monocotyledonous stem (lengthwise section).

(2) Dicotyledonous stem (lengthwise section).

(3) First appearance of bundles in dicotyledonous stem.

(4) Dicotyledonous stem five years or more old (cross-section).

(5) Various bark-cells.

(6) Various cells from wood.

(7) Pith-cells.

(8) Collenchyma-cells.

1 This comparison applies only to most of the woody or tree-like stems. 


\section{CHAPTER VII}

\section{LIVING PARTS OF THE STEM; WORK OF THE STEM}

115. Active Portions of the Stems of Trees and Shrubs. - In annual plants generally and in the very young shoots of shrubs and trees there are stomata or breathing pores which occur abundantly in the epidermis, serving for the admission of air and the escape of moisture, while the green layer of the bark answers the same purpose that is served by the green pulp of the leaf (Chapter XI). For years, too, the spongy lenticels, which succeed the stomata and occur scattered over the external surface of the bark of trees and shrubs, serve to admit air to the interior of the stem. The lenticels at first appear as roundish spots, of very small size, but as the twig or shoot on which they occur increases in diameter the lenticel becomes spread out at right angles to the length of the stem, so that it sometimes becomes a longer transverse slit or scar on the bark, as in the cherry and the birch. But in the trunk of a large tree no part of the bark except the inner layer is alive. The older portions of the bark, such as the highly developed cork of the cork-oak, from which the ordinary stoppers for bottles are made, sometimes cling for years after they are dead and useless except as a protection for the parts beneath against mechanical injuries or against cold. But in many cases, as in the shell-bark hickory and the grapevine, the old bark soon falls off in strips; in birches it finally peels off in bands around the stem. 
The cambium layer is very much alive, and so is the young outer portion of the wood. Testing this "sapwood," particularly in winter, shows that it is rich in starch and proteids.

The heartwood of a full-grown tree is hardly living, unless the cells of the medullary rays retain their vitality, and so it may be that wood of this kind is useful to the tree mainly by giving stiffness to the trunk and larger branches, thus preventing them from being easily broken by storms.

It is, therefore, possible for a tree to flourish, sometimes for centuries, after the heartwood has much of it rotted away and left the interior of the trunk hollow, as shown in Fig. 75 .

116. Uses of the Components of the Stem. - There is a marked division of labor among the various groups of cells that make up the stem of ordinary dicotyledons, particularly in the stems of trees, and it will be best to explain the uses of the kinds of cells as found in trees, rather than in herbaceous plants. A few of the ascertained uses of the various tissues are these:

The pith forms a large part of the bulk of very young shoots, since it is a part of the tissue of comparatively simple structures amid which the fibro-vascular bundles arise. In mature stems it becomes rather unimportant, though it often continues for a long time to act as a storehouse of food.

The medullary rays in the young shoot serve as a channel for the transference of water and plant-food in a liquid form across the stem, and they often contain much stored food. 


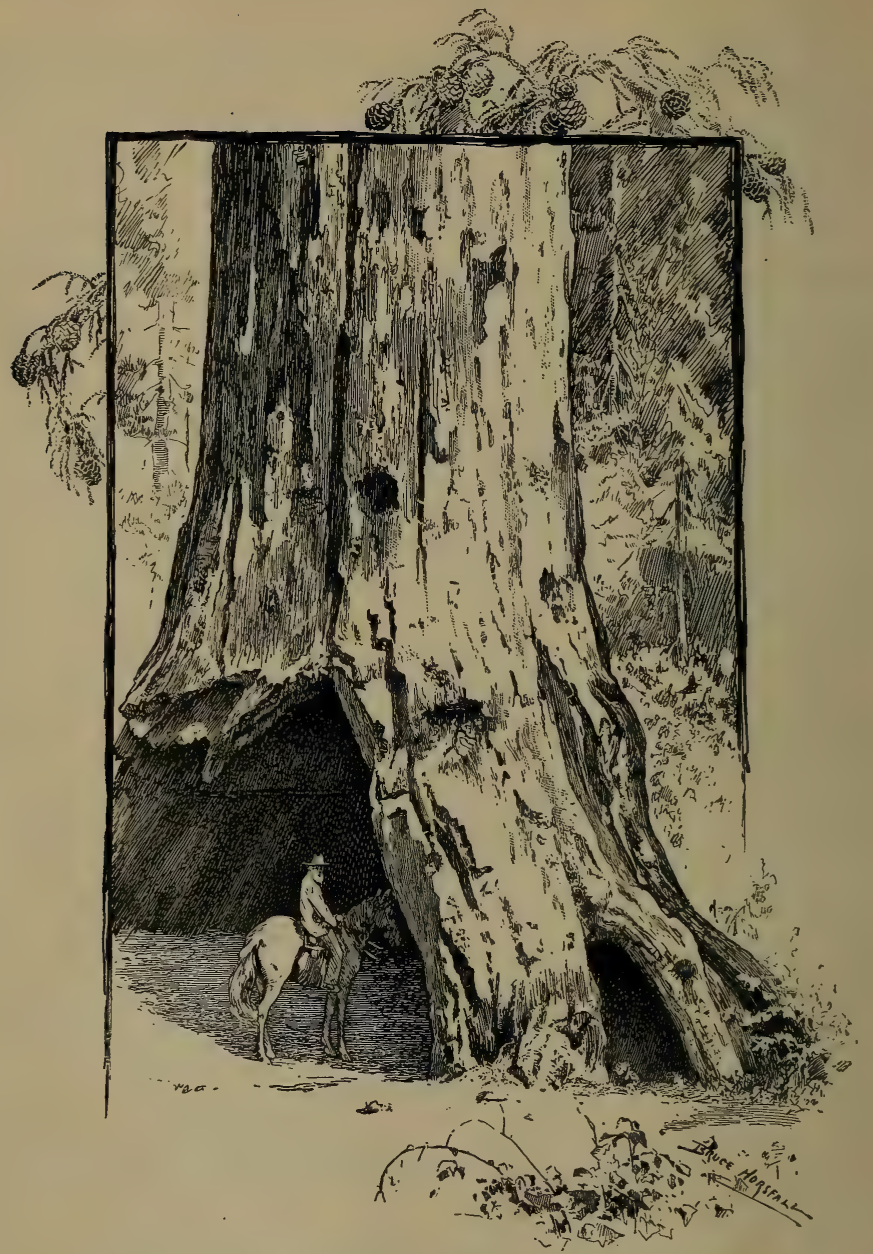

Fig. 75. - Pioneer's Cabin, a Very Large Hollow Sequoia.

The vessels carry water upward and air downward through the stem.

The wood-cells of the heartwood are useful only to give 
stiffness to the stem. Those of the sapwood, in addition to this work, have to carry most of the water from the roots to the leaves and other distant portions of the plant.

The cambium layer is the region in which the annual growth of the tree takes place (Figs. 69, 71).

The most important portion of the inner bark is that which consists of sieve-tubes, for in these digested and elaborated plant-food is carried from the leaves toward the roots.

The green layer of the bark in young shoots does much toward collecting nutrient substances, or raw materials, and preparing the food of the plant from air and water, but this work may be best explained in connection with the study of the leaf (Chapter XI).

117. Movement of Water in the Stem. - The student has already learned that large quantities of water are taken up by the roots of plants.

Having become somewhat acquainted with the structure of the stem, he is now in a position to investigate the question how the various fluids, commonly known as sap, travel about in it. ${ }^{1}$ It is important to notice that sap is by no means the same substance everywhere and at all times. As it first makes its way by osmotic action inward through the root-hairs of the growing plant it differs but little from ordinary spring water or well water. The liquid which flows from the cut stem of a "bleeding" grapevine which has been pruned just before the buds have begun to burst in the spring, is water with a little mucilaginous or slimy material added. The sap which is

1 See the paper on "The So-called Sap of Trees and its Movements," by Professor Charles R. Barnes, Science, Vol. XXI, p. 535. 
obtained from maple trees in late winter or early spring, and is boiled down for syrup or sugar, is still richer in nutritious material than the water of the grapevine, while the elaborated sap which is sent so abundantly into the ear of corn, at its period of filling out, or into the growing pods of beans and peas, or into the rapidly forming acorn or the chestnut, contains great stores of food, suited to sustain plant or animal life.

\section{EXPERIMENT XXI}

Rise of Water in Stems. - Cut some short branches from an apple tree or a cherry tree and stand the lower end of each in red ink; try the same experiment with twigs of oak, ash, or other porous wood, and after some hours ${ }^{1}$ examine with

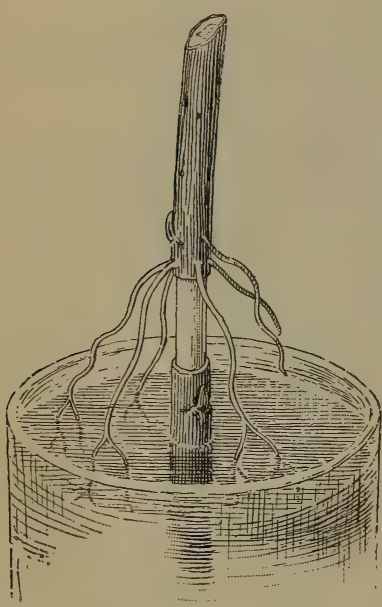

FIG. 76. - A Cutting girdled and sending down Roots from the Upper Edge of the Girdled Ring. the magnifying glass and with the microscope, using the 2-inch objective, successive cross-sections of one or more twigs of each kind. Note exactly the portions through which the ink has traveled. Pull off the leaves from one of the stems after standing in the eosin solution, and notice the spots on the leaf-scar through which the eosin has traveled. These spots show the positions of the leaf-traces, or fibro-vascular bundles, connecting the stem and the leaf. Repeat with several potatoes, cut crosswise through the middle. Try also some monocotyledonous stems, such as those of the lily or asparagus. For the sake of comparison between roots and stems, treat any convenient root, such as a parsnip, in the same way.

${ }^{1}$ If the twigs are leafy and the room is warm, only from 5 to 30 minutes may be necessary. 
Examine longitudinal sections of some of the twigs, the potatoes, and the roots. In drawing conclusions about the channels through which the ink has risen (those through which the newly absorbed soil-water most readily travels), bear in mind the fact that a slow soakage of the red ink will take place in all directions, and therefore pay attention only to the strongly colored spots or lines.

What conclusions can be drawn from this experiment as to the course followed by the sap?

From the familiar facts that ordinary forest trees apparently flourish as well after the almost complete decay and removal of their heartwood, and that many kinds will live and grow for a considerable time after a ring of bark extending all round the trunk has been removed, it may readily be

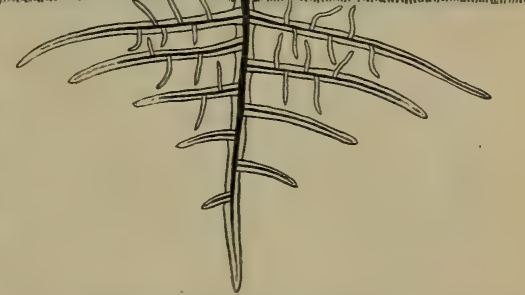

FIG. 77. - Channels for the Movement of Water, upward and downward.

The heary black lines in roots, stems, and leaves show the course of the fibro-rascular bundles through which the principal movements of water take place.

inferred that the crude sap in trees must rise through some portion of the newer layers of the wood. A tree girdled by the removal of a ring of sapwood promptly dies.

118. Downward Movement of Liquids. - Most dicotyledonous stems, when stripped of a ring of bark and then 
stood in water, as shown in Fig. 76, and covered with a bell-jar, develop roots only at or near the upper edge of

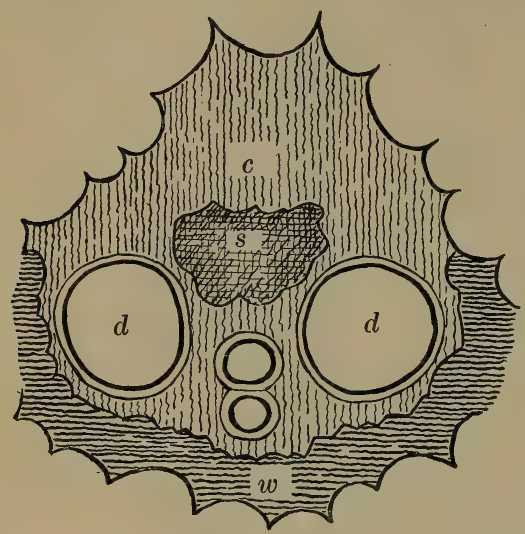

FIG. 78. - Diagrammatic Cross-Section of a Bundle from Sugar-Cane, showing Channels for Air and Water. (Magnified.)

Air travels downward through the two large ducts $d$ (and the two smaller ones between them). Water travels upward through the ducts and through the wood-cells in the region marked $w$. Water with dissolved plant-food travels downward through the sieve-cells in the region marked $s$.

laterally through the stem, and these are at times of much importance to the plant.

Since the liquid building material travels straight down the stem, that side of the stem on which the manufacture of such the stripped portion, ${ }^{1}$ and this would seem to prove that such stems send their building material - the elaborated sap - largely at any rate down through the bark. Its course is undoubtedly for the most part through the sieve-cells (Figs. 63, 64), which are admirably adapted to convey liquids. In addition to these general upward and downward movements of sap, there must be local transfers

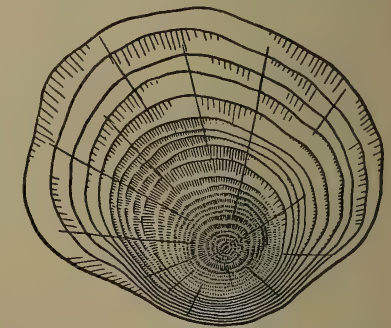

Frg. 79. - Unequal Growth of Rings of Wood in nearly Horizontal Stem of a Juniper. (Natural size.) material is going on most rapidly should grow fastest.

1 This may be made the subject of a protracted class-room experiment. Strong shoots of willow should be used for the purpose. 
Plant-food is made out of the raw materials by the leaves, and so the more leafy side of a tree forms thicker rings than the less leafy side, as shown in Fig. 79.

119. Rate of Movement of Water in the Stem. - There are many practical difficulties in the way of ascertaining exactly how fast the watery sap travels from the root to the leaves. It is, however, easy to illustrate experimentally the fact that it does rise, and to give an approximate idea of the time required for its ascent. The best experiment for beginners is one which deals with an entire plant under natural conditions.

\section{EXPERIMENT XXII}

Wilting and Recovery. - Allow a fuchsia or a hydrangea ${ }^{1}$ which is growing in a flower-pot to wilt considerably for lack of watering. Then water it freely and record the time required for the leaves to begin to recover their natural appearance and position, and the time fully to recover.

The former interval of time will give a very rough idea of the time of transfer of water through the roots and the stem of the plant. From this, by measuring the approximate distance traveled, a calculation could be made of the number of inches per minute that water travels in this particular kind of plant, through a route which is partly roots, partly stem, and partly petiole. Still another method is to treat leafy stems as the student in Exp. XXI treated the twigs which he was examining, and note carefully the rate of ascent of the coloring liquid. This plan is likely to give results that are too low, still it is of some use. It has given results varying from 34 inches per 
hour for the willow to 880 inches per hour for the sunflower. A better method is to introduce the roots of the plant which is being experimented upon into a weak solution of some chemical substance which is harmless to the plant and which can readily be detected anywhere in the tissues of the plant by chemical tests. Proper tests are then applied to portions of the stem which are cut from the plant at short intervals of time.

Compounds of the metal lithium are well adapted for use in this mode of experimentation.

120. Causes of Movements of Water in the Stem. - Some of the phenomena of osmosis were explained in Sect. 62, and the work of the root-hairs was described as due to osmotic action.

Root-pressure (Sect. 66), being apparently able to sustain a column of water only 80 or 90 feet high at the most, and usually less than half this amount, would be quite insufficient to raise the sap to the tops of the tallest trees, since many kinds grow to a height of more than 100 feet. Our Californian "big trees," or Sequoias, reach the height of over 300 feet, and an Australian species of Eucalyptus, it is said, sometimes towers up to 470 feet. Root-pressure, then, may serve to start the soil-water on its upward journey, but some other force or forces must step in to carry it the rest of the way. What these other forces are is still a matter of discussion among botanists.

The slower inward and downward movement of the sap may be explained as due to osmosis. For instance, in the case of growing wood-cells, sugary sap from the leaves gives up part of its sugar to form the cellulose of which the wood-cells are being made. 
This loss of sugar would cause a flow of rather watery sap to take place more rapidly than usual from the growing wood to the leaves, while at the same time a slow transfer of the dissolved sugar will be set up from leaves to wood. The water, as fast as it reaches the leaves, will be thrown off in the form of vapor, so that they will not become distended with water, while the sugar will be changed into cellulose and built into new wood-cells as fast as it reaches the region where such cells are being formed.

Plants in general ${ }^{1}$ readily change starch to sugar, and sugar to starch. When they are depositing starch in any part of the root or stem for future use, the withdrawal of sugar from those portions of the sap which contain it most abundantly gives rise to a slow movement of dissolved particles of sugar in the direction of the region where starch is being laid up.

121. Storage of Food in the Stem. - The reason why the plant may profit by laying up a food supply somewhere inside its tissues has already been suggested (Sect. 91).

The most remarkable instance of storage of food in the stem is probably that of sago-palms, which contain an enormous amount, sometimes as much as 800 pounds, of starchy material in a single trunk. But the commoner plants of temperate regions furnish plenty of examples of deposits of food in the stem. As in the case of seeds and roots, starch constitutes one of the most important kinds of this reserve material of the stem, and since it is easier to detect than any other food material which the plant stores, the student will do well to spend time in looking for starch only.

1 Not including most of the flowerless and very low and simple kinds. 
Cut thin cross-sections of twigs of some common deciduous tree or shrub, in its early winter condition, moisten with iodine solution, and examine for starch with a moderately high power of the microscope. Sketch the section with a pencily coloring the starchy portions with blue ink, used with a mapping pen, and describe exactly in what portions the starch is deposited.

122. Storage in Underground Stems. - The branches and trunk of a tree furnish the most convenient place in which to deposit food during winter to begin the growth of the following spring. But in those plants which die down to the ground at the beginning of winter the storage must be either in the roots, as has been described in Sect. 58, or in underground portions of the stem.

Rootstocks, tubers, and bulbs seem to have been developed by plants to answer as storehouses through the winter (or in some countries through the dry season) for the reserve materials which the plant has accumulated during the growing season. The commonest tuber is the potato, and this fact and the points of interest which it represents make it especially desirable to use for a study of the underground stem in a form most highly specialized for the storage of starch and other valuable products.

123. A Typical Tuber: the Potato. — Sketch the general outline of a potato, showing the attachment to the stem from which it grew. ${ }^{1}$

Note the distribution of the "eyes," - are they opposite or alternate? Examine them closely with the magnifying glass and then with the lowest power of the microscope. What do they appear to be?

If the potato is a stem, it may branch, - look over a lot of potatoes to try to find a branching specimen. If such a one is secured, sketch it.

1 Examination of a lot of potatoes will usually discover specimens with an inch or more of attached stem. 
Note the little scale overhanging the edge of the eye, and see if you can ascertain what this scale represents.

Cut the potato across, and notice the faint broken line which forms a sort of oral figure some distance inside the skin.

Place the cut surface in eosin solution, allow the potato to stand so for many hours, and then examine, by slicing off pieces parallel to the cut surface, to see how far and into what portions the solution has penetrated. Refer to the notes on the study of the parsnip (Sect. 56), and see how far the behavior of the potato treated with eosin solution agrees with that of the parsnip so treated.

Cut a thin section at right angles to the skin, and examine with a high power. Moisten the section with iodine solution and examine again.

If possible, secure a potato which has been sprouting in a warm place for a month or more (the longer the better), and look near the origins of the sprouts for evidences of the loss of material from the tuber.

\section{EXPERIMENT XXIII}

Use of the Corky Layer. - Carefully weigh a potato, then pare another larger one, and cut portions from it until its weight is made approximately equal to that of the first one. Expose both freely to the air for some days and reweigh. What does the result show in regard to the use of the corky layer of the skin?

124. Morphology of the Potato. - It is evident that in the potato we have to do with a very greatly modified form of stem. The corky layer of the bark is well represented, and the loose cellular layer beneath is very greatly developed; wood is almost lacking, being present only in the very narrow ring which was stained by the red ink, but the pith is greatly developed and constitutes the principal bulk of the tuber. All this is readily understood if we consider that the tuber, buried in and supported by the earth, does not need the kinds of tissue which give 
strength, but only those which are well adapted to store the requisite amount of food.

125. Structure of a Bulb; the Onion. - Examine the external appearance of the onion and observe the thin membranaceous skin which covers it. This skin consists of the broad sheathing bases of the outer leaves which grew on the onion plant during the summer. Remove these and notice the thick scales (also formed from bases of leaves as shown in Fig. 48) which make up the substance of the bulb.

Make a transverse section of the onion at about the middle and sketch the rings of which it is composed. Cut a thin section from the interior of the bulb, examine with a moderate power of the microscope, and note the thin-walled cells of which it is composed.

Split another onion from top to bottom and try to find:

(a) The plate or broad flattened stem inside at the base (Fig. 47).

(b) The central bud.

(c) The bulb-scales.

(d) In some onions (particularly large, irregular ones) the bulblets or side buds arising in the axes of the scales near the base.

Test the cut surface for starch.

126. Sugar in the Onion.- Grape sugar is an important substance among those stored for food by the plant. It received its name from the fact that it was formerly obtained for chemical examination from grapes. Old dry raisins usually show little masses of whitish material scattered over the skin which are nearly pure grápe sugar. Commercially it is now manufactured on an enormous scale from starch by boiling with diluted sulphuric acid. In the plant it is made from starch by processes as yet imperfectly understood, and another sugar, called maltose, is made from starch in the seed during germination.

Both grape sugar and maltose (and hardly any other substances) have the power of producing a yellow or 
orange color and throwing down an orange or reddish deposit, when they are added to a brilliant blue alkaline solution of copper, known as Fehling's solution. ${ }^{1}$ The color or deposit will not appear until the solution has been heated to boiling.

\section{EXPERIMENT XXIV}

Testing for Grape Sugar. - Heat to boiling in a test-tube or a small beaker some weak syrup of grape sugar or some honey, much diluted with water. Add Fehling's solution, a few drops at a time, until a decided orange color appears. Repeat the test with the water in which some slices of onion have been boiled, filtering the. water through a paper filter and heating again to boiling before adding the test solution.2

127. Proteids in the Onion. - Since the onion grows so rapidly on being planted in the spring, there must be a large supply of food in the bulb; there may be other substances present besides sugar.

\section{EXPERIMENT XXV}

Testing an Onion for Other Stored Food. - Test a rather thick slice of onion by heating it in a porcelain evaporating dish with a little strong nitric acid until the latter begins to boil and the onion becomes somewhat softened. ${ }^{3}$ Rinse off the slice of onion in a stream of water, then pour on it a few drops of ammonium hydrate and observe any change of color. What is proved? See Sect. 29.

\section{Tabular Review of Experiments.}

[Continue the table from Sect. 74.]

1 For the preparation of the solution see Handbook.

2 The deposit will in this case, even if orange at first, finally become black, probably owing to the presence of sulphur in the onion.

${ }^{3}$ Do not allow the acid to touch the clothing, the hands, or any metallic object. 
129. Review Summary of Work of Stem.

Channels for upward movement
of water $\left\{\begin{array}{l}\text { in young dicotyledonous stems } \\ \text { in dicotyledonous stems several } \\ \text { years old } . . . \\ \text { in monocotyledonous stems } .\end{array}\right.$

Channels for downward move- $\{$ in dicotyledonous stems ment of water in monocotyledonous stems . .

Channels for transverse movements Rate of upward movement

Storage of plant-food

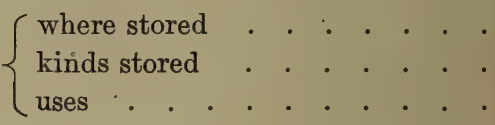




\section{CHAPTER VIII}

\section{BUDS}

130. Structure of Buds. - While studying twigs in their winter condition, as directed in Sects. 77, 78, the student had occasion to notice the presence, position, and arrangement of buds on the branch, but he was not called upon to look into the details of their structure. The most natural time to do this is just before the study of the leaf is begun, since leafy stems spring from buds, and the rudiments of leaves in some form must be found in buds.

131. The Horse-Chestnut Bud. - Examine one of the lateral buds on a twig in its winter or early spring condition. ${ }^{1}$

Make a sketch of the external appearance of the buds as seen with a magnifying glass.

How do the scales with which it is covered lie with reference to those beneath them?

Notice the sticky coating on the scales.

Are the scales opposite or alternate?

Remove the scales in pairs, placing them in order on a sheet of paper, thus :

Make the distance from 1 to 1 as much as 6 or 8 inches.

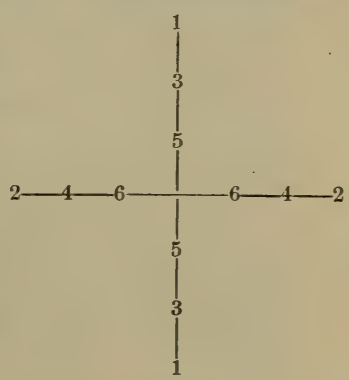

How many pairs are found?

Observe as the scales are remored whether the sticky coating is

1 The best possible time for this examination is just as the buds are beginning to swell slightly in the spring. The bud of buckeye or of cottonwood will do for this examination, though each is on a good deal smaller scale than the horse-chestnut bud. Buds may be forced to open early by placing twigs in water in a very warm, light place for many weeks. 
thicker on the outside or the inside of each scale, and whether it is equally abundant on all the successive pairs.

What is the probable use of this coating?

Note the delicate veining of some of the scales as seen through

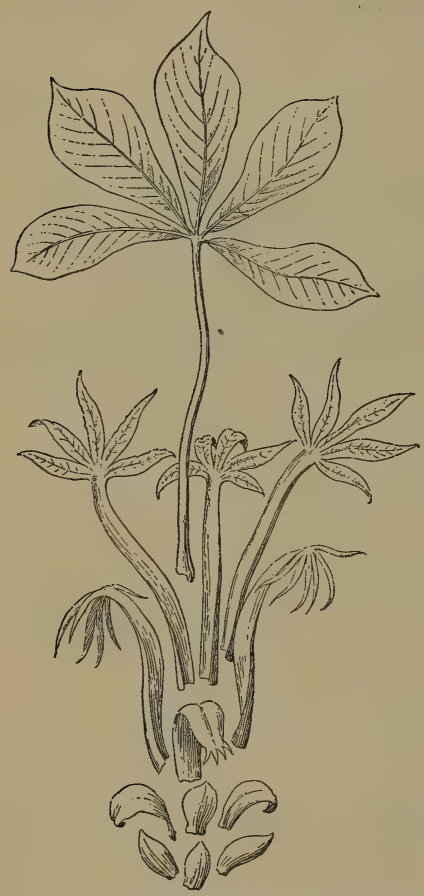

FIG. 80. - Dissected Bud of Buckeye (Asculus macrostachya), showing Transitions from Bud-Scales to Leaves. the magnifying glass. What does this mean?

Inside the innermost pair are found two forked woolly objects; what are these?

Compare with Figs. 87 and 107.

Their shape could be more readily observed if the woolly coating were removed.

Can you suggest a use for the woolly coating?

Examine a terminal bud in the same way in which you have just studied the lateral bud.

Does it contain any parts not found in the other?

What is the appearance of these parts?

What do they represent?

If there is any doubt about their nature, study them further on a horse-chestnut tree during and immediately after the process of leafing out in the spring.

For comparison study at least one of the following kinds of buds in their winter or early spring condition : hickory, butternut, beech, ash, magnolia (or tulip tree), lilac, baln of Gilead, cottonwood, cultivated cherry. ${ }^{1}$

1 Consult the account of the mode of studying buds in Professor W. F. Ganong's Teaching Botanist, pp. 208-210. If some of the buds are studied at home, pupils will have a better chance to examine at leisure the unfolding process. 
132. Nature of Bud-Scales. - The fact that the bud-scales are in certain cases merely imperfectly developed leaves or leaf-stalks is often clearly manifest from the series of steps connecting the bud-scale on the one hand with the young leaf on the other, which may be found in many opening buds, as illustrated by Fig. 80 . In other buds the scales are not imperfect leaves, but the little appendages (stipules, Figs. $98,99)$ which occur at the bases of leaves. This kind of bud-scale is especially well shown in the magnolia and the tulip tree.

133. Naked Buds. - All of the buds above mentioned are winter buds, capable of living through the colder months of the year, and are scaly buds.

In the herbs of temperate climates, and even in shrubs and trees of tropical regions, the buds are often naked, that is, nearly or quite destitute of scaly coverings (Fig. 81).

Make a study of the naked buds of any convenient herb, such as one of the common "geraniums" (Pelargonium), and record what you find in it.

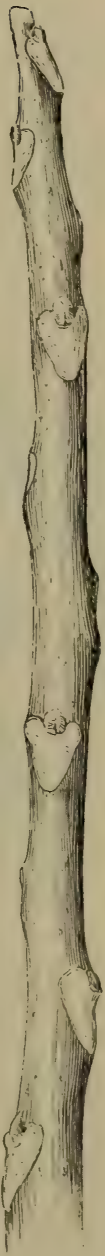

134. Position of Buds. - The dis- Fra. 81. - Tip of Branch tinction between lateral and terminal buds has already been alluded to. 
The plumule is the first terminal bud which the plant produces. Lateral buds are usually axillary, as shown in Fig. 82, that is, they grow in the angle formed by the leaf with the stem (Latin axilla, armpit). But not infrequently there are several buds grouped in some way about

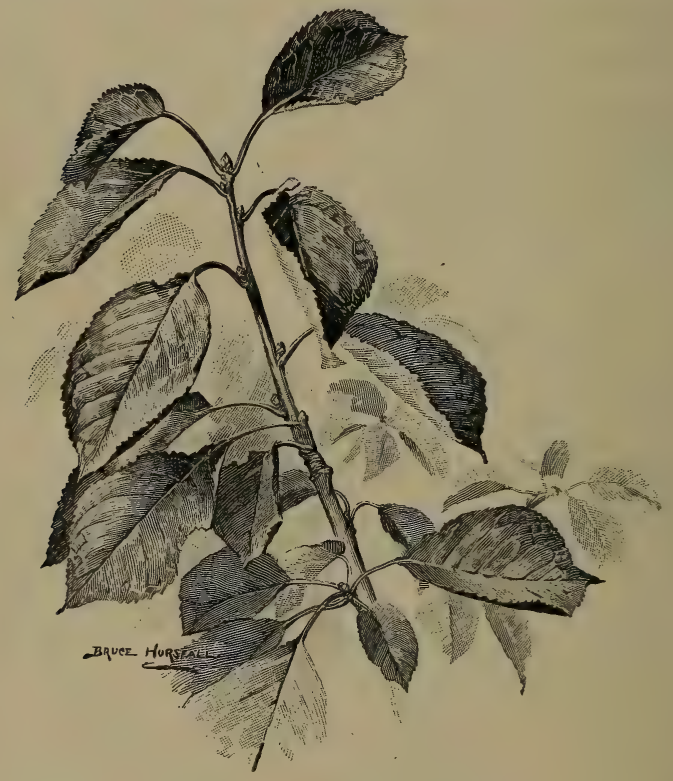

FrG. 82. - Alternate Leaves of Cultivated Cherry, with Buds in their Axils, in October.

a single leaf-axil, either one above the other, as in the butternut (Fig. 84), or grouped side by side, as in the red maple, the cherry, and the box-elder (Fig. 83). -

In these cases all the buds except the axillary one are called accessory or supernumerary buds.

135. Leaf-Buds and Flower-Buds; the Bud an Undeveloped Branch. - Such buds as the student has so far 
examined for himself are not large enough to show in the most obvious way the relation of the parts and their real nature.

Fortunately, it is easy to obtain a gigantic terminal bud which illustrates perfectly the structure and arrangement of the parts of buds in general.

Examine and sketch a rather small, firm cabbage, preferably a red one, which has been split lengthwise through the center ${ }^{1}$ and note

(a) The short, thick, conical stem.

(b) The crowded leaves which arise from the stem, the lower and outer ones largest and most mature, the upper and innermost ones the smallest of the series.

(c) The axillary buds, found in the angles made by some leaves with the stem.
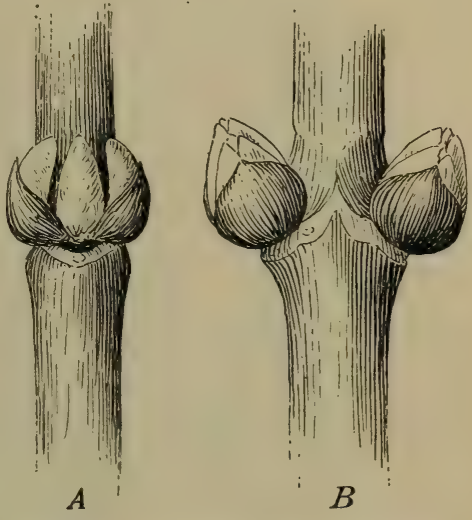

Fra. 83. - Accessory Buds of Box-Elder

(Negundo). (Magnified.)

$A$, front view of group.

- $\quad B$, two groups seen in profile.

Compare the section of the cabbage with Fig. 86 .

Most of the buds so far considered were leaf-buds, that is, the parts inside of the scales would develop into leaves, and their central axes into stems; but some were mixed buds, that is, they contained both leaves and flowers in an undeveloped condition.

Flower-buds contain the rudiments of flowers only.

Sometimes, as in the black walnut and the butternut, the leaf-buds and flower-buds are readily distinguishable

1 Half of a cabbage will be enough for the entire division. 
by their difference in form, while in other cases, as in the cultivated cherry, the difference in form is but slight.

The rings of scars about the twig, shown in Figs. 82

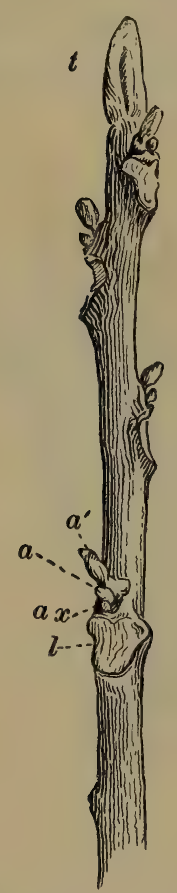

FIG. 84. - Accessory

Buds of Butternut. (Reduced.)

$l$, leaf-scar ; $a x$, axillary bud; $a, a^{\prime}$, accessory buds; $t$, terminal bud. and 85 , mark the place where the bases of bud-scales were attached. A little examination of the part of the twig which lies outside of this ring, as shown in Fig. 82, will lead one to the conclusion that this portion has all grown in the one spring and summer since the bud-scales of that particular ring dropped off. Following out this suggestion, it is easy to reckon the age of any moderately old portion of a branch, since it is equal to the number of segments between the rings. In rapidly growing shoots of willow, poplar, and similar trees, 5 or 10 feet of the length may be the growth of a single year, while in the lateral twigs of the hickory, apple, or cherry the yearly increase may be but a fraction of an inch. Such fruiting "spurs" as are shown in Fig. 85 are of little use in the permanent growth of the tree, and poplars, elms, soft maples and other trees shed the oldest of these every year. Whatever the amount of this growth, it is but the lengthening out and development of the bud, which may be regarded as an undeveloped stem or branch, with its internodes so shortened that successive leaves seem almost to spring from the same point. 
136. Vernation. - Procure a considerable number of buds which are just about to burst, and others which have begun to open. Cut each across with a razor or very sharp scalpel; examine first with the magnifying glass, and then with the lowest power of the microscope. Pick to pieces other buds of the same kinds under the magnifying glass, and report upon the manner in which the leaves are packed away.

The arrangement of leaves in the bud is called vernation; some of the principal modes are shown in Fig. 86.

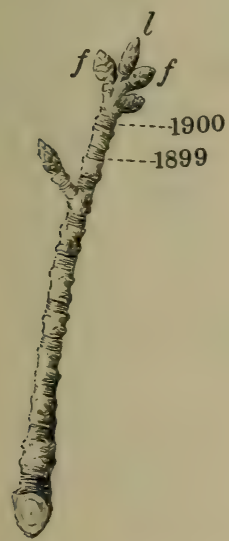

FIG. 85. - A slowly grown Twig of Cherry, 3 inches long and about ten years old.

The pointed bud $l$ is a leaf-bud; the more obtuse accessory buds $f, f$ are flower-buds.

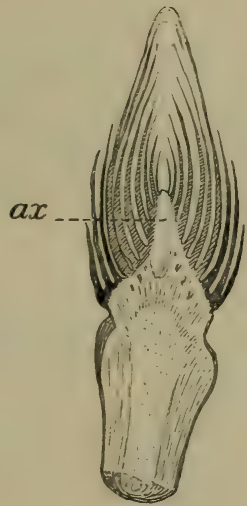

A

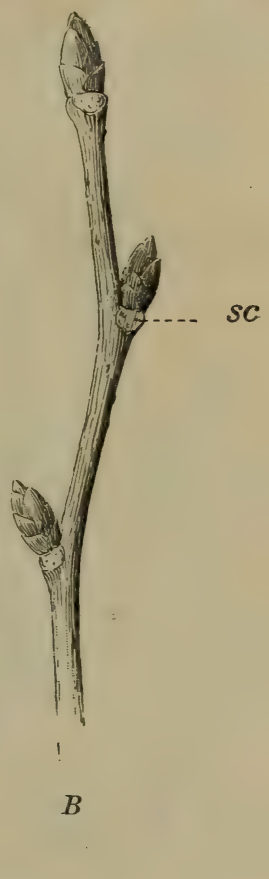

Fig. 86.

$B$, a twig of European elm ; $A$, a longitudinal section of the buds of $B$ (considerably magnified); $a x$, the axis of the bud, which will elongate into a shoot; $s c$, leaf-scars.

In the cherry the two halves of the leaf are folded together flat, with the under surfaces outward; in the walnut the separate leaflets, or parts of the leaf, are folded 
flat and then grouped into a sort of cone ; in the snowball each half of the leaf is plaited in a somewhat fan-like manner, and the edges of the two halves are then brought round so as to meet; in the lady's mantle the fan-like plaiting is very distinct; in the wood sorrel each leaflet

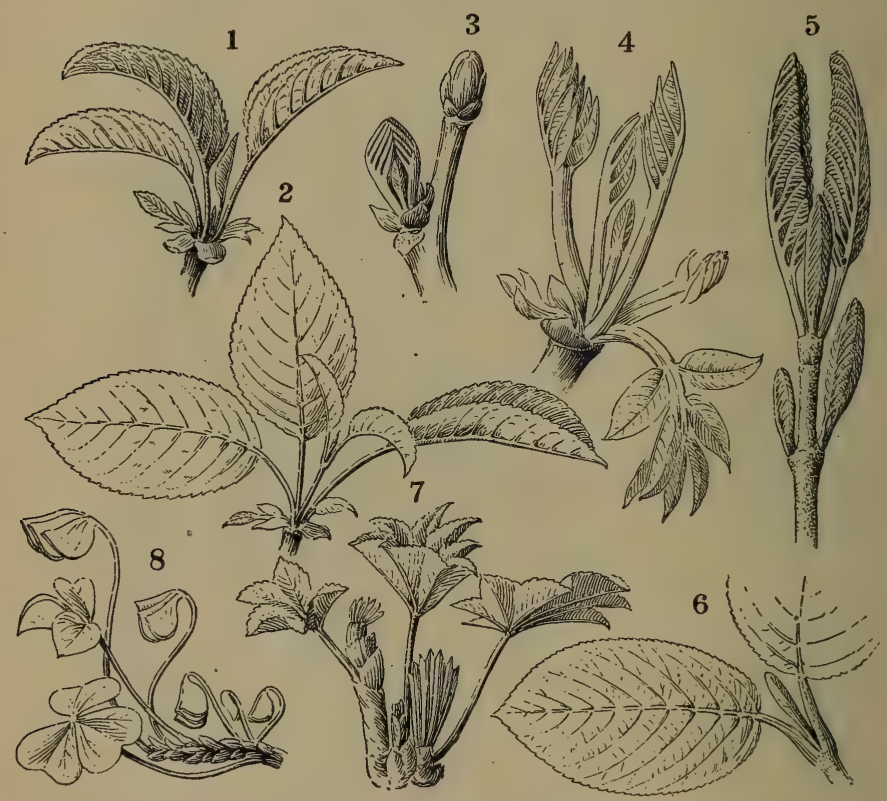

Frg. 87, I. - Types of Vernation.

1, 2, Cherry ; 3, 4, European walnut ; 5, 6, snowball ; 7, lady's mantle ; 8, oxalis.

is folded smoothly, and then the three leaflets packed closely side by side. All these modes of vernation and many others have received accurate descriptive names by which they are known to botanists.

137. Importance of Vernation. - The significance of vernation is best understood by considering that there are two 
important purposes to be served; the leaves must be stowed as closely as possible in the bud, and upon beginning to open they must be protected from too great heat and dryness until they have reached a certain degree of firmness. It may be inferred from Fig. 87, I, that it is common for very young leaves to stand vertically. This protects them considerably from the scorching effect of the sun at the hottest part of the day. Many young leaves, as, for instance, those of the silver-leafed poplar, the pear, the beech, and the mountain ash, are sheltered and pro-
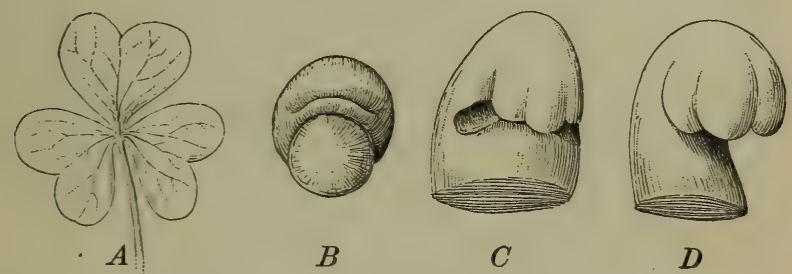

Fig. 87, II. - Development of an Oxalis Leaf.

$A$, full-grown leaf ; $B$, rudimentary leaf, the leaflets not yet evident ; $C$, more advanced stage, the leaflets appearing; $D$, a still more advanced stage; $B, C$, and $D$, considerably magnified.

tected from the attacks of small insects by a coating of wool or down, which they afterwards lose. Those of the tulip tree are enclosed for a little time in thin pouches, which serve as bud-scales, and thus entirely shielded from direct contact with the outside air (see Sect. 117).

138. Dormant Buds. - Generally some of the buds on a branch remain undeveloped in the spring, when the other buds are beginning to grow, and this inactive condition may last for many seasons. Finally the bud may die, or some injury to the tree may destroy so many other buds as to leave the dormant ones an extra supply of food, and 
this, with other causes, may force them to develop and to grow into branches.

Sometimes the tree altogether fails to produce buds at places where they would regularly occur. In the lilac the terminal bud usually fails to appear, and the result is constant forking of the branches.

139. Adventitious Buds. - Buds which occur in irregular places, that is, not terminal nor in or near the axils of leaves, are called adventitious buds; they may spring from the roots, as in the silver-leafed poplar, or from the sides of the trunk, as in our American elm. In many trees, for instance willows and maples, they are sure to appear after the trees have been cut back. Willows are thus cut back or pollarded, as shown in Plate II, in order to cause them to produce a large crop of slender twigs suitable for basket-making.

Leaves rarely produce buds, but a few kinds do so when they are injured. Those of the bryophyllum, a plant allied to the garden live-for-ever, when they are removed from the plant while they are still green and fresh, almost always send out buds from the margin. These do not appear at random but are borne at the notches in the leaf-margin and are accompanied almost from the first by minute roots.

Pin up a bryophyllum leaf on the wall of the room or lay it on the surface of moist earth, and follow, day by day, the formation and development of the buds which it may produce.

This plant seems to rely largely upon leaf-budding to reproduce itself, for in a moderately cool climate it rarely flowers or seeds, but drops its living leaves freely, and from each such leaf one or several new plants may be produced. 


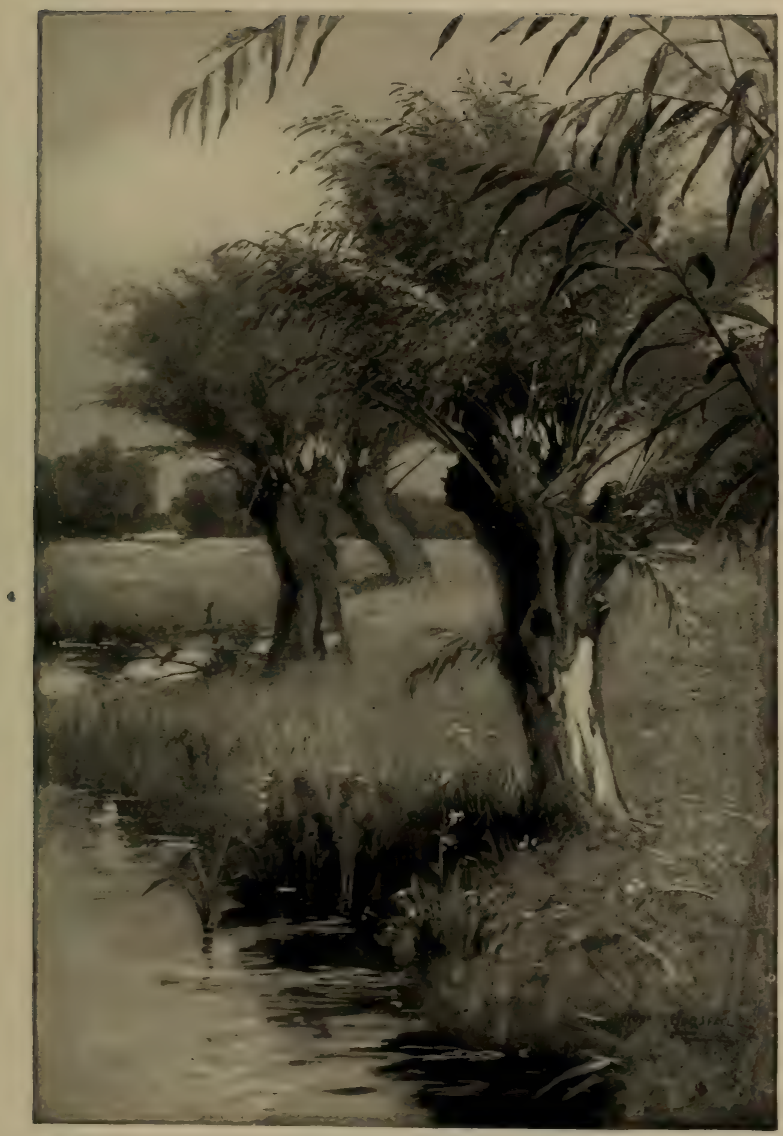

Plate II. - Pollarded IVillows 



\section{BUDS}

\section{Review Summary of Chapter VIII.}

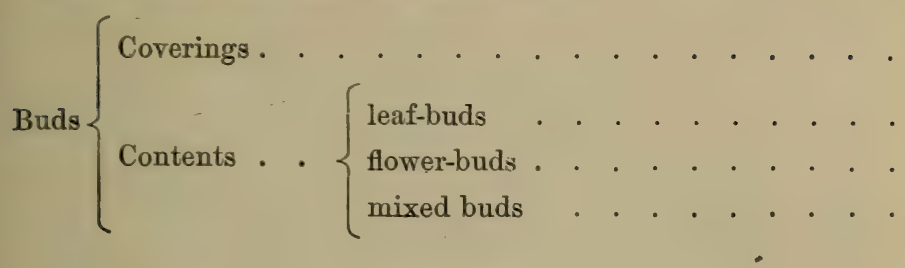

Classes of buds as re-
gards position... regular $\left\{\begin{array}{l}\text { irregular. . . . . . . . . }\end{array}\right.$

Make a sketch of Fig. 82 as it looked in June of the same summer; also as it would look the following June. 


\section{CHAPTER IX}

\section{LEAVES}

141. The Elm Leaf. - Sketch the leafy twig of elm that is supplied to you. ${ }^{1}$

Report on the following points :

(a) How many rows of leaves?

(b) How much overlapping of leaves when the twig is held with the upper sides of the leaves toward you? Can you suggest a reason for this? Are the spaces between the edges of the leaves large or small compared with the leaves themselves?

Pull off a single leaf and make a very careful sketch of its under surface, about natural size. Label the broad expanded part the blade, and the stalk by which it is attached to the twig, leaf-stalk or petiole.

Study the outline of the leaf and answer these questions:

(a) What is the shape of the leaf taken as a whole? (See Fig. 88.) Is the leaf bilaterally symmetrical, i.e., is there a middle line running through it lengthwise, along which it could be so folded that the two sides would precisely coincide?

(b) What is the shape of the tip of the leaf? (See Fig. 89.)

(c) Shape of the base of the leaf? (See Fig. 90.)

(d) Outline of the margin of the leaf? (See Fig. 93.)

Notice that the leaf is traversed lengthwise by a strong midrib and that many so-called veins run from this to the margin. Are

1 Any elm will answer the purpose. Young strong shoots which extend horizontally are best, since in these leaves are most fully developed and their distribution along the twig appears most clearly. Other good kinds of leaves with which to begin the study, if elm leaves are not available, are those of beech, oak, willow, peach, cherry, apple. Most of the statements and directions above given would apply to any of the leaves just enumerated. If this chapter is reached too early in the season to admit of suitable material being procured for the study of leaf arrangement, that topic may be omitted until the leaves of forest trees have sufficiently matured. 


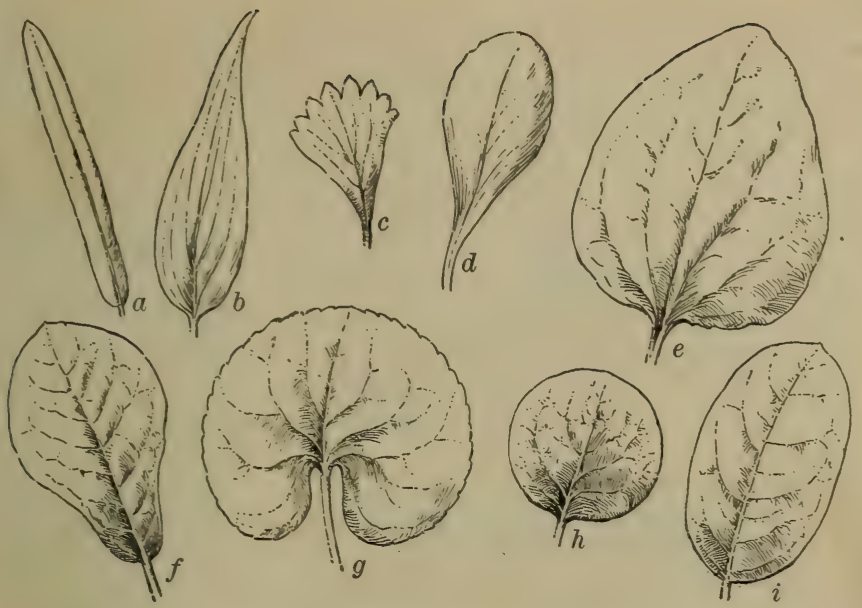

Fig. 88. - General Outline of Leaves.

$a$, linear; $b$, lanceolate ; $c$, wedge-shaped ; $d$, spatulate ; $e$, ovate ; $f$, obovate ; $g$, kidney-shaped; $h$, orbicular ; $i$, elliptical.

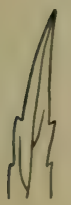

a

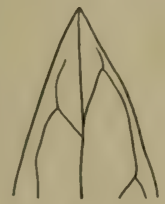

$b$

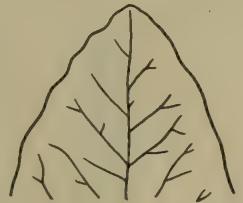

$c$

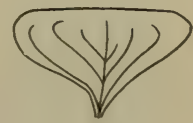

$d$
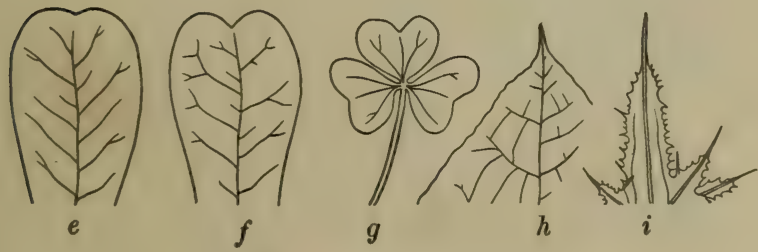

FIG. 89. - Tips of Leaves.

$\boldsymbol{a}$, acuminate or taper-pointed ; $b$, acute ; $c$, obtuse ; $d$, truncate ; $e$, retuse ; $f$, emarginate or notched; $g$ (end leaflet), obcordate; $h$, cuspidate, - the point sharp and rigid; $i$, mucronate, - the point merely a prolongation of the midrib. 


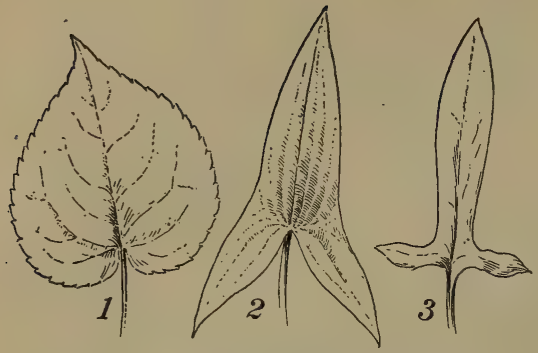

FIG. 90.- Shapes of Bases of Leaves.

1, heart-shaped (unsymmetrically) ; 2, arrowshaped; 3 , halberd-shaped.
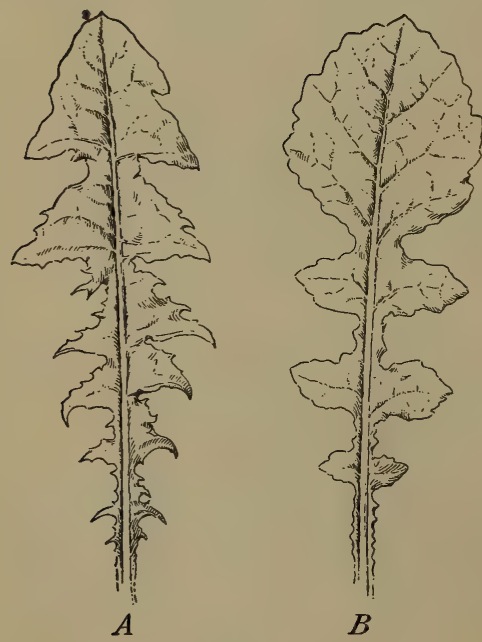

FIG. 92.

$A$, runcinate leaf of dandelion; $B$, lyrate leaf.

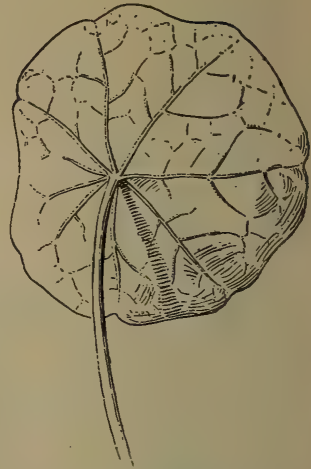

FIG. 91. - Peltate Leaf of Tropæolum.

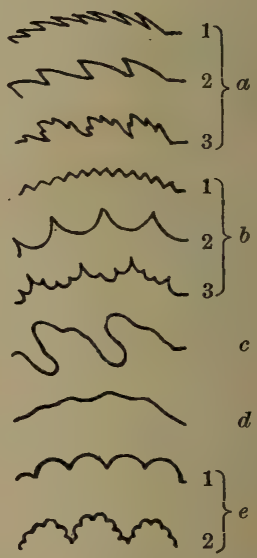

Fig. 93. - Shapes of Margins of Leaves.

$a$ (1), finely serrate ; (2), coarsely serrate; (3), doubly serrate. $b(1)$, finely dentate ; $(2)$, sinuate dentate; (3), doubly dentate. $c$, deeply sinuate. $d$, wavy. $e$ (1), crenate or scalloped; (2), doubly crenate. 
these veins parallel? Hold the leaf up towards the light and see how the main veins are connected by smaller veinlets. Examine

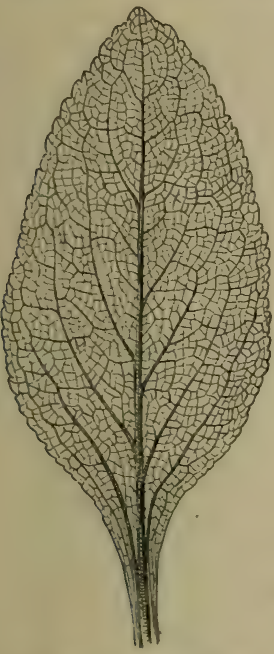

Frg. 94. - Netted Veining (pinnate) in the Leaf of the Foxglove. with your glass the leaf as held to the light and make a careful sketch of portions of one or two veins and the intersecting veinlets. How is the course of the veins shown on the upper surface of the leaf?

Examine both surfaces of the leaf with the glass and look for hairs distributed on the surfaces. Describe the manner in which the hairs are arranged.

The various forms of leaves are classed and described by botanists with great minuteness, ${ }^{1}$ not simply for the study of leaves themselves, but also because in classifying and describing plants the characteristic forms of the leaves of many kinds of plants form a very simple and ready means of distinguishing them from each other and identifying them. The student is not expected to learn the names of the several shapes of leaves as a whole or of their bases, tips, or margins, except in those cases in which he needs to use and apply them.

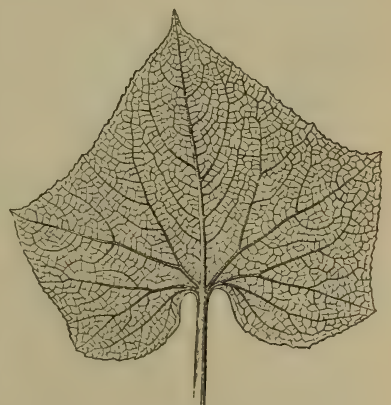

FIG. 95. - Netted Veining (palmate) in Leaf of Melon.

Many of the words used to describe the shapes of leaves are equally applicable to the leaf-like parts of flowers.

1 See Kerner and Oliver's Natural History of Plants, Vol. I, pp. 623-637. 
142. The Maple Leaf. - Sketch the leafy twig.

Are the leaves arranged in rows like those of the elm? How are they arranged?

How are the petioles distorted from their natural positions to bring the proper surface of the leaf upward toward the light?

Do the edges of these leaves show larger spaces between them than the elm leaves did, i.e., would a spray of maple intercept the

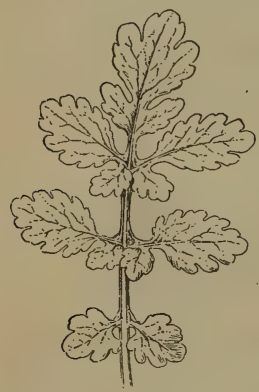

FIG. 96.-Pinnately

Divided Leaf of Celandine.

The blade of the leaf is discontinuous, consisting of several portions between which are spaces in which one part of the blade has been developed. sunlight more or less perfectly than a spray of elm?. Pull off a single leaf and sketch its lower surface, about natural size.

Of the two main parts whose names have already been learned (blade and petiole), which is more developed in the maple than in the elm leaf?

Describe :

(a) The shape of the maple leaf as a whole. To settle this, place the leaf on paper, mark the positions of the extreme points and connect these by a smooth line.

(b) Its outline as to main divisions: of what kind and how many.

(c) The detailed outline of the margin (Fig. 93).

Compare the mode of veining or venation of the elm and the maple leaf by making a diagram of each.

These leaves agree in being netted-veined; i.e., in having veinlets that join each other at many angles, so as to form a sort of delicate lace-work, like Figs. 94 and 95.

They differ, however, in the arrangement of the principal veins. Such a leaf as that of the elm is said to be feather-veined, or pinnately veined.

The maple leaf, or any leaf with closely similar venation, is said to be palmately veined. Describe the difference between the two plans of venation.

143. Relation of Venation to Shape of Leaves. - As soon as the student begins to observe leaves somewhat widely, 
he can hardly fail to notice that there is a general relation between the plan of venation and the shape of the leaf. How may this relation be stated? In most cases the principal veins follow at the outset a pretty straight course, a fact for which the student ought to be able to give a reason after he has performed Exp. XXXII.

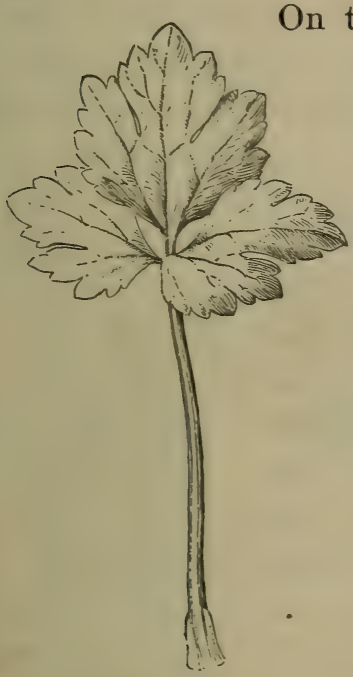

Frg. 97. - Palmately Divided Leaf of Buttercup.

whole, the arrangement of the

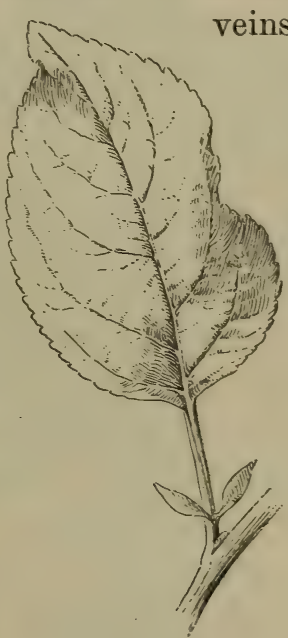

Fig. 98. - Leaf of Apple, with Stipules. such as to stiffen the leaf most in the parts that need

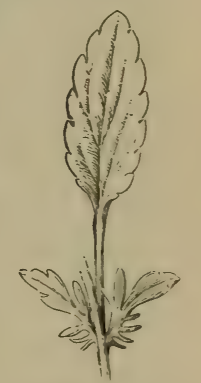

FIG. 99. - Leaf of Pansy, with LeafLike Stipules.

most support, and to reach the region near the margin by as short a course as possible from the end of the petiole.

144. Stipules. - Although they are absent from many leaves, and disappear early from others, stipules form a part of what the botanist regards as an ideal or model leaf. ${ }^{1}$ When present they are sometimes found as little

1 Unless the elm twigs used in the previous study were cut soon after the unfolding of the leaves in spring, t!? stipules may not have been left in any recognizable shape. 
bristle-shaped objects at the base of the leaf, as in the apple leaf (Fig. 98), sometimes as leaf-like bodies, for

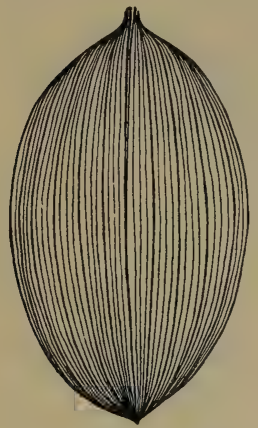

FiG. 100. - ParallelVeined Leaf of Solomon's Seal. example in the pansy (Fig. 99), and in many other forms, one of which is that of spinous appendages, as shown in the common locust (Fig. 103).

145. Parallel-Veined Leaves. - The leaves of many great groups of plants, such as the lilies, the sedges, and the grasses, are commonly parallel-veined, that is, with the veins running nearly parallel, lengthwise through the blade, as shown in Fig. 100, or with parallel veins proceeding from a midrib and thence extending to the margin, as shown in Fig. 101.

146. Occurrence of Netted Veining and of Parallel Veining. - The student has already, in his experiments on germination, had an opportunity to observe the difference in mode of veining between the leaves of some dicotyledonous plants and those of monocotyledonous plants. This difference is general throughout these great groups of flowering plants. What is the difference?

The polycotyledonous pines, spruces, and other coniferous trees have leaves with but a single vein, or two or three

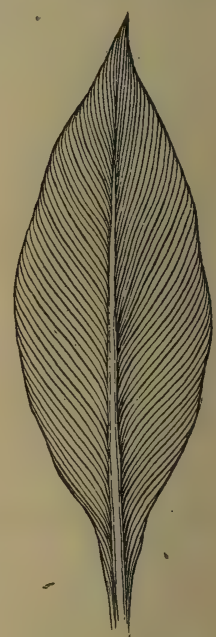

FIG. 101. - Parallel Veining in Canna. Veins running from midrib to margin. parallel ones, but in their case the veining could hardly be other than parallel, since the needle-like leaves are so 
narrow that no veins of any considerable length could exist except in a position lengthwise of the leaf.

The fact that a certain plan of venation is found mainly in plants with a particular mode of germination, of stem structure, and of arrangement of floral parts, is but one of the frequent cases in botany in which the structures of plants are correlated in a way which it is not easy to explain.

No one knows why plants with two cotyledons should have netted-veined leaves, but many such facts as this are familiar to every botanist.

147. Si m ple and Compound Leaves. - The

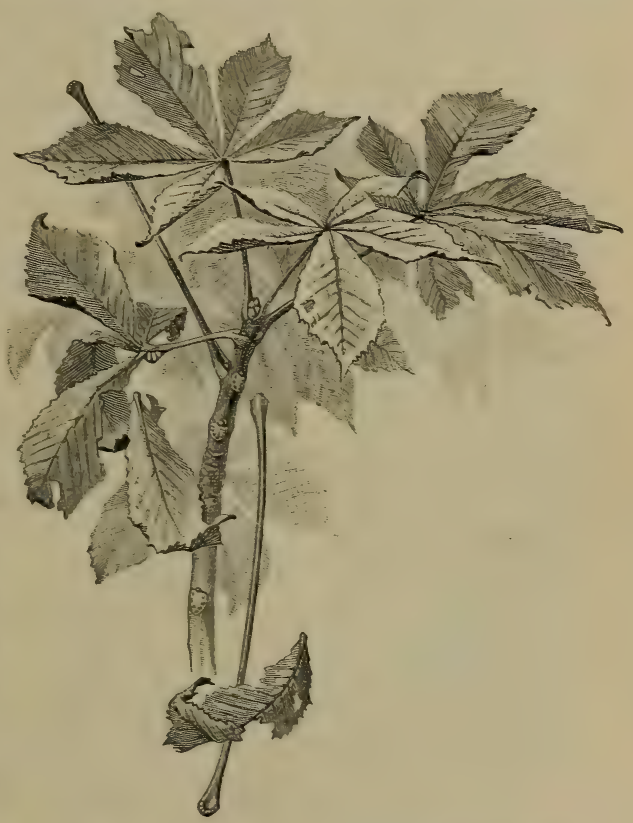

FIG. 102. - The Fall of the Horse-Chestnut Leaf.

leaves so far studied are simple leaves, that is, leaves of which the blades are more or less entirely united into one piece. But while in the elm the margin is cut in only a little way, in some maples it is deeply cut in toward the bases of the veins. In some leaves the gaps between the adjacent portions extend all the way down to the petiole 
(in palmately veined leaves) or to the midrib (in pinnately veined ones). Such divided leaves are shown in Figs. 96 and 97.

In still other leaves, known as compound leaves, the petiole, as shown in Fig. 102 (palmately compound), or the

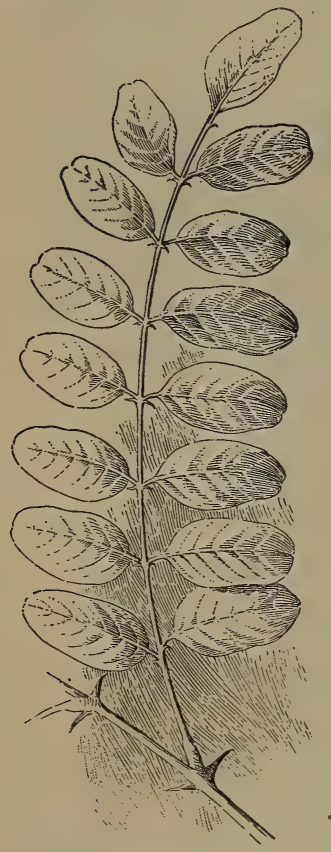

Frg. 103. - Pinnately Compound Leaf of Locust, with Spines for Stipules.

midrib, as shown in Fig. 103 (pinnately compound), bears what look to be separate leaves. These differ in

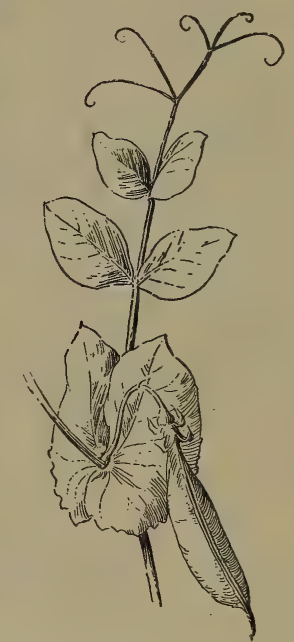

Fig. 104.-Pinnately

Compound Leaf of Pea. A tendril takes the place of a terminal leaflet.

their nature and mode of origin from the portions of the blade of a divided leaf. One result of this difference appears in the fact that some time before the whole leaf is ready to fall from the tree or other plant in autumn, the separate portions or leaflets of a compound leaf are seen to be jointed at their attachments, just as whole leaves are to the part of the stem from which they grow. In Fig. 102 the horse-chestnut leaf is shown at the time of falling, with some of the leaflets already disjointed.

That a compound leaf, in spite of the joints of the 
separate leaflets, is really only one leaf is shown : (1) by the absence of buds in the axils of leaflets (see Fig. 82); (2) by the arrangement of the blades of the leaflets horizontally, without any twist in their individual leaf-stalks ; (3) by the fact that their arrangement on the midrib does not follow any of the systems of leaf arrangement on the stem (Sect. 149). If each leaflet of a compound leaf should itself become compound, the result would be to produce a twice compound leaf. Fig. 113 shows that of an acacia. What would be the appearance of a thrice compound leaf?

\section{Review Summary of Leaves. ${ }^{1}$}

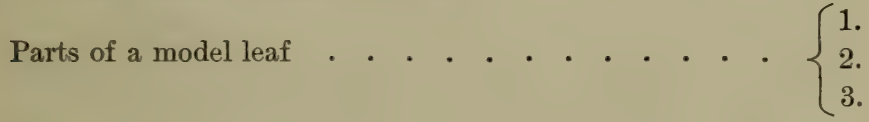

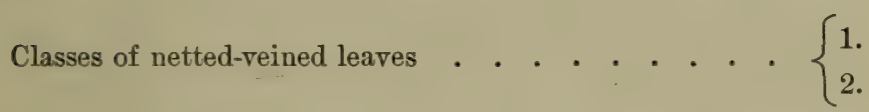

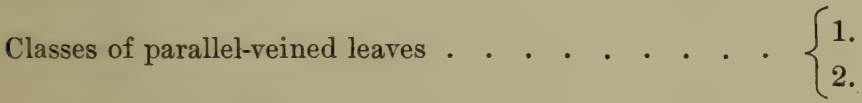

Relation of venation to number of cotyledons .... \{

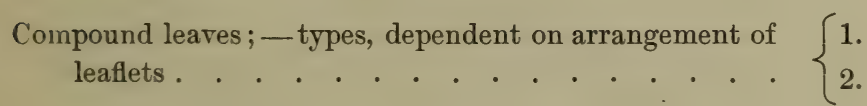

Once, twice, or three times compound . . . . . . . . \{

1 Ilustrate by sketches if possible. 


\section{CHAPTER $\mathrm{X}$}

\section{LEAF ARRANGEMENT FOR EXPOSURE TO SUN AND AIR; MOVEMENTS OF LEAVES AND SHOOTS}

149. Leaf Arrangement. ${ }^{1}$ - As has been learned from the study of the leafy twigs examined, leaves are quite

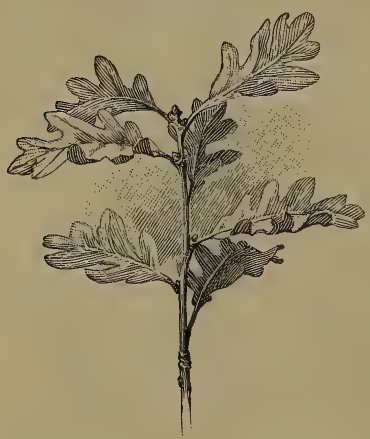
generally arranged so as to secure the best possible exposure to the sun and air. This, in the vertical shoots of the elm, the oak (Fig. 105), the apple, beech, and other alternate-leaved trees, is not inconsistent with their spiral arrangement of the leaves

FIG. 105. - Leaf Arrangement of the Oak.

around the stem. In horizontal twigs and branches of the elm, the beech (Fig. 106), the chestnut, the linden, and many other trees and shrubs, the desired effect is secured by the arrangement of all the

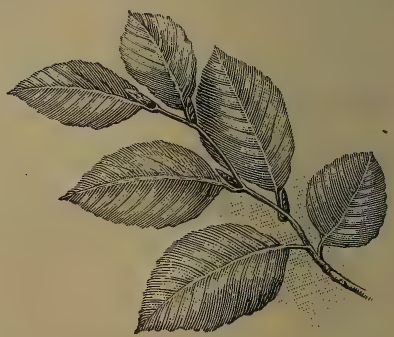

FIG. 106. - Leaf Arrangement of European Beech. leaves in two flat rows, one on each side of the twig.

1 See Kerner and Oliver's Natural History of Plants, Vol. I, pp. 396-424. 


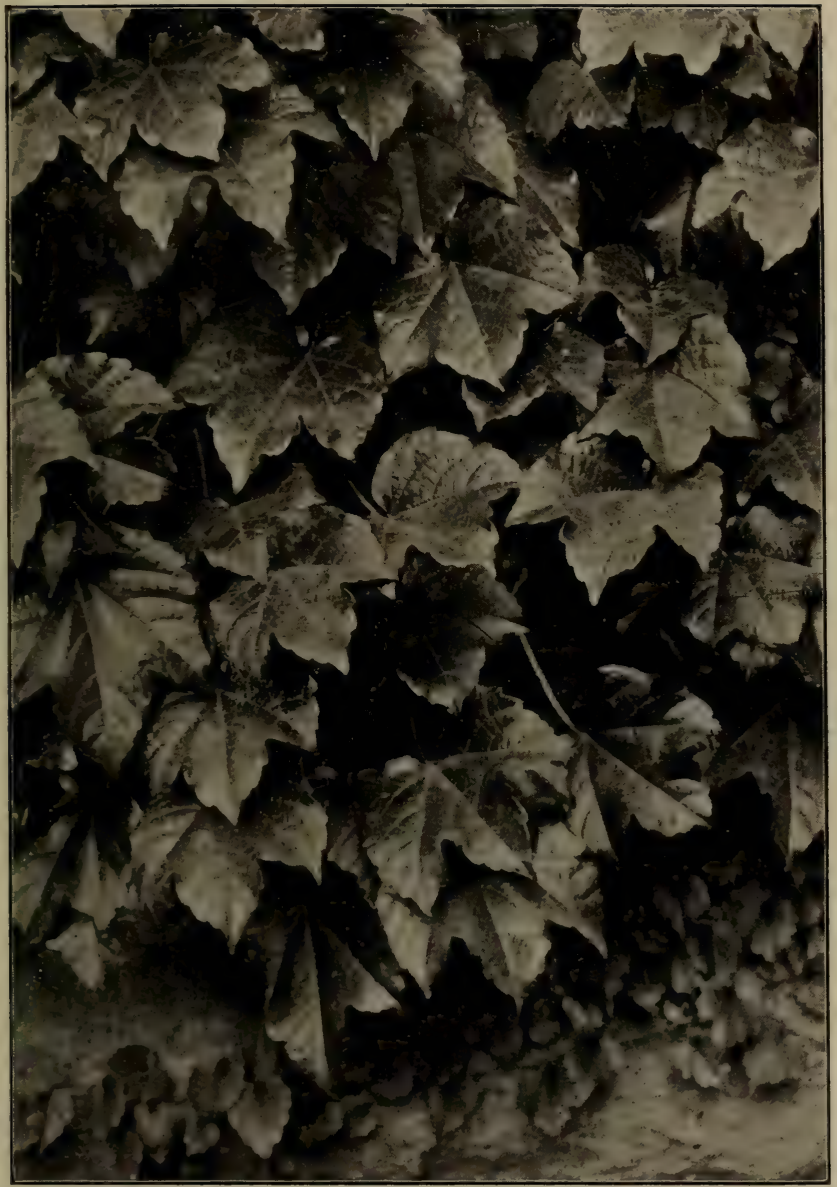

Plate III. - Exposure to Sunlight, Japanese Ivy 

The rows are produced, as it is easy to see on examining such a leafy twig, by a twisting about of the petioles.

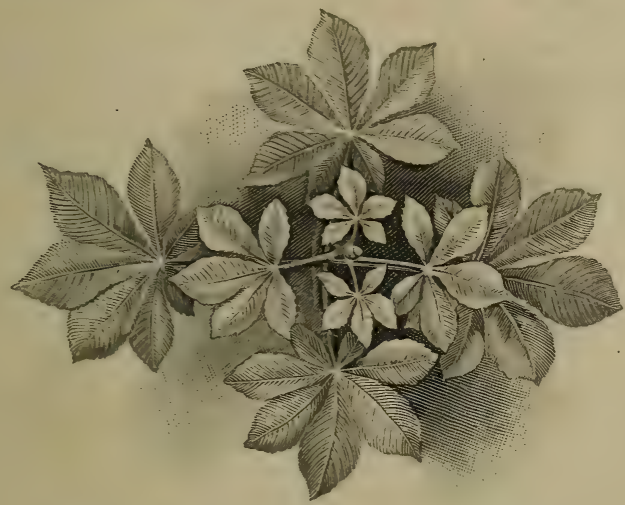

FrG. 107. - Leaf Arrangement of Horse-Chestnut on Vertical Shoots (top view).

$\mathrm{Th}$ e adjustment in many oppositeleaved trees and shrubs consists in having each pair of leaves cover the spaces between the pair below it, and sometimes in the lengthening of the lower petioles so as to bring the blades of the lower leaves outside those of the upper leaves. Examination of Figs. 107 and 108 will make the matter clear.

The student should not fail to study the leafage of several trees of different kinds on the growing tree itself, and in climbers on walls (Plate III), and to notice how circum-

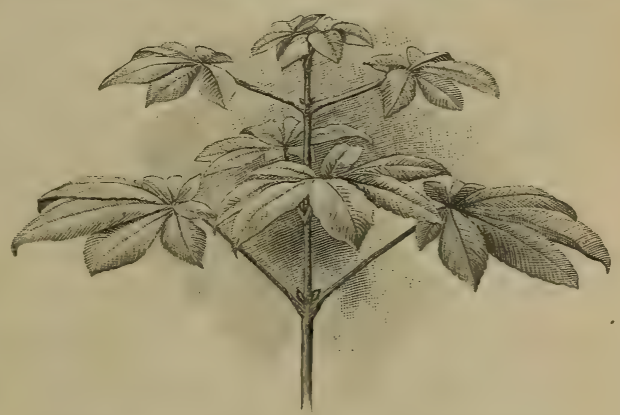

Fig. 108. - Leaf Arrangement of Horse-Chestnut on Vertical Shoots (side view). stances modify the position of the leaves. Maple leaves, for example, on the ends of the branches are arranged much 
like those of the horse-chestnut, but they are found to be arranged more nearly flatwise along the inner portions of the branches, that is, the portions nearer the tree. Figs. 109 and 110 show the remarkable difference in arrangement in different branches of the Deutzia, and equally interesting modifications may be found in alternate-leaved trees, such as the elm and the cherry.

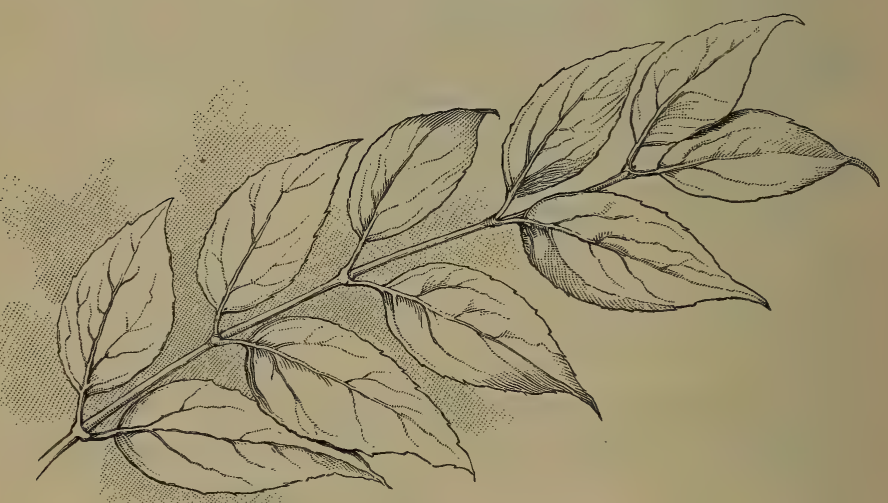

FIG. 109. - Opposite Leaves of Deutzia ${ }^{1}$ (from the same shrub as Fig. 110), as arranged on a Horizontal Branch.

150. Leaf-Mosaics. - In very many cases the leaves at the end of a shoot are so arranged as to form a pretty symmetrical pattern, as in the horse-chestnut (Fig. 107). When this is sufficiently regular, usually with the space between the leaves a good deal smaller than the areas of the leaves themselves, it is called a leaf-mosaic (Fig. 111). Many of the most interesting leaf-groups of this sort (as 
in the figure above mentioned) are found in the so-called root-leaves of plants. Good examples of these are the

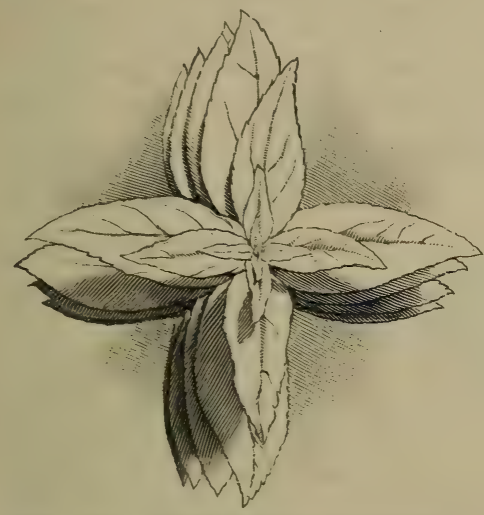

FiG. 110. - Opposite Leaves of Deutzia, as arranged on a Vertical Branch.

dandelion, chicory, fall dandelion, thistle, hawkweed, pyrola, plantain. How are the leaves of these plants kept from shading each other?

151. Much-Divided Leaves. - N ot infrequently leaves are cut into slender fringe-like divisions, as in the carrot, tansy, southernwood, wormwood, yarrow, dogfennel, cypress-vine, and many other common plants. This kind of leaf seems to be adapted to offer considerable surface to the sun without cutting off too much light from other leaves underneath. Such a leaf is in much less danger of being torn by severe winds than are broader ones with undivided margins. The same purposes are served by compound leaves with very many small leaflets, such as those of the honeylocust, mimosa acacia (Fig. 113),

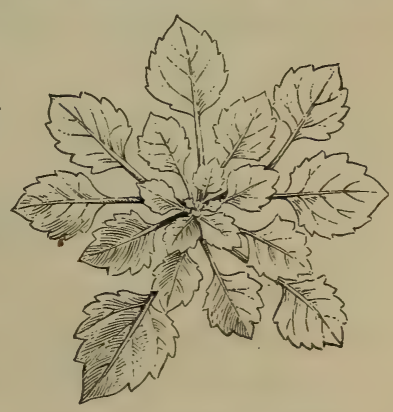

FIG. 111. - Leaf-Mosaic of a Campanula. and other trees and shrubs of the pea family. What kind of shade is produced by a horse-chestnut or a maple tree compared with that of a honey-locust or an acacia? 
152. Daily Movements of Leaves. - Many compound leaves have the power of changing the position of their leaflets to accommodate themselves to varying conditions of light and temperature. Some plants have the power of directing the leaves or leaflets edgewise towards the sun during the hottest parts of the day, allowing them to
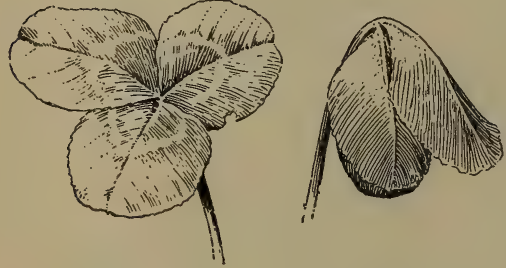

FIG. 112. - A Leaf of Red Clover.

At the left, leaf by day; at the right, the same leaf asleep at night. extend their surfaces more nearly in a horizontal direction during the cooler hours.

The so-called "sleep" of plants has long been known, but this subject has been most carefully studied rather recently.

The wood sorrel, or oxalis, the common bean, clovers, and the locust tree are some of the most familiar of the plants whose leaves assume decidedly different positions at night from those which they occupy during the day. Sometimes the leaflets rise at night, and in many instances they droop, as in the red clover (Fig. 112) and the acacia (Fig. 113). One useful purpose, at any rate, that is served by the leaf's taking the nocturnal position is protection from frost. It has been proved experimentally that when part of the leaves on a plant are prevented from assuming the folded position, while others are allowed to do so, and the plant is then exposed during a frosty night, the folded ones may escape while the others are killed. Since many plants in tropical climates fold their leaves at night, it is certain that this movement has other purposes than protection from frost, and probably there is 
much yet to be learned about the meaning and importance of leaf-movements.

153. Cause of Sleep-Movements. - The student may very naturally inquire whether the change to the nocturnal position is brought about by the change from light to darkness or whether it depends rather upon the time of day. It will be interesting to try an experiment in regard to this.

\section{EXPERIMENT XXVI}

Remore a pot containing an oxalis from a sunny window to a dark closet, at about the same temperature, and note at intervals of five minutes the condition of its leaves for half an hour or more.

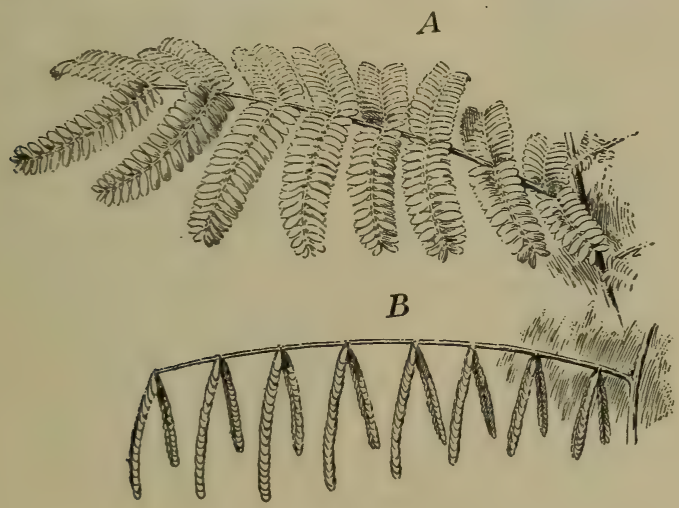

FIG. 113. - A Leaf of Acacia.

$A$, as seen by day ; $B$, the same leaf asleep at night.

154. Structure of the Parts which cause Leaf-Motions. In a great number of cases the daily movements of leaves are produced by special organs at the bases of the leafstalks. These cushion-like organs, called pulvini (Fig. 114), are composed mainly of parenchymatous tissue 
(Sect. 106), which contains much water. It is impossible fully to explain in simple language the way in which the cells of the pulvini act, but in a general way it may be said that changes in the light to which the plant is exposed cause rather prompt changes in the amount of water in

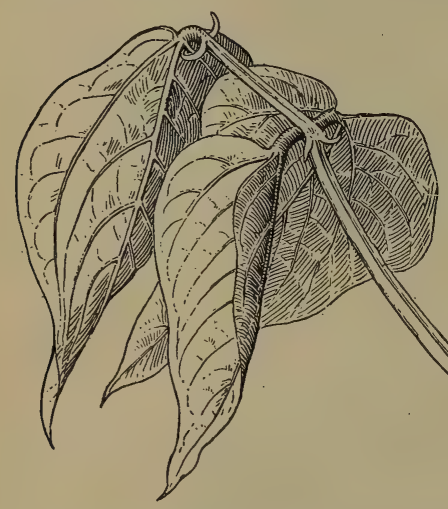

FIG. 114. - Compound Leaf of Bean with Pulvinus. (The pulvinus shows as an enlargement, in the figure about threeeighths inch long, at the base of the petiole.) the cells in one portion or other of the pulvinus. If the cells on one side are filled fuller of water than usual, that side of the pulvinus will be expanded and make the leaf-stalk bend toward the opposite side. The prompt-

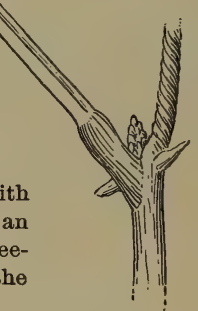

ness of these movements is no doubt in considerable measure due to the fact that in the pulvini (as in many other parts of plants) the protoplasm of adjacent cells is connected. Delicate threads of protoplasm extend through the cellwalls, making the whole tissue a living web, so that any suitable stimulus or excitant which acts on one part of the organ will soon affect the whole organ.

155. Vertically Placed Leaves. - Very many leaves, like those of the iris (Fig. 44), always keep their principal surfaces nearly vertical, thus receiving the morning and evening sun upon their faces, and the noonday sun (which is so intense as to injure them when received full on the 
surface) upon their edges. This adjustment is most perfect in the compass-plant of the prairies of the Mississippi basin. Its leaves stand very nearly upright, many with
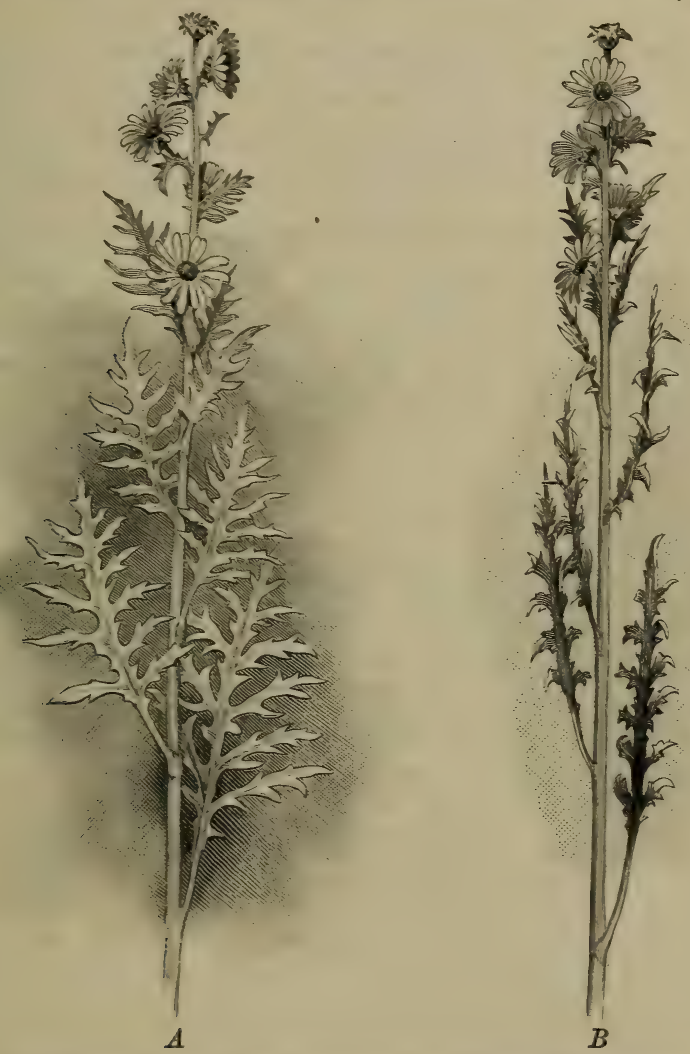

FIG. 115. - Leaves standing nearly Vertical in Compass-Plant (Silphium laciniatum). $A$, view from east or west ; $B$, from north or south.

their edges just about north and south (Fig. 115), so that the rays of the midsummer sun will, during every bright 
day, strike the leaf-surfaces nearly at right angles during a considerable portion of the forenoon and afternoon, while at midday only the edge of each leaf is exposed to the sun.

156. Movements of Leaves and Stems toward or away from Light (Heliotropic Movements). - The student doubtless learned from his experiments with seedling plants that their stems tend to seek light. The whole plant above ground usually bends toward the quarter from which the strongest light comes. Such movements are called heliotropic from two Greek words which mean turning toward the sun. How do the plants in a window behave with reference to the light?

\section{EXPERIMENT XXVII}

How do Young Shoots of English Ivy bend with Reference to Light? - Place a thrifty potted plant of English ivy before a small window, e.g., an ordinary cellar window, or in a large covered box, painted dull black within and open only on the side toward a south window. After some weeks note the position of the tips of the shoots. Explain the use of their movements to the plant.

157. Positive and Negative Heliotropic Movements; how produced. - Plants may bend either toward or away from the strongest light. In the former case they are said to show positive heliotropism, in the latter negative heliotropism. In both cases the movement is produced by unequal growth, brought about by the unequal lighting of different sides of the stem. If the less strongly lighted side grows faster, what kind of heliotropism results? If the more strongly lighted side grows faster, what kind of heliotropism results? How would a plant behave if placed on a 
revolving table before a window and slowly turned during the hours of daylight?

\section{Review Summary of Chapter $\mathbf{X}$.}

Leaf arrangement .. . $\left\{\begin{array}{l}\text { For vertical twigs . . . . } \\ \text { For horizontal twigs }\end{array}\right.$

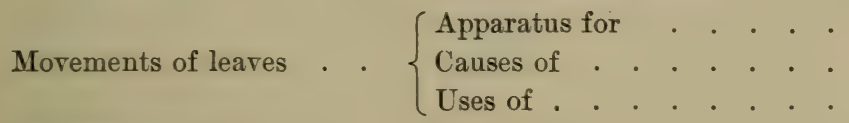

Compass-plants .. . . .

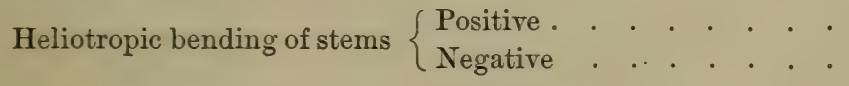




\section{CHAPTER XI}

\section{MINUTE STRUCTURE OF LEAVES; FUNCTIONS OF LEAVES}

159. Leaf of Lily. - A good kind of leaf with which to begin the study of the microscopical structure of leaves in general is that of the lily. ${ }^{1}$

160. Cross-Section of Lily Leaf. - The student should first examine with the microscope a cross-section of the leaf, that is, a very thin slice, taken at right angles to the upper and under surfaces and to the veins. This will show :

(a) The upper epidermis of the leaf, a thin, nearly transparent membrane.

(b) The intermediate tissues.

(c) The lower epidermis.

Use a power of from 100 to 200 diameters. In order to ascertain the relations of the parts, and to get their names, consult Fig. 116. Your section is by no means exactly like the figure; sketch it. Label properly all the parts shown in your sketch.

Are any differences noticeable between the upper and the lower epidermis? Between the layers of cells immediately adjacent to each?

161. Under Surface of Lily Leaf. - Examine with a power of 200 or more diameters the outer surface of a piece of epidermis from the lower side of the leaf. ${ }^{2}$ Sketch carefully, comparing your sketch with Figs. 117 and 118, and labeling it to agree with those figures.

Examine another piece from the upper surface; sketch it.

How does the number of stomata in the two cases compare?

1 Any kind of lily will answer.

2 The epidermis may be started with a sharp knife, then peeled off with small forceps, and mounted in water for microscopical examination. 
Take measurements from the last three sketches with a scale and, knowing what magnifying power was used, answer these questions ! :

(a) How thick is the epidermis ?

(b) What is the length and the breadth of the epidermal cells?

(c) What is the average size of the pulp-cells?

A stoma is a microscopic pore or slit in the epidermis. It is bounded and opened and shut by guard-cells (Fig. $118, g$ ), usually two in number. These are generally

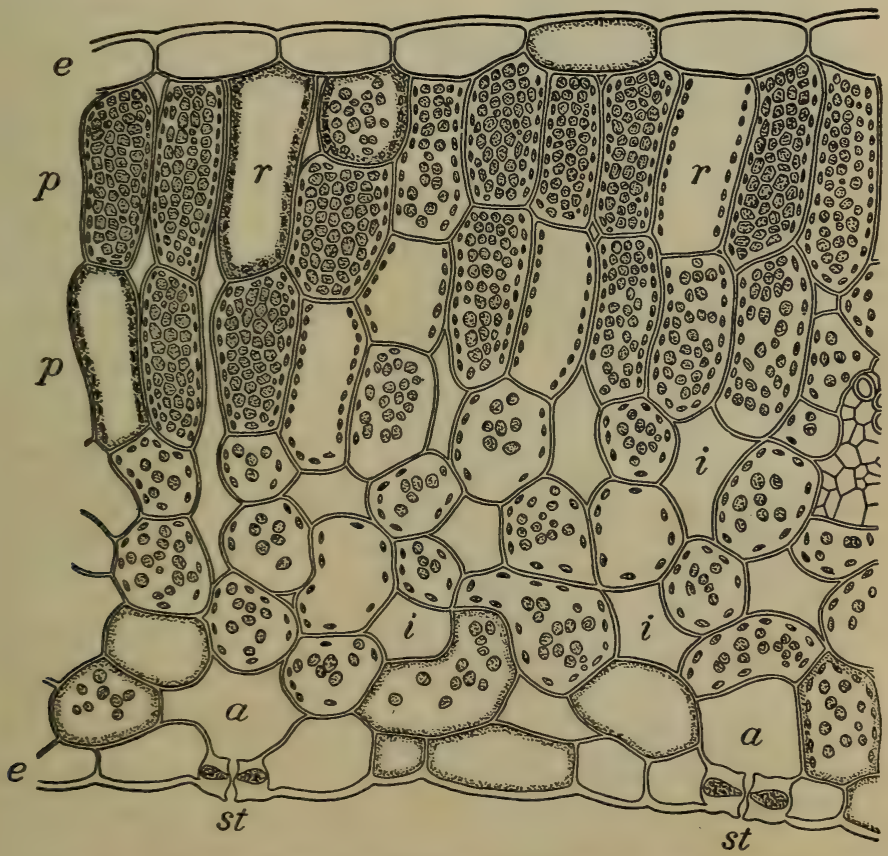

Fig. 116. - Vertical Section of the Leaf of the Beet. (Much magnified.)

$e$, epidermis ; $p$, palisade-cells (and similar elongated cells) ; $r$, cells filled with red cell sap; $i$, intercellular spaces; $a$, air spaces communicating with the stomata; st, stomata, or breathing pores.

1 The teacher may measure the size with the camera lucida. 
somewhat kidney-shaped and become more or less curved as they are fuller or less full of water (see Sect. 170).

162. Calculation of Number of Stomata per Unit of Area. - In order to get a fairly exact idea of the number of stomata on a unit of leaf-surface, the most convenient
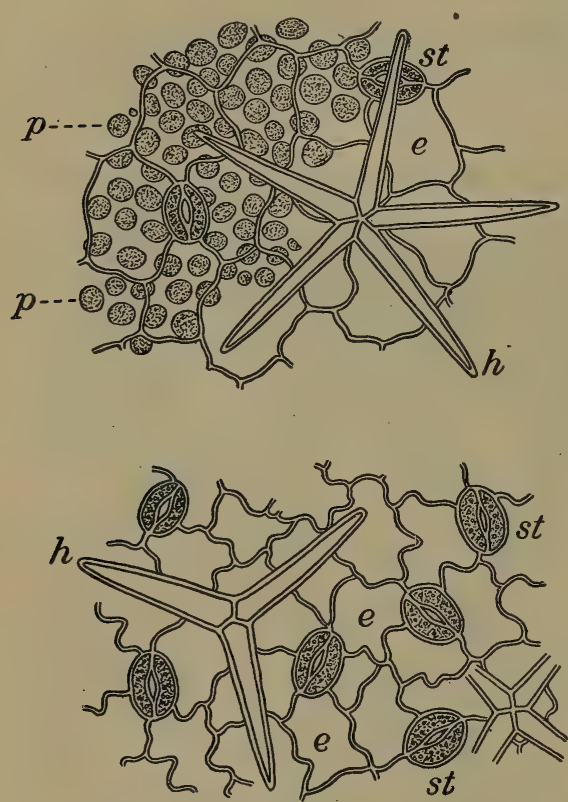

FiG. 117. - Epidermis of Leaf of Althæa. (Much magnified.)

$A$, from upper surface; $B$, from lower surface. $h$, star-shaped compound hairs ; st, stomata ; $p$, upper ends of palisade-cells, seen through the epidermis ; $e$, cells of epidermis. plan is to make use of a photomicrograph. The bromide enlarge$A$ ment No. 12 of the Tower series represents about a twenty-fivehundredth of a square inch of the lower epidermis of the cyclamen leaf, magnified until it $B$ is about fifteen inches square. Count the number of stomata on the entire photograph, then calculate the number of stomata on a square inch of the surface of

this leaf. If a cyclamen plant has twelve leaves, each with an average area of six square inches, calculate the number of stomata of the lower epidermis of all the leaves taken together. 
In the case of an apple tree, where the epidermis of the lower surface of the leaf contains about 24,000 stomata to the square inch, or the black walnut, with nearly 300,000 to the square inch, the total number on a tree is inconceivably large.

163. Uses of the Parts examined. It will be most convenient to discuss the uses of the parts of the leaf a little later, but it will make matters simpler to state at once that the epidermis serves as a mechanical protection to the parts beneath and prevents excessive evaporation, that the palisade-cells
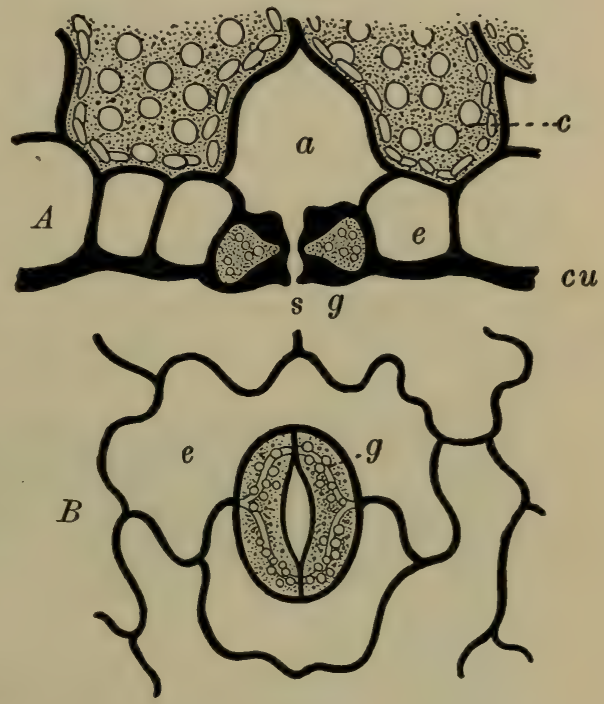

FIG. 118. - A Stoma of Thyme. (Greatly magnified.) $A$, section at right angles to surface of leaf ; $B$, surface view of stoma. $c u$, cuticle; $g$, guard-cells ; $s$, stoma; $e$, epidermal cells; $a$, air chamber; $c$, cells of spongy parenchyma with grains of chlorophyll.

(which it may not be easy to make out very clearly in a roughly prepared section) hold large quantities of the green coloring matter of the leaf in a position where it can receive enough but not too much sunlight, and the cells of the spongy parenchyma share the work of the palisadecells, besides evaporating much water. The stomata admit air to the interior of the leaf (where the air spaces 
serve to store and to distribute it), they allow oxygen and carbonic acid gas to escape, and, above all, they regulate the evaporation of water from the plant.

164. Leaf of "India-Rubber Plant." ${ }^{-}$- Study with the microscope, as the lily leaf was studied, make the same set of sketches, note the differences in structure between the two leaves, and try to discover their meaning.

How does the epidermis of the two leaves compare?

Which has the larger stomata?

Which would better withstand great heat and long drought?

165. Chlorophyll as found in the Leaf. - Slice off a little of the epidermis from some such soft, pulpy leaf as

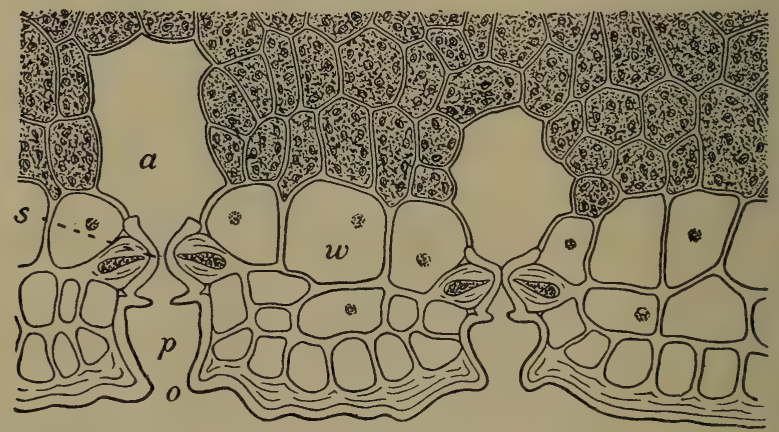

FIG. 119. - Section through Lower Epidermis of Leaf of India-Rubber Plant (Ficus elastica). (Magnified 330 diameters.)

$o$, opening of pit; $p$, pit leading to stoma ; $s$, stoma, with two guard-cells ; $w$, water-storage cells of epidermis ; $a$, an air space; around and above the air spaces are cells of the spongy parenchyma.

that of the common field sorrel, ${ }^{2}$ live-for-ever, or spinach; scrape from the exposed portion a very little of the green pulp; examine with the highest power attainable with your microscope, and sketch several cells.

1 Ficus elastica, a kind of fig tree.

2 Rumex Acetosella. 
Notice that the green coloring matter is not uniformly distributed, but that it is collected into little particles called chlorophyll bodies (Fig. 120, p).

166. Woody Tissue in Leaves. - The veins of leaves consist of fibro-vascular bundles containing wood and vessels much like those of the stem of the plant. Indeed, these bundles in the leaf are continuous with those of the stem, and consist merely of portions of the latter, looking as if unraveled, which pass outward and upward from the stem into the leaf under the name of leaf-traces. These traverse the petiole often in a somewhat irregular fashion.

\section{EXPERIMENT XXVIII}

\section{Passage of Water from} Stem to Leaf. - Place a freshly cut leafy shoot of some plant with large thin leaves, such as Hydrangea hortensia, in eosin solution for a few

FIG. 120. - Termination of a Vein in a Leaf. (Magnified about 345 diameters.)

$v$, spirally thickened cells of the vein ; $p$, parenchyma-cells of the spongy interior of the leaf, with chlorophyll bodies; $n$, nucleated cells.
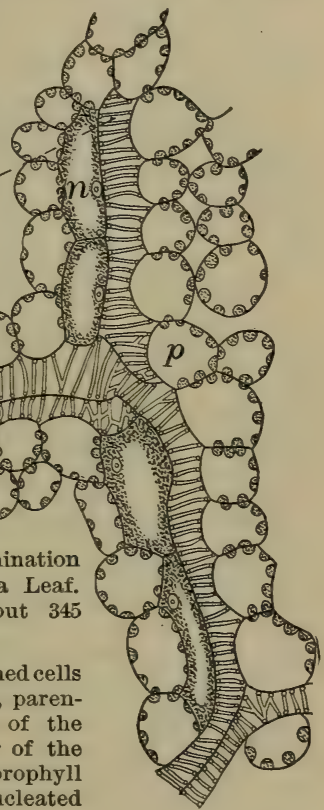

minutes. As soon as the leaves show a decided reddening, pull some of them off and sketch the red stains on the scars thus made. What does this show?

167. Experimental Study of Functions of Leaves. - The most interesting and profitable way in which to find out what work leaves do for the plant is by experimenting upon them. Much that relates to the uses of leaves is 
not readily shown in ordinary class-room experiments, but some things can readily be demonstrated in the experriments which follow.

\section{EXPERIMENT XXIX}

Transpiration. - Take two twigs or leafy shoots of any thin-leafed plant; ${ }^{1}$ cover the cut end of each stem with a bit of grafting wax ${ }^{2}$ to prevent evaporation from the cut surface. Put one shoot into a fruit jar, screw the top on, and leave in a warm room; put the other beside it, and allow both to remain some hours. Examine the relative appearance of the two, as regards wilting, at the end of the time.

Which shoot has lost most? Why? Has the one in the fruit jar lost any water? To answer this question, put the jar (without opening it) into a refrigerator; or, if the weather is cold, put it out of doors for a few minutes, and examine the appearance of the inside of the jar.' What does this show ? ${ }^{3}$

168. Uses of the Epidermis. ${ }^{4}$ — The epidermis, by its toughness, tends to prevent mechanical injuries to the - leaf, and after the filling up of a part of its outer portion with a corky substance it greatly diminishes the loss of water from the general surface. This process of becoming filled with cork (or a substance of similar properties known as cutin) is absolutely essential to the safety of leaves or young portions of stems which have to withstand heat and dryness. The corky or cutinized cellwall is waterproof, while ordinary cellulose allows water

1 Hydrangea, squash, melon, or cucumber is best; many other kinds will answer very well.

2 Grafting wax may be bought of nurserymen or seedsmen.

3 If the student is in doubt whether the jar filled with ordinary air might not behave in the same way, the question may be readily answered by putting a sealed jar of air into the refrigerator.

${ }^{4}$ See Kerner and Oliver's Natural History of Plants, Vol. I, pp. 273-362. 
to soak through it with ease. Merely examining sections of the various kinds of epidermis will not give nearly as good an idea of their properties as can be obtained by studying the behavior during severe droughts of plants which have strongly cutinized surfaces and of those which have not. Fig. 121, however, may convey some notion of the difference between the two kinds of structure. In most cases, as in the indiarubber tree, the external epidermal cells (and often two or three layers of cells beneath these) are filled with water, and thus serve as reservoirs from which the outer parts of the leaf and the stem are at times supplied.

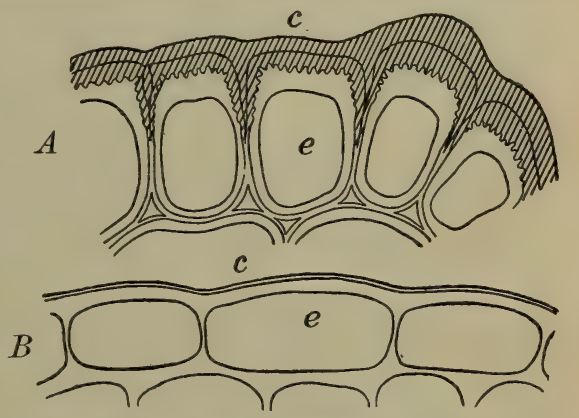

FrG. 121. - Unequal Development of Cuticle by Epidermis-Cells.

$A$, epidermis of Butcher's Broom (Ruscus); $\boldsymbol{B}$, epidermis of sunflower; $c$, cuticle; $e$, epi- . dermis-cells.

In many cases, noticeably in the cabbage, the epidermis is covered with a waxy coating, which doubtless increases the power of the leaf to retain needed moisture, and which certainly prevents rain or dew from covering the leaf-surfaces, especially the lower surfaces, so as to hinder the operation of the stomata. Many common plants, like the meadow rue and the nasturtium, possess this power to shed water to such a degree that the under surface of the leaf is hardly wet at all when immersed in water. The air-bubbles on such leaves give them a silvery appearance when held under water. 
169. Hairs on Leaves. - Many kinds of leaves are more or less hairy or downy, as those of the mullein, the "mullein pink," many cinquefoils, and other common plants. In some instances this hairiness may be a protection against snails or other small leaf-eating animals, but in other cases it seems to be pretty clear that the woolliness (so often confined to the under surface) is to lessen the loss of water through the stomata. The Labrador tea is an excellent example of a plant, with a densely woolly coating on the lower surface of the leaf. The leaves, too, are partly rolled up (see Fig. 224), with the upper surface outward, so as to give the lower surface a sort of deeply grooved form, and on the lower surface all of the stomata are placed. This plant, like some others with the same characteristics, ranges far north into regions where the temperature, even during summer, often falls so low that absorption of water by the roots ceases, since it has been shown that this nearly stops a little above the freezing point of water (see Exp. XVII). Exposed to cold, dry winds, the plant would then often be killed by complete drying if it were not for the protection afforded by the woolly, channeled under surfaces of the leaves. ${ }^{1}$

170. Operation of the Stomata. - The stomata serve to admit air to the interior of the leaf, and to allow moisture, in the form of vapor, to pass out of it. They do this not in a passive way, as so many mere holes in the epidermis might, but to a considerable extent they regulate the rapidity of transpiration, opening more widely in damp weather and closing in dry weather. The opening is

1 This adaptation is sufficiently interesting for class study. 


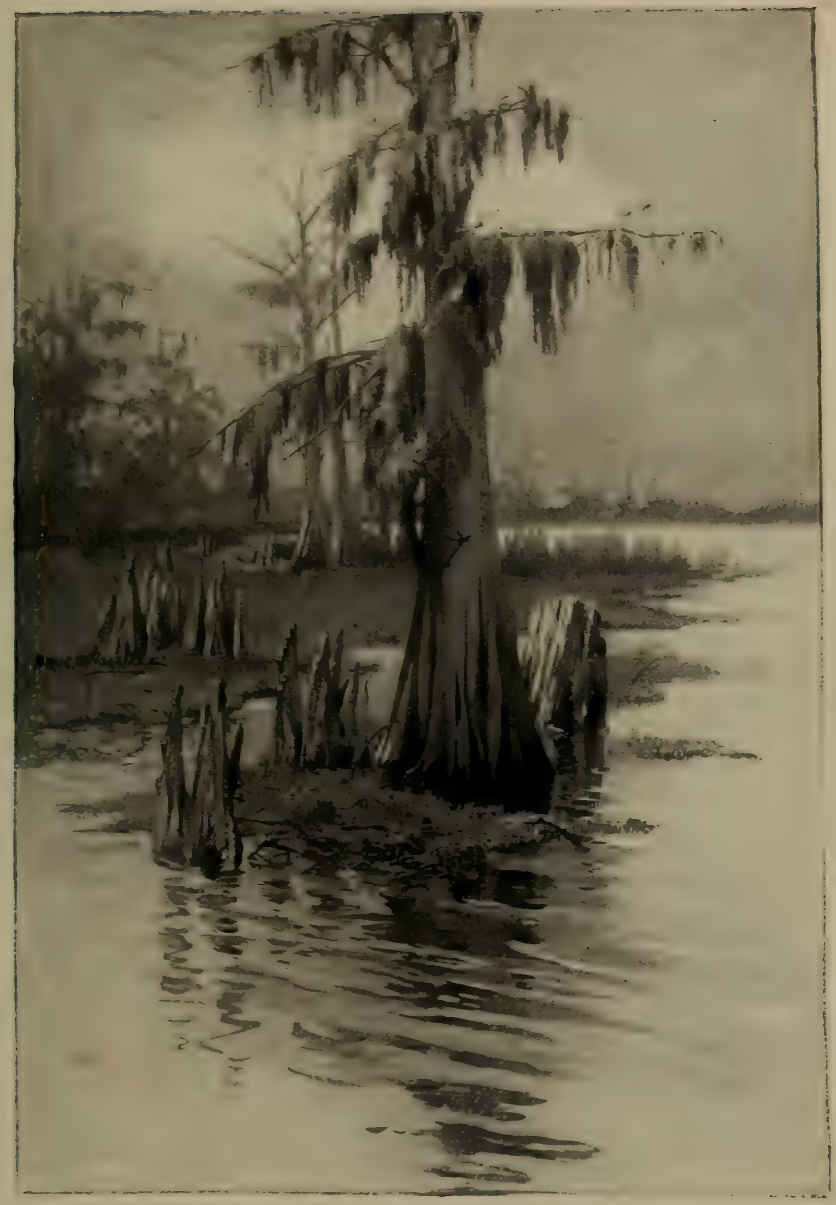

Plate IV. - A Cypress Swamp 

caused by each of the guard-cells bending into a more kidney-like form than usual, and the closing by a straightening out of the guard-cells. The under side of the leaf, free from palisade-cells, abounding in intercellular spaces, and pretty well protected from becoming covered with rain or dew, is especially adapted for the working of the stomata, and accordingly we usually find them in much greater numbers on the lower surface. On the other hand, the little flowerless plants known as liverworts, which lie prostrate on the ground, have their stomata on the upper surface, and so do the leaves of pond lilies, which lie flat on the water. In those leaves which stand with their edges nearly vertical, the stomata are distributed somewhat equally on both surfaces. Stomata occur in the epidermis of young stems, being replaced later by the lenticels. Those plants which, like the cacti, have no ordinary leaves, transpire through the stomata scattered over their general surfaces.

The health of the plant depends largely on the proper working condition of the stomata, and one reason why plants in cities often fail to thrive is that the stomata become choked with dust and soot. In some plants, as the oleander, provision is made for the exclusion of dust by a fringe of hairs about the opening of each stoma. If the stomata were to become filled with water, their activity would cease until they were freed from it; hence many plants have their leaves, especially the under surfaces, protected by a coating of wax which sheds water.

171. Measurement of Transpiration. - We have already proved that water is lost by the leaves, but it is worth while to perform a careful experiment to reduce our 
knowledge to an exact form, to learn how much water a given plant transpires under certain conditions. It is also desirable to find out whether different kinds of plants transpire alike, and what changes in the temperature, the dampness of the air, the brightness of the light, to which a plant is exposed, have to do with its transpiration. Another experiment will show whether both sides of a leaf transpire alike.

\section{EXPERIMENT XXX}

Amount of Water lost by Transpiration. - Procure a thrifty hydrangea $^{1}$ and a small "india-rubber plant," ${ }^{2}$ each growing in a small

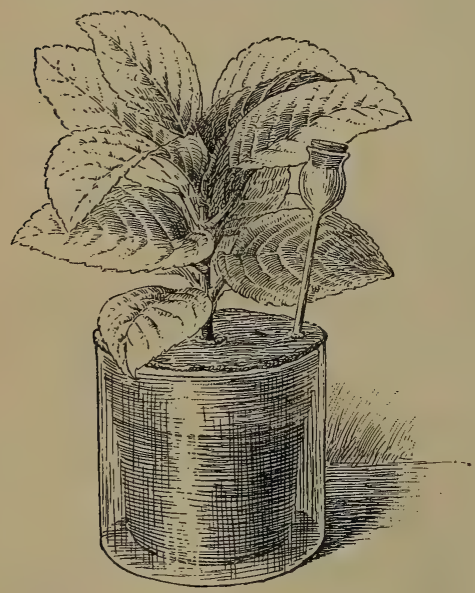

Fig. 122. - A Hydrangea potted in a Battery Jar for Exp. XXX. flower-pot, and with the number of square inches of leaf-surface in the two plants not too widely different. Calculate the area of the leaf-surface for each plant, by dividing the surface of a piece of tracing cloth into a series of squares one-half inch on a side, holding an average leaf of each plant against this and counting the number of squares and parts of squares covered by the leaf. Or weigh a square inch of tinfoil on a very delicate balance, cut out a piece of the same kind of tinfoil of the size of an average leaf, weigh this and calculate the leaf-area from the two weights.

This area, multiplied by the number of leaves for each plant, will give approximately the total evaporating surface for each.

Transfer each plant to a glass battery jar of suitable size. Cover

1 The common species of the greenhouses, Hydrangea hortensia.

2 This is really a fig, Ficus elastica. 
the jar with a piece of sheet lead, slit to admit the stem of the plant, invert the jar and seal the lead to the glass with a hot mixture of beeswax and rosin. Seal up the slit and the opening about the stem with grafting wax. A thistle-tube, such as is used by chemists, is also to be inserted, as shown in Fig. 122.1 The mouth of this may be kept corked when the tube is not in use for watering.

Water each plant moderately and weigh the plants separately on a balance that is sensitive to one or two grams. Record the weights, allow the plants to stand in a sunny, warm room for twenty-four hours and reweigh.

Add to each plant just the amount of water which is lost, ${ }^{2}$ and continue the experiment in the same manner for several days so as to ascertain, if possible, the effect upon transpiration of varying amounts of water in the atmosphere.

Calculate the average loss per 100 square inches of leaf-surface for each plant throughout the whole course of the experiment. Divide the greater loss by the lesser to find their ratio. Find the ratio of each plant's greatest loss per day to its least loss per day, and by comparing these ratios decide which transpires more regularly.

Try the effect of supplying very little water to each, so that the hydrangea will begin to droop, and see whether this changes the relative amount of transpiration for the two plants. Vary the conditions of the experiment for a day or two as regards temperature, and again for a day or two as regards light, and note the effect upon the amount of transpiration.

The structure of the fig (India-rubber plant) leaf has already been studied. That of the hydrangea is looser in texture and more like the leaf of the lily or the beet (Fig. 116).

What light does the structure throw on the results of the preceding experiment?

1 It will be much more convenient to tie the hydrangea if one has been chosen that has but a single main stem. Instead of the hydrangea, the common cineraria, Senecio cruentus, does very well.

2 The addition of known amounts of water may be made most conveniently by measuring it in a cylindrical graduate. 


\section{EXPERIMENT XXXI}

Through which Side of a Leaf of the India-Rubber Plant does Transpiration occur? - The student may already have found (Sect. 164) that there are no stomata on the upper surface of the fig leaf which he studied. That fact makes this leaf an excellent one by means of which to study the relation of stomata to transpiration.

Take two large, sound rubber-plant leaves, cut off pretty close to the stem of the plant. Slip over the cut end of the petiole of each leaf a piece of small rubber tubing, wire this on, leaving about half of it free, then double the free end over and wire tightly, so as to make the covering moisture-proof. Warm some vaseline or grafting wax until it is almost liquid, and spread a thin layer of it smoothly over the upper surface of one leaf and the lower surface of the other. Hang both up in a sunny place in the laboratory and watch them for a month or more.

What difference in the appearance of the two leaves becomes evident? What does the experiment prove?

172. Endurance of Drought by Plants. - Plants in a wild state have to live under extremely different conditions as regards water supply (see Chapter XXIV). Observation of growing plants during a long drought will quickly show how differently the various species of a region bear the hardships due to a scanty supply of moisture. It is still easier, however, to subject some plants to an artificial drought and watch their condition.

\section{EXPERIMENT XXXII}

Resistance to Drought. - Procure at least one plant from each of these groups :

Group I. Melon-cactus (Echinocactus or Mamillaria), prickly pear cactus.

Group II. Aloe, Cotyledon (often called Echeveria), houseleek. 
Group III. Live-for-ever (Sedum Telephium), Bryophyllum, English ivy, "ivy-leafed geranium," (Pelargonium peltatum), or any of the fleshy-leafed begonias.

Group IV. Hydrangea (H. hortensia), squash or cucumber, sunflower.

The plants should be growing in pots and well rooted. Water them well and then put them all in a warm, sunny place. Note the appearance of all the plants at the end of twenty-four hours. If any are wilting badly, water them. Keep on with the experiment, in no case watering any plant or set of plants until it has wilted a good deal. Record the observations in such a way as to show just how long a time it took each plant to begin to wilt from the time when the experiment began. If any hold out more than a month, they may afterwards be examined at intervals of a week, to save the time required for daily observations. If possible, account by the structure of the plants for some of the differences observed. Try to learn the native country of each plant used and the soil or exposure natural to it.

\section{Course traversed by Water through the Leaf. - The} same plan that was adopted to trace the course of water in the stem (Exp. XXI) may be followed to discover its path through the leaf.

\section{EXPERIMENT XXXIII}

Rise of Sap in Leaves. - Put the freshly cut ends of the petioles of several thin leaves of different kinds into small glasses, each containing eosin solution to the depth of one-quarter inch or more. Allow them to stand for half an hour, and examine them by holding up to the light and looking through them to see into what parts the eosin solution has risen. Allow some of the leaves to remain as much as twelve hours, and examine them again. The red-stained portions of the leaf mark the lines along which, under natural conditions, sap rises into it. Cut across (near the petiole or midrib ends) all the principal veins of some kind of large, thin leaf. Then cut off the petiole and at once stand the cut end, to which the blade 
is attached, in eosin solution. Repeat with another leaf and stand in water. What do the results teach?

174. Total Amount of Transpiration. - In order to prevent wilting, the rise of sap during the life of the leaf must have kept pace with the evaporation from its surface. The total amount of water that travels through the roots, stems, and leaves of most seed-plants during their lifetime is large, relative to the weight of the plant itself. During 173 days of growth a corn-plant has been found to give off nearly 31 pounds of water. During 140 days of growth a sunflower-plant gave off about 145 pounds. A grass-plant has been found to give off its own weight of water every twenty-four hours in hot, dry summer weather. This would make about $6 \frac{1}{2}$ tons per acre every twenty-four hours for an ordinary grass-field, or rather over 2200 pounds of water from a field $50 \times 150$ feet, that is, not larger than a good-sized city lot. Calculations based on observations made by the Austrian forest experiment stations showed that a birch tree with 200,000 leaves, standing in open ground, transpired on hot summer days from 700 to 900 pounds, while at other times the amount of transpiration was probably not more than 18 to 20 pounds. $^{1}$

These large amounts of water are absorbed, carried through the tissues of the plant, and then given off by the leaves simply because the plant-food contained in the soilwater is in a condition so diluted that great quantities of water must be taken in order to secure enough of the mineral and other substances which the plant demands from the soil.

1 See B. E. Fernow's discussion in Report of Division of Forestry of U. S. Department of Agriculture, 1889. 
Meadow hay contains about two per cent of potash, or 2000 parts in 100,000 , while the soil-water of a good soil does not contain more than one-half part in 100,000 parts. It would therefore take 4000 tons of such water to furnish the potash for one ton of hay. The water which the root-hairs take up must, however, contain far more potash than is assumed in the calculation above given, so that the amount of water actually used in the growth of a ton of hay cannot be much more than 260 tons. $^{1}$

175. Accumulation of Mineral Matter in the Leaf. - Just as a deposit of salt is found in the bottom of a seaside pool of salt water which has been dried up by the sun, so old leaves are found to be loaded with mineral matter, left behind as the sap drawn up from the roots is evaporated through the stomata. A bonfire of leaves makes a surprisingly large heap of ashes. An abundant constituent of the ashes of burnt leaves is silica, a substance chemically the same as sand. This the plant is forced to absorb along with the potash, compounds of phosphorus, and other useful substances contained in the soil-water; but since the silica is of hardly any value to most plants, it often accumulates in the leaf as so much refuse. Lime is much more useful to the plant than silica, but a far larger quantity of it is absorbed than is needed; hence it, too, accumulates in the leaf.

176. Nutrition, Metabolism.2 - The manufacture of the more complex plant-foods, starch, sugar, and so on, from

1 See the article, "Water as a Factor in the Growth of Plants," by B. T. Galloway and Albert F. Woods, Year-Book of U. S. Department of Agriculture, 1894.

${ }^{2}$ See Kerner and Oliver's Natural History of Plants, Vol. I, pp. 371-483. Also Pfeffer's Physiology of Plants, translated by Ewart, Chapter VIII. 
the raw materials which are afforded by the earth and air and all the steps of the processes by which these foods are used in the life and growth of the plant are together known as its nutrition. When we think more of the chemical side of nutrition than of its relation to plant-life, we call any of the changes or all of them metabolism, which means simply chemical transformation in living tissues. There are two main classes of metabolism - the constructive kind, which embraces those changes which build up more complicated substances out of simpler ones (Sect. 179), and the destructive kind, the reverse of the former (Sect.184). A good many references to cases of plant metabolism have been made in earlier chapters, but the subject comes up in more detail in connection with the study of the work of leaves than anywhere else, because the feeding which the ordinary seed-plant does is very largely done in and by its leaves.

17\%. Details of the Work of the Leaf. - A leaf has four functions to perform: (1) Starch-making; (2) assimilation; ${ }^{1}$ (3) excretion of water ; (4) respiration.

178. Absorption of Carbon Dioxide and Removal of its Carbon. - Carbon dioxide is a constant ingredient of the atmosphere, usually occurring in the proportion of about four parts in every 10,000 of air or one twenty-fifth of one per cent. It is a colorless gas, a compound of two simple substances or elements, carbon and oxygen, the former familiar to us in the forms of charcoal and graphite, the latter occurring as the active constituent of air.

1 In many works on Botany (1) and (2) are both compounded under the term assimilation. Many botanists (most of the American ones) apply the name photosynthesis or photosyntax to the starch-making process, but these names are not wholly satisfactory, and perhaps it is as well (as suggested by Professor Atkinson) to name the process from its result. 
Carbon dioxide is produced in immense quantities by the decay of vegetable and animal matter, by the respiration of animals, and by all fires in which wood, coal, gas, or petroleum is burned.

Green leaves and the green parts of plants, when they contain a suitable amount of potassium salts, have the power of removing carbon dioxide from the air (or in the case of some aquatic plants from water in which it is dissolved), retaining its carbon and setting free part or all of the oxygen. This process is an important part of the work done by the plant in making over raw materials into food from which it forms its own substance.

\section{EXPERIMENT XXXIV}

Oxygen-Making in Sunlight. - Place a green aquatic plant in a glass jar full of ice-cold fresh water, in front of a sunny window. 1 Place a thermometer in the jar, watch the rise of temperature, and note at what point you first observe the formation of oxygen bubbles. Remove to a dark closet for a few minutes and examine by lamplight, to see whether the rise of bubbles still continues.

This gas may be shown to be oxygen by collecting some of it in a small inverted test-tube filled with water and thrusting the glowing coal of a match just blown out into the gas. It is not, however, very easy to do this satisfactorily before the class.

Repeat the experiment, using water which has been well boiled and then quickly cooled. Boiling removes all the dissolved gases from water, and they are not re-dissolved in any considerable quantity for many hours.

1 Elodea, Myriophyllum, Chrysosplenium, Potamogeton, Fontinalis, any of the green aquatic flowering plants, or even the common confervaceous plants, known as pond-scum or "frog-spit," will do for this experiment. 
Ordinary air, containing a known per cent of carbon dioxide, if passed very slowly over the foliage of a plant covered with a bellglass and placed in full sunlight, will, if tested chemically, on coming out of the bell-glass be found to have lost a little of its carbon dioxide. The pot in which the plant grows must be covered with a lid, closely sealed on, to prevent air charged with carbon dioxide (as the air of the soil is apt to be) from rising into the bell-glass.

\section{Disposition made of the Absorbed Carbon Dioxide.}

- It would lead the student too far into the chemistry of botany to ask him to follow out in detail the changes by which carbon dioxide lets go part at least of its oxygen and gives its remaining portions, namely, the carbon, and perhaps part of its oxygen, to build up the substance of the plant. Starch is composed of three elements : hydrogen (a colorless, inflammable gas, the lightest of known substances), carbon, and oxygen. Water is composed largely of hydrogen, and, therefore, carbon dioxide and water contain all the elements necessary for making starch. The chemist cannot put these elements together to form starch, but the plant can do it, and at suitable temperatures starch-making goes on constantly in the green parts of plants when exposed to sunlight and supplied with water and carbon dioxide. ${ }^{1}$ 'The seat of the manufacture is in the chlorophyll bodies, and protoplasm is without doubt the manufacturer, but the process is not understood by chemists or botanists. No carbon dioxide can be taken up and used by plants growing in the dark, nor in an atmosphere containing only carbon dioxide, even in the light.

1 Very likely the plant makes sugar first of all and then rapidly changes this into starch. However that may be, the first kind of food made in the leaf and retained long enough to be found there by ordinary tests is starch. See Pfeffer's Physiology of Plants, translated by Ewart, Vol. I, pp. 317, 318. 


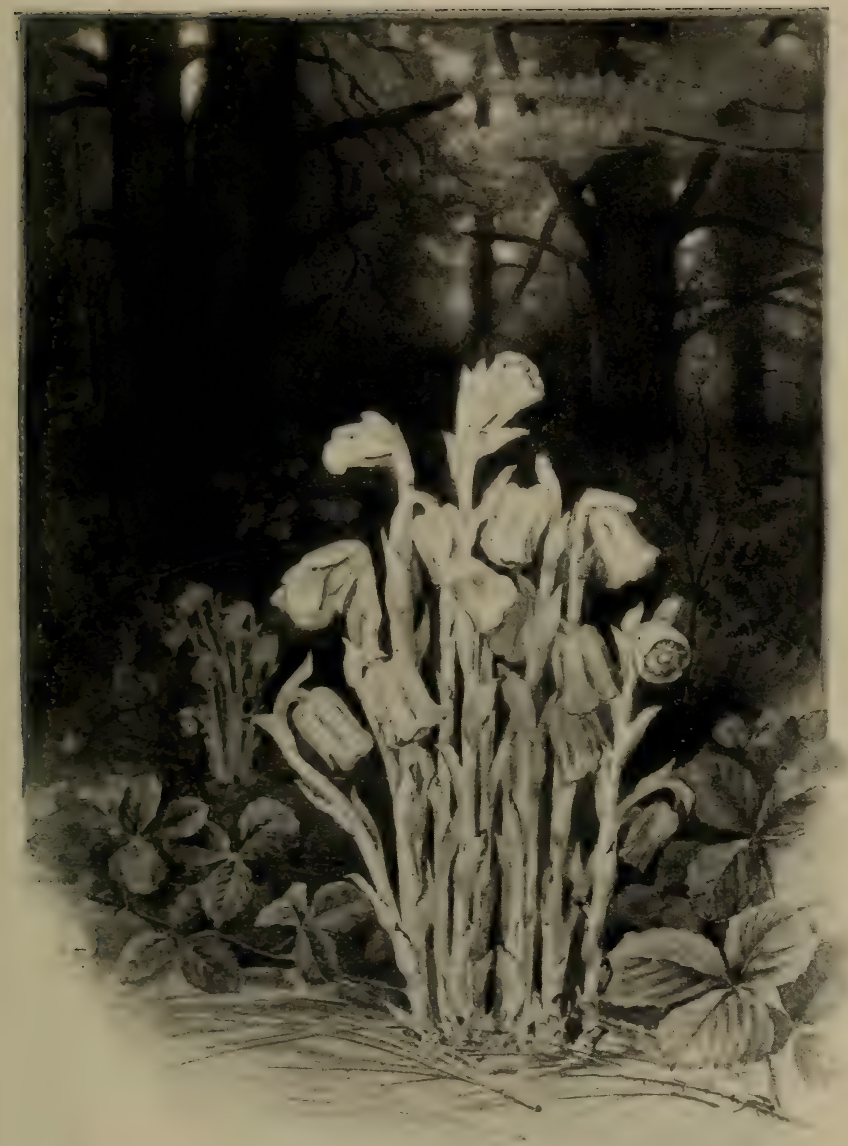

Plate V. - A Saprophyte, Indiau Pipe 

A very good comparison of the leaf to a mill has been made as follows ${ }^{1}$ :

The mill:

Raw material used :

Milling apparatus :

Energy by which the mill is run:

Manufactured product:

Waste product :
Palisade-cells and underlying cells of the leaf.

Carbon dioxide, water.

Chlorophyll grains.

Sunlight.

Starch.

Oxygen.

\section{Plants Destitute of Chlorophyll not Starch-Makers.} - Aside from the fact that newly formed starch grains are first found in the chlorophyll bodies of the leaf and the green layer of the bark, one of the best evidences of the intimate relation of chlorophyll to starch-making is derived from the fact that plants which contain no chlorophyll cannot make starch from water and carbon dioxide. Parasites, like the dodder, which are nearly destitute of green coloring matter, cannot do this; neither can saprophytes or plants which live on decaying or fermenting organic matter, animal or vegetable. Most saprophytes, like the moulds, toadstools, and yeast, are flowerless plants of low organization, but there are a few (such as the Indian pipe (Plate V), which flourishes on rotten wood or among decaying leaves) that bear flowers and seeds.

181. Detection of Starch in Leaves. - Starch may be found in abundance by microscopical examination of the green parts of growing leaves, or its presence may be shown by testing the whole leaf with iodine solution. 


\section{EXPERIMENT XXXV}

Occurrence of Starch in Nasturtium Leaves. - Toward the close of a very sunny day collect some bean leaves or leaves of nasturtium (Tropcolum). Boil these in water for a few minutes, to kill the protoplasmic contents of the cells and to soften and swell the starch grains. ${ }^{1}$

Soak the leaves, after boiling, in strong alcohol for a day or two, to dissolve out the chlorophyll, which would otherwise make it difficult to see the blue color of the starch test, if any were obtained.

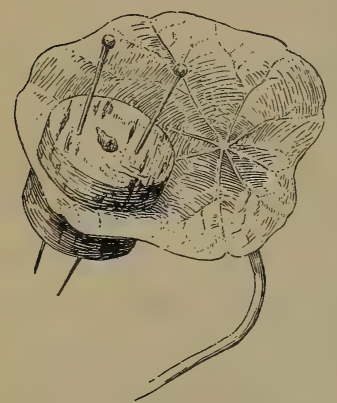

FIG. 123. - Leaf of Tropæolum partly covered with Disks of Cork and exposed to Sunlight.

Rinse out the alcohol with plenty of water and then place the leaves for ten or fifteen minutes in a solution of iodine, rinse off with water and note what portions of the leaf, if any, show the presence of starch.

\section{EXPERIMENT XXXVI}

Consumption of Starch in Nasturtium (Tropcolum) Leaves. - Select some healthy leaves of Tropæolum on a plant growing vigorously indoors or, still better, in the open air. Shut off the sunlight from parts of the selected leaves (which are to be left on the plant and as little injured as may be) by pinning circular disks of cork on opposite sides of the leaf, as shown in Fig. 123. On the afternoon of the next day remove these leaves from the plant and treat as described in the preceding experiment, taking especial pains to get rid of all the chlorophyll by changing the alcohol as many times as may be necessary. What does this experiment show in regard to the consumption of starch in the leaf? What has caused its disappearance?

182. Rate at which Starch is manufactured. - The amount of starch made in a day by any given area of

1 The leaves, collected as above described, may, after boiling, be kept in alcohol for winter use. They also make excellent material for the microscopical study of starch in the leaf. 
foliage must depend on the kind of leaves, the temperature of the air, the intensity of the sunlight, and some other circumstances. Sunflower leaves and pumpkin or squash leaves have been found to manufacture starch at about the same rate. In a summer day fifteen hours long they can make nearly three-quarters of an ounce of starch for each square yard of leaf-surface. A full-grown squash leaf has an area of about one and one-eighth square feet, and a plant may bear as many as 100 leaves. What would be the daily starch-making capacity of such a plant ? ${ }^{1}$

183. Assimilation. - From the starch in the leaf, grapesugar or malt-sugar is readily formed, and some of this in turn is apparently combined on the spot with nitrogen, sulphur, and phosphorus. These elements are derived from nitrates, sulphates, and phosphates, taken up in a dissolved condition by the roots of the plant and transported to the leaves. The details of the process are not understood, but the result of the combination of the sugars or similar substances with suitable (very minute) proportions of nitrogen, sulphur, and phosphorus is to form complex nitrogen compounds. These are not precisely of the same composition as the living protoplasm of plant-cells or as the reserve proteids stored in seeds (Sects. 14, 17), stems (Sect. 127), and other parts of plants, but are readily changed into protoplasm or proteid foods as necessity may demand.

Assimilation is by no means confined to leaves ; indeed, most of it, as above suggested, must take place in other parts of the plant. For instance, the manufacture of the immense amounts of cellulose, of cork, and of the com-

1 See Pfeffer's Physiology of Plants, translated by Ewart, Vol. I, p. 324. 
pound (lignin) characteristic of wood-fiber, that go to make up the main bulk of a large tree must be carried on in the roots, trunk, and branches of the tree.

184. Digestive Metabolism: - Plant-food in order to be carried to the parts where it is needed must be dissolved, and this dissolving often involves a chemical change and is somewhat similar to digestion as it occurs in animals. The newly made starch in the leaf must be changed to a sugar or other substance soluble in water before it can be carried to the parts of the plant where it is to be stored or to rapidly growing parts where it is to be used for building material. On the other hand, starch, oil, and such insoluble proteids as are deposited in the outer portion of the kernel of wheat and other grains are extremely well adapted to serve as stored food, but on account of their insoluble nature are quite unfit to circulate through the tissues of the plant. The various kinds of sugar are not well adapted for storage, since they ferment easily in the presence of warmth and moisture if yeast-cells or suitable kinds of bacteria are present.

Two important differences between starch-making in the green parts of plants and the non-constructive or the destructive type of metabolism should be carefully noticed. These latter kinds of metabolism go on in the dark as well as in the light and do not add to the total weight of the plant.

185. Excretion of Water and Respiration. - Enough has been said in Sect. 174 concerning the former of these processes. Respiration, or breathing in oxygen and giving off carbonic acid gas, is an operation which goes on constantly in plants, as it does in animals, and is necessary to 
their life. For, like animals, plants get the energy with which they do the work of assimilation, growth, reproduction, and performing their movements from the oxidation of such combustible substances as oil, starch, and sugar. ${ }^{1}$

The amount of oxygen absorbed and of carbonic acid given off is, however, so trifling compared with the amount of each gas passing in the opposite direction, while starch-making is going on in sunlight, that under such circumstances it is difficult to observe the occurrence of respiration. In ordinary leafy plants the leaves (through their

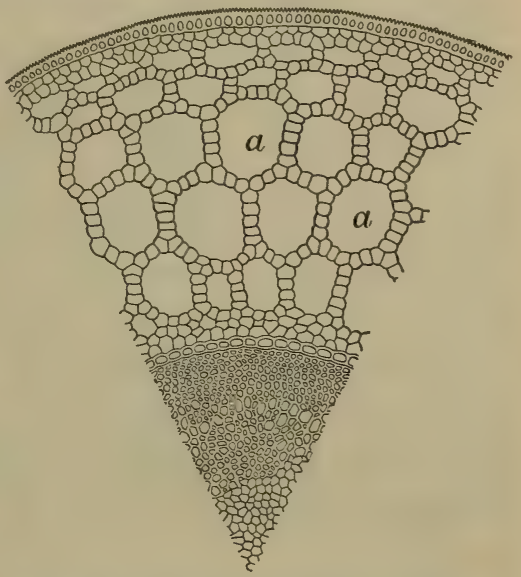

Fig. 124. - Cross-Section of Stem of Marestail (Hippuris) with Air-Passages, $a$.

stomata) are the principal organs for absorption of air, but much air passes into the plant through the lenticels of the bark.

In partly submerged aquatics especial provisions are found for carrying the air absorbed by the leaves down to the submerged parts. This is accomplished in pond lilies by ventilating tubes which traverse the leaf-stalks lengthwise. In many cases such channels run up and down the stem (Fig. 124).

1 The necessity of an air supply about the roots of the plant may be shown by filling the pot or jar in which the hydrangea was grown for the transpiration experiment perfectly full of water and noting the subsequent appearance of the plant at periods twelve to twenty-four hours apart. 


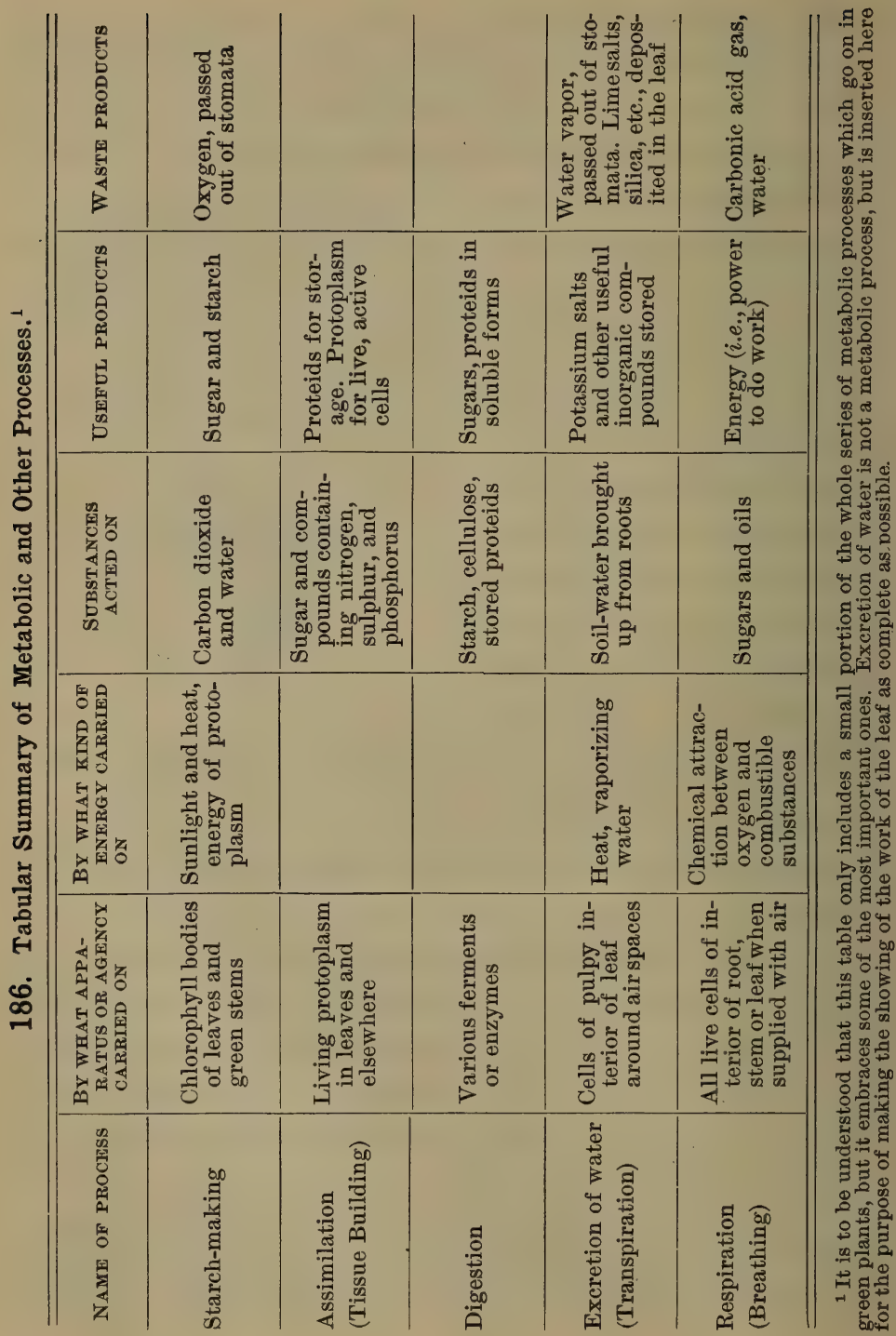


187. The Fall of the Leaf. - In the tropies trees retain most of their leaves the year round; a leaf occasionally falls, but no considerable portion of them drops at any one season. ${ }^{1}$ The same statement holds true in regard to our cone-bearing evergreen trees, such as pines, spruces, and the like. But the impossibility of absorbing soil-water when the ground is at or near the freezing temperature (Exp. XVII) would cause the death, by drying up, of trees with broad leaf-surfaces in a northern winter. And in countries where there is much snowfall, most broadleafed trees could not escape injury to their branches from overloading with snow, except by encountering winter storms in as close-reefed a condition as possible. For such reasons our common shrubs and forest trees (except the cone-bearing, narrow-leafed ones already mentioned) are mostly deciduous, that is they shed their leaves at the approach of winter.

The fall of the leaf is preceded by important changes in the contents of its cells.

\section{EXPERIMENT XXXVII}

\section{Does the Leaf vary in its Starch Contents at Different Seasons?}

Collect in early summer some leaves of several kinds of trees and shrubs and preserve them in alcohol. Collect others as they are beginning to drop from the trees in autumn and preserve them in the same way. Test some of each lot for starch as described in Sect. 181 .

What does the result indicate?

Much of the sugary and protoplasmic contents of the leaf disappears before it falls. These valuable materials

1 Except where there is a severe dry season. 
have been absorbed by the branches and roots, to be used again the following spring.

The separation of the leaf from the twig is accomplished by the formation of a layer of cork cells across the base of the petiole in such a way that the latter finally breaks off across the surface of the layer. A waterproof scar is thus already formed before the removal of the leaf, and there is no waste of sap dripping from the wound where the leafstalk has been removed, and no chance for moulds to attack the bark or wood and cause it to decay. In compound leaves each leaflet may become separated from the petiole, as is notably the case with the horse-chestnut leaf (Fig. 102). In woody monocotyledons, such as palms, the leaf-stalks do not commonly break squarely off at the base, but wither and leave projecting stumps on the stem (Plate VI).

The brilliant coloration, yellow, scarlet, deep red, and purple, of autumn leaves is popularly but wrongly supposed to be due to the action of frost. It depends merely on the changes in the chlorophyll grains and the liquid cell-contents that accompany the withdrawal of the proteid material from the tissues of the leaf. The chlorophyll turns into a yellow insoluble substance after the valuable materials which accompany it have been taken away, and the cell sap at the same time may turn red. Frost perhaps hastens the break-up of the chlorophyll, but individual trees often show bright colors long before the first frost, and in very warm autumns most of the changes in the foliage may come about before there has been any frost.

\section{Tabular Review of Experiments.}

[Continue the table from Sect. 128.] 


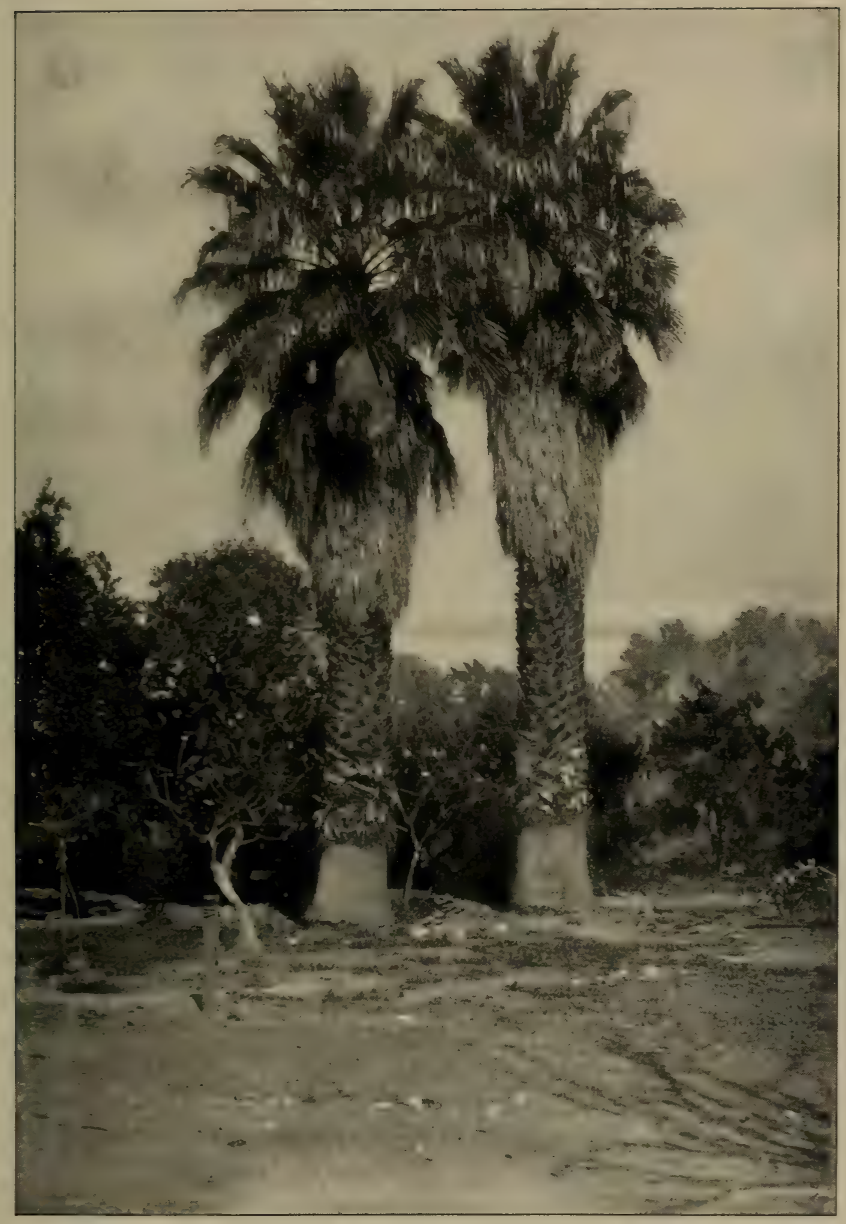

Plate Vi. - Fan Palms 

189. Review Summary of Minute Structure of Leaves. ${ }^{1}$

General structure, distribution of parenchyma, and prosenchyma

Layers of tissue seen on a crosssection

Structure of epidermis

Structure of stomata .

Distribution of stomata

Structure and distribution of chlorophyll bodies . . .

190. Review Summary of Functions of Leaves.

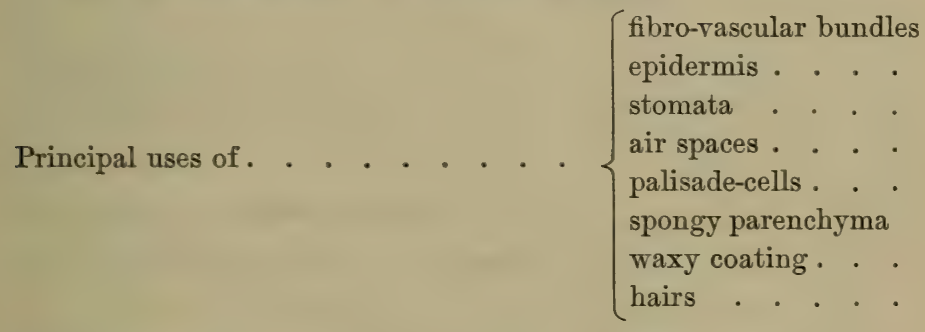

Substances received by the leaf... $\left\{\begin{array}{l}\text { from the air . . } \\ \text { from the soil . . . }\end{array}\right.$

Substances manufactured by the leaf . .

Substances given off by the leaf .. $\left\{\begin{array}{l}\text { into the air } . \\ \text { into the stem }\end{array}\right.$.

Mineral substances accumulated in the leaf

Statistics in regard to transpiration .

Statisties in regard to starch-making . .

${ }^{1}$ Illustrate with sketches and diagrams. 


\section{CHAPTER XII}

\section{PROTOPLASM AND ITS PROPERTIES}

191. The Cell in its Simplest Form. - Sufficient has been said in the preceding chapters, and enough tissues have been microscopically studied, to make it pretty clear what vegetable cells, as they occur in flowering plants, are like. In Chapter XI, leaf-cells have been taken for granted and their work described in some detail. Before going further, it is worth while to consider the structure of an individual cell, and to see of what kinds of activity it is capable.

In studying the minute anatomy of bark, wood, pith, and other tissues the attention is often directed to the cell-wall without much regard to the nature of the cellcontents. Yet the cell-wall is not the cell, any more than the lobster shell or the crayfish shell is the lobster or the crayfish. The contained protoplasm with its nucleus is the cell. ${ }^{1}$ The cell reduced to its lowest terms need not have a cell-wall, but may consist simply of a mass of protoplasm, usually containing a portion of denser consistency than the main bulk, known as the nucleus.

Such cells, without a cell-wall, are not common in the vegetable world, but are frequently encountered among animals.

192. The Slime Moulds. ${ }^{2}$ - One of the best examples of masses of naked protoplasm leading an individual existence

1 See Kerner and Oliver's Natural History of Plants, Vol. I, pp. 21-51.

2 Strasburger, Noll, Schenk, and Schimper's Text-Book of Botany, pp. 50-52 and $302-305$. 
is found in the slime moulds, which live upon rotten tan bark, decaying wood, and so on. These curious organisms have so many of the characteristics both of animals and of plants that they have been described in zoölogies under the former title and in botanies under the latter one. Perhaps it would not really be so absurd a statement as it might seem, to say that every slime mould leads the life of an animal during one period of its existence and of a plant at another period. At any rate, whatever their true nature, these little masses of unenclosed protoplasm illustrate admirably some of the most important properties of protoplasm. Slime moulds spring from minute bodies called spores (Fig. 125, a) which differ from the seeds of seed-plants not only in their microscopic size but still more in their lack of an embryo. The spores of slime moulds are capable, when kept dry, of preserving for many years their power of germination, but in the presence of moisture and warmth they will germinate as soon as they are scattered. During the process of germination the spore swells, as shown at $b$, and then bursts, discharging its protoplasmic contents, as seen at $c$ and $d$. This in a few minutes lengthens out and produces at one end a hairlike cilium, as shown at $e, f, g$. These ciliated bodies are called swarmspores, from their power of swimming freely about by the vibrating motion of the cilia. Every swarmspore has at its ciliated end a nucleus, and at the other end a bubble-like object which gradually expands, quickly disappears, and then again expands. This contractile vacuole is commonly met with in animalcules, and increases the likeness between the slime moulds and many microscopic animals. The next change of the swarmspores is into an 
Amoeba form (so called from one of the most interesting and simplest of animals, the Amoba, found on the surface of
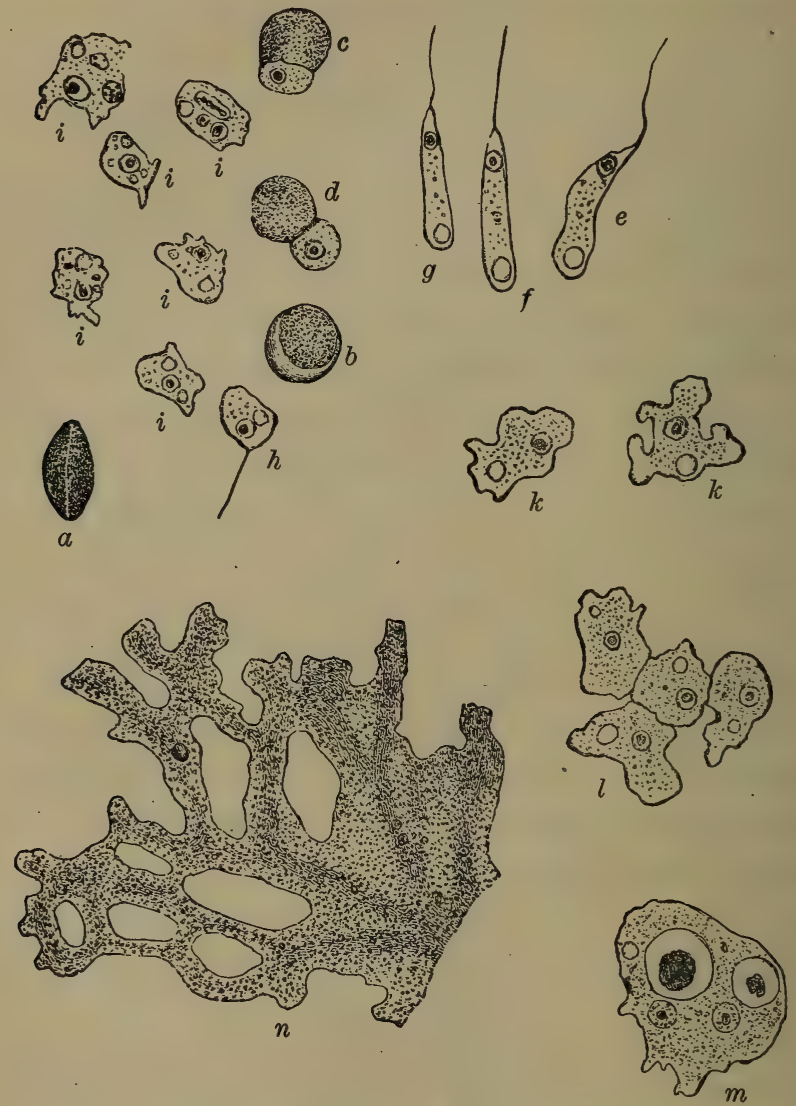

Fig. 125. - A Slime Mould. ( $\alpha-m$, inclusive, $\times 540$ times, $n \times 90$ times.)

mud and the leaves of water plants). In this condition, as shown at $h, i, k$, the spores creep about over the surface of the decaying vegetable material on which the 
slime moulds live. Their movement is caused by a thrusting out of the semi-liquid protoplasm on one side of the mass, and a withdrawal of its substance from the other side. At length many amœba-shaped bodies unite, as at $l$, to form a larger mass, $m$, which finally increases to the protoplasmic network shown at $n$. This eventually collects into a roundish or egg-shaped firm body, inside of which a new crop of spores is produced. It is not easy to trace the manner in which the nourishment of these simple plants is taken. Probably they absorb it from the decaying matter upon which they live during their amœba-like period, and after they have formed the larger masses, $n$.

193. Characteristics of Living Protoplasm. ${ }^{1}$ - The behavior of the slime moulds during their growth and transformations, as just outlined, affords a fair idea of several of the remarkable powers which belong to living protoplasm, which have been summed up as follows:

(1) The power to take up new material into its own substance (selective absorption). This is not merely a process of soaking up liquids, such as occurs when dry earth or a sponge is moistened. The protoplasmic lining of a root-hair, for example, selects from the soil-water some substances and rejects others (Sect. 65).

(2) The ability to change certain substances into others of different chemical composition (metabolism, Sect. 176). Carbon dioxide and water, losing some oxygen in the process, are combined into starch; starch is changed into various kinds of sugar and these back into starch again; starch becomes converted into vegetable acids, into cellulose, or into oil ; or the elements of starch are combined

1 See Huxley's Essays, Vol. I, essay on "The Physical Basis of Life." 
with nitrogen to make various proteid compounds, either for immediate use or for reserve food. Many other complicated transformations occur.

(3) The power to cast off waste or used-up material (excretion). Getting rid of surplus water (Sect. 174) and of oxygen (Sect. 178) constitutes a very large part of the excretory work of plants.

(4) The capacity for growth and the production of offspring (reproduction). These are especially characteristic of living protoplasm. It is true that non-living objects may grow in a certain sense, as an icicle or a crystal of salt or of alum in a solution of its own material does. But growth by the process of taking suitable particles into the interior of the growing substance and arranging them into an orderly structure (Fig. 126) is possible only in the case of live protoplasm.

(5) The possession of the power of originating movements not wholly and directly caused by any external impulse (automatic movements). - Such, for instance, are the lashing movements of the cilia of the swarmspores of slime moulds, or the slow pendulum movements of Oscillatoria (Sect. 269), or the slow vibrating movements of the stipules of the "telegraph plant" (Desmodium), not uncommon in greenhouses.

(6) The power of shrinking or closing up (contractility). This is illustrated by the action of the contractile vacuole of the slime moulds and of many animalcules and by all the muscular movements of animals.

(7) Sensitiveness when touched or otherwise disturbed, for instance, by a change of light or of temperature (irritability). 
194. Nature and Occurrence of Irritability in Plants. ${ }^{1}-$ Mention has already been made of the fact that certain parts of plants respond to suitable stimuli that is exciting

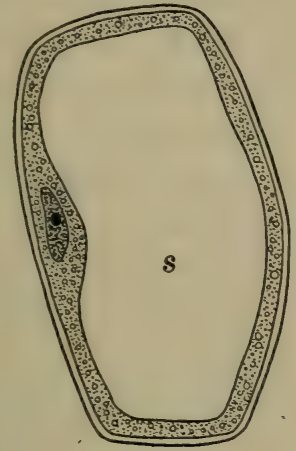

C

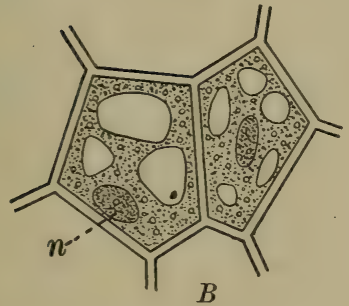

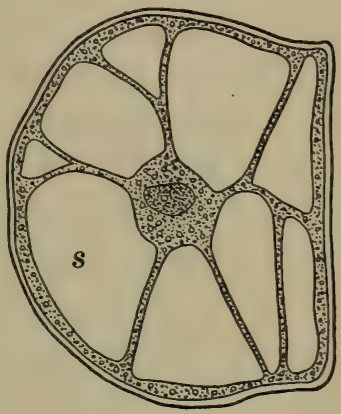

$D$

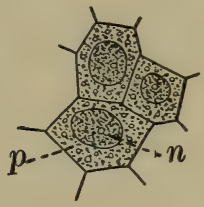

A

Fig. 126. - Protoplasm in Ovule and Fruit of Snowberry (Symphoricarpus racemosus).

$A$, cells from ovule, $\times 340 ; B$, cells from an ovule further developed, $\times 340 ; C, D$, cells from pulp of fruit, $\times 110 ; n$, nucleus ; $p$, protoplasm; $s$, cell-sap.

In the young and rapidly growing cells, $A$ and $B$, the cell-sap is not present, or present only in small quantities, while in the older cells, $C$ and $D$, it occupies a large portion of the interior of the cell.

causes. Geotropic movements (Sect. 70) are due to the stimulating effect of gravitation on roots or shoots.

1 See Strasburger, Noll, Schenk, and Schimper's Text-Book of Botany, pp. 160-162 and 269-274. 
These movements are due to unequal growth induced in the younger portions of the plant by the action of gravi-

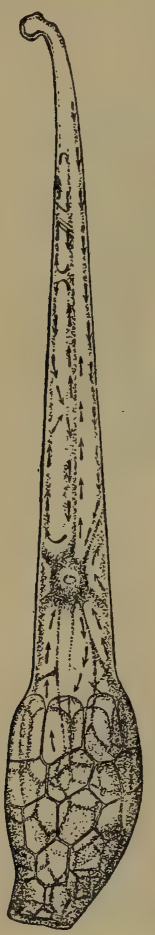

FIG. 127. - Stinging Hair of Nettle, with Nucleus. (Much magnified.) The arrows show the direction of the currents in the protoplasm. tation upon it. Other movements (of ordinary foliage leaves, of the floral leaves of many flowers, and of other parts of a few flowers) are produced by changes in the distention or turgescence of some of the cells in the organs which move and have nothing to do with growth. The closing of the leaves of insect-catching plants is briefly described in Sect. 410, and the "sleep" of leaves, due to movements of the pulvini, was described in Sect. 152. A few facts in regard to the opening and closing of flowers will be found in Sect. 440 .

The stimuli which cause movements of leaves or of the irritable parts of flowers are of several kinds. Light is the main cause which induces leaves to open from their night position to that usual in the daytime. In the case of flowers, it is sometimes light and sometimes warmth which causes them to open. Leaves which catch insects may be made to close by touching them, but the sensitive-plants, of which there are several kinds found in the United States, and a much more sensitive one in tropical America, all fold their leaflets, on being touched, into the same position which they assume at night. 
195. Circulation of Protoplasm. - When confined by a cell-wall, protoplasm often manifests a beautiful and constant rotating movement, traveling incessantly up one side of the cell and down the other. ${ }^{1}$ A more complicated motion is the circulation of protoplasm, shown in cells of the jointed blue hairs in the flower of the common spiderwort and in the stinging hairs of the nettle (Fig. 127). The thin cell-wall of each hair is lined with a protoplasmic layer in which are seen many irregular, thread-like currents, marked by the movements of the granules, of which the protoplasmic layer is full.

1 See Huxley and Martin's Elementary Biology, under Chara. 


\section{CHAPTER XIII}

\section{INFLORESCENCE, OR ARRANGEMENT OF FLOWERS}

ON THE STEM

196. Regular Positions for Flower-Buds. - Flower-buds, like leaf-buds, occur regularly either in the axils of leaves or at the end of the stem or branch and are therefore either axillary or terminal.

19\%. Axillary and Solitary Flowers; Indeterminate Inflorescence. - The simplest possible arrangement for

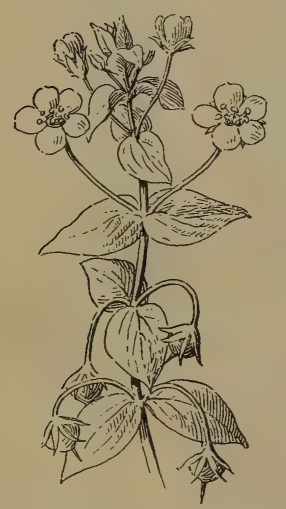

FIG. 128. - Axillary and Solitary Flowers of Pimpernel. flowers which arise from the axils of leaves is to have a single flower spring from each leaf-axil. Fig. 128 shows how this plan appears in a plant with opposite leaves. As long as the stem continues to grow, the production of new leaves may be followed by that of new

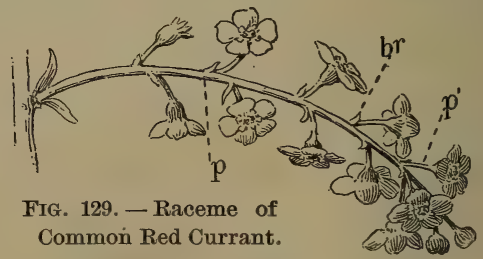

$p$, peduncle ; $p^{\prime}$, pedicel ; $b r$, bract.

flowers. Since there is no definite limit to the number of flowers which may appear in this way, the mode of flowering just described (with many others of the same general character) is known as indeterminate inflorescence. 
198. The Racemes and Related Forms. - If the leaves along the stem were to become very much dwarfed and the

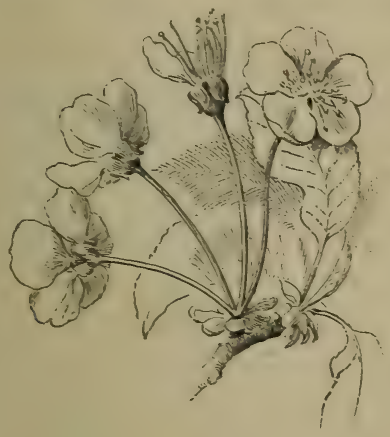

Frg. 130. - Simple Umbel of Cherry. flowers brought closer together, as they frequently are, a kind of flower-cluster like that of the currant (Fig. 129) or the lilyof-the-valley would result. Such an inflorescence is called a $r a$ ceme; the main flower-stalk is known as the peduncle; the little individual flower-stalks are pedi$c e l s$, and the small, more or less scale-like leaves of the peduncle are bracts. ${ }^{1}$

Frequently the lower pedicels of a cluster on the general plan of the raceme are longer than the upper ones and make a somewhat flat-topped cluster, like that of the hawthorn, the sheep laurel, or the trumpet creeper. This is called a corymb.

In many cases, for example the parsnip, the Sweet Cicely, the ginseng, and the cherry, a group of pedicels of nearly equal length

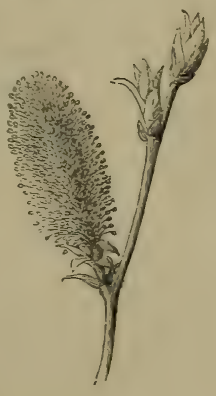

A

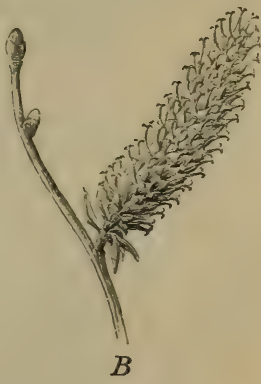

Fig. 131. - Catkins of Willow.

$A$, staminate flowers ; $B$, pistillate flowers.

1 It is hardly necessary to say that the teacher will find it better in every way, if material is abundant, to begin the study of flower-clusters with the examination of typical specimens by the class. 
spring from about the same point. This produces a flower-cluster called the umbel (Fig. 130).

199. Sessile Flowers and Flower-Clusters. - Often the pedicels are wanting, or the flowers are sessile, and then a modification of the raceme is produced which is called *3. a spike, like that of the plantain (Fig. 132). The willow, alder, birch, poplar, and many other common trees bear a short, flexible, rather scaly spike (Fig. 131), which is called a catkin.

The peduncle of a spike is often so much shortened as to bring the flowers into a somewhat globular mass. This is called a head (Fig. 132). Around

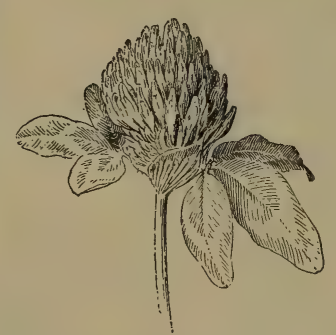

FIG. 132. - Spike of Plantain and Head of Red Clover. the base of the head usually occurs a circle of bracts known as the involucre. The same name is given to a set of bracts which often surround the bases of the pedicels in an umbel.

200. The Composite Head. The plants of one large group, of which the dandelion, the daisy, the thistle, and the sunflower are well-known members, bear their flowers in close involucrate heads on a common receptacle. The whole cluster looks so much like a single flower that it is usually taken for one by non-botanical people. In many of the largest and most showy heads, like that of the sunflower and the daisy, there are two kinds of flowers, the ray-flowers, around the margin, and the tubular diskflowers of the interior of the head (Fig. 133). The early botanists supposed the whole flower-cluster to be a single 

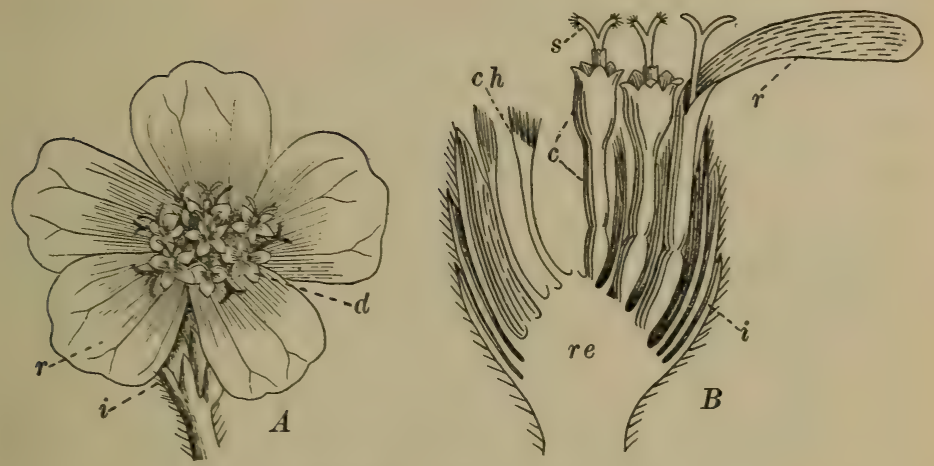

FIG. 133. - Head of Yarrow.

$A$, top view. (Magnified.) $B$, lengthwise section. (Magnified.) re, receptacle; $i$, involucre ; $r$, ras-flowers ; $d$, disk-flowers ; $c$, corolla ; $s$, stigma ; ch, chaff, or bracts of receptacle.

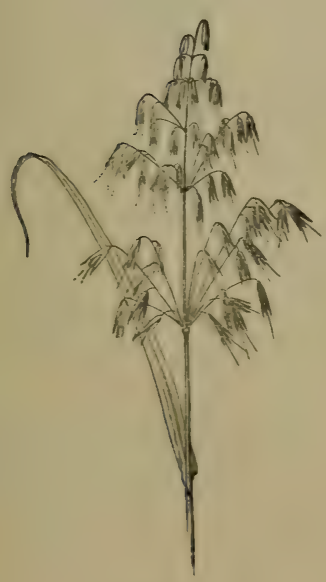

FIG. 134.

Panicle of Oat.

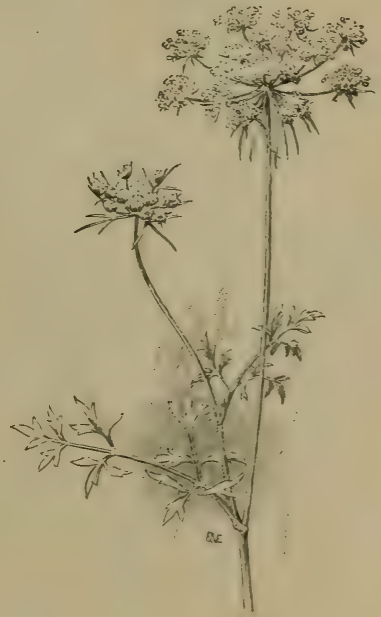

FIG. 135. - Compound E'mbel of Carrot. 
compound flower. This belief gave rise to the name of one family of plants, Compositce, that is, plants with compound flowers. In such heads as those of the thistle, the cud weed, and the everlasting there are no ray-flowers, and in others, like those of the dandelion and the chicory, all the flowers are ray-flowers.

201. Compound Flower-Clusters. - If the pedicels of a raceme branch, they may produce a compound raceme, or

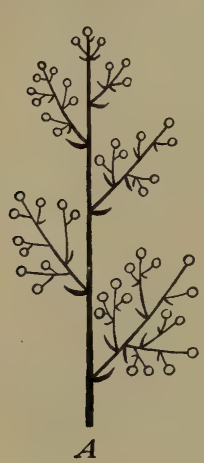

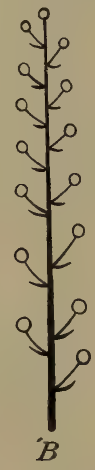
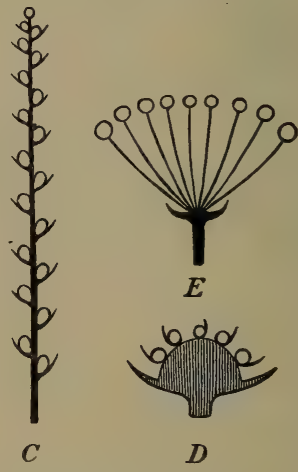

FIG. 136. - Diagrams of Inflorescence.

$A$, panicle ; $B$, raceme ; $C$, spike ; $D$, umbel ; $E$, head.

panicle, like that of the oat (Fig. 134). ${ }^{1}$ Other forms of compound racemes have received other names.

An umbel may become compound by the branching of its flower-stalks (Fig. 135), each of which then bears a little umbel, an umbellet.

202. Inflorescence Diagrams. - The plan of inflorescence may readily be indicated by diagrams like those of Fig. 136 .

The student should construct such diagrams for some rather complicated flower-clusters, like those of the grape, horse-chestnut or buckeye, hardhack, vervain, or many grasses.

1 Panicles may also be formed by compound cymes (see Sect. 204). 
203. Terminal Flowers; Determinate Inflorescence.The terminal bud of a stem may be a flower-bud. In this case the direct growth of the stem is stopped or determined by the appearance of the flower; hence such plants are said to have a determinate inflorescence. The simplest possible case of this kind is that in which the stem bears but one flower at its summit.

204. The Cyme. - Very often flowers appear from lateral (axillary) buds, below the terminal flower, and thus give rise to a flower-cluster called a cyme. This may have only three flowers, and in that case would look very much like a three-flowered umbel. But in the raceme, corymb, and umbel the order of flowering is from below upward, or from the outside of the clus-

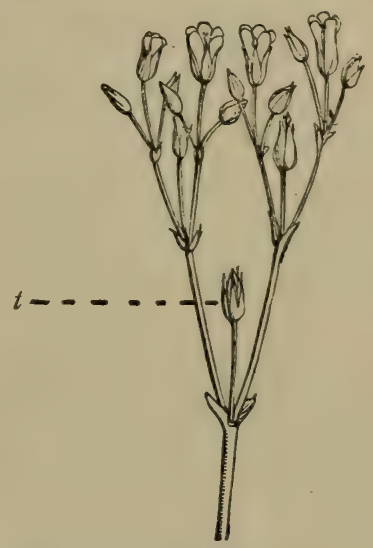

Fig. 137. - Compound Cyme of Mouse-Ear Chickweed. $t$, the terminal (oldest) flower. ter inward, because the lowest or the outermost flowers are the oldest, while in determinate forms of inflorescence the central flower is the oldest, and therefore the order of blossoming is from the center outwards. Cymes are very commonly compound, like those of the elder and of many plants of the pink family, such as the Sweet William and the mouse-ear chickweed (Fig. 137). They may also, as already mentioned, be panicled, thus making a cluster much like Fig. 136, $A$. 


\section{CHAPTER XIV}

\section{THE STUDY OF TYPICAL FLOWERS}

(Only one of the three flowers described to be studied by aid of these directions.)

205. The Flower of the Trillium. - Cut off the flower-stalk rather close to the flower; stand the latter, face down, on the table, and draw the parts then shown. Label the green leaf-like parts sepals, and the white parts, which alternate with these, petals. Turn the flower face up, and make another sketch, labeling the parts as before, together with the yellow enlarged extremities or anthers of the stalked organs called stamens.

Note and describe the way in which the petals alternate with the sepals. Observe the arrangement of the edges of the petals toward the base, - how many with both edges outside the others, how many with both edges inside, how many with one edge in and one out.

Note the veining of both sepals and petals, more distinct in which set? 1

Pull off a sepal and make a sketch of it, natural size ; then remove a petal, flatten it out, and sketch it, natural size.

Observe that the flower-stalk is enlarged slightly at the upper end into a rounded portion, the receptacle, on which all the parts of the flower rest.

Note how the six stamens arise from the receptacle and their relations to the origins of the petals. Remove the remaining, petals

1 In flowers with delicate white petals the distribution of the fibro-vascular bundles in these can usually be readily shown by standing the freshly cut end of the peduncle in red ink for a short time, until colored veins begin to appear in the petals. The experiment succeeds readily with apple, cherry, or plum blossoms; with white gilliflower the coloration is very prompt. Lily-of-thevalley is perhaps as interesting a flower as any on which to try the experiment, since the well-defined stained stripes are separated by portions quite free from stain, and the pistils are also colored. 
(cutting them off near the bottom with a knife), and sketch the stamens, together with the other object, the pistil, which stands in the center.

Cut off one stamen, and sketch it as seen through the magnifying glass. Notice that it consists of a greenish stalk, the filament, and a broader portion, the anther (Fig. 149). The latter is easily seen to contain a prolongation of the green filament, nearly surrounded by a yellow substance. In the bud it will be found that the anther consists of two long pouches or anther-cells, which are attached by their whole length to the filament, and face inward (towards the center of the flower). When the flower is fairly open, the authercells have already split down their margius, and are discharging a yellow, somewhat sticky powder, the pollen.

Examine one of the anthers with the microscope, using the twoinch objective, and sketch it.

Cut away all the stamens, and sketch the pistil. It consists of a stout lower portion, the ovary, which is six-ridged or angled, and which bears at its summit three slender stigmas.

In another flower, which has begun to wither (and in which the ovary is larger than in a newly opened flower), cut the ovary across about the middle, and try to make out with the magnifying glass the number of chambers or cells which it contains. Examine the cross-section with the two-inch objective; sketch it, and note particularly the appearance and mode of attachment of the undeveloped seeds or ovules with which it is filled. Make a vertical section of another rather mature ovary, and examine this in the same way.

Using a fresh flower, construct a diagram to show the relation of the parts on an imaginary cross-section, as illustrated in Fig. 157.1 Construct a diagram of a longitudinal section of the flower, on the general plan of those in Fig. 155, but showing the contents of the ovary.

Make a tabular list of the parts of the flower, beginning with the sepals, giving the order of parts and number in each set.

${ }^{1}$ It is important to notice that such a diagram is not a picture of the section actually produced by cutting through the flower crosswise at any one level, but that it is rather a projection of the sections through the most typical part of each of the floral organs. 
206. The Flower of the Tulip. ${ }^{1}$ - Make a diagram of a side view of the well-opened flower, as it appears when standing in sunlight. Observe that there is a set of outer flower-leaves and a set of inner ones. $^{2}$ Label the outer set sepals and the inner set petals. In most flowers the parts of the outer set are greenish, and those of the inner set of some other color. It is often convenient to use the name perianth, meaning around the flower, for the two sets taken together. Note the white waxy bloom on the outer surface of the outer segments of the perianth. What is the use of this ? Note the manner in which the inner segments of the perianth arise from the top of the peduncle and their relation to the points of attachment of-the outer segments. In a flower not too widely opened, note the relative position of the inner segments of the perianth, how many wholly outside the other two, how many wholly inside, how many with one edge in and one edge out.

Remove one of the sepals by cutting it off close to its attachment to the peduncle, and examine the veining by holding it up in a strong light and looking through it. Make a sketch to show the general outline and the shape of the tip.

Examine a petal in the same way, and sketch it.

Cut off the remaining portions of the perianth, leaving about a quarter of an inch at the base of each segment. Sketch the upright, triangular, pillar-like object in the center, label it pistil, sketch the organs which spring from around its base, and label these stamens.

Note the fact that each stamen arises from a point just above and within the base of a segment of the perianth. Each stamen consists of a somewhat conical or awl-shaped portion below, the filament, surmounted by an ovate linear portion, the anther. Sketch one of the stamens about twice natural size and label it $\times 2$. Is the attachment of the anther to the filament such as to admit of any nodding or twisting movement of the former? In a young flower, note the two tubular pouches or anther-cells of which the anther is composed, and the slits by which these open. Observe the dark-colored pollen

1 Tulipa Gesneriana. As the flowers are rather expensive, and their parts are large and firm, it is not absolutely necessary to give a flower to each pupil, but some may be kept entire for sketching and others dissected by the class. All the flowers must be single.

2 Best seen in a flower which is just opening. 
which escapes from the anther-cells and adheres to paper or to the fingers. Examine a newly opened anther with the microscope, using the two-inch objective, and sketch it.

Cut away all the stamens and note the two portions of the pistil, a triangular prism, the ovary, and three roughened scroll-like objects at the top, the three lobes of the stigma. Make a sketch of these parts about twice natural size, and label them $\times 2$. Touch a small camel's-hair pencil to one of the anthers, and then transfer the pollen thus removed to the stigma. This operation is merely an imitation of the work done by insects which visit the flowers out of doors. Does the pollen cling readily to the rough stigmatic surface? Examine this adhering pollen with the two-inch objective, and sketch a few grains of it, together with the bit of the stigma to which it clings. Compare this drawing with Fig. 162. Make a cross-section of the ovary about midway of its length, and sketch the section as seen through the magnifying glass. Label the three chambers shown cells of the ovary ${ }^{1}$ or locules, and the white egg-shaped objects within ovules. $^{2}$

Make a longitudinal section of another ovary, taking pains to secure a good view of the ovules, and sketch as seen through the magnifying glass.

Making use of the information already gained and the crosssection of the ovary as sketched, construct a diagram of a crosssection of the entire flower on the same general plan as those shown in Fig. $157 .^{3}$

Split a flower lengthwise, ${ }^{4}$ and construct a longitudinal section of the entire flower on the plan of those shown in Fig. 155, but showing the contents of the ovary.

207. The Flower of the Buttercup. - Make a diagram of the mature flower as seen in a side view, looking a little down into it. Label the pale greenish-yellow, hairy, outermost parts sepals, and

1 Notice that the word cell here means a comparatively large cavity, and is not used in the same sense in which we speak of a wood-cell or a pith-cell.

2 The section will be more satisfactory if made from an older flower, grown out of doors, from which the perianth has fallen. In this case label the contained objects seeds.

${ }^{8}$ Consult also the footnote on p. 193.

1 One will do for an entire division of the class. 
the larger bright yellow parts above and within these petals, and the yellow-knobbed parts which occupy a good deal of the interior of the flower stamens.

Note the difference in the position of the sepals of a newly opened flower and that of the sepals of a flower which has opened as widely as possible. Note the way in which the petals are arranged in relation to the sepals. In an opening flower observe the arrangement of the edges of the petals, how many entirely outside the others, how many entirely inside, how many with one edge in and the other out.

Cut off a sepal and a petal, each close to its attachment to the flower; place both, face down, on a sheet of paper, and sketch about twice the natural size and label it $\times 2$. Describe the difference in appearance between the outer and the inner surface of the sepal and of the petal. Note the little scale at the base of the petal, inside.

Strip off all the parts from a flower which has lost its petals, until nothing is left but a slender conical object a little more than an eighth of an inch in length. This is the receptacle or summit of the peduncle.

In a fully opened flower, note the numerous yellow-tipped stamens, each consisting of a short stalk, the filament, and an enlarged yellow knob at the end, the anther. Note the division of the anther into two portions, which appear from the outside as parallel ridges, but which are really closed tubes, the anther-cells.

Observe in the interior of the flower the somewhat globular mass (in a young flower almost covered by the stamens). This is a group of pistils. Study one of these groups in a flower from which the stamens have mostly fallen off, and make an enlarged sketch of the head of pistils. Remove some of the pistils from a mature head, and sketch a single one as seen with the magnifying glass. Label the little knob or beak at the upper end of the pistil stigma, and the main body of the pistil the ovary. Make a section of one of the pistils, parallel to the flattened surfaces, like that shown in Fig. 150, and note the partially matured seed within. 


\section{CHAPTER XV}

\section{PLAN AND STRUCTURE OF THE FLOWER AND ITS ORGANS}

208. Parts or Organs of the Flower. - Most showy flowers consist, like those studied in the preceding chapter, of four circles or sets of organs, the sepals, petals, stamens, and pistils. The sepals, taken together, constitute the calyx; the petals, taken together, constitute the corolla (Fig. 138). ${ }^{1}$ Sometimes it is convenient to have a word to comprise both calyx and corolla; for this the term perianth is used. A flower which contains all four of these sets is said to be complete. Since the work of the flower is to produce seed, and seed-forming is due to the coöperation of stamens and pistils, or, as they are often

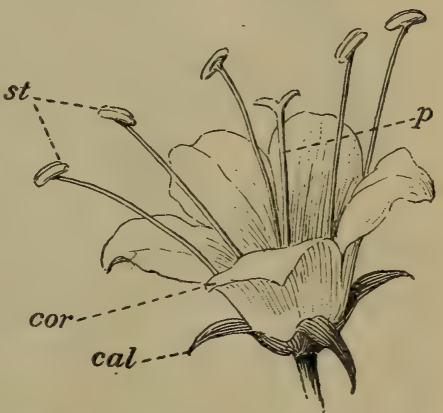

FIG. 138. - The Parts of the Flower. cal, calyx ; $c \cap r$, corolla ; st, stamens; $p$, pistil.

called from their relation to the reproductive organs of spore-plants, microsporophylls and macrosporophylls (see Sect. 374), these are known as the essential organs (Fig. 138). The simplest possible pistil is a dwarfed and

1 The flower of the waterleaf Hydrophyllum canadense, modified by the omission of the hairs on the stamens, is here given because it shows so plainly the relation of the parts. 
greatly modified leaf (Sect. 222), adapted into a seedbearing organ. Such a pistil may be one-seeded, as in Fig. 166, or several-seeded, as in the diagrammatic one (Fig. 150); it is called a carpel. The calyx and corolla are also known as the floral envelopes. Flowers which have the essential organs are called perfect flowers. They may, therefore, be perfect without being complete. Incomplete

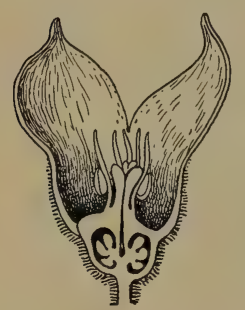

Fig. 139. - Apetalous Flower of (European) Wild Ginger. flowers with only one row of parts in the perianth are said to be apetalous (Fig. 139). 209. Regular and Symmetrical Flowers. - A flower is regular if all the parts of the same set or circle are alike in size and shape, as in the stonecrop (Fig. 140). Such flowers as that of the violet, the monkshood, and the sweet pea (Fig. 141) are irregular. Symmetrical flowers are those whose calyx, corolla, circle of stamens, and set of carpels consist each of the same number of parts, or in which the number in every case is a multiple of the smallest number found in any set. The stonecrop is
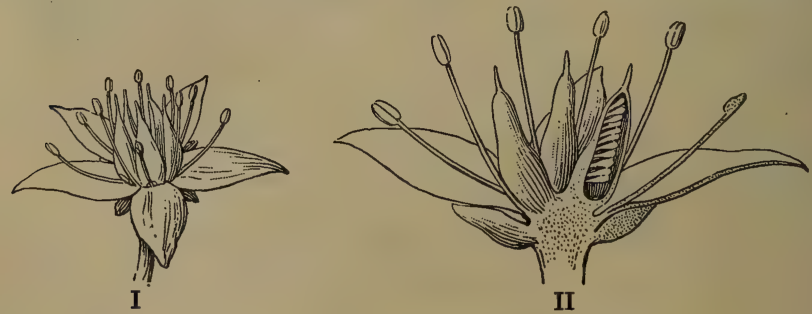

FiG. 140. - Flower of Stonecrop.

I, entire flower (magnified) ; II, vertical section (magnified).

symmetrical, since it has five sepals, five petals, ten stamens, and five carpels. Roses, mallows, and mignonette 
are familiar examples of flowers which are unsymmetrical because they have a large, indefinite number of stamens; the portulaca is unsymmetrical, since it has two divisions of the calyx, five or six petals, and seven to twenty stamens.

210. The Receptacle. - The parts of the flower are borne on an expansion of the peduncle, called the receptacle. Usually, as in the flower of the grape (Fig. 250), this is only a slight enlargement of the peduncle, but in

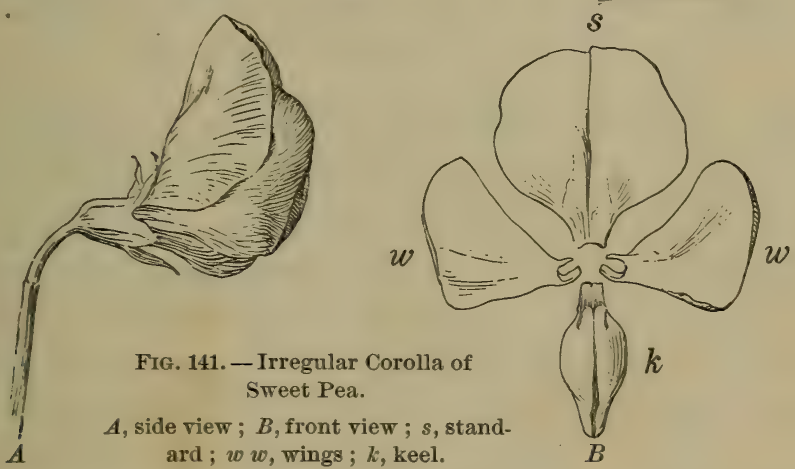

the lotus and the magnolia the receptacle is of great size, particularly after the petals have fallen and the seed has ripened. The receptacle of the rose (Fig. 142) is hollow, and the pistils arise from its interior surface.

211. Imperfect or Separated Flowers. - The stamens and pistils may be produced in separate flowers, which are, of course, imperfect. This term does not imply that such flowers do their work any less perfectly than others, but only that they have not both kinds of essential organs. In the very simple imperfect flowers of the willow (Fig. 143) each flower of the catkin (Fig. 131) consists merely 
of a pistil or a group of (usually two) stamens, springing from the axil of a small bract.

Staminate and pistillate flowers may be borne on different plants, as they are in the willow, or they may be borne on the same plant, as in the hickory and the hazel, among trees, or in the castor-oil plant, Indian corn, and the begonias. When staminate and pistillate flowers are borne on separate plants, such a plant is said to be dioecious, that is, of two households; when both kinds of flower appear on the same individual, the plant is said to be monoecious, that is, of one household.

212. Study of Imperfect Flowers. - Examine, draw, and describe the imperfect flowers of some of the following diocious plants and one of the monœcious plants: 1

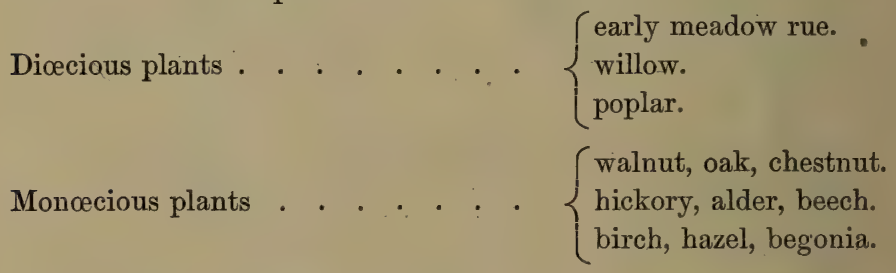

213. Union of Similar Parts of the Perianth. - The sepals may appear to join or cohere to form a calyx which is more or less entirely united into one piece, as in Figs. 139 and 148. In this case the calyx is said to be gamosepalous, that is, of wedded sepals. In the same way the corolla is frequently gamopetalous, as in Figs. 144-148. Frequently the border or limb of the calyx or corolla is more or less cut or lobed. In this case the projecting

1 For figures or descriptions of these or allied flowers consult Gray's Manual of Botany, Emerson's Trees and Shrubs of Massachusetts, Newhall's Trees of the Northern United States, or Le Maout and Decaisne's Traité Général de Botanique. 
portions of the limb are known as divisions, teeth, or lobes. ${ }^{1} \quad$ Special names of great use in accurately describing plants are given to a large number of forms of the gamopetalous corolla. Only a few of these

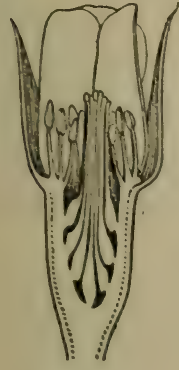

FrG. 142. names are here given, in connection with the figures.

When the parts of either circle of the perianth are wholly unconnected with each other, that is, polysepalous or polypetalous, such parts are said to be distinct.

\section{Parts of the Stamen and the Pistil.} - The stamen usually consists of a hollow portion, the anther (Fig. 149, a), borne on a A Rose, Longitudi- stalk called the filament (Fig. 149, $f$ ), which nal Section. is often lacking. Inside the anther is a powdery or pasty substance called pollen or microspores (Sect. 374 ). The pistil usually consists of a small chamber, the ovary, which contains the ovules, macrospores (Sect. 374), or rudimentary seeds, a slender portion or stalk, called the style, and at the top of this a ridge, knob, or point called the stigma. These parts are all shown in Fig. 150. In many pistils the stigma is borne directly on the ovary.

215. Union of Stamens with Each Other. - Stamens may
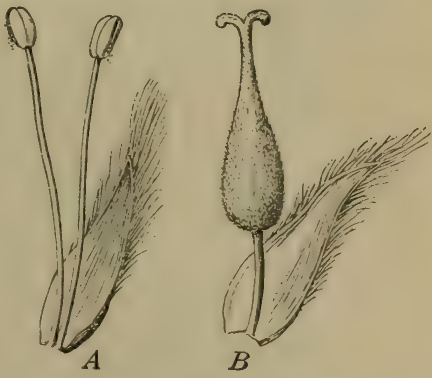

FIG. 143.-Flowers of Willow. (Magnified.) be wholly unconnected with $A$, staminate flower; $B$, pistillate flower.

${ }^{1}$ It would not be safe to assume that the gamosepalous calyx or the gamopetalous corolla is really formed by the union of separate portions, but it is very convenient to speak of it as if it were. 
each other or distinct, or they may cohere by their filaments into a single group, when they are said to be

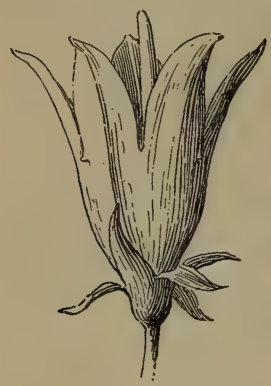

FrG. 144. - Bell-Shaped Corolla of Bell-Flower (Campanula). monadelphous, of one brotherhood (Fig. 151), into two groups (diadelphous) (Fig. $152)$, or into many groups. In some flowers the stamens are held together in a ring by their coherent anthers (Fig. 153).

216. Union of Pistils. - The pistils may be entirely separate from each other, distinct and simple, as they are in the buttercup and the stonecrop, or several may join to form one compound pistil of more or less united carpels. In the latter case the union generally affects the ovaries, but often leaves

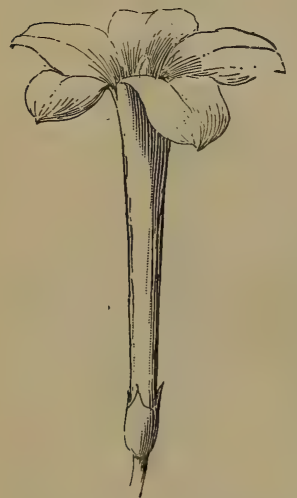

FIG. 145. - Salver-Shaped Corolla of Jasmine. (Magnified.) the styles separate, or it may result in joining ovaries and styles, but leave the stigmas separate or at any rate lobed, so as to show of how many separate carpels the compound pistil is made up. Even when there is no external sign to show the compound nature of the pistil, it can usually be recognized from the study of a cross-section of the ovary.

217. Ce11s of the

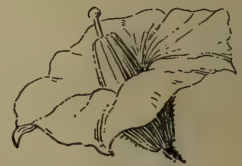

FrG. 146.

Wheel-Shaped Corolla of Potato.

Ovary; Placentas. - Compound ovaries are very commonly several-celled, that is, they consist of a number of 
separate cells ${ }^{1}$ or chambers, more scientifically known as locules. Fig. 154, $B$, shows a three-celled ovary seen in cross-section. The ovules are not borne indiscriminately by any part of the lining of the ovary. In one-celled pistils they frequently grow in a line running along one side of the ovary, as in the pea pod (Fig. 271). The ovule-bearing line is called a placenta; in compound pistils there are commonly as many placentas as there are

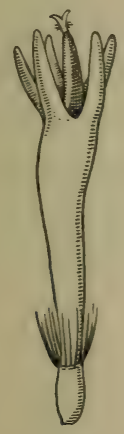

Frg. 147.-Tubular Corolla, from Head of Bachelor's Button.

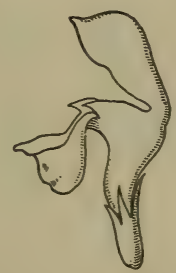

FTG. 148. - Labiate or Ringent Corolla of Dead Nettle.
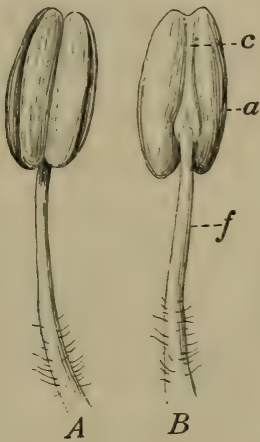

FIG. 149. - Parts of a Stamen.

$A$, front ; $B$, back ; $\alpha$, anther ; $c$, connective ; $f$, filament.

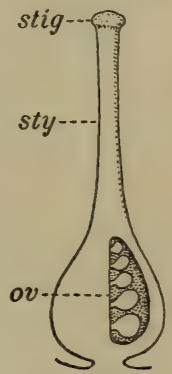

FIG. 150. - Parts of the Pistil.

ov, ovary.

sty, style.

stig, stigma.

separate pistils joined to make the compound one. Placentas on the wall of the ovary, like those in Fig. 154, A, are called parietal placentas; those, which occur as at $B$, in the same figure, are said to be central, and those which, like the form represented in $C$ of the same figure, consist of a column rising from the bottom of the ovary are called free central placentas.

1 Notice that the word cell is here used in an entirely different sense from that in which it has been employed in the earlier chapters of this book. As applied to the ovary, it means a chamber or compartment. 
218. Union of Separate Circles. - The members of one of the circles of floral organs may join those of another circle, thus becoming adnate, adherent, or consolidated.

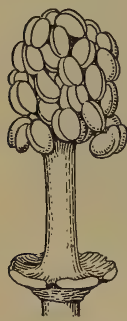

FIG. 151.

Monadelphous

Stamens of

Mallow. In Fig. 139 the calyx tube is adnate to the ovary. In this case the parts of the flower do not all appear to spring from the receptacle. Fig. 155 illustrates three common cases as regards insertion of the parts of the flower. In I they are all inserted on the receptacle, and the corolla and stamens are said to be hypogynous, that is, beneath the pistil. In II the petals and the stamens appear as if they had grown fast to the calyx for some distance, so that they surround the pistil, and they are therefore said to be perigynous, that is, around the pistil. In III all the parts are free or unconsolidated, except the petals and stamens; the stamens may be described as epipetalous, that is, growing on the petals.

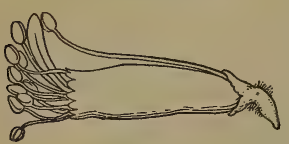

FrG. 152. - Diadelphous Stamens of Sweet Pea. Sometimes some or all of the other parts stand upon the ovary, and such parts are said to be epigynous, that is, on the ovary, like the petals and stamens of the white water-lily (Fig. 156).

219. Floral Diagrams. - Sections (real FIG. 153.-Stamens or imaginary) through the flower lengthwise, like those of Fig. 155, help greatly of a Thistle, with Anthers united into a Ring.

in giving an accurate idea of the relative ${ }^{a \text {, united anthers; } f \text {, }}$ filaments, bearded position of the floral organs. Still more on the sides. 
important in this way are cross-sections, which may be recorded in diagrams like those of Fig. 157.1 In con-
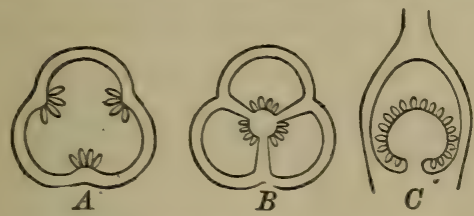

Frg. 15t - Principal Types of Placenta.

$A$, parietal placenta ; $B$, central placenta ;

$C$, free central placenta ; $A$ and $B$, transrerse sections ; $C$, longitudinal section.

structing such diagrams it will often be necessary to suppose some of the parts of the flower to be raised or lowered from their true position, so as to bring them into such relations that all could be cut by a single section. This would, for instance, be necessary in making a diagram for the cross-section of the flower

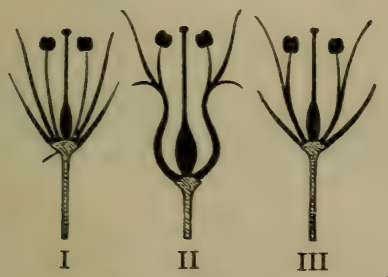

Fig. 155. - Insertion of the

Floral Organs.

I, Hypogynous, all the other parts on the receptacle, beneath the pistil; II, Perigynous, petals and stamens apparently growing out of the calyx, around the pistil; III, corolla hypogynous, stamens epipetalous.

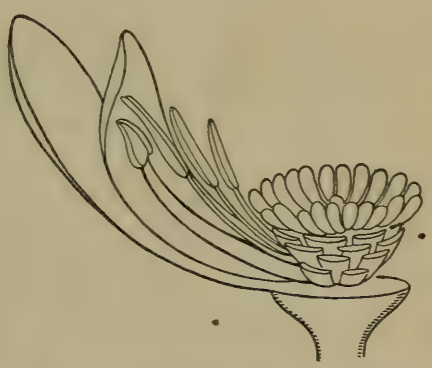

FIG. 156. - White Water-Lily. The inner petals and the stamens growing from the ovary.

of the white water-lily, of which a partial view of one side is shown in Fig. 156. ${ }^{2}$

1 For floral diagrams see Le Maout and Decaisne's Traité Général de Botanique, or Eichler's Blüthendiagramme.

2 It is best to begin practice on floral diagrams with flowers so firm and large that actual sections of them may be cut with ease and the relations of the parts in the section readily made out. The tulip is admirably adapted for this purpose. 
Construct diagrams of the longitudinal section and the transverse section of several large flowers, following the method indicated in Figs. 155 and 157, but making

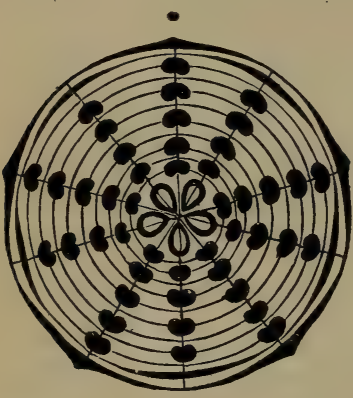

I the longitudinal section show the interior of the ovary. ${ }^{1}$ It is found convenient to distin-

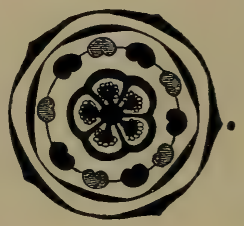

II

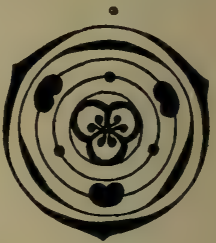

III

FrG. 157. - Diagram of Cross-Sections of Flowers.

I, columbine ; II, heath family ; III, iris family. In each diagram the dot alongside the main portion indicates a cross-section of the stem of the plant. In II every other stamen is more lightly shaded, because some plants of the heath family have five and some ten stamens.

guish the sepals from the petals by representing the former with midribs. The diagrammatic symbol for a stamen stands for a cross-section of the anther, and that for the pistil is a section of the ovary. If any part is lacking in the flower (as in the case of flowers which have some antherless filaments) the missing or abortive organ may be indicated by a dot. In the diagram of the Iris Family (Fig. 157, III) the three dots inside the flower indicate the position of a second circle of stamens, found in most flowers of monocotyledons but not found in this family.

1 Among the many excellent early flowers for this purpose may be mentioned trillium, bloodroot, dogtooth violet, marsh marigold, buttercup, tulip tree, horse-chestnut, Jeffersonia, May-apple, cherry, apple, crocus, tulip, daffodil, primrose, wild ginger, cranesbill, locust, bluebell. 


\section{Review Summary of Chapter XV. ${ }^{1}$}

Kinds of flowers as regards number of circles or $\left\{\begin{array}{l}1 . \\ 2 .\end{array}\right.$ sets of organs present . . . . . . . . $\left\{\begin{array}{l}3 . \\ 4 .\end{array}\right.$

Kinds as regards numerical plan ...... $\left\{\begin{array}{l}1 . \\ 2 .\end{array}\right.$

Kinds as regards similarity of parts of the same $\{1$. circle . . . . . . . . . . . $\left\{\begin{array}{l}1 \\ 2 .\end{array}\right.$

Parts of a stamen . . . . . . . . . . . . $\left\{\begin{array}{l}1 . \\ 2 .\end{array}\right.$

Parts of a pistil $. . \quad . \quad . \quad . \quad . \quad . \quad . \quad\left\{\begin{array}{l}1 . \\ 2 . \\ 3 .\end{array}\right.$

Stamens as regards union with each other . . $\left\{\begin{array}{l}1 . \\ 2 . \\ 3 . \\ 4 .\end{array}\right.$

Pistils as regards union with each other . ..$\left\{\begin{array}{l}1 . \\ 2 .\end{array}\right.$

Degree of union of separate circles . . . . \{

1 Illustrate by sketches. 


\section{CHAPTER XVI}

TRUE NATURE OF FLORAL ORGANS; DETAILS OF THEIR STRUCTURE; FERTILIZATION

221. The Flower a Shortened and greatly Modified Branch. - In Chapter VIII, the leaf-bud was explained as being an undeveloped branch, which in its growth would develop into a real branch (or a prolongation of the main stem). Now, since flower-buds appear regularly
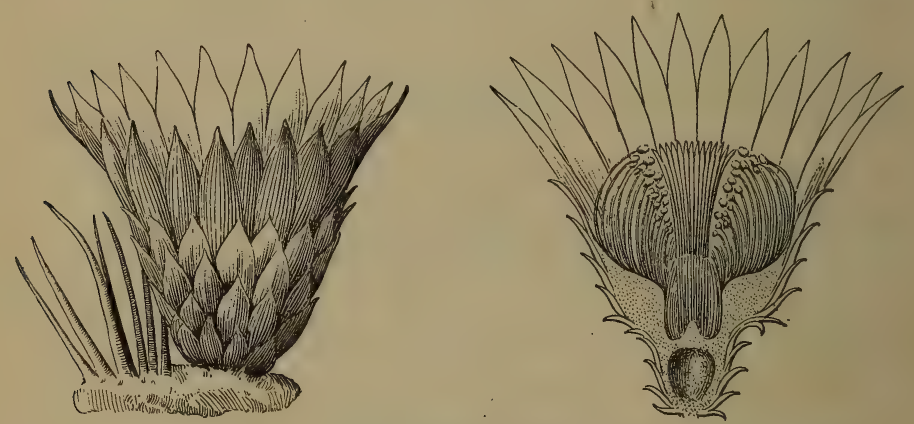

FIG. 158. - Transition from Bracts to Sepals in a Cactus Flower.

either in the axils of leaves or as terminal buds, there is reason to regard them as of similar nature to leaf-buds. This woulel imply that the receptacle corresponds to the axis of the bud shown in Fig. 86, and that the parts of the flower correspond to leaves. There is plenty of evidence that this is really true. Sepals frequently look very much like leaves, and in many cacti the bracts 
about the flower are so sepal-like that it is impossible to tell where the bracts end and the sepals begin (Fig. 158). The same thing is true of sepals and petals in such flowers as the white water-lily. In this flower there is a remarkable series of intermediate steps, ranging all the way from petals, tipped with a bit of anther, through stamens with a broad petal-like filament, to regular stamens, as is shown in Fig. $159, E, F, G, H$. The same thing is shown in
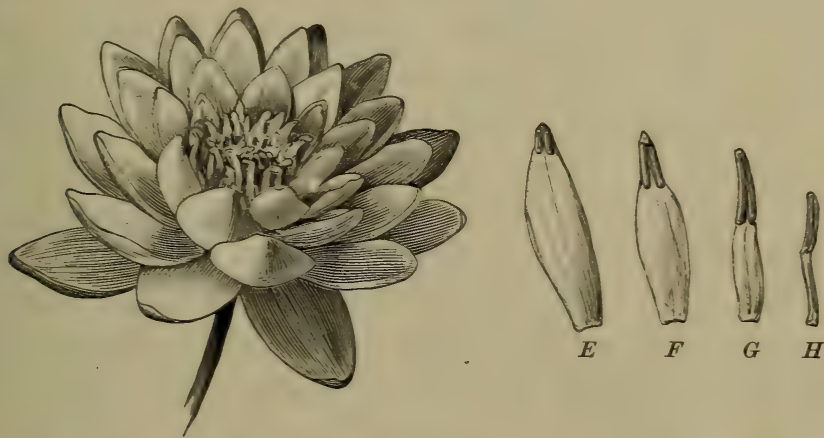

FIG. 159. - Transitions from Petals to Stamens in White Water-Lily.

$E, F, G, H$, various steps between petal and stamen.

many double roses. In completely double flowers all the essential organs are transformed by cultivation into petals. In the flowers of the cultivated double cherry the pistils occasionally take the form of small leaves, and some roses turn wholly into green leaves.

Summing up, then, we know that flowers are altered and shortened branches: (1) because flower-buds have as regards position, the same kind of origin as leaf-buds; (2) because all the intermediate steps are found between bracts, on the one hand, and stamens, on the other; (3) 
because the essential organs are found to be replaced by petals or even by green leaves.

The fact that leaves should be so greatly modified as they are in flowers and given work to do wholly different from that of the other kinds of leaves so far studied need not strike one as exceptional. In many of the most highly developed plants below the seed-plants, organs corresponding to flowers are found, and these consist of modified leaves, set apart for the work of reproducing (Sect. 367).

222. Mode of Formation of Stamens and Pistils from Leaves. - It is hardly possible to state, until after Chapter XXIII has been studied, how stamens stand related to leaves. ${ }^{1}$

The simple pistil or carpel is supposed to be made on the plan of a leaf folded along the midrib until its margins touch, like the cherry leaf in Fig. 87. But the student must not understand by this statement that the little pistil leaf grows at first like an ordinary leaf and finally becomes folded in. The united leaf-margins near the tip would form the stigma, and the placenta would correspond to the same margins, rolled slightly inwards, extending along the inside of the inflated leaf-pouch. Place several such folded leaves upright about a common center, and their cross-section would be much like that of $B$ in Fig. 154. Evidence that carpels are really formed in this way may be gained from the study of such fruits as that of the monkshood (Fig. 168), in which the ripe carpels may be seen to unfold into a shape much more leaf-like than that which they had while the pistil was maturing. What

1 "The anther answers exactly to the spore-cases of the ferns and their allies, while the filament is a small specialized leaf to support it." For a fuller statement, see Potter and Warming's Systematic Botany, pp. 236, 237. 
really occurs is this: the flower-bud, as soon as it has developed far enough to show the first rudiments of the essential organs, contains them in the form of minute knobs. These are developed from the tissues of the plant in the same manner as are the knobs in a leaf-bud, which afterwards become leaves (Fig. 87, II) ; but as growth and development progress in the flower-bud, its contents soon show themselves to be stamens and pistils (if the flower is a perfect one).

223. The Anther and its Contents. - Some of the shapes of the anthers may be learned from Figs. 149 and $160 .^{1}$ The shape of the anther and the way in which it opens depend largely upon the way in which the pollen

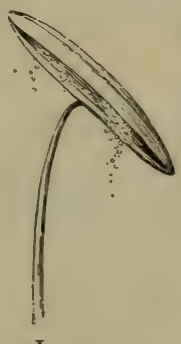

I

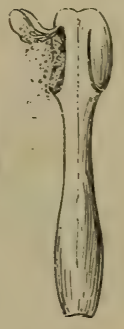

II

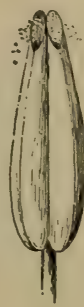

III

FrG. 160.-Modes of discharging Pollen.

I, by longitudinal slits in the anther-cells (amaryllis); II, by uplifted valves (barberry); III, by a pore at the top of each anther-lobe (nightshade).

is to be discharged and how it is carried from flower to flower. The commonest method is to have the anthercells split lengthwise, as in Fig. 160, I. A few anthers open by trap-doors like valves, as in II, and a larger number by little holes at the top, as in III.

The pollen in many plants with inconspicuous flowers, as the evergreen cone-bearing trees, the grasses, rushes, and sedges, is a fine, dry powder. In plants with showy flowers it is often somewhat sticky or pasty. The forms of pollen grains are extremely various. Fig. 161 will serve to furnish examples of some of the shapes which

1 See Kerner and Oliver's Natural History of Plants, Vol. II, pp. 86-95, 
the grains assume; $c$ in the latter figure is perhaps as common a form as any. Each pollen grain consists mainly of a single cell, and is covered by a moderately thick outer wall and a thin inner one. Its contents are thickish protoplasm, full of little opaque particles and usually containing grains of starch and little drops of oil. The knobs on the outer coat, as shown in Fig. $161 b$, mark

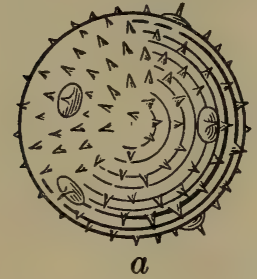

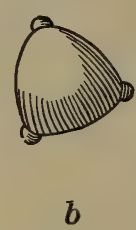
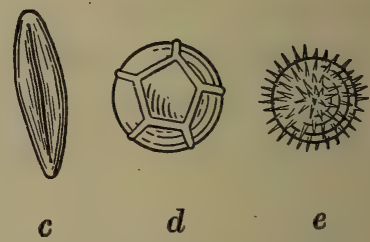

FIG. 161. - Pollen Grains. " (Very greatly magnified.)

$a$, pumpkin ; $b$, enchanter's nightshade ; $c$, Albuca ; $d$, pink ; $e$, hibiscus.

the spots at which the inner coat of the grain is finally to burst through the outer one, pushing its way out in the form of a slender, thin-walled tube. ${ }^{1}$

224. The Formation of Pollen Tubes. - This can be studied in pollen grains which have lodged on the stigma and there been subjected to the action of its moist surface. It is, however, easier to cause the artificial production of the tubes.

\section{EXPERIMENT XXXVIII}

Production of Pollen Tubes. - Place a few drops of suitably diluted syrup with some fresh pollen in a concave cell ground in a microscope slide; cover with thin glass circle; place under a bell-glass, with a wet cloth or sponge, to prevent evaporation of the syrup, and set aside in a warm place, or merely put some pollen in syrup in a

${ }_{1}^{1}$ See Kerner and Oliver's Natural History of Plants, Vol. II, pp. 95-104. 
watch crystal under the bell-glass. Examine from time to time to note the appearance of the pollen tubes. Try several kinds of pollen if possible, using syrups of various strengths. The following kinds of pollen form tubes readily in syrups of the strengths indicated.

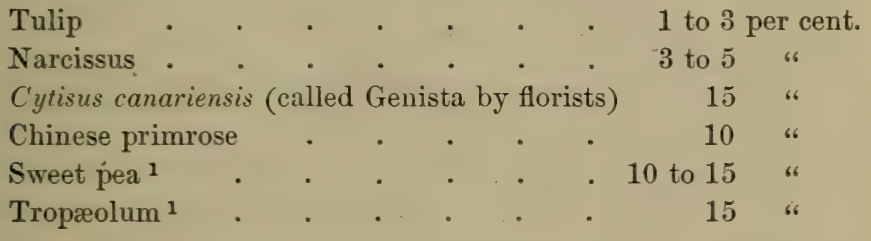

\section{Microscopical Structure of the Stigma and Style. -} Under a moderate power of the microscope the stigma is seen to consist of cells set irregularly over the surface, and secreting a moist liquid to which the pollen grains adhere (Fig. 162). Beneath these superficial cells and running down through the style (if there is one) to the ovary is spongy parenchyma. In some pistils the pollen tube proceeds through the cell walls, which it softens by means of a substance which it exudes for that purpose. In other cases (Fig. 163) there is a canal or passage, along which the pollen tube travels on its way to the ovule.

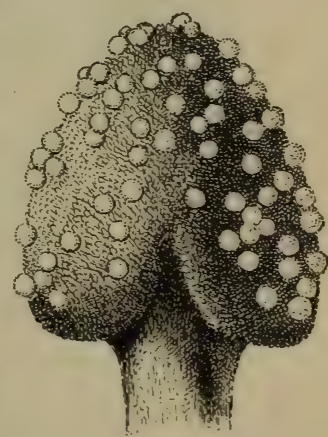

FIG. 162. - Stigma of ThornApple (Datura) with Pollen. (Magnified.)

${ }^{1}$ The sweet-pea pollen and that of Tropæolum are easier to manage than any other kinds of which the author has personal knowledge. If a concaved slide is not available, the cover-glass may be propped up on bits of the thinnest broken cover-glasses. From presence of air or some other reason, the formation of pollen tubes often proceeds most rapidly just inside the margin of the cover-glass. 
226. Fertilization. - By fertilization in seed-plants the botanist means the union of a generative cell from a pol-

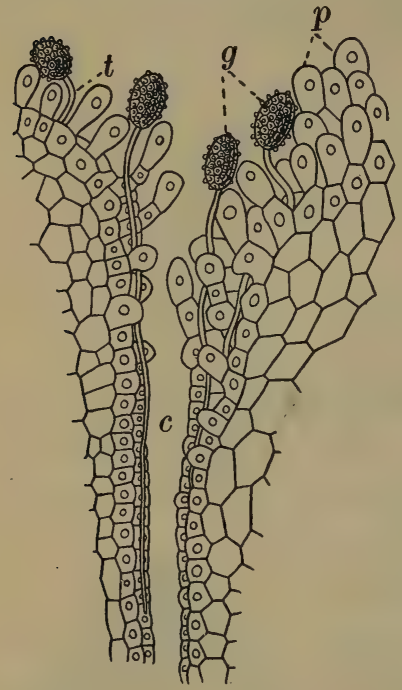

FrG. 163. - Pollen Grains producing Tubes, on Stigma of a Lily. (Much magnified.)

$g$, pollen grains ; $t$, pollen tubes ; $p$, papillæ of stigma ; $c$, canal or passage running toward ovary.

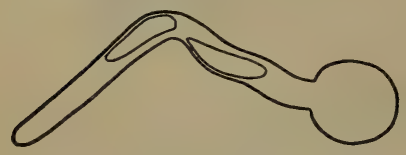

FiG. 164. - Pollen Grain of Snowflake (Leucoium) producing a Pollen Tube with Two Naked Generative Cells. len grain with that of an egg-cell at the apex of the embryo sac (Fig. 165). This process gives rise to a cell which contains material derived from the pollen and from the egg-cell. In a great many plants the pollen, in order to accomplish the most successful fertilization, must come from another plant of the same kind, not from the individual which bears the ovules that are being fertilized.

Pollen tubes begin to form soon after pollen grains lodge on the stigma. The time required for the process to begin varies in different kinds of plants, requiring in many cases twenty-four hours or more. The length of time needed for the pollen tube to make its way through the style to the ovary depends upon the length of the style and other conditions. In the crocus, which has a style several inches long, the descent

takes from one to three days.

Finally the tube penetrates the opening at the apex of 
the ovule $m$, in Fig. 165, reaches one of the cells shown at $e$, and transfers a generative cell into this egg-cell. The latter is thus enabled to divide and grow rapidly into an embryo. This the cell does by forming cell-walls and then increasing by continued subdivision, in much the same way in which the cells at the growing point near the tip of the root, or those of the cambium layer, subdivide. ${ }^{1}$

227. Nature of the Fertilizing Process. The necessary feature of the process of fertilization is the union of the essential contents of two cells to form a new one, from which the future plant is to spring. This kind of union is found to occur in many cryptogams (Chapters XX-XXII), resulting in the production of a spore capable of grow-

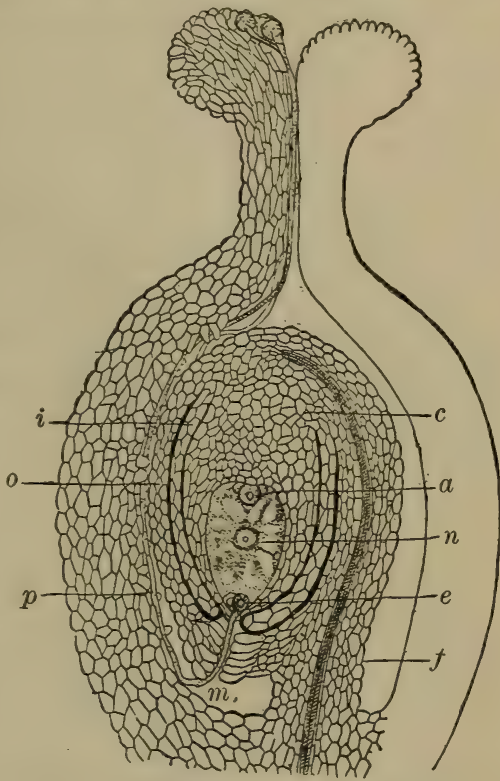

FIG. 165. - Diagrammatic Representation of Fertilization of an Ovule.

$i$, inner coating of ovule; $o$, outer coating of ovule; $p$, pollen tube, proceeding from one of the pollen grains on the stigma; $c$, the place where the two coats of the ovule blend. (The kind of ovule here shown is inverted, its opening $m$ being at the bottom, and the stalk $f$ adhering along one side of the ovule.) a to $e$, embryo sac, full of protoplasm ; $a$, so-called antipodal cells of embryo sac; $n$, central nucleus of the embryo sac; $e$, nucleated cells, one of which, the egg-cell, receives the essential contents of the pollen tube; $f$, funiculus or stalk of ovule; $m$, opening into the ovule. ing into a complete plant like that which produced it.

1 See Kerner and Oliver's Natural History of Plants, Vol. II, pp. 401-420. 
228. Number of Pollen Grains to Each Ovule. - Only one pollen tube is necessary to fertilize each ovule, but so many pollen grains are lost that plants produce many more of them than of ovules. The ratio, however, varies greatly. In the night-blooming cereus there are about 250,000 pollen grains for 30,000 ovules, or rather more than 8 to 1 , while in the common garden wistaria there are about 7000 pollen grains to every ovule, and in Indian corn, the cone-bearing evergreens, and a multitude of other plants, many times more than 7000 to 1 . These differences depend upon the mode in which the pollen is carried from the stamens to the pistil. 


\section{CHAPTER XVII}

\section{THE STUDY OF TYPICAL FRUITS}

229. A Berry, the Tomato. ${ }^{1}$ - Study the external form of the tomato, and make a sketch of it showing the persistent calyx and peduncle.

Cut a cross-section at about the middle of the tomato. Note the thickness of the epidermis (peel off a strip) and of the wall of the ovary. Note the number, size, form, and contents of the cells of the ovary. Observe the thickness and texture of the partitions between the cells. Sketch.

Note the attachments of the seeds to the placentas and the gelatinous, slippery coating of each seed.

The tomato is a typical berry, but its structure presents fewer points of interest than are found in some other fruits of the same general character, so the student will do well to spend a little more time on the examination of such fruits as the orange or the lemon.

230. A Hesperidium, the Lemon. - Procure a large lemon which is not withered, if possible one which still shows the remains of the calyx at the base of the fruit.

Note the color, general shape, surface, remains of the calyx, knob at portion formerly occupied by the stigma. Sketch the fruit about natural size. Examine the pitted surface of the rind with the magnifying glass and sketch it. Remove the bit of stem and dried-up calyx from the base of the fruit; observe, above the calyx, the knob or disk on which the pistil stood. Note with the magnifying glass and count the minute whitish raised knobs at the bottom of the saucer-shaped depression left by the removal of the disk. What are they?

${ }^{1}$ Fresh tomatoes, not too ripe, are to be used, or those which have been kept over from the previous summer in formalin solution. The very smallest varieties, such as are often sold for preserving, are as good for study as the larger kinds. 
Make a transverse section of the lemon, not more than a fifth of the way down from the stigma end and note :

(1) The thick skin, pale yellow near the outside, white within.

(2) The more or less wedge-shaped divisions containing the juicy pulp of the fruit. These are the matured cells of the ovary; count these.

(3) The thin partition between the cells.

(4) The central column or axis of white pithy tissue.

(5) The location and attachment of any seeds that may be encountered in the section.

Make a sketch to illustrate these points, comparing it with Fig. 171.

Study the section with the magnifying glass and note the little spherical reservoirs near the outer part of the skin, which contain the oil of lemon which gives to lemon peel its characteristic smell and taste. Cut with the razor a thin slice from the surface of a lemon peel, some distance below the section, and at once examine the freshly cut surface with a magnifying glass to see the reservoirs, still containing oil, which, however, soon evaporates. On the cut surface of the pulp (in the original cross-section) note the tubes in which the juice is contained. These tubes are not cells, but their walls are built of cells. Cut a fresh section across the lemon, about midway of its length and sketch it, bringing out the same points which were shown in the previous one. The fact that the number of ovary cells in the fruit corresponds with the number of minute knobs in the depression at its base is due to the fact that these knobs mark the points at which fibro-vascular bundles passed from the peduncle into the cells of the fruit, carrying the sap by which the growth of the latter was maintained.

Note the toughness and thickness of the seed-coats. Taste the kernel of the seed.

Cut a very thin slice from the surface of the skin, mount in water, and examine with a medium power of the microscope. Sketch the cellular structure shown and compare it with the sketch of the corky layer of the bark of the potato tuber.

Of what use to the fruit is a corky layer in the skin? (See Sect. 453 for further questions.) 
231. A Legume, the Bean-Pod. ${ }^{1}$ - Lay the pod flat on the table and make a sketch of it, about natural size. Label stigma, style, ovary, calyx, peduncle.

Make a longitudinal section of the pod, at right angles to the plane in which it lay as first sketched, and make a sketch of the section, showing the partially developed seeds, the cavities in which they lie, and the solid portion of the pod between each bean and the next.

Split another pod, so as to leave all the beans lying undisturbed on one-half of it and sketch that half, showing the beans lying in their natural position and the funiculus or stalk by which each is attached to the placenta; compare Fig. 271.

Make a cross-section of another pod, through one of the beans, sketch the section, and label the placenta (formed by the united edges of the pistil leaf) and the midrib of the pistil leaf.

Break off sections of the pod and determine, by observing where the most stringy portions are found, where the fibro-vascular bundles are most numerous.

Examine some ripe pods of the preceding year, ${ }^{2}$ and notice where the dehiscence, or splitting open of the pods, occurs, whether down the placental edge, ventral suture, the other edge, dorsal suture, or both.

232. An Akene, the Fruit of Dock. - Hold in the forceps a ripe fruit of any of the common kinds of dock, ${ }^{3}$ and examine with the magnifying glass. Note the three dry, veiny, membranaceous sepals by which the fruit is enclosed. On the outside of one or more of the sepals is found a tubercle or thickened appendage which looks like a little seed or grain. Cut off the tubercles from several of the fruits, put these, with some uninjured ones, to float in a pan of water, and watch their behavior for several hours. What is apparently the use of the tubercle?

1 Any species of bean (Phaseolus) will answer for this study. Specimens in the condition known at the markets as "shell-beans" would be best, but these are not obtainable in spring. Ordinary "string-beans" will do.

2 Which may be passed round for that purpose. They should have been saved and dried the preceding autumn.

${ }^{3}$ Rumex crispus, $R$. obtusifolius, or $R$. verticillatus. This should have been gathered and dried the preceding summer. 
Of what use are the sepals, after drying up? Why do the fruits cling to the plant long after ripening?

Carefully remove the sepals and examine the fruit within them. What is its color, size, and shape? Make a sketch of it as seen with the magnifying glass. Note the three tufted stigmas, attached by slender threads to the apex of the fruit. What does their tufted shape indicate?

What evidence is there that this seed-like fruit is not really a seed?

Make a cross-section of a fruit and notice whether the wall of the ovary can be seen, distinct from the seed-coats. Compare the dock fruit in this respect with the fruit of the buttercup, shown in Fig. 166. Such a fruit as either of these is called an akene. 


\section{CHAPTER XVIII}

\section{THE FRUIT ${ }^{1}$}

233. What constitutes a Fruit. - It is not easy to make a short and simple definition of what botanists mean by the term fruit. It has very little to do with the popular use of the word. Briefly stated, the definition may be given as follows: The fruit consists of the matured ovary and contents, together with any intimately connected parts. Botanically speaking, the bur of beggar's ticks (Fig. 273), the three-cornered grain of buckwheat, or such true grains as wheat and oats, are as much fruits as is an apple or a peach.

The style or stigma sometimes remains as an important part of the fruit in the shape of a hook, as in the common hooked crowfoot; or in the shape of a plumed appendage, as in the virgin's bower, often called wild hops. The calyx may develop hooks, as in the agrimony, or plumes, as in the thistle, the dandelion, lettuce, and many other familiar plants. In the apple, pear, and very many berries, the calyx becomes enlarged and pulpy, often constituting the main bulk of the mature fruit. The receptacle not infrequently, as in the apple, forms a more or less important part of the fruit.

234. Indehiscent and Dehiscent Fruits. - All of the fruits considered in the next three sections are indehiscent,

1 See Gray's Structural Botany, Chapter VII, also Kerner and Oliver's Natural History of Plants, Vol. II, pp. 427-438. 
that is, they remain closed after ripening. Dehiscent fruits when ripe open in order to discharge their seeds.

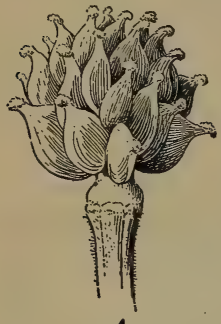

A

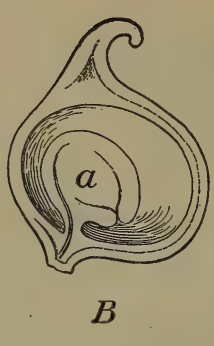

FIG. 166. - Akenes of a Buttercup. $A$, head of akenes ; $B$, section of a single akene (magnified) ; $a$, seed.

The three classes which immediately follow Sect. 237 belong to this division.

235. The Akene. - The one-celled and, one-seeded pistils of the buttercup, strawberry, and many other flowers, ripen into a little fruit called an akene (Fig. 166). Such fruits, from their small size, their dry consistency, and the fact that they never open, are usually taken for seeds by those who are not botanists.

In the group of plants to which the daisy, the sunflower, and the dandelion belong, the akenes consist of the ovary and the adherent calyx tube. The limb of the calyx is borne on the summit of many akenes, sometimes in the form of teeth, sometimes as a tuft of hairs or bristles (Fig. 267).

236. The Grain. - Grains, such as corn, wheat, oats, barley, rice, and so on, have the interior of the ovary completely filled by the seed, and the seed-coats and the wall of the ovary are firmly united, as shown in Fig. 6.

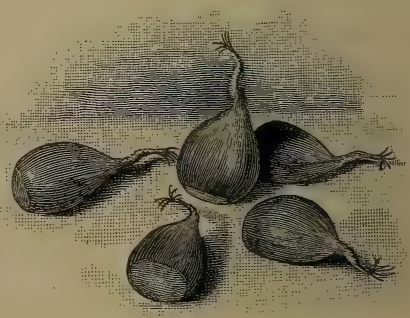

Fig. 167.- Chestnuts.

237. The Nut. - A nut (Fig. 167) is larger than an akene, usually has a harder shell, and commonly contains 
a seed which springs from a single ovule of one cell of a compound ovary, which develops at the expense of all the other ovules. The chestnut-bur is a kind of involucre,

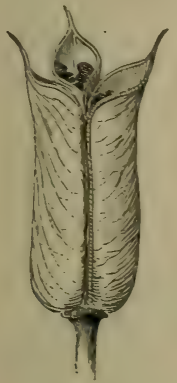
and so is the acorn-cup. The name nut is often incorrectly applied in popular language; for example, the so-called Brazil-nut is really a large seed with a very hard testa.

238. The Follicle. - One-celled, simple pistils, like those of the marsh marigold, the columbine, and a good many other plants, often produce a FIG. 168. - Group of Folli- fruit which dehisces along a single cles and a Single Follicle suture, usually the ventral one. Such
of the Monkshood. a fruit is called a follicle (Fig. 168).

239. The Legume. - A legume is a one-celled pod, formed by the maturing of a simple pistil, which dehisces along both of its sutures, as already seen in the case of the bean pod, and illustrated in Fig. 271.

240. The Capsule. The dehiscent fruit formed by the ripening of a compound pistil is called a capsule. Such a fruit may be onecelled, as in the linear pod of the celandine (Fig. 271), or several-

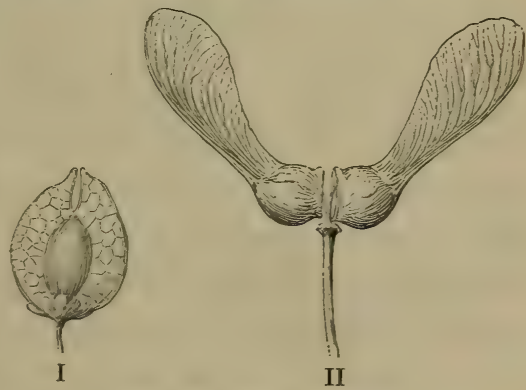

Fig. 169. - Winged Fruits.

I, elm ; II, maple. celled, as in the fruit of the poppy, the morning-glory, and the jimson weed (Fig. 271). 
241. Dry Fruits and Fleshy Fruits. - In all the cases discussed or described in Sects. 238-240, the wall of the ovary (and the adherent calyx when present) ripen into tissues which are somewhat hard and dry. Often, however, these parts become developed into a juicy or fleshy mass by which the seed is surrounded; hence a general division of fruits into dry fruits and fleshy fruits.

242. The Stone-Fruit. - In the peach, apricot, plum, and cherry, the pericarp or wall of the ovary, during the proc-

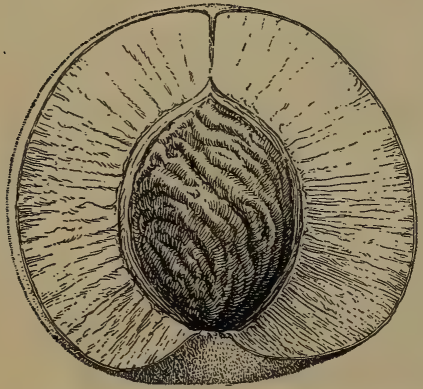

FIG. 170. - Peach. Longitudinal Section of Fruit. ess of ripening, becomes converted into two kinds of tissue, the outer portion pulpy and edible, the inner portion of almost stony hardness. In common language the hardened inner layer of the pericarp, enclosing the seed, is called the stone (Fig. 170), hence the name stone-fruits.

243. The Pome. - The fruit of the apple, pear, and quince is called a pome. It consists of a several-celled ovary, - the seeds and the tough membrane surrounding them in the core, - enclosed by a fleshy, edible portion which makes up the main bulk of the fruit and is formed from the much-thickened calyx, with sometimes an enlarged receptacle. In the apple and the pear much of the fruit is receptacle.

244. The Pepo or Gourd-Fruit. - In the squash, pumpkin, and cucumber, the ripened ovary, together with the thickened adherent calyx, makes up a peculiar fruit (with a firm outer rind) known as the pepo. The relative bulk 
of enlarged calyx and of ovary in such fruits is not always the same.

How does the amount of material derived from fleshy and thickened placenta in the squash compare with that in the watermelon?

245. The Berry. - The berry proper, such as the tomato, grape, persimmon, gooseberry, currant, and so on, consists of a rather thinskinned, one- to severalcelled, fleshy ovary and its contents. In the first three cases above mentioned the calyx forms no part of the fruit, but it does in the last two, and in a great number of berries.

The gourd-fruit and the hesperidium, such as the, orange (Fig. 171), lemon, and lime, are merely decided modifications of the berry proper.

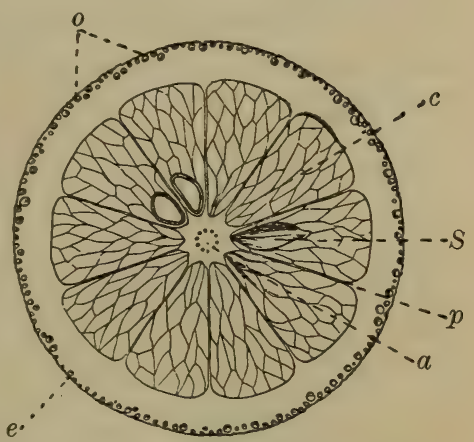

FIG. 171. - Cross-Section of an Orange. $a$, axis of fruit with dots showing cut-off ends of fibro-raseular bundles ; $p$, partition between cells of ovary; $S$, seed; $c$, cell of ovary, filled with a pulp composed of irregular tubes, full of juice; $o$, oil reservoirs near outer surface of rind; $e$, corky layer of epidermis.

246. Aggregate Fruits. - The raspberry, blackberry (Fig. 172), and similar fruits consist of many carpels, each of which ripens into a part of a compound mass, which, for a time at least, clings to the receptacle. The whole is called an aggregate fruit.

To which one of the preceding classes does each unit of a blackberry or of a raspberry belong?

What is the most important difference in structure between a fully ripened raspberry and a blackberry? 
247. Accessory Fruits and Multiple Fruits. - Not infrequently, as in the strawberry (Fig. 172), the main bulk of the so-called fruit consists neither of the ripened ovary nor its appendages. Such a combination is called an accessory fruit.

Examine with a magnifying glass the surface of a small, unripe strawberry, then that of a ripe one, and finally a section of a ripe one, and decide where the separate fruits of the strawberry are found, what kind of fruits they are, and of what the main bulk of the strawberry consists.

The fruits of two or more separate flowers may blend into a single mass, which is known as a multiple fruit. Perhaps the best-known edible examples of this are the

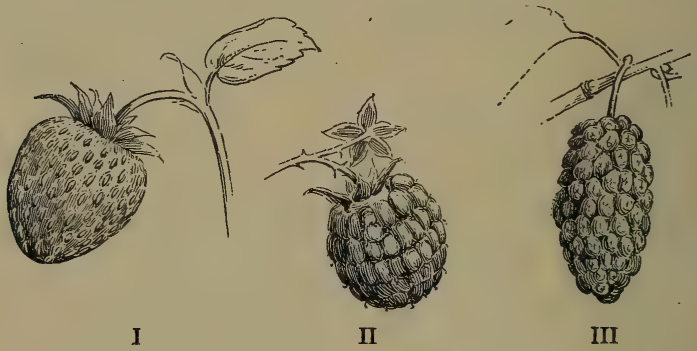

FIG. 172. - I, Strawberry ; II, Raspberry ; III, Mulberry.

mulberry (Fig. 172) and the pineapple. The last-named fruit is an excellent instance of the seedless condition which not infrequently results from long-continued cultivation.

248. Summary. - The student may find it easier to retain what knowledge he has gained in regard to fruits if he copies the following synopsis of the classification of fruits, and gives an example of each kind. 

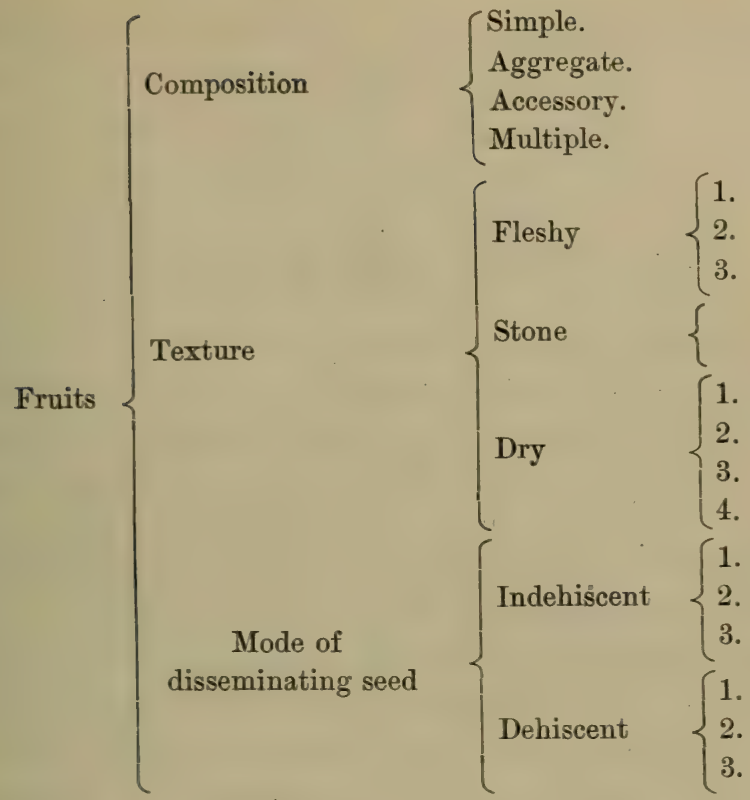


\section{CHAPTER XIX}

\section{THE CLASSIFICATION OF PLANTS ${ }^{1}$}

249. Natural Groups of Plants. - One does not need to be a botanist in order to recognize the fact that plants naturally fall into groups which resemble each other pretty closely, that these groups may be combined into larger ones the members of which are somewhat alike, and so on. For example, all the bulb-forming spring buttercups ${ }^{2}$ which grow in a particular field may be so much alike in leaf, flower, and fruit that the differences are hardly worth mentioning. The tall summer buttercups ${ }^{3}$ resemble each other closely, but are decidedly different from the bulbous spring-flowering kind, and yet are enough like the latter to be ranked with them as buttercups. The yellow water-buttercups ${ }^{4}$ resemble in their flowers the two kinds above mentioned, but differ from them greatly in habit of growth and in foliage, while still another, a very small-flowered kind, ${ }^{5}$ might fail to be recognized as a buttercup at all.

The marsh marigold, the hepatica, the rue anemone, and the anemone all have a family resemblance to buttercups $^{6}$ and the various anemones by themselves form another group like that of the buttercups.

1 See Warming and Potter's Systematic Botany, Strasburger, Noll, Schenk, and Schimper's Text-Book of Botany, Part II, or Kerner and Oliver, Vol.. II, pp. 616-790. ${ }^{2} R$. bulbosus. ${ }^{3} R$. acris. ${ }^{4} R$. multifidus. ${ }^{5} R$. abortivus.

6 Fresh specimens or herbarium specimens will show this. 
250. Genus and Species. - Such a group as that of the buttercups is called a genus (plural genera), while the various kinds of buttercups of which it is composed are called species. The scientific name of a plant is that of the genus followed by that of the species. The generic name begins with a capital, the specific does not, unless it is a substantive: After the name comes the abbreviation for the name of the botanist who is authority for it; thus the common elder is Sambucus canadensis, L., L. standing for Linnæus. Familiar examples of genera are the Violet genus, the Rose genus, the Clover genus, the Golden-rod genus, the Oak genus. The number of species in a genus is very various, - the Kentucky Coffee-tree genus contains only one species, while the Golden-rod genus comprises more than forty species in the northeastern United States alone.

251. Hybrids. - If the pollen of a plant of one species is placed on the stigma of a plant of the same genus but a different species, no fertilization will usually occur. In a large number of cases, however, the pistil will be fertilized, and the resulting seed will often produce a plant intermediate between the two parent forms. This process is called hybridization, and the resulting plant a hybrid. Many hybrid oaks have been found to occur in a state of nature, and hybrid forms of grapes, orchids, and other cultivated plants, are produced by horticulturists at will.

252. Varieties. - Oftentimes it is desirable to describe and give names to subdivisions of species. All the cultivated kinds of apple are reckoned as belonging to one species, but it is convenient to designate such varieties as the 
Baldwin, the Bellflower, the Rambo, the Gravenstein, the Northern Spy, and so on. Very commonly varieties do not, as horticulturists say, "come true," that is to say, the seeds of any particular variety of apple not only are not sure to produce that variety, but they are nearly sure to produce a great number of widely different sorts. Varieties which will reproduce themselves from the seed, such as pop-corn, sweet corn, flint-corn, and so on, are called races.

Only long and careful study of plants themselves and of the principles of classification will enable any one to decide on the limits of the variety, species, or genus, that is, to determine what plants shall be included in a given group and what ones shall be classed elsewhere.

253. Order or Family. - Genera which resemble each other somewhat closely, like those discussed in Sect. 249, are classed together in one order or family. The particular genera above mentioned, together with a large number of others, combine to make up the Crowfoot family. In determining the classification of plants most points of structure are important, but the characteristics of the flower and fruit outrank others because they are more constant, since they vary less rapidly than the characteristics of roots, stems, and leaves do under changed conditions of soil, climate, or other surrounding circumstances. Mere size or habit of growth has nothing to do with the matter, so the botanist finds no difficulty in recognizing the strawberry plant and the apple tree as members of the same family.

This family affords excellent illustrations of the meaning of the terms genus, species, and so on. Put in a 
tabular form, some of the subdivisions of the Rose family are as follows :

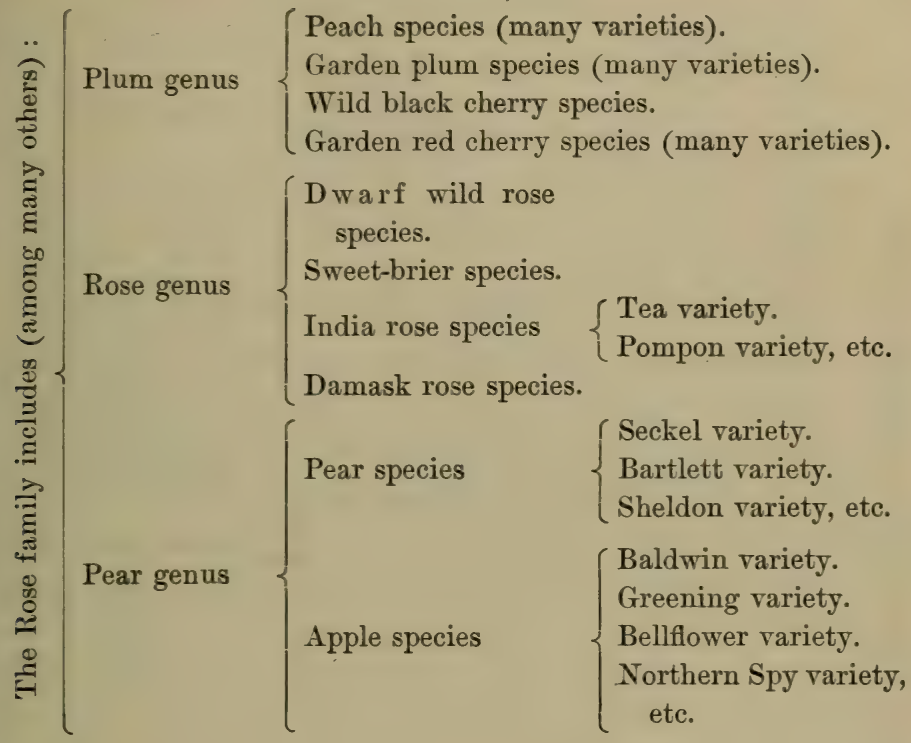

254. Grouping of Families. - Families are assembled into classes, and these again into larger groups. The details of the entire plan of classification are too complicated for any but professional botanists to master, but an outline of the scheme may be given in small space.

The entire vegetable kingdom is divided into two great divisions, the first consisting of cryptogams or spore-plants, the second of phanerogams or seed-plants. Here the relations of the various subdivisions may best be shown by a table. ${ }^{1}$

1 This is, of course, only for consultation, not to be committed to memory. 


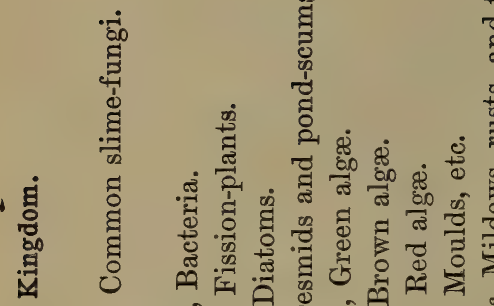

,

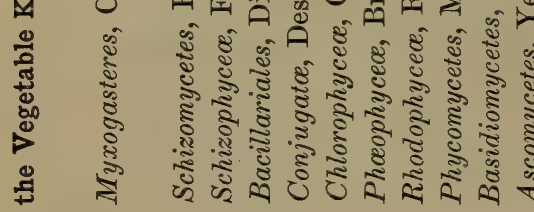

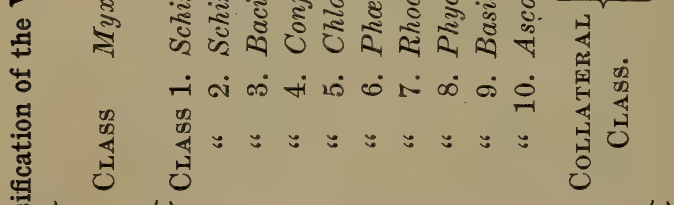

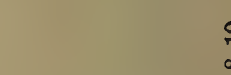

$\frac{8}{1}$

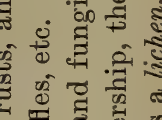
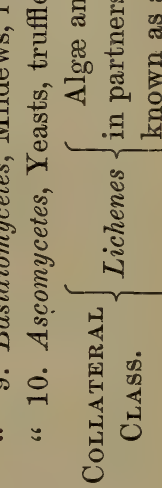

.
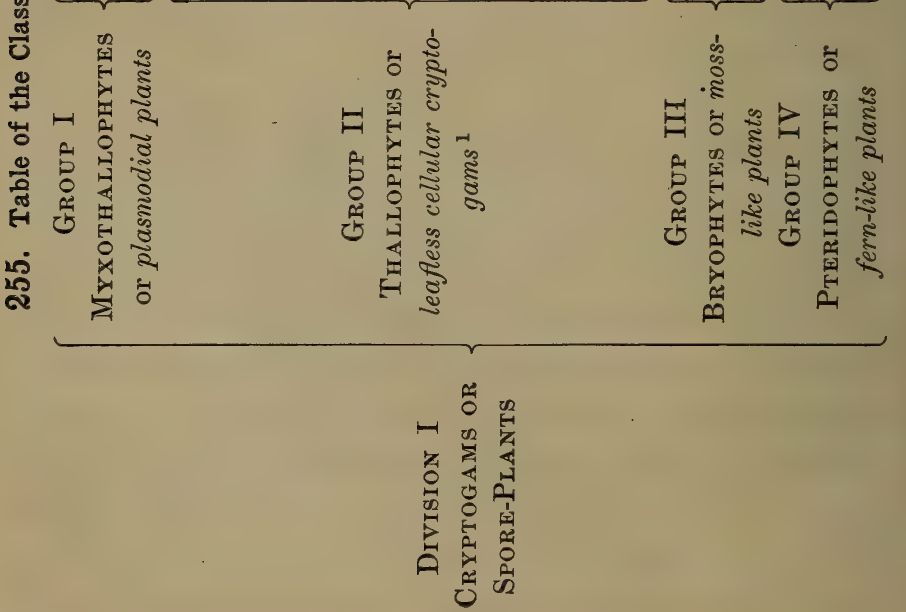

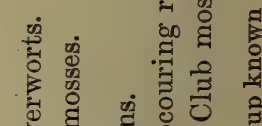

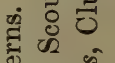

है

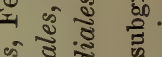

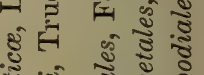

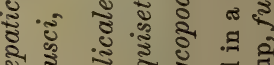

ปิ 로 요

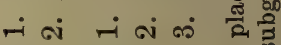

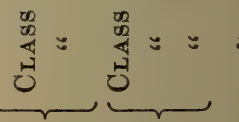
क्.

क.

5 응 然 


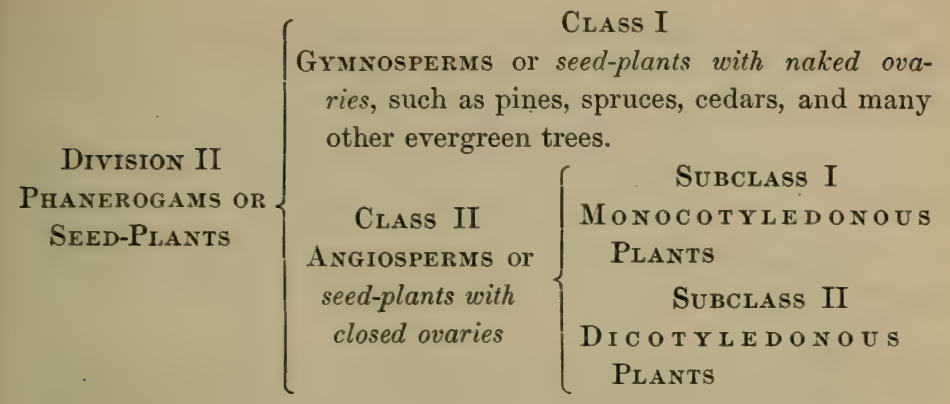

256. The Groups of Cryptogams. - The student is not to suppose that the arrangement of cryptogams into the four great groups given in the preceding table is the only way in which they could be classed. It is simply one way of dividing up the enormous number of spore-bearing plants into sections, each designated by marked characteristics of its own. But the amount of difference between one group and another is not always necessarily the same. The pteridophytes and the bryophytes resemble each other much more closely than the latter do the thallophytes, while the myxothallophytes are but little like other plants and it is extremely probable that they are really animals.

The classes given in the table do not embrace all known cryptogams, but only those of which one or more representatives are described or designated for study in this book. Lichens in one sense hardly form a class, but it is most convenient to assemble them under a head by themselves, on account of their extraordinary mode of life, a partnership between algæ and fungi.

257. The Classes of Seed-Plants. - The gymnosperms are much less highly developed than other seed-plants. 
The angiosperms constitute the great majority of seedplants (or, as they have been more commonly called, flowering plants). Only one family of gymnosperms (the Coniferce) is described in Part III of this book, though there are other families of great interest to the botanist, but with no representatives growing wild in the Northern United States.

When people who are not botanists speak of plants they nearly always mean angiosperms. This class is more interesting to people at large than any other, not only on account of the comparatively large size and the conspicuousness of the members of many families, but also on account of the attractiveness of the flowers and fruit of many. Almost all of the book which precedes the present chapter (except Chapter XII) has been occupied with seed-plants.

Seed-plants of both classes frequently offer striking examples of adaptation to the conditions under which they live, and these adaptations have lately received much study, and are now treated as a separate department of botany (see Part II). 


\section{CHAPTER XX}

\section{TYPES OF CRYPTOGAMS; THALLOPHYTES}

258. The Group Thallophytes. - Under this head are classed all the multitude of cryptogams which have a plant-body without true roots, stems, or leaves. Such a plant-body is called a thallus. In its simplest form it consists of a portion of protoplasm not enclosed in a cell-wall and without much of any physiological division of labor among its parts (Fig. 125). Only a little less simple are such enclosed cells as that of Pleurococcus (Sect. 278) or one of the segments of Oscillatoria (Sect. 268). The most complex thallophytes, such as the higher algæ and fungi, have parts definitely set aside for absorption of food and for reproduction. The latter is sometimes accomplished by more than one process and is occasionally aided by some provision for scattering the reproductive bodies or spores about when they are mature.

259. Spores. - Before beginning the study of sporeplants it is well for the student to know what a spore is. A spore is a cell which becomes free and capable of developing into a new plant. Spores are produced in one of two ways: either asexually, from the protoplasm of some part of the plant (often a specialized spore-producing portion), or sexually, by the combination of two masses of protoplasm, from two separate plants, or from different parts of the same plant. 
Asexually produced spores are sometimes formed, each by the condensation of the protoplasm of a single cell, as shown in Fig. $174, E$. They are also formed by the contents of spore-cases breaking up into many spores (Fig. $173, B$; Fig. $210, D$ ). Spores are sometimes produced by the spontaneous division of a mass of protoplasm into a small definite number of segments (Fig. 188, $t$ ). Spores which have the power of moving (swimming) freely are known as zoöspores (Fig. 179, B).

Sexually produced spores are formed in many ways. One of the simplest modes is that shown in Fig. 178, resulting in zygospores. Other methods are illustrated in Figs. 185 and 187.1

\section{THE STUDY OF SLIME MOULDS ${ }^{2}$}

260. Occurrence. - Slime moulds occur in greenhouses, in tanyards, or on old logs and decaying leaves in woods. They may be cultivated in the laboratory.

They have been described in their vegetative condition on page 179.

261. Examination with the Magnifying Glass. - Stemonitis is one of the most available genera to illustrate the fruiting of slime moulds. At maturity the motile protoplasm of the vegetative stage quickly transforms itself into numerous sporangia or spore-cases with dustlike spores. With the naked eye and with a magnifying glass note the color, form, and feathery appearance of the spore-case of Stemonitis. The outer wall disappears at an early stage, leaving only an inner structure and spores. Sketch the general outline under a magnifying glass.

262. Examination with the Microscope. - With a low power of the microscope sketch the network of branching hairs which compose the structure of the sporangium. Note the presence or absence

1 See Vine's Student's Text-Book of Botany, pp. 68-71.

2 This should logically precede Sect. 258. 
of a central column. Have any of the branches free tips? With a power of 250 or more examine the spores. A much higher power may be used to advantage. Describe the surface of the spore.

\section{THE STUDY OF BAC'TERIA}

263. Occurrence. - "Bacteria may occur anywhere but not every. where." In water, air, soil, and almost any organic substance, living

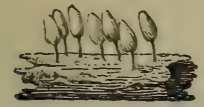

$A$
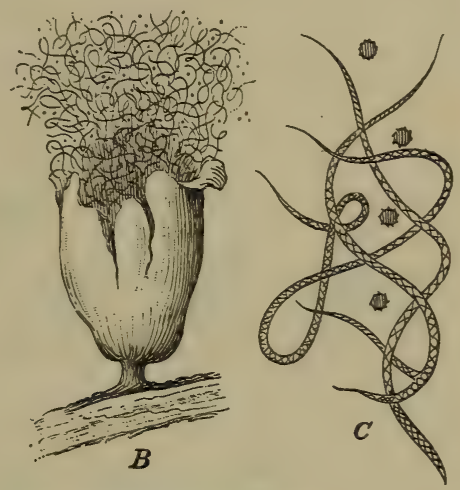

FrG. 173. - Spore-Cases of Slime Moulds.

$A$, a group of spore-cases of Arcyria; $B$, a spore-case of Trichia, bursting open and exposing its spores to the wind, $\times 20 ; C$, threads of the same, with spores between them, $\times 250$.

or dead, some species of plant belonging to the group Bacteria may occur. A small bunch of hay placed in a tumbler of water will, at a suitable temperature, yield an abundant crop in a few days or hours. Raw peas or beans soaked for a week or two in water in a warm place will afford a plentiful supply.

264. Cultures. - Pure cultures of bacteria are commonly made in some preparation of gelatine in sterilized test-tubes. Boiled potatoes serve a good purpose for simple (but usually not pure) cultures.

Select a few small roundish potatoes with skins entire and boil in water for a sufficient time to cook them through. Cut them in halves with a knife well scalded or sterilized, i.e., freed from all living 
organisms in a flame, and lay each on a saucer, with cut surface up, covering each with a glass tumbler. The tumblers and saucers should be well scalded or kept in boiling water for half an hour and used without wiping. Sterilization may be improved by baking them in an oven for an hour.

265. Inoculation. - The culture media prepared as above may now be inoculated. Uncover them only when necessary and quickly replace the cover. Scrape a little material from the teeth, tongue, kitchen sink, floor of house or schoolroom, or any other place you may desire to investigate. With the point of a knife blade or a needle sterilized in a flame, inoculate a particle of the material to be cultivated into the surface of one of the potatoes. Several cultures

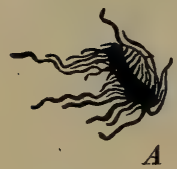

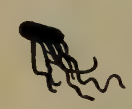

$B$
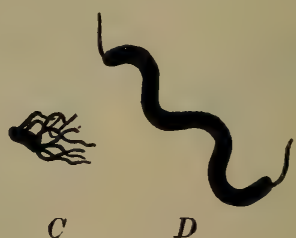

$D$

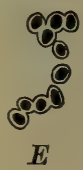

FIG. 174. - Bacteria stained to show Cilia.

$A$, Bacillus subtilis ; $B$, Bacillus typhi (the bacillus of typhoid fever); $C$, Bacillus

tetani (the bacillus which causes lockjaw); $D$, Spirillum undula; $E$, Bacillus

tetani forming spores. (All five are magnified 1000 diameters.)

may be made in this way and one or more left uninoculated as checks. Another may be left uncovered in the air for half an hour. Others may be made with uncovered potatoes. Number each culture and keep a numbered record.

Keep watch of the cultures, looking at them daily or oftener. As soon as any change is noticed on the surface of a culture, make a descriptive note of it and continue to record the changes which are seen. Note the color of the areas of growth, their size, outline, elevation above the surface, and any indications of wateriness. Any growth showing peculiar colors or other characters of special interest may be inoculated into freshly prepared culture media, using any additional precautions that are practicable to guard against contamination. 
266. Microscopic Examination. - Exainine some of the cultures. Place a particle of the growth on a slide, dilute it with a drop of clear water, and place a cover-glass over it. Examine with the highest obtainable power of the microscope, at least $\frac{1}{6}$ in. objective. Note the forms and movements, also the sizes if practicable, of any bacteria that are found.

\section{THE STUDY OF OSCILLATORIA ${ }^{1}$}

267. Occurrence. - Oscillatoria may occur floating in stagnant water or on damp soil in ditches, roadsides, dooryards, paths, or pots in greenhouses. Other nearly related plants occur on surfaces of ponds sometimes covering considerable areas or adhering in small spheres to submerged vegetation. Algæ of this class are particularly noxious in water supplies, as they partake of the nature of bacteria, to which they are related.

268. Examination with the Microscope. - After washing a particle of Oscillatoria material in a drop of water to remove as much of the earth as possible, place it in a clean drop of water, pull to shreds with needles, cover, and examine under a power of 200 or more diameters.

Note the color and compare it with chlorophyll green.

The filament is not one plant, but each of the cells which compose it is one plant. They are packed together in the filament like coins and sometimes may be found separating singly. The usual mode of reproduction is by the separation of a number of adhering cells as a short filament from one end of a longer one, and this increases in length by the dividing of its individual cells.

269. Movement. - At ordinary temperatures, favorable to growth, movement may be observed in the filaments. Describe the movement. What has it to do with the name of the plant?

${ }^{1}$ A genus of the class Schizophyceæ. 


\section{THE STUDY OF DIATOMS}

270. Occurrence. - Diatoms of different species may be found in sediment in water in various kinds of places or mixed with or

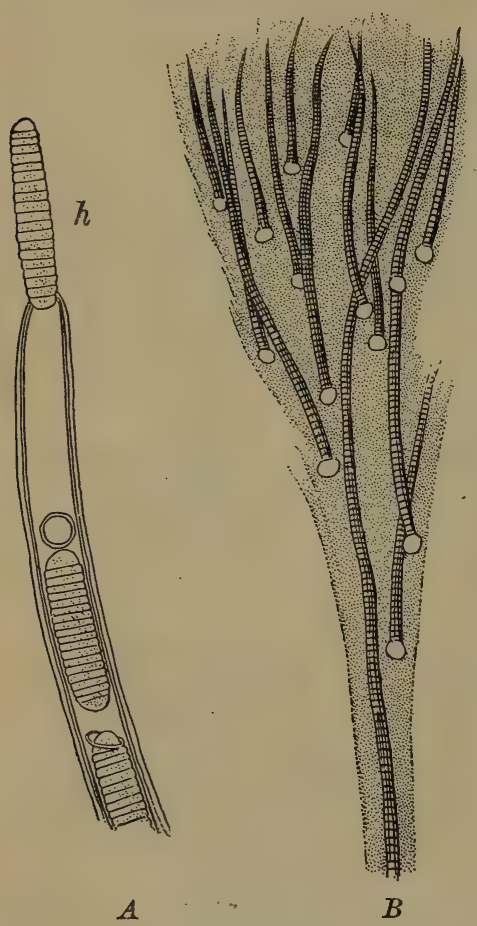

FIG. 175. - Schizophycex.

$A$, a filament of Calothrix, reproducing by hormogonia, $h$, segmented portions which escape from the sheath of the filament; $B$, Rivularia. (Both $A$ and $B$ greatly magnified.) adhering to fresh-water or marine algæ, in ponds and ditches or on sand or earth at the bottom of clear brooks. In the last place they may be detected with the eye, forming a yellowish coloring. They may often be obtained by straining hydrant water. Where diatoms have been very abundant their remains sometimes form beds of rock, and fossil diatoms compose some of the polishing powders of commerce.

271. Microscopical Examination of Diatoms. - Place a drop of water containing diatoms on a slide and put a cover-glass over it. Examine with a power of 200 or more diameters. Diatoms occur singly, resembling triangles, wheels, boats, rods, and a great variety of other forms (Fig. 176), or adhering in long bands, as spokes of a wheel, etc. The boat-shaped kinds are among the commonest. The color of the contents is yellowish. The cell-wall is encrusted with a shell of silica whose surface is covered with beautiful markings, dots or lines, which are conspicuous in some species, in others so minute that the most powerful microscopes are required to detect them. By boiling 
in nitric acid, the cellulose wall and its contents may be destroyed and the markings of the siliceous shell more easily observed. Each diatom consists of a single cell.

272. Movements of Diatoms. - Liring diatoms exhilit a peculiar power of morement. In the boat-shaped species the morement is much like that of a row-boat, forward or backward.

\section{THE STLDY OF SPIROGYRA}

273. Occurrence. - Spirogyra, one of the plants commonly known as pond-scum, or "frog-spit," occurs widely distributed throughout the country in ponds, springs, and clear streams. It is of a green or yellowish-green color, and in sumny weather usually floats on or near the surface of the water, buoyed up by the numerous oxygen bubbles which it sets free. It may be found flourishing in unfrozen springs, even in midwinter.

274. Examination with the Magnifying Glass. $^{1}$ - Float a little of the material in a white plate, using just water enough to cover the bottom of the latter. Study with the magnifying glass and note the green color of the threads and their great length as compared with their thickness. Are all the filaments about equal to each other in diameter?

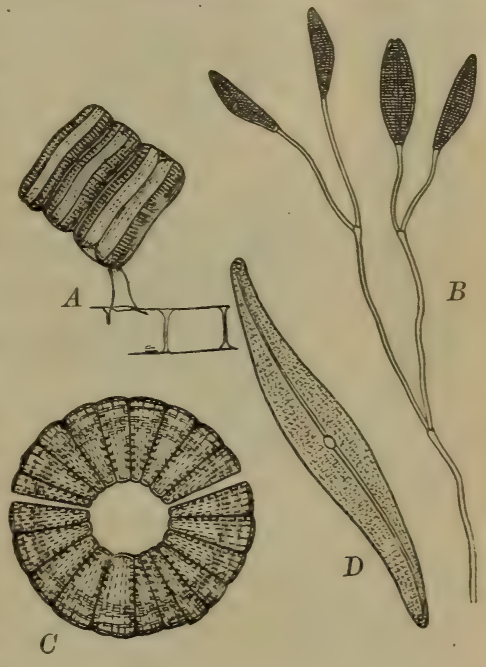

Fig. 176. - A Group of Diatoms.

A, Achnanthes; $B$, Cocconema; C, Meridion; $D$, Pleurosigma.

Handle a mass of the material and describe how it feels between the fingers.

275. Examination with the Microscope. - Mount in water under a large corer-glass and examine first with a power of about 100

1 Consult Huxley's Biology and Spalding's Introduction to Botany. 
diameters, then with a power of 200 diameters or more. Note the structure of the filaments. Of what is each made up? Compare with the structure of Oscillatoria.

Move the slide so as to trace the whole length of several filaments, and, if the unbroken end of one can be found, study and sketch it.

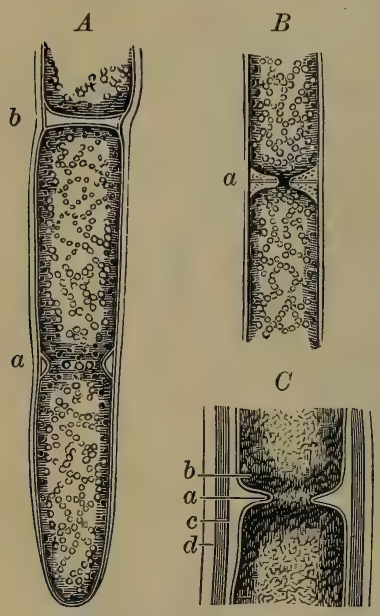

Fig. 177. - Process of Cell-Multiplication in a Species of PondScum. (Considerably magnified.)

$A$, portion of a filament partly separated at $a$ and completely so at $b ; B$, separation nearly completed, a new partition of cellulose formed at $a$; $C$, another portion more magnified, showing mucous covering $d$, general cell-wall $c$, and a delicate membrane $a$, which covers the cell-contents $b$.

Study with the higher power a single cell of one of the larger filaments and ascertain the details of structure. Try to discover, by focusing, the exact shape of the cell. How do you know that the cells are not flat? Count the bands of chlorophyll. The number of bands is an important characteristic in distinguishing one species from another.

Run in five-per-cent salt solution at one edge of the cover-glass (withdrawing water from the other edge with a bit of blotting paper). If any change in the appearance of the cell becomes evident, make a sketch to show it. What has happened to the cell-contents? Explain the cause of the change by reference to what you know of osmose.

On a freshly mounted slide run under the cover-glass iodine solution, a little at a time, and note its action on the nucleus. Is any starch shown to be present? If so, just how is it distributed through the cell?

276. Reproduction of Spirogyra. The reproductive process in Spirogyra is of two kinds, the simplest being a process of fission, or celldivision. The nucleus undergoes a very complicated series of transformations, which result in the division of the protoplasmic contents of a cell into two independent portions, each of which is at length surrounded by a complete cell-wall of its own. In Fig. 176 
the division of the protoplasm and formation of a partition of cellulose in a kind of pond-scum are shown, but the nucleus and its changes are not represented.

Another kind of reproduction, namely by conjugation, is found in Spirogyra. This process in its simplest form is found in such unicellular plants as the desmids (Fig. 178). Two cells (apparently precisely alike) come in contact, undergo a thinning-down or absorptive process in the cell-walls at the point of contact, and finally blend their protoplasmic cell-contents, as shown in the figure, to form a mass known as a spore, or more accurately a zygospore, from which, after

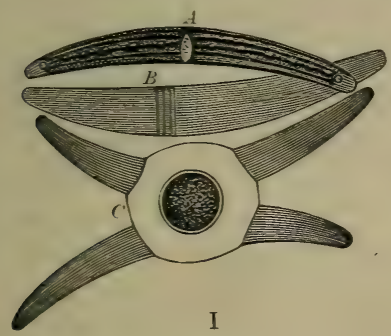

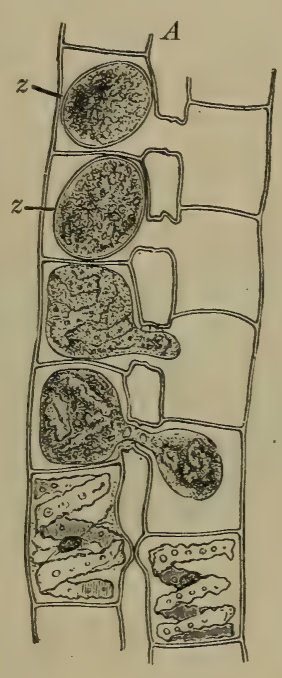

II

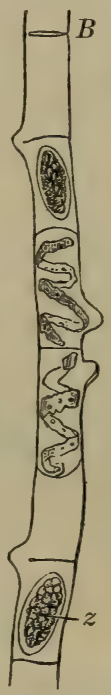

Fig. 178. - Conjugation of Cells of Green Algæ. (Much magnified.)

I. Conjugation of Desmids. $A$, a single plant in its ordinary condition; $B$, empty cell-wall of another individual ; $C$, conjugation of two individuals to form a spore by union of their cell-contents.

II. Conjugation of Spirog!/rr. A, two filaments of Spirogyra side by side, with the contents of adjacent cells uniting to form spores, $z$. At the bottom of the figure the process is shown as beginning at the top as completed, and the cells of one filament emptied; $B$, a single filament of another kind of Spirogyra, containing two spores, one lettered $z$. ( $A$ magnified 240 diameters, $B 150$ diameters.)

a period of rest, a new individual develops. In Spirogyra each cell of the filament appears to be an individual and can conjugate like the one-celled desmids. It is not easy to watch the process, since the spore-formation takes place at night. It is possible, 
however, to retard the occurrence of conjugation by leaving the Spirogyra filaments in very cold water over night, and in this way the successive steps of the conjugating process may be studied by daylight. In such ways the series of phenomena shown in Fig. 178 , II, has been accurately followed. If the student cannot follow these operations under the microscope, he may, at least, by looking over the yellower portions of a mass of Spirogyra find threads containing fully formed zygospores, like those shown in $B$, Fig. 178.

\section{THE STUDY OF PLEUROCOCCUS}

277. Occurrence. - Pleurococcus may be found on old fences, roofs, and many similar places, particularly on the bark of the north side of trees. The individual plants cannot be detected by the naked eye, but when grouped in masses they form a powdery green covering over indefinite areas of bark. Plenty are seen where it is moist.

278. Microscopical Examination of Pleurococcus. - Scrape a minute quantity of Pleurococcus from a specimen on bark, place it in a drop of water on a slide, distributing it slightly in the water, lay on it
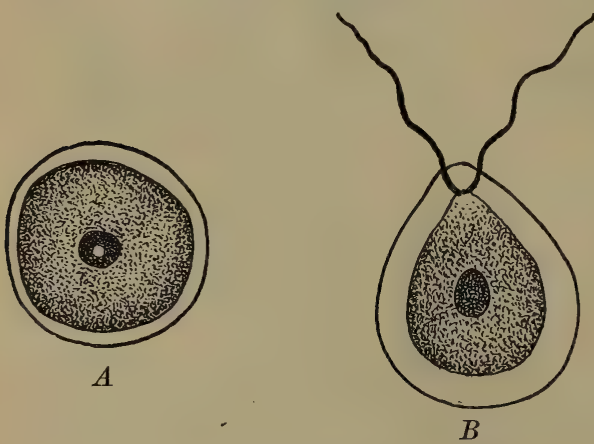

Fig. 179. - Two Cells of Protococcus. (Greatly magnified.)

$A$, a spherical cell of the still form ; $B$, a motile cell with its protoplasm enclosed in a loose cell-wall and provided with two cilia. a cover-glass and examine with a power of 200 or more diameters. Sketch with the camera lucida one of the largest cells, some of intermediate size, and one of the smallest, beside several divisions of the stage micrometer.

Note the clearly defined cell-wall of cellulose, enclosing the protoplasmic contents, usually green through-

out. Do any cells show a nucleus like that in Fig. 179, $A$ ?

Test the cells with iodine solution for starch. 
Note that in reproduction the cell-contents in many individuals has divided into two parts which become separated from each other by a cellulose partition. Each of these again divides, and the process continues until thirty-two or more cells may be found in one mass or they may fall apart at an earlier stage.

279. Nutrition of Pleurococcus. - Pleurococcus can flourish only with an abundance of light and moisture. In daylight it can absorb carbon dioxide and fix carbon (giving off the oxygen at the same time as bubbles of oxygen) and can assimilate mineral substances. It is a capital example of an individual cell capable of independent existence.

280. Motile Forms. - No motile form is known in Pleurococcus. Hcematoccus, often known as Protococcus (Fig. 179), is a better object for study than Pleurococcus. It may sometimes be found in water of stagnant pools, particularly those which contain the drainage of barnyards or manure-heaps, in mud at the bottom of eaves-troughs, in barrels containing rain-water, or in water standing in cavities in logs or stumps. Its presence is indicated by a greenish or sometimes by a reddish color. It is sometimes found in an actively swimming condition, in which case each cell is called a zoöspore.

\section{THE STUDY OF VAUCHERIA}

281. Occurrence. - Species of Vaucheria are found in ponds, streams, and pools, immersed or floating like Spirogyra and at all seasons may be sought in greenhouses, where they grow on the moist earth of beds and pots, forming a green felt.

282. Examination with the Magnifying Glass. - The magnifying glass will show the growth of Vaucheria to consist of numerous green filaments similar to those of Spirogyra. Select a small portion and spread out the filaments carefully in a drop of water on a slide. Does the glass reveal any indications of cross-partitions, of branching, or of fruiting organs as short lateral branches? Does it show the form or arrangement of the green coloring matter?

283. Examination with the Microscope. - Prepare as directed for the magnifying glass and place a corer-glass over the preparation, with sufficient water. With the lowest power observe the 
continuity of the cell-cavity and (in young plants growing on soil) search for root-like portions, in those growing in water for branching portions, and fruiting organs in the form of. swellings or short lateral branches.

With a power of about thirty to sixty diameters sketch a selected plant of moderate extent as nearly complete as possible or else

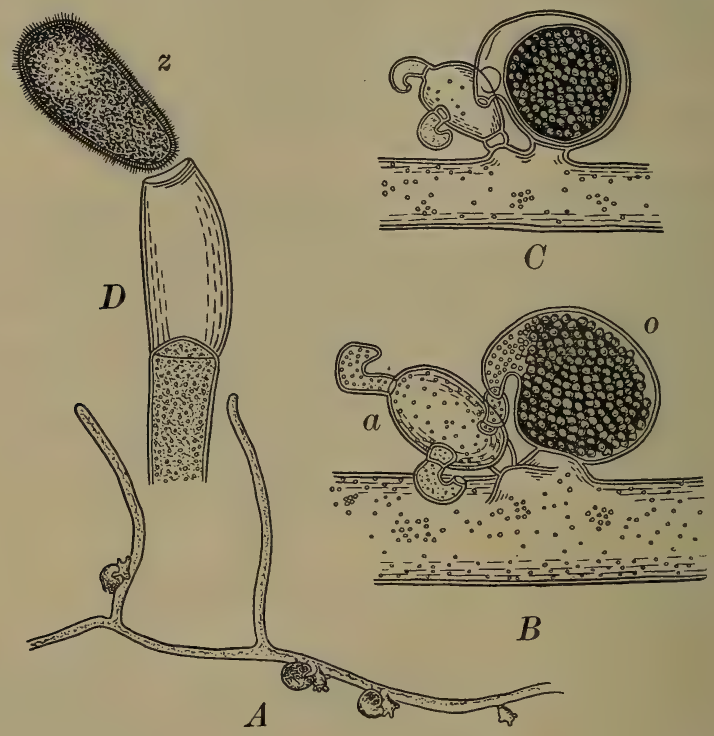

FIG. 180. - Vaucheria synandra.

$A$, a filament with archegonia and antheridia (considerably magnified); $B$, part of same much more highly magnified; $o$, oögonium; $a$, antheridium; $C$, a later stage of $B ; D$, end of a filament with a zoöspore, $z$, escaping (highly magnified).

sketch a portion showing the branching and a root-like portion. Note and indicate the absence or presence and arrangement of chlorophyll. Can Vaucheria probably use carbon dioxide?

284. Reproduction in Vaucheria. - Make an outline sketch of fruiting organs, if found. See if any filaments can be found with the contents massing or escaping at the tips. In some species 
zoöspores are formed in this way, having their entire surface clothed with cilia. They are the largest motile cells known. In other species a portion of the filament is separated and cut off by a cell-wall. Such spores soon germinate and may be found in various stages of growth. They often serve for propagation through several generations before spores are produced by fertilization.

With a power of about 200 diameters sketch a portion of a filament to show the form and location of chlorophyll. Sketch the fruiting organs in detail, if any can be found. ${ }^{1}$

Antheridia and oögonia are formed near together on the same filament. The antheridium is a cell forming the terminal portion of a short branch, which is rather slender, straight or curved. Its contents form numerous minute antherozoids, each with two cilia. The cilia can be seen only with great difficulty, if at all, but their presence is indicated by their active movements.

The oögonium is a short, somewhat spheroidal branch separated by a cross-partition at the base. The cell-wall becomes ruptured at the tip, allowing the entrance of the antherozoids by which it is fertilized. After fertilization a cell-wall is formed about the oösphere, and it matures as an oöspore and enters upon a period of rest.

\section{THE STLDY -OF NITELLA}

285. Occurrence. - Vitella is a green plant growing attached to the bottom of ponds and streams, usually in shallow water. It is not common everywhere but is widely distributed. Chara is similar and may be used as a substitute but is more complicater.

286. General Aspect. - With the naked eye and a magnifying glass note the general aspect of Nitella, the length of the stemlike portions, from the root-like parts to the tip, the length of some of the joints (internodes), the arrangement of leaf-like and branchlike portions.

287. Protoplasm. - Examine the cells of sterns or leaves under a low power. Select a vigorous cell of moderate size and examine

1 Goebel states that the formation of the fruiting organs begins in the evening, is completed the next morning, and that fertilization takes place during the day between ten and four o'clock. 
under a power of 200 or more diameters. Select the terminal cell of the leaf if Chara is used. The protoplasm is nearly colorless but usually contains bodies which can be seen moving in the current of

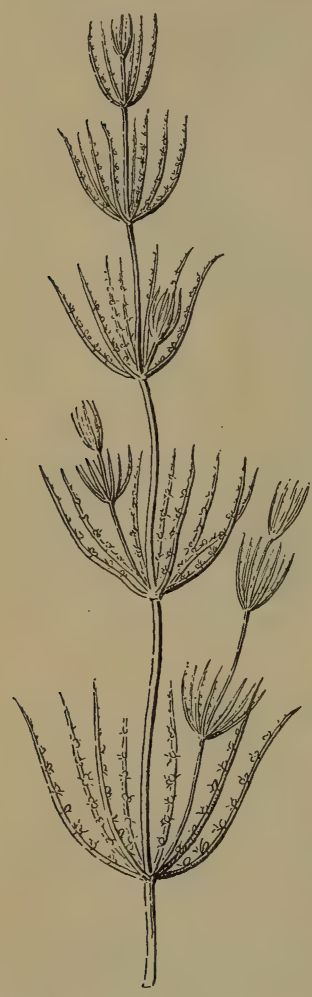

FIG. 181. - End of a Main Shoot of Chara. (About natural size.) protoplasm. The protoplasm will show normal activity at the temperature of a comfortable living room. By focusing, see if the current of protoplasm can be detected moving in more than one direction.

Note the form and arrangement of the chlorophyll and any places lacking chlorophyll, and see if you can tell whether the arrangement has any relation to the current of protoplasm. With a low power trace the course in several cells. How many cells constitute each internode of Nitella? If Chara is used, internodes will be found to be covered with a layer of many corticating cells. Under a high power compare the general structure of node and internode and see if the attachment of leaves and branches can be clearly determined. Compare the tip of a leaf with the tip of a stem or branch if the material permits. Are the fruiting organs produced on the stems or the leaves?

288. Antheridia. - The antheridia are globular bodies, bearing male fertilizing cells and becoming red at maturity (Fig. 182). Eight cells compose the outer wall. They have radial lines indicating folds and join one another by irregular sutures. Note a round spot in the middle of each cell which marks the point of attachment within of the stalk on which antherozoid-producing cells are borne.

289. Oögonia. - The egg-shaped fruits, known as oögonia (Fig. 182), are borne near the antheridia in monœcious species. Count the number of pointed cells which constitute the "crown" of the fruit. Does each tip consist of one or two short cells? Examine 
the surface of the enveloping cells which enclose the spore. What is their number and form? What is their relation to the cells forming the crown? Focus so as to see the large egg-cell (oösphere or oöspore) which constitutes the center of the fruit. Can you determine anything regarding its contents?

Search for young oögonia and if practicable describe and draw them in several stages of development. Their structure can be seen much more easily than that of the antheridia. Make drawings to illustrate various details of structure.

290. Char aceæ. - Nitella and Chara are the genera composing the group Characea, a group of green algæe differing widely from any others. They show in a wonderful manner simplicity of cell-structure with a high degree of organization. Scarcely less wonderful are the care and precision with which botanists have worked

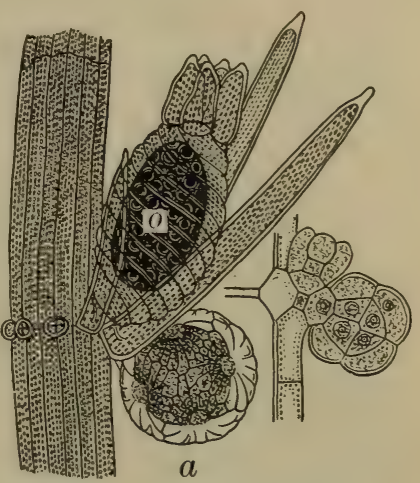

FIG. 182. - Part of a Leaf of Fig. 181.

(Considerably magnified.)

$a$, antheridium; o, oögonium. At the right are a young antheridium and archegonium. out their life history. As a study in evolution the Characece may be considered as representing the highest development attained along the line of filamentous green algæ, which, while preserving their algal characteristics, are comparable in a remarkable degree with moss- and fernplants and with seed-plants. Every cell in the plant has been accounted for and is understood in regard to origin, relationship, and function. With harmony of structure throughout, it has organs comparable to root, stem, and leaf in seed-plants, each with characteristic structure and 
mode of growth. The stem has nodes and internodes. The stem increases by the growth of an apical cell, but growth in length depends chiefly on the elongation of each internodal cell instead of the multiplication of numerous internodal cells.

\section{THE STUDY OF ROCKWEED ${ }^{1}$}

291. Occurrence. - The common rockweed is abundant everywhere on rocks, between high and low tide, on the New England

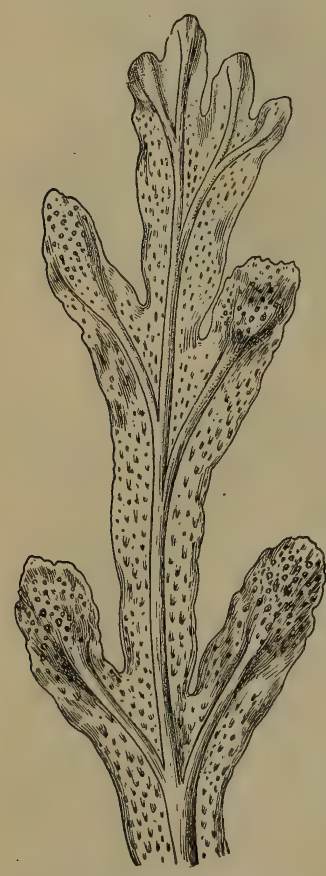

FIG. 183. - Part of Thallus of a Rockweed (Fucus platycarpus), natural size. The two uppermost branchlets are fertile. coast and southward.

292. The Frond. - A plant of rockweed consists mostly of a growth which is somewhat leaf-like, but, in fact, stem and leaf are not separately developed, and the growth is therefore called a thallus. This combined stem and leaf has many flat leathery branches which are buoyed up in the water by air-bladders. Cut one of the bladders open and note its form and appearance. Note whether they occur singly or how grouped. Note the prominent midrib running throughout the middle of each branch. Examine the swollen tips of some of the branches and note their peculiarities. Sketch a portion of a frond to show the characteristics so far noted.

293. Reproduction. - Cut across through the middle of one of the swollen fruiting tips. Note the fruiting papillæ (conceptacles) as they appear in this section, and make a simple sketch to show their position.

Select some plants with brighter colored tips and some less bright, if any difference

1 Fucus vesiculosus is the most available species. Others may be substituted. 
can be detected. After making the microscopic examination which follows, note what correspondence of structure with color has been observed. Cut very thin sections through fruiting tips from different plants, keeping those from each plant separate. Be sure that some of the cuts pass through the conceptacle as near the middle as possible.

Examine with a power of about sixty diameters sections from different fronds, searching for one kind containing rather large egg-shaped cells and another containing bundles of numerous smaller sac-shaped cells. IVith a power of 200 diameters study the details of the sections. Note the character of the cells forming the surface of the frond, those of the inner structure, and those limiting the cavity of the conceptacle. In a conceptacle cut through the middle note the form of the orifice. Examine the slender hairs or filaments (paraphyses) which, arising at right angles, line the walls of the conceptacle.

294. Oögonia and Antheridia. - In conceptacles containing egg-shaped cel's (oögonia) note the form, mode of attachment (sessile or stalked), and different stages of development. At maturity the contents are divided, forming eight oöspheres; but not all can be seen
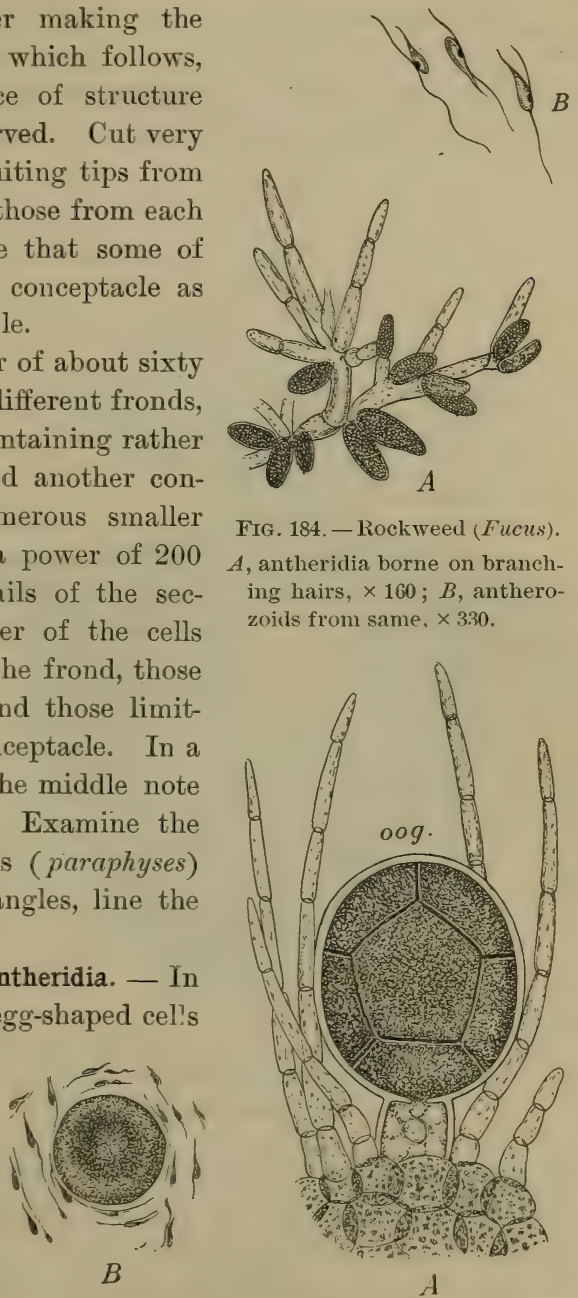

FIG. 184. - Rockweed (Fucus).

$A$, antheridia borne on branching hairs, $\times 160 ; B$, antherozoids from same, $\times 330$.

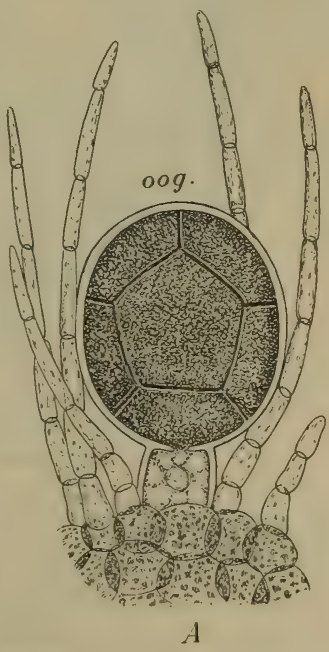

FiG. 185. - Rockweed (Fucus).

at once, some being be- $A$, oögonium, its contents dividing into eight oöspheres, neath the others. therozoids, $\times 160$. 
In conceptacles of the other kind examine the numerous small sac-shaped cells (antheridia). At maturity the contents of each divide to form numerous very minute motile antherozoids, each with two delicate hairs or cilia. Dissect, by picking and by friction under

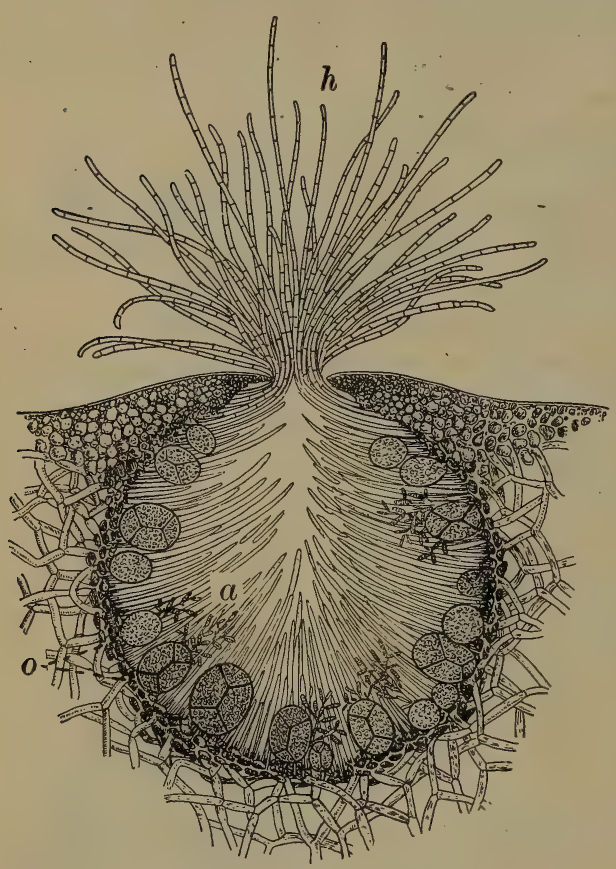

FIG. 186. - Transverse Section of Conceptacle of a Rockweed (Fucus platycarpus). ( $\times$ about 35 ) $h$, hairs ; $a$, antheridia ; $o$, oögonia. cover-glass, a bunch of antheridia and note the branching filaments upon which they are borne.

Make drawings to illustrate the various, points of structure.

295. N u m ber of Antherozoids required for Fertilization. - The bulk of an oösphere has been estimated equal to that of thirty thousand to sixty thousand antherozoids, but apparently an oösphere may be fertilized by only one antherozoid. Yet a large number swarm around each oösphere after both have escaped from the conceptacles, and often their movements àre so active as to cause the rotation of the oösphere. The process of fertilization may be discerned in fresh material by squeezing oöspheres and antherozoids from their respective conceptacles into a drop of water on a slide. In some species, as Fucus platycarpus (Fig. 186), antheridia and oögonia are found in the same conceptacle. 


\section{THE STUDY OF NEMALION}

296. Dccurrence. - Seven or eight species of Nemalion are known in the world, but only one ${ }^{1}$ is widely diffused, being found in Europe and on the New England coast from Rhode Island northward. It grows in salt vater attached to exposed rocks at low-water mark. Vemalion represents the largest of the groüps of algæ, nearly'all of which live in salt water and have the characteristic color; but a few live in fresh water.

297. Color. - Fresh specimens or those properly dried for the herbarium show the color which is characteristic of the great group to which Nemalion belongs. Dried specimens of "Irish moss" (Chondrus) and many other species furnish good illustrations. There are many rariations of shade and intensity.

Place a piece of a fresh or dried specimen of some species in a beaker of fresh water orer night or longer and note the color of the solution and of the treated specimen. Treat another piece similarly with alcohol. A few genera related to Nemalion grow in fresh water. What do you infer regarding their color?

298. Form and General Character. - Examine specimens of Nemalion and note the size, shape, mode of branching, nature, or - consistency of their substance. Examine a fragment of the plant with a power of about sixty diameters and note how the structure differs from what it appears to be to the naked eye. Do cells appear more densely packed or differently colored at any points?

299. Structure. - From a small portion of the plant cut thin longitudinal and transverse sections or pull it to pieces with needles so as to expose the inner portion. Place on a slide under a coverglass in a drop of water. With a power of about 250 diameters or more examine the general structure of the frond, as shown by a slide prepared as above. Note the central portion (axis) of the frond as dissected out, consisting of long, slender, thread-like cells. Examine and draw the branching rows of cells which, radiating from the axis, form the surrounding outer structure of the frond. Note the tips of these branches and look for the fruiting organs and fruit (spores). 


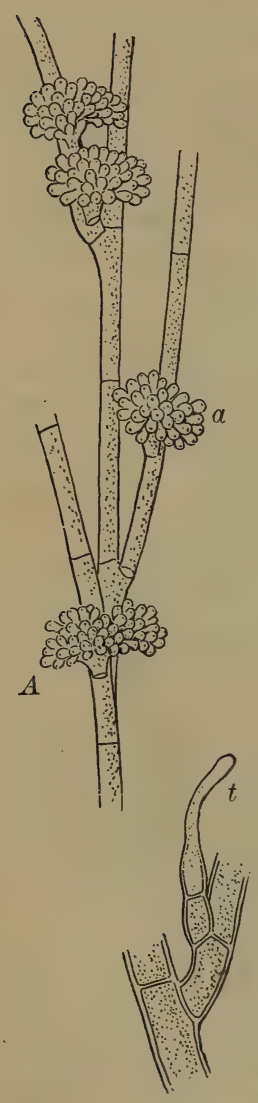

B
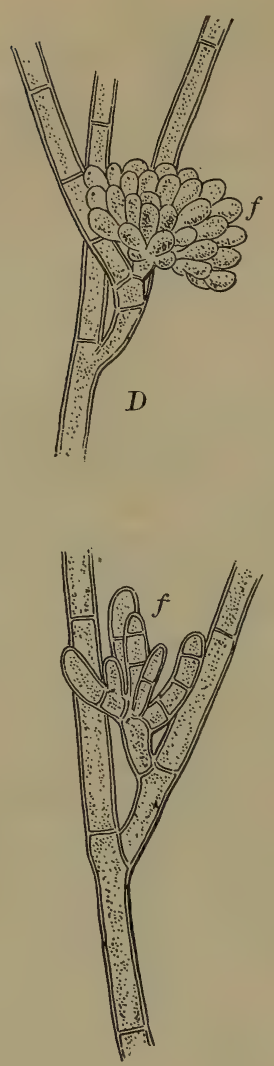

C
FIG. 187.- Portions of Thallus of a Red Alga (Chantransia). (Much magnified.)

$A$, filaments with antheridia, $a$; $B$, young receptive hair, or trichogyne, $t$; $C$ and $D$, successive stages in the growth of the clustered fruit, $f$.
300. Organs for Reproduction. - The fruiting organs are to be sought on the radiating branching filaments and are usually produced in great abundance during the summer. Various stages of development may be expected at a given time. The antherozoids are small spheres without cilia, non-motile, with a thin cell-wall. Look for cells in which they are formed (antheridia), occurring in groups at the tips of the branches. Compare these with the vegetative cells.

\section{Spore-Production.}

-Look for spore-producing organs in various stages. In the young stage at the time of fertilization, antherozoids, carried by currents of water, may be found adhering. Note the shape of the tip (trichogyne) and the base (carpogonium), and find whether there is any partition separating them at this stage. Draw or describe a few later stages in development, and note the arrangement of the spores at maturity. Are they naked or enclosed in any sort of envelope? Are they arranged in masses, chains, or otherwise? 
302. Other Florideæ. - Nemalion represents one of the simplest modes of fruiting in the red algæe. In others there is great variety in structure and great complication in the morle of fruiting. Some species of Polysiphonia (or Dasya) may well be studied in comparison with Nemalion and in further illustration of this important group. ${ }^{1}$ Understanding that a siphon, in algæ, is a row of cells, end to end, study the structure of a plant of Polysiphonia as illustrating its name. How many siphons are there? Do the main branches have any other cells corering the surface (corticating cells)?

Note the tufts of repeatedly forking, onesiphoned filaments.

303. Fruiting of Polysiphonia. - The antheridia are to be sought on the branching filaments just mentioned. Note how they differ from those of Nemalion. The clustered fruits or cystocarps will be recognized as ovoidglobose or urn-shaped bodies attached externally to the frond. Note whether the group of spores is naked or otherwise, whether the spores are produced singly or in chains; how attached; shape.

Many Floridece have another kind of fruiting bodies, spores produced without fertilization, coördinate with the asexual spores of black mould (see Sect. 308). In Floridece such spores are usually found in fours and are called tetraspores.

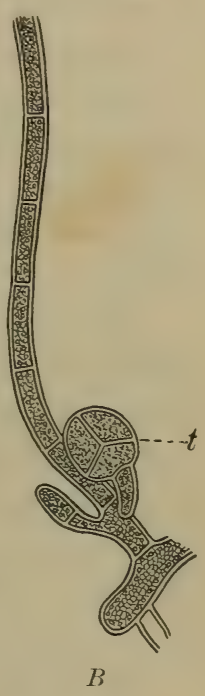

Fig. 188.

$A$, spores of Nemalion (greatly magnified); $B$, portion of thallus of a red alga, Lejolisia, with tetraspores, $t$.

Are tetraspores usually found on separate plants?

In Polysiphonia the tetraspores appear to be formed in threes (tripartite), the fourth being underneath the three. When found, describe their position and arrangement.

304. Algæ. - Diatom, Oscillatoria, Pleurococcus, Spirogyra, Vaucheria, Nitella, Fucus, Nemalion, these eight

1 It is desirable also to exhibit fresh or pressed specimens of various genera to show their general aspect. 
plants which we have just studied, are types of several families of plants which together make the great group called Algce. Something of its importance in nature is indicated by these facts: The number of known species is about 12,000 . In size, the individuals in various species range from a single cell of microscopic dimensions, as in Pleurococcus, to the giant kelp of California which reaches a length of more than 1000 feet. The form ranges from a simple spherical cell as in Pleurococcus to an extensive, branching cell in Vaucheria and its allies, specialized organs in the form of root, stem, leaf, air-bladder, and fruiting organs in Sargassum, which is an álly of Fucus.

The algæ illustrate a series of modes of propagation from simple division in Oscillatoria to the union of two similar masses of protoplasm to form a spore in Spirogyra, the direct fertilization of a germ-cell by motile antherozoids in Vaucheria, Nitella, Fucus; the indirect fertilization of fruiting cells by non-motile antherozoids in Nemalion. In allies of the latter there are more intricate variations of the same mode.

The algæ fall into five natural groups based primarily on the mode of fruiting. In most cases color is coördinate with class and may be relied upon as a superficial guide in grouping; but there are a few exceptions, e.g., some fruiting like the red group are, nevertheless, green.

The nutrition of the brown and the red algæ is similar to that of the green algæ, since the brown or red color merely conceals the green of the chlorophyll which is present in all and enables them all to take in and decompose carbon dioxide. ${ }^{1}$

1 See Murray's Introduction to the Study of Seaweeds, pp.4-6. London, 1895. 


\section{Classification of Types studied.}

Diatomace.e.

Diatoms.

CyanophyceE.

Oscillatoria.

Chlorophyce.

Pleurococcus, Spirogyra,

Vaucheria, Nitella.

Рндорнасеж.

Fucus.

Floridef.

Nemalion.

Polysiphonia.
Yellowish.

Blue-green or some similar color.

Olive.

Red.

\section{THE STUDY OF BLACK MOULD (RHIZOPUS NIGRICANS)}

306. Occurrence. - This mould may be found in abundance on decaying fruits, such as tomatoes, apples, peaches, grapes, and cherries, or on decaying sweet potatoes or squashes. For class study it may most conveniently be obtained by putting pieces of wet bread on plates for a few days under bell-jars and leaving in a warm place until patches of the mould begin to appear.

307. Examination with the Magnifying Glass. - Study some of the larger and more mature patches and some of the smaller ones. Note :

(a) The slender, thread-like network with which the surface of the bread is covered. The threads are known as hypha, the entire network is called the mycelium.

(b) The delicate threads which rise at intervals from the mycelium and are terminated by small globular objects. These little spheres are spore-cases. Compare some of the spore-cases with each other and notice what change of color marks their coming to maturity.

308. Examination with the Microscope. - Sketch a portion of the untouched surface of the mould as seen (opaque) with a two-inch objective, then compare with Fig. 189. 
Wet a bit of the mould, first with alcohol, then with water. Examine in water with the half-inch objective, and sketch a little of the mycelium, some of the spore-cases, and the thread-like stalks on which they are borne. Are these stalks and the mycelium filaments solid or tubular? Are they one-celled or several-celled?

Mount some of the mature spore-cases in water, examine them with the highest obtainable power, and sketch the escaping spores.

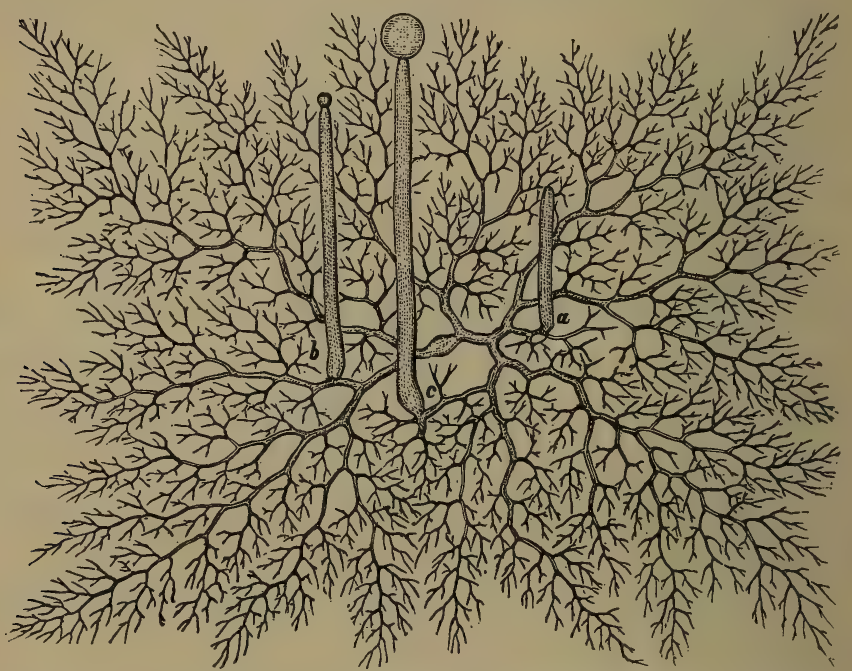

FIG. 189, - Unicellular Mycelium of a Mould (Mucor Mucedo), sprung from a Single Spore.

$a, b$, and $c$, branches for the production of spore-cases, showing various stages of maturity. (Considerably magnified.)

Sow some of these spores on the surface of "hay-tea," made by boiling a handful of hay in just water enough to cover it and then straining through cloth or filtering through a paper filter. After from three to six hours examine a drop from the surface of the liquid with a medium power of the microscope (half-inch objective) to see how the development of hyphæ from the spores begins. Sketch. 
After about twenty-four hours examine another portion of the mould from the surface of the liquid and study the more fully developed mycelium. Sketch.

309. Zygospores. - Besides the spores just studied, zygospores are formed by conjugation of the hyphre of the black moulds. It is not very easy to find these in process of formation, but the student may be able to gather from Fig. 190 the nature of the process by which they are formed, - a process which cannot fail to remind him of the conjugation of pond-scum.

\section{THE STUDY OF WHEAT} RUST (PUCCINIA GRAMINIS)

310. Occurrence. - Wheat rust is common on cultivated wheat and other grains, and also on many wild and cultivated forage grasses. In fact, this or similar rusts occur on a very large number of grasses, and many species of such rusts are recognized. A rust may have one, two, or three kinds

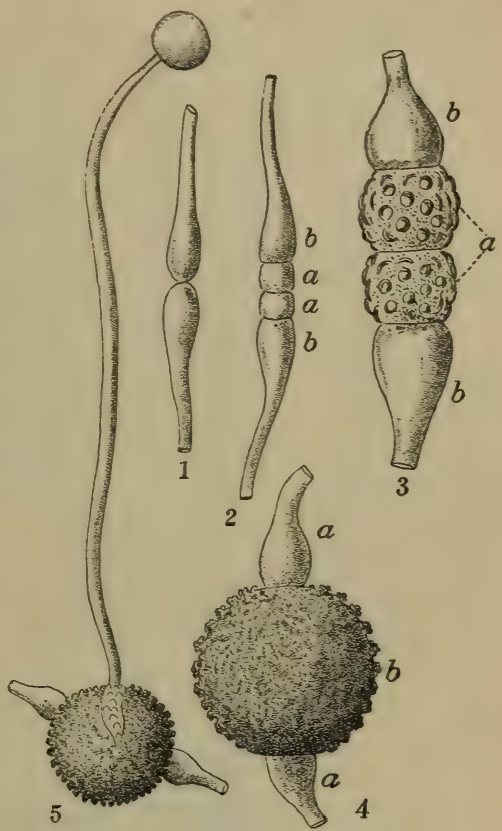

FIG. 190. - Formation of Zygospores in a Mould (Mucor Mucedo).

1, threads in contact previous to conjugation; 2, cutting off of the conjugating cells, $a$, from the threads, $b ; 3$, a later stage of the process ; 4 , ripe zygospore ; 5 , germination of a zygospore and formation of a spore-case. (1-4 magnified 225 diameters, 5 magnified about 60 diameters.) of spores, and when three occur one is known as the cluster-cup stage and the others as rerl rust and black rust, according to the usual approximate color of the spores. The rust called Puccinia graminis growing on wheat has its cluster-cup stage on the leaves of barberry in June. The spores from the cluster-cups are carried by the wind to the wheat, where they germinate and in a few days produce the 
red rust. A little later the black spores appear, produced from the same mycelium. This growth is chiefly upon the stems and sheaths.

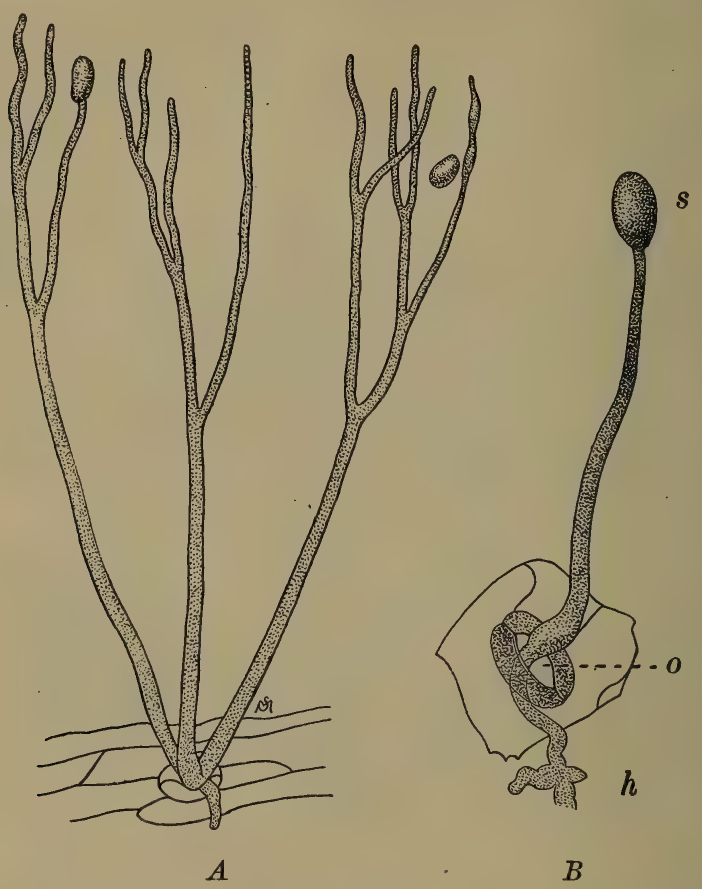

FIG. 191. - Spore-Formation in Potato-Blight (Phytophthora infestans).

$A$, a well-developed group of stalks, proceeding from a mass of mycelium inside the leaf and escaping through a stoma; $B$, a young, unbranched stalk. $h$, hyphæ of mycelium; o, stoma; $s$, spore. (Both figures greatly magnified, $B$ more than $A$.)

311. Cluster-Cup Stage. - Note with the naked eye and with a magnifying glass the appearance of the cluster-cups upon the barberry leaf. Fresh specimens should be used, if available. Note whether the leaf is changed in form or color in any part occupied by the fungus. Note the number of cups in a cluster, the position on the leaf (which surface?), the form and size, especially the height. 
Are they straight or curved? Describe the margin of the cup, the color without, and the color of the contents.

With a power of 200 diameters or more examine some of the cells composing the cup and note the form, color, and nature of the surface. Draw. With the point of a needle or knife pick out a bit of the contents of the cup and examine as above. Note the characters as before and compare in detail with the cells of the cup. The cells within the cup are the spores. Can you tell how they are attached?

A thin section through the cup will show the mode of attachment and the relation of the spores to the cup.

312. Examination of Red and Black Rust. - Under the magnifying glass examine the eruptions of spores (sori) on the wheat plant, some of red spores and some of black spores. The red spores are faded in dried specimens. Note the approximate size and shape and any other peculiarities. Prepare slides of each kind of spores and see if both can be found in one sorus. The spores may be taken from the host-plant on the point of a knife by picking rather deeply down into the sorus. Place the small quantity of spores so

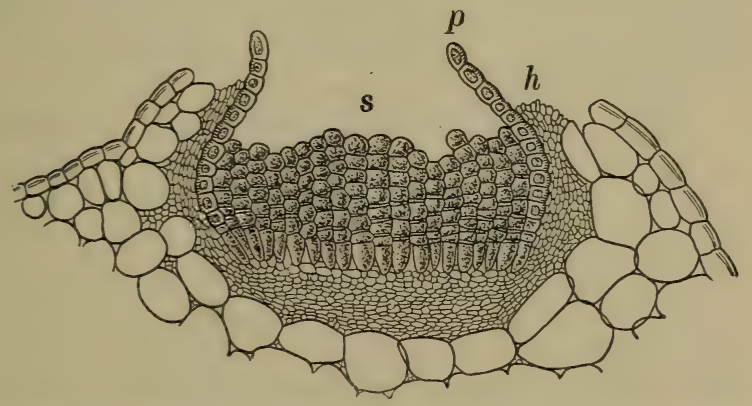

Fig. 192.-A Cluster-Cup of Anemone Rust (Puccinia fusca). (× 120.) $s$, chains of spores ; $p$, the covering or peridium of the cup; $h$, hyphæ.

obtained in a drop of water on a slide, spread with dissecting needles and cover. Examine under a power of 200 or more diameters.

The red spores (uredospores) have each a stalk from which they easily fall. They may be seen attached to their stalks if properly 
prepared cross-sections through the sorus are available, especially if the material is fresh. Examine the spores and note the shape, color, and surface. If the spores are shrunken, a drop of potash solution will restore the natural plumpness. Draw. Spore-measurements are important in determining species. The uredospores of Puccinia graminis may be distinguished from those of other species common

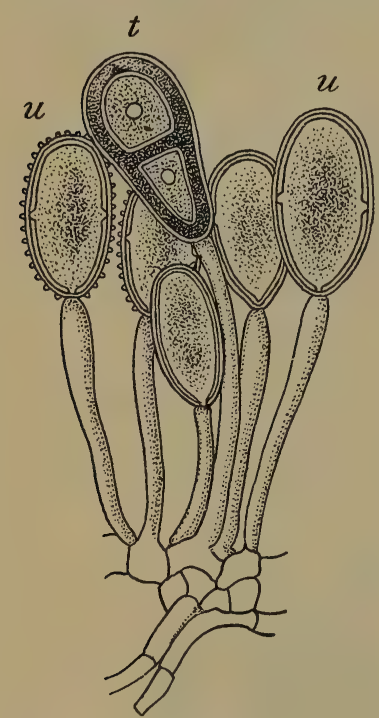

Fig. 193.-A Group of Spores of Wheat Rust (Puccinia graminis). ( $\times$ about 440 .) $u, u$, uredospores ; $t$, a teleutospore. on grasses by the greater proportionate length.

The structure of the black spores (teleutospores) can be made out without difficulty. Some should be found attached at the base. Note the parts and the differences in color in different portions. Make careful drawings to show shape and structure of both kinds of spores.

- Boil a portion of a rust-injured plant in potash solution, pick it to pieces on a slide under the magnifier or dissecting microscope, use a cover-glass and examine the preparation for mycelium, using a high power.

313. Cultivation on a Host-Plant. If practicable, find some wheat or grass which has remained over winter with the black rust upon it. Tie a bunch of this to a barberry bush while the leaves are young or unexpanded. When the time arrives for the appearance of the cluster-cups, note whether they are any more abundant on this bush than on others. Are you sure that the rust you have is the one to which the barberry cluster-cups belong? 


\section{THE STUDY OF MICROSPHERA}

314. Occurrence. - Species of Microsphara and allied forms occur in late summer and fall on leaves of various herbaceous and woody plants. The growth is confined to the surfaces of the leaf (upper, lower, or both). Among the most available species are those which grow upon lilac, oak, grape, cherry, willow, and wild plants of the sunflower family. Some species are known to occur on only one host-plant, others occur on several or a large number, and the host-plants may belong to one or more than one family.

Besides Microsphara there are about five other genera, any of which may be substituted or studied comparatively. They are distinguished by the form of the appendages, together with the number of spore-sacs (asci) in each sac-receptacle or perithecium.

The species of fungi which Microsphara represents are called powdery mildews.

With naked eye and magnifying glass examine the surface of a leaf bearing powdery mildew. Note which surface and what portion of the surface is occupied by the fungus, whether the occupied area is restricted or not, the color, and any other characters.

315. Examination with the Microscope. - Place a small drop of water on the leaf where the fungus occurs, if possible where darkcolored specks occur among the mycelium. Pick from the leaf a portion of the fungus loosened by the water and place with a drop of water on a slide. Place a cover-glass over it. Examine under a power of about fifty diameters. The dark-colored specks will be seen as somewhat spherical bodies (perithecia). Note their structure and color and their appendages. Have the perithecia any regular way of opening? Note the length of the appendages as compared with the diameter of the perithecia; also note the form of the tips and of the base, the color and any variation of color in different parts of the appendages. Keep the left hand on the focusing screw, and with the needle in the right hand press with gentle but varying stress upon the cover-glass to rupture the perithecia. Even with great care broken cover-glasses may result, but this pressure should force out the contents of the perithecia. Another method is to remove the slide from the microscope and, with a pencil rubber 
applied to the cover-glass, rupture the perithecia by gentle grinding between the cover and slide. Note the number and form of the spore-sacs (asci) expelled from each of several perithecia. Examine

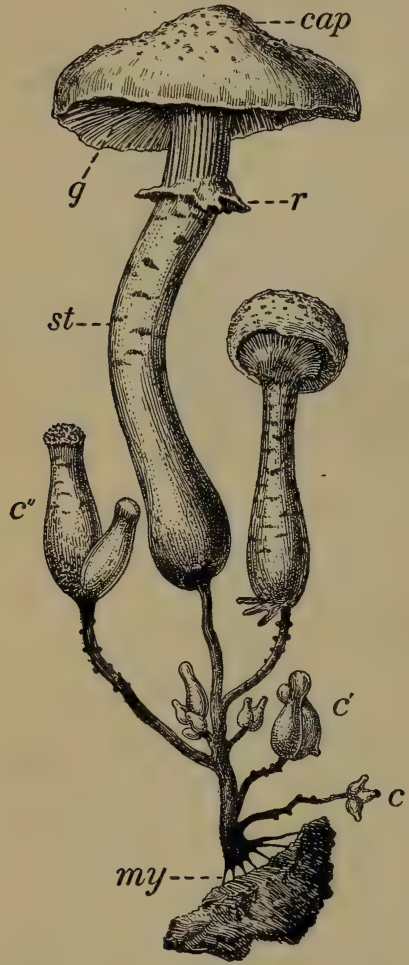

Frg. 194. - A Mushroom (Agaricus melleus).

$m y$, mycelium ; $c, c^{\prime}, c^{\prime \prime}$, young "buttons"; $s t$, stipe or stalk; $r$, ring; $g$, gills. under a power of about 200 diameters and count the number of spores in the asci. Gentle pressure may make them more distinctly visible. Make drawings to illustrate the structural characters observed.

\section{THE STUDY OF AGARICUS}

316. Occurrence. - The common mushroom, Agaricus campestris, grows in open fields and pastures in the United States and Europe. It is the mushroom most extensively cultivated for market, and if not found in the field it may be raised from "spawn" (mycelium), put up in the shape of bricks, and sold by seedsmen in the large cities. Those who make a specialty of selling it furnish directions for culture free. A moderately warm cellar or basement makes an excellent winter garden for mushrooms.

317. Structure of Mycelium. Examine some of the spawn, or mycelium, with the magnifying glass and the low power of the microscope, and with a power of 200 diameters or more examine the individual hyphæ which compose it. Are the hyphæ united in cord-like strands or otherwise, or are they entirely separate? Look for cross-partitions in the hyphæ. Is there any peculiar structure to be found at these places? Are the cross-partitions near together or widely separated? 
318. The Spore-Plant. - Search for indications of fruiting, and note the appearance of the "button mushrooms" in all available stages. Draw. See if at any stage up to maturity an outer envelope of tissue (volva) can be found enclosing the entire fruiting body. If such be present, what becomes of it at maturity? If material is available, compare the species of Amanita (poisonous) in regard to this.

Examine specimens in which the cap is expanding and see if there is another tissue forming a veil covering the under surface of the cap. If such be present, how is it attached and what becomes of it?

Take a fresh, wellexpanded mushroom or toadstool. Remove the stalk, or stipe, close under the cap, or pileus, and lay the latter, gills down, on a piece of paper. Let it remain undisturbed for a few hours, or over night, so that the spores may fall upon the paper. Note carefully their color, also
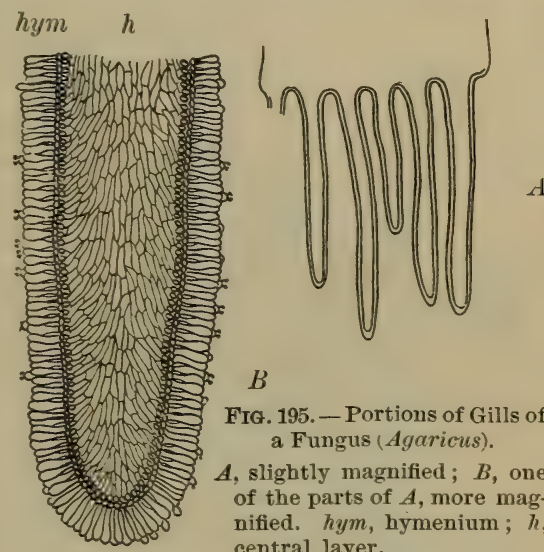
the form in which they $B$ FrG. 195. - Portions of Gills of a Fungus (Agaricus).

$A$, slightly magnified; $B$, one of the parts of $A$, more magnified. hym, hymenium ; $h$, eentral layer.

are arranged on the paper. What determines this form? Examine some of the spores under the highest available power of the microscope. Measure and draw.

Describe the stipe. Is it a hollow tube or solid? Does it taper? Note length, diameter, color.

Describe the cap, or pileus, in regard to diameter, thickness, nature and color of the upper surface, also color below.

Examine the plates, or gills, which compose the under portion of the pileus. Cut a complete pileus and stipe, through the center, and draw an outline to show the shape, noting particularly how the gills are attached. What is the color of the gills?

319. Origin of Spores. - Make a cross-section of one of the gills, and with a magnifying power of about 200 diameters examine the 
fruiting cells (basidia) which project at right angles to the gill and bear the spores. At how many points (sterigmata) on each basidium are spores attached? Draw a basidium, preferably one from which the spores have not yet fallen.

\section{THE STUDY OF YEAST (SACCHAROMYCES CEREVISI}

320. Growth of Yeast in Dilute Syrup. - Mix about an eighth of a cake of compressed yeast with about a teaspoonful of water and stir until a smooth, thin mixture is formed. Add this to about half

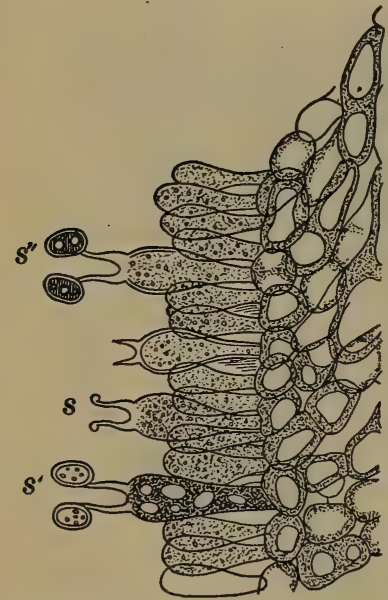

FrG. 196. - Part of the Preceding Figure. ( $\times$ about 300 .)

$C$, layer of cells immediately under the hymenium ; $s, s^{\prime}, s^{\prime \prime}$, three successive stages in growth of spores. a pint of water in which a tablespoonful of molasses has been dissolved. Place this mixture in a wide-mouthed bottle which holds one or one and a half pints, stopper very loosely ${ }^{1}$ and set aside for from twelve to twenty-four hours in a place in which the temper$C \quad$ ature will be from 70 to 90 degrees. Watch the liquid meantime and note :

(a) The rise of bubbles of gas in the liquid.

(b) The increasing muddiness of the liquid, a considerable sediment usually collecting at the end of the time mentioned.

(c) The effect of cooling off the contents of the bottle by immersing it in broken ice if convenient, or, if this is not practicable, by standing it for half an hour in a pail of the coldest water obtainable, or leaving it for an hour in a refrigerator, afterwards warming the liquid again.

(d) The effect of shutting out light from the contents of the bottle by covering it with a tight box or large tin can.

1 If the cork is crowded into the neck with any considerable force, pressure of gas and an explosion may result. 
(e) The result of filling a test-tube or a very small bottle with some of the syrup-and-yeast mixture, from which gas-bubbles are freely rising, and immersing the small bottle up to the top of the neck for fifteen minutes in boiling water. Allow this bottle to stand in a warm place for some hours after the exposure to hot water. What has happened to the yeast-plants?

$(f)$ The behavior of a lighted match lowered into the air space abore the liquid in the large bottle, after the latter has been standing undisturbed in a warm place for an hour or more.

(g) The smell of the liquid and its taste.

321. Microscopical Examination of the Sediment. ${ }^{1}$ - Using a very slender glass tube as a pipette, take up a drop or two of the liquid and the upper layer of the sediment and place on a glass slide, cover with a very thin cover-glass and examine with the highest power that the microscope affords.

Note :

(a) The general shape of the cells.

(b) Their granular contents.

(c) The clear spot, or vacuole, seen in many of the cells.

Sketch some of the groups and compare the sketches with Fig. 197.

Run in a little iodine solution under one edge of the cover-glass, at the same time touching a bit of blotting paper to the opposite edge, and notice the color of the stained cells. Do they contain starch?

Place some vigorously growing yeast on a slide under a coverglass and run in a little eosin solution or magenta solution. Note the proportion of cells which stain at first and the time required for others to stain. Repeat with yeast which has been placed in a slender test-tube and held for two or three minutes in a cup of boiling water.

With a very small cover-glass, not more than three-eighths of an inch in diameter, it may be found possible by laying a few bits of blotting paper or cardboard on the cover-glass and pressing it against the slide to burst some of the stained cells and thus show their thin, colorless cell-walls and their semi-fluid contents, protoplasm, nearly colorless in its natural condition but now stained by the iodine.

1 See Huxley and Martin's Biology, under Torula. 


\section{EXPERIMENT XXXIX}

Can Yeast grow in Pure Water or in Pure Syrup? - Put a bit of compressed yeast of about the size of a grain of wheat in about four fluid ounces of distilled water, and another bit of about the same size in four fluid ounces of 10 per cent solution of rock candy in distilled water; place both preparations in a warm place, allow to remain for twenty-four hours, and examine for evidence of the growth of the yeast added to each.

322. Size, Form, and Structure of the Yeast-Cell. - The student has discovered by his own observations with the microscope that the yeast-cell is a very minute object, — much smaller than most of the vegetable cells which he has hitherto examined. The average diam-

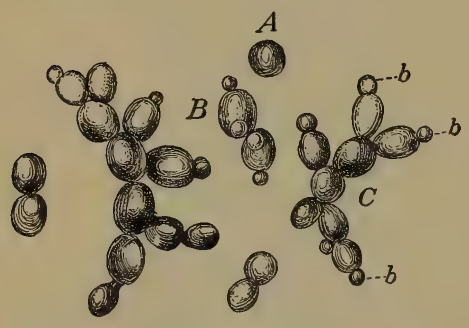

FIG. 197. - Yeast (Saccharomyces ellipsoideus) budding actively.

$A$, a single cell ; $B$, group of two budding cells ; $C$, a large group ; $b$, buds. eter of a yeast-cell is about $\frac{1}{3000}$ of an inch, but they vary greatly both ways from the average size. The general form of most of the cells of ordinary yeast is somewhat egg-shaped. The structure is extremely simple, consisting of a thin cell-wall, which is wholly destitute of markings, and a more or less granular semi-fluid protoplasm, sometimes containing a portion of clearer liquid, the vacuole, well shown in the larger cells of Fig. 197.1

323. Substances which compose the Yeast-Cell. - The cell-wall is composed mostly of cellulose; the protoplasm consists largely of water, together with considerable portions of a proteid substance, ${ }^{2}$

1 This is not the ordinary commercial yeast.

2 It may be found troublesome to apply tests to the yeast-cell on the slide, under the cover-glass. Testing a yeast cake is not of much value, unless it may be assumed that compressed yeast contains little foreign matter and consists mostly of yeast-cells. Still the test is worth making. Millon's reagent does not work well, but the red or maroon color which constitutes a good test for proteids is readily obtained by mixing a teaspoonful of granulated sugar with enough strong sulphuric acid to barely moisten the sugar throughout, and then, as quickly as possible, mixing a bit of yeast cake with the acid and 
some fat, and very minute portions of sulphur, phosphorus, potash, magnesia, and lime. It is destitute of chlorophyll, as would be inferred from its lack of green color, and contains no starch.

324. Food of the Yeast-Cell; Fermentation. - The diluted molasses in which the yeast was grown in Exp. XXXIX contained all the mineral substances mentioned in Sect. 323, together with sugar, proteid materials, and water. The addition of a little nitrate of ammonium would probably have aided the growth of the yeast in this experiment, by supplying more abundantly the elements out of which the yeast constructs its proteid cell-contents. A great deal of sugar disappears during the growth of the yeast. ${ }^{1}$ Most of the sugar destroyed is changed into carbon dioxide (which the student saw rising through the liquid in bubbles) and alcohol, which can be separated from the liquid by simple means. The process of breaking up weak syrup into carbon dioxide and alcohol by aid of yeast is one kind of fermentation; it is of great practical importance in bread-making and in the manufacture of alcohol. Since grape juice, sweet cider, molasses and water, and similar liquids, when merely exposed to the air soon begin to ferment and are then found to contain growing yeast, it is concluded that dried yeast-cells, in the form of dust, must be everywhere present in ordinary air.

325. Yeast a Plant; a Saprophyte. - The yeast-cell is known to be a plant, and not an animal, from the fact of its producing a coating of cellulose around its protoplasmic contents and from the fact that it can produce proteids out of substances from which animals could not produce them. ${ }^{2}$

On the other hand, yeast cannot live wholly on carbon dioxide, nitrates, water, and other mineral substances, as ordinary green plants can. It gives off no oxygen, but only carbonic acid gas, and is therefore to be classed with the saprophytes, like the Indian pipe, among flowering plants (Sect. 180).

sugar. A comparative experiment may be made at the same time with some other familiar proteid substance, e.g., wheat-germ meal.

1 The sugar contained in molasses is partly cane sugar and partly grape sugar. Only the latter is detected by the addition of Fehling's solution. Both kinds are destroyed during the process of fermentation.

2 For example, tartrate of ammonia. 
326. Multiplication of Yeast. - It is worth while to notice the fact that yeast is one of the few cryptogams which have for ages been largely cultivated for economic purposes. Very recently yeast producing has become a definite art, and the cakes of compressed yeast so commonly sold afford only one instance of the success that has been attained in this process. While yeast-cells are under favorable conditions for growth, they multiply with very great rapidity. Little protrusions are formed at some portion of the cell-wall, as the thumb of a mitten might be formed by a gradual outgrowth from the main portion. Soon a partition of cellulose is constructed, which shuts off the newly formed outgrowth, making it into a separate cell, and this in turn may give rise to others, while meantime the original cell may have thrown out other offshoots. The whole process is called reproduction by budding. It is often possible to trace at a glance the history of a group of cells, the oldest and largest cell being somewhere near the middle of the group and the youngest and smallest members being situated around the outside. Less frequently the mode of reproduction is by means of spores, new cells (usually four in number), formed inside one of the older cells (ascus). At length the old cell-wall bursts, and the spores are set free, to begin an independent existence of their own.

In examining the yeast-cell the student has been making the acquaintance of plant life reduced almost to its lowest terms. The very simplest plants consist, like the slime moulds, of a speck of jelly-like protoplasm. Yeast is more complex, from the fact that its protoplasm is surrounded by an envelope of cellulose, the cell-wall.

\section{THE STUDY OF PHYSCIA}

327. Occurrence. - Physcia is one of the commonest lichens. It grows attached to the bark of various trees.

328. The Thallus. - Physcia consists chiefly of an irregularly expanded growth somewhat leaf-like in texture. It is best to be wet for study. Is it separable from the bark to which it is attached or is it combined with it (incrusted)? Describe the general outline of the margin, the general color, and any special variations of color above, also below. How is the thallus attached to the bark? 
329. The Fruit. - Look for small lance-shaped disks seated upon the thallus. Note the approximate sizes and color within and without. These disks are called apothecia. Note the very minute black specks (spermogones) which are scattered in the surface of the thallus. Pick one from the thallus, with as little of the thallus as possible, and examine under high power. It may be macerated in a drop of potash solution and crushed under the cover-glass. If the contents are not easily defined, they may then be made more opaque by a drop of acetic acid or a stain. The minute colorless bodies contained in the spermogones are

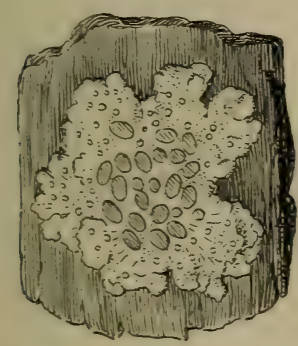

FIG. 198. - A Lichen (Xanthoria). (Natural size.)

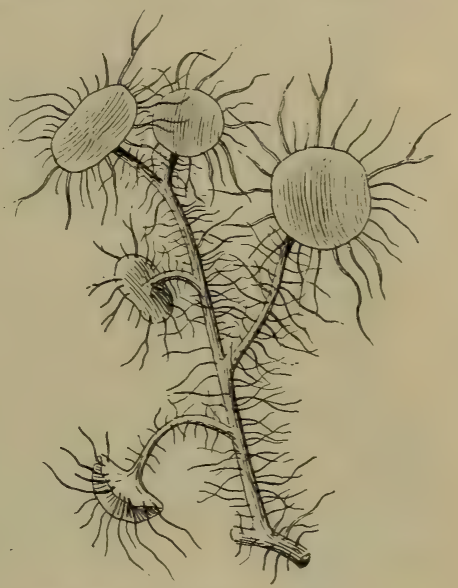

Frg. 199. - A Lichen (Usnea).

(Natural size.)

called spermatia. Their office in Physcia is obscure, but in a few lichens they are thought to unite with a trichogyue cell, as in the red algæ. ${ }^{1}$ Note the minute, powdery masses (soredia) on the surface of the thallus. Macerate if necessary under the cover-glass and examine under a high power. Compare with the structure of the thallus as seen in cross-section. (See next paragraph.) These soredia easily become detached and derelop into new plants.

Prepare for sectioning by imbedding a small portion of the thallus with an apothecium in a piece of pith or by any suitable device for sectioning, and cut thin sections of thallus and fruit.

1 This, however, is doubtful. See Strasburger, Noll, Schenk, and Schimper's Text-Book of Botany, p. 380 . 
330. Examination of the Thallus. - The thallus of Physcia as seen in cross-section will be found to consist of four layers, the upper cortical, gonidial, medullary, and the lower cortical. The cortical layers will be seen to serve for protection, answering the purpose of an epidermis or bark. The cells which compose them make what is called a false parenchyma, - resembling parenchyma in form but

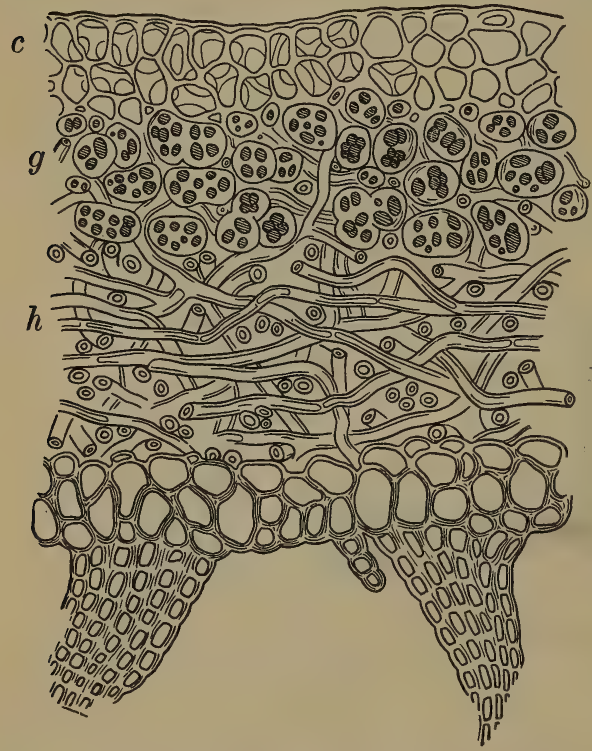

Frg. 200.- Transverse Section through Thallus of a Lichen (Sticta fuliginosa). ( $\times 500$.)

$c$, cortical or epidermal layer; $g$, gonidia ; $h$, hyphæ. as to origin being transformed fungal hyphæ. Note the form of the hyphæ composing the medullary layer. Are there any cross-partitions? Do any cells appear circular, and if so, what is the explanation? The upper portion of the cortical layer, having green cells intermixed, constitutes the gonidial layer. Why should the green cells be at the upper part of the medullary layer? Can you detect any connection between the green cells and the hyphæ? Do these green cells resemble any cells previously studied?

Make a diagram to show the structure of the thallus.

What arrangement of layers would you expect to find in a lichen thallus, upright or suspended? Compare the arrangement in the fruit-body (apothecium), describe, and sketch. How does the layer of cells beneath the spore-sacs resemble the cortical layer? All but these two layers may be considered as part of the thallus. To make out the details of the fruit, the section must be very thin. 
Examine the spore-sacs (asci) and look for spores in different stages of formation. How many spores are found in each ascus? What other bodies occur among the asci? Draw these, also asci and spores.

331. Lichens. - Lichens were formerly supposed to be a distinct class of plants, and it is only about thirty years since their real nature began to be understood. A lichen is now known to be a combination of two plants. The green cells, called the gonidia, belong to some species of alga, and the remainder, the larger portion of the growth, is a fungus parasitic upon that alga. The groups of lichens correspond in structure to certain groups of fungi, but the genera are sufficiently distinct so that lichens are best considered by themselves for purposes of study and classification.

The relation of the fungus and its algal host is not that of destructive parasitism, but rather a mutual relation (symbiosis) in which both fungus and alga may have a vigorous growth. The relationship has been investigated in various ways, and it has been found that, while the alga may grow independent of the fungus, the germinating fungus spores can grow only to a limited extent if deprived of the algal host; but if supplied naturally or artificially with the proper alga they make a normal growth.

The same alga may serve as gonidia to a number of lichens, often of very different form, and while the number of lichens reaches into the thousands, the number of algæ known to serve as gonidia is quite small.

Lichens are widely distributed in all zones but flourish particularly in northern regions where other vegetation is scanty. Some were formerly important as sources of 
dyes. "Iceland moss" is a lichen used for food, and a finely branching form, growing in extensive mats on the soil, serves as food for the reindeer and is known as " reindeer moss."

Most lichens grow on the bark of trees, on rocks, or soil where they have little moisture except during rainfall, but some grow where they are constantly wet. Some of the latter are gelatinous. Most of the conspicuous lichens are foliaceous or else have a thallus composed of branching, cylindrical, thread-like portions. But many species, often less conspicuous, are crustaceous, growing as if they formed part of the bark or rock to which they are attached.

332. Fungi. - The yeasts, moulds, rusts, mildews, and mushrooms represent an immense group of plants of which about forty-five thousand species are now known in the world. They range from the very simple to quite complex forms, growing as saprophytes or parasites under a great variety of conditions. Their structure and life history are so varied as to constitute a long series of divisions and subdivisions. ${ }^{1}$ Chlorophyll is absent from fungi, and they are destitute of starch, but produce a kind of cellulose which appears to differ chemically from that of other plants. Unable to build up their tissues from carbonic acid gas, water, and other mineral matters, they are to be classed, with animals, as consumers rather than as producers, acting on the whole to diminish rather than to increase the total amount of organic material on the earth.

1 See Strasburger, Noll, Schenk, and Schimper's Text-Book of Botany, pp. 340-381 incl., also Potter and Warming's Systematic Botany, p. 1, and Engler's Syllabus der Pflanzenfamilien, Berlin, 1898, pp. 25-47. 
333. Occurrence and Mode of Life of Fungi. - Among the most important cryptogamous plants are those which, like the bacteria of consumption, of diphtheria, of typhoid fever, or of cholera, produce disease in man or in the lower animals. The subclass which includes these plants is known by the name Bacteria. Bacteria are now classed by some as a separate group, lower than fungi. Some of the most notable characteristics of these plants are their extreme minuteness and their extraordinary power of multiplication. Many bacteria are on the whole highly useful to man, as is the case with those which produce decay in the tissues of dead plants or animals, since these substances would, if it were not for the destructive action of the bacteria of putrefaction and fermentation, remain indefinitely after death to cumber the earth and lock up proteid and other food needed by new organisms.

The mushrooms and their allies include about one-fourth of the fungi. Some, such as the "dry-rot" fungus, mistakenly so called, cause great destruction to living and dead tree trunks and timber in economic use. The common mushroom, Agaricus campestris, is the most important edible species. Probably five hundred kinds can be eaten, but only a few are good food, and even these contain but little nutriment. Some species are dangerous, and a few are deadly poisons. The puffballs are a small group allied to the mushrooms. Most of them are edible and of good quality.

The mildews (Microsphora, etc.) and the "black-knot" of the plum trees are of a group which likewise includes about one-fourth of the fungi. A considerable number are parasites, injurious to vegetation, while thousands of others grow on dead leaves, twigs, etc. 
The "rust" of wheat and the "smut" of corn represent groups numbering only a few hundreds of species, which are very important because they are all parasites on living plants, many on our most important economic plants.

Fig. 191, representing another small group of destructive parasites, shows clearly how a parasitic fungus grows from a spore which has found lodgment in the tissues of a leaf and pushes out stalks through the stomata to distribute its spores. 


\section{CHAPTER XXI}

\section{TYPES OF CRYPTOGAMS ; BRYOPHYTES}

334. The Group Bryophytes. - Under this head are classed the liverworts and the mosses. Both of these classes consist of plants a good deal more highly organized than the thallophytes. Bryophytes have no true roots, but they have organs which perform the work of roots. Some of them have leaves (Fig. 206), while others have none (Fig. 201 ). Fibro-vascular bundles are wanting. The physiological division of labor is carried pretty far among all the bryophytes. They have special apparatus for absorbing water and sometimes for conducting it

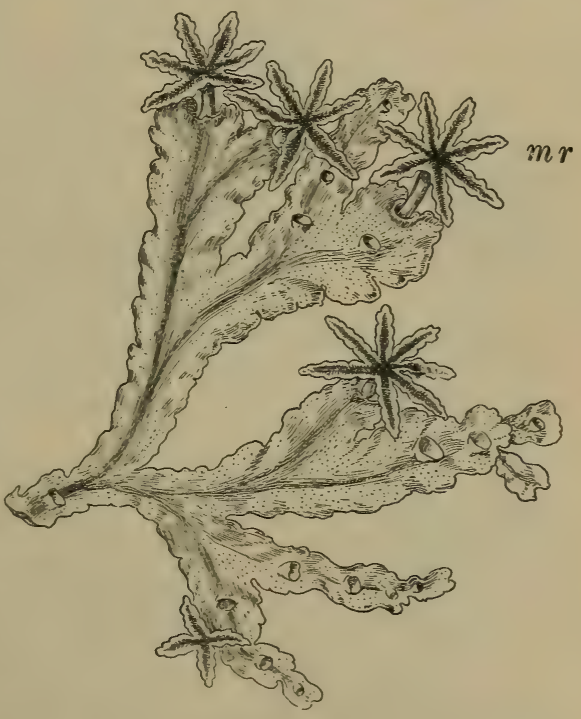

FIG. 201. - Part of Male Thallus of a Liverwort (Marchantia disjuncta). (Enlarged.)

$m r$, male receptacle. through the stem; stomata are often present and sometimes highly developed. There are chlorophyll bodies, often arranged in cells extremely well situated for acting 
on the carbon dioxide gas which the plant absorbs, that is, arranged about rather large air chambers.

Reproduction is of two kinds, sexual and asexual, and the organs by which it is carried on are complicated and highly organized. An alternation of generations occurs, that is, the life history of any species embraces two forms: a sexual generation, which produces two kinds of cells that

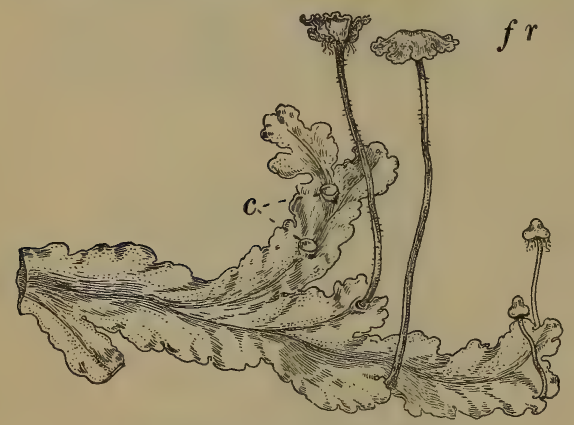

FIG. 202. - Part of Female Thallus of

M. disjuncta. (Enlarged.)

$f r$, female receptacle; $c$, cups with gemmæ.

by their union give rise to a new plant; the asexual generation, which multiplies freely by means of special cells known as spores.

\section{THE STUDY OF}

\section{MARCHANTIA}

335. Occurrence. Marchantia grows on soil or rocks in damp shaded places and is widely distributed.

336. The Thallus. - In general form the thallus bears some resemblance to that of some of the lichens, as Parmelia, but is plainly different in color, mode of branching, and internal structure under the microscope. Under the microscope (see below) the individual cells may be compared with those of the medullary layer in Physcia.

Note the color and general shape of the thallus and study carefully the mode of branching. The origin of the growing cells is at the tip, but cells so originating afterward multiply more rapidly, so that the tip comes to be in a notch.

Viewing the thallus as an opaque object, note the diamond-shaped network on the upper surface and the dot-like circle in the middle of each diamond.

Examine the under surface for (1) rhizoids and (2) scales. 
337. Internal Structure. - Cut thin cross-sections of the thallus in the same way as for Physcia, making some pass through the cir-

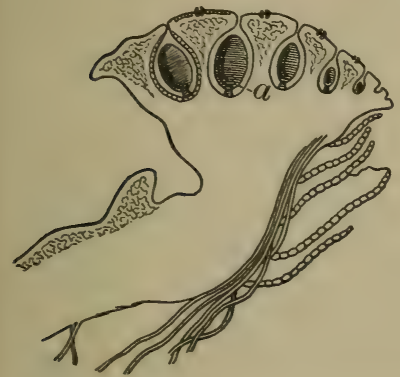

FTG. 203. - Section through Antheridial Receptacle of Marchantia. (Magnified.)

$$
a \text {, antheridium. }
$$
cular dots mentioned above. Examine under a high power and note the different kinds and layers of cells composing the thallus. Note the character of the cells forming the upper and lower surfaces. Describe the cells which are next above those of the lower epidermis, their shape, color of contents, approximate number of horizontal rows. Have they any evident intercellular spaces? Find cells connecting these with the upper epidermis and constituting the network of lines seen on the surface of the thallus. Note the air cavity bounded by these lines and the loose cells which occupy it in part. What is the color of their contents? How are they attached, and how arranged? Can you discover any opening through the epidermis? If so, describe it.

Make drawings to illustrate the details of structure observed.

338. Gemmæ. - Look for a thallus bearing little green cups formed of its own substance. Describe the contents of the cup. The bodies are called gemma. They originate by vegetative growth alone and when detached may grow into new plants.

339. Fruiting Organs, - Look for thalli bearing stalks with umbrella-like expansions. The umbrellas are of two kinds, one disk-like with crenate points (how

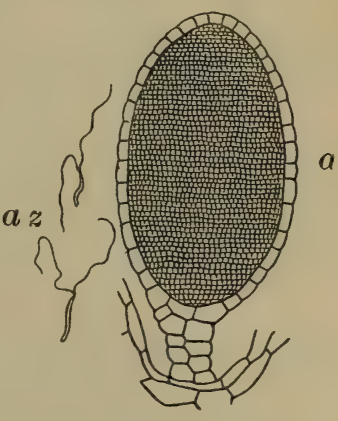

FIG. 204.-Sectional View of an Antheridium of Marchantia.

$a$, antheridium ; $a z$, antherozoids, $\times 700$. many?) and the other has rays (how many?) elongated and curving downward. Is there any difference in the height of the two kinds? 
Do both occur on the same thallus? On what part of the thallus do they occur, and do they differ in this respect?

340. Antheridia. - The antheridia are formed as outgrowths from the upper surface of the crenate receptacle, but by further growth of the receptacle they become imbedded. They should be examined under a high power and sketched in outline. The antheridium produces numerous motile antherozoids, each with two cilia.

341. Archegonia and Sporophytes. - The receptacle with recurved rays bears the archegonia. Note whether they occur above or below and in what relation to the rays. How are the archegonia protected?

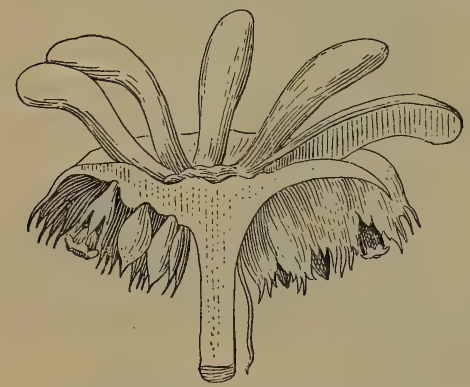

FIG. 205. - Sectional View of Female Receptacle of Marchantia. ( $\times 5$.)

Note the cells which surround the central canal and form the elongated neck of the archegonium. Does the archegonium open upward or downward? At the base look for the germ-cell.

The antherozoids enter the central canal and penetrating to the egg-cell fertilize it, after which it begins to divide and grows into a sporophyte. In the older specimens, therefore, the sporophytes will be found more or less developed. The archegonium remains upon the tip of the sporophytes. The mature sporophyte contains the spores and also peculiar elongated tapering threads with spiral thickenings. These are called elaters.

342. Hepaticæ. - Marchantia represents only a small division of the Hepaticce, and is not typical of the larger number of species. In spite of this it is chosen for study, because it is widely distributed and more available for study than most others. In most species the fruit lasts but a little while and good material is hard to obtain. In Marchantia the fruiting organs are abundant, more gradual in their development, and more persistent. Marchantia and 
its allies consist chiefly of the thallus in the regetative condition, while the greater number of Hepatice have a stem and leaves. Thus they approach closely to the mosses. But mosses usually have leaves on all sides of the stem, while the leaves of Hepaticæ are two-ranked, spreading laterally, with sometimes a third row of leaves or scales underneath. The leaves of mosses usually have more than one layer of cells in some part, but the leaves of the leafy Hepaticæ have but one layer of cells throughout. The forms of the leaves are often very curious and interesting. The sporophyte of most mosses consists of a capsule with a lid, while in the leafy Hepaticæ the capsule usually opens by splitting longitudinally into two to four valves.

Different species of Hepaticæ grow on damp soil, rocks, and the bark of trees. Many are capable of enduring drought and reviving with moisture.

\section{THE STUDY OF PIGEON-WHEAT MOSS}

\section{(POLYTRICHUM COMMUNE)}

343. Occurrence. - This moss is widely distributed orer the surface of the earth, and some of its relatives are among the best known mosses of the northern Lnited States. Here it grows commonly in dry pastures or on hillsides, not usually in densely shaded situations.

344. Form, Size, and General Characters. - Study sereral specimens which have been pulled up with root-hairs. Note the size, general form, color, and texture of all the parts of the plants examined. Some of them probably bear spore-capsules or sporophytes like those shown in Fig. 206, while others are without them. Sketch one plant of each kind, about natural size.

What difference is noticeable between the appearance of the leaves in those plants which hare spore-capsules and those which have none? Why is this? 
In some specimens the stem may be found, at a height of an inch or more above the roots, to bear a conical, basket-shaped enlargement,

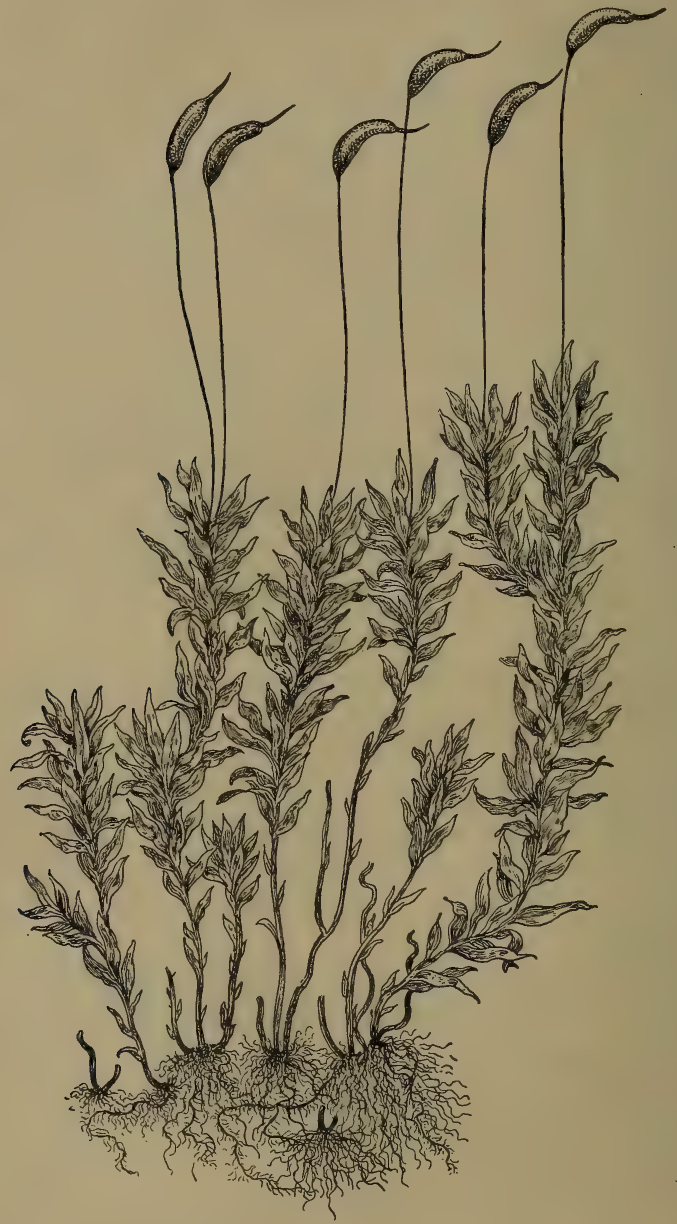

FIG. 206. - A Moss, Catharinea.

The sporophytes of this moss are usually rather more slender than as here represented. 
out of the center of which a younger portion of the stem seems to proceed; and this younger portion may in turn end in a similar enlargement, from which a still younger part proceeds.

Note the difference in general appearance between the leaves of those plants which have just been removed from the moist collectingbox and those which hare been lying for half an hour on the table. Study the leaves in both cases with the magnifying glass in order to find out what has happened to them. Of what use to the plant is this change? Put seme of the partially dried leaves in water, in a

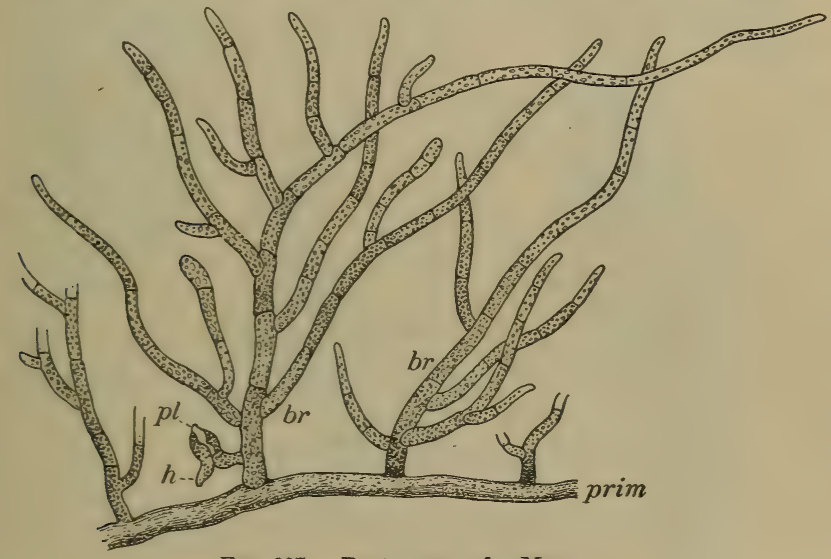

FIG. 207. - Protonema of a Moss.

prim, primary shoot ; $h$, a young root-hair ; $p l$, young moss-plant ;

$b r$, branches of primary shoot.

cell on a microscope slide, corer, place under the lowest power of the microscope, and examine at intervals of ten or fifteen minutes. Finally sketch a single leaf.

345. Minute Structure of the Leaf and Stem. - The cellular structure of the pigeon-wheat moss is not nearly as simple and convenient for microscopical study as is that of the smaller mosses, many of which have leaves composed, over a large part of their surfaces, of but a single layer of cells, as shown in Fig. 209. If any detailed study of the structure of a moss is to be made, it will, therefore, be better for the student to provide himself with specimens of almost 
any of the smaller genera, ${ }^{1}$ and work out what he can in regard to their minute anatomy.

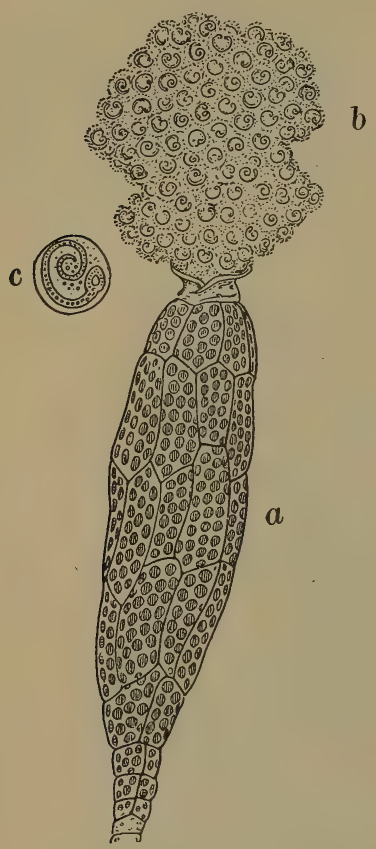

FIG. 208. - The Antheridium of a Moss (Funaria) and its Contents.

$a$, antheridium ; $b$, escaping antherozoids, $\times 350$; $c$, a single antherozoid of another moss, $\times 800$.

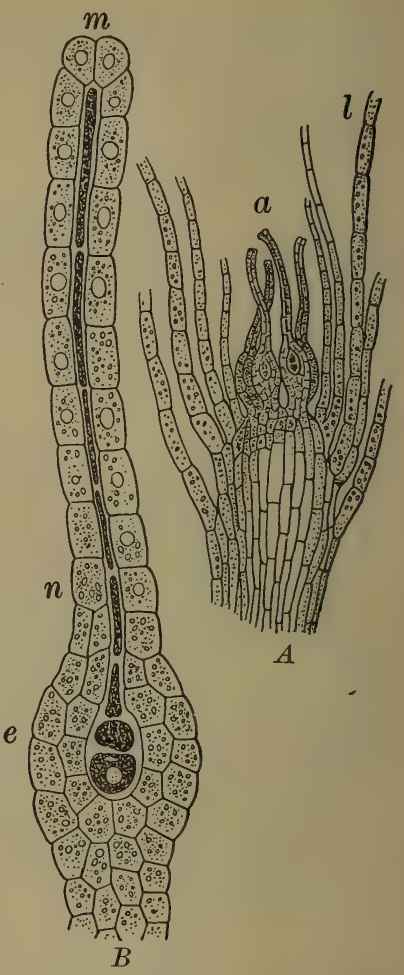

FIG. 209. - Portions of Fertile Plant of a Moss (Funaria).

$A$, longitudinal section of summit of plant, $\times 100 ; a$, archegonia ; $l$, leaves ; $B$, an archegonium, $\times 550$; $e$, enlarged ventral portion with central cell; $n$, neck; $m$, mouth.

346. Sporophytes. - That part of the reproductive apparatus of a common moss which is most apparent at a glance is the sporophyte or spore-capsule (Fig. 206). This is covered, until it reaches maturity, with a hood which is easily detached. Remove the hood from one 
of the capsules, examine with a magnifying glass, and sketch it. Note the character of the material of which its outer layer is composed.

Sketch the uncovered capsule as seen through the magnifying glass, noting the little knob at its base and the circular lid.

Pry off this lid, remove some of the mass of spores from the interior of the capsule, observe their color as seen in bulk through the magnifying glass, then mount in water, examine with the highest obtainable power of the microscope, and sketch them. These spores, if sown on moist earth, will each develop into a slender, branched organism, consisting, like pond-scum, of single rows of cells (Fig. 207) called the protonema.

347. Other Reproductive Apparatus. - The student cannot, without spending a good deal of time and making himself expert in the examination of mosses, trace out for himself the whole story of the reproduction of any moss. It is sufficient here to give an outline of the process. The protonema develops buds, one of which is shown in Fig. 207, and the bud grows into an ordinary moss plant. This plant, in the case of the pigeon-wheat moss, bears organs of a somewhat flower-like nature, which contain either antheridia (Fig. 208), organs which produce fertilizing cells called antherozoirs, or archegonia (Fig. 209), organs which produce egg-cells, but in this moss antheridia and archegonia are not produced in the same "mossflower." The plants therefore correspond to diøecious ones among flowering plants.

After the fertilization of the egg-cell, by the penetration of antherozoids to the bottom of the flask-shaped archegonium, the development of the egg-cell into sporophyte begins; the latter rises as a slender stalk, while the upper part of the archegonium is carried with it and persists for a time as the hood or calyptra. 


\section{CHAPTER XXII}

\section{TYPES OF CRYPTOGAMS; PTERIDOPHYTES}

348. The Group Pteridophytes. - Under this head are classed the ferns, the scouring-rushes, and the club-mosses. They are the most highly organized of cryptogams, having true roots, and often well-developed stems and leaves.

\section{THE STUDY OF A FERN 1}

349. Conditions of Growth. - If the specimens studied were collected by the class, the collectors should report exactly in regard to the soil and exposure in which the plants were found growing. Do any ferns occur in surroundings decidedly different from these? What kind of treatment do ferns need in house culture?

350. The Underground Portion. - Dig up the entire underground portion of a plant of ladyfern. Note the color, size, shape, and appendages of the rootstock. If any. are at hand which were collected in their late winter or early spring condition, examine into the way in which the leafy parts of the coming season originate from the rootstock, and note their peculiar shape (Fig. 210, A). This kind of vernation (Sect. 136) is decidedly characteristic of ferns. Observe the number and distribution of the roots along the rootstock. Bring out all these points in a sketch.

1 The outline here given applies exactly only to Asplenium filix-fomina. Any species of Asplenium or of Aspidium is just as well arapted for study. Cystopteris is excellent, but the indusium is hard to find. Polypodium vulgare is a simple and generally accessible form, but has no indusium. Pteris aquilina is of world-wide distribution, but differs in habit from most of our ferns. The teacher who wishes to go into detail in regard to the gross anatomy or the histology of ferns as exemplified in Pteris will find a careful study of it in Huxley and Martin's Biology, or a fully illustrated account in Sedgwick and Wilson's Biology. 
351. The Frond. - Fern leaves are technically known as fronds. Observe how these arise directly from the rootstock.

Make a somewhat reduced drawing of the entire frond, which consists of a slender axis, the rhachis, along which are distributed many leaflets or pinnce, each composed of many pinnules. Draw the under side of one of the pinnæ, from near the middle of the frond, enlarged to two or three times its natural size, as seen through the magnifying glass. Note just how each pinnule is attached to its secondary rhachis.

Examine the under side of one of the pinnules (viewed as an opaque object without cover-glass) with the lowest power of the microscope, and note:

(a) The "fruit-dots" or sori (Fig. 210, B) (already seen with the magnifying glass, but now much more clearly shown).

(b) The membranous covering or indusium of each sorus (Fig. $210, C)$. Observe how this is attached to the veins of the pinnule. In such ferns as the common brake (Pteris) and the maidenhair (Adiantum) there is no separate indusium, but the sporangia are covered by the incurved edges of the fronds.

(c) The coiled spore-cases or sporangia, lying partly covered by the indusium. How do these sporangia discharge their spores?

Make a drawing, or several drawings; to bring out all these points.

Examine some of the sporangia, dry, with a power of about fifty or seventy-five diameters, and sketch. Scrape off a few sporangia, thus disengaging some spores, mount the latter in water, examine with a power of about 200 diameters, and draw.

352. Life History of the Fern. - When a fern-spore is sown on damp earth it gradually develops into a minute, flattish object, called a prothallium (Fig. 211). It is a rather tedious process to grow prothallia from spores, and the easiest way to get them for study is to look for them on the earth or on the damp outer surface of the flower-pots in which ferns are growing in a greenhouse. All stages of germination may readily be found in such localities.

Any prothallia thus obtained for study may be freed from particles of earth by being washed, while held in very small forceps, in a gentle stream of water from a wash-bottle. The student should then mount the prothallium, bottom up, in water in a shallow cell, 

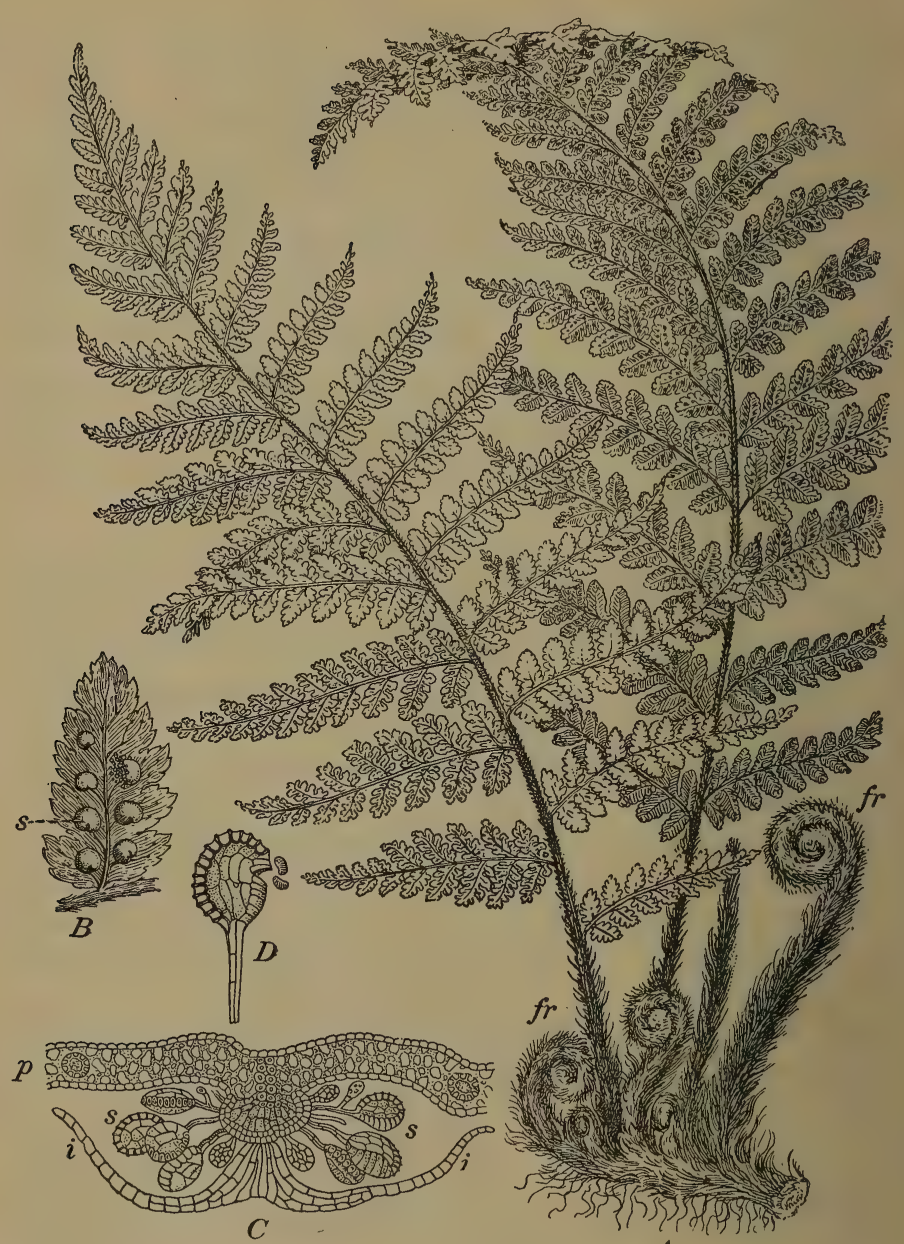
cover with a large cover-glass, and examine with the lowest power of the microscope. Note:

(a) The abundant root-hairs, springing from the lower surface of the prothallium.

(b) The variable thickness of the prothallium, near the edge, consisting of only one layer of cells.

(c) (In some mature specimens) the young fern growing from the prothallium, as shown in Fig. 211, $B$.

The student can hardly make out for himself, without much expenditure of time, the structure of the antheridia and the archegonia (Fig. 211, A), by the coöperation of which fertilization takes place on much the same plan as that already described in the case of mosses. The fertilized eggcell of the archegonium gives rise to the young fern, the sporophyte which grows at first at the expense of the parent prothallium but soon develops roots of its own and leads an independent existence.

353. Nutrition. The mature fern

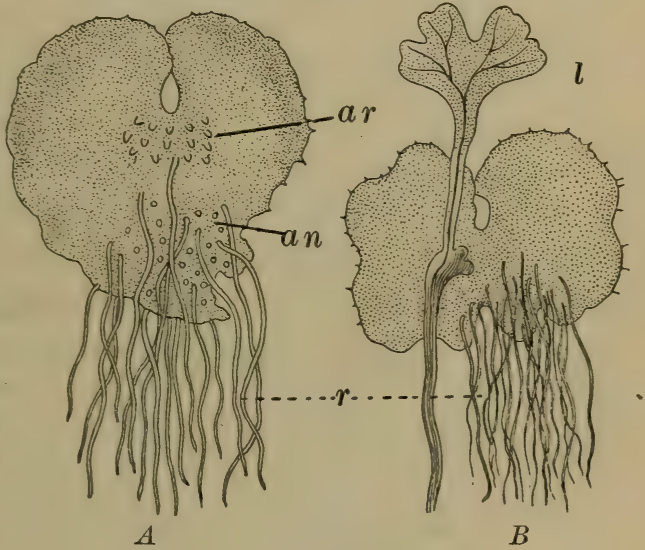

FIG. 211. - Two Prothallia of a Fern (Aspidium).

$A$, under surface of a young prothallium ; $a r$, archegonia ; $a n$, antheridia ; $r$, rhizoids ; $B$, an older prothallium with a young fern-plant growing from it; $l$, leaf of young fern. (Both $\times$ about 8 .)

makes its living, as flowering plants do, by absorption of nutritive matter from the soil and from the air, and its abundant chlorophyll makes it easy for the plant to decompose the supplies of carbon dioxide which it takes in through its stomata. 


\section{FERNS}

354. Structure, Form, and Habits of Ferns.-The structure of ferns is much more complex than that of any of the groups of cryptogamous plants discussed in the earlier portions of the present chapter. They are possessed of well-defined fibro-vascular bundles, they form a variety of parenchymatous cells, the leaves have a distinct epidermis - and are provided with stomata.

Great differences in size, form, and habit of growth are found among the various genera of ferns. The tree ferns of South America and of many of the islands of the Pacific Ocean sometimes rise to a height of forty feet, while the most minute species of temperate and colder climates are not as large as the largest mosses. Some species climb freely, but most kinds are non-climbing plants of moderate size, with well-developed rootstocks, which are often, as in the - case of the bracken-fern, or brake, ${ }^{1}$ and in Osmunda, very large in proportion to the parts of the plant visible above ground.

355. Economic Value of Ferns. - Ferns of living species have little economic value, but are of great interest, even to non-botanical people, from the beauty of their foliage.

During that vast portion of early time known to geologists as the Carboniferous Age, the earth's surface in many parts must have been clothed with a growth of ferns more dense than is now anywhere found. These ferns, with other flowerless herbs and tree-like plants, produced the vegetable matter out of which all the principal coal beds of the earth have been formed.

1 Pteris aquilina. 
356. Reproduction in Ferns. - The reproduction of ferns is a more interesting illustration of alternation of generations than is afforded by mosses. The sexual plant, gametophyte, is the minute prothallium, and the nonsexual plant, sporophyte, which we commonly call the fern, is merely an outgrowth from the fertilized egg-cell, and physiologically no more important than the sporophyte of a moss, except that it supplies its own food instead of living parasitically. Like this sporophyte, the fern is an organism for the production of vegetative spores, from which new plants endowed with reproductive apparatus may grow.

\section{THE STUDY OF A CLUB-MOSS (LYCOPODIUM)}

357. Occurrence. - Sereral species of Lycopodium are common in rich woods in the northern and mountainous portions of the eastern Inited States. Any species may be studied.

358. Examination. - Note whether the plant is chiefly erect or prostrate and vine-like. Describe the mode of branching. Are the leaves arranged flat-wise or equally on all sides of the stem? Describe the leaves briefly. Are they all of one kind or do some portions of the plant evidently have smaller leaves?

Select fruiting specimens and determine the position of the sporangia. Is the leaf, near whose base each sporangium is situated, like the ordinary foliage leaves of the plant? Are the fruiting portions of the plant similar in general aspect or different from the rest of the plant and raised above it on stalks? Examine the spores. Are they all of one kind?

If Selaginella is used in place of Lycopodium or for comparison, two kinds of sporangia are to be sought, differing chiefly in shape. Describe each briefly. Compare the number of spores in each. The larger spores (macrospores) germinate and at length produce prothallia bearing archegonia, while the smaller produce prothallia bearing antheridia. The archegonia, after fertilization, develop each 
an embryo. This grows, remaining for a time attached to the macrospore, and at length forms a new spore-plant.

\section{THE STUDY OF A SCOURING-RUSH (EQUISETUM)}

359. Occurrence. - The common horse-tail, Equisetum arvense, is widely distributed in the United States, east, west, north, and south. It is very often found on sand hills and along railroad embankments.

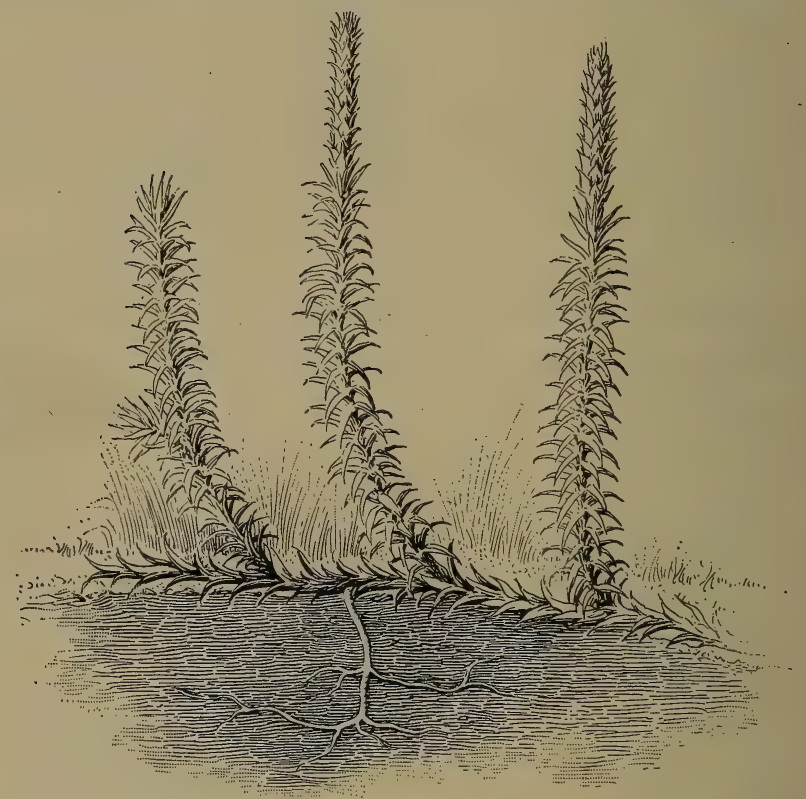

FIG. 212. - Plant of Lycopodium (L. annotinum).

The fruiting stems appear very early in the spring and are of short duration. The sterile vegetative growth follows, becoming well grown in June.

360. Examination of Rootstocks and Roots. - Examine the underground portions of the plant with reference to general size, position, color, shape, and position of notches. After studying the stems 
above ground insert here any evident points of comparison. Do you find any special forms of stem development suited to a special purpose? Are there any organs in the nature of leaves?

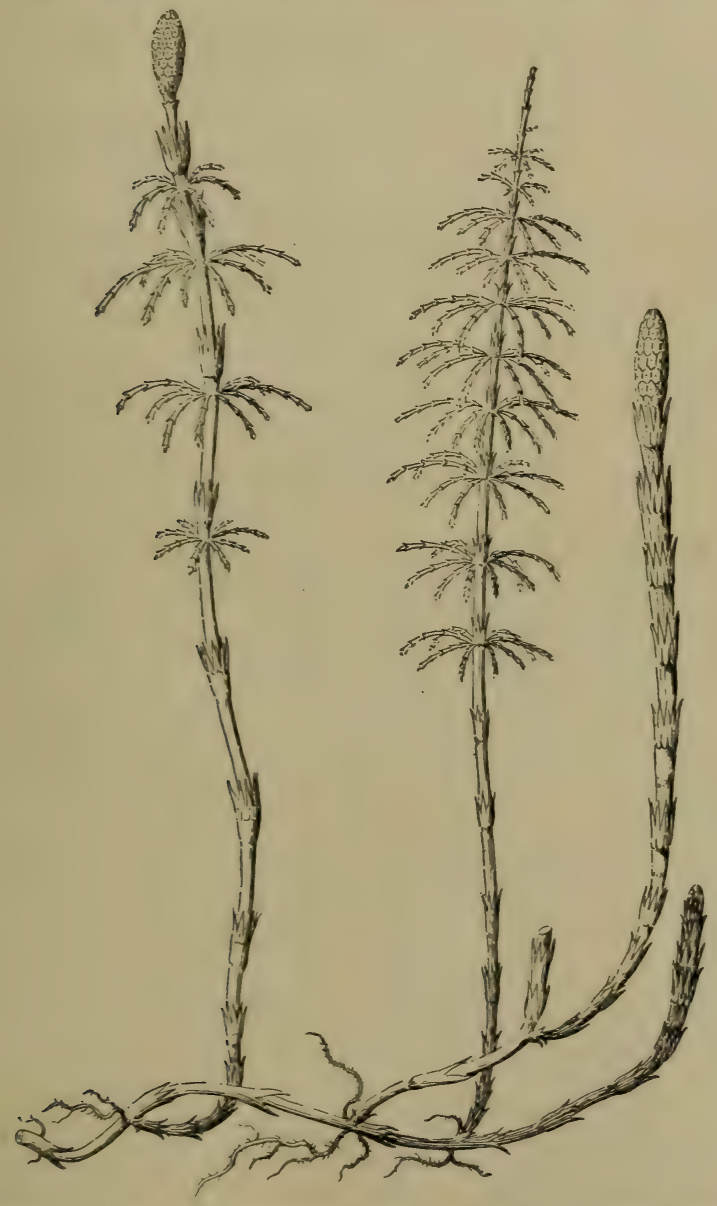

Frg. 213. - A Scouring-Rush (Equisetum sylvaticum). At the right is a colorless fertile stem, in the middle a green sterile one, and at the left a green fertile one. 
361. Sterile Stems. - Examine the stems above ground with reference to their color and mode and degree of branching. What is the character of the leaves? Do the stems in any sense serve as leaves? Observe the nodes composing the stem and note the position of the leaves on the stems. Do they appear to be placed several at the same level (whorled)?

Examine with a magnifying glass the surface of the stem and note the number of ridges and grooves. Compare the number and position of the leaves with reference to these.

362. Mineral Matter in Stem. - Treat small pieces of the stem with strong nitric acid to remove all vegetable substance and note the mineral substance remaining. Treat in a similar way thin crosssections and examine under the microscope. The substance is silica. It gives the plant its gritty feeling and its name and use as "scouring-rush." Of what use is it to the plant? Use of the same substance in outer rind of corn stem, bamboo stem, and straw of grains?

363. Microscopic Examination. - Make thin cross-sections of the stem and examine under the lowest power of the microscope. Make a diagrammatic sketch to indicate the central cavity, the number and position of the fibro-vascular bundles, the cavity or canal in each, the ring of tissue surrounding the ring of bundles, and the larger cavities or canals outside of this. Where is the chlorophyll located? Can stomata be found, and if so, what is their location and arrangement?

364. Fertile Stems. - Describe the fruiting stem with reference to general aspect, size, color, number, and length of internodes, position of spore-bearing portion, color of spores in mass. Note the shieldshaped bodies (transformed leaves or sporophylls) composing the cone-like "flower" and see whether any joints can be detected where they are attached. Examine the inner surface of the shields for sporangia and spores. Examine the sporangia under a low power of the microscope. Examine some spores under a higher power. Note the two bands, elaters, on each spore, crossing each other and attached only at the point of crossing, forming four loose appendages. Watch these while some one moistens them by gently breathing upon them as they lie uncovered on the slide under the microscope 
and note the effect. Also note the effect of drying. How does this affect the spores? Use of the bands?

365. Germination of Spores. - The spores germinate while fresh and form prothallia corresponding to those of ferns, but generally diceious. The prothallium which bears the antheridia remains comparatively small, and the antheridia are somewhat sunken. The others grow much larger and branch profusely. The terminal portion becomes erect and ruffled. Near this part the archegonia are formed, quite similar to those of ferns. The embryo plant developing from the germ-cell has its first leaves in a whorl. This at length grows into a sporeplant like that shown in Fig. 213.

About twenty-five species of Equisetum are known. Several may be looked for in any locality and may well be compared with the one described above, in regard to form, mode of branching, and mode of fruiting.

\section{Fern-Plants (Pteridophytes). -} The Pteridophytes (literally fern-plants) include in their general category not only ferns as commonly recognized, but several other small groups which are very interesting on account of their diversity. All cryptogams higher than mosses belong in this group. In moss plants the individuals growing from spores and bearing antheridia and archegonia, the gametophytes, are full-grown leafy plants, and the spore-bearing plant, or sporophyte, is merely a stalk bearing a sporangium. In all the fern-plants the reverse is true. The individuals growing from spores and bearing antheridia and archegonia are of

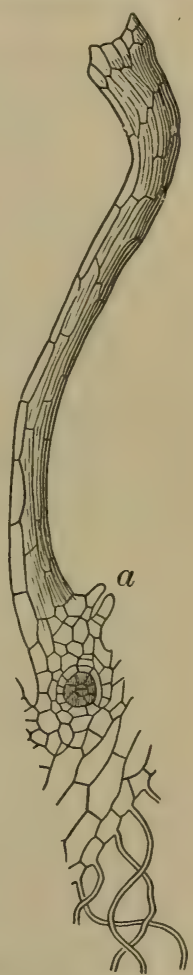

FIG. 214. - Part of a Lobe of the Mature Female Prothallium of Equisetum. ( $x$ about 50 .)

$a$, mouth of a fertilized archegonium. 
minor vegetative development ( prothallia), while the sporebearing plant is a leafy plant, even a tree in some ferns.

The ferns in the strictest sense have sporangia derived from the epidermis (transformed hairs), while a few plants closely resembling them in general aspect (Botrychium, etc.) have sporangia formed in the tissue of the leaf.

In the next subdivision, the water-ferns (Fig. 215), there is little resemblance to the common ferns. The sporangia are in special receptacles at the basal portion of the plant. The spores are of two kinds, dioecious, one on germination, producing antheridia, the other archegonia. This group includes two rooting forms, Marsilea (with leaves resembling a four-leaved clover) and Pilularia, bearing simple linear leaves, and two floating forms, Salvinia (Fig. 215) and Azolla.

The remaining groups of fern-plants are the horse-tails and the club-mosses. The horse-tails have only one kind of spore and are peculiar chiefly in their vegetative aspect (Fig. 213), while the spore-bearing leaves, or sporophylls, are arranged in the form of a cone, as already shown.

The club-mosses include some plants which, as their name implies, have a superficial resemblance to a large moss, with the addition of a club-shaped stalked fruiting spike. These are the so-called "ground pines" and the running ground "evergreens" used for Christmas festoons in New England. Technically the group is distinguished by the possession of firm-walled sporangia formed singly near the bases of the leaves. The ordinary club-mosses already referred to have but one kind of spore, while plants called Selaginella and Isoetes have two kinds of spores, in this respect resembling Marsilea. In many 
species of Selaginella the leaves are arranged flat-wise on the stem, so that considered physiologically the branching stem and its leaves together serve as a foliage leaf. In one of the commonest American forms, however, the stem is more nearly erect, and the leaves are all alike and four-ranked.

Isoetes (quill-wort) grows attached to the soil in shallow water at the bottoms of ponds. It has the aspect of short grass growing in bunches. The large sporangia are at the broad bases of the leaves.

367. High Organization of Pteridophytes. - The student may have noticed that in the scouring-rush and the clubmoss studied there are groups of leaves greatly modified for the purpose of bearing the sporangia. These groups are more nearly equivalent to flowers than anything found in the lower spore-plants, and the fern-plants which show such structures deserve to be ranked just below seed-plants in any natural system of classification.

The variety of tissues which occur in pteridophytes is frequently nearly as great as is found in ordinary seedplants, and the fibro-vascular system is even better developed in many ferns than in some seed-plants.

Starch-making is carried on by aid of abundant chlorophyll bodies contained in parenchyma-cells to which carbonic acid gas is admitted by stomata. In many cases large amounts of reserve food are stored in extensive rootstocks, so that the spring growth of leaves and stems is extremely rapid. 


\section{CHAPTER XXIII}

\section{THE EVOLUTIONARY HISTORY OF PLANTS}

368. The Earliest Plant Life. - What sort of plants first appeared on the earth has never been positively ascertained. The oldest known rocks contain carbon (in the form of black lead or graphite) which may represent the remnants of plants charred at so high a temperature and under so great pressure as to destroy all traces of plant structure. Some objects supposed by many to be the remains of large algæ have been found in rocks that date back to a very early period in the life history of the earth, before there were any backboned animals, unless possibly some fishes. Judging from the way in which the various groups of plants have made their appearance from the time when we can begin clearly to trace their introduction upon the earth, it is probable that some of the simplest and lowest forms of thallophytes were the first to appear. Decaying animal or vegetable matter must have been less abundant than is now the case, so that a plant that could make part or all of its food from raw materials would have had a better chance than a saprophyte that could not. Waterplants are usually simpler than land-plants, so it is highly probable that some kind of one-celled aquatic alga was the first plant.

369. Fossil Plants. - Fossils are the remains or traces of animals or plants preserved in the earth by natural processes. Fossil plants, or parts of plants, are very 298 
common ; the impressions of fern-leaves in bituminous coal and pieces of wood turned into a flint-like substance are two of the best known examples.

The only way in which we can get knowledge about the animals and plants that inhabited the earth's surface before men did is by studying such rocks as contain the remains of living things. In this way a great deal of information has been gained about early forms of animal life and a less amount about early plant life, - less because as a general thing plants have no parts that would be as likely to be preserved in the rocks as are the bones and teeth of the higher animals and the shells of many lower ones.

370. The Law of Biogenesis. - An extremely important principle established by the study of the development of animals and plants from the egg or the seed, respectively, to maturity is this: The development of every individual is a brief repetition of the development of its tribe. The principle just stated is known as the law of biogenesis. As eggs develop during the process of incubation, the young animals within for a considerable time remain much alike, and it is only at a comparatively late stage that the wing of the bird shows any decided difference from the fore-leg of the alligator or the turtle. Zoölogists in general are agreed that this likeness in the early stages of the life history of such different animals proves beyond reasonable doubt that they all have a common origin, that is, are descended from the same kind of ancestral animal.

Among plants the liverworts and ferns supply an excellent illustration of the same principle. In both of the groups the fertilized egg-cells, as the student may have learned 
by his own observations, are much alike. As the egg-cell grows and develops, the sporophyte of a liverwort, which proceeds from the egg-cell, is extraordinarily unlike the "fern" or asexual generation (gametophyte) among Filices. Now this progressive unlikeness between liverworts and ferns, as they develop from the fertilized egg-cell, points to the conclusion that both groups of plants have a common origin or that the more highly organized ferns are direct descendants of the less highly organized liverworts.

371. Plants form an Ascending Series. - All modern systems of classification group plants in such a way as to show a succession of steps, often irregular and broken, seldom leading straight upward, from very simple forms to highly complex ones. The humblest thallophytes are merely single cells, usually of microscopic size. Class after class shows an increase in complexity of structure and of function until the most perfectly organized plants are met with among the dicotyledonous angiosperms. During the latter half of the present century it first became evident to botanists that among plants deep-seated resemblances imply actual relationship, the plants which resemble each other most are most closely akin by descent, and (if it were not for the fact that countless forms of plant life have wholly disappeared) the whole vegetable kingdom might have the relationships of its members worked out by a sufficiently careful study of the life histories of individual plants and the likeness and differences of the several groups which make up the system of classification. ${ }^{1}$

1 See Campbell's Evolution of Plants and Warming's Systematic Botany, Preface and throughout the work. In the little flora of the present book, the families are arranged in the order which, according to the best recent German authorities, most nearly represents their relationships. 
372. Development of the Plant from the Spore in Green Algæ, Liverworts, and Mosses. - The course which the forms of plant life have followed in their successive appearance on the earth may be traced by the application of the law above named. Such algæ as the pond-scums produce spores which give rise directly to plants like the parent.

In many liverworts the spore by its germination produces a thallus which at length bears antheridia and archegonia. The fertilized archegonium develops into a sporophyte which remains attached to the thallus, although it is really a new organism. Liverworts, then, show an alternation of generations, one a sexual thallus, the gametophyte, the next a much smaller, non-sexual sporophyte, and so on.

A moss-spore in germination produces a thread-like protonema which appears very similar to green algæ of the pond-scum sort. This at length develops into a plant with stem and leaves, the sexual generation of the moss. The fertilized archegonium matures into a sporophyte which is the alternate, non-sexual generation. This is attached to the moss-plant, or gametophyte, but is an important new organism. In the moss, as in the liverwort, the sexual generation is the larger and the more complex; the nonsexual generation being smaller and wholly dependent for its food supply on the other generation, to which it is attached.

373. Development of the Plant from the Spore in Pteridophytes. - In the pteridophytes there is an alternation of generations, but here the proportions are reversed, the prothallium, or sexual generation, or gametophyte, being short-lived and small (sometimes microscopic), and the 
non-sexual generation, the sporophyte, often being of large size. The ferns (non-sexual generation), for instance, are

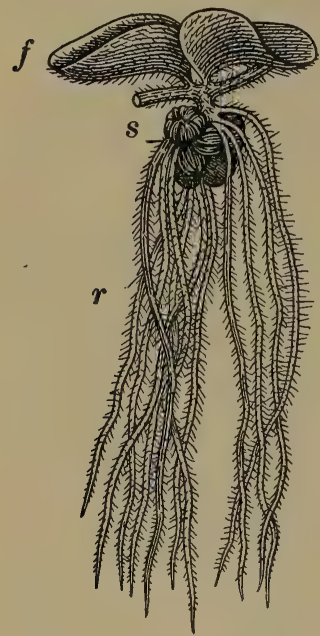

Frg. 215. - A Water-Fern (Salvinia). perennial plants, some of them treelike.

Some pteridophytes, as the Salvinia, a small floating aquatic plant, sometimes known as a water-fern (Fig. 215), produce two kinds of spores, the large ones known as macrospores, and the small ones known as microspores (Fig. 216). Both kinds produce microscopic prothallia, those of the former bearing only archegonia, those of the latter only antheridia. From the prothallia of the macrospores a plant (non-sexual generation) of considerable complexity of structure is formed.

374. Parts of the Flower which correspond to Spores. In seed-plants the spore-formation of cryptogams is represented, though in a way not at all evident without careful explanation. The pistil is the macrospore-producing leaf or macrosporophyll, and the stamen is the microspore-producing leaf or microsporophyll. Pines and other gymnosperms produce a large cell (the embryo sac) in the ovule

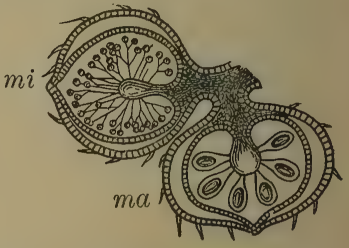

FIG.216.-TwoIndusia of Salvinia. $m i$, microspores ; $m a$, macrospores. (Fig. 217), which corresponds to the macrospore, and a pollen grain which represents the microspore. In its 
development the macrospore produces an endosperm which is really a small cellular prothallium, concealed in the ovule. The microspore contains vestiges of a minute prothallium.

In the angiosperms the macrospore and its prothallium are still less developed, and the microspore, or pollen grain, has lost all traces of a prothallium and is merely an antheridium which contains two generative cells. ${ }^{1}$ These are most easily seen in the pollen grain, but sometimes they are plainly visible in the pollen tube (Fig. 164).

Phanerogams are distinguished from all other plants by their power of producing seeds, or enclosed macrosporangia, with embryos.

375. The Law of Biogenesis and the Relationships of the Great Groups of Plants. - On summing up Sects. $372-374$ it is evident that the sexual generation in general occupies a less and less important share in the life of the

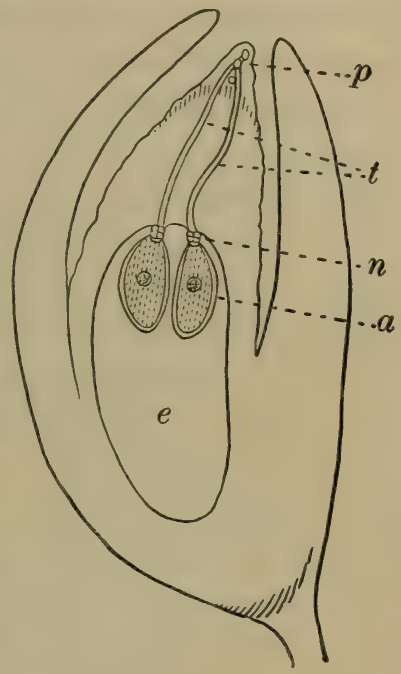

FIG. 217.-Longitudinal Section through Fertilized Ovule of a Spruce.

$p$, polleu grains ; $t$, pollen tubes ; $n$, neck of the archegonium; $a$, body of archegonium with nucleus; $e$, embryo sac filled with endosperm.

plant as one goes higher in the scale of plant life. ${ }^{2}$ In the case of the rockweed, for instance, the sexual generation is the plant. Among mosses and liverworts the sexual

1 Sometimes only one generative cell escapes from the pollen grain into the pollen tube, and there it divides into two cells.

2 A good many plants of low organization, however, are not known to pass through any sexual stage. 
generation is still very prominent in the life of the plant. Ordinary ferns show us the sexual generation existing only as a tiny independent organism, living on food materials which it derives from the earth and air. In the Salvinia it is reduced to microscopic size and is wholly dependent on the parent-plant for support. Among seed-plants the sexual generation is so short-lived, so microscopic, and so largely enclosed by the tissues of the flower that it is comparatively hard to demonstrate that it exists.

The fact that the life history of so many of the classes of plants embraces a sexual stage, in which an egg-cell is fertilized by some sort of specialized cell produced wholly for use in fertilization, tends strongly to show the common origin of the plants of all such classes. We have reason to believe, from the evidence afforded by fossils, that plants which have only a sexual generation are among the oldest on the earth. It is therefore likely that those which spend the least portion of their entire life in the sexual condition were among the latest of plants to appear. Then, too, those which have the least developed sexual generation are among the latest of plants. Judged by these tests the angiosperms must be the most recently developed of all plants.

If one were to attempt to arrange all the classes of existing plants in a sort of branching series to show the way in which the higher plants have actually descended from the lower, he would probably put some one of the green algæ at the bottom and the angiosperms at the top of the series.

376. The 01dest Angiosperms. - It is impossible to give any of the reasons for the statements of this section 
without making an unduly long chapter. Briefly, it may be stated that the monocotyledons are the simplest and probably the oldest angiosperms; the dicotyledons are higher in organization and came later. The descent and various relationships of the families of dicotyledons can be discovered by the study of the flower, fruit, and seed better than by the examination of the vegetative organs.

The entire pedigree of the several families cannot be represented by arranging the names of the families in a straight line. It is, however, in a general way, as indicated by the succession of families in the Flora which accompanies this book, the Willow Family being perhaps the oldest (of the more familiar ones) and the Composite Family the youngest. 



\section{PART II}

\section{ECOLOGY}

\section{CHAPTER XXIV}

\section{PLANT SOCIETIES}

377. Ecology. - Plant ecology includes all that portion of botany which has to do with the way in which plants get on with their animal and plant neighbors, and especially the way in which they adjust themselves to the nature of the soil and climate in which they live. Ecology, in short, discusses the relations of plants to their surroundings or environment. A good deal of what has been said in previous chapters about such topics as parasitic plants, the occurrence of winter bud-scales, the movements of leaves, the coating of hairs on stems and leaves, the storage of water in epidermis-cells, is really ecological botany, although it is not so designated in the sections where it occurs.

378. Plant Societies. - In a single acre of woodland, of marsh, or of meadow, there will usually be found a large number of species of plants. One species may be sufficiently abundant and conspicuous to give a name to the whole tract, so that it may, for instance, be recognized as a bit of birch wood or of cat-tail swamp. But under the birches and among the cat-tails there are plants, it may 
be, of a hundred other kinds - the seed-plants - not all in bloom at any one season, but coming along in succession from earliest spring until the approach of winter. The entire set of plants which naturally occupies a given area of land under somewhat uniform conditions is called a plant society.

379. Similar Societies due to Similar Conditions. - As soon as the young botanist begins to collect plants in a set of localities new to him, he discovers that his old acquaintances are still to be found grouped as he has been accustomed to see them. The rich black loam of a wooded bank a hundred miles away from his familiar collecting ground will show the same assemblage of slippery elms and lindens, red buds, bladdernuts, and wahoos, hepaticas, bloodroots, Dutchman's breeches, trilliums, pepper root, and wild ginger, with a multitude of later-blooming herbaceous plants, that he has learned to know so well. The muddy borders of ponds from Maine to Minnesota and beyond are fringed with the same kinds of bur-reeds and sedges, set with water-plantain, and decorated with the soft white blossoms of the arrowhead. The sand dunes along the northern Atlantic coast and those that border Lake Michigan are clothed with a sparse vegetation which in both cases includes the little beach plum, such coarse grasses as that shown in Plate I, and the straggling sea rocket. Barnyards and waste grounds about farm buildings from Massachusetts to Missouri contain such weeds as the dog fennel, the low mallow ("cheeses"), motherwort, catnip, and some smartweeds.

A little study of such cases soon leads one to the conclusion that these plant societies and multitudes of others 
exist because all the plants in each society are adapted to their special environment. Wherever such an environment occurs such a society will be found in it, ${ }^{1}$ or, if not already there, will flourish when introduced.

380. Similar Species replace Each Other. - Two sets of localities alike in many respects but unlike in some points are often inhabited by different species of the same genus. For instance, the pine barrens of New England and the adjacent states are commonly covered with the northern pitch pine, while far southward, in sandy soil, its place is taken by the long-leaved pine. Along streams and swamps northward the speckled alder is generally found, while southward the smooth alder is most common. In rich woods of the northeastern United States the painted trillium and the erect trillium ("Benjamin," or "squaw root") are the commonest species, while far south, in similar localities, the sessile trillium, Underwood's trillium, and the large-flowered trillium are abundant.

In all such cases - and they are very numerous - we are to infer that the genus is peculiarly well adapted to some especial set of conditions, as sandy soil, brooksides, or the rich, shaded soil of woodlands. But the more northerly species are capable of enduring the severe winters and brief summers of their region, while the more southerly ones perhaps cannot do so. The relative warmth of the climates in which they live may not be the only reason, or even the principal reason, for the distribution of such plants as those just mentioned, but it is one factor at any rate. And it is certain that, on the whole, most of our

1 That is, in localities not separated by such natural barriers as seas, high mountains, or deserts. 
native and thoroughly naturalized plants are growing under what is, for them, the best environment, since they cannot usually be made to exchange places with each other. If a square mile of land in Louisiana were to be planted with Minnesota species, and a square mile in Minnesota with Louisiana species, it is very improbable that either tract, if left to itself, would long retain its artificial flora. To this rule there are, however, important exceptions (see Sect. 457).

381. Plant Formations. - It is not uncommon to find tracts of land or water inhabited by great numbers of plants of the same species so as almost to exclude all other plants except microscopic cryptogams. Ponds and slowly flowing streams are often filled in this way with the water hyacinth or the American lotus. The canebrakes of the south and the wild rice swamps along northern lakes and rivers are other examples of an extremely simple flora spread over large areas. Prairies not infrequently for hundreds of square miles are covered mainly (not entirely) with a very few kinds of grasses. Such assemblages are called plant formations or plant colonies.

382. Ecological Classification of Plants. - The ordinary classification of plants, as set forth in Chapter XIX, is based, as far as possible, on their actual relationships to each other. But when plants are classified ecologically they are grouped according to their relations to the world about them. They may, therefore, be gathered into as many (or more than as many) different groups as there are important factors influencing their modes of life. We may classify plants as light-loving and darkness-loving, as requiring free oxygen, and not requiring it, and so on. 
Indeed, one of the most useful classifications of bacteria, for practical purposes, is into species which must have free oxygen, that is, oxygen not chemically combined with other substances, in order to grow and increase, and those which can live without it.

The most important consideration in classifying seedplants on ecological grounds is based on their requirements in regard to water. Grouped with reference to this factor in their life all plants may be classed as:

(1) Hydrophytes, or water-loving plants.

(2) Xerophytes, or drought-loving (or perhaps drought-tolerating) plants.

(3) Mesophytes, or plants which thrive best with a moderate supply of water.

These three classes do not fully express all the relations of plants to the water supply, so two others are found convenient.

(4) Tropophytes, or seasonal plants which are hydrophytes during part of the year and xerophytes during another part. ${ }^{1}$

(5) Halophytes, or salt marsh plants and "alkali" plants, species which can flourish in a very saline soil.

383. Difficulties in Ecological Classification. - It seems at first sight a simple matter to group plants in regard to their need of water. There can be no difficulty in classifying as hydrophytes all plants like the bladderworts, water cresses, certain mosses, and many lower spore-plants which live only in water. Cactuses, aloes, and similar plants are recognized at sight as xerophytes. But the chief difficulty

1 The plants which E. Warming, one of the foremost authorities, classes as mesophytes are many of them grouped by another great authority, A. F. W. Schimper, as tropophytes. 
is in dividing mesophytes from the other two classes, into which they shade by indefinite gradations. In order to know whether the plants of a region have plenty of water or not, we must know not only how many inches of yearly rainfall there are, but also what the soil is like, what is the temperature of the soil and air, whether or not there

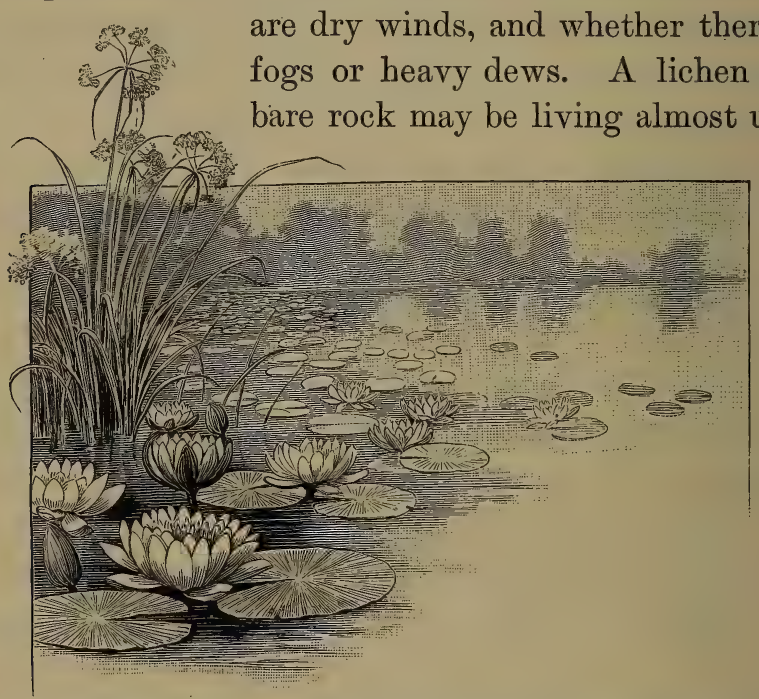

FIG. 218. - Aquatic Plants : Pond-Lilies with Floating Leaves and Sedges with Aërial Leaves.

desert conditions, while a pitcher-plant in a bog near by has its roots in standing water (or in ice) nearly all the year round.

384. Hydrophytes. - Some of these are herbaceous aquatic plants, like the duckweed, the pickerel-weed, the pond-lily, and the water-crowfoot; others, such as the "calla" (Richardia), the buckbean, the cat-tail, and the sweet flag, many ferns, mosses, and liverworts, prefer 
damp air and soil. All of them transpire freely, and many of them cannot live at all under the moisture conditions which suit ordinary plants.

Some aquatics have their leaves wholly submerged, others, such as the duckweed and the pond-lilies (Fig. 218), have them floating, and still others, like the sedges in the same picture, have their leaves freely exposed to the air. A few plants have both water-leaves and air-leaves (Fig. 219). Some aquatic plants are rooted in the mud, while others have no roots at all, or, like the duckweed, have only water-roots.

The leaves of land-plants in very rainy, subtropical climates are exposed to the attacks of parasitic sporeplants which flourish on their surfaces. To ward off the attacks of these it is

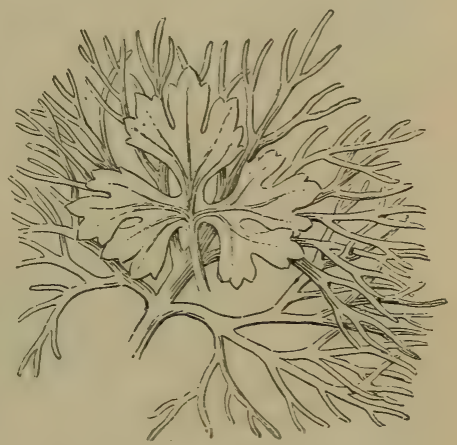

Fig. 219. - Submerged and Aërial Leaves of a European Crowfoot (Ranunculus Purshii). The leaf with thread-like divisions is the submerged one. necessary to keep water from accumulating on the surfaces of the leaves. This result is secured by a waxy deposit on the epidermis and also by the slender prolongation to drain off surplus water, shown in Fig. 221. That this slender leaf tip is useful in the way suggested is proved by the fact that when it is cut squarely off the leaf no longer sheds water freely.

385. Xerophytes. - A xerophyte is a plant which is capable of sustaining life with a very scanty supply of water. Since the first plants which existed were aquatics 


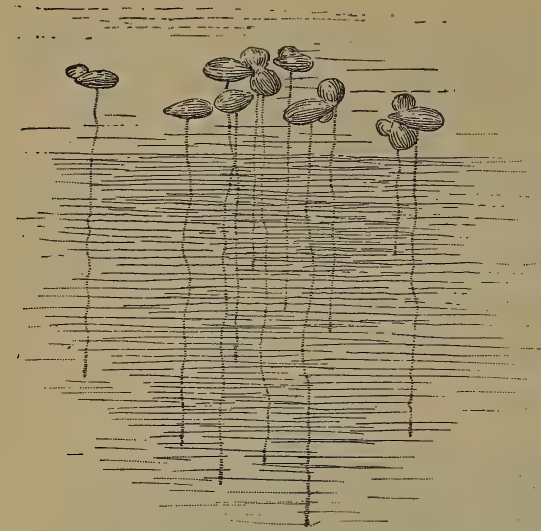

FrG. 220. - The Duckweed, a Floating Aquatic Plant.
(Sect. 368), we must consider that xeropyhtes are highly specialized and modified forms adapted to extremely trying conditions of life. A typical xerophyte is one which can live in a very dry soil in a nearly rainless region. The yucca in Plate VII and the melon-cactus (Fig. 49)

are good examples of such plants. Less extremely xerophytic are plants like the date-palm (Fig. 54), which flourishes in the oases of the Sahara, where the soil is moist from the presence of springs, though rains are almost unknown, or the houseleeks and stonecrops found in many gardens, the so-called Spanish moss (Plate IV), and lichens (Figs. 198, 199), all of which grow most rapidly in moist air, but cling to bare rocks and trunks of trees, from which they get no water. A xerophyte must be capable of storing water and transpiring very slowly, like cactuses, aloes, stonecrops, and such fleshy plants

1 Ficus religiosa.

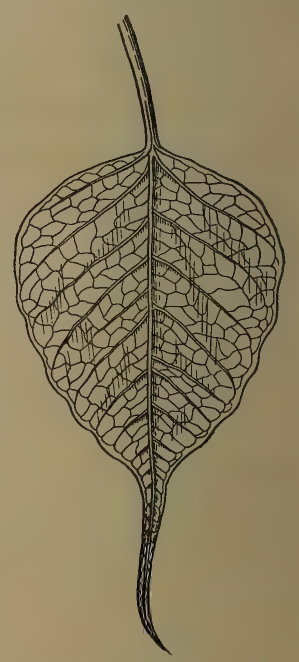

FrG. 221.-Leaf of an East Indian Fig Tree, 1 with a Slender Tapering Point to drain off Water. 


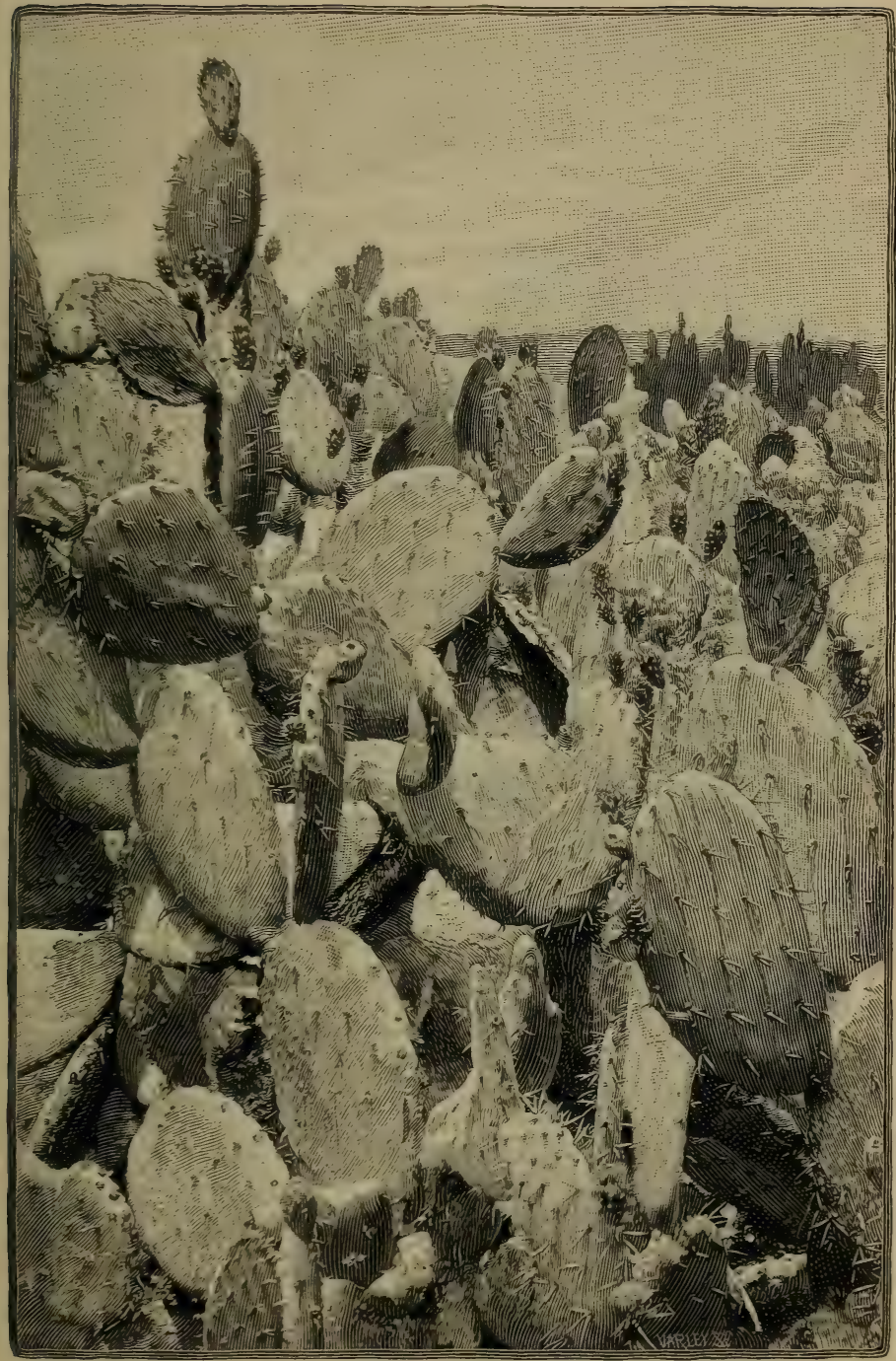

Fig. 222. - A Field of Prickly-Pear Cactus Plants: Xerophytes. 
with a thick epidermis, or else it must be able to revive after being thoroughly dried. A few seed-plants and many such spore-plants as lichens, Pleurococcus (Sect. 277), yeast, and some bacteria (Sect. 263), thrive just as
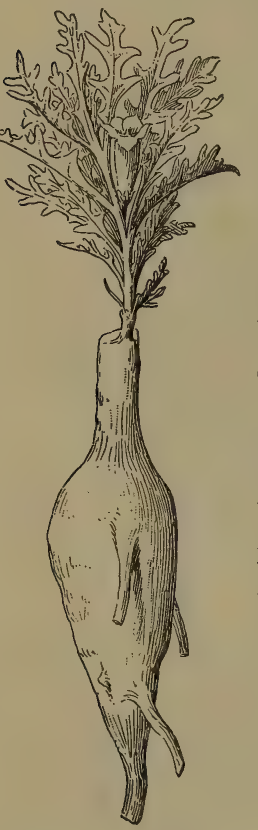

FIG. 223. - Harpagophytum, a South African Xerophyte. well after remaining for some months or years in a dried condition as they did before drying. A good illustration of this fact as regards yeast is found in the use of dried yeast cakes, made of a mixture of yeast and corn meal. These will raise dough promptly when mixed with it, even if they have been kept dry for a year or more.

386. Roots and Stems of Xerophytic Seed-Plants. - Some xerophytes have roots which show no peculiarities of form or structure, but many make special provision for storing food and water in their roots. Such roots are fleshy and often, as in Harpagophytum (Fig. 223), are of great size compared with the portion of the plant above the ground.

Xerophytic stems are frequently very thick in proportion to their length, sometimes even globular, and they commonly contain large amounts of water. In leafless plants, like the cacti, the surface for transpiration is much less than that offered by leafy plants. Many species which bear leaves shed most of them at the beginning of the dry season, and some remain thus in a half dormant condition for long periods, as is the case with many Euphorbias 


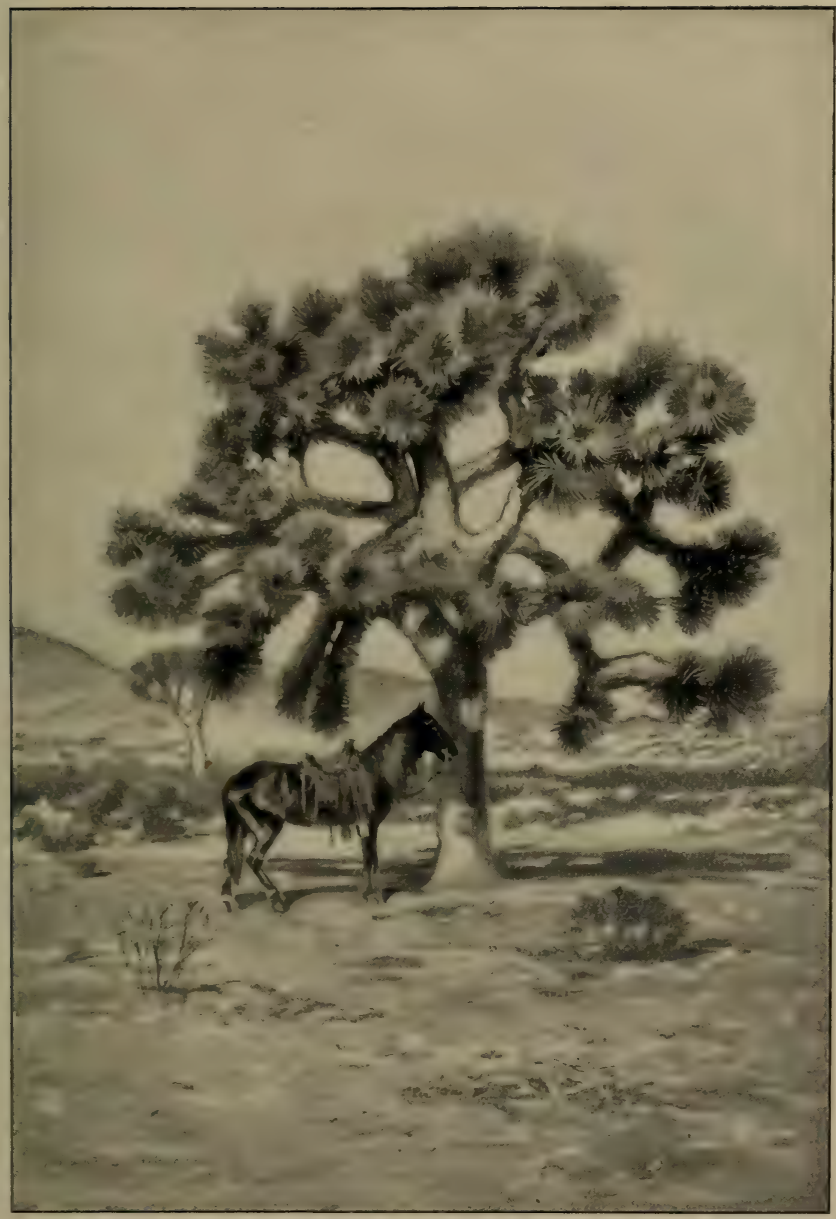

Plate VII. - Tree Yucca in the Mohave Desert 

(Fig. 245). The epidermis, even on the younger portions of the stem, is highly cutinized (Fig. 121), and this structure makes any evaporation very slow.

387. Leaves of Xerophytes. - In regions where the greatest dangers to vegetation arise from long droughts and the excessive heat of the sun, the leaves of plants usually offer much less surface to the sun and air than is the case in temperate climates. Sometimes the blade of the leaf is absent and the expanded petiole answers the purpose of a blade, or, again, foliage le a ves are alto-

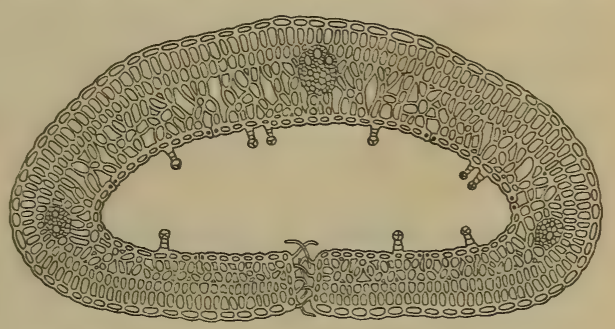

FIG. 224. - Cross-Section of Rolled-Up Leaf of CrowBerry (Empetrum nigrum). (Magnified.) gether lacking, as in the cactuses (Fig. 222), and the green outer layers of the stem do the work of the leaves.

388. Rolled-Up Leaves. - Leaves which receive but a scanty supply of water are often protected from losing it too rapidly by being rolled up, so that the evaporating, i.e., stomata-containing, surface is on the inside of the roll. Sometimes, as in the crow-berry (Fig. 224), the curled condition is permanent. In other plants, as in such grasses as Stipa (Fig. 225), and in Indian corn, the leaf rolls up when the weather is very dry and unrolls again when it receives a better supply of water.

389. Mesophytes. - A mesophyte is a plant which thrives best with a moderate supply of water. The great majority of the wild and the cultivated plants of the United States are mesophytes, and what has been learned 
from Part I of this book about the forms, structure, and habits of ordinary plants, together with what the student's own observation, aside from the study of botany, has taught him, should suffice to give him a fair idea of mesophytic plant life.

The typical mesophyte of the northern United States is an annual, since most of our larger perennials pass the winter in a xerophytic condition, to avoid destruction by drying up during the long period when the roots can absorb little or no water
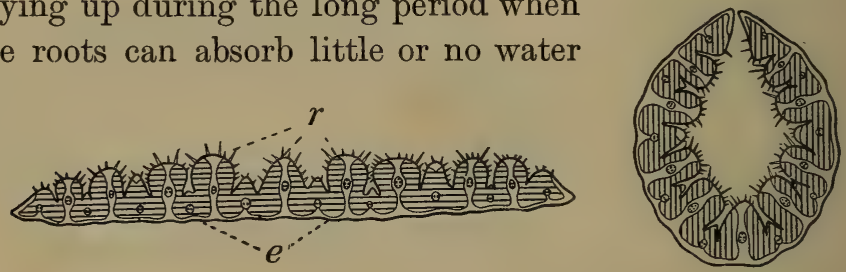

Fig. 225. - Cross-Section of Leaves of a Grass, ${ }^{1}$ unrolled for Exposure to Sunlight and rolled up to prevent Evaporation.

$r$, ridges of the upper epidermis, with many stomata on their surfaces; $e$, thick lower epidermis, without stomata.

from the frozen soil. Our evergreen coniferous trees, such as pines, spruces, cedars, and so on, have leaves of decidedly xerophytic structure. So also do such evergreen shrubs as the rhododendrons, wintergreen, arbutus, holly, and bearberry. Our deciduous trees and shrubs and most perennial herbs are tropophytes (Sect. 390).

390. Tropophytes, or Seasonal Plants. - Examples of these are most deciduous trees and the majority of the perennials of temperate regions, for instance oaks, elms, birches among trees, and tulips, crown imperials, lilies, hyacinths, spring-beauties, peonies, dahlias, and potatoes among herbs. Such plants have a pretty large surface for 
transpiration during the summer (or in regions like Southern California in the rainy season) and a greatly reduced surface during the winter (or the dry season).

In the case of trees the reduction of surface is brought about by the fall of the leaves (Sect. 186), and in the case of herbaceous perennials it is secured by the death of the green stem and the leaves, so that only a compact root, rootstock, or bulb is left alive underground. That is to say, the perishable or annual part of tropophytes has the characteristics of mesophytes or even of moisture-loving plants, while the perennial part is constructed on the plan of xerophytes.

391. Halophytes. - A halophyte is a plant which can thrive in a soil containing much common salt or other saline substances. The seaside obviously occurs to one as the region of halophytic vegetation, but many inland areas contain halophytic plants, for instance the neighborhoods about salt springs and the "alkali" lands of the southwest and the Pacific Slope. The presence of salt in the soil renders absorption of the

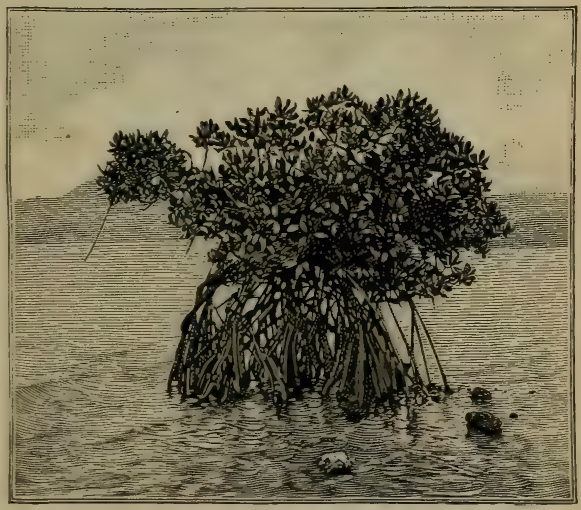

Fig. 226. - The Mangrove, a Halophytic Tree of Southern Florida and the Tropics. soil-water comparatively difficult, since osmosis takes place more readily between ordinary water and the liquid 
contents of root-hairs and young roots than between salt water and the liquids inside the root. Halophytes, therefore, are put on short rations as regards water, even though they may be growing in a watery marsh. Consequently halophytes often have much the appearance of fleshy xerophytes and the structure of xerophytes.

The mangrove tree (Fig. 226) is one of the most remarkable of halophytes. It grows in shallow water along the seashore and sends out many aërial roots which at length find their way down into the salt mud. In this way it collects drift material and gradually extends the shore line farther out to sea.

392. Other Kinds of Ecological Classes. - It is easy to class plants according to their habits in many other regards than according to their relative power of transpiration (see Chapter XXVI). Only one other kind of classification need, however, be mentioned in this chapter, that is, the division into sun-loving and shade-loving plants. Even in very dense forests some plants will be found growing on the soil in the twilight formed by the shade of the trees. Some of this undergrowth is of seed-plants, and there are many ferns and mosses which flourish in such situations. Shade-plants commonly have large pale leaves, and generally (except in ferns) the leaves are not much cut or lobed.(Fig. 227, I). Sun-loving plants, on the other hand, usually have comparatively little leaf-surface, and the leaves are often cut into narrow divisions (Fig. 227, II). Apparently the broad leaf-surfaces in the one class are to expose many green cells to the light for starch-making, while in the other class the slender leaf-divisions expose enough assimilating cells, and at the same time the 
narrowness of the division permits plenty of light to penetrate to the plant's lower leaves. It is also, doubtless, much easier for leaves like those of the yarrow, the dog fennel, the tansy, the carrot, and their like, to withstand the action of severe winds, to which they are often exposed, than it would be for leaves like those of the jackin-the-pulpit (see Frontispiece), the trilliums, the lily-ofthe-valley, and similar leaves.

393. Transition of a Plant from Shade Conditions to Sun Conditions. - It is characteristic of many kinds of forest trees that the young seedlings are much more tolerant of

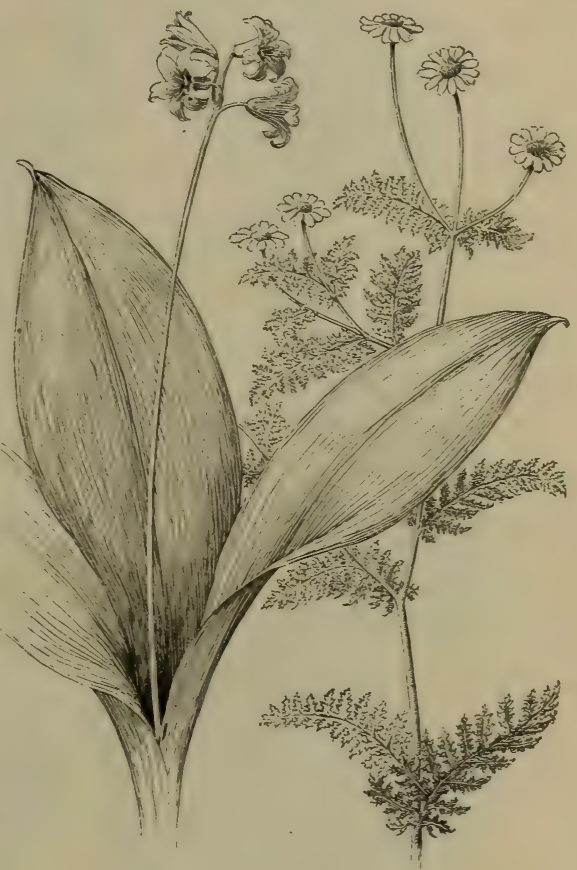

I

II dense shade than the adult trees are. Fir. 227. - I, a Shade-Plant (Ciintonia); II, a SunPlant, Dog Fennel (Maruta).

Sometimes their seeds will hardly germinate at all unless thoroughly shaded, and the young trees for the first few years flourish best in the shade. Afterwards most trees neeả a good deal of sunlight, but they may live long with a scanty supply of light. The red spruce sometimes 


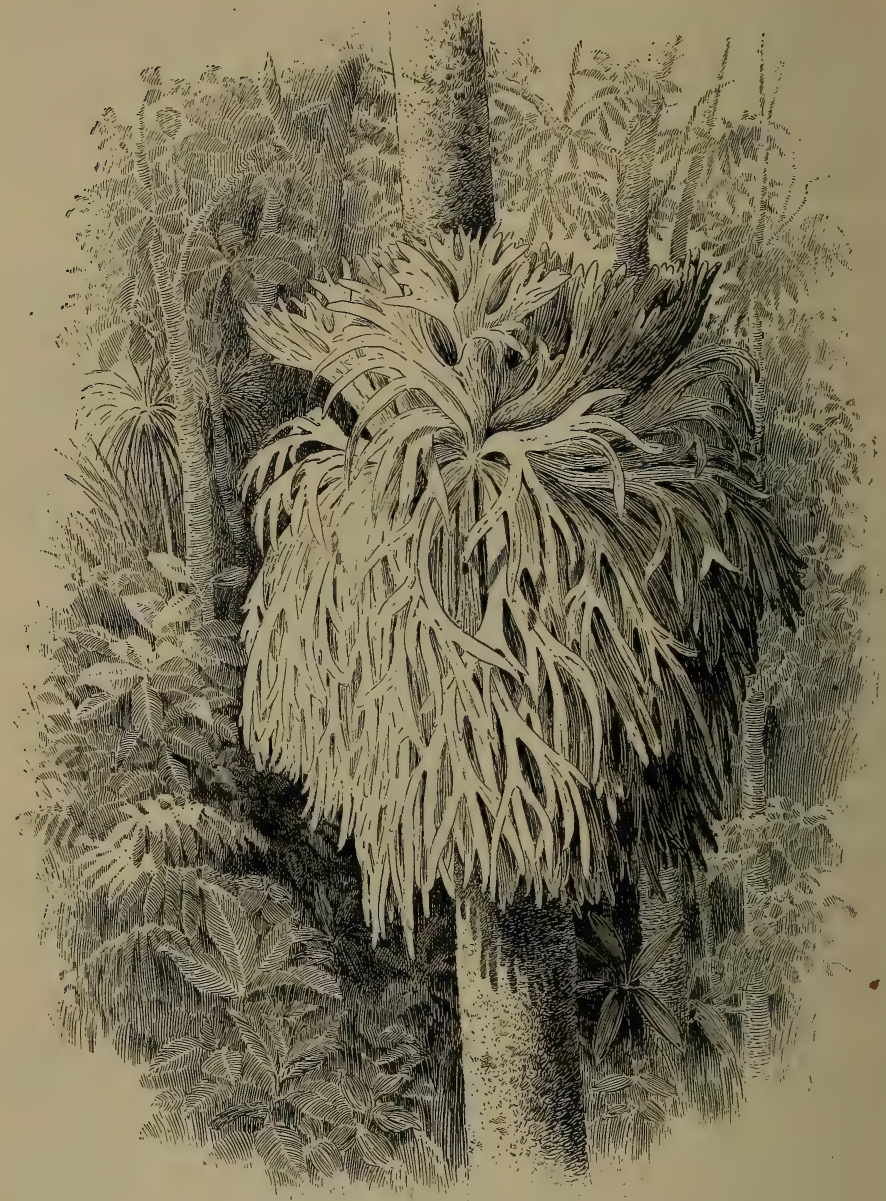

FIG. 228. - An Epiphytic Fern (Platycerium) on a Tree Trunk.

The more upright leaves next the trunk of the tree serve to collect water and to accumulate a deposit of decaying vegetable matter, while the outer leaves serve as foliage and bear spores. 
lingers on for fifty or a hundred years, reaching meantime a diameter of not more than two inches, and then, on getting more light, shoots up into a large and valuable timber tree. ${ }^{1}$

394. Epiphytes. - It is even easier for a plant to secure enough sunlight in a forest region by perching itself upon the trunk or branches of a tree than by climbing, as our wild grapevines and the great tropical lianas do. There is a large number of such perched plants, or epiphytes, embracing species of many different groups of seed-plants and of spore-plants. The fern shown in Fig. 228 is a good example of an epiphyte. Instances among seed-plants are the so-called Florida moss (Plate IV) and orchids like those in Fig. 13.

I See the Primer of Forestry, Part I, U. S. Department of Agriculture, 1899 , pp. $33-35$. 


\section{CHAPTER XXV}

\section{BOTANICAL GEOGRAPHY}

395. Regions of Vegetation. - The earth's surface (that of the land) has been described by one of the greatest of geographical botanists ${ }^{1}$ as divided into twenty-four regions of vegetation. This classification takes account of all the principal continental areas which have a characteristic set of plants of their own, as well as of the most important islands. But a simpler arrangement is to consider the plant life of the earth as distributed among the following regions:
1. The tropical zone.
2. The temperate zones.
3. The arctic zones.
4. Mountain-heights.
5. Bodies of water.

Any good geography gives some account of at least the land vegetation of the earth. It is necessary in the present chapter only to point out a few of the most important characteristics of the plants of the zones and other areas mentioned above and to give some reasons why the plant population of each has its special characteristics.

396. Tropical Vegetation. - Within the tropics two of the great factors of plant life and growth, namely, light and heat, are found in a higher degree than elsewhere on the earth. Moisture, the third requisite, is in some 
regions very abundant (over sixteen feet of rainfall in a year) or sometimes, in desert areas, almost lacking. We find here, accordingly, the greatest extremes in amount of vegetation, from the bare sands or rocks of the Sahara desert (Fig. 229) to the densely wooded basin of the Kongo and of the Amazon. Xerophytic plants, many of them with extremely complete adaptations for supporting life for long periods without water, are characteristic of tropical deserts, while many of the most decided hydrophytes among land-plants are found in the dripping sub-

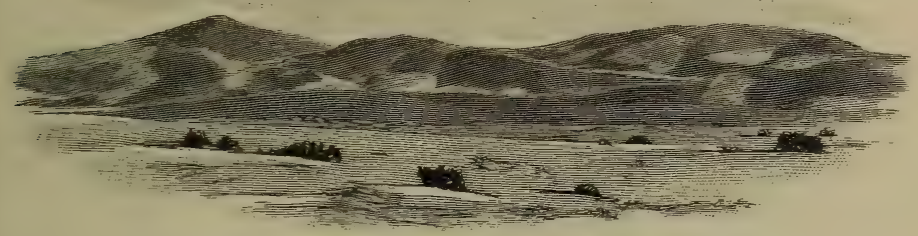

FrG. 229. - Hills of Drifted Sand in the Sahara.

tropical forest interiors. Throughout a large part of the zone, reaching five degrees each way from the equator, there are daily rains the year round.

397. Vegetation of the Temperate Zones. - We are all familiar in a general way with the nature of the plant life of the north temperate zone; that of the south temperate is in most ways similar to our own. Most of the annuals and biennials are of a medium type, not decided xerophytes nor hydrophytes, and the perennials are mainly tropophytes. There are no desert areas so large or so nearly destitute of plants as those found in subtropical regions, neither are there any such luxuriant 
growths as occur in the rainy forest regions of the tropics. On the other hand, the largest trees on earth, the "big trees," or Sequoias (Fig. 32), occur in the temperate portion of North America, along the Sierra Nevada, and the taller, though less bulky, gum trees (Eucalyptus) of Australia grow in a warm temperate region.

398. Temperate Plant Societies due to Special Conditions

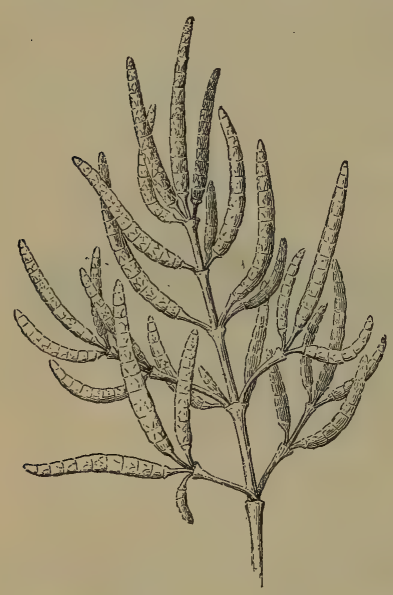

FIG. 230.-A Halophytic Plant (Salicornia). of Soil. - Even where the climate is a moderate one as regards temperature and rainfall, peculiar soils may cause the assemblage of exceptional plant societies. Some of the most notable of such societies in temperate North America are those of the salt marshes, the sand dunes, and the peat bogs.

In salt marshes the water supply is abundant, but plants do not readily absorb salt water by their roots, so that the plants which grow in salt marshes usually have something of the structure and appearance of xerophytes. Some of them are fleshy (Fig. 230), and some species are practically leafless.

Sand dunes, whether along the seacoast or near the great lakes, offer a scanty water supply to the roots during much of the year, and the soil-water contains less of the raw materials for plant food than is offered by that of ordinary soils. Many grasses thrive, however, in these shifting sands (Plate I), and some, like the beach-grass 
(Ammophila) of the Atlantic coast and the great lakes, will continue to grow upward as the sand is piled about

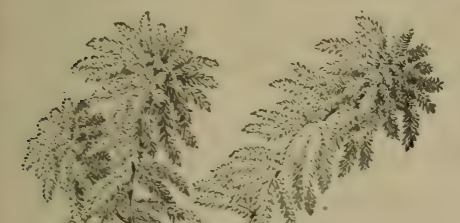
them by the winds until they have risen to a level of a hundred feet above the starting point.

Peat bogs are especially . characterized by the predominance of the peat mosses (Fig. 231) from which they take their name.

These plants and the others which associate with them are mostly hydrophytes, living usually with a considerable portion of the plant continually submerged in the bog water. The water of such bogs contains little mineral matter and only a very scanty supply of nitrogen, in the form of nitrates dissolved in it. The bog-plants, therefore, must either get on with an exceptionally small supply of nitrogen or they must get it from an unusual source. The peat mosses adopt the former alternative, while the sun dews (Fig. 238), the pitcher-plants (Fig. 237 ), and some other species adopt the latter and derive their nitrogen supply largely from insects which they catch, kill, and digest.

399. Arctic Vegetation. - The seed-plants of the FIG. 231. aretic flora are mostly perennials, never trees. Peat Moss. By the large bulk of the underground portion as compared with that of the part above ground, they are adapted to a climate in which they must lie dormant 
for not less than nine months of the year. The flowers are often showy and appear very quickly after the brief summer begins. Mosses and lichens are abundant, - the latter of economical importance because they furnish a considerable part of the food of reindeer.

400. Mountain or Alpine Vegetation. - In a general way the effect of ascending a mountain, so far as vegetation is

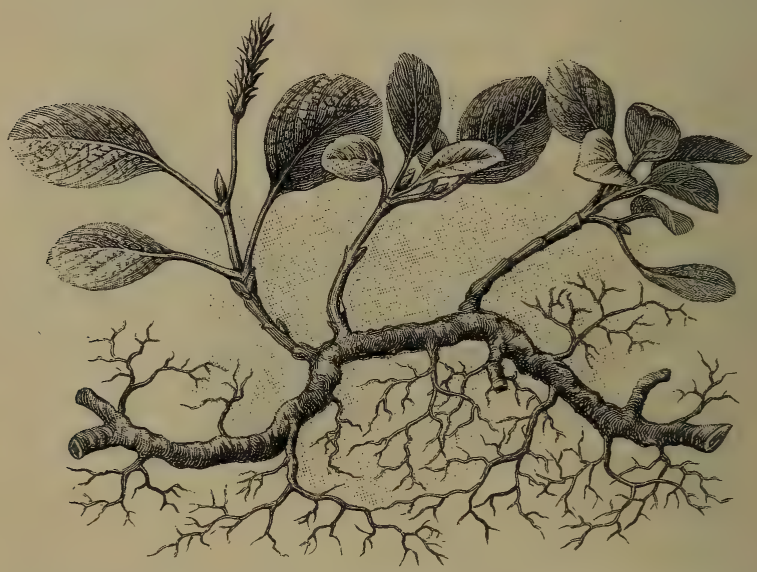

FiG. 232.-A Plant of Arctic Willow. (About natural size.)

concerned, is like that of traveling into colder regions. It was long ago suggested, in regard to Mount Ararat, that on ascending it one traversed first an Armenian, then a South European, then a French, then a Scandinavian, and finally an arctic flora. Up to a certain height, which varies in different latitudes, the slopes of mountains are very commonly forest-covered. The altitude up to which trees can grow (or as it is commonly called in this country the "timber line") is somewhat over twelve thousand feet 
in the equatorial Andes and lessens in higher latitudes as one goes either way from the equator. In the White Mountains, for instance, the timber line only rises to about four thousand five hundred feet. The seed-plants of alpine regions in all parts of the earth have a peculiar and characteristic appearance. It is easiest to show how such plants differ from those of the same species as they look when

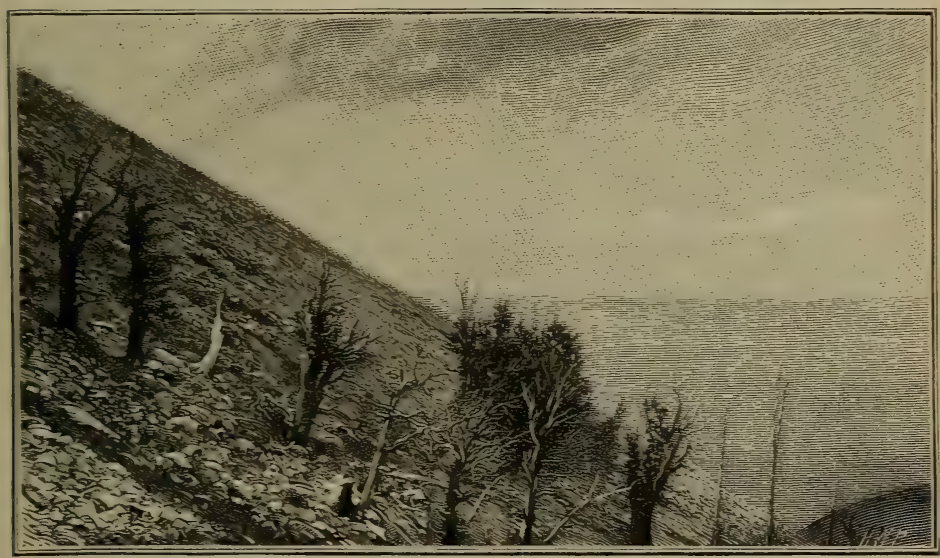

Fig. 233. - Trees near the Timber Line on the Slope of Pikes Peak.

growing in ordinary situations by reference to the plants themselves or to good pictures of them (see Fig. 235). The differences between alpine and non-alpine plants of the same or closely related species have been summed up as follows: ${ }^{1}$

"The alpine individuals have shorter stems, smaller leaves, more strongly developed roots, equally large or somewhat larger and usually somewhat more deeply colored flowers, and their whole structure is drought-loving (xerophilous)."

1 By A. F. W. Schimper. 


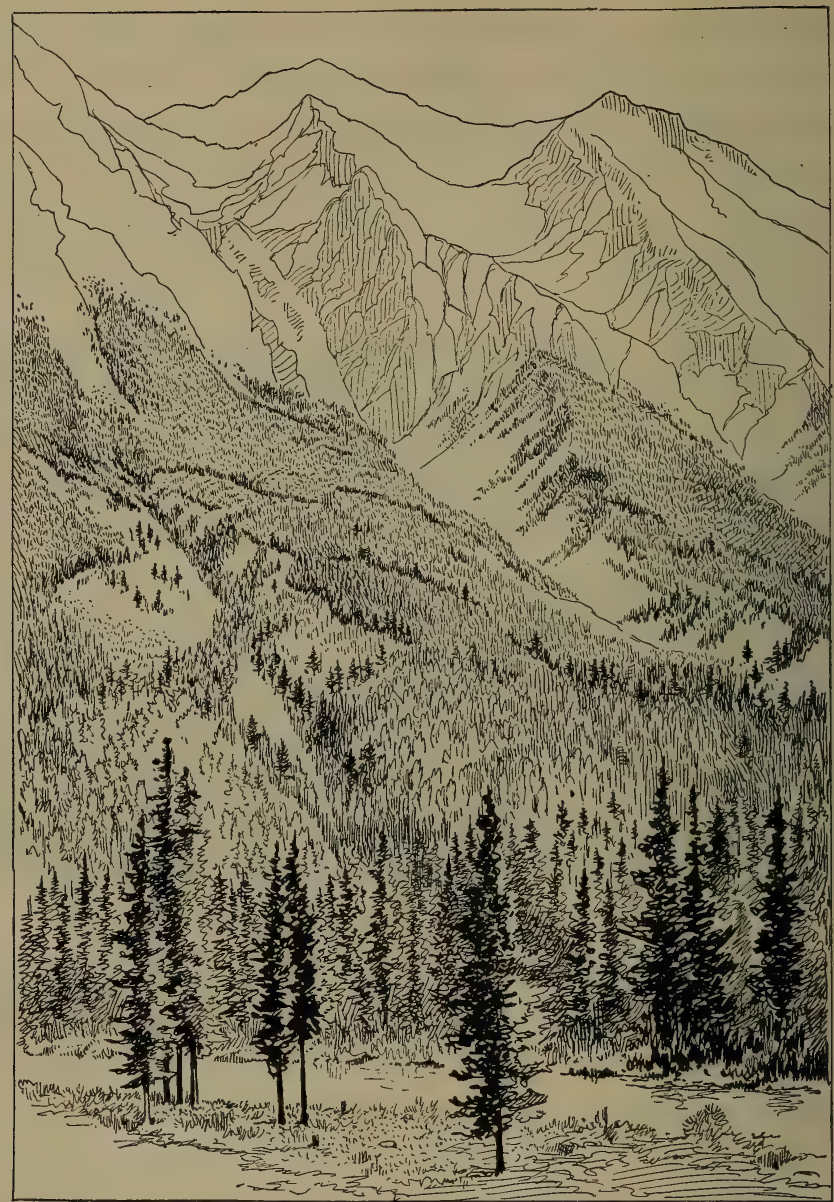

FIG. 234. - Decrease in Size of Trees at High Elevations (Canadian Rockies).

Trees at great elevations become much gnarled and stunted, as their growth is necessarily very slow (Fig. 233). The gradual diminution of the height of the 
trees on ascending a mountain is well shown in Fig. 234. The treeless character of the mountain summit is also plain. ${ }^{1}$

Recent experiments have shown that many ordinary plants promptly take on alpine characteristics when they are transferred to moderate heights on mountains. For instance, a rather commonly cultivated sunflower, ${ }^{2}$ when planted at a height of about six thousand five hundred feet, instead of having a tall leafy stem produces a rosette of very hairy leaves lying close to the ground, thus becoming almost unrecognizable as a sunflower. The change was even greater than that shown in the rock

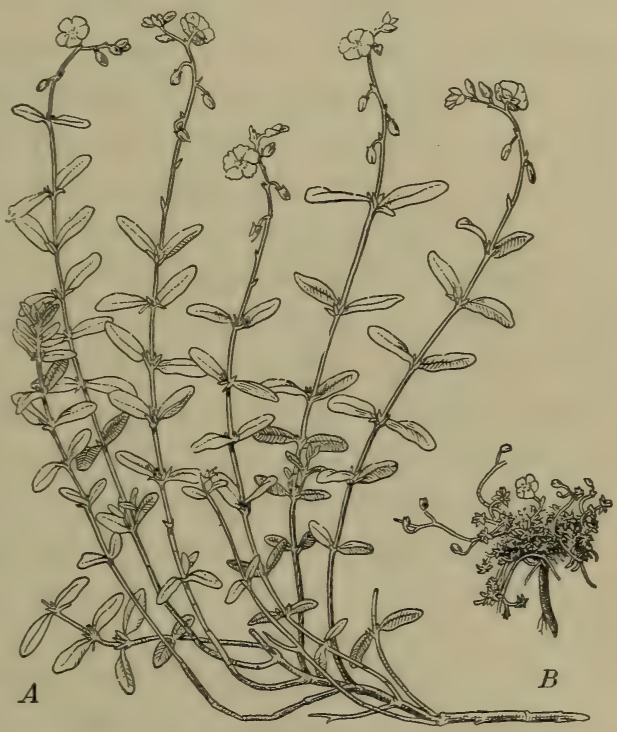

FIG. 235. - Two Plants of Rock Rose (Helianthemum). (Both drawn to the same scale.) $A$, low ground form ; $B$, alpine form. rose (Fig. 235) cultivated by the same experimenter. The peculiarities of alpine plants appear to be due mainly to the intense light which they receive during the daytime,

1 Part of the diminution is only apparent, - the effect of distance, - but the growth at the highest levels is often less than waist high.

2 Helianthus tuberosus, the so-called Jerusalem artichoke. 
to the strongly drying character of the air in which they grow (due partly to its rarefaction), and to the low temperature which they must endure every night.

401. Aquatic Vegetation. - Plants which live wholly in water often need a less complicated system of organs than land-plants. True roots may be dispensed with altogether, as in many seaweeds, in most fresh-water algæ, and in some seed-plants. A few such plants have mere holdfasts that keep them from drifting with the waves or the current. Sometimes roots may, as in the duckweeds (Fig. 220), serve the purpose of a keel and keep the flat, expanded part of the plant from turning bottom up. The tissues that give strength to the stems and leaves of land-plants are not usually much developed in submerged aquatics, since the water supports the weight of such plants. In some algæ, as the common rockweed or bladder-wrack (Fig. 183), the weight of the plant is admirably buoyed up by large air-bladders. Transpiration is done away with, and whatever carbonic acid gas or oxygen is absorbed or given off passes directly through the cellwalls into the interiors of the cells. Generally waterplants do not reach any great size, but some species are the longest of known plants, Macrocystis, the great kelp of the Pacific Ocean, attaining, it is said, the length of a thousand feet or more. In spite of the moderate size of most algæ the total bulk in the various oceans must be extremely large. The Sargasso Sea alone, in the Atlantic Ocean, reaches most of the way from the Bahamas to the Azores and extends over seventeen degrees of latitude. The whole area is occupied by a nearly compact mass of floating seaweed. 
Besides the comparatively well-known and readily seen larger algæ there is a great amount of vegetation floating in what is known as the plankton. This is a mass of microscopic animals and plants, found floating scum-like or submerged in fresh and in salt water and often accumulated in great quantities near shores, to which it is swept by the action of the wind and waves and currents. Much of the plant life of the plankton, both of fresh and of salt water, often consists of the flinty-shelled one-celled microscopic algæ known as diatoms (Fig. 176).

402. Botanical Geography of the United States. - All of the continuous territory of the United States ${ }^{1}$ lies in the north temperate zone. There is material for a large volume in the discussion of the distribution of plants over our territory in this continent alone, but it is possible to sum up a mere outline of the matter in a very few words. Excluding the floras of many single mountains and mountain ranges, the land surface of the country may for botanical purposes be divided into four great areas, as follows:

1. The Forest Region. - This occupies the eastern and central portion of the United States. It is bounded on the west by an irregular line, most of which lies to the eastward of the hundredth meridian. In some places this forest boundary extends eastward across the Mississippi River, while in others it recedes from the river five hundred miles or more to the westward.

2. The Great Plains Region. - This extends westward from the region above named to the Rocky Mountain Plateau.

I That is, not counting in Alaska, our West Indian possessions, the Sandwich Islands, or the Philippines. 
3. The Pacific Highland Region. - This includes the Rocky Mountains, the Sierra Nevada, and the various plateaus between them.

4. The Pacific Slope. - This extends from the Cascade Range and the Sierra Nevada to the sea.

403. Characteristics of the Four Regions. - The forest region is mainly remarkable for its great variety of hardwood trees, of which it contains a larger number of useful species than any equal area of the earth with a temperate climate. In the northeasterly portion and in much of the southerly portion there are extensive forests of the cone-bearing evergreens, such as pines, spruces, hemlocks, and cedars. The vegetation is in general such as thrives in medium conditions as regards heat and rainfall.

The plains region is largely covered with grasses, many of them xerophytes. Some of the most characteristic plants associated with the grasses are Compositæ, such as sunflowers, rosin-weeds (Silphium), cone-flowers, gum-weeds (Grindelia), and blazing-stars (Liatris).

The Pacific highland region includes a very great variety of plant societies, from the heavily wooded mountain slopes and valleys to high sterile plains which are almost deserts. Cone-bearing evergreen trees are very characteristic of the forests. Great numbers of alpine species of herbs and shrubs are found on the mountains at and above the timber line. In the alkali regions, where the soil is too full of mineral salts to permit ordinary plants to grow, many kinds of xerophytes, such as the salty sage (Atriplex) and the greasewood (Sarcobatus), occur. In the southern portion cactuses abound. 


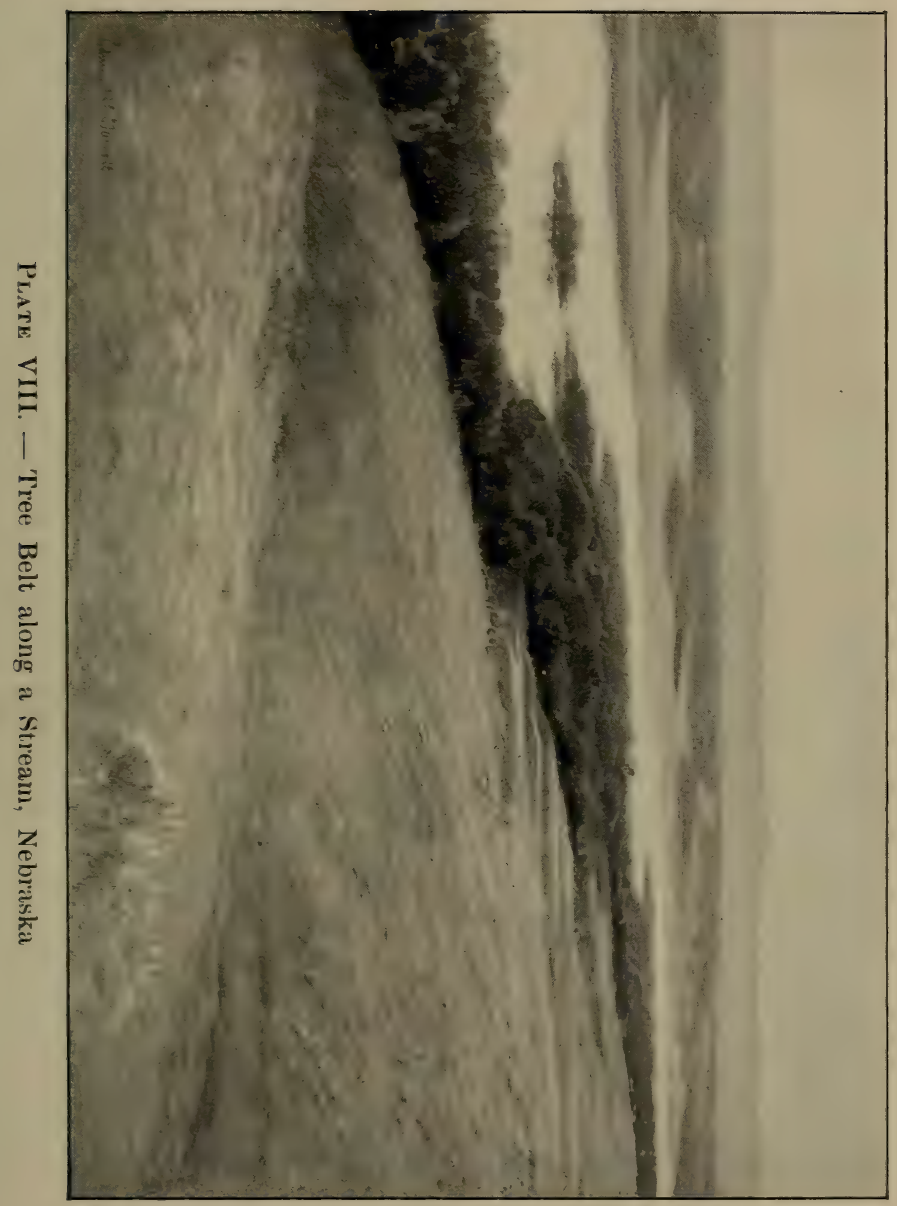



The Pacific Slope is characterized by cone-bearing evergreens in great abundance in the mountains and along the foothills. Chief among these in point of size are the redwoods and the "big trees" (Sequoias) (Fig. 32). Oaks are represented by a good many species, several of them evergreen. There are many xerophytes, some of them characteristic of alkali regions; and in Southern California, on account of the long dry season, plants with large roots or rootstocks and bulb-bearing plants (many of them belonging to the lily family) are abundant. The tree yucca (Plate VII) is one of the largest and most interesting xerophytic plants of North America. 


\section{CHAPTER XXVI}

\section{PARASITES, ENSLAVED PLANTS, MESSMATES, CARNIVOROUS PLANTS}

404. Parasites. - A little was said in Chapter IV about parasitic plants, and the life history of one of them, the dodder, was briefly outlined ; another, the wheat rust, was discussed in Sects. 310-313. A parasitic plant is one which draws its supply of food partially or wholly from another living plant or animal known as the host. Some parasites are seed-plants, but a far greater number of species are spore-plants.

405. Half-Parasitic Seed-Plants. - Half-parasites or partial parasites are those which take a portion of their food (or of raw materials to make food) from their host and manufacture the rest for themselves. Usually they take mainly the newly absorbed soil-water from the host and do their own starch-making by combining the carbonic acid gas, which they absorb through their leaves, with the water stolen by the parasitic roots or haustoria imbedded in the wood of the host. Evidently the needed water may just as well be taken from the underground parts of the host as from the upper portions, and accordingly many halfparasites are parasitic on roots. This is the case with many of the beautiful false foxgloves (Gerardia), with the painted-cup (Castillea), and some species of bastard toadflax (Comandra); see Flora. Usually these root-parasites are not recognized by non-botanical people as parasites at 


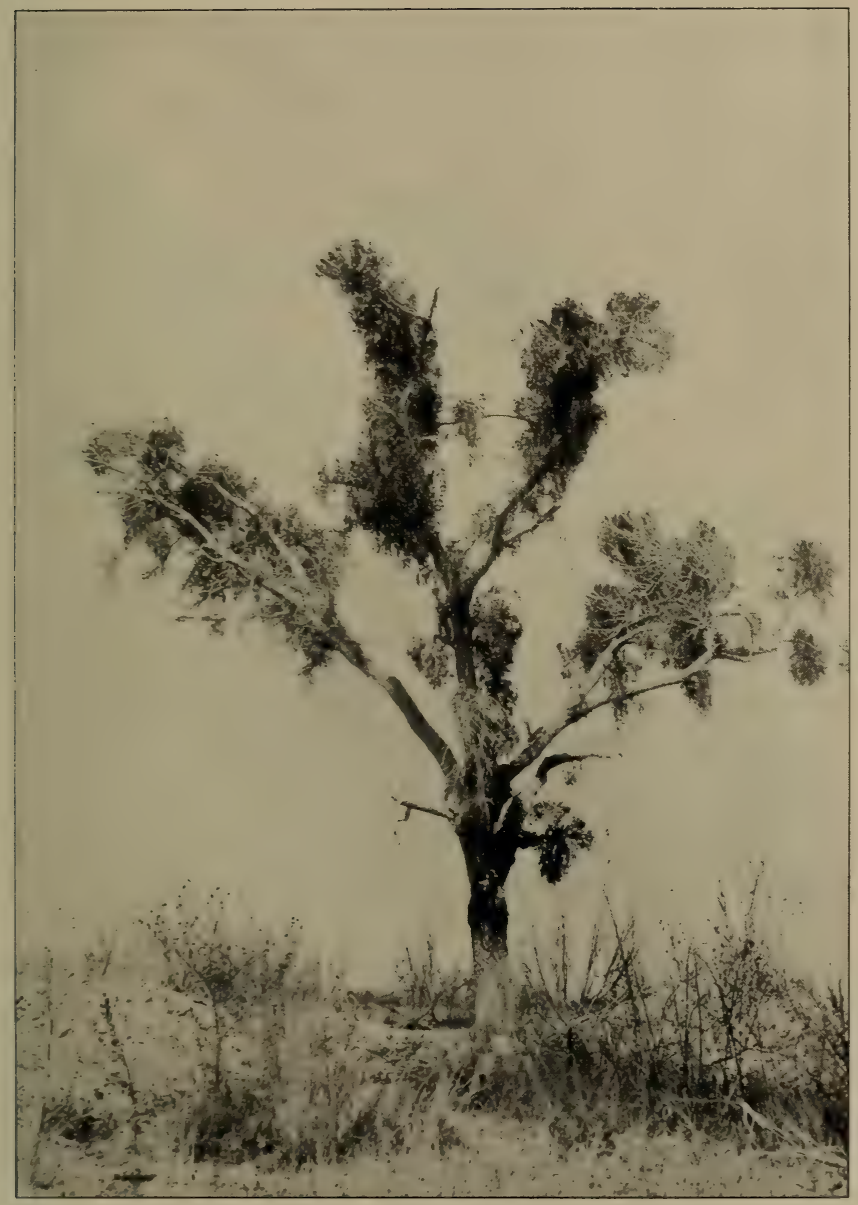

Plate IX. - A Cottonwood covered with Mistletoe 

all, but in Germany a species common in grain fields ${ }^{1}$ and the eyebright, which abounds in grass fields, are respectively known as "hunger" and "milk-thief," from the injury they do to the plants on which they fasten themselves. The mistletoe is a familiar example of a half-parasite, which roots on branches (Plate IX). Among the scanty belts of cottonwood trees along streams in New Mexico it is necessary to lop off the mistletoe every year to give the tree any chance to grow. Half-parasites may be known from plants that are fully parasitic by having green or greenish foliage, while complete parasites have no chlorophyll and so are not at all green.

406. Wholly Parasitic Seed-Plants. - These are so nearly destitute of the power of assimilation that they must rob other plants of all needed food or die of starvation. Some; like the cancer-root (see Flora), are root-parasites; others, like the dodder, are parasitic on stems above ground. The most dependent species of all, such as the flax-dodder, can live on only one kind of host, while the coarse orangestemmed dodder, ${ }^{2}$ which is common all over the central and the northeastern states, grows freely on many kinds of plants, from golden-rods to willows.

407. Parasitic Cryptogams. - The wheat rust (Sect. 310) affords an excellent example of the relations between parasitic fungi and their hosts. The illustration showing the potato blight escaping from a stoma of the potato leaf (Fig. 191) shows plainly one way in which a microscopic parasite finds its way out of the tissues of the host-plant to ripen and scatter its spores. 
Perhaps the most interesting, certainly to us the most practically important, cases of parasitism are those in which the bodies of animals, and especially of men, are attacked by parasitic plants. Bacilli and other bacteria of many species (Sect. 263) are among the commonest parasites which use the bodies of animals as hosts, and two or three examples will serve to illustrate how they find a lodgment in the host.

Rich garden soil, the dust of stables, and a good many other sources often contain immense numbers of a bacillus ${ }^{1}$ which causes lockjaw. A män in cleaning harness scratches his hand with a buckle, introduces the bacilli into his system, and is soon taken with an attack of lockjaw. Sewage water often swarms with the bacilli of typhoid fever ${ }^{2}$ (Fig. 174). The people in a city drink unfiltered water from a river into which sewage has been allowed to run higher up stream, the bacilli multiply at a rapid rate in the intestines of those who have drunk the water, and many of them are taken sick with typhoid fever. The phlegm expectorated by consumptive patients is full of the consumption bacillus ; ${ }^{3}$ this phlegm becomes dried up on floors, streets, or sidewalks, it is breathed by every one in the form of fine dust, and in the lungs of many who breathe it colonies of the bacillus are formed and the disease (consumption) becomes established in these persons.

408. Enslaved Plants. - Cases in which one kind of plant is useful in procuring food (or the raw materials of food) for another kind are quite common.

The relations on which algæ and fungi live together in
1 Bacillus tetani.
2 Bacillus typhi.
3 Bacillus tuberculosis. 
the form of lichens have already been described (Sect. 331) It is not correct to describe the condition of such algæ as slavery if the term is meant to imply that they derive no benefit from the association. Perhaps serfdom is a

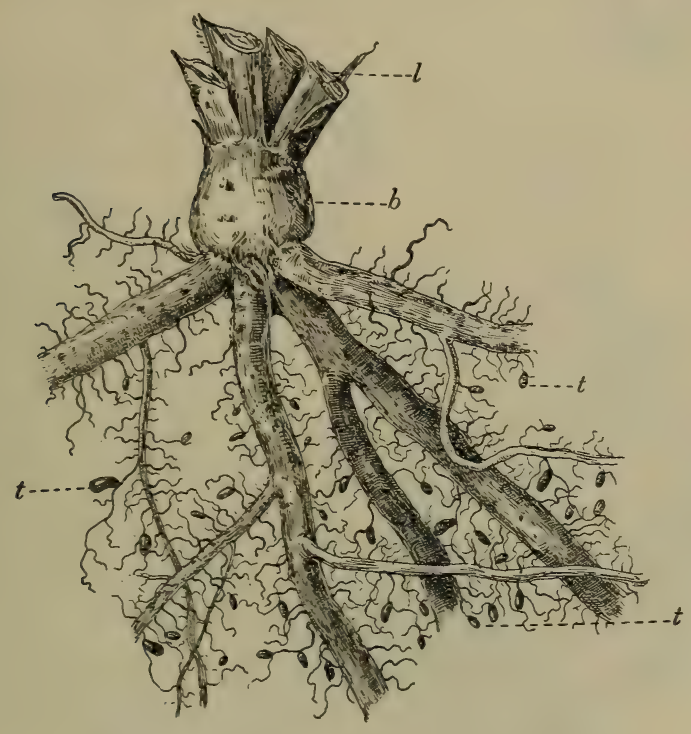

FIG. 236. - Roots of Red Clover with Tubercles.

$l$, sections of ascending branches ; $b$, enlarged base of stem; $t$, root-tubercles containing bacteria.

more suitable word, though it is not the term used by botanists. At all events, the alga is enclosed within a network of fungus hyphæ from which it cannot readily escape, and there does most of the work of the lichen, including all of the manufacture of food from carbon dioxide. 
409. Messmates. ${ }^{1}$ - Plants of very diverse character, which live most intimately together to the advantage of both parties, may be called messmates, since in some fashion

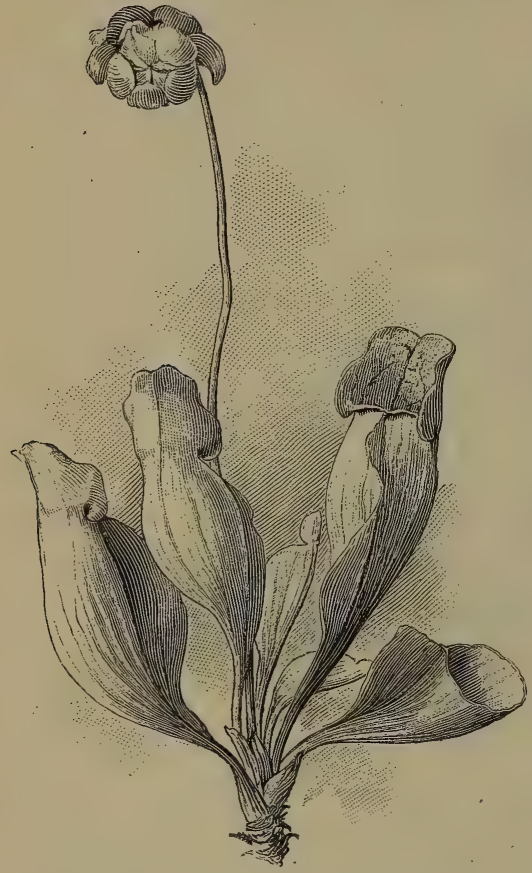

FIG. 237. - Common Pitcher-Plant. ${ }^{2}$

At the right one of the pitcher-like leaves is shown in cross-section. or other they divide the food supply between them.

Bacteria live in colonies enclosed in roottubercles on the roots of certain plants, for instance, beans, peas, lupines, vetches, and clover (Fig. 236), and render the greatest service to the plant to which the roots belong, from which they also derive food and shelter. Such plants do not develop roottubercles and will not grow well in sterilized soil, that is, soil in which the bacteria have been killed by baking. It is found that the bacteria serve to change nitrogen taken from the air of the soil into nitric acid, which is a most important ingredient in the manufacture of proteids.

Many trees, for example, oaks, beeches, and the cone-

1 This term is borrowed from the zoölogists as a much simpler one than symbionts to express the relation variously known as symbiosis, commensalism, or mutualism.

2 Sarracenia purpurea. 


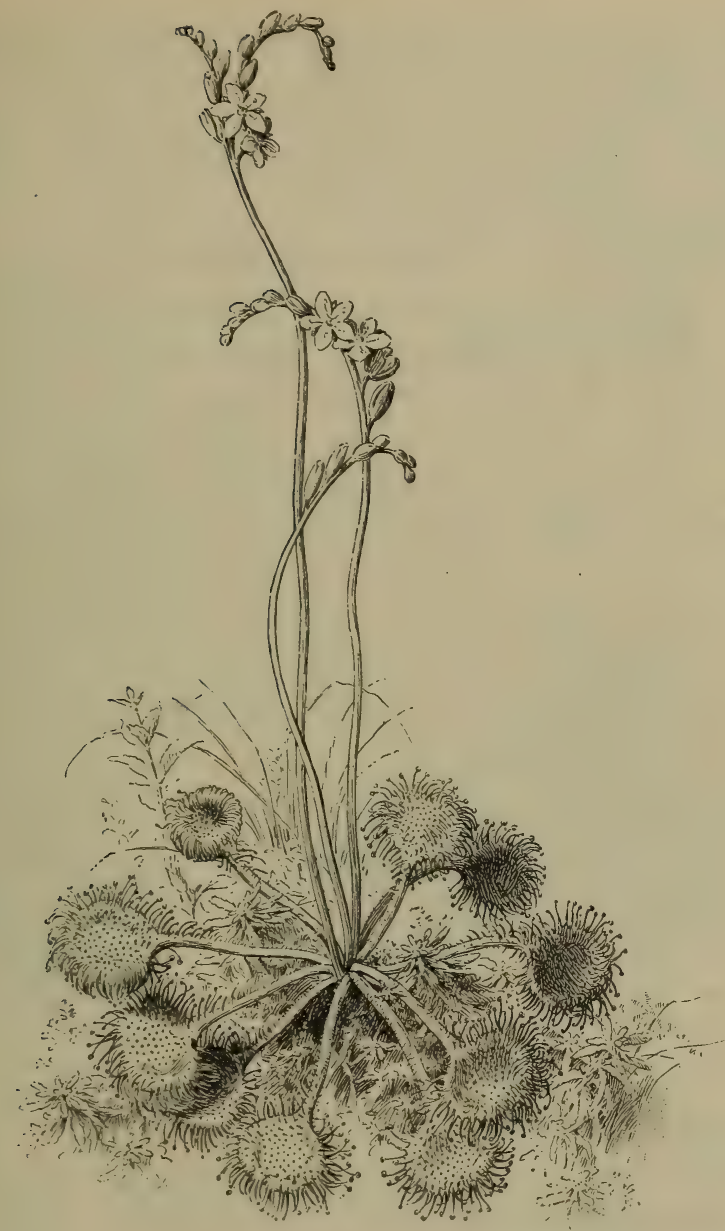

FIG. 238. - Sundew (Drosera rotundifolia).

bearing evergreens, and a considerable number of herbaceous plants, such as the Indian pipe (Monotropa, Plate V), are covered with a growth of fungus hyphæ (Sect. 307). 


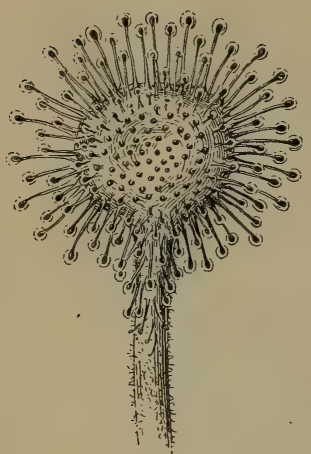

FIG. 239. - Blade of Leaf of Sundew. (Somewhat magnified.)

This growth completely surrounds the young, active tips of all the roots and the threads of the mykorhiza, as it is called, seem to do the work of roothairs.

410. Carnivorous Plants. - In the ordinary pitcher-plants (Fig. 237) the leaf appears in the shape of a more or less hooded pitcher. These pitchers are usually partly filled with water, and in this water very many drowned and decaying insects are commonly to be found. The insects have flown or crawled into the pitcher, and, once inside, have been unable to escape on account of the dense growth of bristly hairs about the mouth, all pointing inward and downward. How much the common American pitcherplants depend for nourishment on the drowned insects in the pitchers is not definitely known, but it is certain that some of the tropical species require such food. ${ }^{1}$

In other rather common plants, the sundews, insects are
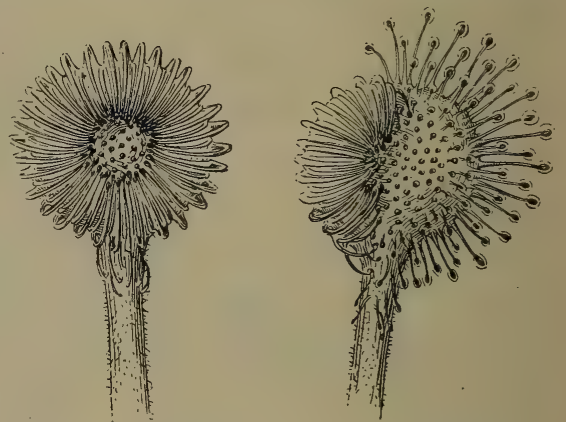

FIG. 240. - Leaves of Sundew. (Somewhat magnified.)

The one at the left has all its tentacles closed over captured prey; the one at the right has only half of them thus closed.

1 Where the Sarracenia is abundant it will be found interesting and profitable to make a careful class study of its leaves. See Geddes, Chapters in Modern Botany, Chapters I and II. 
caught by a sticky secretion which proceeds from hairs on the leaves. In one of the commonest sundews the leaves consist of a roundish blade, borne on a moderately long petiole. On the inner surface and round the margin of the blade (Fig. 239) are borne a considerable number of short bristles, each terminating in a knob which is covered with a clear, sticky liquid. When a small insect touches one of the sticky knobs, he is held fast and the hairs at once begin to close over him, as shown in Fig. 240. Here he soon dies and then usually remains for many days, while the leaf pours out a juice by which the soluble parts of the insect are digested. The liquid containing the digested portions is then absorbed by the leaf and contrib-

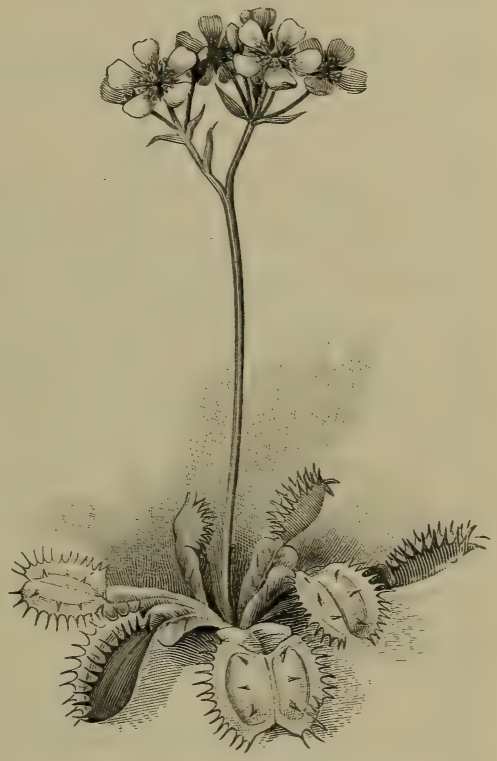

FiG. 241. - Venus Flytrap. utes an important part of the nourishment of the plant, while the undigested fragments, such as legs, wing-cases, and so on, remain on the surface of the leaf or may drop off after the hairs let go their hold on the captive insect.

In the T'enus flytrap, which grows in the sandy regions of eastern North Carolina, the mechanism for catching insects is still more remarkable. The leaves, as shown in 
Fig. 241, terminate in a hinged portion which is surrounded by a fringe of stiff bristles. On the inside of each half of the trap grow three short hairs. The trap is so sensitive that when these hairs are touched it closes with a jerk and very generally succeeds in capturing the fly or other insect which has sprung it. The imprisoned insect then dies and is digested, somewhat as in the case of those caught by the sundew, after which the trap reopens and is ready for fresh captures.

411. Object of catching Animal Food. - It is easy to understand why a good many kinds of plants have taken to catching insects and absorbing the digested products. Carnivorous, or flesh-eating, plants belong usually to one of two classes as regards their place of growth ; they are bog-plants or air-plants. In either case their roots find it difficult to secure much nitrogen-containing food, that is, much food out of which proteid material can be built up. Animal food, being itself largely proteid, is admirably adapted to nourish the growing parts of plants, and those which could develop insect-catching powers would stand a far better chance to exist as air-plants or in the thin, watery soil of bogs than plants which had acquired no such resources. 


\section{CHAPTER XXVII}

\section{HOW PLANTS PROTECT THEMSELVES FROM ANIMALS}

412. Destruction by Animals. - All animals are supported directly or indirectly by plants. In some cases the animal secures its food without much damaging the plant on which it feeds. Browsing on the lower branches of a tree may do it little injury, and grazing animals, if not numerous, may not seriously harm the pasture on which they feed. Fruit-eating animals may even be of much service by dispersing seeds (Sect. 453). But seed-eating birds and quadrupeds, animals which, like the hog, dig up fleshy roots, rootstocks, tubers or bulbs, and eat them, or animals which, like the sheep, graze so closely as to expose the roots of grasses or even of forest trees to be parched by the sun, destroy immense numbers of plants. So too with wood-boring and leaf-eating insects, and snails, which consume great quantities of leaves.

413. Some Modes of Protection from Animals. - Many of the characteristics of plants may be wholly or partly due to adaptations for protective purposes, while in particular cases we cannot be sure of the fact. Perching on lofty rocks or on branches of trees, burying the perennial part (bulb, rootstock, etc.) underground, growing in dense masses, like a canebrake or a thicket of blackberry bushes; all such habits of plants may be partly or altogether valuable to the plant as means of avoiding the attacks of animals, but this cannot be proved. On the other hand, 
there are plenty of instances of structures, habits, or accumulations of stored material in their tissue which plants seem to have acquired mainly or entirely as means of defense. Some of the most important are:

(1) The habit of keeping a bodyguard of ants.

(2) Mimicking the appearance of dangerous or uneatable plants, or imitating pebbles or earth, so that they may be overlooked.

(3) Forming tough, corky, woody, limy or flinty and therefore nearly uneatable tissue.

(4) Arming exposed parts with cutting edges, sharp or stinging hairs, prickles, or thorns.

(5) Accumulating unpleasant or poisonous substances in exposed parts.

414. Ant-Plants. - Some ants live on vegetable food, but most of them eat only animal food, and these latter are extremely voracious. It has been estimated by a careful scientist, an authority on this subject, that the ants of a single nest sometimes destroy as many as one hundred thousand insects in a day. The Chinese orangegrowers in the Province of Canton have found how useful ants may be as destroyers of other insects, and so they place ant nests in the orange trees and extend bamboos across from one tree to another, to serve as bridges for the ants to travel on.

Certain tropical trees, in order to insure protection by ants, offer them especial inducements to establish colonies on their trunks and branches. The attractions which are offered to ants by various kinds of trees differ greatly. One of the most interesting adaptations is that of an acacia $^{1}$ (Fig. 242), which furnishes little growths at the ends of the leaflets which serve as ant food. These little 
growths are known from their discoverer as Belt's bodies. The ants bore holes into the large hollow stipular thorns shown in the figure, live in these thorns, feed on the Belt's bodies, and protect the acacia from insect and other enemies. A nectary on the leaf furnishes additional food to the ant inhabitants of the tree. A great multitude of plants, some of them herbs, offer more or less important

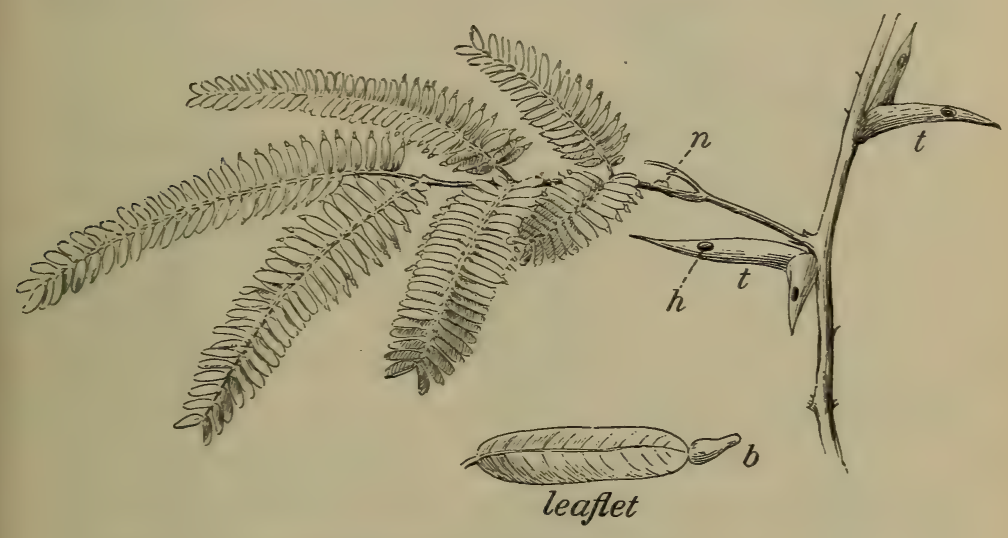

Fig. 242. - An Ant-Plant (Acacia).

$t$, thorns ; $h$, hole in thori ; $n$, nectary ; $b$, Belt's body on tip of leaflet.

inducements to attract ant visitors; the species which are known to do this number over three thousand.

415. Plants which mimic Plants or Other Objects. Instances of mimicry of protected plants by unprotected species are not very common. One of the best-known cases is that of the dead-nettle, which is so called because it looks like the stinging nettle, though it is. perfectly harmless. Some South African plants (Kleinias) appear to mimic pebbles. Certain Mesembryanthemums of the 
same region can hardly be distinguished from the earth in which they grow.

416. Plants of Uneatable Texture. - Whenever tender and juicy herbage is to be had, plants of hard and stringy texture are left untouched. The flinty-stemmed scouringrushes (Equisetum, Sect. 361) and the dry, tough rushes are familiar examples of uneatable plants of damp soil. In pastures there grow such perennials as the bracken fern and the hardhack of New England and the ironweed and vervains of the Central States, which are so harsh and woody that the hungriest browsing
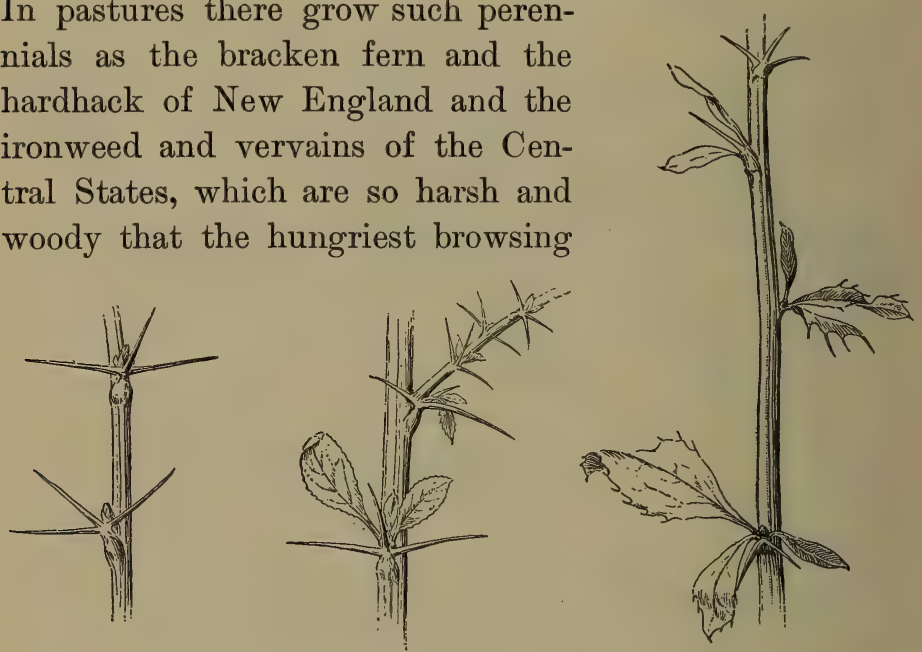

FIG. 243. - Spiny Leaves of Barberry.

animal is rarely, if ever, seen to molest them. Still other plants, like the knotgrass and cinquefoil of our dooryards, are doubly safe, from their growing so close to the ground as to be hard to graze and from their woody and unpalatable nature. The date-palm (which can easily be raised from the seed in the schoolroom or the laboratory) is an excellent instance of the same uneatable quality, found in a tropical or sub-tropical plant. 
417. Plants with Weapons for Defense. ${ }^{1}$ - Multitudes of plants, which might otherwise have been subject to the attacks of grazing or browsing animals, have acquired what have with reason been called weapons. Shrubs and trees not infrequently produce sharp-pointed branches, familiar in our own crab-apple, wild plum, thorn trees, and above all in the honey locust (Fig. 34), whose formidable thorns often branch in a very complicated manner.

Thorns, which are really modified leaves, are very perfectly exemplified in the barberry (Fig. 243). It is much commoner to find the leaf extending its midrib or its veins out into spiny

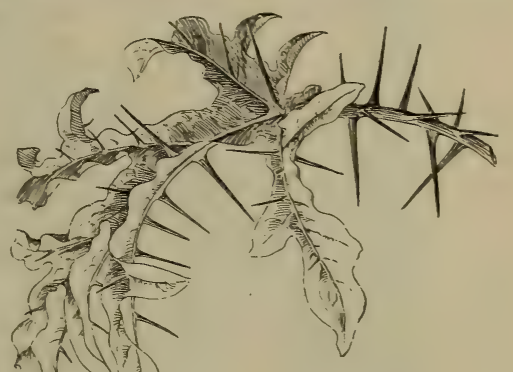
points, as the thistle does, or bearing spines or prickles on its midrib, as is the case with the nightshade shown in Fig. 244, and with so many roses. Prickles, which are merely hard, sharp-pointed projections from the epidermis, are of too common occurrence to need illustration.

Stipules are not infrequently found occurring as thorns, and in our common locust (Fig. 246) the bud, or the very young shoot which proceeds from it, is admirably protected by the jutting thorn on either side.

418. Pointed, Barbed, and Stinging Hairs. - Needlepointed hairs are an efficient defensive weapon of many plants. Sometimes these hairs are roughened, like those

1 See Kerner and Oliver's Natural History of Plants, Vol. I, p. 430. 
of the bugloss (Fig. 247, $b$ ); sometimes they are decidedly barbed. If the barbs are well developed they may cause the hairs to travel far into the flesh of animals and cause intense pain. In the nettle (Fig. 247, a) the hairs are efficient stings, with a brittle tip, which on breaking off

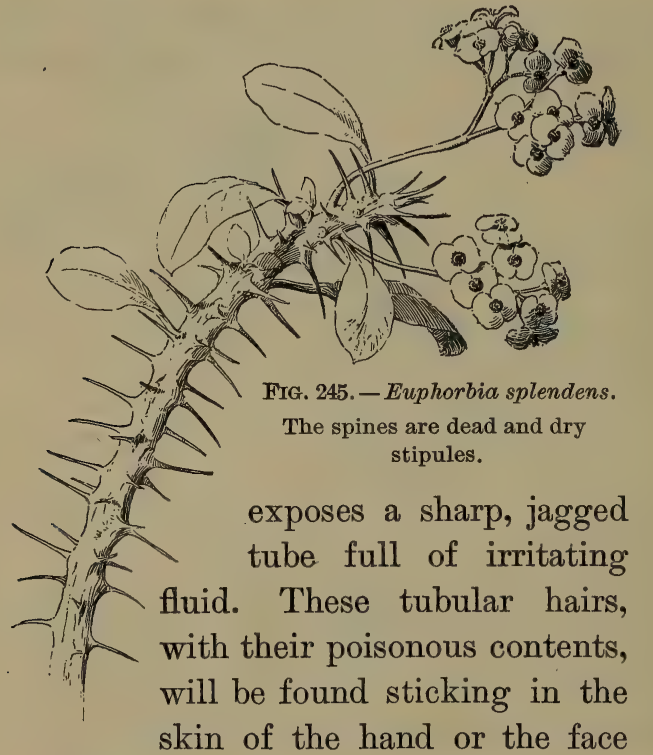

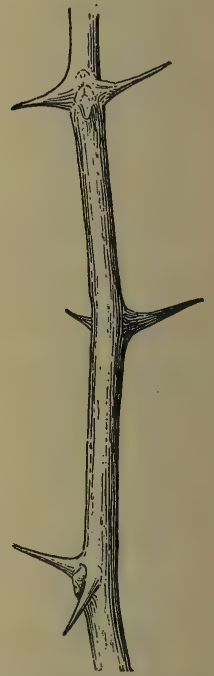

FIG. 246. - Thorn Stipules of Locust.

after incautious contact with nettles, and the violent itching which follows is only too familiar to most people.

419. Cutting Leaves. - Some grasses and sedges are generally avoided by cattle because of the sharp-cutting edges of their leaves, which will readily slit the skin of one's hand if they are drawn rapidly through the fingers. Under the microscope the margins of such leaves are seen to be regularly and thickly set with sharp teeth like those of a saw (Fig. 247, $c, d$ ). 
420. Weapons of Desert Plants. - In temperate regions, where vegetation is usually abundant, such moderate means of protection as have just been described are generally sufficient to insure the safety of the plants which have developed them. But in desert or semi-desert regions the
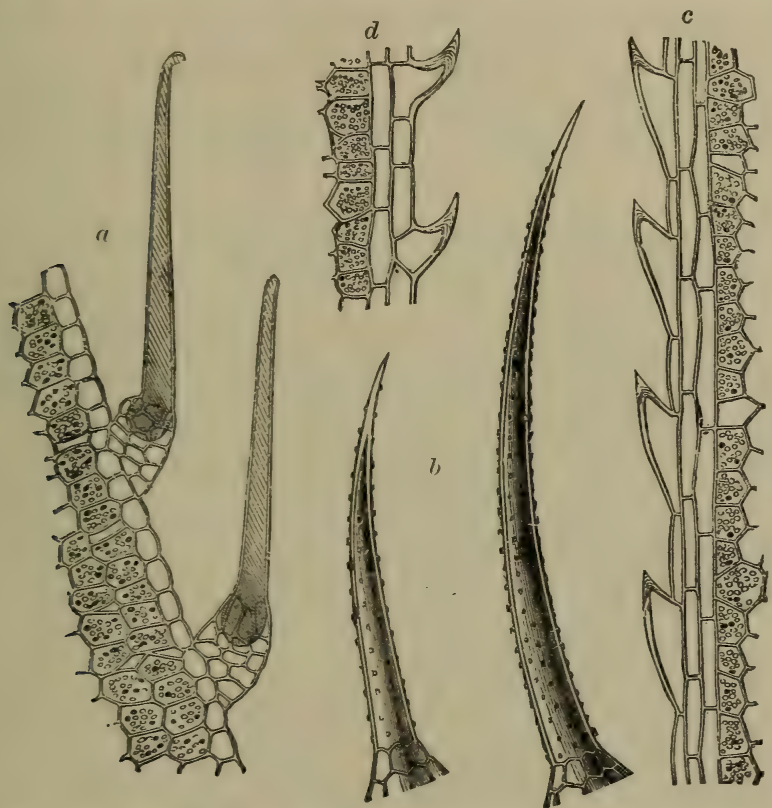

FIG. 247. - Stinging Hairs and Cutting Leaves. (All much magnified.) $a$, stinging hairs on leaf of nettle; $b$, bristle of the bugloss ; $c$, barbed margin of a leaf of sedge ; $d$, barbed margin of a leaf of grass.

extreme scarcity of plant life exposes the few plants that occur there to the attacks of all the herbivorous animals that may encounter them. Accordingly, great numbers of desert plants are characterized by nauseating or poisonous qualities or by the presence of astonishingly developed thorns, while some combine both of these means of defense. 
421. Offensive or Poisonous Plants. - A disgusting smell is one of the common safeguards which keep plants from being eaten. The dog fennel (Fig. 227), the hound's-tongue (Cynoglossum), the Martynia, and the tomato-plant are common examples of rank-smelling plants which are offensive to most grazing animals and so are let alone by them. Oftentimes, as in the case of the jimson weed (Datura), the tobacco-plant, and the poison hemlock (Conium), the smell serves as a warning of the poisonous nature of the plant.

A bitter, nauseating, or biting taste protects many plants from destruction by animals. Buckeye, horse-chestnut, and maple twigs and leaves are so bitter that browsing animals and most insects let them alone. Tansy, ragweed, boneset, southernwood, and wormwood are safe for the same reason. The nauseous taste of many kinds of leaves and stems, such as those of the potato, and the fiery taste of pepper-corns, red peppers, mustard, and horse-radish, make these substances uneatable for most animals. Probably both the smell and the taste of onions serve to insure the safety of the bulbs from the attacks of most grubs, and the hard corm of the jack-in-the-pulpit (Ariscema) (Frontispiece) is carefully let alone on account of the blistering nature of its contents.

Poisonous plants are usually shunned by grown-up animals, though the young ones will sometimes eat such plants and may be killed by them. Almost any part of a poisonous species may contain the poison characteristic of the plant, but, for obvious reasons, such substances are especially apt to be stored in the parts of the plant where its supply of reserve food is kept. 


\section{CHAPTER XXVIII}

\section{ECOLOGY OF FLOWERS}

422. Topics of the Chapter. - The ecology of flowers is concerned mainly with the means by which the transference of pollen or pollination is effected, and with the ways in which pollen is kept away from undesirable insect visitors and from rain.

423. Cross-Pollination and Self-Pollination. - It was long supposed by botanists that the pollen of any perfect flower needed only to be placed on the stigma of the same flower to insure satisfactory fertilization. But in 1857 and 1858 the great English naturalist, Charles Darwin, stated that certain kinds of flowers were entirely dependent for fertilization on the transference of pollen from one plant to another, and he and other botanists soon extended the list of such flowers until it came to include most of the showy, sweet-scented, or otherwise conspicuous kinds. It was also shown that probably nearly all attractive flowers, even if they can produce some seed when selfpollinated, do far better when pollinated from the flowers of another plant of the same kind. ${ }^{1}$ This important fact was established by a long series of experiments on the number and vitality of seeds produced by a flower when treated with its own pollen, or self-pollinated, and when

1 See Darwin's Cross and Self-Fertilization in the Vegetable Kingdom (especially Chapters I and II). 
treated with pollen from another flower of the same kind, or cross-pollinated. ${ }^{1}$

424. Wind-Pollinated Flowers. ${ }^{2}$ - It has already been mentioned that some pollen is dry and powdery, and other kinds are more or less sticky. Pollen of the dusty sort is light, and therefore adapted to be blown about by the wind. Any one who has been much in cornfields after the corn has "tasseled" has noticed the pale yellow dusty pollen which flies about when a cornstalk is jostled, and which collects in considerable quantities on

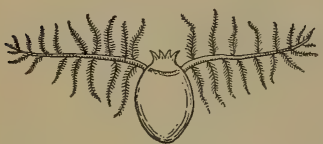

Frg. 248. - Pistil of a Grass, provided with a Feathery Stigma, adapted for WindPollination. the blades of the leaves. Corn is monœcious, but fertilization is best accomplished by pollen blown from the "tassel" (stamens) of one plant being carried to the "silk" (pistils) of another plant. This is well shown by the fact, familiar to every observing farmer's boy, that solitary cornstalks, such as often grow very luxuriantly in an unused barnyard or similar locality, bear very imperfect ears or none at all. The cornmon ragweed, another monœcious plant, is remarkable for the great quantities of pollen which shake off it on to the shoes or clothes of the passer-by, and it is wind-pollinated. So, too, are the monœcious pines, and these produce so much pollen that it has been mistaken for showers of sulphur, falling often at long distances from the woods where it was produced. The pistil of wind-pollinated flowers is often feathery and thus adapted to catch flying pollen-grains (Fig. 248). Other

1 On dispersion of pollen see Kerner and Oliver, Vol. II, pp. 129-287.

2 See Miss Newell's Botany Reader, Part II, Chapter VII. 
characteristics of such flowers are the inconspicuous character of their perianth, which is usually green or greenish, the absence of odor and of nectar, the regularity of the corolla, and the appearance of the flowers before the leaves or their occurrence on stalks raised above the leaves.

Pollen is, in the case of a few aquatic plants, carried from flower to flower by the water on. which it floats.

425. Insect-Pollinated Flowers. - Most plants which require cross-pollination depend upon insects as pollencarriers, ${ }^{1}$ and it may be stated as a general fact that the showy colors and markings of flowers and their odors all serve as so many advertisements of the nectar (commonly but wrongly called honey) or of the nourishing pollen which the flower has to offer to insect visitors.

Many insects depend mainly or wholly upon the nectar and the pollen of flowers for their food. Such insects usually visit during any given trip only one kind of flower, and therefore carry but one kind of pollen. Going straight from one flower to another with this, they evidently waste far less pollen than the wind or water must waste. It is therefore clearly advantageous to flowers to develop such adaptations as fit them to attract insect visitors, and to give pollen to the latter and receive it from them.

426. Pollen-Carrying Apparatus of Insects. ${ }^{2}-$ Ants and some beetles which visit flowers have smooth bodies, to which little pollen adheres, so that their visits are often of slight value to the flower, but many beetles, all butterflies and moths, and most bees have bodies roughened with scales or hairs which hold a good deal of pollen entangled.

1 A few are pollinated by snails; many more hy humming-birds ancl other birds.

2 See Müller's Fertilization of Flowers, Part II. 
In the common honey-bee (and in many other kinds) the greater part of the insect is hairy, and there are special collecting baskets, formed by bristle-like hairs, on the hind

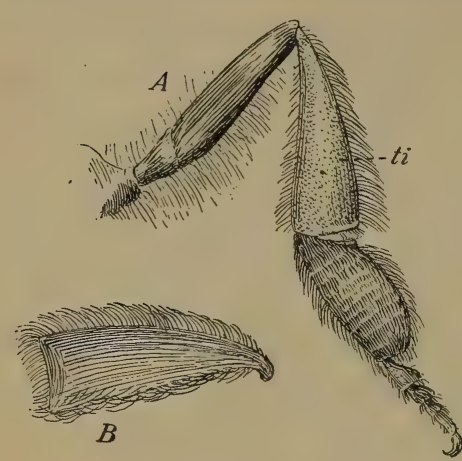

Frg. 249. legs (Fig. 249). It is easy to see the load of pollen accumulated in these baskets after such a bee has visited several flowers. Of course the pollen which the bee packs in the baskets and carries off to the hive, to be stored for food, is of no use in pollination. In fact such pollen is in one sense entirely

$A$, right hind leg of a honey-bee (seen from behind and within); $B$, the tibia, $t i$, seen from the outside, showing the collecting basket formed of stiff hairs.

wasted. But since such bees as have these collecting baskets are the most industrious visitors to flowers, they accomplish an immense share of the work of pollination by means of the pollen grains which stick to their hairy coats and are then transferred to other flowers of the same kind next visited by the bee.

427. Nectar and Nectaries. - Nectar is a sweet liquid which flowers secrete for the purpose of attracting insects. After partial digestion in the crop of the bee, nectar becomes honey. Those flowers which secrete nectar do so by means of nectar glands, small organs whose structure is something like that of the stigma, situated often near the base of the flower, as shown in Fig. 250. Sometimes the nectar clings in droplets to the surface of the nectar glands ; sometimes it is stored in little cavities or pouches 
called nectaries. The pouches at the bases of columbine petals are among the most familiar of nectaries.

428. Odors of Flowers. - The acuteness of the sense of smell among insects is a familiar fact. Flies buzz about the wire netting which covers a piece of fresh meat or a dish of syrup, and bees, wasps, and hornets will fairly besiege the window screens of a kitchen where preserving is going on. Many plants find it possible to attract as many insect visitors as they need without giving off any scent, but small flowers, like the mignonette, and nightblooming ones, like the white tobacco and the evening primrose, are sweet-scented to attract night-flying moths. It is interesting to observe that the majority of the flowers which bloom at night are white, and that they are much more generally sweet-scented than flowers which bloom during the day. A few flowers are carrion-scented (and purplish or brownish colored) and attract flies.

429. Colors of Flowers. - Flowers which are of any other color than green probably in most cases display their colors to attract insects, or occasionally birds. The principal color of the flower is most frequently due to showy petals; sometimes, as in the marsh marigold, it belongs to the sepals; and not infrequently, as in some cornels and Eu-

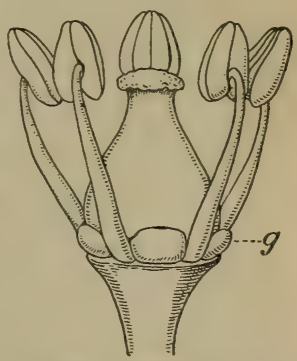

FIG. 250.- Stamens and Pistil of the Grape (magnified), with a Nectar Gland, $g$, between Each Pair of Stamens. phorbias (Fig. 245), the involucre is more brilliant and conspicuous than any part of the flower strictly so called.

Different kinds of insects appear to be especially artracted by different colors. In general, dull yellow, 
brownish, or dark purple flowers, especially if small, seem to depend largely on the visits of flies. Red, violet, and blue are the colors by which bees and butterflies are most readily enticed. The power of bees to distinguish colors has been shown by a most interesting set of experiments in which daubs of honey were put on slips of glass laid on separate pieces of paper, each of a different color, and exposed where bees would find them. ${ }^{1}$

It is certain, however, that colors are less important means of attraction than odors from the fact that insects are extremely near-sighted. Butterflies and moths cannot see distinctly at a distance of more than about five feet, bees and wasps at more than two feet, and flies at more than two and a fourth feet. Probably no insects can make out objects clearly more than six feet away. ${ }^{2}$ Yet it is quite possible that their attention is attracted by colors at distances greater than those mentioned.

430. Nectar Guides. - In a large number of cases the petals of flowers show decided stripes or rows of spots, of a color different from that of most of the petal. These commonly lead toward the nectaries, and it is possible that such markings point out to insect visitors the way to the nectaries. Following this course, the insect not only secures the nectar which he seeks, but probably leaves pollen on the stigma and becomes dusted with new pollen, which he carries to another flower.

431. Facilities for Insect Visits. - Regular polypetalous flowers have no special adaptations to make them singly

1 See Lubbock's Flowers, Fruits, and Leaves, Chapter I. On the gener:1 subject of colors and odors in relation to insects, see Müller's Fertilization of Flowers, Part IV.

2 See Packard's Text-Book of Entomology, p. 260. 
accessible to insects, but they lie open to all comers. They do, however, make themselves much more attractive and afford especial inducements in the matter of saving time to flower-frequenting insects by being grouped. This purpose is undoubtedly served by dense flower-clusters, especially by heads like those of the clovers and by the peculiar form of head found in so-called composite flowers, like the sunflower, the bachelor's button, and the yarrow (Fig. 133). In many such clusters the flowers are specialized, some carrying a showy strapshaped corolla, to serve as an advertisement of the nectar and pollen contained in the inconspicuous tubular flowers (see Plate XI). Irregular flowers probably always are more or less adapted to particular insect (or other) visitors. The adaptations are extremely numerous; - here only a rery few of the simpler ones will be pointed out. Where there is a drooping

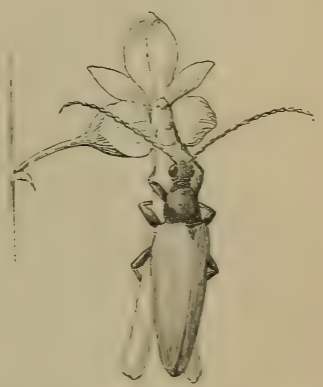

Fig. 251. - A Betie on the Flower of the Twayblade. (Enlarged three times.)

lower petal (or, in the case of a gamopetalous corolla, a lower lip), this serves as a perch upon which flying insects may alight and stand while they explore the flower, as the beetle is doing in Fig. 251. In Fig. 252 one bumblebee stands with his legs partially encircling the lower lip of the dead-nettle flower, while another perches on the sort of grating made by the stamens of the horse-chestnut flower. The honey-bee entering the violet clings to the beautifully bearded portion of the two lateral petals, while it sucks the nectar from the spur beneath. 
432. Protection of Pollen from Unwelcome Visitors. - It is usually desirable for the flower to prevent the entrance of small creeping insects, such as ants, which carry little pollen and eat a relatively large amount of it. The means adopted to secure this result are many and curious. In .

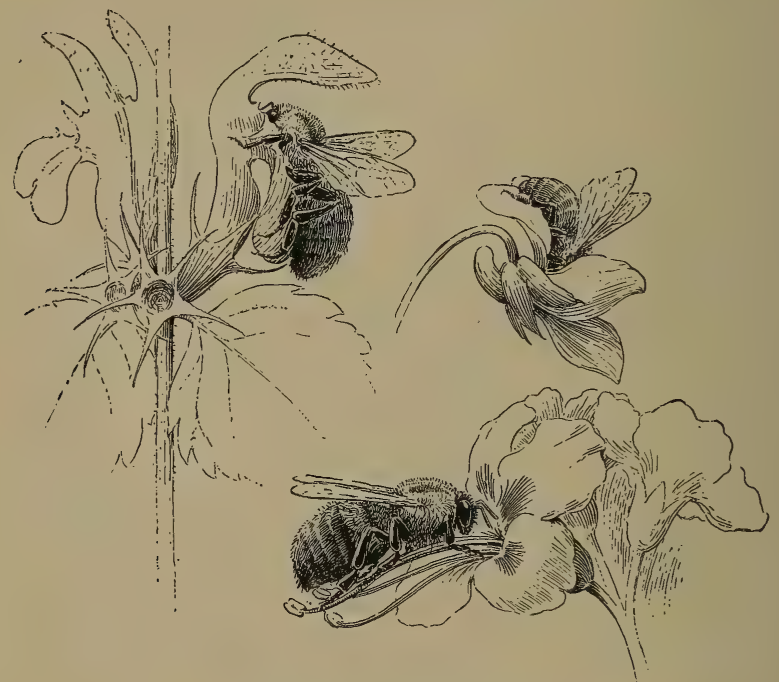

FIG. 252. - Bees visiting Flowers.

At the left a bumblebee on the flower of the dead nettle; below a similar bee in the flower of the horse-chestnut; above a honey-bee in the flower of a violet.

some plants, as the common catchfly, there is a sticky ring about the peduncle, some distance below the flowers, and this forms an effectual barrier against ants and like insects. Very frequently the calyx tube is covered with hairs, which are sometimes sticky. How these thickets of hairs may appear to a very small insect can perhaps be more easily realized by looking at the considerably 
magnified view of the hairs from the outer surface of mullein petals, shown in Fig. 253.1

Sometimes the recurved petals or divisions of the corolla stand in the way of creeping insects. In other cases the

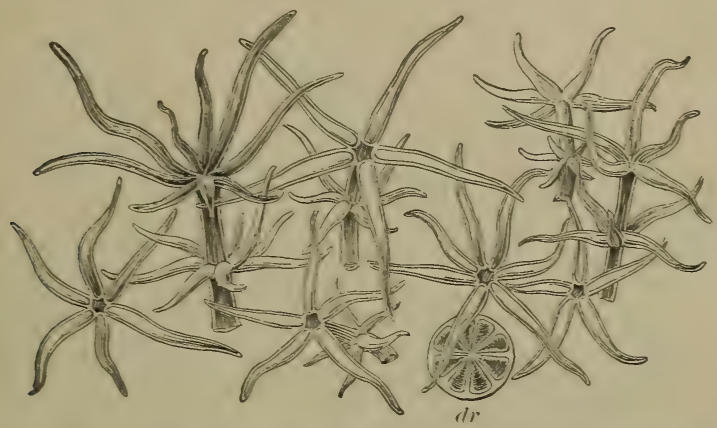

FIG. 253. - Branching Hairs from the Outside of the Corolla of the Common Mullein. (Magnified.) $d r$, a gland.

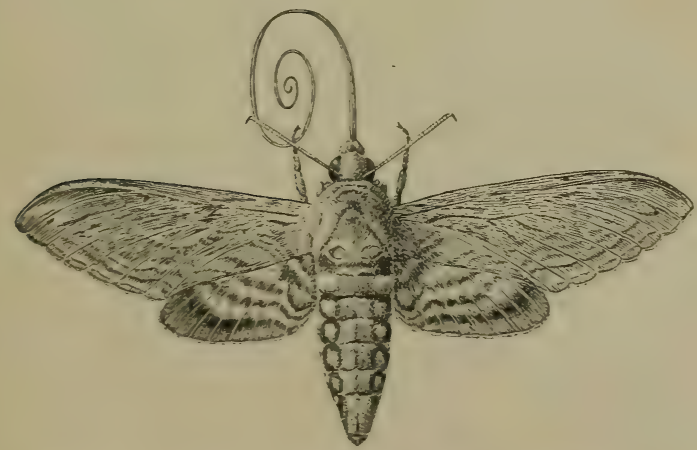

FIG. 254. - A Sphinx Moth, with a Long Sucking-Tube.

throat of the corolla is much narrowed or closed by hairs, or by appendages. Those flowers which have one or more

1 On protection of pollen, see Kerner and Oliver, Vol. II, pp. 95-109. 
sepals or petals prolonged into spurs, like the nasturtium and the columbine, are inaccessible to most insects except those which have a tongue or a sucking-tube long enough to reach to the nectary at the bottom of the spur. The large sphinx moth, shown in Fig. 254, which is a common visitor to the flowers of the evening primrose, is an example of an insect especially adapted to reach deep into long tubular flowers.

A little search among flowers, such as those of the columbine or the foxglove, will usually disclose many which have had the corolla bitten through by bees, which are unable to get at the nectar by fair means or unwilling to take the trouble to do so ; and they therefore steal it.

433. Bird-Pollinated Flowers. - Some flowers with very long tubular corollas depend entirely upon birds to carry their pollen for them. Among garden flowers the gladiolus, the scarlet salvia, and the trumpet honeysuckle are largely dependent upon humming-birds for their pollination. The wild balsam or jewel-weed and the trumpet-creeper (Plate $\mathrm{X}$ ) are also favorite flowers of the humming-bird.

434. Prevention of Self-Fertilization. - Diœcious flowers are of course quite incapable of self-pollination. Pistillate monœcious flowers may be pollinated by staminate ones on the same plant, but this does not secure as good seed as is secured by having pollen brought to the pistil from a different plant of the same kind.

In perfect flowers self-pollination would commonly occur unless it were prevented by the action of the essential organs or by something in the structure of the flower. In reality many flowers which at first sight would appear to be designed to secure self-pollination are almost or quite 


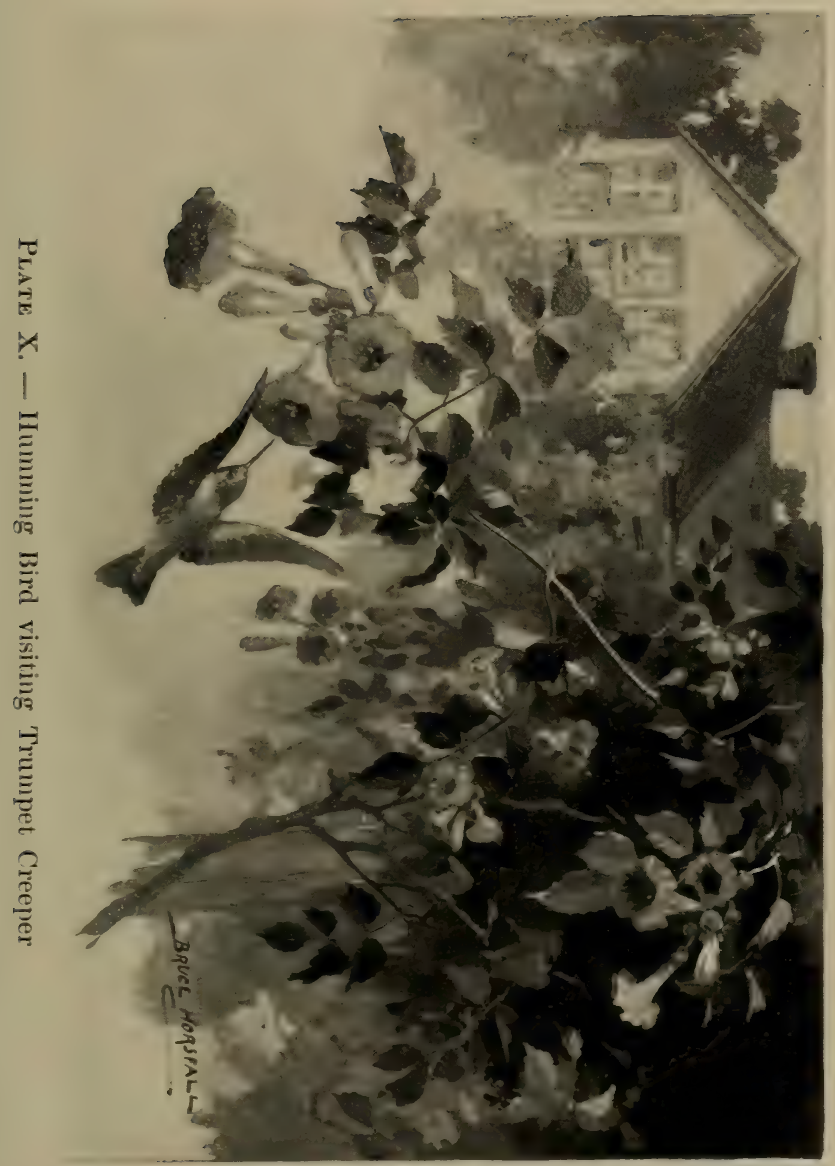



incapable of it. Frequently the pollen from another plant of the same species prevails over that which the flower may shed on its own pistil, so that when both kinds are placed on the stigma at the same time it is the foreign pollen which causes fertilization. But apart from this fact there are several means of insuring the presence of foreign pollen, and only that, upon the stigma. just when it is mature enough to receive pollen tubes.

435. Stamens and Pistils maturing at Different Times. - If the stamens mature at a different time from the pistils, self-pollination is as effectually prevented as though the plant were diœcious. This unequal maturing or dichogamy occurs in many kinds of flowers. In some, the figwort and the common plantain for example, the pistil develops before the stamens, but usually the

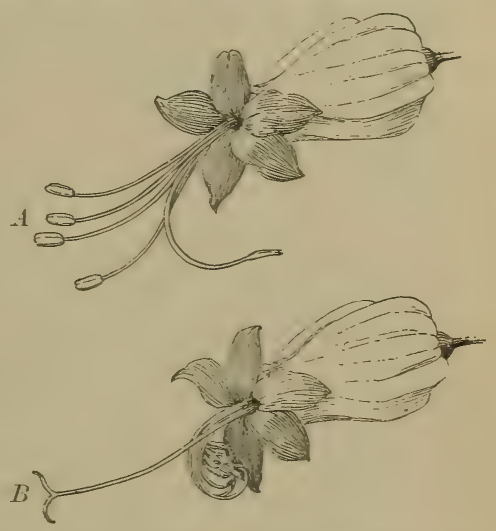

Frg. 255. - Flower of Clerodendron in Two Stages.

In $A$ (earlier stage) the stamens are mature, while the pistil is still undeveloped and bent to one side. In $B$ (later stage) the stamens have withered and the stigmas have separated, ready for the reception of pollen.

reverse is the case. The Clerodendron, ${ }^{1}$ a tropical African flower (Fig. 255), illustrates in a most striking way the development of stamens before the pistil. The insect visitor, on its way to the nectary, can hardly fail to brush against the protruding stamens of the flower in its earlier stage (at A), but it cannot deposit any pollen on the stigmas, 
which are unripe, shut together, and tucked aside out of reach. On flying to a flower in the later stage the pollen just acquired will be lodged on the prominent stigmas and

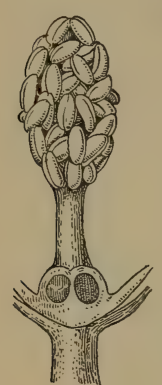

I thus produce the desired cross-pollination.

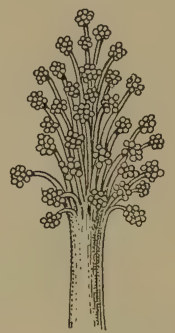

II

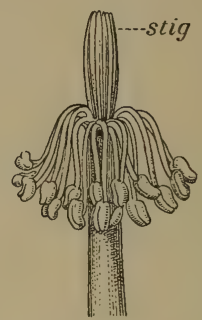

III

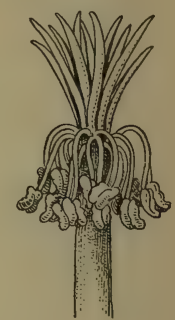

IV

FIG. 256. - Provisions for Cross-Pollination in the High Mallow.

I, essential organs as found in the bud; II, same in the staminate stage, the anthers discharging pollen, pistils immature; UI, intermediate stage, stig, the united stigmas; IV, pistillate stage, the stigmas separated, stamens withered.

Closely related flowers often differ in their plan of pollination. The high mallow, a plant cultivated for its purplish flowers, which has run wild to some extent, is admirably adapted to secure cross-pollination, since when

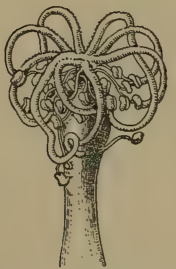

Fig. 257. - Stamens and Pistils of RoundLeafed Mallow. The stigmas curled round among the stamens to admit of self-pollination. its stamens are shedding pollen, as in Fig. 256, II, the pistils are incapable of receiving it, while when the pistils are mature, as at IV, the stamens are quite withered. In the common low mallow of our dooryards and waysides insect pollination may occur, but if it does not the curling stigmas finally come in contact with the projecting stamens and receive pollen from them, as is indicated in Fig. 257. 
436. Movements of Floral Organs to aid in Pollination. - Besides the slow movements which the stamens and pistil make in such cases as those of the Clerodendron and the mallow, already described, the parts of the flower often admit of considerable and rather quick movements to assist the insect visitor to become dusted or smeared with pollen.

In some flowers whose stamens perform rapid movements when an insect enters, it is easy to see how directly

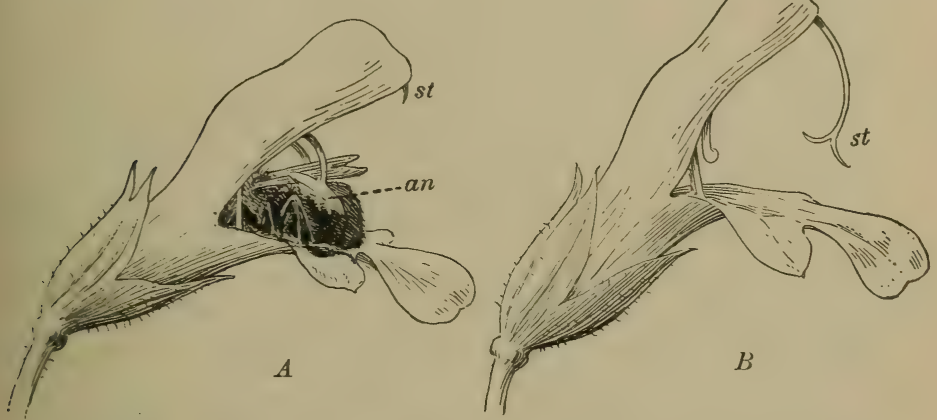

Fig. 258. - Two Flowers of Common Sage, one of them visited by a Bee.

useful the motion of the stamens is in securing crosspollination. The stamens of the laurel, Kalmia, throw little masses of pollen, with a quick jerk, against the body of the visiting insect. Barberry stamens spring up against the visitor and dust him with pollen. The common garden sage matures its anthers earlier than its stigmas. In Fig. 258, $A$, the young flower is seen, visited by a bee, and one anther is shown pressed closely against the side of the bee's abdomen. The stigma, st, is hidden within the upper lip of the corolla. In $B$, an older flower, the 
anthers have withered and the stigma is now lowered so as to brush against the body of any bee which may enter.
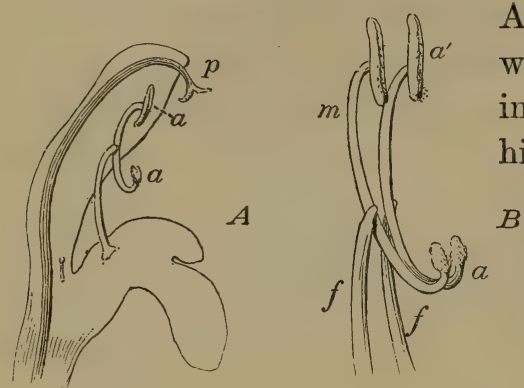

A little study of Fig. 259 will make clear the way in which the anthers are hinged, so that a bee strik-

$B$

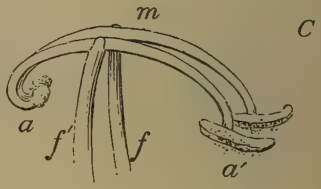

FiG. 259. - Flower and Stamens of Common Sage.

$A, p$, stigma ; $\alpha$, anthers ; $B$, the two stamens in ordinary position ; $f$, filaments ; $m$, connective (joining anther-cells); $a^{\prime}$, anther-cells; $C$, the anthers and connectives bent into a horizontal position by an insect pushing against $a$.

ing the empty or barren anther-lobes, $a$, knocks the pollenbearing lobes, $a^{\prime}$, into a horizontal position, so that they will lie closely pressed against either side of its abdomen.

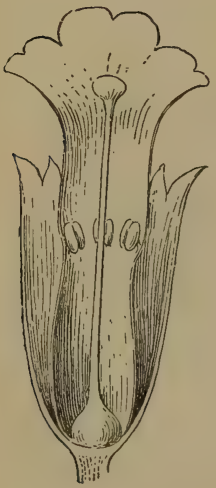

I

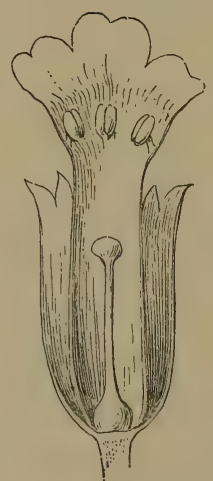

II

Frg. 260. - Dimorphous Flowers of the Primrose.

I, a long-styled flower; II, a shortstyled one.

43\%. Flowers with Stamens and Pistils Each of Two Lengths. - The flowers of bluets, partridge-berry, the primroses, and a few other common plants secure crosspollination by having essential organs of two forms (Fig. 260). Such flowers are said to be dimorphous (of two forms). In the short-styled flowers, II, the anthers are borne at the top of the corolla tube and the 
stigma stands about halfway up the tube. In the longstyled flowers, I, the stigma is at the top of the tube and the anthers are borne about halfway up. An insect pressing its head into the throat of the corolla of II would become dusted with pollen, which would be brushed off on the stigma of a flower like I. On leaving a long-styled flower the bee's tongue would be dusted over with pollen, some of which would necessarily be rubbed off on the stigma of the next short-styled flower that was visited. Cross-pollination is insured, since all the flowers on a plant are of one kind, either long-styled or short-styled, and since the pollen is of two sorts, each kind sterile on the stigma of any flower of similar form to that from which it came.

Trimorphous flowers, with long, medium, and short styles, are found in a species of loosestrife. ${ }^{1}$

438. Studies in Insect Pollination. - The student cannot gather more than a very imperfect knowledge of the details of cross-pollination in flowers without actually watching some of them as they grow, and observing their insect visitors. If the latter are caught and dropped into a wide-mouthed stoppered bottle containing a bit of cotton saturated with chloroform, they will be painlessly killed, and most of them may be identified by any one who is familiar with our common insects. The insects may be observed and classified in a general way into butterflies, moths, bees, flies, wasps, and beetles, without being captured or molested.

Whether these out-of-door studies are made or not, several flowers should be carefully examined and described as regards their arrangements for attracting and utilizing insect visitors (or birds). The following list includes a considerable number of the most accessible flowers of spring and early summer, about which it is easy to get information from books.

${ }^{1}$ See Miss Newell's Reader in Botany, Part II, pp. 60-63. 


\section{LIST OF INSECT-POLLINATED FLOWERS. ${ }^{1}$}

\section{I}

1. Flax . . . . . Linum usitatissimum . . . . . . Müll.

2. Missouri currant . Ribes aureum . . . . . . . . . Müll.

3. Snowberry . . . Symphoricarpus racemosus . . . . Müll.

4. Lilac . . . . . Syringa persica . . . . . . . . Müll.

5. Periwinkle . . . Vinca minor . . . . . . . . . Müll.

6. Mignonette . . . Reseda odorata . . . . . . . . Müll.

7. Pansy . . . . . Viola tricolor . . . . . . . . . Müll.

8. Dead nettle . . . Lamium album . . . . . . . Lubbock.

9. Bleeding heart . . Dicentra (Diclytra) spectabilis . . . Müll.

10. Columbine . . . Aquilegia vulgaris . . . . . . . Müll.

11. Monkshood . . . Aconitum Napellus . . . . . . . Müll.

II

12. Larkspur . . . . Delphinium elatum, D. consolida . . Müll.

13. Herb Robert. . . Geranium robertianum . . . . . . Müll.

14. Pink . . . . . Dianthus (various species) . . . . Müll.

15. Fireweed . . . . Epilobium angustifolium . . . . . Gray.

16. Nasturtium . . . Tropceolum majus . . . Newell, Lubbock.

17. Lily-of-the-valley . Convallaria majalis . . . . . . . Müll.

18. Heal-all . . . . Brunella (Prunella) vulgaris . . . . Müll.

19. Ground ivy . . . Nepeta Glechoma . . . . Müll., Newell.

20. Lousewort . . . Pedicularis canadensis . . . Müll., Newell.

21. Snapdragon . . . Antirrhinum majus . . . . . . . Müll.

22. Iris . . . . . . Iris versicolor . . . . . . . Newell.

23. Bellflower . . . Campanula rapunculoides . . . . Müll.

24. Horse-chestnut . . Assculus Hippocastanum . . . . Newell.

1 The plants in this list are arranged somewhat in the order of the complexity of their adaptations for insect pollination, the simplest first. It would be well for each student to take up the study of the arrangements for the utilization of insect visitors in several of the groups above, numbered with Roman numerals. The teacher will find explanations of the adaptations in the works cited by abbreviations at the right. Müll. stands for Müller's F'ertilizution of Flowers; Lubbock, for British Wild Flowers, considered in Relation to Insects; Gray, for Gray's Structural Botany; and Newell, for Miss Newell's Outlines of Lessons in Botany, Part II. Consult also Weed's Ten New England Blossoms. 
III

25. Yarrow . . . Achillea millefolium . . . \& . Müll.

26. Oxeye daisy . . . Chrysanthemum Leucanthemum . . . Müll.

27. Dandelion . . . Taraxacum officinale . . Müll., Newell.

IV

28. Barberry . . . Berberis vulgaris . . . . . . Lubbock.

29. Mountain laurel . Kalmia latifolia . . . . . . . Gray.

V

30. White clover. . . Trifolium repens . . . . . . . Müll.

31. Red clover . . . Trifolium pratense . . . . . . . Müll.

32. Locust. . . . Robinia Pseudacacia . . . . . . Gray.

33. Wistaria . . . Wistaria sinensis . . . . . . Gray.

34. Vetch . . . . Vicia cracca . . . . . . . . Müll.

35. Pea . . . . . . Pisum sativum . . . . . . . Müll.

36. Bean . . . . Phaseolus vulgaris . . . . . Gray.

37. Ground-nut . . Apios tuberosa . . . . . . Gray.

\section{VI}

38. Partridge-berry . . Mitchella repens . . . . . . . Gray.

39. Primrose . . . Primula grandiflora, P. officinalis . Lubbock.

40. Loosestrife . . . Lythrum Salicaria . . . . . . Gray.

\section{VII}

41. Milkweed . . . Asclepias Cornuti . . . . Müll., Newell.

\section{VIII}

42. Lady's-slipper . . Cypripedium acaule . . . . Newell.

439. Cleistogamous Flowers. - In marked contrast with such flowers as those discussed in the preceding sections, which bid for insect visitors or expose their pollen to be blown about by the wind, are certain flowers which remain closed even during the pollination of the stigma. These flowers are called cleistogamous and of course are not 
cross-pollinated. Usually they occur on plants which also bear flowers adapted for cross-pollination, and in this

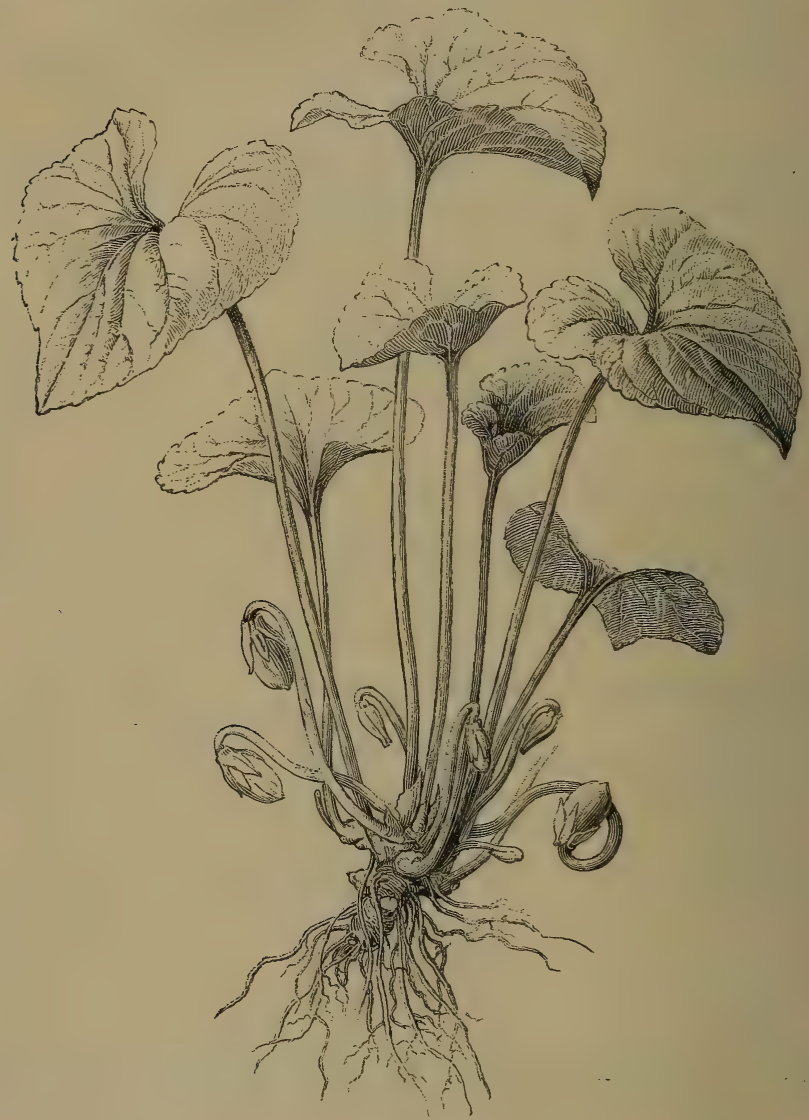

FIG. 261. - A Violet, with Cleistogamous Flowers.

The objects which look like flower-buds are cleistogamous flowers in various stages of development. The pods are the fruit of similar flowers. The plant is represented as it appears in late July or August, after the ordinary flowers have disappeared. 
case the closed flowers are much less conspicuous than the others, yet they produce much seed. Every one knows the ordinary flowers of the violet, but most people

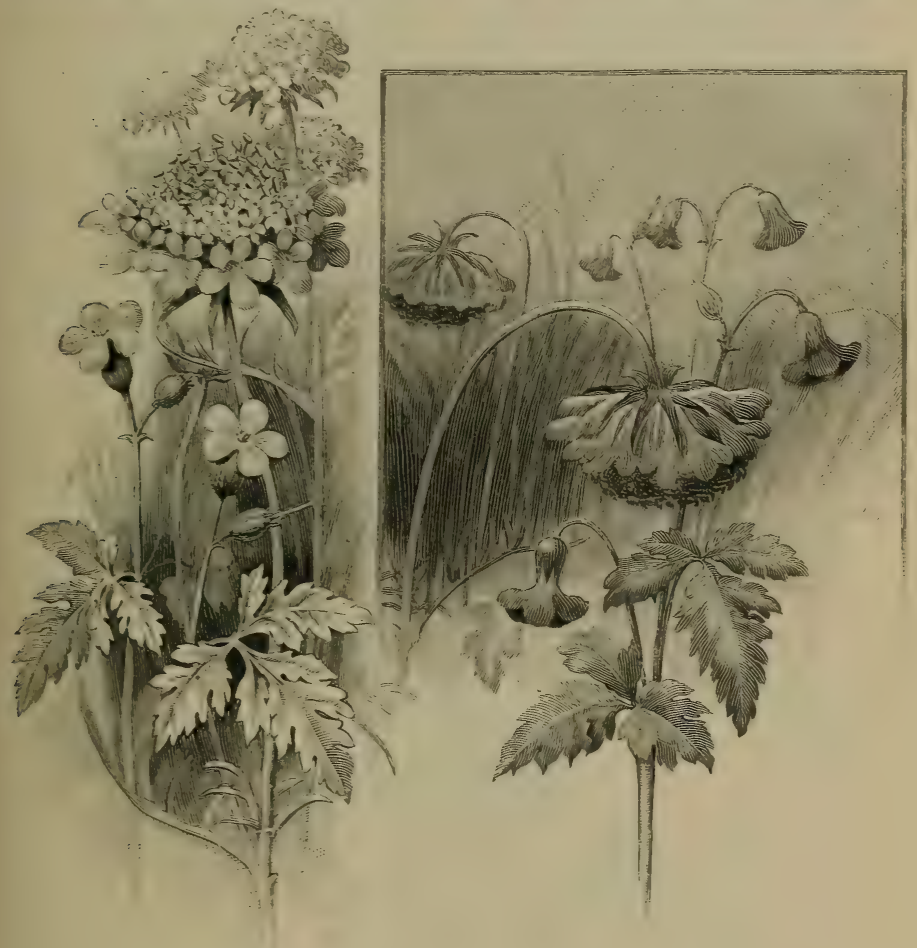

FIG. 262. - Protection of Pollen from Moisture.

At the left herb Robert and sweet scabious in sunny weather; at the right the same flowers during rain.

do not know that violets very generally, after the blossoming season (of their showy flowers) is over, produce many cleistogamous flowers, as shown in Fig. 261. 
440. Protection of Pollen from Rain. - Pollen is very generally protected from being soaked and spoiled by rain or dew either by the natural position of the flower preventing rain from entering, as in the case with most gamopetalous, nodding flowers, or by changes in the position of the flower, and by its opening in sunny weather and closing at night or during rain. Sometimes the flower both changes its position and closes, as is the case with the herb Robert and the sweet scabious (Fig. 262). The adaptations of flowers to protect their pollen from becoming wet can best be understood by actually examining the same flower in sunshine and during rain. 


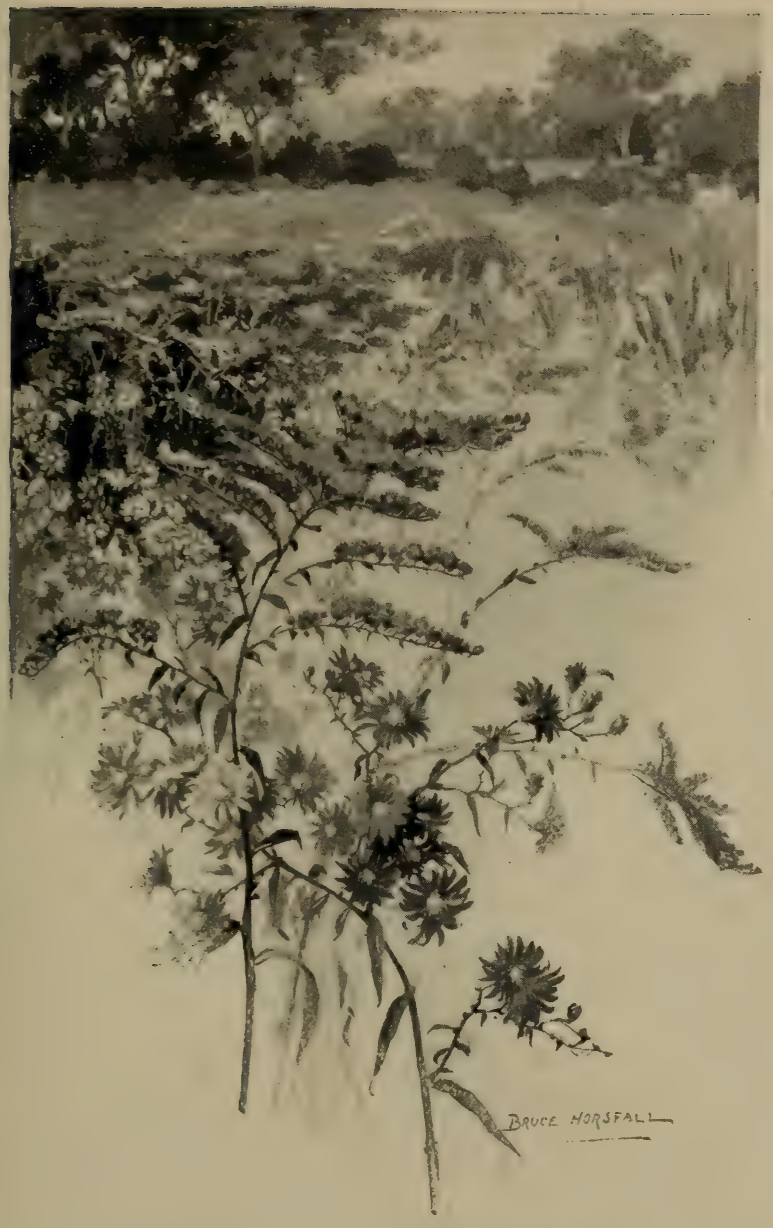

Plate XI. - Aster and Golden-Rod 



\section{CHAPTER XXIX}

\section{HOW PLANTS ARE SCATTERED AND PROPAGATED}

\section{Means of Propagation among Cryptogams. - Some}

of the highest cryptogams, as the ferns, spread freely by means of their creeping rootstocks, and the gardener who wishes quickly to get large, strong ferns often finds it the easiest plan to cut to pieces and reset the rootstocks of a well-established plant. Some ferns also grow readily from bulblets produced on the fronds. In the walking fern the tip of the frond roots and begins a new plant. Most flowerless plants, however, are reproduced either by a process of fission, as in Pleurococcus (Sect. 278), Diatoms (Sect. 271), Bacteria (Sect. 266), and many other groups, or by some kind of spore (Sect. 259). The spore is usually so small an object that it is carried with the greatest ease by currents of water or of air, as the case may be, so that it is no sooner liberated than it is swept away, often to a very distant locality, where it can grow and not be interfered with by too many neighbors of its own kind. Thus spores of any of the marine algæ are certainly carried thousands of miles by ocean currents, and spores of tree ferns may be blown great distances from one oceanic island to another, or the spore contents of a puff-ball might travel on the wind half the breadth of a continent.

442. Dispersal of Seed-Plants by Roots and Rootstocks. The student has learned (in Chapters IV and V) that roots and underground stems of many kinds may serve to 
reproduce the plant. Either roots or rootstocks may travel considerable distances horizontally in the course of their growth and then shoot up and produce a new plant, which later becomes independent of the parent. The sedges (Fig. 43) are excellent illustrations of this process, and trees

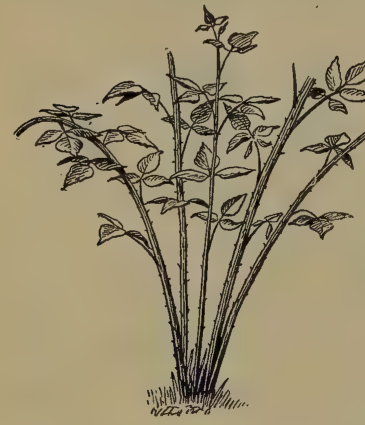

FIG. 263. - Plant of a Black Raspberry, showing One Branch (Stolon) with Several Tips rooting.

like the common locust and the silver-leaf poplar become great nuisances in the neighborhood of lawns and gardens by sending up sprouts in many places. When growing wild, such trees as these depend largely upon spreading by the roots to keep up their numbers. ${ }^{1}$

443. Dispersal of Seed-Plants by Branches. - There is a shrub of the Honeysuckle Family, ${ }^{2}$ common in the northern woods, which is quite generally known as hobble-bush, or witch-hobble, and sometimes as trip-toe. This is because the branches take root at the end and so form loops which catch the foot of the passer-by. The same habit of growth is found in the raspberry-bush (Fig. 263), in one species of strawberry-bush (Euonymus), and some other shrubs. Many herbs like the strawberry-plant and the cinquefoil send 
out long, leafless runners which root at intervals and so propagate the plant, carrying the younger individuals off to a considerable distance from the parent plant.

Living branches may drop freely from the tree and then take root and grow, after having been blown or been carried by a brook or river to a favorable spot, perhaps hundreds of yards away. The so-called snap-willows lose many live twigs under conditions suitable for starting new trees.

A slightly different mode of dispersal from that of the raspberry is one in which buds separate from the plant and serve to propagate it. In the bladderwort (Fig. 264), at the close of the growing season, the

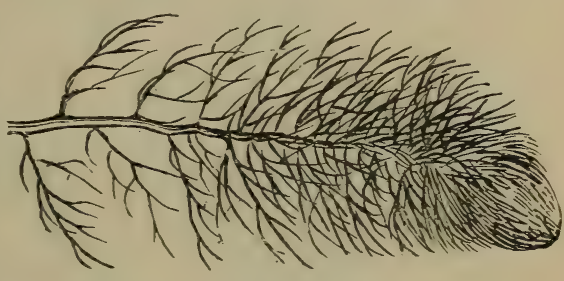

Frg. 264. - A Free Branch and Two Buds of Bladderwort.

terminal buds are released by the decay of the stem and sink to the bottom of the water in which the plants live, there to remain dormant until spring. Then each bud starts into life and gives rise to a new individual.

444. Dispersal of Seed-Plants by Bulblets. - Almost every farmer's boy knows what "onion-sets" are. These are little bulbs, produced at the top of a naked flowerstalk or scape by some kinds of onions which do not usually flower or bear seed. Tiger-lilies produce somewhat similar bulblets in the axils of the leaves, and there is a large number of species, scattered among numerous families of plants, all characterized by the habit of producing 
bulblets. When mature the bulblets fall off readily, and if they find lodgment on unoccupied soil, they grow readily into new plants. Sometimes they are carried moderate distances by wind or water, and if the ground slopes, they may easily roll far enough to get started in new places.

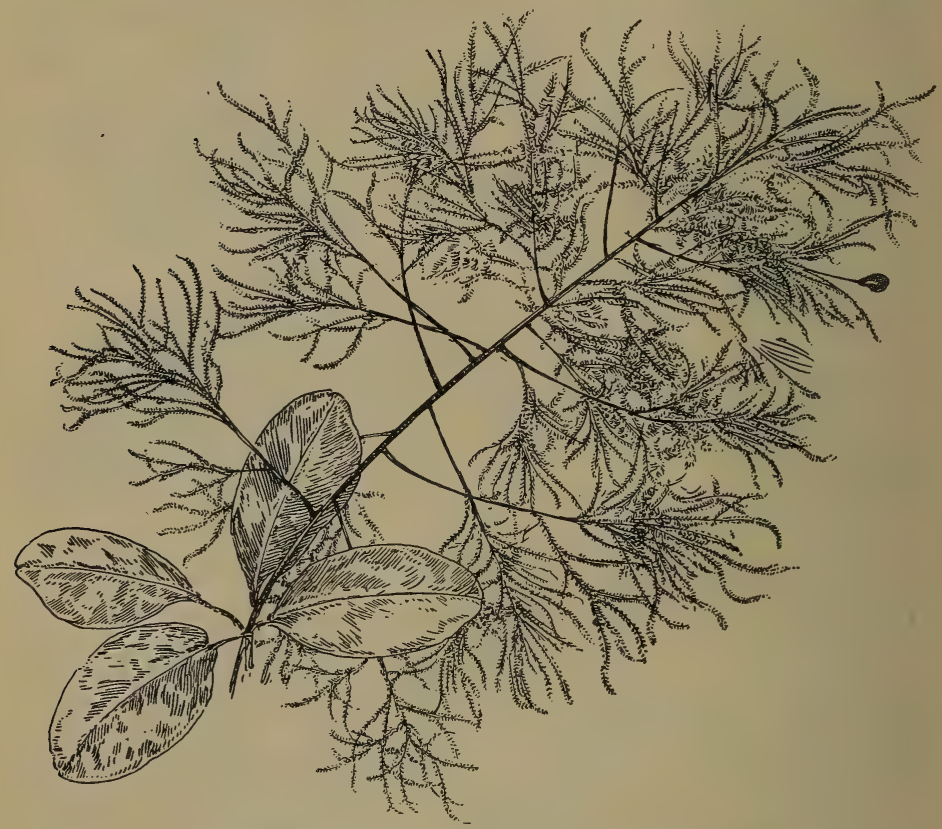

FIG. 265. - Fruit of Smoke-Tree (Rhus Cotinus).

Only one pedicel bears a fruit, all the others are sterile, branched, and covered with plumy hairs.

445. Dispersal of Seeds. - Seeds are not infrequently scattered by apparatus by which the plant throws them about. More commonly, however, they depend upon other agencies, such as wind, water, or animals, to carry them. Sometimes the transportation of seeds is due to 
the structure of the seeds themselves, sometimes to that of the fruit in which they are enclosed; the essential point is to have transportation to a long distance made as certain as possible, to avoid overcrowding.

446. Explosive Fruits. - Some dry fruits burst open when ripe in such a way as to throw their seeds violently about. Interesting studies may be made, in the proper season, of the fruits of the common blue violet, the pansy, the wild balsam, the garden balsam, the crane'sbill, the herb Robert, the witch-hazel, the Jersey tea, and some other common plants. The capsule of the tropical American

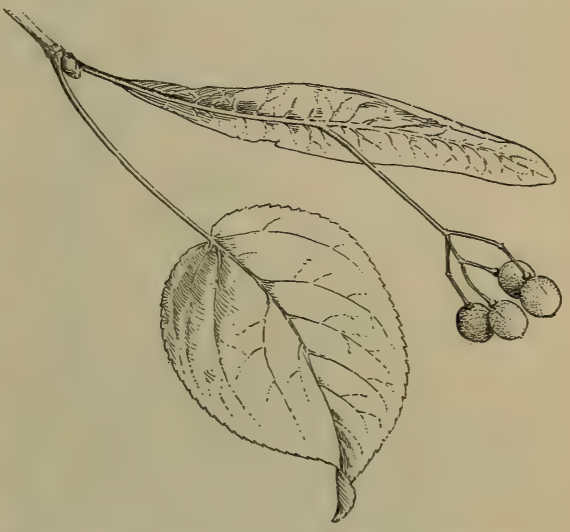

FIG. 266. - Fruits of Linden, with a Bract joined to the Peduncle and forming a Wing.

sand-box tree bursts open when thoroughly dry with a noise like that of a pistol shot.

447. Winged or Tufted Fruits and Seeds. - The fruits of the ash, box-elder, elm, maple (Fig. 169), and many other trees, are provided with an expanded membranous wing. Some seeds, as those of the catalpa and the trumpetcreeper, are similarly appendaged. The fruits of the dandelion, the thistle (Fig. 267), the fleabane, and many other plants of the group to which these belong, and the seeds of the willow, the milkweed (Fig. 267), the willowherb, and other plants, bear a tuft of hairs. 
The student should be able, from his own observations on the falling fruits of some of the trees and other plants above mentioned, to answer such questions as the following:

What is the use of the wing-like append-

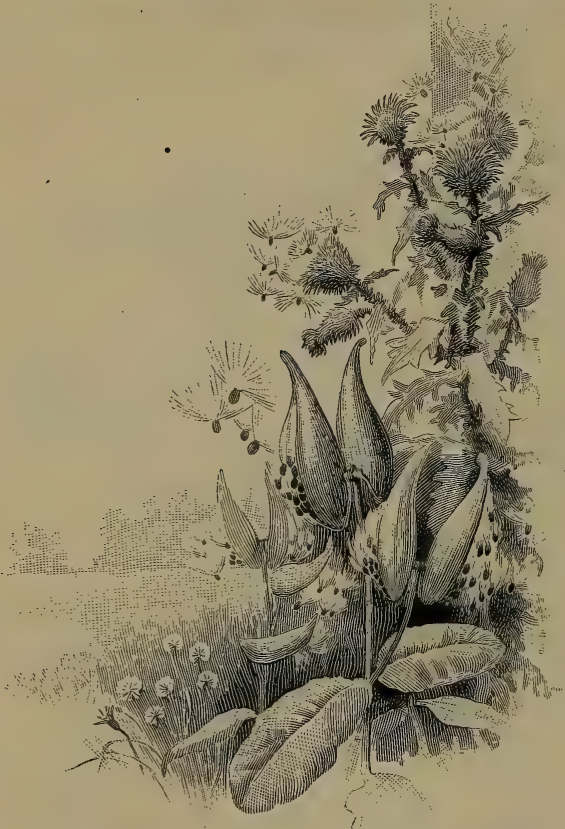

FIG. 267. - Winged Fruits of Thistle ; Winged Seeds of Milkweed. ages? of the tufts of hairs?

Which set of contrivances seems to be the more successful of the two in securing this object?

What particular plant of the ones available for study seems to have attained this object most perfectly?

What is one reason why many plants with tufted fruits, such as the thistle and the dandelion, are extremely troublesome weeds?

A few simple experiments, easily devised by the student, may help him to find answers to the questions above given. ${ }^{1}$

448. Tumbleweeds. - Late in the autumn, fences, particularly on prairie farms that are not carefully tilled, often serve as lodging-places for immense numbers of certain dried-up plants known as tumbleweeds. These blow about over the level surface until the first snow falls and

1 See Kerner and Oliver, Vol. II, pp. 833-875; also Beal's Seed Dispersal. 
even after that (Fig. 269), often traveling for many miles before they come to a stop, and rattling out seeds as they go. Some of the commonest tumbleweeds are the Russian thistle (Fig. 268), the pigweed (Amarantus albus, Fig. 269), the tickle-grass (Fig. 270), and a familiar pepper-grass (Lepidium). In order to make a successful tumbleweed, a plant must be pretty nearly globular in form when fully grown and dried, must be tough and light, must break off near the ground, and drop its seeds only a few at a time as it travels. A single plant of Russian thistle is sometimes as much as three feet high and six feet in diameter and carries not less than two hundred thousand seeds.

\section{Many-Seeded Pods} with Sma11 0penings. There are many fruits which act somewhat like pepperboxes. The capsule of the poppy is a good instance of this kind, and the fruit of lily, monkshood (Fig. 168), columbine, larkspur, and jimson weed (Fig. 271) acts in much the same way. Clamping the dry peduncle of any one of these ripe fruits, so as to hold it up-

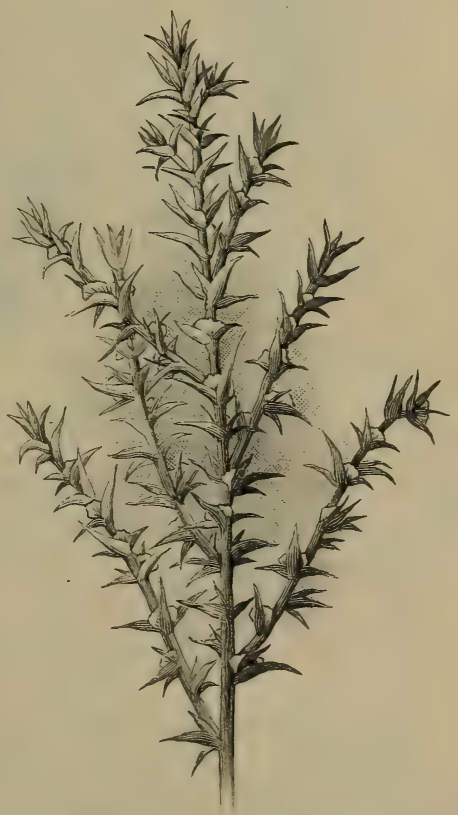

FIG. 268. - Russian Thistle. right above the table-top, and then swinging it back and forth, will readily show its efficiency in seed dispersal. 
450. Study of Transportation by Water. - Nothing less than a long series of observations by the pond-margin and the brookside will suffice to show how general and impor-

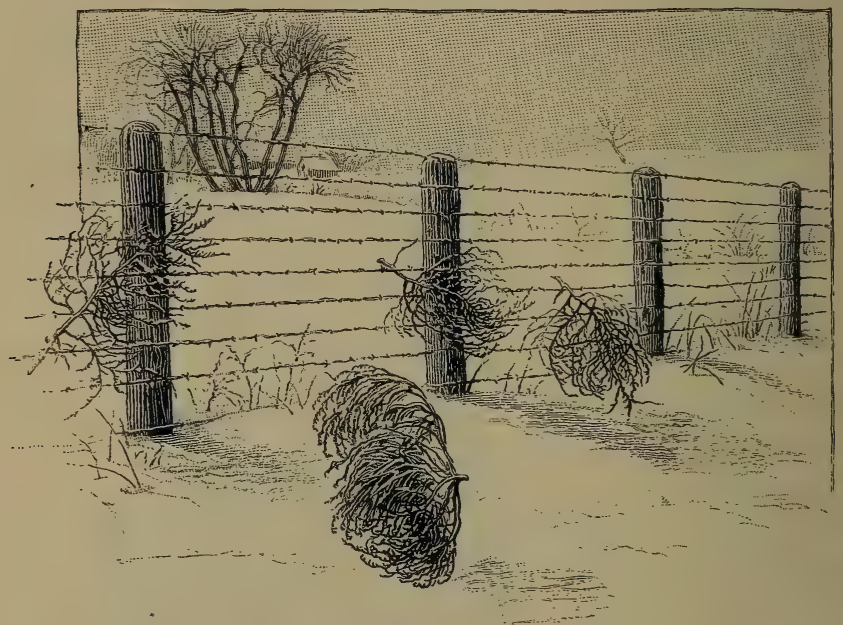

FiG. 269. - Tumbleweeds ${ }^{1}$ lodged against a Wire Fence in Winter.

tant is the work done by water in carrying the seeds of aquatics. An experiment will, however, throw some light on the subject.

\section{EXPERIMENT XL}

Adaptation for Transportation by Water. - Collect fruits of as many aquatic, semi-aquatic, or riverside and brookside species of plants as possible, place them on shallow pans of water and notice what proportion of all the kinds studied will float. Leave them twenty-four hours or more and see whether all the kinds that floated at first are still afloat. Some desirable fruits for this experiment

1 Amarantus albus. 
are : aquatic grasses, rushes and sedges, polygonums, water-dock, bur-reed, arrowhead, water-plantain, pickerel-weed, alder, buttonbush, water-parsnip (Sium), water-hemlock (Cicuta), water pennywort (Hydrocotyle).

451. Distances traversed by Floating Seeds. - Ocean currents furnish transportation for the longest journeys that are made by floating seeds. It is a well-known fact that cocoa-palms are among the first plants to spring up on newly formed coral islands. The nuts from which these palms grew may readily have floated a thousand miles or more without injury. On examining a cocoanut with the fibrous husk attached, just as it fell from the tree, it is easy to see how well this fruit is adapted for transportation by water. There are altogether about a hundred drifting fruits known, one (the Maldive nut) reaching a weight of twenty to twenty-five pounds.

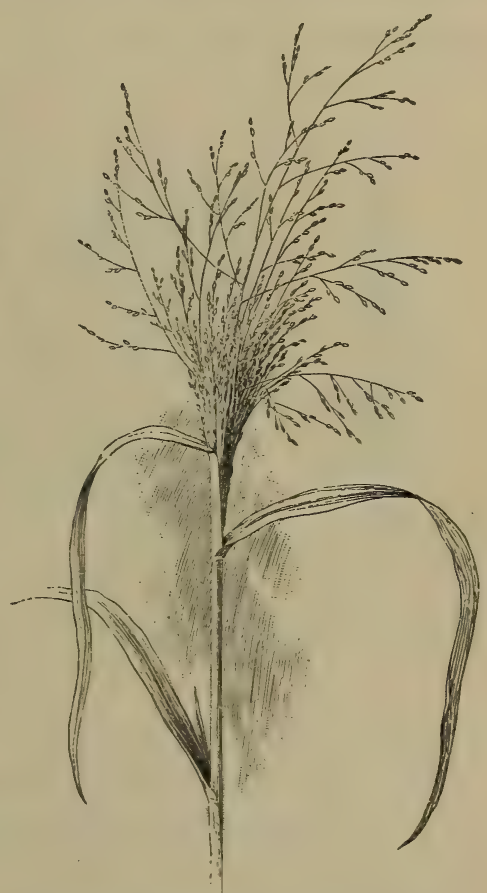

Fig. 270. - Panicle of Tickle-Grass, a Common Tumbleweed.

452. Burs. - A large class of fruits is characterized by the presence of hooks on the outer surface. These are sometimes outgrowths from the ovary, sometimes from 
the calyx, sometimes from an involucre. Their office is to attach the fruit to the hair or fur of passing animals. Often, as in sticktights (Fig. 272), the hooks are comparatively weak, but in other cases, as in the cocklebur (Fig. 272), and still more in the Martynia, the fruit of which in the green condition is much used for pickles, the hooks are exceedingly strong. Cockleburs can hardly be removed from the tails of horses and cattle, into which
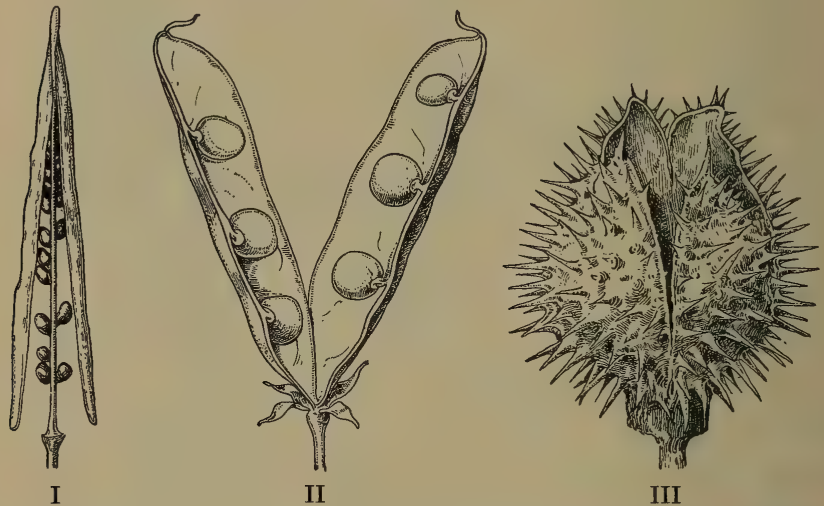

FIG. 271. - Three Fruits adapted for Dispersal by the Shaking Action of the Wind.

I, celandine ; II, pea ; III, jimson weed (Datura).

they have become matted, without cutting out all the hairs to which they are fastened.

A curious case of distribution of this kind occurred in the island of Ternate; in the Malay Archipelago. A buffalo with his hair stuck full of the needle-like fruits of a grass ${ }^{1}$ was sent as a present to the so-called King of Ternate. Scattered from the hair of this single animal, the grass soon spread over the whole island. 
Why do bur-bearing plants often carry their fruit until late winter or early spring?

What reason can be given for the fact that the burdock, the cocklebur, the beggar's-ticks, the hound's-tongue, and many other common burs, are among the most persistent of weeds?

453. Uses of Stone Fruits and of Fleshy Fruits to the Plant. - Besides the dry fruits, of which some of the principal kinds have been mentioned, there are many kinds
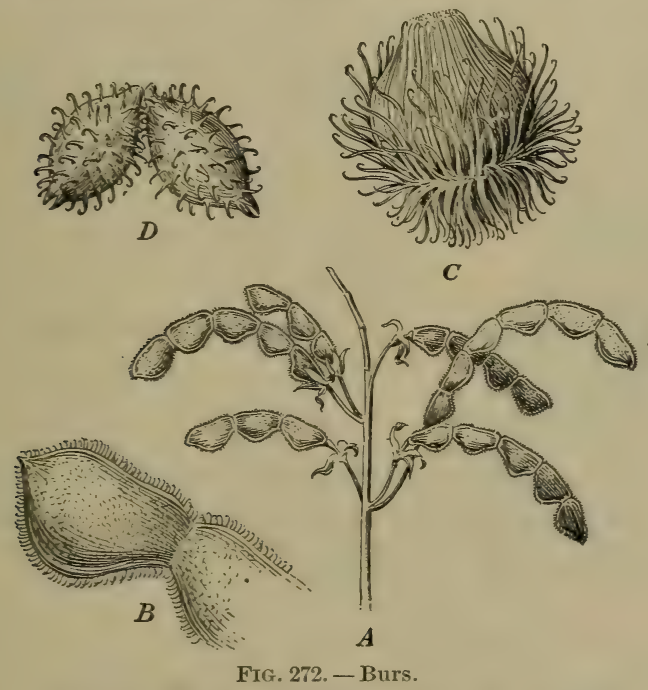

$A$, sticktights ; $B$, sticktights, two segments, magnified ;

$C$, burdock; $D$, cockleburs.

of stone fruits and other fleshy fruits (Sects. 242-247). Of these the great majority are eatable by man or some of the lower animals, and oftentimes the amount of sugar and other food material which they contain is very considerable. It is a well-recognized principle of botany, and 
of zoölogy as well, that plants and animals do not make unrewarded outlays for the benefit of other species. Evidently the pulp of fruits is not to be consumed or used

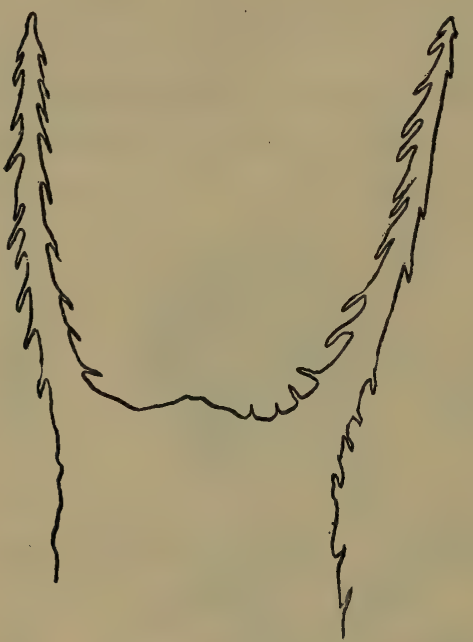

I
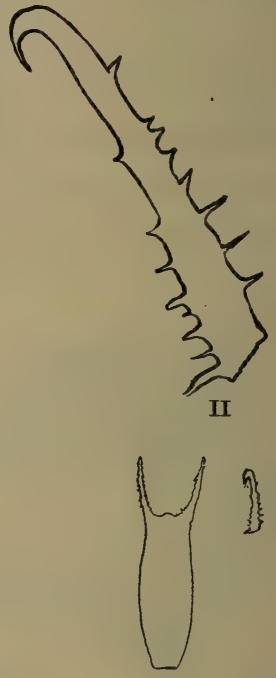

III IV

Fig. 273. - Barbs and Hooks of Burs.

I, barbed points from fruit of beggar's-ticks, magnified eleven times; II, hook of cocklebur, magnified eleven times; III, beggar's-ticks fruit, natural size; IV, cocklebur hook, natural size.

as food by the plant itself or (in general) by its seeds. It is worth while, therefore, for the student to ask himself some such questions as these: 1

(1) Why is the pulp of so many fruits eatable?

(2) Why are the seeds of many pulpy fruits bitter or otherwise unpleasantly flavored, as in the orange?

(3) Why are the seeds or the layers surrounding the

1 See Kerner and Oliver's Natural History of Plants, Vol. II, pp. 442-450. 
seeds of many pulpy fruits too hard to be chewed, or digested, as in the date and the peach?

(4) Why are the seeds of some pulpy fruits too small to be easily chewed, and also indigestible, as in the fig and the currant?

(5) Account for the not infrequent presence of currant bushes or asparagus plants in such localities as the forks of large trees, sometimes at a height of twenty, thirty, or more feet above the ground (Fig. 274).

Careful observation of the neighborhood of peach, plum, cherry, or apple trees at the season when the fruit is ripe and again during the following spring, and an examination into the distribution of wild apple or pear trees in pastures where they occur, will help the student who can make such observations to answer the preceding questions. So, too, would an examination of the habits of fruit-eating quadrupeds and of the crop and gizzard of fruiteating birds during the season when the fruits upon which they feed are ripe.

\section{Seed-Carrying purposely} done by Animals. - In the cases referred to in the preceding sections, animals have been seen

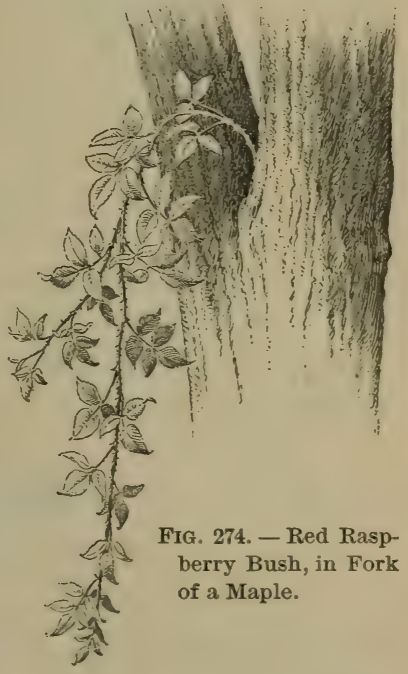
to act as unconscious or even unwilling seed-carriers. Sometimes, however, they carry off seeds with the plan of storing them for food. Ants drag away with them to 
their nests certain seeds which have fleshy growths on their outer surfaces. Afterwards they eat these fleshy

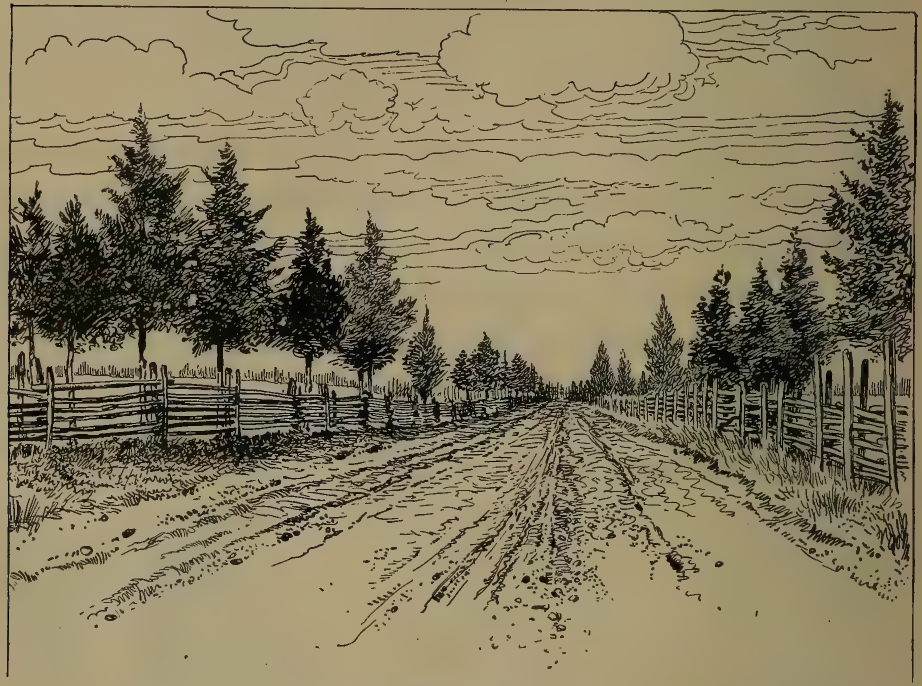

FrG. 275. - Red Cedar Trees planted by Birds roosting on Fences.

parts at their leisure, leaving the seed perfectly fit to grow, as it often does. ${ }^{1}$

Squirrels and bluejays are known to carry nuts and acorns about and bury them for future use. These

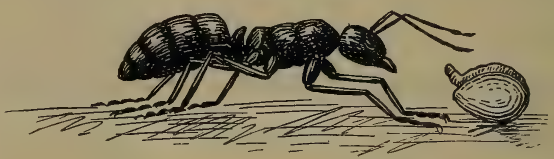

FIG. 276. - Seed of Bloodroot with Caruncle or Crest, which serves as a Handle for Ants to hold on to. Ant ready to take the seed.

deposits are often forgotten and so get a chance to grow, and in this way a good deal of tree-planting is done.

1 See Beal's Seed Dispersal, pp. 69, 70. 


\section{CHAPTER XXX}

\section{THE STRUGGLE FOR EXISTENCE AND THE SURVIVAL OF THE FITTEST ${ }^{1}$}

455. Weeds. - Any flowering plant which is troublesome to the farmer or gardener is commonly known as a weed. Though such plants are so annoying from their tendency to crowd out others useful to man, they are of extreme interest to the botanist on account of this very hardiness. The principal characteristics of the most successful weeds are their ability to live in a variety of soils and exposures, their rapid growth, resistance to frost, drought, and dust, their unfitness for the food of most of the larger animals, in many cases their capacity to accomplish self-pollination, in default of cross-pollination, and their ability to produce many seeds and to secure their wide dispersal. Not every weed combines all of these characteristics. For instance, the velvet-leaf or butterprint, ${ }^{2}$ common in cornfields, is very easily destroyed by frost; the pigweed and purslane are greedily eaten by pigs, and the ragweed by some horses. The horse-radish does not usually produce any seeds.

It is a curious fact that many plants which have finally proved to be noxious weeds have been purposely introduced into the country. The fuller's teasel, melilot, horse-radish, wild carrot, wild parsnip, tansy, oxeye daisy,

1 See Darwin's Origin of Species, Chapters III and IV.

2 Abutilon Avicennæ. 
and field-garlic are only a few of the many examples of very troublesome weeds which were at first planted for use or for ornament.

456. Study of Weeds. - Select two or more out of the following list of weeds and report on the qualities which make them troublesome from the farmer's point of view (successful from their own). ${ }^{1}$

\section{LIST OF WEEDS 2}

1. Barn-grass,* Panicum Crus-galli.

2. Beggar's lice,* Cynoglossum officinale.

3. Beggar's-ticks, Bidens frondosa.

4. Black mustard,* Brassica nigra.

5. Blue thistle,* Echium vulgare.

6. Buffalo bur, Solanum rostratum.

7. Burdock,* Arctium Lappa.

8. Buttercup,* Ranunculus bulbosus.

9. Butterweed,* Erigeron canadensis.

10. Carpet weed, Mollugo verticillata.

11. Charlock,* Brassica Sinapistrum.

12. Chess or cheat,* Bromus secalinus.

13. Chickweed, Stellaria media.

14. Chicory,* Cichorium Intybus.

15. Clover dodder,* Cuscuta Trifolii.

16. Cocklebur,* Xanthium spinosum.

17. Corn cockle,* Agrostemma Githago.

1 This study will be of little value in city schools, since the plants should be examined as they grow. Specimens of the mature weed and of its fruits and seeds may be preserved by the teacher from one season to another for class use. Whole specimens of small plants, such as purslane, may be put into preservative fluid (see Handbook). Ordinary weeds, such as ragweed, pigweed, etc., may be pressed and kept as roughly prepared herbarium specimens, while such very large plants as jimson weed, dock, etc., may be hung up by the roots and thus dried.

2 Names marked in the list thus * are those of plants introduced from other countries, mostly from Europe. 
18. Cow herb,* Saponaria Vaccaria.

19. Daisy, oxeye,* Chrysanthemum Leucanthemum.

20. Dandelion,* Taraxacum officinale.

21. Dock, Rumex crispus.

22. Dog fennel,* Anthemis cotula.

23. Fox-tail grass,* Setaria glauca.

24. Horse-nettle, Solanum carolinense.

25. Jamestown weed or Jimson weed,* Datura Stramonium or D. Tatula.

26. Johnson grass, Andropogon halepensis.

27. Mallow,* Malva rotundifolia.

28. Milkweed, Asclepias Cornuti.

29. Nettle, Urtica gracilis.

30. Pigweed,* A marantus retroflexus.

31. Pigweed,* Chenopodium album.

32. Plantain,* Plantago major.

33. Pokeberry, Phytolacca decandra.

34. Purslane, Portulaca oleracea.

35. Quick-grass,* Witchgrass, Agropyrum repens.

36, Ragweed, Ambrosia artemisiafolia.

37. Rib grass, ${ }^{*}$ Plantago lanceolata.

38. Sand bur, Cenchrus tribuloides.

39. Shepherd's purse,* Capsella Bursa-pastoris.

40. Snartweed, Polygonum Hydropiper.

41. Sorrel,* Rumex Acetosella.

42. Spanish needles, Bidens bipinnata.

43. Sticktights, Desmodium canadense.

44. Thistle,* Cirsium lanceolatum, $C$. arvense.

45. Yarrow, Achillea Millefolium.

457. Origin of Weeds. ${ }^{1}-\mathrm{By}$ far the larger proportion of our weeds are not native to this country. Some have been brought from South America and from Asia, but most of the introduced kinds come from Europe. The importation of various kinds of grain and of garden-seeds,

1 See the article "Pertinacity and Predominance of Weeds," in Scientific Papers of Asa Gray, selected by C. S. Sargent, Vol. II, pp. 234-242. 
mixed with seeds of European weeds, will account for the presence of many of the latter among us. Others have been brought over in the ballast of vessels. Once landed, European weeds have succeeded in establishing themselves in so many cases, because they were superior in vitality and in their power of reproduction to our native plants. This may not improbably be due to the fact that the European and western Asiatic vegetation, much of it consisting from very early times of plants growing in comparatively treeless plains, has for ages been habituated to flourish in cultivated ground and to contend with the crops which are tilled there.

458. Plant Life maintained under Difficulties. - Plants usually have to encounter many obstacles even to their bare existence. For every plant which succeeds in reaching maturity and producing a crop of spores or of seeds there are hundreds or thousands of failures, as it is easy to show by calculation. The morning-glory (Ipomoea purpurea) is only a moderately prolific plant, producing, in an ordinary soil, somewhat more than three thousand seeds. ${ }^{1}$ If all these seeds were planted and grew, there would be three thousand plants the second summer, sprung from the single parent plant. Suppose each of these plants to bear as the parent did, and so on. Then there would be :

$9,000,000$ plants the third year.

$27,000,000,000$ plants the fourth year.

$81,000,000,000,000$ plants the fifth year. $243,000,000,000,000,000$ plants the sixth year. $729,000,000,000,000,000,000$ plants the seventh year.

1 Rather more than three thousand two hundred by actual count and estimation. 
It is not difficult to see that the offspring of a single morning-glory plant would, at this rate, soon actually cover the entire surface of the earth. The fact that morning-glories do not occupy any larger amount of territory than they do must therefore depend upon the fact that the immense majority of their seeds are not allowed to grow into mature plants.

There are many plants which would yield far more surprising results in a calculation similar to that just given than are afforded by the morning-glory. For instance, a foxglove capsule contains on an average nearly 1800 seeds. A small foxglove plant bears from 140 to 200 capsules and a large one from 530 to 700 . Therefore a single plant may produce over $1,250,000$ seeds. A single orchid plant ${ }^{1}$ has been shown to produce over $10,000,000$ seeds.

459. Importance of Dispersal of Seeds. - It is clear that any means of securing the wide distribution of seeds is of vital importance in continuing and increasing the numbers of any kind of plant, since in this way destruction by overcrowding and starvation will be lessened.

A few of the means of transportation of seeds have been described in Sects. $445-454$, but the cases are so numerous and varied that a special treatise might well be devoted to this subject alone.

460. Destruction of Plants by Unfavorable Climates. Land-plants, throughout the greater part of the earth's surface, are killed in enormous numbers by excessive heat and drought, by floods, or by frost. After a very dry spring or summer the scantiness of the crops, before the era of railroads which nowadays enable food to be brought 1 Maxillaria, see Darwin's Fertilization of Orchids, Chapter IX. 
in rapidly from other regions, often produced actual famine. Wild plants are not observed so carefully as cultivated ones are, but almost every one has noticed the patches of grass, apparently dead, in pastures and the withered herbaceous plants everywhere through the fields and woods after a long drought.

Floods destroy the plants over large areas, by drowning them, by sweeping them bodily away, or by covering them with sand and gravel.

Frosts kill many annual plants before they have ripened their seeds, and severe and changeable winters sometimes. kill perennial plants.

461. Destruction by Other Plants. - Overcrowding is one of the commonest ways in which plants get rid of their weaker neighbors. If the market-gardener sows his lettuce or his beets too thickly, few perfect plants will be produced, and the same kind of effect is brought about in nature on an immense scale. Sometimes plants are overshadowed and stunted or killed by the growth all about them of others of the same kind; sometimes it is plants of other kinds that crowd less hardy ones out of existence.

Whole tribes of parasitic plants, some comparatively large, like the dodder and the mistletoe, others microscopic, like blights and mildews, prey during their whole lives upon other plants.

462. Adaptations to meet Adverse Conditions. - Since there are so many kinds of difficulties to be met before the seed can grow into a mature plant and produce seed in its turn, and since the earth's surface offers such extreme variations as regards heat, sunlight, rainfall, and quality of soil, it is evident that there is a great opportunity 
offered for competition among plants. Of several plants of the same kind, growing side by side, where there is room for but one full-grown one, all may be stunted, or one may develop more rapidly than the others, starve them out, and shade them to death. Of two plants of different kinds the hardier will crowd out the less hardy, as ragweed, pigweed, and purslane do with ordinary garden crops. Weeds like these are rapid growers, stand drought or shade well, will bear to be trampled on, and, in general, show remarkable toughness of organization.

Plants which can live under conditions that would be fatal to most others will find much less competition than the rank and file of plants are forced to encounter. Lichens, growing on barren rocks, are thus situated, and so are the fresh-water plants, somewhat like pond-scum in their structure, which are found growing in hot springs at temperatures of $140^{\circ}$, or in some cases nearly up to $200^{\circ}$.

463. Examples of Rapid Increase. - Nothing but the opposition which plants encounter from overcrowding or from the attacks of their enemies prevents any hardy kind of plant from covering all suitable portions of a whole continent, to the exclusion of most other vegetable life. New Zealand and the pampas of La Plata and Paraguay, in South America, have, during the present century, furnished wonderful examples of the spread of European species of plants over hundreds of thousands of square miles of territory. The newcomers were more vigorous, or in some way better adapted to get on in the world than the native plants which they encountered, and so managed to crowd multitudes of the latter out of existence. 
In our own country a noteworthy case of the kind has occurred so very recently that it is of especial interest to American botanists. The so-called Russian thistle (Fig. 268), which is merely a variety of the saltwort, so common along the Atlantic coast, was first introduced into. South Dakota in flaxseed brought from Russia and planted in 1873 or 1874 . In twenty years from that time the plant had become one of the most formidable weeds known, over an area of about twenty-five thousand square miles.

464. Importance of Adaptiveness in Plants. - It may be inferred from the preceding sections that a premium is set on all changes in structure or habits which may enable plants to resist their living enemies or to live amid partially adverse surroundings of soil or climate. It would take a volume to state, even in a very simple way, the conclusions which naturalists have drawn from this fact of a savage competition going on among living things, and it will be enough to say here that the existing kinds of plants to a great degree owe their structure and habits to the operation of the struggle for existence, this term including the effort to respond to changes in the conditions by which they are surrounded. How the struggle for existence has brought about such far-reaching results will be briefly indicated in the next section.

465. Survival of the Fittest. - When frost, drought, blights, or other agencies kill most of the plants in any portion of the country, it is often the case that many of the plants which escape do so because they can stand more hardship than the ones which die. In this way delicate individuals are weeded out and those which are more robust survive. But other qualities besides mere toughness 
often decide which plant or plants of any particular kind shall live and which ones shall die out. In every grove of oaks there are some with sweeter and others with more bitter acorns. One shellbark hickory bears nuts whose shell is easily cracked by hogs, while another protects its seeds by a shell so hard that it is cracked only by a pretty heavy blow. In case of all such differences, there is a strong tendency to have the less eatable fruit or seed preserved and allowed to grow, while the more eatable varieties will be destroyed. Some individuals of the European holly produce bright red berries, while others produce comparatively inconspicuous yellow ones. It has been found that the red berries are much more promptly carried off by birds, and the seeds therefore much more widely distributed than the yellow ones are. The result of this kind of advantage, in any of its countless forms, is sometimes called survival of the fittest, and sometimes natural selection. The latter name means only that the outcome of the process just described, as it goes on in nature, is much the same as that of the gardener's selection, when, by picking out year by year the earliest ripening peas or certain kinds of the oddest-colored chrysanthemums, he obtains permanent new varieties. Natural agencies, acting on an enormous scale through many ages, may well be supposed to have brought about the perpetuation of millions of such variations as are known to be of constant occurrence among plants, wild as well as cultivated. 



\section{N D EX}

Starred page-numbers indicate where cuts occur.

\section{Parts I AND II}

Absorption of carbon dioxide, 166170.

Acacia, leaf of, *145.

Accessory buds, $122, * 123$.

Accessory fruits, *226.

Acuminate, *131.

Acute, *131.

Adaptations to conditions of existence, 394.

Adherent, 204.

Adnate, 204.

Adrentitious buds, 128.

Adventitious roots, 36 .

Aerial roots, $36, * 37, * 38, * 39$.

Agaricus, study of, 264-266*.

Age of trees, 71 .

Aggregate fruits, 225, *226.

Ailanthus twig, *121.

Air, relation to germination, 10 12.

Air chamber, $* 151, * 153, * 154$.

Air-passages in Hippuris stem, ${ }^{*} 173$.

Akene, *222.

Albuminous substances, 22 .

Algæ, 232, 241-257*.

Algæ, classification of, $* 257$.

Algæ, study of, 241-257*.
Alternate, $* 65,66$.

Alternate leaves, *140.

Alternation of generations, 278 .

Althæa leaf, *152.

Anatomy of plants (see under root, stem, leaf, flower, fruit, structure of).

Angiosperms, 233.

Angiosperms, oldest, 304, 305.

Amimal food, need of, 344 .

Animals, defenses against, 345$352 *$.

Annual growth, indefinite, 69.

Annual ring, *100, *101.

Annuals, 71.

Anther, 201, 202, *203.

Anther, modes of opening, *211.

Antheridia, *284, 285.

Antherozoids, 247, 248, *251, 254,

*279, *284.

Antipodal cells, $* 215$.

Ant-plants, 346, $* 347$.

Ants plant seeds, $* 386$.

Apetalous, *198.

Apothecia, 271.

Apple leaf, stipules of, *135.

Aquatic roots, 37 . 
Arch of hypocotyl, 25-27.

Archegonia, *284, 285, *295.

Arctic willow, *328.

Aristolochia stem, bundle of, $* 88$.

Aristolochia stem, cross-section of, *87, 88.

Arrangement of leaves, $* 140, * 141$.

Arrow-shaped, *132.

Asci, 263, 270, 273.

Ascomycetes, 232.

Asexual generation, 278.

Ash tree, naturally grafted, $* 99$.

Asparagus, 79, *80.

Aspidium, *288.

Asplenium, study of, 286-289*.

Assimilation, 171, 172.

Autumn leaves, coloration of, 176 .

Axillary bud, *122.

Axillary flowers, *186.

Bacillariales, 232.

Bacilli, *237.

Bacteria, 232, *237.

Bacteria, manufacture of nitric acid by, 340 .

Bacteria, study of, 238, 239.

Barbed hairs, *351.

Barberry, spiny leaves of, *348.

Bark, 86, *91, 104.

Basidia, *266.

Basidiomycetes, 232.

Bast, *87, *91, *92.

Bast-bundle, *92.

Bean-pod, study of, 219.

Bean seed, 7, 8.

Beech twig, 64 .

Beech-wood, cross-section of, *101.

Bees, 355, *356, *360.

Beet leaf, *151.

Beggar's ticks, *384.

Begonia leaf, osmose in, 51.
Bell-shaped, *202.

Belt's bodies, *347.

Berry, *225.

Berry, study of, 217.

Biennial, 47, 71.

Biogenesis, law of, 299,300 .

Birch, branching of, *71.

Bird-pollinated flowers, 362 .

Birds plant seeds, 385 , $* 386$.

Black mould, study of, 257, 258, 259.

Bladder-wrack, *250.

Botanical geography, 324-335.

Botanical geography of United States, 333-335.

Botany, definition of, 1.

Box-elder, buds of, *123.

Box-elder, radial and cross-sections of stem of, $* 89$.

Bract, *186, 187.

Branches formed from adventitious buds, 128.

Brauching, alternate, $* 65,66$.

Branching and leaf-arrangement, 64,65 .

Branching, opposite, $* 65$.

Branch-spine, $* 69$.

Brazil nut, food stored in, 23, 24.

Breathing-pore, *153.

Bryophytes, 232, 277, 278.

Buckeye, bud of, *120.

Bud, horse-chestnut, 119, 120.

Bud-scales, 121.

Buds, 118-129.

Buds, adventitious, 128.

Buds, dormant, 127, 128.

Buds, naked, 121.

Buds, position of, 121, *122, *123, *124.

Buds, structure of, $119, * 125$.

Bulb, 77, *79. 
Bulb, hyacinth, *79.

Bulb, onion, 77.

Bulblets, 375, 376 .

Bulrush, cross-section of stem of, *84.

Burs, 381, 382, *383.

Buttercup, leaf of, *135.

Buttercup, study of flower of, 195. 196.

Butternut, buds of, *124.

Cabbage, a bud, 123.

Cactus, *80, *315.

Cactus flower, transitions in, ${ }^{2} 208$.

Caladium, $76, * 77$.

Calyx, *197.

Cambium, *87, *88, *89, 95-100.

Cambium-ring, 96, *97.

Canna, parallel veining in, 136 .

Capsule, 223.

Carbon dioxide, absorption of, 166168.

Carbon dioxide, disposition of, 168 , 169.

Carnivorous plants, $342-344$ *

Carpel, 198.

Castor bean, germination of, *7.

Castor-oil plant, early history of stem, *95.

Castor-oil plant, fibro-rascular bundle of, $* 95$.

Catharinea, *282.

Catkin, *187.

Celandine, leaf of, *134.

Cell, 20, 21.

Cell-contents, $* 19, * 155,180, * 183$, *184.

Cell-contents, continuity of, 146 .

Cell-division, *183, *242, 245.

Cell-multiplication in pond-scum, *242.
Cell-sap, *183.

Cell, simplest form of, 178, *179, 180.

Cell-wall, 178.

Cells, isolated wood-, *91.

Cellulose, a compound of carbon, hydrogen, and oxygen; the chief constituent of ordinary cell-walls, $156,171,268$.

Central cylinder, $* 42$.

Central placenta, *205.

Chara, *248, *249.

Characeæ, 249, 250.

Chemical changes in leaves before falling, 175, 176.

Cherry, buds in axils of leaves, *122.

Cherry twig, *63, *125.

Chestnut fruit, $* 222$.

Chlorophyceæ, 232.

Chlorophyll, 168, 169, 176.

Chlorophyll bodies, *154, *155.

Cilium, 180.

Circulation of protoplasm, *184, 185.

Cladophyll, 79, *81.

Class, 231.

Classification, 228-234.

Cleistogamous flowers, 369, *370.

Clerodendron, *363.

Climbing plants, $73-75$.

Climbing shrubs, stem-structure, 99, 100.

Climbing stems, $* 73, * 74, * 75$.

Clinostat, *58, 59 .

Clover leaf, *144.

Club-moss, study of, 291, *292.

Cluster-cup, 259, *261.

Coherent, 200.

Cohesion, 204, *205.

Collenchyma, *95. 
Colocasia, *77.

Coloration of autumn leaves, 176.

Colors of flowers, 357,358 .

Common receptacle, $* 189$.

Compass-plant, nearly vertical leaves of, $* 147$.

Composite head, 188, *189, 190.

Compound cyme, *191.

Compound leaves, *137, *138, 139.

Compound pistil, 202.

Compound umbel, *189.

Conceptacles, 250, *252.

Condensed stems, 78.

Conifers, wood of, $* 93, * 94$.

Coniferous wood, structure of, 92 , $* 93, * 94$.

Conjugatæ, 232.

Conjugating cell, *243, *259.

Conjugation, *243.

Consolidated, 204.

Continuity of protoplasm, 146.

Contractile vacuole, 180.

Contractility, 182.

Cork, 90, *100, 104, 115.

Corm, a bulb-like, fleshy stem, or base of stem, " a solid bulb."

Corn, aerial roots of, $* 38$.

Corn, cross-section of stem of, *83.

Corn, germination of, 8 .

Corn, grain of, *16.

Corn, root-tip, section, $* 42$.

Corn-stem, structure of, $* 83,84$.

Corolla, *197.

Corymb, *186, 187.

Cotyledon, 7.

Cotyledon, disposition made of, 28 , 29.

Cotyledons, thickened, use of, 29.

Crenate, 132.

Cross-pollination, 353.

Crow-berry, rolled-up leaf of, $* 317$.
Cryptogams, 231.

Cryptogams, classes of, 232, 233.

Cuspidate, *131.

Cuticle, unequal development of, by epidermis-cells, 156, *157.

Cutin, 156.

Cutting leaves, *351.

Cyme, *191.

Cypress, 71.

Dahlia, thickened roots of, *41.

Daily movements of leaves, *144, *145, *146.

Dandelion, *72.

Darwin, Charles, 353.

Date-palms, *85.

Datura, stigma of, *213.

Deciduous, 175.

Defenses against animals, 345-352.*

Definite annual growth, 69 .

Dehiscent fruits, 222 , $* 223$.

Deliquescent trunk, $66, * 67$.

Dentate, 132.

Descent of water, $109, * 110$.

Desert, Sahara, *325.

Desmids, $* 243$.

Destruction of plants, 391, 392.

Determinate inflorescence, 191.

Deutzia leaves, $* 142, * 143$.

Diadelphous, 202.

Diagrams, floral, 204, *205, *296.

Diatoms, study of, *240, 241.

Dichogamy, *363, *364.

Dicotyledonous plants, 34, 233.

Dicotyledonous stem, annual, gross structure of, $86, * 87$.

Dicotyledonous stem, cross-section of, $* 87, * 89, * 91, * 96, * 100$.

Dicotyledonous stem, mechanical importance of distribution of material in, 89, 90. 
Dicotyledonous stem, minute structure of, 86-98*.

Dicotyledonous stem, rise of water in, 107,108 , *109.

Dimorphous flowers, *366, 367 .

Diœcious, 200.

Discharge of pollen, *211.

Disk-flowers, 188, *189.

Dispersal of seeds, 376-386*.

Dispersal of seed-plants, 373-376.

Distinct, 201.

Distribution of material in monocotyledonous stems, $* 84,85$.

Dock fruit, study of, $219,220$.

Dodder, 39, *40, 41.

Dormant buds, 127, 128.

Double flowers, 209.

Drip-leaves, $* 314$.

Drosera, *341, *342, 343.

Drought, endurance of, $162,163$.

Drought-plants, 313-317*.

Dry fruits, 224.

Duckweed, 314.

Duct, $* 92$.

Earliest plants, 298.

Ecology, 2, 307.

Egg, osmosis in, 50, *51.

Egg-cell, *249, *251, 280, *284, 285.

Elaters, 294.

Elliptical, *131.

Elm, $* 67$.

Elm bud, *125.

Elm fruit, $* 223$.

Elm leaf, 130, 133.

Elm, twig of, *125.

Emarginate, *131.

Embryo, 6, 17.

Embryo sac, *215.

Endosperm, *15, *16, 17, 19.

Energy, source of, in plants, 173 .
Enslaved plants, 338, *339.

Epidermis, uses of, 156, $* 157$.

Epidermis of root, $* 42, * 44$.

Epigynous, 204, *205.

Epipetalous, 204, *205.

Epiphytes, 322, *323.

Equisetales, 232.

Equisetum, study of, 292-295*.

Essential organs, $* 197$.

Euphorbia splendens, *350.

Evergreen, 175.

Evolutionary history of plants, 298-305.

Excretion of water, 172, 173.

Excurrent trunk, $* 66$.

Existence, struggle for, 387-393.

Exogenous, 96.

Explosive fruits, 377.

Fall of horse-chestnut leaf, *137.

Fall of the leaf, 175, 176.

Family, 230.

Family, subdivisions of, 231.

Fascicled roots, *41.

Fermentation, 269.

Fern, study of, 286-289*.

Fern-plants, 295-297.

Ferns, 290, 291.

Fertilization, *214, *215, 216.

Fibrous roots, $* 41$.

Fibro-vascular bundles, *83.

Ficus elastica, leaf of, $* 154$.

Ficus religiosa, drip-leaf of, *314.

Fig, transpiration in, 160 , *161, 162.

Filament, 201, 202, *203.

Filicales, 232.

Fir wood, *93.

Fission, ${ }^{242}$.

Fission-plants, 232.

Fittest, survival of, 394, 395. 
Flax, cross-section of stem of, *91.

Fleshy fruits, 224.

Fleshy fruits, uses of, 383-385.

Fleshy roots, $45,46, * 47$.

Floating seeds, 381 .

Floral diagrams, 204, *205, $* 206$.

Floral envelopes, 198.

Floral organs, movements of, 365 , 366.

Florideæ, 255.

Flower, nature of, 208-211*.

Flower, organs of, *197.

Flower, plan of, 197-206*.

Flower-buds, position of, 186.

Flowerless plants, 232, 233, 235297.

Flowers, bird-pollinated, 362 .

Flowers, colors of, 357, 358.

Flowers, ecology of, 353-372*.

Flowers, odors of, 357.

Flytrap, Venus, *343, 344.

Follicle, $* 223$.

Food in embryo, 14.

Food, storage of, in root, $46, * 47$.

Food, storage of, in stem, 113-117.

Food, storage outside of embryo, 15.

Formative tissue, 95 .

Fossil plants, 298, 299.

Fossils, 298.

Four-o'clock seed, 15.

Foxglove, pinnate leaf of, $* 133$.

Free, 204.

Free central placentation, $* 205$.

Frond, 287, *288.

Frost, action of, 394 .

Fruit, 221-227*.

Fruit, definition of, 221.

Fruit-dots, *288.

Fruits, study of, 217-220.

Fruits, uses of, 376-386*.
Fucus, 250-252*.

Funaria, *284.

Fungi, 232, 274-276.

Gametophyte, 291.

Gamopetalous, 200.

Gamosepalous, 200.

Gemmæ, 279.

Generations, alternation of, 278 .

Generative cells, in pollen tube, *214.

Genus, 229.

Geography, botanical, 324-335.

Geography, botanical, of the United States, 333-335.

Geotropism, *57, *58, 59, 68 .

Germination, 5-13.

Gernination, chemical changes during, 11-13.

Germination, conditions of, 8-11.

Gills, *264, 265.

Gonidia, 273.

Gourd-fruit, 224.

Grafting, 98, *99.

Grain, 222.

Grape sugar, test for, 116, 117.

Gray, Asa, 71.

Green layer of bark, 86, *91.

Groups, 231.

Growing point, $* 42$.

Growth, measurement of, in stem, 32.

Growth, secondary, *96, *97, *100.

Guard-cells, *151; *153, *154, 158, 159.

Gymnosperms, 233.

Hæmatococcus, *244.

Hairs, 158.

Hairs, stinging, 349, 350, *351.

Halberd-shaped, *132. 
Half-parasites, 336 .

Halophytes, 311, *319, 320, *326.

Hard bast, *87, *91, *92.

Haustoria, 39.

Head, *188.

Heart-shaped, *132.

Heartwood, 105.

Heliotropism, 148.

Hemlock, lateral extension of roots, $* 60$.

Hepaticæ, 232, 280, 281.

Hepaticæ, study of, 278-280*.

Herbs, 70.

Hesperidium, *225.

High mallow, provisions for crosspollination of, $* 364$.

Hilum, 6.

Honey-bee, leg of, *356.

Honey-gland, *357.

Honey locust, spine, $* 69$.

Hop, twining of, *75.

Hormogonia, *238.

Horse-chestnut bud, study of, 119, 120.

Horse-chestnut, germination, 8 .

Horse-chestnut twig, 62-64.

Host, 39.

Hot springs, plants in, 393.

Hyacinth, bulb of, *79.

Hybrid, 229.

Hybridization, 229.

Hydrangea, transpiration in, 159161*.

Hydrogen, 168.

Hydrophytes, 311, *312, *313, *314.

Hymenium, *265.

Нурһæ, 257, *258.

Hypocotyl, 6, 25-27.

Hypocotyl, cross-section of, 95.

Hypogynous, 204，*205.
Iceland moss, 274 .

Imperfect flowers, 199.

Indefinite annual growth, 69.

Indehiscent fruits, 221, *222.

Indeterminate inflorescence, 186.

Indian corn, germination of, 8 .

Indian corn, kernel of, 16.

Indian corn, root-tip, $* 42,43$.

Indian corn, structure of stem, *83, 84 .

Indian pipe, 169.

India-rubber plant, leaf of, $* 154$.

India-rubber plant, transpiration of, $160-162$.

Indusium, 287, *288.

Inflorescence, 186-191*.

Inflorescence, determinate, 191.

Inflorescence, diagrams of, *190.

Inflorescence, indeterminate, 186.

Insectivorous plants, 340-344*.

Insect pollination, 355-369*.

Insect pollination, study of, 367369.

Insects, pollen-carrying apparatus of, $355, * 356$.

Insects, sense of smell of, 357 .

Insects, vision of, 358 .

Insect-traps, leaves as, *342, *343.

Insect visits, 358-362*, *365.

Insertion of floral organs, *205.

Intercellular spaces, $* 95$.

Internode, 32, 83.

Involucre, 188, *189.

Ipomœa Jalapa, 46.

Ipomœa, rate of increase of, 390, 391.

Iris, rootstock of, *77.

Irish moss, 253.

Irritability in plants, nature and occurrence of, 182-184.

Ivy, aerial roots of, *39. 
Keel, *199.

Kidney-shaped, *131.

Knots, *102.

Labiate, $* 203$.

Ladyfern, 286.

Lanceolate, $* 131$.

Lateral buds, 63, 121.

Leaf, 130-139*.

Leaf, accumulation of mineral matter in, 165.

Leaf-arrangement, $* 140, * 141, * 142$, *143.

Leaf-bases, $* 132$.

Leaf-buds, 122, 123.

Leaf, fall of, 175, 176.

Leaf-like stems, $78,79, * 81$.

Leaf-margins, *132.

Leaf-mosaics, 142 , *143.

Leaf-outlines, *131.

Leaf-sections, *151, *154.

Leaf-spine, $* 348$.

Leaf-stalk, 130.

Leaf-tendril, *138.

Leaf-tips, $* 131$.

Leaf-traces, 155.

Leaves as insect-traps, $* 342, * 343$.

Leaves, compound, *137, *138, 139.

Leaves cutting, $350, * 351$.

Leaves, divided, 143.

Leaves, functions of, 155-174.

Leaves, movements of, *144, $* 145$, *146.

Leaves, simple, 137.

Leaves, structure of, 150-158*.

Legume, 223.

Lemon, study of, 217, 218.

Lenticels, 104.

Leucoium, pollen tube with generative cells, $* 214$.

Lianas, *73.
Lichen, 232.

Lichenes, 232.

Lichens, nature of, 273, 274.

Lichens, study of, 270-273*.

Light, exposure to, 140-149*.

Light, movements towards, 148, 149.

Lignin, 171, 172.

Lily leaf, 150.

Lily, pollen grains producing tubes on stigma, $* 214$.

Limb of calyx or corolla, 200.

Lime, 165.

Linden, fruit cluster of, $* 377$.

Linden fruit, $* 377$.

Linden wood, structure of, $* 100$.

Linear, *131.

Liverworts, 277-281*.

Living parts of the stem, 104, 105.

Lobe, 201.

Locules, 203.

Locust, pinnately compound leaf of, $* 138$.

Locust, thorn-stipules of, 350 .

Luffa, 86.

Lupine, white, 8.

Lycopodiales, 232.

Lycopodium, study of, 291, *292.

Macrospores, 291, *302.

Macrosporophyll, 302.

Magnolia, forking of, *70, *71.

Mahogany wood, structure of, $* 101$.

Maldive nut, 381.

Mallows, pollination in, 364 .

Malt, 13.

Maltose, 116.

Mangrove, *319.

Maple fruit, $* 223$.

Maple leaf, 134.

Marchantia, study of, 278-281*. 
Marestail, air-passages of, *173.

Mechanics of monocotyledonous stems, $* 84,85$.

Medullary ray, 45, *101.

Melon, palmately netted-veined leaf of, *133.

Melon-cactus, $78, * 80$.

Messmates, 340.

Mesophytes, 317, 318.

Mesquite, root-system of, 48.

Metabolism, 165-176.

Metabolism, digestive, 172.

Micropyle, 6.

Microsphæra, study of, 263, 264.

Microspores, *302.

Microsporophyll, 302.

Midrib, *133.

Mildews, powdery, 263, *264.

Mimicry, 347, 348.

Mineral matter accumulated in the leaf, 165.

Mistletoe, 337.

Modified leaves, 121.

Moisture-plants, 311-313.

Monadelphous, 202, *204.

Monocotyledonous plants, 34, 233.

Monocotyledonous stems, *83, *84, *85, 86.

Monocotyledonous stems, growth of, in thickness, $85,86$.

Monocotyledonous stems, rise of water in, *110.

Monocotyledons, 233.

Moncecious, 200.

Monotropa, 169.

Morning-glory, rate of increase of, $390,391$.

Morphology, 1, 33.

Moss, study of, 281-285.

Mosses, 281-285*.

Moths, *361, 362.
Mould, black, study of, 257, 258, 259.

Movement of water in plants, 107, *108, *109, *110, 111, 112, 113.

Movements of floral organs, *365, *366.

Movements of leaves, *144, *145, *146.

Movements toward light, 148.

Mucronate, *131.

Mulberry, *226.

Mullein, hairs from corolla of, *361.

Multiple fruits, *226.

Multiple primary roots, 14 .

Musci, 232.

Mushroom, study of, 264-266*.

Mutilated seedlings, growth of, 14 .

Mycelium, 257, *258.

Mykorhiza, 342.

Myrsiphyllum, 79, *81.

Myxogasteres, 232.

Myxothallophytes, 232, 233.

Naked buds, 121.

Nasturtium leaves, starch in, *170.

Natural selection, 394, 395 .

Nectar, 356.

Nectar-glands, 356.

Nectar-guides, 358.

Nectaries, 357.

Negundo, radial and cross-sections of stem of, $* 89$.

Nemalion, study of, $253,254, * 255$.

Netted-veined, *133.

Nettle, stinging hair of, *184.

Nightshade, leaf of, $* 349$.

Nitella, study of, 247-250.

Nitrogen, 171, 340.

Nocturnal position, *144, *145.

Node, 31, 32, 83. 
Nucleus, 178.

Nucleus of root-hair, $* 49$.

Nut, *222, 223.

Nutrient substances, 168, 169, 171.

Nutrition of plants, 165-176.

Oak leaves, arrangement of, *140.

Oat, root-system of, 48.

Obovate, *131.

Obtuse, *131.

Odors of flowers, 357 .

Offensive-smelling plants, 352.

Oil, 21, 22.

Oil, essential, 24.

Oil, extraction, 22.

Oil, testing seeds for, 21, 22.

Onion, bulb of, 77 .

Onion leaf, section of, *79.

Onion, structure of, 116 .

Onion, tests for food-materials in, $116,117$.

Oögonia, *251.

Oösphere, *249, *251, 280, *284, 285.

Oöspore, 247, 249.

Opposite, *65, *140, *141, *142.

Orbicular, *131.

Orchid, aerial roots of an, *37.

Order, 230.

Organs, essential, *197.

Organs, vegetative, 30.

Oscillatoria, study of, 239, 240.

Osmosis, 50-54.

Osmosis in an egg, 50, *51.

Osmosis in root-hairs, $53,54$.

Ovary, 201, 202, *203, $* 205$.

Ovate, *131.

Ovoid, egg-shaped.

Ovule, 202, *203.

Ovule, spruce, fertilized, $* 303$.

Ovule, structure of, *215.
Oxalis leaf, development of, $* 127$.

Oxidation, 11, 12.

Oxygen, 11, 12, 166, 167, 168.

Oxygen-making, 167, 168.

Palisade-cells, *151.

Palmate, *133.

Pampas region, 393.

Panicle, *189, 190.

Panicum, *381.

Pansy, leaf-like stipules of, $* 135$.

Papilionaceous corolla, *199.

Papillæ on stigma of a lily, *214.

Paraphyses, 251, *252.

Parasites, 39, 336-338.

Parasitic roots, $39, * 40$.

Parenchyma, 94.

Parietal placenta, 203, *205.

Parsnip root, study of, 45,46 .

Pea seed, 8.

Pea seedling, mutilated, 14.

Pea seedling on clinostat, 58 .

Peat bogs, 327.

Peat moss, *327.

Pedicel, *186, 187 .

Peduncle, *186, 187.

Peg of squash seedling, 27 .

Pepo, 224.

Perennial, 47, 71.

Perfect, 198.

Perianth, *197.

Pericarp, 224.

Perigynous, 204, *205.

Perithecia, 263.

Permanganate test, 28.

Petal, 197.

Petiole, 130, 134.

Phæophyceæ, 232.

Phanerogams, 231, 233.

Phanerogams, classes of, 233.

Phosphorus, 165. 
Phycomycetes, 232.

Physcia, 270-273.

Physiology, vegetable, 1.

Pigeon-wheat moss, study of, 281285.

Pileus, *264, 265.

Pine, seedling, *33.

Pine wood, *94.

Pinnæ, leaflets of a pinnately compound leaf, 138.

Pinnate, *133.

Pinnules, *288.

Pistil, *197, 201, 202, *203.

Pistil, parts of, *203.

Pitcher-plant, *340.

Pith, *83, *87, *88, *89.

Placenta, 203, *205.

Plankton, 333.

Plant colonies, 310.

Plant formations, 310.

Plant physiology, definition of, 1.

Plant societies, $307-323, * 312, * 322$.

Plants of uneatable texture, 348 .

Plants, classes of, in relation to economy of water, 311 .

Plants, destruction of, by animals, 345.

Plants, earliest appearance of, 298.

Plants, mimicry by, 347,348 .

Plasmolysis, 52, 53.

Pleurococcus, study of, 244,245 :

Plumule, 7.

Pod, 219, 223.

Poisonous plants, 352 .

Poisonous seeds, 24.

Poisons, plants containing, 352.

Pollarded trees, 128.

Pollen, 201, 211, *212.

Pollen-carrying apparatus, 355, 366.

Pollen, discharge of, *211.
Pollen grains, $* 212$.

Pollen grains, number of, per ovule, 216.

Pollen, protection of, from visitors, 360-362.

Pollen, protection of, from rain, *371, 372.

Pollen tubes, 212, 213, *214.

Pollination, 353-355.

Polypetalous, 201.

Polysepalous, 201.

Polysiphonia, 255.

Polytrichum, 281-285.

Pome, 224.

Pond-scum, study of, 241-244*.

Potash in hay, 165.

Potato tuber, 76, *78, 114-116.

Prickle, *349.

Prickly leaves, *349.

Prickly pear, $* 315$.

Primary root, 36 .

Primrose, pollination in flowers of, *366, 367 .

Procambium, *96.

Prosenchyma, 94, 95.

Propagation, by root, 61 .

Propagation, means of, among cryptogams, 373.

Propagation of plants, 373-386*.

Protection of plants from animals, 345-352.

Protection of pollen from rain, *371, 372 .

Proteids, 22, 23.

Proteids, tests for, 23.

Prothallium, 287, *289.

Protococcus, *244.

Protonema, 283.

Protoplasm, 52, 178.

Protoplasm, characteristics of, 181, 182. 
Protoplasm, circulation of, $* 184$, 185.

Protoplasm, continuity of, 146.

Pteridophytes, 232.

Pteridophytes, remarks on, 286, 295-297.

Puccinia, study of, 259-262*.

Pulvini, 145, *146.

Race, 230.

Raceme, *186.

Raspberry, *374.

Ray, medullary, 45.

Ray-flowers, 188, *189.

Receptacle, 199.

Red clover, leaf of, *144.

Regions of vegetation, 324 .

Regular flowers, 198.

"Reindeer moss," 274.

Reproduction in algæ, 256.

Reproduction in ferns, 287 , *288, *289, 291.

Reproduction in flowering plants, 212-215*.

Reproduction in fungi, *258, *259, *260, *261, *262, *265, *266, *268, *270.

Reproduction in morning-glory, $390,391$.

Reproduction in mosses, $* 284,285$.

Resin passage, $* 93$.

Respiration, 172, 173.

Retuse, *131.

Rhachis, 287, *288.

Rhizoids, hairs serving as roots in mosses and liverworts, *282, *289.

Rhizopus, study of, 257, 258, 259.

Rhodophyceæ, 232.

Rhubarb roots, *47.

Ring, annual, *100, *101.
Ringent, *203.

Rise of water in stems, 108-113.

Rockweed, study of, 250-252*.

Root, 36-61.

Root, adaptation to work, 59, 60 .

Root-cap, *42.

Root-climbers, *39, 73 .

Root, dicotyledonous, section, $* 44$.

Root, elongation of, 30,31 .

Root, exogenous, $* 44$.

Root, fleshy, 45, 46, *47.

Root-hair, $31, * 32, * 49,50$.

Root-pressure, 54, *55.

Root-section, *42, *44.

Root-sheath or root-pocket, 37 .

Root-system, 47, 48.

Roots, absorbing surface of, 49 , 50.

Roots, absorption and temperature, . 55,56 .

Roots, adventitious, 36 .

Roots, aerial, $36, * 37, * 38, * 39$.

Roots, brace-, *38.

Roots, fascicled, *41.

Roots, fibrous, *41.

Roots, growth of, 30, 31 .

Roots, hemlock, lateral extension of, $* 60$.

Roots, movements of young, 56, *57, *58, 59 .

Roots, parasitic, $39, * 40$.

Roots, primary, 36.

Roots, propagation by, 61 .

Roots, selective action of, 54 .

Roots, soil-, 36.

Roots, storage of nourishment in, $46, * 47$.

Roots, structure of, 41-46.

Roots, water, 37.

Rootstock, $75, * 76, * 77$.

Rotation of protoplasm, *184, 185. 


\section{INIDEX}

Round-leafed mallow, stamens and pistils of, 364 .

Russian thistle, *379.

Russian thistle, spread of, 394.

Rust, 259.

Rust, wheat, study of, 259-262*.

Rye grass, 76.

Sage, pollination in flowers of, *365, *366.

Sago-palm, 113.

Salver-shaped, *202.

Salvinia, *302.

Sap, descent of, *109, 110.

Sap, rise of, 107, 108, *109.

Saprophytes, 169, 269.

Sapwood, 105.

Scalloped, *132.

Schizomycetes, 232.

Schizophyceæ, 232, *238.

Scirpus, cross-section of stem of, *84.

Sclerenchyma, 84 .

Scouring-rush, study of, 292-295*.

Seasonal plants, 311.

Secondary growth, *96, *97, *100.

Secondary root, 36.

Secondary roots, direction of, 59 .

Sections, leaf, *151, *154.

Sections, root, $* 42, * 44$.

Sections, wood, *100, *101, *102.

Sedge, rootstock of, $* 76$.

Seed, 5-24.

Seed-leaf, $* 6,7$.

Seedlings, 25-35.

Seedlings, mutilated growth of, 14 .

Seed-plants, 231, 233.

Seed-plants, classes of, 233.

Seeds, containing poisons, 24.

Seeds, dispersal of, $377-386 \%$.

Selection, natural, 395.
Selective absorption, 53,54 .

Self-pollination, 353.

Sepal, 197.

Separated flowers, 199, 200, *201.

Sequoia, *66, 71, *106.

Series, plants form a, 300 .

Serrate, *132.

Sexual generation, 278.

Shade plants, *321.

Shoot, 30.

Shrubs, 69, 70.

Sieve-cells, *93, 110.

Sieve-plate, *93.

Sieve-tubes, *93.

Silica, 165, 241, 294.

Simple leaves, 137.

Simple pistil, 202.

Simple umbel of cherry, *187.

Sinuate, *132.

Sleep of leaves, $* 144, * 145$.

Slime-fungi, 232.

Slime moulds, 178 , *179, 180, 181, *236, 237.

"Smilax," 79, *81.

Snowflake, pollen tube of, with generative cells, *214.

Solomon's seal, parallel-veined leaf of, *136.

Soredia, 271.

Sori, $261,287, * 288$.

Spatulate, *131.

Species, 229.

Spermagones, 271.

Spermatia, 271.

Spike, 188.

Spine, *347, *348, *350.

Spiral vessel, $* 92$.

Spirogyra, study of, $241,242, * 243$, 244.

Sporangium, 287, *288.

Spore, 235, *236. 
Spore-capsules, 281.

Spore-cases, $* 258, * 259$.

Spore-fruits, $* 254$.

Spore-plants, 231, 232.

Spore-plants, classes of, 232.

Spore-sacs, 263, 270, 273.

Spores of slime moulds, 180.

Sporophyll, 294.

Sporophyte, 281, *282, 284, 285, 289, 291.

Spruce, fertilized ovule of, *303.

Squash seed, 5, 6 .

Squash seed, section, 6 .

Squash seedling, 25-27.

Stamen, *197, 201, 202, *203.

Stamen, parts of, *203.

Standard, *199.

Starch, 17-20, *19.

Stareh disappears during germination, 21.

Starch in leaves, $169, * 170$.

Starch-making, rate of, $170,171$.

Starch, testing seed for, 18 .

Stem, 30-117.

Stem, definition of, 62 .

Stem, dicotyledonous, annual, gross structure of, 86, *87.

Stem, dicotyledonous, minute structure of, 86-98*.

Stem, early history of, $* 95,96$.

Stem, functions of cells of, 105, 106, 107.

Stem, modifiability of, 79-82*.

Stem, monocotyledonous; *83, *84, *85, 86 .

Stem, structure of, 83-103*.

Stemless plants, $* 72,73$.

Stems, 62-118.

Stems, climbing, 74, *75.

Stems, storage of food in, 113-115.

Stems, twining, $* 75$.
Stem-structure, early history of, $* 95,96$.

Sterigmata, *266.

Sterilization, 238.

Stigma, 201, *203.

Stigma, structure of, 213-215*.

Stinging hair, $* 184$.

Stipa, cross-section of rolled and unrolled leaves of, *318.

Stipe, *264, 265.

Stipules, *135, 136.

Stolon, with tips rooting, $* 374$.

Stomata, 104,*151, *152,*153,*154.

Stomata, operation of, 158, 159.

Stone-fruit, 224.

Storage of food in the root, $46, * 47$.

Storage of food in the stem, 113-

117.

Strawberry, *226.

Struggle for existence, 387-394.

Study of buttercup flower, 195, 196.

Study of lemon, 217, 218.

Study of tomato, 217.

Study of trillium flower, 192, 193.

Study of tulip flower, 194, 195.

Style, 201, *203.

Sugar, 13, 116, 117, 168, 171, 172.

Sugar, formed during germination, 13.

Sugar-cane, cross-section of a bundle from, *110.

Sundew, *341, *342, 343.

Sun-plants, $* 321$.

Supernumerary buds, 122, *123, *124.

Survival of the fittest, 394, 395.

Swarmspores, 180.

Sweet pea, flowers; $* 199$.

Symbiont, 340.

Symbiosis, 273, 340.

Symmetrical, 198. 
Taper-pointed, *131.

Taproot, *41.

Teleutospores, *262.

Temperature and root-absorption, $55,56$.

Temperature, relation to germination, 9 .

Tendril, *138.

Tendril climbers, *74.

Terminal bud, 63, 121, 122, *124, *125.

Terminal flowers, 186, *191.

Tertiary root, 36 .

Testa, 6 .

Tetraspores, $* 255$.

Thallophytes, 232, 235-275.

Thallophytes, study of, 237-273*.

Thallus, 235, 250.

Thermostat, 9 .

Thistle, Russian, *379, 394.

Thorns as branches, $68, * 69$.

Thyme, stoma of, *153.

Tickle-grass, *381.

"Timber line," *329, *330.

Tissue, 94, 95.

Tomato, study of, 217.

Tracheids, 92, 93, *94.

Transition from stamens to petals, *209.

Transpiration, 156.

Transpiration, amount of, 164, 165.

Transpiration, measurement of, $159, * 160,161$.

Transportation by water, 380,381 .

Trees, 69.

Trees, age of, 71 .

Trillium, study of flower of, 192, 193.

Trimorphous flowers, 367 .

Tropæolum leaf, *132.

Tropæolum leaves, starch in, *170.
Tropæolum, petiole, coiling of,* 75 .

Tropical vegetation, 324,325 .

Tropophytes, 311, 318, 319.

Truncate, *131.

Trunk, *66, *67.

Tuber, 76, *78.

Tubercles on clover roots, *339.

Tubular corolla, *203.

Tulip, study of flower of, 194, 195.

Tumble-weeds, 378, *379, *380.

Turgescence, 184.

Turnip, seedling, *32.

Twayblade, beetle on flower of, *359.

Twigs, study of, 62-64.

Twiners, 74, *75.

Twining, rate of, 74,75 .

Types, order of appearance of, 298-305.

Umbel, *187.

Umbellet, 190.

Underground stems, $75, * 76, * 77$, *78, *79.

Uneatable plants, 348 .

Union of pistils, 202, 203.

Union of stamens, 201, 202.

Uredospores, 261, *262.

Usnia, *271.

Vacuole, contractile, 180.

Variety, 229, 230.

Vaucheria, study of, 245, *246, 247.

Vegetable physiology, 1 .

Vegetation, alpine, $328, * 329, * 330$, *331.

Vegetation, aquatic, 332, 333.

Vegetation, arctic, 327, *328.

Vegetation, regions of, 324 .

Vegetation, temperate, 325, 326. 
Vegetation, tropical, 324, 325.

Vegetative organs, 30 .

Vein, $130, * 133$, *136.

Veining, *133, *136.

Venation, *133, 134, 135, *136.

Venus flytrap, *343, 344 .

Vernation, 125, *126, 127.

Vertically placed leaves, $146, * 147$, 148.

Vessel, *92, 106.

Volva, *265.

Water, absorption by roots, 53-55.

Water, amount transpired, 159165.

Water, course through leaf, 163, 164.

Water, excretion of, $172,173$.

Water, movement of, 107 , *108, *109, *110, 111, 112, 113.

Water, relation to germination, 10 .

Water-lily, white, insertion of floral organs, $* 205$.

Water-lily, white, transitions from petals to stamens in, *209.

Water roots, 37.

Weapons of plants, 349-351*.

Wedge-shaped, *131.

Weeds, 387-390.

Weeds, study of, 388, 389 .

Wheat-grain, section of, *19.
Wheat rust, study of, 259-262*.

Wheel-shaped, *202.

Whorled, *293, 294.

Willow, adventitious buds of, 128 .

Willow, arctic, *328.

Willow, flowers of, *201.

Wilting, 111.

Wind-pollination, 354.

Windsor bean sprouting over imercury, $56, * 57$.

Winged fruits, $377, * 378$.

Wings, *199.

Wood, coniferous, structure of, 92 , *93, *94.

Wood of linden, *100.

Wood sections, $* 100$, $* 101$, $* 102$.

Wood, structure of, *93, *100, *101.

Wood-cell, *89, *91, *101.

Wood-parenchyma, 94 .

Xanthoria, *271.

Xerophytes, 311, 313-317*.

Yarrow, head of, *189.

Yeast, study of, 266-270, *268.

Yucca, 335.

Zones, vegetation of, 324-328.

Zoöspores, 236, *244.

Zygospores, 236, *243, *259. 


\section{BERGEN'S BOTANY}

\section{KEY AND FLORA.}

\section{NORTHERN AND CENTRAL STATES EDITION}

BY

JOSEPH Y. BERGEN, A.M.

Isstructor in Biology, ENglish High School, Boston

BOSTON, U.S.A.

GINY \& COMPANY, PUBLISHERS

The Atbenxum press 
COPYRIGHT, 1901

BY JOSEPH Y. BERGEN

ALL RIGH'TS RESERVED 


\section{PREF A CE}

THIs flora furnishes a key to the commoner spring-flowering families of Phanerogams and descriptions of the characteristics of these families, together with such genera and species under each as seem most available for school study in the central and northeastern states. The descriptions have been in part compiled by the author from various sources, and in part written with the plants themselves in hand. The characterizations of many families and of some genera are taken with slight simplifications from Hooker's Student's Flora of the British Islands; a few are from Warming's Systematic Botany. The remainder are mostly adapted from the floras of Gray and Wood, from Sargent's Silva of North America, and from Britton and Brown's illustrated Fiora of the Northern States and Canada.

The sequence of the families (and sometimes the genera under their respective families) is based on Engler's Syllabus der Pflanzenfamilien, which has also been followed as regards nomenclature of families. In other regards the sixth edition of Gray's Manual, and Bailey's revision of Gray's Field, Forest, and Garden Botany have been followed as authorities. Valuable information concerning the precise time of flowering of many species has been derived from Darlington's Flora Cestrica and Ward's Guide to the Flora of Washington and Vicinity.

By arrangement with Professor S. M. Tracy a considerable portion of the key and a large number of the following descriptions have been copied (a little simplified) from his Flora of the Southeastern States; these are designated by an asterisk at the end of each description. 
Especial acknowledgments are due to Professor Benjamin L. Robinson, Director of the Gray Herbarium of Harvard University, who has given most valuable advice and has revised the manuscript of the keys and flora, thus contributing greatly to any value which they may be found to possess.

Much aid has been derived from the careful proof-reading of Professor J. M. Holzinger of the Minnesota State Normal School, Professor L. H. Pammel of the Iowa State College, and Miss Mary P. Anderson of the Somerville, Mass., English High School. The author wishes heartily to thank these critics for the many errors which they have corrected and the valuable additions which they have suggested.

The territory covered overlaps that dealt with by Professor Tracy in the flora above cited, and nearly meets that embraced in Miss Eastwood's Flora of the Rocky Mountains and the Salt Lake Basin, since many of the species treated in the present work range west as far as the hundredth meridian.

The plants chosen to constitute this flora are those which bloom during some part of the latter half of the ordinary school year, and which have a rather wide territorial range. Enough forms have been described to afford ample drill in the determination of species. Gray's Manual of Botany or Field, Forest, and Garden Botany will of course be employed by the student who wishes to become familiar with most of the seed-plants of the region here touched upon. Those species which occur in the central and northeastern United States only as cultivated plants are so designated. The illustrations are mainly redrawn from German sources. A few of them are the work of Mr. E. N. Fischer of Boston, but the greater portion are by Dr. J. W. Folsom of the Illinois Industrial University.

$$
\text { J. Y. B. }
$$

CAMbridge, Mass., January, 1901. 


\section{HOW TO USE THE KEY AND FLORA}

Is order to determine an unknown species, the student is first to make a careful examination of the plant in hand. After noting in a general way the appearance of the root, stem, and leaf, including a cross-section of the stem, he should study the number, coherence, and adnation of the parts of the flower, then make and draw a cross-section and a lengthwise section of it. Irregularities in calyx or corolla, peculiarities in the shape, structure, or operation of the essential organs, such, for instance, as anthers discharging through chinks in the end, should be noted.

Next, the inquirer should look carefully through the Key to the families. He is first to decide whether the plant in question is a Gymnosperm or an Angiosperm; if not a coniferous tree or shrub, it will of course belong to the latter division. He is then to settle the question whether it is a Monocotyledon or a Dicotyledon; then under what division of the group the plant comes; and, finally, to decide upon its family.

Turning now to the page at which the family is described, a rapid inspection of the characteristics of the genera will make it evident to which one the species under examination belongs. It may not infrequently prove that none of the genera described agree with the plant studied, and in that case the student must either consult a larger flora or rest satisfied with having determined the family to which his 
specimen belongs. ${ }^{1}$ The identification of the species, after the genus has been reached, presents no difficulty in a little flora like the present one.

The author does not believe in spending much of the time of a class upon identifying species, but would rather recommend comparative studies of as many plants of a group as are accessible, and making these studies thorough enough to bring out fully the idea of the family, the genus, and the species. $^{2}$. The descriptions in this flora may be used as a check on the cruder ones which the pupil is first to frame for himself.

1 It will greatly simplify matters if the teacher selects for examination only such species as are here described.

2 The teacher will find abundant suggestions for such a course in Spalding's Introduction to Botany, pp. 152-260. 


\section{KEY TO THE FAMILIES OF FLOWERING PLANTS DESCRIBED IN THIS FLORA}

\section{CLASS I}

GYMNOSPERIMS. Ovules not enclosed in an ovary.

Trees or slurubs. Leaves usually evergreen and needle-shaped, awl-shaped, or scale-like. Flowers monœcious or diœcious. Fruit a scaly cone, or sometimes appearing berry-like.

1. Pine Fanily, page 13

\section{CLASS II}

ANGIOSPERIMS. Orules enclosed in an ovary.

SUBCLASS I. - MONOCOTYLEDONS. Flowers usually with their parts in threes, never in fives. Leaves usually parallel-veined. Cotyledon 1.

Flowers enclosed by chaffy bracts.

FAMIII

PAGE

Flowers 2-bracted. Leaves 2-ranked. Stem cylindrical

4. Grass . . . . 23

Flowers 1-bracted. Leaves 3-ranked. Stem triangular ............

5. Sedge. . . . 23

Flowers on a spadix.

Spadix slender, hairy, and bristly . . . . 2. Cat-tail . . . 20

Spadix fleshy .......... 6. Arum . . . . 23

Flowers not on a spadix.

Carpels usually numerous and nearly or entirely separate . . . . . . . . . . . . . .

Carpels united.

Perianth free or adnate only to the base of the ovary.

Perianth regular, its parts similar, green, or chaffy

3. Water-plantain . 21

Perianth of 2 sets, one sepal-like, the other petal-

9. Rush . . . . 29

like.

Style and stigma 1. Petals 3 or 2, soon disappearing

7. Spiderwort . . 26 
Styles or stigmas 3, separate. Petals 3, lasting

Style 1, stigma 3-lobed, or 6-toothed.

Corolla irregular. Aquatic herbs with parallel-veined leaves . . . . . . . . .

Perianth regular, its divisions all alike, or nearly

so, petal-like

Perianth adnate to the ovary.

Anthers 6 . . . . . . . . . . . . . . . 11. Amaryllis . . . 42

Anthers 3 . . . . . . . . . . . . . . . 12. Iris. . . . . 45

Anthers 1 or 2 . . . . . . . . . . 13. Orchis . . . 46

SUBCLASS II. - DICOTYLEDONS. Flowers usually with their parts in fives or fours. Leaves netted-veined. Cotyledons 2.

I. Apetalous Division. Flowers without a corolla or without either calyx or corolla. ${ }^{1}$

A.

Flowers monœcious or diœcious, one or both sorts in catkins.

Staminate flowers in catkins, the pistillate ones solitary or clustered.

Leaves pinnately compound .. . . . . . . . 16. Walnut. . . . 49

Leaves simple . . . . . . . . . . 18. Beech . . . . 55

Both kinds of flowers in catkins.

Leaves alternate.

Ovaries in fruit becoming fleshy and combining into an aggregate fruit . . . . . . . . .

Fruit 1-seeded, a stone-fruit or minute nut. Aromatic shrubs . . . . . . . . . . . 15. Bayberry . . . 49

Fruit a capsule, seeds with silky hairs . . . . 14. Willow . . . . 47

Fruit a minute nut or akene. Mostly large shrubs or trees, not very aromatic . . . . . . . . 17. Birch . . . . . 51 Leaves opposite, small parasitic shrubs . . . 22. Mistletoe . . . 63

B.

Flowers not in catkins, both caly $\mathrm{x}$ and corolla warting 44. Sycamore.... 105

1 When only one floral envelope is present, this is said to be the calyx and the corolla is considered to be missing. 
c.

FAMILY

PAGE

Flowers not in catkins ; calyx present, sometimes petal-like.

Trees or shrubs.

Flowers not hypogynous ; plants not climbing . . 73. Dogwood . . . 162

Flowers not hypogynous ; climbing plants . . . . 24. 1)utchman's Pipe 64 Flowers hypogynous.

Style single, not cleft, fruit a key. (Fraximus) . 78. Olive . . . . . 175

Style single, not cleft, fruit a stone-fruit . . . . 37. Laurel . . . . 88

Styles 2 or 2-cleft, fruit 1-celled . . . . . . . 19. Elm . . . . . . 59

Styles 2 or 2-cleft, fruit 2-celled . . . . . . 58. Maple . . . . 140

Styles 3, each 2-cleft. Ovary 3-celled . . . . . 53. Spurge . . . . 135 Herbs.

Flowers not hypogynous; ovary 6-celled . . . . . 24. Dutchuan's Pipe 64

Flowers not hypogynous; ovary 1-celled ; flowers in

umbel-like clusters . . . . . . . . 23. Sandalwood . . 64

Flowers hypogynous; ovary 1-celled.

Stamens many . . . . . . . . . . . . . . 32. Buttercup . . . 77

Stamens few.

Stipules sheathing the joints . . . . . . 25. Buckwheat. . 66

Stipules wanting.

Rather fleshy herbs . . . . . . . . . 26. Goosefoot . . 68

Not fleshy.

Ovules on a free central placenta; delicate, soft-leaved herbs. (Stellaria) . . . 30. Pink . . . . 71

Ovule single. Tough, with awl-shaped leaves.

(Scleranthus)

30. Pink . . . 71

Ovary several-celled.

Small prostrate herb; leaves spatulate, whorled . 28. Ice-plant . . . . 69

Stipules present, not sheathing.

Style single . . . . . . . . . . . . . . 21. Nettle . . . . . 62

Styles 2 . . . . . . . . . . . 20. Mulberry . . 61

Flowers hypogynous, orary 3-celled . . . . . . 53. Spurge . . . . 135

Flowers hypogynous, ovary 5-10-celled ; fruit a berry 27. Pokeweed . . . 69

II. Polypetalous Division. Calyx and corolla both present, the petals not united.

Stamens more than 10 .

A.

Trees, shrubs, or woody vines. Leaves alternate.

Ovary 1, simple.

Fruit a stone-fruit 
Ovary 1, compound ; fruit dry.

FAMTLY

PAGE

Ovary 5-celled, 1-2-seeded at maturity . . . . 63. Linden . . . . 146

Ovary 3-celled, many-seeded . . . . . . . 68. Begonia . . . 152

Ovary 1, compound; fruit fleshy . . . . . 45. Rose . . . . 105 Ovaries numerous.

Leaves with stipules.

Stamens inserted on the receptacle . . . . 34. Magnolia . . 85

Stamens inserted on the calyx . . . . . 45. Rose . . . . 105

Leaves not with stipules.

Small trees .......... 36. Pawpaw . . 88

Leaves opposite ; fruit dry.

Ovary single, 3-5-celled . . . . . . . . 43. Saxifrage . . 101

Ovaries several, enclosed by the calyx tube . . 35. Calycanthus . . 87 Herbs.

Ovary single, simple; fruit a berry . . . . . . 33. Barberry . . . 84 Ovaries several, simple.

Stamens inserted on the receptacle . . . . . 32. Buttercup . . . 77

Stamens inserted on the calyx . . . . . . . 45. Rose . . . . 105 Ovary compound.

Aquatic herbs, leaves flat . . . . . . . 31. Water-lily... . 75

Marsh herbs, leaves tubular . . . . . . . 42. Pitcher-plant . 101

Terrestrial herbs.

Ovary 1-celled.

Placentæ central, juice watery . . . . 29. Purslane . . 70

Placentæ parietal, juice milky or colored . 38. Poppy . . . . 89

Placentæ 2, parietal . . . . . . . . . . 40. Caper . . . . 99

Placentæ 3 or more, parietal.

Leaves alternate . . . . . . . . 41. Mignonette . 100

Leaves opposite . . . . . . . . 65. St. Johnswort . 148

Leaves apparently wanting, stems fleshy . 69. Cactus . . . . 154

Ovary several-celled, stamens monadelphous . 64. Mallow . . . . 147

Ovary 3-celled, stamens not much if at all monadelphous, stems fleshy, juice watery and acid . . . . . . . . . . 68. Begonia. . . 152

B.

Stamens not more than 10 .

Trees, shrubs, or woody vines.

Fruit a stone-fruit.

Stamens 2, rarely 3-4 
Stamens as many as the petals.

FAMILY

PAGE

Flowers perfect.

Stamens 4, alternate with the petals . . 73. Dogwood . . 162

Stamens 5, alternate with the petals . . . 54. Sumac . . . . 137

Stamens 4-5, opposite the petals . . . . 61. Buckthorn . 143

Fruit a berry.

Stamens alternate with the petals.

Inserted on the calyx, leaves simple . . . . 43. Saxifrage . . 101

Inserted on a disk surrounding the ovary,

leaves compound . . . . . . . 71. Ginseng . . 157

Stanens opposite the petals . . . . . . 62. Grape or Vine . 145

Fruit a 2-seeded capsule or a key.

Leaves compound . . . . . 51. Rue . . . 133

Fruit a 3-5-celled capsule, flowers small, greenish, or brown-purple, leaves simple . . . . . . .

Fruit 5-lobed, the 5 carpels separating when ripe, flowers rather large, white, or of showy colors, leaves simple . . . . . . . . . . . . . .

Fruit a 1-3-celled capsule, leaves compound, flowers irregular . . . . . . . . . . . .

Fruit a 3-celled bladdery capsule, leaves compound,

flowers regular . . . . . . . . . . . .

Fruit a legume 46. Pea or Pulse 117

Herbs.

Ovary single, 1-celled, simple or compound.

Corolla regular, or nearly so.

Sepals and petals $4-5$; stamens 5,10 , or 12 , distinct.

Leaves alternate.

Stigma single . . . . . . . . . 46. Pea or Pulse. . 117

Stigmas 4. . . . . . . 43. Saxifrage . . 101

Leares opposite, punctate, flowers yellow . . 65. St. Johnswort . 148

Leaves opposite, flowers white or red . . . 30. Pink . . . . 71

Sepals and petals 4-5; stamens 5, united . . 67. Passion Flower 151

Sepals 2, petals 4-5 . . . . . . . . 29. Purslane . . 70

Sepals 6, stamens hypogynous, opposite the petals 33. Barberry . . 84 Corolla irregular.

Fruit a legume . . . . . . . . . . . 46. Pea or Pulse. . 117

Fruit a capsule.

Stamens 5 . . . . . . . . . . . . 66. Violet . . 149

Stamens 6, in 2 sets . . . . . . . . . . . . . 38 . Poppy . . . . 89 
Ovary single, 2-5-celled, fruit dry.

FAMILY

PAGE

Ovary 2-celled.

Flowers in umbels, stamens 5 . . . . . . . 72. Parsley . . . . 158

Flowers not in umbels, petals 4 or 0 , stamens 6 . 39. Mustard . . . . 93

Flowers not in umbels, petals 3 , stamens 6 or 8 . 52. Polygala . . . . 134

Ovary a 4-celled capsule . . . . . . . . . . 70. Evening Primrose 156

Ovary of 3 nearly distinct lobes, which become

thick and fleshy in fruit . . . . . . . . . 49. Indian Cress . . 132

Ovary a 5-celled capsule.

Leaves simple.

Parasitic white or yellowish herbs, or ever-

green herbs, not parasitic, capsule many-

seeded . . . . . . . . . . . . . 74. Pyrola . . . . 164

Terrestrial, not much if at all fleshy, capsule

5-10-seeded . . . . . . . . . . . 47. Geranium . . 129

Terrestrial, stem fleshy and translucent, cap-

sule elastic, several-seeded . . . . . 60. Balsam . . . . 143

Leaves of 3 leaflets . . . . . . . . . . . . 48. Wood-sorrel . . 131

Ovary of 5 principal cells, each more or less divided

by a partition into 2 cells; seeds flattish, with a

mucilaginous coating . . . . . . . 50. Flax. . . . . 132

Ovary single, 2-5-celled; fruit a berry . . . . . . 71. Ginseng . . . . 157

Ovaries 2, seeds hairy-tufted . . . . . . . 81. Milkweed . . . 180

III. Gamopetalous Division. Calyx and corolla both present, the petals more or less united.

Trees, shrubs, or woody vines.

Leaves alternate.

Fruit splitting open.

Fruit a legume . . . . . . . . . 46. Pea or Pulse . . 117

Fruit a 5-celled capsule . . . . . . . . . 75. Heath . . . . . 166

Fruit not splitting open, a stone-fruit . . . . 55. Holly . . . . . 138

Fruit a berry.

Ovary not adnate to the calyx ; seeds few, large 77. Ebony . . . . 174

Ovary not adnate to the calyx; seeds many, small . . . . . . . . . . . . 88. Nightshade. . . 198

Ovary adnate to the calyx . . . . . . . 75. Heath . . . . 166 Leaves opposite.

Fruit a 2-celled, 2-seeded capsule . . . . . . 95. Madder . . . . 212

Fruit a 2-celled, many-seeded capsule.

Seeds winged . . . . . . . . . . . . 90. Bignonia. . . 206 
Seeds not winged; shrubs . . . . . . . 96. Honeysuckle . 215

Fruit a 5-celled eapsule . . . . . . . . 75. Heath. . . . 166

Fruit a stone-fruit or berry.

Fruit 1-2-seeded; stamens 2 . . . . . . . 78. Olive . . . . . 175

Fruit 1-4seeded; stamens 4 . . . . . . . 86. Verbena . . . 192

Herbs.

Fruit 1-5-seeded; stamens 5 . . . . . 96. Honeysuckle . 215

Ovary not adnate to the calyx, flowers regular.

Ovary separating into 2 distinct follicles.

Style single, stamens distinct

80. Dogbane . . 178

Styles 2, stamens united . . . . . . . . 81. Milkweed . . 180

Ovary 1-celled.

Fruit a legume

46. Pea or Pulse . 117

Fruit a capsule.

Leaves alternate.

Stamens opposite the lobes of the corolla

76. Primrose . . 171

Stamens alternate with the lobes of the corolla

84. Waterleaf . . 187

Leares opposite . . . . . . . . . 79. Gentian . . . 177

Leaves all reduced to mere scales, plants never green, root-parasites

91. Broom-rape . . 208

Ovary 2-several-celled.

Stamens 2 or 4

94. Plantain . . 211

Stamens 5, cells of the ovary 1-2-seeded.

Fruit separating into 4 nutlets

85. Borage : . . 188

Fruit a capsule

82. Morning-glory . 183

Stamens 5, cells of the ovary several-seeded.

Stigma 1 .

88. Nightshade . . 198

Stigmas 3

83. Phlox 185

Orary not adnate to the calyx, flowers irregular.

Ovary 1-celled.

Fruit a legume . . . . . . . . . . 46. Pea or Pulse . 117

Fruit a capsule . . . . . . . . . . . 92. Bladderwort. . 209 Ovary 2-4-celled.

Cells each 1-seeded.

Ovary deeply 4-lobed

87. Mint . . . 193

Orary not deeply lobed.

Stamens 2 or 4

86. Verbena . . 192

Stamens 8 .

52. Polygala 134

Colls each 2-several-seeded, 
FAMILY PAGE

Corolla lobes imbricated in the bud . . . . 89. Figwort . . . 201

Corolla lobes convolute in the bud . . . . 93. Acanthus . . 210 Ovary adnate to the calyx tube.

Flowers in an involucrate head . . . . . . 100. Composite . . 224 Flowers not in heads.

Stamens 3.

Leaves opposite . . . . . . . . . 97. Valerian . . 220

Leaves alternate . . . . . . . . 98. Gourd . . . 221 Stamens 4-5.

Leaves alternate . . . . . . . . . 99. Campanula . 223

Leaves opposite or whorled . . . . . . 95. Madder . . . . 212 


\section{CLASS I. - GYMNOSPERMS.}

Plants destitute of a closed ovary, style, or stigma. Ovules generally borne naked on a carpellary scale, which forms part of a cone. Cotyledons often several (Fig. 1).

\section{CONIFER}

Trees or shrubs with wood of peculiar structure (Part I, Ch. VI), destitute of ducts, with resinous and aromatic juice. Leaves generally evergreen, and needle-shaped or awl-shaped. Flowers destitute of floral envelopes, monœcious or diœcious, the staminate ones consisting of catkin-like spikes of stamens and the pistillate ones consisting of ovule-bearing scales, arranged in spikes, which ripen into cones.

A.

Each scale of the cone borne in the axil of a bract. Seeds 2, with wings.

Leares evergreen, in bundles of $2-5$.

Pinus, I.

Leaves evergreen, solitary, sessile, keeled on both surfaces.

Picea, II.

Leares evergreen, solitary, petioled, flat. Tsuga, III.

Leaves solitary, evergreen, flat above, keeled below. Abies, IV.

Leaves clustered, deciduous, flat.

Larix, V.

B.

Scales of the cone without bracts, cone becoming globular and woody. Leaves linear.

Leaves alternate, deciduous.

Taxodium, VI. 
C.

Scales of the cone few, without bracts. Leaves evergreen, generally scale-like or awl-shaped.

Cones dry and thin-scaled.

Cones berry-like.

Thuya, VII. Juniperus, VIII.

\section{PINUS, Tourn.}

Sterile flowers somewhat resembling inconspicuous catkins, borne at the base of the young shoot of the season, each flower consisting of pollen-scales in spiral groups (Fig. 1, 2). Fertile flower-spikes which consist of spirally arranged carpelscales, each scale springing from the axil of a bract and bearing at its own base two ovules (Fig. 1, 3). Fruit a cone, formed of the thickened carpellary scales, ripening the second autumn after the flower opens. Primary leaves, thin and chaffy bud-scales, from the axils of which spring the bundles of 2-5 nearly persistent, needle-like, evergreen leaves, from 1-15 in. long (Fig. 1).

1. P. Strobus, L. White Pine. A tall tree, $75-160 \mathrm{ft}$. high, much branched and spreading when growing in open ground, but often with few or no living branches below the height of $100 \mathrm{ft}$. when growing in dense forests. Leaves clustered in fives, slender, 3-4 in. long, smooth, and pale, or with a whitish bloom. Cones $5-6$ in. long, not stout. The wood is soft, durable, does not readily warp, and is therefore very valuable for lumber. In light soil, commonest $\mathrm{N}$.

2. P. Tæda, L. Loblolly Pine, Oldfield Pine. A large tree; bark very thick and deeply furrowed, becoming flaky with age, twigs scaly. Leaves in threes, 6-10 in. long, slender, very flexible; sheaths $\frac{2}{3}-1$ in. long. Cones solitary, oblong-conical, 3-5 in. long; scales thickened at the apex, the transverse ridge very prominent and armed with a short, stout, straight, or recurved spine. Common and often springing up in old fields ; trunk containing a large proportion of sap wood; timber of little value for outside work.*1

3. P. rigida, Mill. Northern Pitch Pine. A stout tree, 30-80 ft. high, with rough scaly bark. Leaves in threes, 3-5 in. long, stiff and flattened. Cones ovoid-conical, 2-3 in. long, their

1 Descriptions followed by an asterisk are taken (more or less simplified) from Professor Tracy's flora in the Southern States Edition. 
scales tipped with a short, abruptly curred spine. Wood hard, coarse and resinous, mainly used for fuel. Poor, sandy soil, especially eastward.

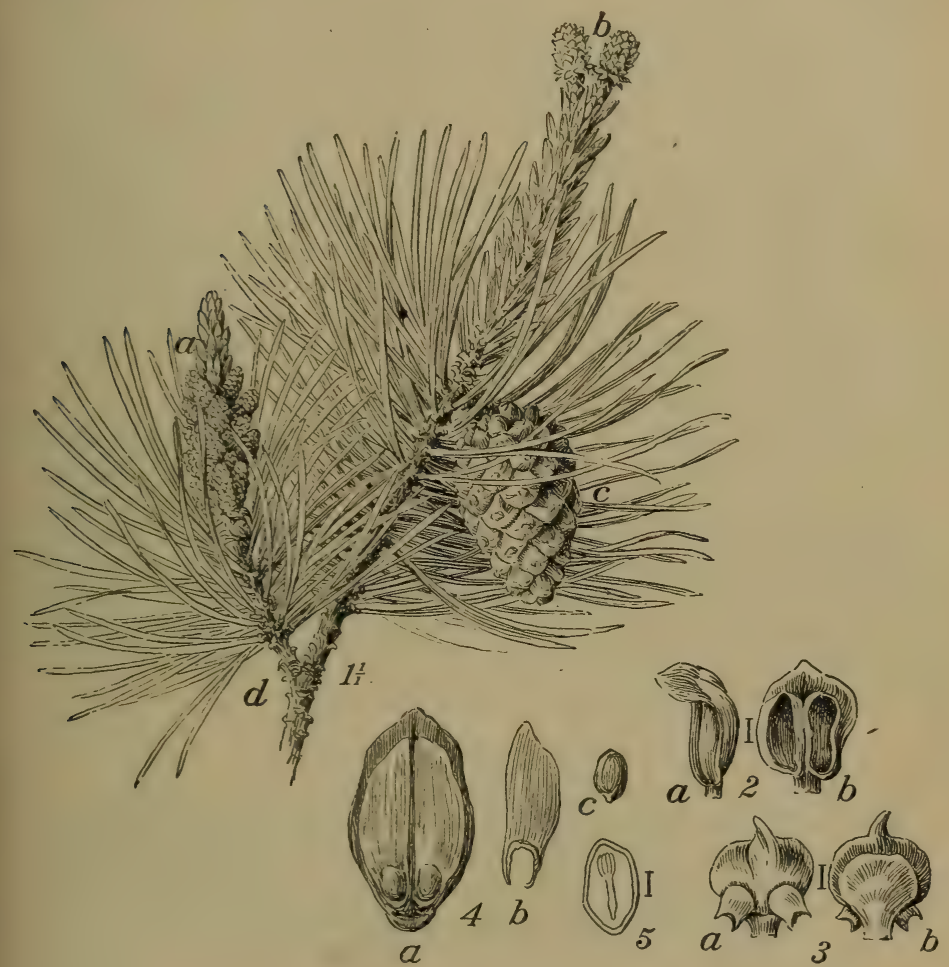

FiG. 1. - Seoteh Pine (P. sylvestris).

1, a twig showing: $a$, staminate catkins; $b$, pistillate catkins; $c$, a cone ; $d$, needles. 2 , an anther, $a$. side view ; $b$, outer surface. 3 , a carpel-scale, $a$, imner surface ; $b$, outer surface. 4 , a cone-scale, a seed-wing, and a seed. 5 , section of a seed, showing the embryo. (1) is natural size ; the other parts of the figure are magnified by the amount indicated by comparison with the vertical line alongside each.

4. P. inops, Ait. Scrub Prxe. A small tree, usually $20-30 \mathrm{ft}$. high, but sometimes much taller; bark of the trunk rough, nearly black; twigs smooth and with a bloom. Leaves in twos, 1-2 in. 
long, rigid, sheaths very short. Staminate catkins dull yellowishpurple, 1 in. long. Cones solitary, short-peduncled, often reflexed, ellipsoid-conic, about 2 in. long; scales thickened at the apex and armed with a slender, straight, or recurved prickle. On dry, sandy soil; wood light, soft, weak, and of little value.**

5. P. sylvestris, L. Scotch Pine (wrongly called Scotch Fir). A medium-sized tree, with the older bark reddish and scaly. Leaves in twos, $1 \frac{1}{2}-2 \frac{1}{2}$ in. long. Cones rather small and tapering (Fig. 1, I c). Cultivated from Europe.

6. P. resinosa, Ait. Red Pine, Norway Pine. A tall, rather slender tree, with bark reddish-brown and moderately smooth. Leaves in twos, slender, and 5-6 in. long. Cones borne at the ends of the branches, smooth, about 2 in. long. A valuable timber tree, which often grows in small, scattered clumps; wood firm, pale red, and not very resinous; used in house and bridge building, and for masts and spars.

7. P. palustris, Mill. Long-Leaved Pine. A large tree; bark thin-scaled, wood very resinous, old trees with only a few spreading branches near the top. Leaves in threes, 10-15 in. long. Sheaths 1-1 $\frac{1}{4}$ in. long, crowded near the ends of very scaly twigs. Staminate catkins 2-3 in. lopg, bright purple, conspicuous. Cones terminal, ellipsoid-conical, 6-10 in. long, diameter 2-3 in. before opening, 4-6 in. when fully opened; scales much thickened at the apex and armed with a short recurved spine at the end. The most common tree in the pine barrens; wood hard, strong, and durable, especially valuable for floors and inside work.*

\section{PICEA, Link.}

Sterile flowers generally axillary (sometimes terminal), borne on the twigs of the preceding year. Fertile flowers terminal. Fruit a nodding, thin-scaled cone, ripening in the first autumn. Leaves evergreen, needle-shaped, four-angled, scattered or spirally arranged.

1. P. nigra, Link. Black Spruce. A small tree, usually only 20 or $30 \mathrm{ft}$. high, often less. Leaves strongly 4-angled, bluish-green, and glaucous, $\frac{1}{4}-\frac{3}{4}$ in. long. Cones ovoid, pointed, $\frac{1}{2}-1 \frac{1}{2}$ in., usually about 1 in. long, persisting sometimes for 20-30 years. Wood of little value except for paper-pulp. The tree is especially abundant northward, and is of common occurrence in peat-bogs.

2. P. rubra, Dietrich. Red Spruce. A large tree, 70-80 or even 100 or more feet high, of strict conical habit. Leaves dark green or yellowish and glossy, $\frac{1}{2}-\frac{5}{8}$ long. Cones ovoid-oblong, acute, usually $1 \frac{1}{2}-2$ in. long, mostly falling the first year. This is the principal 
timber-spruce of the northeastern United States, and furnishes much rather tough lumber for use in floor-joists, scantling, and similar purposes.

3. P. alba, Link. White Spruce, Skunk Spruce, Cat Spruce. A tall, rather conical tree, $60-70 \mathrm{ft}$. high. Leaves pale and with a bloom sometimes $\frac{3}{4}$ in. long. Cones cylindrical, with rounded ends, about 2 in. long, falling inside of one year. A handsome tree, valuable for timber, ranging far northward.

4. P. excelsa, Link. Norway Spruce. A large tree. Leaves dark greeu, $\frac{3}{4}-1$ in. long. Cones $5-7$ in. long. Cultivated from Europe.

\section{TSUGA, Carrière.}

Sterile flowers, clusters of stamens springing from the axils of leaves of the preceding year. Cones terminal, on twigs of the preceding year, drooping, thin-scaled, ripening the first year. Leaves minutely petioled, short, flat, white beneath, 2-ranked.

1. T. canadensis, Carrière. НемLоск. A large tree, in age branchless below when growing in dense woods. When young the spray is very graceful and abundant. Leaves short-linear. Cones $\frac{3}{4}$ in. or less in length. The wood is coarse and splintery, but useful for fences and other rough work. The thick reddish bark is of great value for tanning.

\section{ABIES, Link.}

Sterile flowers from axils of leaves of the preceding year. Cones erect, on the sides of the branches, with deciduous scales, ripening the first year. Leaves scatterer, but on horizontal branches appearing 2-ranked, flat above, silvery, and with a prominent midrib below.

1. A. balsamea, Miller. BAlsam Fir. A slender tree, 50-60 ft., occasionally $80 \mathrm{ft}$., high, with dense foliage. Leaves narrowly linear, less than $1 \mathrm{in.}$ long. Cones violet-colored until old, cylindrical, 2-4 in. long. The bark contains many large blisters, filled with the well-known Canada balsam. The wood is brittle, and of little value.

\section{LARIX, Tourn.}

Flower-spikes short, opening in early spring, before the leaves; the fertile ones, while still young, of a beautiful crim- 
son color. Fruit a small cone, with thin scales. Leaves none of them scaly, but all needle-shaped, soft, deciduous, very numerous, in little brush-like bundles.

1. L. americana, Michx. American Larch, Tamarack, HackMA TACK (wrongly, but quite generally, called Cypress and Juniper). A tall, slender tree, 30-100 ft. high. Leaves slender and less than 1 in. long, very pale bluish-green. Cones $\frac{1}{2}-\frac{3}{4}$ in. long, few-scaled. Wood hard, tough, and heavy, of considerable use for ship-building.

2. L. europæa, DC. European LARCH. Leaves bright green and longer; cones longer than in the preceding species and manyscaled. Cultivated from Europe.

\section{TAXODIUM, Richard.}

Trees; leaves spreading so as to appear 2-ranked, deciduous ; flowers monœcious, appearing before the leaves; staminate ones numerous, globose ; forming long, terminal, drooping, panicled spikes; anthers 2-5-celled; pistillate flowers single or in pairs, bractless, the peltate scales 2-ovuled; cone globose; the very thick woody scales angular, separating at maturity; seeds 3 -angled, pyramidal.*

1. T. distichum, Richard. BALD Cypress. A very large tree; bark dark brown, rough, fibrous ; many of the twigs deciduous with the leaves. Leaves alternate, opposite, or whorled, 2-ranked, flat, linear, $\frac{1}{2}-\frac{3}{4}$ in. long. Cones terminal, globose, about 1 in. in diameter; ends of the scales much thickened, wrinkled, and with a distinct triangular marking. Common in swamps and on the borders of streams; wood reddish, soft, light; specially valuable for shingles and fence posts, and for boat-building.*

\section{THUYA, Tourn.}

Flowers small, terminal, monœcious, on different branches. Stamens each consisting of a scale-like portion bearing 4 anthercells. Pistillate flowers consisting of a few overlapping scales which ripen into a small, loose cone. Leaves evergreen, opposite, and closely overlapping on the stem, of two kinds, those on the more rapidly growing twigs awl-shaped, the others mere scales.

1. T. occidentalis, L. Arbor Vit 2 , Cedar. A small tree, 20-50 ft. high, with soft fibrous bark. Leaves mostly awl-shaped and blunt. 
Cones ellipsoidal, their scales 2-seeded. Grows on rocky ledges, but reaches its greatest size in cool cedar swamps. Wood soft, yellowish, fragrant, durable, prized for shingles and fence posts.

\section{JUNIPERUS, L.}

Flowers very small, lateral, diœcious, or sometimes monœcious. Scales of the staminate flower shield-shaped, with 3-6 anther-cells. Fertile flowers with 3-6 fleshy scales which unite into a berry-like, 1-3-seeded fruit. Leaves awl-shaped or scale-shaped.

1. J. communis, L. Juxiper. A low, spreading shrub (one variety prostrate in circular masses). Leaves linear-awl-shaped, with needle-like points, each marked with a distinct stripe of bloom along the center of the upper surface, borne in whorls of three. Fruit a dark blue aromatic berry, $\frac{1}{4}$ in. or more in diameter. Grows in dry pastures and on sterile hillsides $\mathrm{N}$.

2. J. virginiana, L. Red Cedar, SAvix. Ranges in size and shape from a low, rather erect. shrub to a conical tree $90 \mathrm{ft}$. high. Leares of two kinds, those on the rapidly growing shoots awl-shaped and pointed, those on the shortest twigs scale-shaped, obtuse, or nearly so, and closely appressed to the stem. Fruit small, bluish, with a white bloom. Found all the way from British America to Florida. Wood soft, fragrant, reddish, exceedingly durable in the ground, valued for the manufacture of moth-proof chests and espe cially for lead-pencils. 


\section{CLASS II. - ANGIOSPERMS.}

Plants with a closed ovary, in which the seeds are matured. Cotyledons 1 or 2 .

\section{SUBCLASS I. - MONOCOTYLEDONOUS PLANTS.}

Stems with the fibro-vascular bundles scattered among the parenchyma cells; in perennial plants no annual rings of wood. Leaves usually parallel-veined, alternate, nearly always entire. Parts of the flower generally in threes (never in fives). Cotyledon 1.

\section{TYPHACE}

Perennial marsh or aquatic plants. Rootstock stout, creeping; stem simple, cylindrical, erect. Leaves simple, strapshaped, sheathing at the base, nerved and striate. Flowers monœcious, in a single terminal spike, staminate part of the spike uppermost, each part subtended by spathe-like deciduous bracts; perianth of fine bristles ; staminate flowers sessile; stamens 2-7. Filaments connate, subtended by minute bracts ; pistillate flowers short-pediceled. Ovary 1-2-celled; styles 1-2. Fruit small, nut-like.*

\section{TYPHA, Tourn.}

Characters of the family.

1. T. latifolia, L. CAt-TAIL. Stem erect, jointed below, $5-8 \mathrm{ft}$. high. Leaves nearly as long as the stem, about $1 \mathrm{in}$. wide, netted and with a bloom. Spike cylindrical, dark brown or black; staminate portion above the pistillate, usually without any interval between them, each 4-8 in. long and about 1 in. in diameter. Fruit furrowed. Common in marshes and shallow ponds.* 


\section{Alismace五. Water-plantain Family.}

Annual or perennial marsh herbs, usually with creeping runners or rootstocks. Stems scape-like. Leaves long-petioled, sheathing at the base ; petiole rounded; blade nerved, netted, or sometimes wanting. Flowers in racemes or panicles, perfect, monœcious or diœecious; pedicels in bracted whorls. Sepals 3, persistent, petals 3 or wanting. Stamens 6 or more. Ovaries few or many, 1-celled, 1-seeded. Style short or none. Fruit a 1-seeded akene.*

\section{ALISMA, L.}

Annual or perennial herbs. Leaves erect or floating, blades prominently ribbed and netted, or even pinnately veined. Scapes erect, becoming longer than the leaves, cylindrical, spongy. Flowers perfect, in paniculate 3-bracted umbels, small, white or pink. Stamens 6--9. Ovaries numerous in one or more whorls on a flat receptacle. Fruit 1-seeded akenes which are ribbed on the back and sides.*

1. A. Plantago, L. Water Plantain. Perennial; root fibrous. Leaves ovate or somewhat cordate, $5-\overline{7}$-nerved when erect, floating leares narrower and sometimes linear. Scapes usually single; panicle 1-2 ft. long; flowering branches whorled, subtended by three narrow, striate bracts; pedicels slender, elongated. Ovaries 15-20 in a single whorl ; base of the short style persistent, forming a beak at the inner angle of the akene. Akenes obliquely obovate, 2-3keeled on the back. Common in ponds and muddy places.*

\section{SAGITTARIA.}

Perennial; rootstocks mostly knobby or tuber-bearing. Seapes erect or decumbent. Leaves long-petioled, sheathing at the base, the blade round and netted, or wanting. Flowers monœecious or diœcious, racemed in 3-bracted whorls of threes, the upper flowers usually staminate. Sepals 3, persistent. Petals 3, withering-persistent or deciduous. Stamens few or many. Ovaries in globose heads, 1-ovuled; style short, persistent. Fruit a subglobose head of flattened akenes.* 
1. S. variabilis, var. latifolia, Willd. BroAd-LEAved ArRowHEAD. Leaves very variable in size and shape, from broadly sagittate to linear; those growing on the drier soil being usually the broader; petioles 6-30 in. long. Scape smooth or slightly downy, 6-36 in. high; bracts acute. Flowers monoecious or sometimes diøcious, white, 1 in. or more in width; pedicels of the staminate flowers twice the length of those of the fertile flowers. Filaments long, smooth, and slender. Akenes with beak nearly horizontal. Ditches and muddy places.*

2. S. graminea, Michx. Grass-Leaved Sagittaria. Leaves long-petioled, lanceolate, or elliptical, and acute at each end, 3-5nerved, or often linear, the earlier often reduced to flattened petioles. Scape slender, usually longer than the leaves, simple, weak, often prostrate in fruit; bracts small, ovate, connate at the base. Flowers monœcious or diœcious, on long, threadlike pedicels, about $\frac{1}{2}$ in. wide. Stamens 10-20, filaments downy. Akenes nearly beakless. In ditches and shallow pools.*

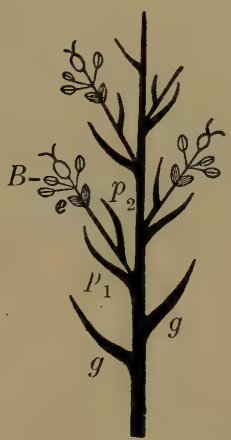

FIG. 2. - Diagram of Inflorescence of a Grass.

$g$, sterile glumes; $P_{1}$, a flowering glume; $P_{2}$, a scaly bract (palea); e, transparent scales (lodicules) at the base of the flower; $B$, the flower.

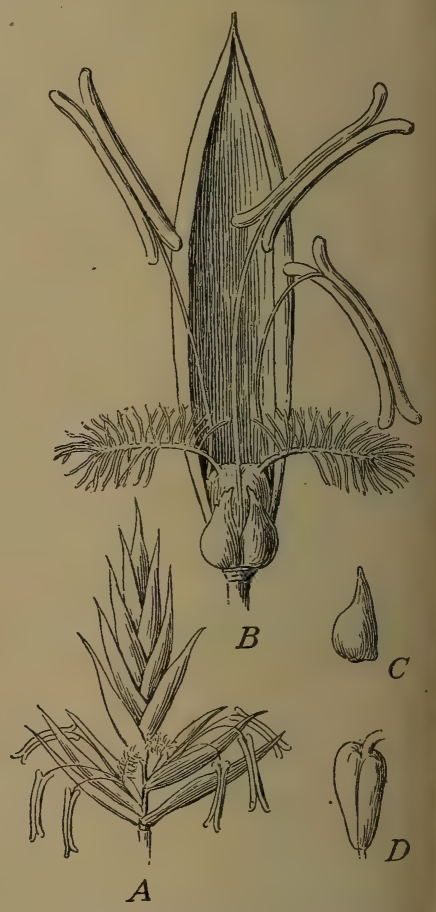

Frg. 3. - Fescue-grass (Festuca pratensis).

$A$, spikelet (compare Fig. 2) ; $B$, a flower, the lodicules in front and the palea behind; $C$, a lodicule; $D$, ovary. 


\section{Gramine瓜. Grass Family.}

Mostly herbs, with usually hollow stems, closed and enlarged at the nodes. Leaves alternate, in two ranks, with sheathing bases, which are split open on the side opposite the blade. Flowers nearly or quite destitute of floral envelopes, solitary, and borne in the axils of scaly bracts called glumes, which are arranged in two ranks overlapping each other on 1-many-flowered spikelets; these are variously grouped in spikes, panicles, and so on. Fruit a grain. (The family is too difficult for the beginner, but the structure and grouping of the flowers may be gathered from a careful study of Figs. 2, 3.)

\section{CYPERACE e. Sedge Family.}

Grass-like or rush-like herbs, with solid, usually triangular, stems, growing in tufts. The sheathing base of the generally 3 -ranked leaves, when present, is not slit as in grasses. The flowers are usually somewhat less enclosed by bracts than those of grasses; the perianth is absent or rudimentary; stamens generally 3 ; style 2-cleft or 3 -cleft.

The general appearance of a common sedge may be learned from Part I, Ch. V, and the flower-cluster and the flower understood from an inspection of Fig. 4.

The species are even more difficult to determine than those of grasses.

\section{ARACER. ARUM FAMily.}

Perennial herbs, with pungent or acrid juice, leaves often netted-veined, small flowers (perfect or imperfect) clustered along a peculiar fleshy spike called a spadix, and frequently more or less covered by a large, hood-like bract called a spathe. Perianth, when present, of 4-6 parts ; often wanting. Fruit usually a berry. 


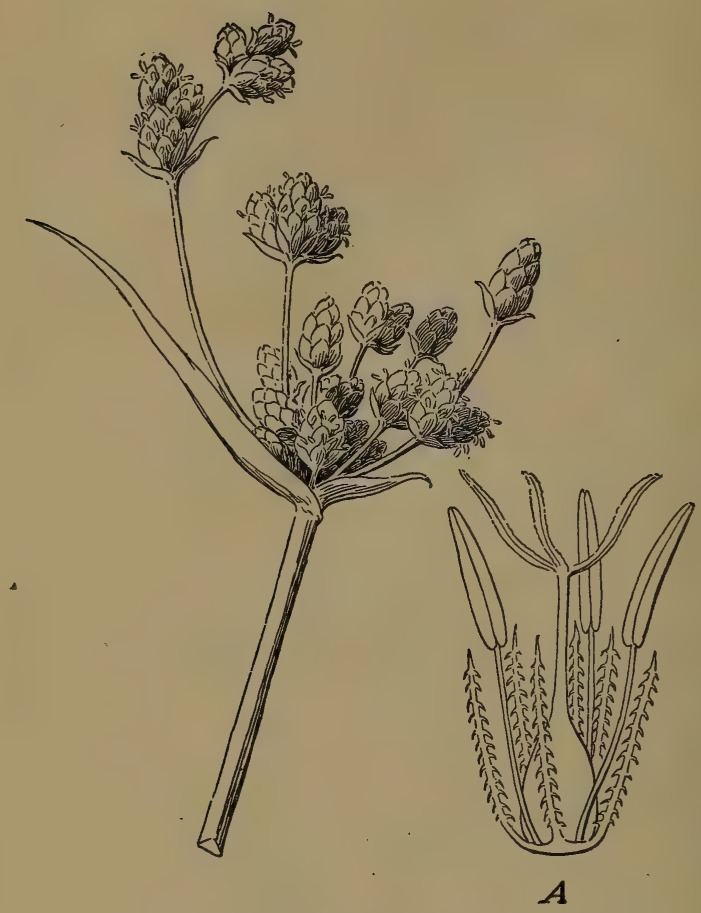

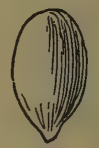

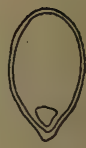

$B$

C

FIG. 4. - Inflorescence, Flower, and Seed, of a Sedge.

(Great Bulrush, Scirpus lacustris.)

$A$, magnified flower, surrounded by a perianth of hypogynous bristles; $B$, the seed; $C$, section of the seed, showing the small embryo enclosed in the base of the endosperm.

\section{ARISAEMA, Martius.}

Perennial herbs, springing from a corm or a tuberous rootstock.

Spathe rolled up at base. Summit of spadix naked, the lower part flower-bearing; staminate flowers above, pistillate ones below. Stigma flat; ovary 1-celled; berry 1-fewseeded. 
1. A. triphyllum, Torr. INDIAN TURnip, JACK-IN-THE-PUlPIT. Leaves generally 2, each of 3 elliptical-ovate, pointed leaflets. Spadix club-shaped, bearing usually only one kind of fully developed flowers ; that is, full-sized pistillate and rudimentary staminate ones, or the reverse. Spathe much longer than the spadix, and covering it like a hood. Corm turnip-like, but much wrinkled, very starchy, and filled with intensely burning juice.

2. A. Dracontium, Schott. Green Dragon, Dragon Root. Leaf usually single, divided into 7-11 rather narrow-pointed leaflets; spadix tapering to a long, slender point, often bearing fully developed staminate and pistillate flowers.

\section{SYMPLOCARPUS, Salisb.}

Rootstock very stout, with many long, cylindrical roots. Leaves clustered, very large, and entire. Spathe shell-shaped, very thick. Spadix globular, thickly covered with perfect flowers. Sepals 4. Stamens 4. Style 4-angled. Fruit globular or ellipsoidal, with the seeds slightly buried in the enlarged spadix.

Coarse, stemless herbs, with a powerful scent like that of the skunk and of onions.

1. S. fœtidus, Salisb. Sкunk Caвbage. Leaves many, slightly petioled, 1-2 ft. long, appearing after the flowers. The latter are usually seen before the ground is wholly free from frost, often earlier than any other flower. Bogs and wet meadows, very common $\mathrm{N}$.

\section{ACORUS, $\mathrm{L}$.}

Rootstocks horizontal, long, and moderately stout, aromatic. Leaves long, upright, sword-shaped. Spathe much like the leaves. Spadix projecting from the edge of the spathe, consisting of numerous perfect flowers. Sepals 6 . Stamens 6 . Ovary 2-3-celled, with numerous ovules. Fruit 1-few-seeded.

1. A. Calamus, L. Sweft Flag. Scape with a long, leaf-like prolongation (spathe) beyond the green, very closely flowered, spadix. Along borders of brooks and swamps.

The rootstocks furnish the well-known calamus or "sweet flagroot" sold everywhere by druggists. 


\section{COMMMELINACE E. SPIDERWOR'T FAMILY.}

Herbs, with slimy or mucilaginous juice; stems somewhat succulent, jointed, leafy, simple or branched. Leaves simple, succulent, narrow, entire, sheathing at the base, sheaths entire
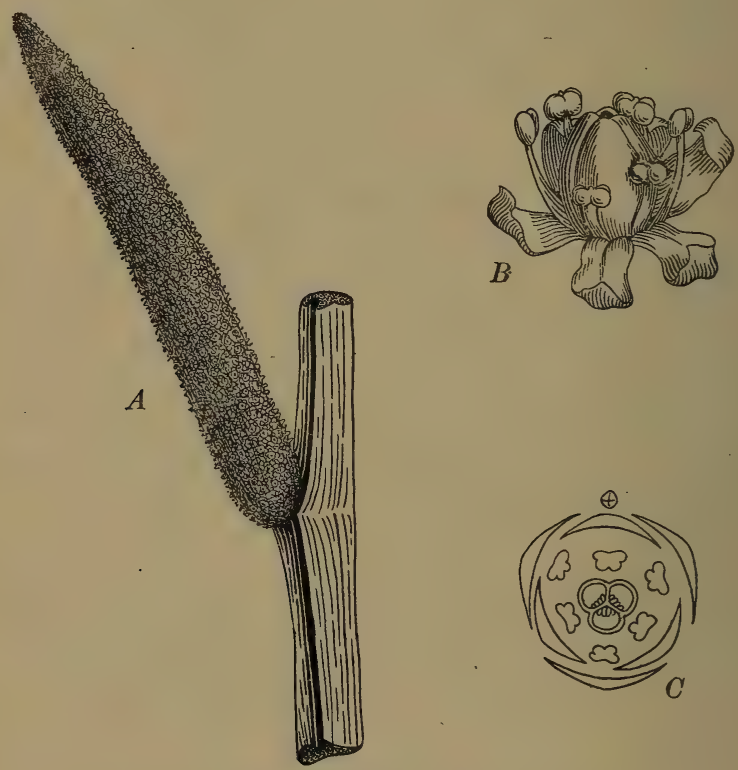

Fig. 5. - Acorus Calamus.

$A$, spadix ; $B$, a single flower, enlarged ; $C$, diagram of flower, enlarged.

or split. Flowers in terminal cymes or umbels, perfect, often irregular. Sepals 3, persistent, foliaceous or colored. Petals 3, soon falling or liquefying; stamens 6 or fewer, often some of them abortive. Ovary $2-3$-celled ; style single, stigma entire or 3-lobed, fruit a 2-3-celled, 2-3-valved capsule, seeds solitary or several in each cell.* 


\section{COMmelina, Dill.}

Annual or perennial, stem branching, erect or procumbent, smooth or downy. Leaves petioled or sessile, entire, the floral ones heart-shaped, folded, and forming a spathe enclosing the base of the cymes. Flowers irregular, sepals mostly colored, 1 of them smaller. Petals blue, unequal, 2 of them kidney-shaped and long-clawed, the other smaller. Stamens 6 , only 3 of them fertile, filaments smooth. Capsule 1-3-celled, seeds $1-2$ in each cell.*

1. C. virginica, L. Virginia DaYflower. Stem erect, downy, 1-2 ft. high. Leares lanceolate to oblong-lanceolate, taper-pointed, 3-5 in. long, somewhat rough abore, sheaths inflated, hairy, the opening often fringed. Spathes containing a slimy secretion. Flowers 1 in. wide, the odd petal lanceolate. Capsule 3-seeded, the dorsal cell not splitting open. On moist, sandy soil.**

\section{TRADESCANTIA, I.}

Perennial, stem simple or branched. Leaves very narrow. Flowers in terminal and axillary bracted umbels, regular, 1 in. broad. Sepals 3, herbaceous. Petals 3, soon falling or liquefying to jelly. Stamens 6 , sometimes 3 shorter than the others, filaments bearded or smooth. Ovary 3-celled, with 2 orules in each cell, pedicels recurved in fruit. Capsule 3-celled, 3-valved, 3-6-seeded.*

1. T. virginica, L. SPiderwort. Stem erect, stout, smooth, or with long, soft hairs, 1-2 ft. high. Leares linear, keeled, often purple-veined, long, taper-pointed, $1 \mathrm{ft}$. or more in length. Bracts similar to the leaves, umbels sessile, 2-many-flowered, flowers in 2 rows in the loud. Petals blue or purple, twice as long as the sepals. Stamens hlue, filaments densely bearded. Capsule oroid or oblong. On dry, sandy soil.**

2. T. pilosa, Lehm. IIAiry Spinerwort. Stem stout, erect, or ziqzag, branched, with long, soft hairs, or nearly smooth, 1-2 ft. high. Leares linear-oblong, taper-pointed at the apex, narrowed at the base, hairy on both sides. [mulels axillary and terminal, manyflowered. Pedicels and sepals with soft, glandular hairs. Flowers blue or purple, $\frac{3}{4}-1$ in. wide. Seeds pitted. In rich soil.** 


\section{ZEBRINA.}

Trailing or slightly climbing herbs. Leaves often striped. Flowers irregular, usually in pairs. Calyx with a short tube, regularly or irregularly 3-parted. Corolla nearly regular, with tube longer than the calyx. Filaments naked or bearded. Ovary 3-celled, 3-6-ovuled.

1. $z$. pendula, Schnitzl. WANDERING JEW. Stems perennial, prostrate, or nearly so, branching freely, rooting easily at the nodes. Leaves somewhat succulent, lance-ovate or oblong, crimson beneath, green or dark purplish above, often with two wide silvery stripes. Cultivated from Mexico.

\section{PONTederiace e. Pickerel-weed Family.}

Perennial marsh or aquatic herbs, stems simple or branched, succulent. Leaves simple, alternate. Flowers solitary or spiked, each subtended by a leaf-like spathe, perfect, mostly irregular. Perianth corolla-like, 6-parted. Stamens 3 or 6, unequal, inserted irregularly in the tube or throat of the perianth. Ovary free, style single, stigma entire or toothed, ovary 1 or 3 celled. Fruit a 1 -seeded utricle.*

\section{PONTEDERIA, L.}

Stem erect, from a thick, creeping rootstock, bearing a single leaf above the middle and several sheathing, bract-like leaves at its base. Radical leaves numerous, thick, parallelveined. Petiole long, from a sheathing base. Flowers in terminal spikes. Perianth 2-lipped, lobes of the upper lip ovate, of the lower oblong, spreading. Stamens 6 , the 3 upper short and often imperfect, the 3 lower protruding. Ovary 3-celled, but only 1 cell ovule-bearing. The 1 -seeded utricle enclosed by the base of the perianth.*

1. P. cordata, L. Pickerel-weed. Stem stout, erect, 2-4 ft. high. Leaves long, from heart-shaped to lanceolate and often halberdshaped, apex and basal lobes obtuse, finely nerved. Spike dense, 
2-4 in. long, peduncles enclosed by the spathe. Perianth hairy, blue, the upper lip with 2 yellow spots, tube 6-ribbed, curved, rather longer than the lobes. Ovary oblong. In ponds and slow streams.*

\section{Juncaceze. Rush Family.}

Grass-like perennial or annual herbs, mostly growing on wet soil. Stems mostly erect but sometimes creeping, simple or branched, naked or leafy and jointed. Leaves cylindrical, sheathing at the base, very slender and pointed or flattened and grass-like. Flowers in cymes or panicles, which may be very loose and spreading, or so compact as to form a head, sometimes with a rigid scape prolonged beyond the flowercluster. Flowers usually bracted, perianth of 6 nearly equal scale-like persistent divisions. Stamens 3 or 6 , inserted on the base of the perianth. Ovary free, 1 or 3 celled, manyovuled. Style single, stigmas 3 , usually hairy. Fruit a 1 or 3 celled, 3-many-seeded cansule. [Most speciec a ... or late in the season, and their identification is too difficult for one without considerable experience.] *

\section{Liliace ex. Lily Family.}

Mostly herbs. Flowers regular and symmetrical. Perianth free from the ovary. Stamens nearly always 6 , one before each division of the perianth. Ovary usually 3-celled. Fruit a pod or berry, few-many-seeded.

Except in the genus Trillium the divisions of the perianth are colored nearly alike. 


\section{SUBFAMILY I. - LILIACE Æ PROPER.}

Not tendril-climbers, rarely diocious.

A.

Styles or sessile stigmas 3, more or less separate.

Leaves 3-ranked, strongly nerved and plaited. Flowers somewhat monøcious, small.

Veratrum, I.

Leaves flat, lanceolate, or spatulate. Flowers diœecious, showy.

Chamælirium, II.

Leaves grass-like. Flowers perfect, showy. Amianthium, III.

B.

Style undivided (in No. XXIII, 3 sessile stigmas). Plants from rootstocks.

Leaves pus= 1:ate. Flowers solitary, drooping, yellow.

Uvularia, IV.

Leaves broad, clasping. Flowers solitary or nearly so, drooping, yellow.

Oakesia, $\mathrm{Y}$.

Leaves scale-like. Thread-like branches borne in their axils. Flowers small, bell-shaped.

Asparagus, XVII.

Leaves several-many, sessile or clasping, alternate. Flowers small, 6-parted, white, in a terminal simple or compound raceme.

Smilacina, XVIII.

Leaves only $2-3$, sessile or slightly petioled. Flowers very small, 4-parted, solitary or in a small terminal cluster.

Maianthemum, XIX.

Leaves clasping. Flowers solitary or in pairs, greenish-white or rose-purple, borne on pedicels abruptly bent near the middle. Streptopus, $\mathbf{X X}$.

Leaves nearly sessile or partly clasping. Flowers axillary, greenish, on pedicels jointed near the flower.

Polygonatum, XXI. 
Leaves only 2, directly from the rootstock. Flowers in a raceme, bell-shaped, white, sweet-scented. Convallaria, XXII.

Leaves 3, netted-veined. Flower single, large, terminal.

Trillium, XXIII.

C.

Style undivided. Plants from fibrous roots.

Flowers yellow or orange.

Hemerocallis, VI.

Flowers white.

Yucca, XVI.

D.

Style usually undivided. Plants from coated or solid-looking bulbs.

Leafy-stemmed plants. Flowers large, solitary, or apparently umbelled.

Fritillaria, IX.

Apparently stemless plants.

(a) Plants with the smell of onions or garlic. Flowers umbelled.

Allium, VII.

(b) Flower solitary, erect, large. Tulipa, X.

(c) Flower solitary, nodding. Erythronium, XI.

(d) Flowers racemed. Perianth with hardly any tube. Stigma a single knob. Scilla, XII.

(e) Flowers racemed. Perianth with hardly any tube. Stigma 3-cleft.

Camassia, XIII.

(f) Flowers corymbed. Perianth with hardly any tube. Leaves linear.

Ornithogalum, XIV.

(g) Flowers racemed. Perianth with a tube. Leaves lance-linear. Hyacinthus, XV.

E.

Style undivided. Plants from scaly bulbs.

Lilium, VIII.

SUBFAMILY II. - SMILACEAE.

Climbers, often tendril-bearing. Flowers dicecious. Smilax, XXIV. 


\section{VERATRUM, Tourn.}

Simple-stemmed perennials. Roots fibrous, from the thickened base of the stem, poisonous, emetic. Leaves 3-ranked, plaited, and veiny. Flowers panicled, greenish, or brownish. Sepals 6, spreading, nearly free from the ovary. Stamens shorter than the perianth, and inserted on its base. Ovary of 3 carpels united at base. Fruit a few-seeded capsule, splitting into 3 parts.

1. v. viride, Ait. White Hellebore, Indian Poke. Stem stout, 2-7 ft. high, very leafy. Flowers very numerous, in a panicle, composed of spike-like racemes. Sepals yellowish-green. Wet meadows and brooksides.

2. V. Woodii, Robbins. Stem slender, $2-5 \mathrm{ft}$. high, not very leafy. Flowers in a long, narrow panicle. Sepals greenishh-purple or almost black. Woods and dry hillsides.

\section{CHAMIELIRIUM, Willd.}

Rootstock short and thick, bitter. Stem simple, erect, leafy, smooth. Lower leaves spatulate to obovate, the stem-leaves narrower. Flowers small, white, in a spike-like raceme, diœeious. Perianth of 6 linear-spatulate segments. Stamens 6 , filaments longer than the perianth. Ovary 3-celled, styles 3. Fruit an ovoid, 3-angled, many-seeded capsule.*

1. C. carolinianum, Willd. Unicorn-Root, Devil's Bit. Stem furrowed, staminate plants 1-2 ft. high, pistillate taller, often $3 \mathrm{ft}$. or more. Lower leaves obovate, clustered, the upper small and bract-like. Staminate racemes slender and drooping, the pistillate erect. Flowers short-pediceled. Capsule 3-valved, seeds linearoblong, winged at the ends. On low ground.*

\section{AMIANTHIUM, Gray.}

Stem simple, glabrous, erect from a bulbous base. Leaves long and slender. Flowers white, in a simple terminal raceme, perfect. Perianth of 6 segments which are sessile and glandless. Stamens 6, inserted in the base of the perianth. Ovary 3-lobed, 3-celled, fruit a dehiscent, 3-lobed capsule, the lobes becoming awl-shaped by the persistent style bases; cells fewseeded.* 
1. A. muscætoxicum, Gray. Fly Porsox. Bulb ovoid or oblong. Stem somewhat angled below, 1-3 ft. high. Lower leaves strapshaped, channeled, the upper small and bract-like. Raceme dense, cylindrical, pedicels from the axils of minute ovate bracts. Perianth segments orate, white, becoming greenish, nearly as long as the slender stamens. Styles spreading. Capsule with divergent lobes; seeds ovoid, red. In rich woods.*

\section{UVULARIA, L.}

Rather low plants with short rootstocks. Leaves alternate, broad, and parallel-veined. Flowers yellow or yellowish, drooping, borne singly at the end of the forking stem. Perianth of 6 similar and separate narrow spatulate sepals, each grooved and nectar-bearing inside toward the base. Stamens 6, with linear anthers, which are much longer than the filaments. Style 3-cleft. Pod 3-lobed, 3-celled, fewseeded.

1. U. grandiflora. LARGer Bellwort. Leaves oblong, with the base clasping the stem so as to make it appear to run through the leaf a little way from the base ; flowers greenish-yellow, $1 \frac{1}{2}$ in. long, anthers obtuse. A leafy plant, 1-2 ft. high.

2. U. perfoliata. Mealy Bellwort. Leaves much as in the preceding species; flowers very pale yellow, with shining grains on the inner surfaces of the twisted sepals; anthers sharp-pointed; plant about $\frac{2}{3}$ the size of the preceding.

\section{OAKESIA, Watson.}

Plants with much the aspect of the preceding genus, but with merely sessile leaves, triangular winged pods, and slender creeping rootstocks.

1. 0. sessilifolia. Wild Oats, Straw Lilies. Stem slender, zigzag. Leares lance-oral, thin, smooth, pale beneath, $1-1 \frac{1}{2}$ in. long. Flower cream-color, nearly 1 in. long.

\section{HEMEROCALLIS, L.}

Perennial, from a fascicle of fleshy roots. Stem erect, branched, smooth. Leaves mostly basal and linear. Flowers on branching scapes, large, yellow or orange, solitary or 
corymbed, perianth funnel-form, with a spreading limb much longer than the tube. Stamens 6, inserted in the top of the tube, shorter than the lobes, curved upward. Ovary 3-celled, many-ovuled, style longer than the stamens, curved upward, stigma knobbed. Fruit a 3-celled, 3-angled capsule.*

1. H. fulva, L. DAy Lily. Scapes stout, branched above, with a few bract-like leaves, smooth, 3-5 ft. high. Leaves very long, strapshaped, acute, channeled. Flowers short-pediceled, tawny-yellow, perianth lobes oblong, netted-veined, lasting only one day. Introduced from Asia and common in old gardens.*

\section{ALLIUM, L.}

Stemless herbs from coated bulbs with the characteristic odor of onions. Bulbs solitary or clustered. Leaves narrowly linear or slender-tubular, with a bloom. Flowers small on slender pedicels, in terminal umbels on naked scapes, the umbels often bracted or enclosed in a spathe. Perianth 6 -parted, persistent; stamens 6, inserted on the base of the perianth, filaments filiform or dilated below. Ovary sessile, 3-celled. Style thread-like, jointed; stigma entire. Fruit a 3-celled, 3-valved, few-seeded capsule. Flowers sometimes changed into bulblets.*

1. A. canadense, L. Meadow Garlic. Bulbs ovoid, the outer coats of white and thin, dry, netted fibers. Leaves narrowly linear, flat, or concave above. Scape cylindrical, $1 \mathrm{ft}$. high. Bracts of the umbel 2-3, ovate, acuminate; umbel consisting mostly of sessile bulblets. The few flowers long-pediceled, rose-colored. Perianth about as long as the stamens. Filaments dilated below. Capsule shorter than the perianth, 6-toothed, ovules 2 in each cell. On moist soil.*

2. A. striatum, Jacq. Striped Wild Onion. Bulbs clustered, outer coat membranaceous. Leaves linear, concave, striate on the back. Scape 6-12 in. high. Umbel 3-10-flowered, bracts 2, pedicels 1-2 in. long. Perianth nearly white, longer than the stamens, the outer segments green-keeled on the back. Capsule not toothed, seeds several in each cell. Low pine barrens.**

3. A. vineale, L. Field Garlic. Bulb mostly solitary. Leaves cylindrical, hollow, very slender. Scape slender, sheathed below the middle by the bases of the leaves. Umbels often crowded with bulblets. A troublesome weed in moist meadows and fields eastward, giving milk a strong flavor of onions or garlic. 


\section{LILIUM, $\mathbf{L}$.}

Perennial, from scaly bulbs, stem erect, leafy, usually tall and slender. Leaves sessile, scattered, or whorled. Flowers large, erect, or drooping. Perianth corolla-like, deciduous. Segments 6 , spreading or recurved above, sessile or clawed, each with a nectar-bearing groove near the base. Stamens 6, elongated, anthers linear, versatile. Ovary 3-celled, manyovuled, style long and slender, stigma 3-lobed. Fruit a 3-celled, dehiscent, many-seeded capsule.

1. L. longiflorum, Thunb. Long-Flowered White LiLy. Stem 1-3 ft. high. Leaves thick, lanceolate, scattered. Flower single, pure white, funnel-shaped, 5-6 in. long. Var. eximium, the Easter lily, bears several very showy and sweet-scented flowers.

2. L. philadelphicum, L. WiLd Red Liliy. Stem 2-3 ft. high. Leares linear-lanceolate, the upper ones generally whorled. Flower usually solitary (sometimes 2 or 3 ), erect, reddish-orange, with tawny or purplish spots inside. Sepals with claws. Dry or sandy ground, borders of thickets, etc.

3. L. canadense, L. Wild Yellow Lily, Meadow Lily. Stem 2-5 ft. high. Leaves lanceolate, 3-nerved, the margins and nerves roughish with short hairs, whorled. Flowers usually 3 , sometimes more numerous, all nodding, on peduncles $3-6$ in. long, yellow or orange, with dark-purple or brown spots inside. Sepals without claws, recurved. Moist meadows and borders of woods.

\section{FRITILLARIA, Tourn.}

Leafy-stemmed perennials, from scaly or coated bulbs. Flowers single or several, nodding. Perianth bell-shaped, a nectar-bearing spot above the base of each division. Stamens as long as the petals.

1. F. Meleagris, L. Guinea-hen Flower. Stem $1 \mathrm{ft}$. high. Leares linear, alternate, channeled. Flower usually single, large, purplish, checkered with blue and purple or yellow. Cultivated from Europe.

2. F. imperialis, L. Crown Imperial. Stem 3-4 ft. high. Leaves abundant in whorls about the middle or lower part of the stem, lanceolate or lance-oblong. Flowers several, large, yellow or red, in an umbel-like cluster beneath the terminal crown of leaves. Cultivated from Asia. 


\section{TULIPA, Tourn.}

Stemless herbs from coated bulbs. Leaves sessile. Scape simple. Flower solitary, erect. Perianth bell-shaped. Stamens short, awl-shaped, with broadly linear anthers. Style short, stigma thick, 3-lobed. Ovary and pod triangular.

1. T. gesneriana, L. Common Tulip. Leaves 3-6, ovate-lanceolate, close to the ground. Flower large, on a smooth peduncle, color red, yellow, white, or variegated. Cultivated from Asia Minor. Many garden varieties exist.

\section{ERYTHRONIUM, L.}

Nearly stemless herbs, arising from rather deeply buried bulbs. Leaves 2 , long and smooth, with underground petioles. Scape arising from between the bases of the leaves. Flower commonly single, nodding.

1. E. americanum, Ker. Yellow Adder's-tongue. Leaves mottled. Flowers handsome. Perianth light yellow, style clubshaped, stigmas united.

2. E. albidum, Nutt. White Dog's-тоoтh Violet. Leaves not much mottled. Perianth bluish-white. Stigmas 3, short and spreading.

\section{SCILLA, $\mathbf{L}$.}

Perennial stemless herbs from coated bulbs. Leaves linear. Flowers racemed on a scape, generally blue. Divisions of the perianth 1-nerved, parted almost to the base. Filaments 6, often broad at the base. Style slender, with a knob-like stigma. Ovary 3-angled, 3-celled.

1. S. sibirica, Andr. Siberian Squill. Scapes $3-8$ in. high, several from each bulb, 2-3-flowered. Leaves 2-4, narrowly strapshaped. Flowers intense blue, short-peduncled, often nodding. Cultivated from Russia and Siberia.

\section{CAMASSIA, Lindl.}

Stemless herbs, from coated bulbs. Leaves linear. Flowers racemed, on a scape. Perianth of 6 blue or purple spreading sepals. Stamens with thread-like filaments, from the base of the perianth. Style thread-like, ending in a knobbed stigma. Capsule 3-angled, 3-celled, several-seeded. 
1. C. Fraseri, Torr. Wild Hracintr. Leaves keeled, weak, shorter than the scape. Flowers in a long-bracted raceme, pale blue. River bottoms and other damp, rich soil.

\section{ORNITHOGALUM, Tourn.}

Stemless herbs from coated bulbs. Leaves linear, fleshy. Scape erect. Flowers in corymbs or racemes, bracted. Perianth segments 6, white, nerved, persistent. Stamens 6, hypogynous, slender. Filaments flattened. Ovary sessile, 3-celled, few-ovuled. Fruit a roundish, 3-angled capsule, seeds black.*

1. 0. umbellatum, L. Star of Bethlehem. Bulb ovoid, membranous-coated. Leaves numerous, linear, fleshy, mid-vein nearly white, as long as the scape. Scape slender, 6-12 in. high. Flowers opening in sunshine, long-pediceled. Bracts linear-lanceolate, about as long as the pedicels. Perianth segments oblong-lanceolate, white with a green stripe on the back, twice the length of the stamens. Introduced from Europe ; very common about old gardens.*

\section{HYACINTHUS, L.}

Stemless herbs from coated bulbs. Leaves linear, fleshy. Flowers in an erect spike, pediceled, bracted. Perianth tubular below, lobed and spreading above. Stamens short, included. Style short, stigma knobbed. Ovary 3-celled, many-ovuled.*

1. H. orientalis, L. Hyacinth. Leaves lance-linear, thick and fleshy, smooth. Scape erect, many-flowered. Segments united about half their length, white, blue, or red. Filaments very short. Ovary rarely maturing seed. Common in cultivation.*

XVI. YUCCA, L.

Plants with woody and leafy stems. Leaves numerous, rigid, spine-pointed, persistent. Flowers in large terminal racemes or panicles, bracted, nodding. Perianth bell-shaped, segments 6, nearly alike, deciduous. Stamens 6, filaments thickened above, often papillose. Anthers small. Ovary sessile, 3-celied, or becoming 6-celled, 3-angled, many-ovuled. Fruit an oblong, 3-angled, many-seeded, dehiscent capsule, or fleshy and indehiscent.* 
1. Y. filamentosa, L. Spanish Dagger. Stem stout, 4-12 in. high. Leaves linear or linear-lanceolate, slender-pointed, narrowed above the spreading and clasping base, spreading or recurved, smooth, with loose, thread-like filaments on the margins. Panicle elongated, with bract-like leaves on the scape, widely branched, downy-hairy above, 3-6 ft. high. Perianth white, bell-shaped, 2 in. wide. Capsule oblong, angles rounded, sides furrowed, at length 3 -valved and dehiscent. In sandy soil, and often cultivated for ornament.*

\section{ASPARAGUS, Tourn.}

Stem from fleshy fibrous roots, erect, branched, branches slender, with thread-like branchlets in the axils of scales which take the place of leaves. Flowers small, solitary, or racemed. Perianth 6-parted, segments distinct or slightly united. Stamens 6, perigynous, filaments thread-like. Ovary 3-celled, 6-ovuled, style short, slender, stigmas 3, recurved. Fruit a berry.*

1. A. officinalis, L. Asparagus. Stem succulent and simple, with fleshy scales when young, becoming taller, more woody and widely branched when old. Flowers axillary, solitary, or 2 or 3 together on slender, jointed, drooping pedicels, greenish, segments linear. Berry red, few-seeded. Introduced from Europe, common in cultivation, and often escaped.**

\section{SMILACINA, Desf.}

Perennial, simple-stemmed herbs, with rootstocks. Leaves usually sessile, nerved, alternate. Flowers white, in a terminal raceme. Perianth spreading, 6-parted. Stamens 6, springing from the base of the perianth. Filaments slender. Anthers short, facing inward. Ovary 3-celled, 6-ovuled. Style short and stout, with a somewhat 3-lobed stigma. Fruit a 1-2-seeded berry.

1. S. racemosa, Desf. False Spikenard. A showy plant with curved stem 1-3 ft. high, downy throughout. Leaves abundant, oval or ovate-lanceolate, taper-pointed. Flowers small, in a compound raceme. Berries pale red, speckled with dark red or purple. Moist thickets.

2. S. stellata, Desf. Plant $1 \mathrm{ft}$. or less in height, nearly smooth. Leaves broadly lanceolate, acute, clasping. Flowers few, larger than in No. 1, in a simple raceme. Berries very dark red. Along river banks. 


\section{MAIANTHEMUM, Wigg.}

Stem low. Leaves 2-3, lanceolate or ovate, with a heartshaped base. Flowers small, white, solitary, or in a simple raceme. Perianth 4-parted. Stamens 4. Ovary 2-celled. Stigma 2-lobed.

1. M. canadense, Desf. Two-leaved Solomox's Seal, Wild Lily-OF-THE-YALlEY. Plant $3-6$ in. high. Leaves very shortpetioled. Fruit a globular or oroid berry, whitish, with brownishred blotches. Woods and shaded banks $\mathrm{N}$.

\section{STREPTOPUS, MichX.}

Herbs with forking stems from a creeping rootstock. Leaves clasping. Flowers sinall, borne singly or in pairs on peduncles which arise above the leaf-axils and which are sharply bent or twisted near the middle. Anthers arrow-shaped. Ovary 3-celled, ripening into a red, many-seeded berry.

1. S. amplexifolius, D. C. Liver-Berry. Stem smooth, $2 \mathrm{ft}$. or more high. Leares smooth-margined. Flowers greenish-white. Damp woods.

2. S. roseus, Michx. Liver-Berry, JACOB's LA Dder. Branches with a few bristly hairs. Lower leaves margined with fine bristles. Flowers reddish or purplish. Cold, damp moods $\mathbf{N}$.

\section{POLYGONATUM, Tourn.}

Rootstock creeping, jointed, scarred. Stems simple, erect, scaly below, leafy above. Leaves alternate, oval, or oblong. Flowers on axillary, 1-4-flowered, drooping, jointed peduncles. Perianth tubular, 6-cleft. Stamens 6, included, inserted about the middle of the tube. Anthers arrow-shaped. Ovary 3-celled, many-ovuled, style slender, stigmas knobbed or 3-lobed. Fruit a few-seeded berry.*

1. P. biflorum, Ell. Hairy Solomox's Seal. Stem simple, erect, arched. nearly naked below, 1-2 ft. high. Leares 2-ranked, sessile or clasping, 3-i-nerved, smonth above, pale and downy beneath. Peduncles short, 1-4, often 2-flowered. Perianth greenish, 1-2 in. long. Filaments thread-shaped, roughened. Berry dark blue. Shady banks.* 
2. P. giganteum, Dietrich. Sмоотн Solomon's Seal. Stem simple, stout, curving above, $3-8 \mathrm{ft}$. high. Leaves lanceolate to ovate, many-nerved, partly clasping, smooth on both sides. Peduncles nearly half as long as the leaves, 2-6-flowered. Perianth greenish-yellow, $\frac{3}{4}$ in. long. Filaments smooth. Berry blue, $\frac{1}{2}$ in. in diameter. In rocky woods and along streams.*

\section{CONVALLARIA, L.}

Low, smooth, stemless, perennial herbs. Leaves 2, oblong; with long petioles, from a slender, creeping rootstock. Scape slender, angled, enclosed at the base by the leaf-stalks. Flowers racemed, white, drooping. Perianth bell-shaped, with recurved lobes. Stamens borne on the base of the perianth. Ovary 3-celled, ripening into a few-seeded red berry.

1. C. majalis, L. LiLY-oF-THE-VALLeY. A familiar garden flower, cultivated from Europe, and also found wild in mountain woods from Virginia to Georgia.

\section{TRILLIUIM, L.}

Low herbs with the stem springing from a short rootstock. Leaves 3, large, netted-veined, in a whorl. Flower large, terminal. Perianth of 6 parts, the 3 sepals unlike the 3 petals in color and in texture. Stamens 6, with the linear anthers usually opening inward, longer than the filaments. Stigmas 3 , sessile, spreading at the tips. Ovary 3 or 6-angled, 3-celled, many-seeded. Fruit a roundish, many-seeded purple berry.

1. T. sessile, L. Rootstock erect or ascending, corm-like. Stem slender, 1-8 in. high. Leaves broadly oval, obtuse or acute at the apex, rounded and sessile at the base, 3-5-nerved, smooth, bright green, not mottled. Flowers sessile, sepals lanceolate, $\frac{2}{3}-1$ in. long, petals purple, elliptical, about the length of the sepals. Stamens half the length of the petals. Styles elongated, straight. In rich woods.**

2. T. Underwoodii, Small. UNDERWOOD's WAKE-ROBIN. Rootstock horizontal, stem stout, 4-12 in. high. Leaves ovate-lanceolate to broadly ovate, acute or short taper-pointed at the apex, rounded and sessile at the base, wavy on the margins, 3-5-nerved, smooth, prominently mottled with different shades of green. Flowers sessile. Sepals lanceolate, $1 \frac{1}{2}-2$ in. long, often purplish green. Petals purple, lanceolate to oblanceolate, $2-3$ in. long. Stamens $\frac{1}{4}-\frac{1}{3}$ the length of the petals. Style very short, stigmas recurved. Fruit an ovoid berry. In rich woods.* 
3. T. erectum, L. SQUAWRoot, Benjamin. Rootstock rather upright, large and stout. Leaves broadly diamond-shaped, tapering to a short point. Pedicel 1-3 in. long, not quite erect. Petals ovate to lanceolate, much broader than the sepals, of a rich brownishpurple or sometimes white or pale. Stigmas distinct, stout, and spreading. The disagreeable scent of the flower has given rise to several absurd popular names for it. In rich woods.

4. T. grandiflorum, Salisb. LARGE-FLOWERED WAKE-ROBIN. Rootstock horizontal, stem slender, 12-18 in. high. Leaves rhombicorate, taper-pointed at the apex, rounded and sessile or slightly peduncled at the base, smooth and with a bloom, 5-7-nerred, bright green. Peduncle longer than the erect or slightly declined flower. Sepals lanceolate-acute, $1-1 \frac{1}{2}$ in. long. Petals white, fading to pink, longer than the sepals. Stamens less than half the length of the petals. Style short, stigmas recurved. Fruit a black, roundish berry. In rich woods.*

5. T. nivale, Riddell. Dwarf White Trillium. Plant 2-4 in. high. Leaves petioled, oval to ovate. Flower white, erect. Petals $\frac{1}{2}-1 \frac{1}{4}$ in. long, ovate-spatulate. Rich, damp woods, blooming with the very earliest spring flowers.

6. T. erythrocarpum, Michx. Painted Trillium. Plant 8-12 in. high. Rootstock oblique to the rest of the stem, rather small; roots long and fibrous. Leaves ovate, taper-pointed. Petals white, penciled at the base, with purple stripes, lance-ovate, somewhat recurved, wavy. Cold woods, especially N.

\section{SMILAX, Tourn.}

Mostly woody vines, usually with prickly stems, climbing by tendrils. Rootstock often large and tuberous. Leaves alternate, prominently nerved, netted-veined, petioled, stipules replaced by persistent tendrils. Flowers regular, diœcious, small, greenish, in axillary umbels. Perianth bell-shaped, segments 6. Stamens 6, distinct. Ovary 3-celled, 3-6-ovuled, stigmas 1-3, sessile or nearly so. Fruit a 1-6-seeded globose berry.

1. S. herbacea, L. CARrion-flower. Stem herbaceous, erect, simple or branched, not prickly, 1-3 ft. high. Leaves few, ovate, acute, and inucronate at the apex, somewhat heart-shaped at the base, 5-7-nerved, thin, smooth above, downy below, the upper sometimes whorled and the lower bract-like; petiole.short. Peduncles as long as the leaves, growing from below the petiole. Umbel manyflowered, flowers carrion-scented. Berry blue-black, 2-4-seeded. Dry, fertile soil.* 
2. S. glauca, Walt. Green-Brier. Stem cylindrical, slender, with scattered prickles, branches angled, and usually without prickles. Leaves ovate or subcordate, pointed at the apex, mostly 5-nerved, smooth, white beneath, with a bloom, margin entire. Peduncle flattened, 2-3 times as. long as the petiole, few-flowered. Berry black, 3-seeded. Margin of swamps.*

3. S. Bona-Nox, L. Bamboo-vine. Stem stout, cylindrical, or slightly angled, scurfy when young, armed with numerous stout prickles. Branches 4-angled, usually unarmed. Leaves triangular, ovate, or often halberd-shaped, 5-7-ribbed, smooth on both sides and often discolored, margins usually fringed with fine prickles. Peduncles twice as long as the petioles, flattened. Umbels many-flowered, pedicels short. Berries 8-20 in a cluster, black, 1-seeded. In swamps and thickets.*

4. S. Walteri, Pursh. Green-brier. Stem low, with few prickles, 2-5 ft. long, branches slightly 4-angled, unarmed. Leaves oblong-lanceolate to oval, obtuse or acute at the apex, rounded or cordate at the base, 5-ribbed, smooth. Peduncles flattened, about as long as the petioles and pedicels. Berry bright red, ripening the first year. Wet pine barrens.*

5. S. rotundifolia, L. Green-Brier, Cat-Brier, Dog-Brier, Horse-brier, Wait-A-BIT. Stem green, strong; branchlets, and sometimes the branches, 4 -angled, armed with stout hooked prickles. Leaves ovate or round-ovate, with a slightly heart-shaped base and an abruptly pointed tip. Berries black, with a bloom. Thickets, the commonest species N. E.

\section{AMARYLLIDACE Ae. Amaryllis Family.}

Mostly smooth perennial herbs, from bulbs. Leaves radical, with no distinction between petiole and blade. Flowers borne on a scape, nearly or quite regular. Stamens 6 . Style 1. Tube of the 6-parted, corolla-like perianth adnate to the 3-celled ovary. Capsule 3-celled, several-many-seeded.

\section{ZEPHYRANTHES, Herb.}

Stemless, from a coated bulb. Leaves linear, fleshy. Scape erect, 1-few-flowered. Flowers large, erect, or declined, subtended by a 1-2-leaved spathe. Perianth 6-parted, naked in the throat, tube short, segments petal-like, spreading. Stamens free, anthers versatile. Ovary 3-celled, many-ovuled. Style 
elongated, declined. Stigma 3-cleft. Fruit a many-seeded, 3 -valved capsule, seeds black, compressed, or angled.*

1. Z. Atamasco, Herb. Atamasco Lily. Bulbs about 1 in. in diameter. Leaves narrow, concave above, smooth, usually longer than the scape. Scape 6-12 in. high, 1-flowered. Spathe 1-leaved, 2-cleft. Flowers 2-3 in. long, white, tinged with pink or purple, bell-shaped, short-peduncled. Stamens longer than the tube, shorter than the style. Capsule depressed-globose, seeds angled. In rich, damp soil, ofien cultivated.*

\section{NARCISSUS, $\mathbf{L}$.}

Scapes with 1-several flowers from a thin, dry spathe. Flowers with a cup-shaped or other crown on the throat of the perianth ; tube of the perianth somewhat cylindrical, the 6 divisions of the limb widely spreading. Stamens 6 , inserted in the tube.

1. N. Pseudo-narcissus, L. Daffodil, Daffy, Easter-Flower. Scape short, bearing 1 large yellow flower ; tube of perianth short and wide, crown with a crimped margin. Cultivated from Europe.

2. N. Tazetta, var. orientalis. Chinese SAcred Lily. Bulb large, often with many smaller ones attached to its base. Scape $1 \mathrm{ft}$. or more high. Flowers several, umbeled, fragrant. Perianth white or nearly so, the crown rather spreading, finely scalloped, yellow or orange. Cultivated from China.

3. N. poeticus, L. Poet's Narcissus. Scape 1-flowered. Perianth pure white, the crown very narrow, edged with pink. Cultivated from S. Europe.

\section{HYPOXIS, L.}

Small, stemless herbs. Leaves grass-like, hairy, from a solid bulb. Scapes thread-like, few-flowered. Perianth 6-parted, wheel-shaped, the 3 outer divisions greenish on the outside, the whole perianth withering on the pod. Seeds numerous.

1. H. erecta, L. StaR-gRass. Leaves longer than the scape, hoth sparsely set with long, soft hairs. Scape $3-\delta$ in. high. Flowers $1-t$, about $\frac{1}{2}$ in. across, yellow. Common in meadows and dry woods. 


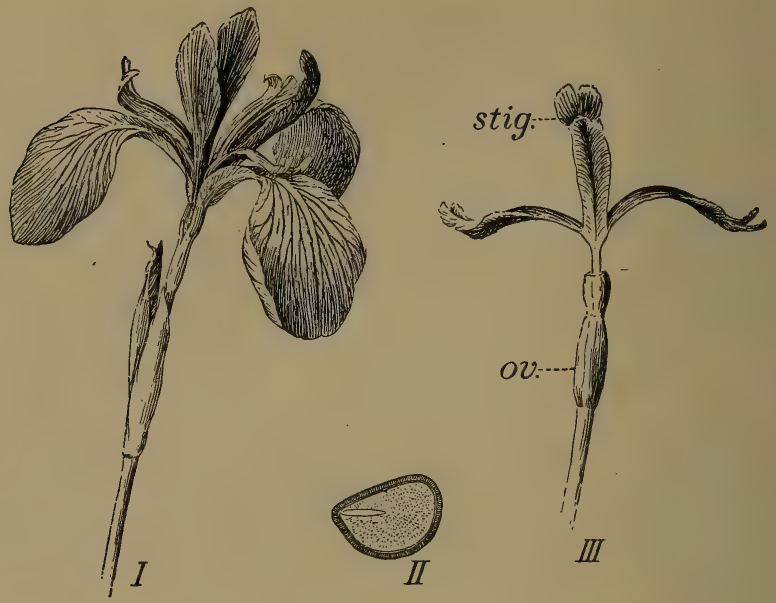

FIG. 6. - Iris.

I, flower ; II, seed, longitudinal section ; III, flower with outer segments of perianth removed; stig., stigma, ov., ovary.
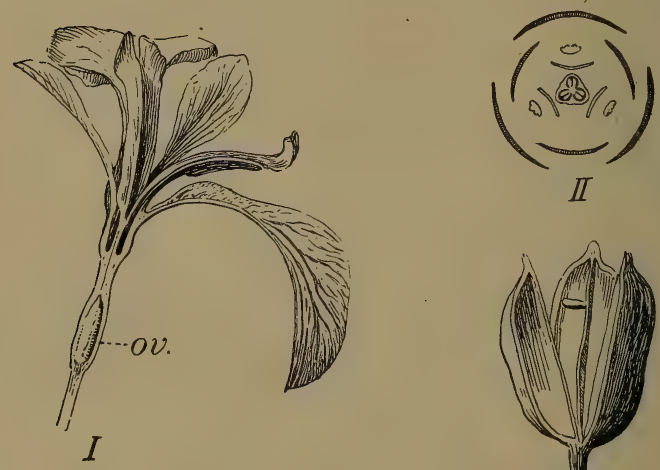

FIG. 7. - Iris.

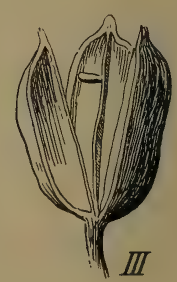

I, flower, longitudinal section, ov., ovary ; II, diagram, showing stigmas opposite the stamens; III, capsule, splitting between the partitions. 


\section{IRIDACEAE. IRIS FAMILY.}

Perennial herbs from bulbs, corms, or rootstocks. Leaves 2-ranked, equitant. Flowers perfect, regular or irregular, each subtended by two bracts. Perianth 6 -parted, the tube adherent to the ovary, the segments in 2 series of 3 each, equal, or the inner ones smaller. Stamens 3, distinct or united, opposite the outer segments. Ovary forming a 3-celled, 3-angled, 3 -valved, many-seeded, dehiscent capsule.*

\section{CROCUS, L. Crocus.}

Leaves radical. Flowers sessile on the corm. Tube of the perianth very long and slender, its divisions all alike or nearly so. Stigmas 3-cleft.

1. C. vernus. Spring Crocus. Leaves linear. Stigmas short. Flowers white, blue, or purple. Our earliest garden flower. Cultivated from Europe.

\section{IRIS, Tourn.}

Rootstock thick, creeping, branching, horizontal, sometimes tuberous. Stems erect, simple, or branched. Leaves linear or sword-shaped. Flowers showy, epigynous, the outer perianth segments spreading or recurved, often bearded within, the inner segments usually smaller and erect. Stamens inserted in the base of the outer segments. Style deeply 3-parted, the divisions broad and petal-like, covering the stamens. Fruit an oblong or oval, 3 or 6 angled, many-seeded capsule.*

1. I. versicolor, L. LARge Blue Flag. Rootstock thick, horizontal. Stem crlindrical, smooth, simple or branched, leafy, 2-3 ft. high. Leaves linear, sword-shaped, finely nerved, with a bloom, the lower $1 \frac{1}{2}-2 \mathrm{ft}$. long, the upper shorter. Bracts longer than the pedicels. Flowers terminal, single, or few together, blue variegated with white, yellow, and purple, perianth segments not bearded, the inner ones smaller. Ovary 3 -angled, longer than the inflated perianth tube. Capsule oblong, slightly lobed, seeds 2 rows in each cell. In wet places.*

2. I. germanica, L. FLeU R-DE-LIs. Rootstock thick, matted. Stem stout, branched, leafy, 2-3 ft. high. Leaves strap-shaped, 
acute, erect, shorter than the stem, bracts scarious. Flowers sessile, large and showy, blue, variegated with white and yellow, sometimes nearly all white, outer segments large, recurved, bearded, the inner narrower, erect, or arched inward. Introduced from Europe ; common in gardens and naturalized in many places.*

3. I. fulva, Ker. Yellow Flag. Rootstock fleshy. Stem simple or branched, grooved, 1-angled below, bearing 2-3 leaves, 2-3 ft. high. Leaves linear, sword-shaped, with a bloom, shorter than the stem, bracts small. Pedicels short, flowers axillary and terminal, dull yellow or reddish-brown, variegated with blue and green, perianth segments not bearded. Style branches but little exceeding the stamens, ovary about as long as the inflated perianth tube. Capsule ovate, 6 -angled. Swamps and wet places.*

\section{SISYRHINCHIUM, $\mathbf{L}$.}

Small, grass-like perennials. Stems erect, flattened, or winged. Roots fibrous. Leaves linear or lanceolate. Flowers small, blue, quickly withering, in terminal 2-bracted umbels. Perianth corolla-like, of 6 bristle-pointed segments, tube nearly or wholly lacking. Stamens 3 , completely monadelphous. Stigmas 3, thread-like. Fruit a nearly globular 3 -angled capsule. Species too difficult for the beginner.

\section{ORCHIDACEAE. ORChis FAMiLy.}

Perennial herbs with simple stems, often arising from bulbs or tubers. Leaves simple, usually alternate and entire. Flowers perfect, generally showy, often extraordinarily irregular. Perianth of 6 divisions, adnate to the 1-celled ovary. Stamens 1 or 2 , united with the pistil ; pollen of comparatively few grains held together in masses by cobweb-like threads. Ovary 1-celled, containing many (sometimes more than a million) very minute ovules.

The family is a difficult one, and most of the genera are so rare that specimens should not be collected in large numbers for class study. Two of the most familiar genera are Cypripedium, or lady's slipper, and Spiranthes, or lady's tresses. Many of the genera are tropical air-plants like Part I, Fig. 13. 


\section{SUBCLASS II. - DICOTYLEDONOUS PLANTS.}

Stems composed of bark, wood, and pith; the fibro-vascular bundles in rings; in woody stems which live over from year to year, the wood generally in annual rings, traversed at right angles by medullary rays. Leaves netted-veined. Parts of the flower usually in fours or fives. Cotyledons 2 (rarely none).

\section{SALICACE 2 . Willow Family.}

Diœcious trees or shrubs, with flowers in catkins (Ch. XIII), destitute of floral envelopes. Fruit a 1-celled pod, with numerous seeds, provided with rather long and silky down, by means of which they are transported by the wind.

\section{POPULUS, Tourn.}

Trees with prominent scaly buds, twigs more or less angled. Leaves usually long-petioled.

Flowers borne in long, drooping catkins, which appear before the leaves; scales of the catkins irregularly cut toward the tip. Stamens $8-30$ or more. Stigmas 2-4. Capsules opening early by 2 to 4 valves.

1. P. tremuloides, Michx. AMerican Aspen, Quaking Asp. A tree 20 to $60 \mathrm{ft}$. high, with greenish-white bark; leaves roundish, heart-shaped, abruptly pointed, with small regular teeth. Leafstalk long, slender, and flattened at right angles to the broad surfaces of the leaf, causing it to sway edgewise with the least perceptible breeze. Common especially N.

2. P. grandidentata, Michx. LARge-toothed Poplar. A tree 60 to $80 \mathrm{ft}$. high, with rather smooth gray bark; leaves $3-5$ in. long, roundish orate and irregularly sinuate-toothed; when young completely corered with white silky wool, which is shed as soon as the leaf matures. The petiole is somewhat flattened, but not nearly as much so as that of the preceding species. Rich woods $\mathrm{N}$.

3. P. heterophylla, L. Swamp Poplar. Branches only slightly angled. Leaves ovate, mostly obtuse at the apex, rounded or subcordate at the base, serrate with obtuse teeth, densely woolly when 
young, but becoming smooth with age ; petioles cylindrical. Pistillate catkins smooth, erect, or spreading, loosely flowered. Capsule ovoid, usually shorter than the pedicel. Common in river swamps. A large tree with soft light wood, which is often used in making cheap furniture.*

4. P. monilifera, Ait. CоттоNwood. A large and very rapidly growing tree, 75 to 100 or more feet in height, often with a markedly excurrent trunk. Leaves large and broadly triangular, with crenateserrate margins and long, tapering acute tips; petioles long and considerably flattened. The numerous pediceled capsules are quite conspicuous when mature, and the air is filled with the downy seeds at the time when the capsules open. Common W., especially along streams and planted as a shade-tree.

\section{SALIX, Tourn.}

Shrubs or trees, branches usually very slender. Buds with single scales. Leaves usually long and narrow ; stipules sometimes leaf-like or often small and soon deciduous. Bracts of the catkins entire; staminate catkins erect or drooping, staminate flowers with $2-10$, mostly 2 , distinct or united stamens. Pistillate catkins usually erect, flowers with a small gland on the inner side of the bract, stigmas short, 2-lobed. Capsule 2-valved.*

1. S. nigra, Marsh. BlAcK WiLlow. Leaves elliptical or narrowly lanceolate, acute at each end, serrate, short-petioled, downy when young and becoming smooth with age, 2-3 in. long; stipules persistent or deciduous. Staminate catkins 1-2 in. long; the pistillate 2-4 in. long. Stamens 3-7, distinct, filaments soft, hairy below. Capsule twice the length of the pedicel, ovate, taper-pointed, pointed by the prominent style. A small tree with very brittle branches. Along streams and borders of marshes.*

2. S. babylonica, Tourn. WeEprng WrLlow. Leaves narrowly lanceolate, taper-pointed, serrate, slightly downy when young and becoming smooth with age, green above, pale beneath, often 5-7 in. long, petioles short, glandular. Catkins on short lateral branches. Stamens 2. Style almost none. Capsule sessile, smooth. Introduced and cultivated for ornament, becoming a large tree.*

[Some 20 species of willow are found growing wild in the northeastern and north central states, but they are very hard, even for botanists, to identify.] 


\section{MYRICACE E. BAYBERRY FAMILY.}

Shrubs with alternate, simple, resinous-dotted leaves; monœcious or diœcious. Flowers in short, bracted catkins, perianth none. Staminate flowers 2-10, stamens inserted on the receptacle. Pistillate flowers surrounded by 2-6 scales. Ovary 1-celled, style short, stigmas 2.

\section{MYRICA, L.}

Shrubs or small trees with the branches clustered at the end of the growth of the previous season. Leaves shortpetioled. entire, lobed or toothed, the margin usually revolute, without stipules. Perianth none. Staminate flowers in oblong or cylindrical catkins, stamens $2-10$, with the filaments united below. Pistillate flowers surrounded by a cup of 2-6 scales, ovary solitary, becoming a 1-celled, roundish stone-fruit or nut, often covered with waxy grains. Whole plant usually fragrant.**

1. M. cerifera, L. WAXEerRY, BAYBerRY. A spreading shrub or small tree; roung branches downy. Leaves lanceolate or oblonglanceolate, entire or sometimes serrate near the mostly obtuse apex, smooth or downy on the reins beneath, tapering into a short petiole. Flowers mostly dioecious. Staminate catkins numerous, stamens 4 . Pistillate catkins small, bracts slightly 3-lobed, scales of the orary 4, fringed with hairs; stigmas 2. Fruit very abundant, incrusted with white $\operatorname{wax}, \frac{1}{8}-\frac{1}{6} \mathrm{in}$. in diameter, sometimes persistent for 2 or 3 years. Common on wet soils, especially near the coast.*

2. M. asplenifolia, Endi. Sweet Ferx. A shrub $2 \mathrm{ft}$. or less in height, with brown twigs. Leares fern-like, linear-lanceolate, 20-30lobed, $3-5$ in. long and rers fragrant. Often monœecious. Staminate catkins crlindrical. Pistillate catkins globular. Orary surrounded by 8 long. linear, a rl-shaped, hairy and glandular seales which encircle the ripened fruit. Nut nearly oroid, smooth, small, but eaten by children.

16. JUglandaceze. Walxet Family.

Trees with alternate, odd-pinnate leaves without stipules. Flowers monœcious, the staminate in long and drooping catkins, stamens few or many. Calyx 2-6-parted. Fertile 
flowers solitary or in small clusters. Calyx 3-5-lobed, minute petals sometimes present. Ovary 1-celled or incompletely 2-4-celled. Fruit with a dry husk enclosing a bony nut.*

\section{JUGLANS, $\mathbf{L}$.}

Staminate catkins cylindrical, solitary, borne on wood of the previous year, stamens numerous, filaments short, calyx 4-6-parted. Pistillate flowers single or a few together on a short peduncle at the base of the growth of the season. Calyx 4-parted. Petals 4, minute, adnate to the ovary. Styles 2, short, plumose. Fruit large, roundish or oval, husk fibrousfleshy, becoming dry, indehiscent, nut bony, very rough.*

1. J. nigra, L. Black Walnut. Leaflets 13-21, ovate-lanceolate, serrate, taper-pointed, somewhat cordate or oblique at the base, nearly smooth above, downy beneath, petioles minutely downy. Fruit usually single, roundish, about 2 in. in diameter. On rich soil, rare near the coast. One of the most valuable of our native trees, the wood being very durable and highly prized for cabinet work.*

2. J. cinerea, L. Butternut. Leaflets 15-19, ovate-lanceolate, taper-pointed at the apex, rounded or slightly unsymmetrical at the base, serrate, downy beneath ; petioles, branchlets, and fruit clothed with short, sticky hairs. Fruit often somewhat in clusters, oblong, large. More common northward. Wood less valuable and nut less oily than the black walnut. The English walnut ( $J$. regia) is occasionally seen in cultivation. It has 7-11 leaflets and a nearly smooth nut.*

\section{CARYA, Nutt.}

Leaflets serrate; staminate catkins usually in threes on a common peduncle, or sometimes sessile at the base of the growth of the season; calyx 2-3-parted, stamens 3-10, filaments short. Pistillate flowers $2-5$ in terminal clusters, calyx 4-parted, petals none, styles 2 or 4, fringed. Fruit somewhat globular, husk separating more or less completely into 4 valves. Nut smooth or angled.*

1. C. olivæformis, Nutt. PECAN. A large tree with rough gray bark, young twigs and leaves downy, nearly smooth when inature. Leaflets 11-15, oblong-lanceolate, acuminate, serrate, scythe-shaped. Staninate catkins nearly sessile, 5-6 in. long. Husk thin nut oval 
or oblong, thin-shelled. River bottoms. Rarely native east of the Mississippi River, but widely planted for its fruit.*

2. C. alba, Nutt. Shellbark Hickory. A large tree with bark scaling off in long plates, young twigs and leaves downy, becoming smooth with age. Leaflets 5, the lower ones oblong-lanceolate, the upper one longer and obovate, taper-pointed at the apex, narrowed to the sessile base. Inner bud-scales becoming large and conspicuous. Staminate catkins in threes. Fruit globose, husk thick, splitting into four sections, nut white, compressed, 4-angled, pointed, thin-shelled. On rich soil. More common N. Wood strong and elastic, but not durable when exposed.*

3. C. sulcata, Nutt. Big Shellbark, King Nut, Bull Nut. A tree 70-90 ft. high, with shaggy bark. Leaflets 7 or 9 , the terminal one nearly sessile. Fruit large, ovoid or nearly so, 4-grooved toward the outer end, the husk very thick, nut pointed at each end, $1 \frac{1}{2}-2$ in. long, thick-shelled, with a very sweet kernel. IVood hard and heavy. Common in rich, damp soil W.

4. C. amara, Nutt. Pignut, Swamp Hickory. A mediumsized tree, with rather smooth bark. Leaflets $7-11$, lanceolate or oblong-lanceolate. Fruit not large, husk thin, nut globular, with a short point, very thin-shelled, kernel extremely bitter. Moist soil, common in the Middle States.

\section{Betulace仺. Birci Family.}

Trees or shrubs, with alternate, simple, petioled leaves with usually deciduous stipules. Flowers monœcious in cylindrical or subglobose catkins, staminate catkins drooping; flowers $1-3$ in the axil of each bract, calyx none, or membranous and 2-4-parted; stamens 2-10, distinct. Pistillate catkins drooping, spreading, or erect and spike-like; flowers with or without a calyx, ovary solitary, 1-2-celled, ovules 1-2 in each cell. Fruit a 1-celled nut or key.*

\section{CARPINUS, $\mathbf{L}$.}

Trees with thin, straight-veined leaves, which are folded in the bud. Flowers appearing before the leaves; staminate flowers in slender drooping catkins, sessile at the end of the growth of the previous season; stamens $3-12$, subtended by a bract, filaments forked, anthers hairy. Pistillate catkins 
spike-like, each pair of flowers subtended by a deciduous bract, and each flower by a persistent bractlet which becomes large and leaf-like in fruit; ovary 2-celled, 2-ovuled; stigmas 2, thread-like. Fruit a small angular nut.*

1. C. caroliniana, Walt. Hornbeam. A small tree with smooth and close gray bark; twigs slender. Leaves ovate-oblong, acute or taper-pointed, sharply and doubly serrate, the straight veins terminating in the larger serrations; downy when young and soon becoming smooth. Staminate catkins $1-1 \frac{1}{2}$ in. long. Pistillate catkins longpeduncled, 8-12-flowered ; bractlets becoming nearly 1 in. long, cuttoothed, the middle tooth much longer than the others. In rich, moist woods. Often known as "blue beech" and "iron-wood." *

\section{OSTRYA, Micheli.}

Small trees with gray bark and very hard wood. Leaves open and concave in the bud and somewhat plaited on the veins. Staminate flowers on slender, drooping catkins, sessile at the end of the growth of the previous season; stamens 3-12, subtended by a bract, filaments forked, anthers hairy. Pistillate flowers surrounded by a tubular bractlet which becomes large and bladder-like at maturity. Fruit a small, pointed, smooth nut; mature catkins hop-like.*

0. virginica, Willd. A small tree with brownish, furrowed bark; leaves ovate, acute, doubly serrate, often inequilateral at the base, short-petioled; staminate and fertile catkins 2-3 in. long. In rich woods. Often known as "iron-wood" and "lever-wood." *

\section{CORYLUS, Tourn.}

Shrubs with prominently veined, cut-toothed leaves which are folded lengthwise in the bud. Flowers expanding before the leaves. Staminate flowers in slender, drooping catkins; stamens 8, anthers 1-celled. Fertile flowers several in a cluster or in very short catkins at the ends of the twigs of the season; ovary incompletely 2-celled, style short, stigmas 2 , bractlets 2 , becoming enlarged and enclosing the single bony nut at maturity.*

1. C. americana, Walt. Hazelnut. A shrub 2-5 ft. high, young twigs and petioles covered with brownish, stiff hairs. Leaves not 
very thin, round-cordate, acute or slightly taper-pointed, irregularly toothed, nearly smooth above, downy below. Involucre longer than the nut and partially enclosing it, glandular-hairy. Nut subglobose, pointed, edible. On rich soil, borders of meadows and fields, and in oak-openings.

2. C. rostrata, Ait. Beaked Hazelnut. A shrub 4-8 ft. high. Young twigs near ends smooth. Leares thin, little, if at all, heartshaped, doubly serrate or incised, taper-pointed, stipules linearlanceolate. Involucre completely corering the nut and prolonged into a beak beyond it. Common $\mathrm{N}$. [The latter species is not nearly as widely distributed as the former ; they cannot be readily distinguished from each other until the fruit is somewhat mature. The principal points of difference discernible before the fruit is nearly mature are the hairy twigs of No. 1 and the smooth ones of No. 2, and the fact that No. 1 has buds rounded at the apex and more slender and longer staminate catkins, while No. 2 has buds acute at the apex and thicker and shorter staminate catkins.]

\section{BETULA, Tourn.}

Trees with slender, aromatic twigs and thin, usually straightveined leaves. Staminate catkins drooping, flowers usually 3 in the axil of each bract, stamens 4, short, anthers 1-celled. Pistillate catkins erect, flowers 2 or 3 in the axil of each bract; ovary sessile, 2-celled, styles 2 ; bracts 3 -lobed; perianth none. Nut broadly winged.*

1. B. nigra, L. Black Birch, River Birch. A medium-sized tree with reddish-brown bark. Leares rhombic-orate, acute at the apex, acute or obtuse at the base, sharply and doubly serrate, whitedowny below, becoming smoother with age, petioles short. Staminate catkins $2-3$ in. long. Pistillate catkins $1-1 \frac{1}{2}$ in. long, peduncles short, bracts nearly equally 3-cleft, woolly. River banks, especially S. and W.*

2. B. lenta, L. Cherry Birch. Leaves ovate or oblong-ovate, acute, heart-shaped, finely and doubly serrate, silky when young; petioles about $\frac{1}{2}$ in. long. Staminate catkins clustered, $3-4$ in. long: Pistillate catkins sessile, about $1 \mathrm{in}$. long, cylindrical bracts spreading, acute, smooth. River banks, especially N. A large tree with aromatic twigs. The oil contained in the bark and twigs is distilled and used as a substitute for wintergreen.*

3. B. populifolia, Ait. Gray BIRCH. A tall shrub or slender, straggling tree, 15-30 ft. high, seldom growing erect, often several trunks springing from the ground almost in contact and slanting away from each other. Leaves triangular, with a long taper point 
and truncate base, unevenly twice serrate, with rather long, slender petioles, which allow the leaves to quiver like those of the aspen. Bark scaling off in white strips and layers, but not in nearly as large sheets as that of the rarer canoe birch ( $B$. papyrifera). The commonest birch of New England.

4. B. alba, L. European White Birch, Cut-leaved Birch. A tree 50 to $60 \mathrm{ft}$. high, often with drooping branches. Leaves triangular-ovate, truncate, rounded or somewhat heart-shaped at the base, not strongly taper-pointed except in the cut-leaved form. Commonly cultivated from Europe. Resembles No. 3, but has whiter bark and (the weeping form) much more slender branches.

\section{ALNUS, Tourn.}

Shrubs or small trees. Leaves petioled, serrate. Flowerbuds stalked, appearing the previous season; staminate catkins racemed, drooping, flowers 3-6 in the axil of each bract, subtended by 1-2 bractlets, perianth 4-parted, stamens 4 , fila-

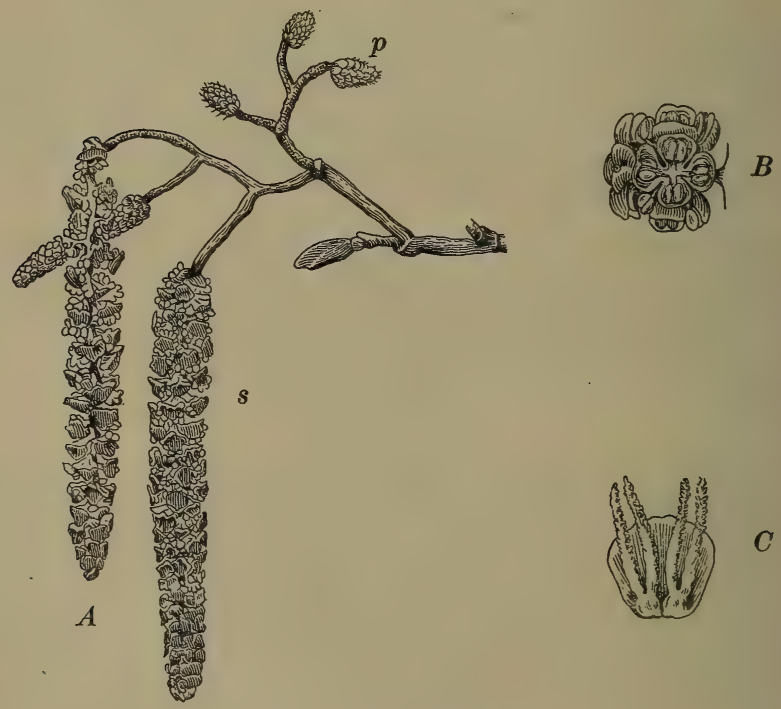

FiG. 8.- Alnus glutinosa.

$A$, a flowering twig; $s$, staminate catkins ; $p$, pistillate catkins ; $B$, a group of staminate flowers, enlarged; $C$, two pistillate flowers, enlarged. 
ments short. Pistillate catkins erect; flowers $2-3$ in the axil of each bract, perianth replaced by $2-4$ minute bractlets which are adherent to the bract; ovary 2-celled, styles 2. Fruit a winged or angled nut; bracts of the pistillate flowers somewhat fleshy, persistent, becoming woody in fruit.*

1. A. serrulata, Willd. Sirooth Alder. A shrub or small tree with smooth bark. Leaves obovate, rounded or obtuse at the apex, acute at the base, sharply and minutely serrate, smooth above, downy beneath, petioled, stipules oval, deciduous. Staminate catkins 2-4 in. long; fruiting catkins ovoid, short-peduncled. Fruit ovate, wingless. Banks of streams and borders of marshes, ranging far S. Leaves often persistent during the winter.*

2. A. incana, Willd. Speckled Alder. A shrub 8-20 ft. high. Leaves broadly oval or ovate, rounded at the base, sharply (sometimes doubly) serrate, white and usually downy beneath. Fruit round. Forming thickets by streams, very common N.

\section{FAGACE}

Trees or shrubs. Leaves alternate, simple, pinnately veined; stipules deciduous. Flowers monœcious, the staminate in heads, or in drooping, spreading, or erect catkins, calyx minute, petals none, stamens 4-20. Pistillate flowers solitary or in small clusters, each flower subtended by more or less united bracts which at maturity form a cup or bur, calyx minutely toothed, petals none; ovary $2-7$-celled, but becoming 1-celled. Fruit a 1-seeded nut.*

\section{FAGUS, Tourn.}

Trees with smooth, close, ash-gray bark, and slender, often horizontal branches. Staminate flowers in long, slenderpeduncled, roundish clusters, calyx bell-shaped, 4-6-cleft, stamens $8-12$, anthers 2-celled; pistillate flowers solitary or more often in pairs, peduncled, surrounded by a 4-lobed involucre and numerous linear bracts; ovaries 3 -celled with 2 ovules in each cell, but usually only 1 ovule matures in each ovary; styles 3 , thread-shaped, fruit a thin-shelled, 3-angled nut.* 
1. F. ferruginea, Ait. BEECH. Large trees. Leaves oblong-ovate, taper-pointed at the apex, serrate, straight-veined, very white-silky when young, nearly smooth with age. Involucre densely covered with short recurved spines. Nuts thin-shelled, edible. Common on damp soil everywhere. The wood is very hard, tough, and closegrained, and is especially valuable for the manufacture of small tools.*

2. F. sylvatica, L. The European beech is occasionally found planted as a shade-tree. The variety known as the copper beech is most usual, and is readily recognized by its dark, crimson-purple leaves.

\section{CASTANEA, Tourn.}

Trees or shrubs with rough, gray, rather close bark. Leaves straight-veined, undivided, prominently toothed. Flowers appearing later than the leaves. Staminate catkins erect or spreading, loosely flowered, flowers several in the axil of each bract, calyx 4-6-parted, stamens 8-16. Pistillate flowers at the base of the staminate catkin or in small separate clusters, usually 3 in each involucre ; ovary 4-celled, surrounded by $5-12$ abortive stamens. Fruit a 1-celled nut enclosed in the greatly enlarged and very prickly involucre.*

1. C. sativa, Mill., var. americana, Wats. American Chestnut. A large tree, bark somewhat rough, and splitting into longitudinal plates. Leaves oblong-lanceolate, taper-pointed at the apex, usually acute at the base, coarsely and sharply serrate with ascending teeth, smooth, dark green above, lighter below; petioles stout, short. Staminate catkins erect, 6-10 in. long. Nuts usually 3 in each bur. Rich soil, especially N. Rarely found on soils containing much lime.*

2. C. pumila, Mill. Chinquapin. A small tree or shrub. Leaves oblong, acute or obtuse at both ends, serrate with divergent teeth, dark green and smooth above, white-woolly below. Nuts solitary, nearly globular. Common southward in rich woods.*

\section{QUERCUS, $\mathbf{L}$.}

Trees or shrubs with entire, serrate, or lobed leaves, which are often persistent. Staminate flowers in slender catkins, each subtended by quickly deciduous bracts, and consisting 
of 3-12 stamens enclosed by a 4-8-parted perianth, often . containing an abortive ovary. Pistillate flowers solitary or in small clusters, each consisting of a 3-celled ovary with 2 ovules in each coll, though rarely more than 1 ovule matures; styles short, erect, or recurved. Pistillate flowers surrounded by a scaly involucre which at maturity becomes a cup enclosing the base of the fruit or sometimes a large part of it. Fruit an ovoid or subglobose, 1-seeded, thinshelled nut (acorn).

A. Fruit biennial; leares entire or with bristle-pointed lobes.*

1. Q. rubra, L. Red OAK. A large tree. Leaves oval or obovate, green abore, pale and slightly downy beneath, sinuses shallow and rounded, lobes 8-12, taper-pointed; petioles long. Cup saucer-shaped, with fine scales ; acorn ovate or oblong, about 1 in. long. Common; wood not valuable; leares turning red after frost and often remaining on the tree through the winter.*

2. Q. coccinea, var. tinctoria, Gray. BLACK OAK. A large tree with rough, dark brown outer bark and thick, bright yellow inner bark; leares broadly oval, usually cut more than halfway to the midrib, sinuses rounded; lobes about 7 , sharply toothed at the apex, smooth abore, usually dorny on the veins beneath; cup hemispherical or top-shaped, with coarse scales, short-peduncled, enclosing about half the roundish acorn. Common; wood not valuable, but the inner bark used for tanning and dyeing.*

3. Q. falcata, Michx. SPANish OAK. A small or medium-sized tree with leaves $3-5$-lobed at the apex, obtuse or rounded at the base, grayish-downy beneath, lobes lanceolate and often scytheshaped, sparingly cut-toothed. Cup top-shaped, with coarse scales, euclosing about half the nearly round acorn. Common in dry woods. Foliage quite variable in outline and lobing; bark valuable for tanning.**

4. Q. nigra, L. BцACK-JACK ОАK. A small tree; leaves obovate, usually with three rounded lobes at the apex, the lobes bristle-pointed, rounded, or slightly cordate at the base, rusty-pubescent beneath, shining abore, coriaceous, short-petioled; cup top-shaped, shortpeduncled, with coarse and truncate scales, enclosing about onethird of the oblong-orate acorn. An almost worthless tree, its presence indicating a thin and sterile soil.**

5. Q. Phellos, L. Wrilow OAK. A tree of medium size, leaves lanceolate or elliptical, scurfy when young and becoming smooth with age; very short-petioled ; cup shallow, sessile; acorn subglobose. Wet soil ; often planted for shade.* 
$B$. Fruit annual; leaves not bristle-tipped, though often mucronate.

6. Q. alba, L. Wніте OAк. A large tree with light gray bark. Leaves obovate-oblong, 3-9-lobed, lobes rounded and mostly entire, bright green above, paler below, short-petioled. Cup hemispherical, scales rough, woolly when young, but becoming smooth with age; acorn oblong-ovate, about 1 in. long. Common in damp soil ; wood strong and durable; one of the most valuable timber trees.*

7. Q. stellata, Wang. Post OAK. A tree of medium size with rough gray bark. Leaves broadly obovate, deeply lyrate-pinnatified into 5-7 rounded, divergent lobes, upper lobes much the longer, smooth above, yellowish-downy beneath, petioles about 1 in. long. Cup hemispherical, nearly sessile; acorn ovoid, 2-3 times as long as the cup. On dry soil ; wood hard and valuable.

8. Q. macrocarpa, Michx. Bur OAK. A medium-sized to very large tree, with roughish gray bark. Leaves obovate or oblong, lyrately and deeply sinuate-lobed, smooth above, pale or downy beneath. Cup very deep and thick, abundantly fringed about the margin, $\frac{3}{4}$ in. to 2 in. in diameter. Acorn, half or more [sometimes entirely] enclosed by the cup. Reaches its full size only on rich bottom lands S. and W., where it becomes one of the finest timber oaks. Wood very hard and heavy.

9. Q. lyrata, Walt. SwAmp OAK. A large tree with gray or reddish bark. Leaves obovate-oblong, deeply pinnatifid, lobes narrow, often toothed, thin, smooth above, white, densely woolly beneath. Cup round-ovate, scales cuspidate, enclosing nearly the whole of the depressed-globose acorn. On wet soil; wood strong and very durable.*

10. Q. prinus, L. Swamp Chestrut OAK. A large tree with brown, ridged bark. Leaves oblong or oblong-lanceolate, rather obtuse, crenately toothed, minutely downy beneath, petioles slender, about 1 in. long. Cup hemispherical, peduncles longer than the petioles, scales acute, tubercular, appressed; acorn oblong, acute, 1 in. or less in length, edible. Common on low ground. Wood strong and valuable.**

11. Q. Muhlenbergii, Engelm. Yellow Chestrut OAK. A tree of medium or large size with gray bark. Leaves oblong or oblanceolate, usually acute at the apex and obtuse or rounded at the base, coarsely and evenly toothed; veins straight, impressed above and prominent beneath ; petioles slender. Cup hemispherical, sessile or short-peduncled, with flat scales, $\frac{1}{2}$ in. broad, enclosing about half the ovoid acorn, which is $\frac{2}{3}-\frac{3}{4}$ in. long. Common on dry soil, wood close-grained, durable, and valuable.

12. Q. virginiana, Mill. Lrve OAK. A large tree with rough 
gray or brown bark and a low, spreading top. Leaves leathery, evergreen, oblong or oblanceolate, often somewhat 3-lobed on young trees, margin rolled under, dark green and shining above, pale below ; petioles short, stout. Fruit often in short racemes, cup topshaped, scales closely appressed, hoary, peduncles $\frac{1}{2}-1$ in. long ; acorn from subglobose to oblong, the longer form occurring on the younger trees. On low ground near the coast; wood very hard and durable ; valued for shipbuilding:*

\section{ULmaCE}

Trees or shrubs with watery juice, alternate, simple, petiolate, serrate, stipulate leaves, which are usually 2-ranked; and small, perfect, or somewhat monœeious, apetalous flowers. Calyx of 3-9 sepals which are distinct or partly united,

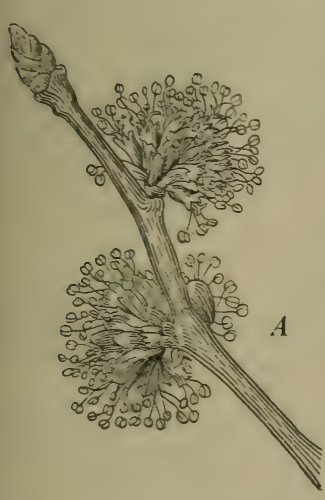
stamens as many as the sepals and opposite them. Ovary 1-2-celled, styles 2, spreading: Fruit a key, nut, or stone fruit.*
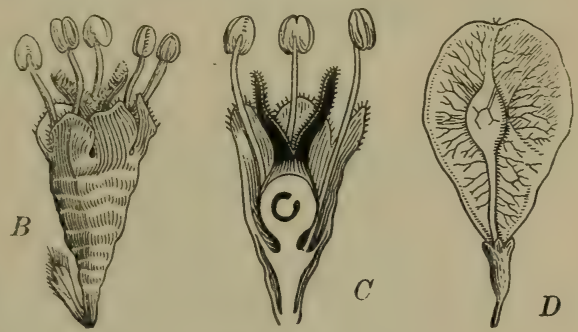

FIG. 9. - Ulmus campestris.

$A$, a flowering twig ; $B$, a flower; $C$, longitudinal section of a flower; $D$, a fruit.

\section{ULMUS, L.}

Trees with straight-veined, unsymmetrical, doubly serrate leaves; stipules early deciduous. Flowers perfect, calyx bell-shaped, 4-9-cleft. Stamens slender, protruding. Ovary compressed, styles 2, spreading. Fruit membranaceous, flat, winged on the edge.* 
1. U. americana, L. White Elm. A large tree with gray bark, drooping branches, and smooth or slightly downy twigs. Leaves oval or obovate, abruptly taper-pointed at the apex, obtuse and oblique at the base, slightly rough above, soft downy or soon smooth beneath. Flowers in close fascicles, peduncles slender, smooth. Fruit oval or obovate, with 2 sharp teeth bending toward each other at the apex, wing reticulate-veined, downy on the margin. In moist, rich soil. A widely planted ornamental tree; wood strong but warping badly, and not durable when exposed.*

2. U. alata, Michx. WINGED Elm. A small tree with branches corky-winged. Leaves small, ovate-lanceolate, acute, sharply serrate, base nearly equal-sided, rough above, downy beneath, nearly sessile. Flowers in small clusters. Fruit oblong, downy on the sides, ciliate on the edges. On rich soil. Occasionally producing a second set of flowers and fruit from September to November.*

3. U. fulva, Michx. Slippery Elm. A tree of medium size with rough downy twigs, and rusty, densely woolly bud-scales. Leaves large, thick, very rough above, downy beneath, ovate or obovate, taper-pointed at the apex, unsymmetrical, obtuse or somewhat cordate at the base, coarsely and doubly serrate, calyx-lobes and pedicels downy. Fruit broadly oval, downy over the seed, the wing smooth. Inner bark very fragrant when dried, and a popular domestic remedy.*

\section{CELTIS, Tourn.}

Trees or shrubs with entire or serrate, petioled leaves. Flowers greenish, axillary, on wood of the same season, the staminate in small clusters, the fertile single or 2-3 together. *

1. C. occidentalis, L. HACKBERRY. A large or medium-sized tree having much the appearance of an elm, bark dark and rough. Leaves ovate, taper-pointed at the apex, abruptly obtuse and inequilateral at the base, sharply serrate, often 3-nerved from the base, smooth above, usually somewhat downy below. Fruit a small, dark purple stone fruit. On rich soil.

2. C. mississippiensis, Bosc. Southern Hackberry. A tree usually smaller than the preceding, bark gray, often very warty. Leaves broadly lanceolate or ovate, long taper-pointed at the apex, obtuse or sometimes heart-shaped at the base, entire or with very few serratures, smooth on both sides, 3-nerved. Fruit a purplishblack, globose stone fruit.* 


\section{Mírace a. Mulberry Family.}

Trees, shrubs, or herbs, usually with milky juice, alternate leares, large deciduous stipules and small monœcious or diœcious flowers crowded in spikes, heads or racemes, or enclosed in a fleshy receptacle. Staminate flowers with a 3-4-lobed calyx, stamens $3-4$, inserted on the base of the calyx, filaments usually inflexed in the bud, straightening at maturity. Pistillate flowers 3-5̌-sepalous ; ovary 1-2-celled, 1-2-ovuled ; styles 2 , receptacle and perianth often fleshy at maturity.*

\section{MORUS, Tourn.}

Trees or shrubs with milky juice, rounded leares, and monœcious flowers in axillary spikes. Staminate flowers with a 4 -parted perianth, and 4 stamens inflexed in the bud. Pistillate flowers with a 4-parted perianth which becomes fleshy in the multiple fruit, the pulpy part of which consists of the thickened calyx, bracts and so on of many flowers; ovary sessile, stigmas 2 , linear, spreading; the fleshy perianth enclosing the ovary at maturity.**

1. M. rubra, L. Red Mrlberry. A small tree. Leaves cordate-orate, often 3-5-lobed on rigorous shoots, taper-pointed at the apex. serrate, rough abore, white, densely woolly beneath. Mature fruiting spikes oblong, drooping, dark red or purple, edible. On rich soil. Wood rery durable, bearing exposure to the weather.

2. M. alba, L. White MclberRx. A small tree. Leares orate, heart-shaped. acute at the apex, rounded and often oblique at the base, serrate or sometimes lobed. Smooth and shining on both sides. Mature fruit light red or white. Introduced and common about old dwellings.*

\section{MACLURA, Nutt.}

A small tree with milky juice. Leares alternate, petioled, spines axillary. Flowers diœcious. Staminate flowers in short axillary racemes; calyx 4-parted; stameus 4, inflexed in the bud. Pistillate flowers in axillary, peduncled, capitate clusters: calyx 4-parted. orary sessile, style long; calyces becoming thickened and fleshy in fruit and aggregated into a large, dense, globular head.** 
1. M. aurantiaca, Nutt. Osage Orange. A small tree with ridged, yellowish-brown bark. Leaves minutely downy when young, becoming smooth and shining with age, ovate or ovate-oblong, taperpointed at the apex, obtuse or subcordate at the base, entire, petioled. Staminate racemes about 1 in. long. Pistillate flower clusters about 1 in. in diameter. Fruit yellowish, tubercled, 3-4 in. in diameter. In rich soil. Native in Texas and extensively planted for hedges. Wood very durable when exposed to the weather, and therefore used for fence posts. As the wood does not swell or shrink with changes in its moisture, it is highly valued for wheel hubs, etc.*

\section{BROUSSONETIA, L'Her.}

Small trees with milky juice. Leaves alternate, petioled; flowers diœcious. Staminate in cylindrical spikes, with a 4-cleft calyx, 4 stamens, and a rudimentary ovary. Pistillate flowers in capitate clusters. Calyx 3-4-toothed. Ovary stalked, style 2-cleft, fruit in a globular head.*

1. B. papyrifera, Vent. Paper Mulberry. A round-topped tree with yellowish-brown bark. Leaves cordate, often irregularly 2-3lobed, serrate, rough above, downy beneath, long-petioled. Staminate spikelets peduncled, 2-3 in. long. Pistillate heads stout, peduncled, about 1 in. in diameter. Introduced from Asia and very common S. about old dooryards.*

\section{CANNABIS, Tourn.}

Coarse herbs with very tough, fibrous bark. Leaves usually opposite, palmately compound. Flowers small, diœcious, greenish, the staminate ones in compound racemes or panicles, the pistillate ones in spikes. Calyx of the staminate flowers of 5 sepals, that of the pistillate flowers of 1 large sepal which covers the ovary and the akene.

1. C. sativa, L. Сомmon Hemp. An erect plant, 4-8 ft. high. Leaves large, petioled, of 5-7 lanceolate, irregularly serrate or toothed leaflets. Cultivated from Europe, S. and W., for its fiber, and sometimes runs wild along roadsides in rich soil.

\section{URticacez. Ne. Netle Family.}

Herbs with watery juice, stem and leaves often clothed with stinging hairs. Leaves undivided, stipulate. Flowers 
small, greenish, imperfect, apetalous in axillary clusters. Calyx of the staminate flowers 4-5-parted or 4-5-sepalous; stamens as many as the sepals and opposite them, filaments inflexed in the bud and straightening at maturity, anthers 2-celled. Calyx of pistillate flowers 2-4-sepalous; ovary sessile, 1-celled, stigma simple or tufted. Fruit an akene commonly enclosed in the dry, persistent calyx.**

\section{URTICA, Tourn.}

Annual or perennial herbs. Leaves with stinging hairs, opposite, petioled, several-nerved, dentate, or incised, stipulate. Flowers monœcious or diœcious. Calyx of the staminate flowers 4-parted; stamens 4, inserted around a rudimentary ovary. Pistillate flowers with 4 unequal sepals, the inner ones dilated in fruit; akenes smooth, compressed.*

1. U. urens, L. Syall Netrle. Annual ; stem stout, 4-angled, hairy, 12-18 in. tall, with few stinging hairs; branches slender. Leares elliptical or ovate, serrate or incised, 3-5-nerved, acute or obtuse at the ends, thin, hairy ; petioles often as long as the blades ; stipules short. Flower clusters axillary, in pairs, loose, mostly shorter than the petioles. On damp soil in waste places.*

\section{LORanthace E. Mistletoe Family.}

Parasitic shrubs or herbs, leaves opposite, leathery, without stipules. Flowers monœcious or diœcious, clustered or solitary; perianth of both calyx and corolla, or of a calyx only, or sometimes wanting; calyx-tube adnate to the ovary, sepals 2-8. Stamens as many as the sepals, and opposite them; ovary 1-celled, orule 1 . Fruit a berry.*

\section{PHORADENDRON, Nutt.}

Evergreen, shrubby plants, parasitic on trees; branches greenish, jointed, and very brittle. Leaves leathery. Flowers diøecious, in short jointed spikes. Staminate flowers globular, calyx 2-4-lobed, stamens sessile at the base of the lobes, 
anthers transversely 2-celled. Pistillate flowers with the calyx-tube adnate to the ovary, stigma sessile, berry 1-seeded.*

1. P. flavescens, Nutt. American Mistletoe. Very round, bushy; branches very brittle at the joints, opposite or whorled, 6 in. to $2 \mathrm{ft}$. long. Leaves flat, leathery, or somewhat fleshy, nearly veinless, obovate, entire, with short petioles. Flowering spikes solitary or $2-3$ together in the axils of the leaves. Berry roundish, white, glutinous. Parasitic on many deciduous trees.*

\section{SANTALACE瓜. Sandalwood Family.}

Herbs, shrubs, or trees with entire leaves. Flowers usually small. Calyx 4-5-cleft, its tube adnate to the ovary. Corolla wanting. Stamens as many as the calyx-lobes and opposite them, inserted on the margin of a fleshy disk. Style 1. Ovary 1-celled, with 2-4 ovules borne at the top of a free central placenta. Fruit 1-seeded.

\section{COMANDRA, Nutt.}

Low, smooth perennials with herbaceous stems, rather woody below, often parasitic. Leaves alternate and nearly sessile. Flowers nearly white, in small umbel-like clusters, perfect. Calyx bell-shaped at first. Stamens borne on a 5-lobed disk which surrounds the pistil, anthers connected by a tuft of hairs to the calyx-lobes.

1. c. umbellata, Nutt. Bastard Toad-Flax. Plant 8-10 in. high, with very leafy stems. Roots attached to the roots of trees, from which they draw nourishment. Leaves oblong or oblanceolate, pale, nearly $1 \mathrm{in}$. long. Umbel-like clusters about 3-flowered, longer than the leaves. Rocky, dry woods.

\section{ARISTOlOChiace庄. Dutchman's Pipe Family.}

Herbaceous plants, stemless or with twining and leafy stems. Leaves alternate, without stipules, petioled, mostly roundish or kidney-shaped. Flowers axillary, solitary or clustered, perfect, regular or irregular. Calyx tubular, 3 or 
6 lobed, usually colored. Petals none. Stamens 6-12, inserted on the ovary. Pistils 1 , ovary mostly 6-celled, many-seeded.*

\section{ASARUM, Tourn.}

Perennial, stemless, aromatic herbs, with slender, branching rootstocks. Leaves long-petioled, from kidney-shaped to halberd-shaped. Flowers axillary, peduncled. Calyx regular, 3-lobed, withering-persistent. Stamens 12, the filaments partially united with the style and usually prolonged beyond the anthers. Ovary 6-celled with parietal placentæ, many-seeded. Mature capsule roundish, often somewhat fleshy.*

1. A. canadense, L. Wild Gixger. Plant soft, hairy. Leaves 2. large, kidney-shaped, on long petioles, with the flower borne on a short peduncle between them. Flower greenish outside, brownishpurple inside. Calyx-tube wholly adnate to the orary, calyx-lobes taper-pointed, widely spreading, reflexed at the tip. Rich, shady woods, common $\mathrm{N}$.

2. A. virginicum, L. Virgivia Asarcm. Leares erergreen, 1-3 to each plant, smooth, mottled, round-cordate, entire, 2-3 in. long and broad; petioles smooth or downy along one side, 3-7 in. long. Flowers nearly sessile, greenish without. dull purple within, $\frac{2}{3}-\frac{3}{4}$ in. long, tube inflated below, narrow at the throat, lobes spreading. Rich, shady woods.**

\section{ARISTOLOCHIA, Tourn.}

Erect or twining perennial herbs or woody vines. Leaves alternate, heart-shaped at the base, palmately nerved, petioled, entire. Flowers irregular, solitary, or in small clusters. Calyx more or less adnate to the ovary, tubular, irregular. Stamens mostly 6, sessile, adnate to the angled and fleshy 3-6-lobed or angled stigma. Capsule naked, 6-valved, seeds very numerous.*

1. A. Sipho, L'Her. Detchirax's Pipe. Pipe Vine. A tall climber. Leares dark green. smooth, round-kidney-shaped, sometimes $1 \mathrm{ft}$. wide. Peduncles 1 -flowered, with a single clasping bract. Calyx $1 \frac{1}{2} \mathrm{in}$. long, bent into the shape of a pipe, its border abruptly spreading. lirownish-purple. Rich woods, often cultivated.

2. A. tomentosa, Sims. Detchias's Pipe. Stem woody, climbing high. lranches and leaves densely woolly: Leares heart-shaped, prominently reined, $3-5$ in. long and broad. Flowers axillary, 
mostly solitary, on slender peduncles. Calyx bent in the shape of a pipe, yellowish-green with a dark purple throat, limb unequally 3 -lobed, rugose, reflexed. Anthers in pairs below the 3 spreading lobes of the stigma. Capsule oblong. Stems sometimes $30 \mathrm{ft}$. long. Rich woods S.*

\section{POLYGONACE $Æ$. BuCKwheat Family.}

Herbs with alternate, entire leaves and usually with sheathing stipules above the swollen joints of the stem. Flowers apetalous, generally perfect, with a 3-6-cleft calyx, generally colored and persistent. Fruit a compressed or 3-angled akene, enclosed in the calyx. Seeds with endosperm, which does not generally enclose the embryo. Stamens $4-12$, on the base of the calyx.

\section{RUMEX, L.}

Coarse herbs, many of them troublesome weeds. Flowers small, usually green or greenish, generally in whorls borne in panicled racemes. Calyx of 6 nearly distinct sepals, the 3 inner larger and more petal-like than the 3 outer, and one or more of them usually with a little knob or tubercle on its back. Stamens 6. Styles 3. Stigmas short, fringed. Fruit a 3 -angled akene, closely covered by the 3 inner calyx-lobes, enlarged and known as valves.

1. R. Acetosella, L. Sheep Sorrel. Erect annual or perennial herbs with creeping rootstocks. Stem simple or branched, smooth. Leaves petioled, narrowly halberd-shaped, usually widest above the middle, the apex acute or obtuse, upper stem-leaves often nearly linear and not lobed. Flowers diøcious, small, in terminal, naked, panicled, interrupted racemes. Calyx greenish; the pistillate panicles becoming reddish. Fruit less than $\frac{1}{12}$ in. long, granular, longer than the calyx. A common introduced weed, in dry fields and on sour soils. Foliage very acid.*

2. R. verticillatus, L. Swamp Dock. Perennial, stem stout, smooth, erect or ascending, 3-5 ft. tall. Lower leaves oblong, obtuse at the apex and usually heart-shaped at the base, longpetioled, often 12-18 in. long, upper leaves narrower and often acute at both ends. Flowers perfect or somewhat monœcious, in dense whorls, pedicels slender, $\frac{1}{2}-\frac{2}{3}$ in. long, tapering downward, 
reflexed at maturity. Calyx green, the valres broadly triangular, alruptly pointed, reticulated, a distinct long and narrow tubercle on the back of each. Swamps and wet ground.*

3. R. crispus, L. Yellow Dock. Stout, smooth, 3-4 ft. high. Leaves lanceolate, margins very wavy, acute, the lower more or less heart-shaped. Root long, tapering gradually downward, yellow, very tough. Flowers in whorls crowded in long, straight, slender racemes. Valves roundish heart-shaped, mostly tubercled. A very hardy weed, introduced from Europe.

\section{POLYGONUM, $\mathrm{L}$.}

Annual or perennial, terrestrial or aquatic herbs, with enlarged joints and simple, alternate, entire leaves; the sheathing stipules often cut or fringed. Flowers perfect, usually white or rose-colored, each flower or cluster subtended by a membranaceous bract, similar to the stipules of the leaves. Calyx mostly 5-parted, the divisions petal-like, erect and persistent. Stamens 3-9. Styles 2-3-parted. Fruit lens-shaped or 3-angled.*

1. P. aviculare, L. KNot-GrAss. Annual or perennial. Stem prostrate or ascending, diffuse, smooth, 6-24 in. long. Leaves small, lanceolate or linear-oblong, obtuse, nearly or quite sessile. Stipules thin and dry, 2-3cleft or cut. Flower-clusters axillary, 1-5flowered, flowers inconspicuous, nearly. sessile. Calyx greenish-white, 5-parted, the lobes with white or colored borders. Stamens 5-8. Style 3-parted; akene 3-angled, not shining. A common weed in dooryards and where the ground is trampled.*

2. P. Dumetorum, L. False Buckwheat. Perennial; stems slender, twining, branched, 2-10 ft. long. Leaves orate,

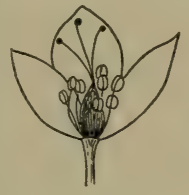

$A$

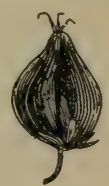

$B$

Frg. 10, - Buckwheat.

$A$, flower, longitudinal section ; $B$, fruit (both somewhat enlarged). taper-pointer, heart-shaped to halberd-shaped at the base, longpetioled. Stipules cylindrical, truncate. Flowers in axillary, more or less compound and leafy racemes. Calyx greenish-white, the outer lobes winged and forming a margin on the pedicel. Stamens 8. Stigmas 3: akene 3-angled, black, smooth, and shining. Margins of fields and thickets.* 
26. Chenopodiace 2 . Goosefoot Family.

Herbs or shrubs. Leaves simple, alternate, without stipules. Flowers small, regular, either perfect or more or less monœcious or diøcious. Calyx free from the ovary. Corolla wanting. Stamens usually 5, opposite the sepals. Styles or stigmas generally 2. Fruit with 1 seed, usually enclosed in a small, bladdery sac, sometimes an akene.

\section{SPINACIA, Tourn.}

Herbs. Flowers diœcious, in close axillary clusters. Staminate flowers 3-5-sepaled, with 4 or 5 projecting stamens. Pistillate flowers with a tubular 2 -toothed or 4 -toothed calyx.

1. S. oleracea, Mill. Spinach. A soft annual or biennial herb. Leaves triangular, ovate, or halberd-shaped, petioled. Cultivated from Asia as a pot-herb.

\section{CHENOPODIUM, Tourn.}

Annual or perennial herbs. Stems erect or spreading. Leaves alternate, usually white-mealy. Flowers small, green-

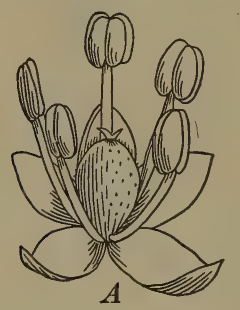

FIG. 11. - Chenopodium.

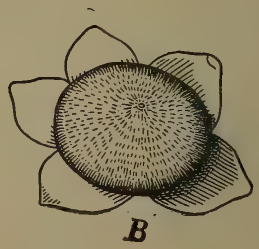

$A$, flower ; $B$, fruit.

ish, in panicled spikes. Calyx 3-5-parted, the lobes often slightly fleshy and keeled. Stamens 5 ; filaments threadshaped. Styles 2-3, distinct or united at the base. Seed lens-shaped.* 
1. C. hybridum, L. Maple-leated Goosefoot. A tall annual herb 2-t ft. high. Leaves 2-6 in. long, thin, bright green, long, taper-pointed, with sereral angled lohes on each side, terminating in pointed teeth. Flower-clusters rather large, consisting of loosely panicled racemes. A rather common weed.

2. C. Botrys, L. Jertsalem OAK. A low spreading plant corered with sticky down. Leares with slender petioles, oblong, sinuately lobed or the lobes pinnate. Flowers in loose, diverging, leafless racemes. The whole plant is sweet-scented. Introduced from Europe and naturalized in gardens and along roadsides.

\section{PHytolacCACE巴E. Pokeweed Family.}

Plants with alternate entire leaves. Flowers perfect, 5parted, with the characters of the Goosefoot Family, but the ovary generally consisting of several carpels, which unite to form a berry.

\section{PHYTOLACCA, Tourn.}

Perennial herbs. Stems tall, branching. Leaves large, entire. Flowers small, in terminal racemes, pedicels bracted. Calyx of $4-5$ nearly equal, persistent sepals. Stamens 5-15, inserted at the base of the calyx. Styles 5-12, recurved at the apex. Fruit a depressed-globose, juicy berry.*

1. P. decandra, L. Pokeweed. Stems erect, smooth, branched abore, usually dark purple, $t-7 \mathrm{ft}$. tall ; root large, fleshy, poisonous. Leares orate-lanceolate, smooth, acute, long-petioled. Racemes peduncled, many-flowered, opposite the leaves, flowers white, becoming purplish. Stamens 10, shorter than the sepals. Styles 10, carpels 10 ; fruit a dark purple berry. A weed on waste ground. The young branches are often eaten like asparagus, and the root, known as "garget root," is used in medicine.*

\section{AIZOACEZE. ICE-PLANT FAmily.}

Mostly fleshy plants, mainly natives of Africa. Flowers often large and showy. Stamens often doubled and some of them petal-like. Ovary 2-many-celled.

[Our only very common genus belongs to a subfamily which has little resemblance to the fleshy "ice-plants," found in some gardens, which best represent the family as a whole.] 


\section{MOLLUGO, L.}

Low branching annuals. Sepals 5 , greenish outside, white inside. Corolla wanting. Stamens 5, alternate with the sepals, or 3, alternate with the cells of the ovary. Capsule 3-celled, many-seeded.

1. M. verticillata, L. CARPET-WEed. Stems branching and forming radiating patches. Leaves clustered in apparent whorls at the joints of the stem, spatulate. Flowers in little sessile umbels at the joints. Stamens commonly 3. A troublesome weed in sandy soil and common on sandy beaches and river banks.

\section{PORtulacaceæ. Purslane Family.}

Generally herbs. Leaves opposite or alternate, entire; stipules dry and membranaceous. Sepals 2 . Petals 4 or more, distinct or united below. Stamens 4 or more, free or adnate to the petals. Ovary usually free, 1-celled; style simple or 3-cleft; ovules 2-many. Capsule opening transversely with a lid, or $2-3$-valved.

\section{CLAYTONIA, Gronov.}

Perennial; stem simple, smooth, erect, 4-10 in. high. Leaves 2, opposite, smooth, succulent. Flowers in a terminal raceme. Sepals 2, ovate, persistent. Petals 5, sometimes coherent at the base. Stamens 5, inserted on the base of the petals. Style 3-cleft, ovary 1-celled, 3-6-seeded.

1. C. virginica, L. Spring Beauty. Stem simple, erect from a deep, tuberous root. 'The 2 stem-leaves narrowly elliptical, $3-6$ in. long, smooth, fleshy; basal leaves occasionally produced. Flowers on short pedicels. Petals white or pink, with darker veins, $\frac{1}{4}-\frac{3}{8} \mathrm{in}$. long, notched. Capsule shorter than the persistent sepals. Common in rich woods.*

2. C. caroliniana, Michx. Northern Spring Beauty. Flowers fewer, smaller, and whiter than No. 1, fragrant. Leaves 1-2 in. long, ovate-lanceolate or spatulate, pretty distinctly petioled. Moist woods, especially $\mathrm{N}$. 


\section{PORTULACA, Tourn.}

Annual; stems low, diffuse, and spreading, fleshy. Leaves entire, mostly alternate. Flowers terminal. Sepals 2, united at the base and coherent with the ovary. Petals usually 5, inserted on the calyx, quickly withering. Stamens 8-20, inserted on the calyx. Style 3-8-parted. Capsule globose, opening by the upper portion coming off like a lid, 1-celled, manyseeded.*

1. P. oleracea, L. Prrsine. Stems prostrate, diffuse, fleshy. Leares alternate, flat, oborate. or wedge-shaped. Flowers solitary, sessile, opening in bright sunshine in the morning, and usually withering before noon. Sepals broad, acute. Petals yellow. Stamens 10-12. Capsule rery-many-seeded, seeds small, wrinkled. A common garden weed.*

2. P. grandiflora, Hook. Gardex Portulaca. Stems fleshy, erect, or ascending, densely hairy or nearly smooth, 3-6 in. long. Leares alternate, crlindrical, fleshy, $\frac{1}{2}-1$ in. long. Flowers 1-2 in. wide, white, yellow; or red, showy, opening only in sunlight. Common in cultiration and often growing spontaneously.*

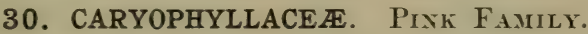

Herbs sometimes woody below, with thickened nodes. Leaves opposite, entire; stipules small and dry or none. Sepals 4-5. Petals 4-כ (rarely 0), usually hy pogynous. Stamens usually 8-10, hypogynous or perigynous. Styles 2-5 (rarely 1). Ovules 2-many. Fruit a capsule.

A.

Sepals distinct or nearly so. Petals (if any) without claus. Capsule several-many-seeded.

Styles usually 3. Capsule ovoid.

Styles 5 or 4: Capsule cylindrical.

Stellaria, I. Cerastium, II.

B.

Sepals united into an urn-shaped tube. Petals none. Fruit 1-seeded. Scleranthus, III. 
C.

Sepals more or less united. Petals with claws. Capsule severalmany-seeded.

(a) Calyx without bracts, its lobes long and leaf-like. Agrostemma, IV.

(b) Calyx without bracts, lobes not leaf-like. Styles 3 or 4 . Silene, V.

(c) Calyx without bracts, lobes not leaf-like. Styles 5 (rarely 4 ). (d) Calyx with little bracts at the base. Styles 2.

Lychnis, VI.

Dianthus, VII.

I. STELLARIA, L. Chickweed.

Slender, usually smooth herbs. Flowers small, white, solitary, or in forking cymes. Sepals 5 (rarely 4 ). Petals 5 (rarely 4), 2-cleft or divided. Stamens 10 (rarely 8,5 , or 3 ), maturing in 2 sets. Styles 3 (rarely 4 or 5 ), opposite the same number of petals; ovary 1-celled, many-ovuled. Capsule short, splitting into as many valves as there are styles.

1. S. media, Cyrill. Сомmon Chickweed. Stem prostrate, 6-18 in. long, with a line or two of hairs along it. Leaves ovate, taper-pointed, the lower petioled, the upper sessile. Petals shorter than the sepals, sometimes wanting. An annual weed, introduced from Europe, common in damp, shady places N.

2. S. longifolia, Muhl. Long-Leaved Stitchwort. Stem slender, usually erect, 8-18 in. high, often sharply 4-angled. Leaves linear or nearly so, spreading. Flower-clusters peduncled, manyflowered, the pedicels spreading. Petals 2-parted, at length longer than the calyx. Perennial in meadows and grassy thickets, especially $\mathrm{N}$.

\section{CERASTIUM, $\mathbf{L}$.}

Annual or perennial. Stems diffuse, usually downy ; leaves opposite. Flowers white, peduncled, in terminal, regularly forking cymes. Sepals 4-5. Petals 4-5, notched or 2-cleft. Stamens 10. Styles 5 or less. Capsule cylindrical, 1-celled, many-seeded.*

1. C. vulgatum, L. Mouse-ear Chickweed. Annual or sometimes perennial. Stems diffuse, tufted, clammy-downy, 6-12 in. 
high. Lower leaves spatulate, the upper oblong. acute, or obtuse ; bracts thin and dry. Flowers in loose cymes, pedicels becoming much longer than the calyx. Sepals lanceolate, acute, about as long as the 2-cleft petals. Slender capsule becoming twice as long as the calyx and curved upward. A common garden weed.*

\section{SCLERANTHUS, $\mathrm{L}$.}

Low tufted herbs. Leaves opposite, clasping, awl-shaped, sharp-pointed. Flowers very small and greenish. Calyxtube funnel-shaped or urn-shaped, hardening into an envelope for the fruit; calyx-lobes $4-5$, short, erect. Petals none. Stamens 1,2 , 5 , or 10 , inserted on the throat of the calyx. Styles 2, thread-like. Fruit 1-seeded, never opening.

1. S. annuus, L. KNAwEL. A much-branched annual weed, 2-8 in. high. Stem and leaves pale green; the leares $\frac{1}{4}$ to $\frac{1}{2}$ in. long, rather prickly pointed. Flowers solitary in the lower axils and somewhat clustered above. Calyx-teeth with narrow whitish margins. Introduced from Europe, common in sandy roads and waste ground E.

\section{AGROSTEMMA.}

Annual ; stem pubescent, branching above. Leaves linearlanceolate or linear, pubescent, sessile. Flowers showy, on long and naked peduncles in terminal corymbs. Calyx tubular, the tube oblong, 10-ribbed, lobes elongated, leaf-like, deciduous. Petals 5, shorter than the calyx lobes, entire. Stamens 10. Styles 5, capsules 1-celled.*

1. A. Githago, L. Corn Cockle. Stem erect, rather slender, 1-3 ft. tall, gray, with long, appressed hairs. Leaves linear-lanceolate, acuminate, erect, 2-4 in. long. Petals obovate, notched, purple. Capsule 5-toothed, many-seeded; seeds black. An introduced weed, common in grain fields.*

\section{SILENE, $\mathrm{L}$.}

Annual or perennial herbs. Stems erect or decumbent and diffuse. Leaves often connate or whorled. Flowers clustered or solitary, usually pink or white. Calyx tubular, more or less inflated, 5 -toothed, 10-nerved, bractless. Petals 5, longclawed, and with the ten stamens inserted at the base of the ovary. Styles 3, ovary 1-celled or 3-celled at the base, opening by 6 teeth, many-seeded. Seeds usually roughened.* 
1. S. Cucubalus, Wibel. Snappers, Rattlebox. A perennial branched herb about $1 \mathrm{ft}$. high. Leaves opposite, smooth, ovate, or ovate-lanceolate. Calyx thin and bladdery, beautifully veined. Petals white, 2-cleft. Capsule nearly globular. In fields and along roadsides, especially eastward. Introduced from Europe.

2. S. pennsylvanica, Michx. Wild Pink. A perennial with low clustered stems (4-8 in.). Rot-leaves wedge-shaped or spatulate, those of the stem lanceolate. Flowers medium-sized, clustered. Petals wedge-shaped, notched, pink, with a crown at the throat of the corolla. Gravelly soil E.

3. S. virginica, L. Fire Pink. A slender perennial with erect stem, 1-2 ft. high. Root-leaves spatulate, the upper leaves oblonglanceolate. Flowers few, peduncled, large and showy, bright crimson. Corolla crowned, petals deeply 2-cleft. Woods.

4. S. Armeria, L. Catchfly, None-so-pretty. A smooth, erect annual or biennial, 6-15 in. high. Several nodes of the stem are usually covered for part of their length with a sticky substance. Leaves very smooth, with a bloom keneath, lanceolate or oblonglanceolate, clasping. Flowers showy, dark pink, nearly $\frac{1}{2}$ in. in diameter, in flat-topped clusters. Calyx club-shaped. Petals somewhat notched. Cultivated from Europe and introduced.

5. S. antirrhina, L. Sleepy Catchfly. Stem smooth, slender, 8-30 in. high, sticky in spots. Leaves lanceolate or linear. Flowers rather few and small, panicled. Calyx ovoid. Petals inversely heart-shaped, pink, opening only for a short time in sunshine. Dry waste ground.

6. S. noctiflora, L. Night-flowering Catchfly. A tall, coarse annual or biennial weed, covered with sticky hairs. Lower leaves spatulate, the upper ones lanceolate and pointed. Flowers large, white, opening at night or in cloudy weather. Calyx-teeth very long and awl-shaped. Petals 2-parted. In fields and gardens, introduced from Europe.

\section{LYCHNIS, $\mathbf{L}$.}

Plants with nearly the same characteristics as Silene, but usually with 5 styles.

1. L. chalcedonica, L. Scarlet Lychnis, London Pride. A tall, hairy perennial (about $2 \mathrm{ft}$.). Leaves lance-ovate, somewhat clasping. Flower-cluster flat-topped and very dense. Flowers bright scarlet, not very large. Petals 2-lobed. Common in old gardens ; from Russia.

2. L. coronaria, Lam. Mullein Prnk. A forking perennial plant, $2 \mathrm{ft}$. high, covered with white, cottony down. Root-leaves very wavy, spatulate; stem-leaves ovate-lanceolate, wavy, clasping. 
Peduncles long, 1-flowered. Flowers about $1 \frac{1}{4}$ in. broad, deep crimson. Calyx-tube very strongly 5 -ribbed, with 5 smaller ones between; calyx-teeth short and slender. Petals somewhat notched. Cultivated in old gardens; from Italy.

\section{DIANTHUS, $\mathbf{L}$.}

Tufted, mostly perennial herbs, often shrubby at the base. Leaves narrow and grass-like. Flowers solitary or variously clustered. Calyx tubular, 5-toothed, with overlapping bracts at the base. Petals 5, with long claws. Stamens 10, maturing 5 at a time. Styles 2 ; ovary 1-celled. Capsule cylindrical, 4-valved at the top.

1. D. Armeria, L. Deptford Pixk. Rather erect, annual, with stiff stems 1-2 ft. high. Leares rery dark green, linear, 1-2 in. long, the lower obtuse, the upper acute. Flowers loosely clustered, small, dark pink. Calyx-tube $\frac{1}{2}-\frac{3}{t}$ in. long, nearly cylindrical. Petals narrow, speckled with rery small whitish dots. In sandy fields eastward. introduced from Europe: sometimes cultivated.

2. D. barbatus, L. Sweet Willian. Perennial, often in large clumps. Stems erect, branching above. smooth, 1-2 ft. tall. Leaves lanceolate, 2-3 in. long, acute. Flowers crimson-pink, white or rariegated, in terminal clusters, hracts linear, as long as the calyx. Common about old gardens; from Europe.**

3. D. plumarius, L. Commox Prsk, Grass Pixk. Leares grasslike, with a whitish bloom. Petals white, pink, or variegated, with the limb fringed. Flowers solitary, fragrant. Hardy perennials, cultivated from Europe.

4. D. Caryophyllus, L. Cariation, Clove Pixk. Much like the preceding species, but with larger fragrant flowers; the broad petals merely crenate. Hothouse perennials (some hardy varieties), cultivated from Europe.

\section{NYMPHEACEE. Water-LILY FaMili:}

Perennial aquatic herbs. Leaves usually floating, often shield-shaped. Flowers borne on naked scapes. Floral envelopes and stamens all hypogynous or else adnate to a fleshy disk that encloses the carpels. Sepals 3-6. Petals 3-5 or often very numerous. Stamens many. Carpels 3 or more, free, in a single circle or united with the disk. Fruit a berry or a group of separate earpels. 


\section{NELUMB0, Tourn.}

Rootstock large and stout. Leaves round, shield-shaped, often raised above the water. Flowers large, raised above water at first, but often submerged after blooming. Sepals and petals hypogynous, numerous, the inner sepals and outer petals not distinguishable from each other. Stamens many, hypogynous. Pistils several, 1-ovuled, borne in pits in the flattish upper surface of a top-shaped receptacle, which enlarges greatly in fruit.

1. N. lutea, Pers. American Lotus. Water Chinquapin. Rootstock often 3-4 in. in diameter, horizontal. Leaves $1 \frac{1}{2}-2 \frac{1}{2} \mathrm{ft}$. broad, prominently ribbed, with much bloom above, often downy beneath. Petioles and peduncles stout. Flowers pale yellow, 5-9 in. broad. Sepals and petals falling quickly. Fruit top-shaped, $3-4$ in. in diameter; the seeds $\frac{1}{2}$ in. in diameter. In ponds and slow-running streams W., introduced from the Southwest.*

\section{NYMPHÆA, Tourn.}

Rootstock horizontal, creeping extensively. Leaves floating, entire, shield-shaped or heart-shaped. Flowers showy. Sepals 4, green without, white within. Petals many, white, becoming smaller towards the center. Stamens many, the outer with broad and the inner with linear filaments. Ovary many-celled, stigmas shield-shaped and radiating. Fruit berrylike, many-seeded.*

1. N. odorata, Ait. White WAter-LILY. Rootstock large, branched but little. Leaves floating, entire, the notch narrow, and basal lobes acute, green and smooth above, purple and downy beneath. Petioles and peduncles slender. Flowers white, very fragranit, opening in the morning, 3-5 in. broad. Fruit globose, seeds enclosed in a membranaceous sac. In ponds and still water.*

\section{NUPHAR, Smith.}

Rootstock horizontal, thick, cylindrical. Leaves heartshaped, floating or erect. Flowers yellow. Sepals 4-6, green on the outside, obovate, concave. Petals many, hypogynous, the inner ones becoming small and stamen-like. Stamens many, hypogynous. Ovary cylindrical, many-celled, stigma disk-shaped. Fruit ovoid.* 
1. N. advena. Yellow Poxd Lily, Cow Lily, Spatterdock. Leares oval or orbicular, rather thick, often downy beneath. Flowers bright yellow, 2-3 in. in diameter, depressed-globular. Sepals 6. Petals thick and fleshy, truncate. Stamens in sereral rows, anthers nearly as long as the filaments. In slow streams and still water.*

\section{RanunCUlace}

Herbs, rarely shrubs, usually with biting or bitter juice. Leaves radical or alternate (in Clematis opposite ; stem-leaves or involucre whorled in anemone); stipules none or adnate to the petiole. Floral organs all distinct and unconnected. Sepals 5 or more (rarely 2-4), falling early, often petal-like. Petals none, or 5 or more (rarely 3 ). Stamens many. Carpels many, 1-celled; stigmas simple; ovules 1 or more. Fruit composed of 1-seeded akenes or many-seeded follicles. Seeds small.

Flowers irregular.

A.

With a spur.

With a hood.

Delphinium, VII. Aconitum, VIII.

Flowers regular.

B.

1. Petals present (in $c$ not very unlike the stamens).

(a) Petals very large and showy.

Pæonia, I.

(b) Petals small, tubular at the tip.

Coptis, IV.

(c) Petals narrow, spatulate, on slender claws.

Actæa, V.

(d) Petals prolonged backward into spurs. Aquilegia, VI.

(e) Petals flat, with a little scale at the base, inside.

Ranunculus, XIII.

2. Petals none, or very small and stamen-like.

(a) Sepals yellow.

Caltha, II.

(b) Sepals greenish or white, falling as the flower opens.

Thalictrum, XIV.

(c) Sepals white or colored, involucre sepal-like. Hepatica, X.

(d) Sepals 4. Plants climbing.

Clematis, XII. 
(e) Sepals 5, white. Flowers axillary and terminal. Pods 2-several-seeded. Isopyrum, III.

$(f)$ Sepals white or colored. Plants not climbing. Akenes more or less tailed with the styles in fruit.

Anemone, IX.

(g) Sepals 5-10, white. Flowers in an umbel. Roots tuberous. Anemonella, XI.

\section{PAEONIA, $\mathbf{L}$.}

Perennial; from thick, fleshy roots ; stems shrubby or herbaceous. Leaves much divided. Flowers terminal, large and showy. Sepals 5, leaf-like and persistent. Petals 5 or more. Pistils 3-5 ; ovaries surrounded by a disk.*

1. P. officinalis, L. Garden PÆONY. Herbaceous; flowering stems 1-2 ft. high. Leaves ample; leaflets lance-ovate, cut or incised, smooth. Flowers double, white or red. Follicles 2, erect, many-seeded. Common in gardens.*

\section{CALTHA, $\mathbf{L}$.}

Smooth perennials with large, roundish leaves. Sepals petal-like, 5-9. Petals none. Pistils 5-10, each consisting of a 1-celled ovary with a nearly sessile stigma. Fruit a many-seeded follicle.

1. C. palustris. Marsh Marigold, Cowslips, Meadow ButterCuP (both the latter unsuitable names, but in common use). Stem hollow, smooth, ascending; leaves smooth, roundish and heartshaped, or kidney-shaped, with crenate, dentate, or nearly entire margins; the broad oval sepals bright yellow. Swamps or wet ground.

\section{ISOPYRUM, $\mathbf{L}$.}

Small, smooth herbs. Leaves $2-3$ times compound, in threes; the leaflets 2-3-lobed. Flowers peduncled, white. Sepals 5, petal-like, soon falling. Petals wanting (in our species). Stamens 10-40. Pistils 3-6 or more.

1. I. biternatum, Torr. and Gr. A delicate, erect plant, with alternate branches, looking much like Anemonella, with clustered stems from perennial tuberous roots. Damp woods. 
IV. COPTIS, Salisb.

Low, smooth perennials with 3-divided root-leaves. Flowers small, white, on scapes. Sepals $\tilde{5}-7$, petal-like, soon falling. Petals 5- $\bar{\tau}$, small, club-shaped, tubular at the apex. Stamens 15-25. Pistils 3-7, stalked. Pods thin and dry, 4 -8-seeded.

1. C. trifolia, Salisb. Gold Thread. A pretty, delicate plant, with slender, 1-flowered scapes, from long, bright-yellow, thread-like rootstocks, which are bitter and somewhat medicinal. Leaves later than the flowers, each of 3 wedge-shaped leaflets, which finally become shining and evergreen. Damp, cold woods and bogs.

\section{ACT AEA, L.}

Perennial; stem simple. Leaves $2-3$, compound in threes. Leaflets ovate, sharply cut or toothed. Flowers white, in a short and thick terminal raceme. Sepals 4-5, soon deciduous. Petals 4-10, small. Pistil single; stigma 2-lobed. Fruit a many-seeded berry.*

1. A. alba, Bigel. BaNeBerRy. Stem erect, smooth or nearly so, 18-24 in. high. Leares large and spreading; leaflets thin. Racemes rery broad. Petals slender, truncate. Pedicels red, thickened in fruiting; berries white. In rich woods, more common S.*

2. A. spicata, var. rubra, Ait. Red Baxeberry. Stem about $2 \mathrm{ft}$. high. Raceme oroid or hemispherical. Petals acute. Pedicels slender. Berries usually red, sometimes white, ovoid. Common N.

\section{AQUILEGIA, Tourn.}

Perennials with leaves twice or thrice palmately compound, the divisions in threes.

Sepals 5, petal-like, all similar. Petals 5, all similar, each consisting of an expanded portion, prolonged backward into a hollow spur, the whole much longer than the calyx. Pistils 5 , forming many-seeded pods.

1. A. canadensis, L. Wild Colcubrive. Flowers scarlet without, rellow within, nodding; spurs rather long.

2. A. vulgaris, L. Gardex Columbine. Flowers often double and white, blue, or purple. Spurs shorter and more hooked. Cultivated from Europe, and sometimes become wild. 


\section{DELPHINIUIM, Tourn.}

Annual or perennial herbs ; stem erect, simple, or branched. Leaves alternate, petioled, palmately divided. Flowers in terminal racemes or panicles, showy. Sepals 5, colored, irregular, the upper one prolonged into a spur. Petals 4, unequal, the two upper ones with long spurs which are enclosed in the spur of the upper sepal, the other two short-stalked. Pistils 1-5; ovaries many-seeded.*

1. D. tricorne, Michx. Dwarf Larkspur. Perennial. Stem simple, from a tuberous root, usually low ( $\frac{1}{2}$ to $1 \mathrm{ft}$. high), but sometimes $2 \mathrm{ft}$. high. Leaves deeply 5-parted, the divisions irregularly 3-5-cleft. Racemes few-flowered, loose. Flowers blue, sometimes white. Pods diverging. Southward.

2. D. azureum, Michx. Blue Larkspur. Perennial. Stem usually simple, slender, downy, 1-2 ft. high. Leaves 2-3 in. wide, $3-5$-parted, the divisions cleft into 3-5 narrow, toothed, or entire lobes. Flowers in a strict, many-flowered, terminal raceme, showy, blue or whitish. Spur ascending, curved ; lower petals bearded, 2cleft. Pods erect. On rich or rocky soil in open places. Northward.*

\section{ACONITUM, $\mathrm{L}$.}

Erect, perennial herbs. Leaves alternate, palmately lobed or cut. Flowers irregular, in panicles or racemes. Sepals 5, the back one large, arched, and hooded, the front one the narrowest. Petals 2-5, small, the 2 back ones clawed and covered by the hood of the sepals; 3 lateral ones small or wanting. Follicles $3-5$. Seeds many, wrinkled.

1. A. Napellus, L. Monkshood. An erect, poisonous plant, 1-2 ft. high. Raceme simple and densely flowered. Flowers dark blue. Cultivated from Europe.

\section{ANEMONE, Tourn.}

Perennial herbs, usually with radical leaves, and 2 or 3 opposite or whorled stem-leaves, constituting an involucre some distance below the flower or flower-cluster. Sepals few or numerous, colored and petal-like. Petals usually wanting. Akenes pointed, or with long, feathery tails.

1. A. patens, var. nuttalliana, Gray. PASQUE Flower. Low plants, 1 in. to $1 \mathrm{ft}$. high, clothed with long, silky hairs. Leaves 
divided in threes. Flower single, large, showy, pale-purplish, borne on a peduncle dereloped before the leares. Carpels many, with long, hairy styles, which in fruit form tails 2 in. long. Prairies and bluffs, N. W.

2. A. caroliniana, Walt. Carolina Anemone. Stem simple, from a roundish tuber, slightly downy, 6-12 in. high, bearing a single flower about $1 \mathrm{in}$. broad. Root-leaves 2-3, long-petioled, compound in threes, the divisions cut or lobed; stem-leaves sessile, compound in threes, the divisions wedge-shaped. Sepals 12-20, white; head of fruit becoming oblong; akenes woolly. In open woods W.*

3. A. cylindrica. Long-Fruited Anemone. Plants about 2 ft. high, branching, with an involucre of long-petioled, divided and cleft leaves, from within which spring several long, naked peduncles. Flowers greenish-white. Sepals obtuse. Head of fruit cylindrical. composed of rery many densely woolly akenes. Dry woods and prairies.

4. A. virginiana, L. Plant hairy, 2-3 ft. high. Peduncles 6-12 in. long, sometimes forking, the first ones naked, the later ones with a little 2-leared involucre at the middle. Leares of the involucre 3 , each 3-parted, the divisions orate-lanceolate, pointed. Sepals acute. Head of fruit ovoid. Woods and meadows.

5. A. quinquefolia, L. Wixd-flower, Wood Axemone. Stem simple, from a thread-like rootstock; involucre of 3 leaves, each petioled, and of 3 leaflets, which are cut, toothed, or parted. Peduncle 1-flowered. Sepals 4-7, white, often tinged with purple outside. Carpels 15 or 20 . This species is very nearly related to, but now regarded as distinct from, the European A. nemorosa.

\section{HEPATICA, Dill.}

Involucre of 3 small, simple leaves, so close to the flower as to look like a calyx. Leaves all radical, 3-lobed, heart-shaped, thick, and evergreen, purplish-red beneath. Flowers single, on rather slender hairy scapes.

1. H. triloba, Chaix. Round-Lobed Hepatica. Lobes of the leares obtuse or rounded; those of the involucre obtuse; sepals $6-12$, varying from blue to white.

2. H. acutiloba, DC. Sharp-lobed Hepatica. Closely similar to the former, except for the acute lobes of the leaves and tips of the involucre.

[Both species have many local names, such as Liverleaf, Liverwort, Noble Liverwort, Spring Beauty.] 


\section{ANEMONELLA, Spach.}

Small, perennial herbs. Leaves compound, smooth, those from the root long-petioled, those of the stem sessile. Flowers in a terminal umbel, slender-pediceled. Sepals petal-like. Petals none. Pistils 4-15 ; stigmas sessile, truncate.*

1. A. thalictroides, Spach. Rue Anemone. Stem slender, 6-10 in. high, from a cluster of tuberous roots. Radical leaves long-petioled, twice compound in threes, leaflets oval, heart-shaped, 3-5-lobed. Stem-leaves 2-3 compound in threes whorled, the long-stalked leaflets veiny, forming an involucre of 6-9 apparently simple leaves. Flowers $3-6$ in an umbel, $\frac{1}{2}-\frac{3}{4}$ in. wide; sepals $6-10$, white. In rich woods.*

\section{CLEMATIS.}

Perennial herbs or slightly woody vines, usually climbing by the leaf-stalks. Leaves opposite, simple, or compound. Sepals 4, petal-like. Petals very small or wanting. Pistils numerous, tipped by the persistent styles which often become long and plumose in fruit.*

1. C. crispa, L. Marsh Clematis. Stem climbing, a little woody below, slightly downy above, $3-5 \mathrm{ft}$. high. Leaves pinnately compound; leaflets 5-7, varying from lanceolate to ovate, thin, entire, or 3-5-lobed. Flowers showy, perfect, solitary, on long, axillary peduncles. Sepals lanceolate, taper-pointed, thick, wavy on the margins, twice the length of the stamens, light bluish-purple, 1-1 $\frac{1}{2}$ in. in length. Tails of the ripened akenes $1 \mathrm{in}$. long, silky. Rich woods and river banks S.*

2. C. viorna, L. Leather Flower. Stem climbing, nearly smooth, 6-10 ft. long. Leaves usually pinnately compound, the lowest pair often compound in threes and the upper pair simple. Leaflets usually $5-7$, oblong-ovate or oval, acute, firm, entire, or lobed. Calyx bell-shaped, nodding; sepals ovate, taper-pointed with a short, recurved point, thick and leathery, reddish-purple, $1 \mathrm{in.} \mathrm{long.}$ Tails of the akenes plumose, $1 \frac{1}{2}$ in. long, brownish. On river banks and rich soil.*

\section{RANUNCULUS, Tourn.}

Annual or perennial herbs. Leaves alternate, usually deeply lobed or parted. Flowers axillary or in corymbs, white or yellow. Sepals 3-5. Petals 3-5, flat, with a small 
pit or scale inside at the narrowed base. numerous. Pistils few or several in a head. Akenes flattened, pointed.*

1. R. pusillus, Poir. Low Spearwort. Perennial. Stems several, erect or ascending, branched, smooth, 6-15 in. high. Leaves entire or slightly toothed, the lower round or cordate, long-petioled, the upper lanceolate or elliptical, nearly or quite sessile. Flowers very small, about $\frac{1}{6}$ in. wide, yellow. Petals $1-5$, as long as the sepals. Stamens $3-10$. Akenes smooth, with a very short point. On muddy banks.*

2. R. abortivus, L. Small-Flowered Crowfoot. Perennial. Stems smooth, branching, 12-18 in. high. Root-leaves round-cordate, crenate, petioled. Stem-leaves 3-5-parted, with wedge-shaped or linear divisions, sessile. Flowers very small, pale yellow. Sepals reflexed, longer than the petals. Akenes in a globose head, smooth, without a beak. Common on wet ground and waste places.*

3. R. recurvatus, Poir. Hooken Crowfoot. Perennial. Stem erect, hairy, 1-2 ft. high. Leaves all nearly alike, petioled, 3-5-lobed with the lobes wedge-shaped, cut or toothed at the apex. Flowers small, pale yellow. Petals minute, shorter than the reflexed sepals. Akenes in a globular head, smooth, with a slender, recurved beak. On low ground.**

4. R. pennsylvanicus, L. Bristly Crowfoot. Perennial. Stems rough-hairy, erect, $2-3 \mathrm{ft}$. high. Leares compound in threes, on long and very hairy petioles; leaflets long-stalked, 3-parted, the divisions sharply lobed or toothed. Flowers small. Petals yellow, shorter than the sepals. Akenes flat, smooth, in oblong heads, beak broad and straight. On low ground.*

5. R. bulbosus, L. Bulbous Buttercup, Early Buttercup. Stem upright, from a solid bulb about as large as a filbert, about $1 \mathrm{ft}$. high, hairy. Root-leaves 3-divided, the divisions lobed and cleft. Peduncles furrowed. Flowers large and showy ( $\frac{1}{2}$ to 1 in. in diameter). Sepals strongly reflexed. Petals roundish, wedge-shaped at the base. Akenes with a rery short beak. Introduced from Europe. Common in grass fields in New England.

6. R. acris, L. Tall Buttercup. Erect, hairy, 2-3 ft. high. Leaves 3-7-parted, the divisions of the lower ones wedge-shaped, deeply cut and lobed. Peduncles not furrowed. Sepals spreading, downy. Petals obovate, a little smaller and paler yellow than in No. 5. A common weed, introduced from Europe, in grass fields and elsewhere, especially eastward. 


\section{THALICTRUM, L.}

Erect perennial herbs. Leaves compound, with stipules. Flowers in panicles or racemes, often somewhat monoecious or diøecious, wind-fertilized. Sepals 4-5, petal-like. Petals none. Stamens many. Carpels few or many ; ovule 1. Fruit a small head of akenes. [The following species are both usually diøcious.]

1. T. dioicum, L. Early Meadow Rue. Plant 1-2 ft. high, smooth and pale or with a bloom. Leaves all petioled, most of them thrice compound in threes; leaflets thin and delicate, roundish, 3-7lobed. Flowers in slender panicles, purplish or greenish ; staminate ones with slender, thread-like filaments, from which hang the conspicuous yellowish anthers. Rocky woods and hillsides.

2. T. polygamum, Muhl. Tall Meadow RUe. Stems from fibrous roots, tall and coarse, nearly or quite smooth, $4-8 \mathrm{ft}$. tall. Leaves twice compound, those of the stem sessile, the others longpetioled; leaflets oval or oblong, often cordate, smooth or downy beneath, quite variable in size on the same plant. Flowers small, in large panicles. Sepals 4 or 5, white. Filaments club-shaped. Akenes short-stalked. Thickets and meadows E.

\section{BERBERIDACE ÆE. BARBERRY FAMILY.}

Herbs or shrubs. Leaves alternate, simple or compound, usually without stipules. Sepals petal-like. Petals hypogynous, distinct, their number some multiple of 2,3 , or 4 , never of 5 . Stamens one opposite each petal, anthers opening by 2 uplifted lids. Pistil 1, 1-celled, ovules 2 or more. Fruit a berry or capsule.

\section{BERBERIS, $\mathbf{L}$.}

Spiny shrubs with yellow wood. Leaves spinous-toothed, jointed on the very short petiole, often reduced to 3-7-cleft spines. Flowers in racemes, solitary, or in pairs. Sepals 8-9, the outer minute. Petals 6, each with 2 nectar glands at the base. Stamens 6. Ovules few. Berry 1-2-seeded; seeds bony-coated.

1. B. vulgaris, L. Сommon Barberry. A shrub 4-6 ft. high. Leaves obovate, spinous-serrate; those on the old shoots mere 
spines. Flowers pale yellow, in drooping racemes. Stamens irritable, closing quickly toward the center of the flower when touched. Berry $\frac{1}{2}$ in. long, nearly ellipsoidal in shape, scarlet or orange-scarlet, very acid, eatable when cooked. Cultivated from Europe and introduced in eastern New England and locally in the upper Mississippi valley.

2. B. Thunbergii, DC. A low shrub. Leaves entire, turning red and remaining so for a considerable time in autumn. Flowers solitary or in pairs. Berries bright red, remaining on the branches all winter. Cultivated from Japan.

\section{CAULOPHYLlUM, Michx.}

A perennial smooth herb, $1-2 \frac{1}{2} \mathrm{ft}$. high. Leaf large, single, sessile, thrice compound in threes, borne high up on the stem ; there is also a large, very compound radical leaf. Flowers racemed or panicled, yellowish-green. Sepals 6 , with 3 bractlets. Petals 6, gland-like, somewhat curved inward at the tip, much smaller than the sepals. Pistil 2-ovuled, the ovary soon bursting open and leaving the 2 blue seeds to ripen naked.

1. C. thalictroides, Michx. Blue Cohosh, Pappoose Root. Whole plant purplish and covered with a bloom when young. Flowers appearing before the leaf is fully developed. Rich woods.

\section{PODOPHYLLUM, L.}

Perennial. Stem simple, smooth, erect, 12-15 in. tall, bearing 2 leaves with a large white flower between them. Sepals 6, falling off as the flower opens. Petals 6-9, obovate. Stamens twice as many as the petals. Pistil 1, stigma large, flat, sessile. Fruit berry-like, 1-celled, many-seeded.*

1. P. peltatum, L. MAY-APPLE. Rootstock rather large. Leaves orbicular, shield-shaped, 5-9-lobed and toothed, smooth, 9-12 in. wide. Flowers 1-2 in. wide, on a peduncle 1-2 in. long. Stamens prominent, anthers opening longitudinally. Fruit $1 \frac{1}{2}-2$ in. long, oral, fragrant, edible ; each seed surrounded by a pulpy covering. In rich woods. The roots and leaves are used in medicine.*

34. magnoliace死. Magnolia Family.

Trees or shrubs. Leaves alternate, not toothed or serrate. Flowers solitary, large, and showy. Floral envelopes and 
stamens hypogynous. Calyx and corolla colored alike, the parts of the perianth forming 3 or more circles of 3 parts each. Stamens many. Carpels many, usually cohering over the long receptacle and forming a sort of cone-shaped fruit, which may be either fleshy or dry.

\section{MAGNOLIA.}

Aromatic trees or shrubs; leaves alternate, often in clusters at the ends of the branches, entire, usually thick and leathery; stipules large, quickly deciduous ; flowers terminal, showy, perfect; sepals 3 , caducous ; petals $6-12$, in 2-4 rows, concave; stamens numerous ; ovaries numerous, 1 -celled, 2 -seeded, the mature follicles opening at the beak, and the fleshy seeds remaining for some time suspended by slender threads.**

1. M. grandiflora, L. Large-Flowered Magnolia. A large tree. with spreading branches and a rounded top; bark nearly smooth. Leaves very thick, evergreen, smooth and shining above, rusty-downy beneath, entire, oval or oblong, 6-9 in. long. Flowers white, very fragrant, 6-9 in. in diameter. Petals 9 or more, obovate, concave. Fruit a rusty-downy cone 3-4 in. long, seeds bright scarlet. Common on light soils in Arkansas and the Gulf States.*

2. M. Fraseri, Walt. Long-Leaved Umbrella Tree. A small tree with a slender trunk and widely spreading branches. Leaves clustered at the ends of the branches, deciduous, oblong or obovate, contracted, cordate and eared at the base, smooth on both sides, $8-12$ in. long ; petioles slender. Flowers white and fragrant, 6 in. broad. Petals longer than the sepals, spatulate or oblong, obtuse at the apex, narrowed at the base. Cone 3-4 in. long, pink at maturity. In rich woods S.**

3. M. macrophylla, Michx. Large-Leaved Umbrella Tree. A small tree with gray bark. Leaves clustered at the ends of the branches, oblong or obovate, obtuse at the apex, cordate at the base, green and glabrous above, white and downy beneath, $1 \frac{1}{2}-3 \mathrm{ft}$. long; petioles stout. Flowers white with a purple center, fragrant, 8-12 in. wide; petals oblong, obtuse, two or three times as long as the sepals. Cone ovate, 4-6 in. long, bright red at maturity. Shady woods on light soil S.**

4. M. virginiana, L. Sweet Bay. A small tree with light gray bark. Leaves scattered on the branches, evergreen, thick and leathery, oval or oblong, smooth and green above, white and with 
a bloom, downy beneath, 4-6 in. long. Flowers white, fragrant, 2-3 in. in diameter; petals 9. concave. Cone $1 \frac{1}{2}-2$ in. long, pink. Common in swamps and along streams, New York and southward (a few in eastern Massachusetts). The leaves often used in flavoring soups, etc.

\section{LIRIODENDRON, L.}

A large tree with rough, dark-colored bark. Leaves scattered on the branches, deciduous, 3-lobed, truncate, stipuled, petioled. Flowers perfect. Sepals 3, reflexed. Petals 6, erect. Stamens numerous. Ovaries numerous, 2-ovuled, cohering over each other on the elongated receptacle, never opening, deciduous.*

1. L. tulipifera, L. Tulip Tree. The largest tree in the family. Leares roundish in outline, mostly 3 -lobed, the terminal lobe truncate or broadly notched, usually heart-shaped at the base, smooth, green above, lighter beneath. Petioles slender. Flowers terminal, bell-shaped, greenish-yellow marked with orange. Petals obovate, obtuse, about as long as the sepals. Mature cones ovate, acute, 2-3 in. long. Common on low ground, Pennsylvania and S. Often called "white wood" or, incorrectly, "white poplar." Wood valuable for making boxes and light furniture.*

\section{Calycanthaces. Calycanthus Family.}

Shrubs. Leaves opposite, entire, without stipules. Flowers solitary, often sweet-scented. Sepals and petals numerous, the outer sepals bract-like. Stamens many, short, the inner ones usually sterile. Ovaries several, inserted on the inside of an irregular, hollow, pear-shaped receptacle something like a large rose-hip, forming 1-seeded akenes in fruit.

\section{CALYCANTHUS, $\mathbf{L}$.}

Shrubs, 4-8 ft. tall; branches opposite. Leaves oval, downy beneath, short-petioled; both leaves and bark aromatic. Sepals and petals many, in several rows, somewhat fleshy, indistinguishable. Pistils several, inserted on the inner side of the persistent calyx-tube. Mature fruit pearshaped, dry, enclosing the akenes.* 
1. C. floridus, L. Sweet-scented Shrub, Strawberry Bush, Spice Bush, Shrub. A widespreading bush, 4-8 ft. high; twigs downy. Leaves oval or oblong, acute or taper-pointed, rough above, downy beneath, 2-3 in. long. Flowers 1 in. wide, brownishpurple, very fragrant; sepals united below to form a cup, on the inside of which the other parts of the flower are inserted, cup leafybracted on the outside. Banks of streams and rich hillsides S., often cultivated.*

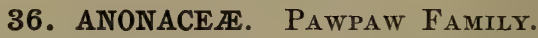

Trees or shrubs. Leaves alternate, entire ; pinnately veined. Flowers perfect, hypogynous, axillary, solitary. Calyx of 3 sepals, corolla of 6 thickish petals in 2 rows. Stamens many, filaments very short. Pistils several or many, becoming fleshy or pulpy in fruit.

ASIMINA, Adans.

Shrubs or small trees. Leaves deciduous. Flowers nodding. Sepals 3, ovate. Petals 6, the 3 outer ones larger and spreading. Stamens very numerous, crowded on the globular receptacle. Ovaries 3-15, sessile, 1-celled, severalovuled. Fruit a large, fleshy, oblong berry, seeds large, horizontal.*

1. A. triloba, Dunal. Pawpaw. A small tree, 10-20 ft. high ; bark nearly smooth, lead-colored. Leaves oblong-obovate, acute at the apex, obtuse at the base, rusty-downy when young and becoming smoother with age, 6-10 in. long. Flowers on branches of the previous season, appearing before or with the leaves; the short peduncles and the sepals brown-downy. Petals purple, obovate, 3-4 times longer than the sepals. Fruit 3-5 in. long, edible when ripe. Common on banks of streams, especially S. and S. W. The bark is very tough and is often used in the place of rope.*

\section{LaURaCe}

Aromatic plants, nearly always trees or shrubs. Leaves alternate, simple, usually entire, and marked with translucent dots. Calyx regular, hypogynous, of 4 or 6 colored sepals. 
Stamens in 3 or 4 circles of 3 each, the anthers opening by valves. Style single. Fruit a 1-seeded berry or stone-fruit.

\section{SASSAFRAS, Nees.}

A tree with rough, yellowish bark and a spreading top. Leaves deciduous, entire or 2-3-lobed. Flowers diœecious, involucrate, at the end of the twigs of the previous season. Calyx 6-parted, persistent in the pistillate flowers. Stamens 9 , in 3 rows. Pistillate flowers with $4-6$ abortive stamens and a single ovary. Fruit a stone-fruit.*

1. S. officinale, Nees. SAssafras. A tree, usually small and slender, but sometimes with a trunk $3 \mathrm{ft}$. in diameter and $125 \mathrm{ft}$. high. Leaves oval, entire, mitten-shaped or 3-lobed, downy when young but becoming smooth with age, dark green above, paler below, petiolate. Racemes several.in a cluster, peduncled ; flowers yellow. Stamens about as long as the sepals. Fruit dark blue, oroid, on thickened, red pedicels. All parts of the tree aromatic; trees producing pistillate flowers rare. Common. The wood is valuable for cabinet-making, and an aromatic oil is extracted from the bark.*

\section{LINDERA, Thunb.}

Shrubs; leaves deciduous, entire. Flowers in lateral, sessile clusters, appearing before the leaves, diœcious or somewhat monœcious. Involucre of 4 scales. Stamens 9 in the staminate flowers, filaments slender. Pistillate flowers with $12-15$ abortive stamens and a single globose ovary with a short style.*

1. L. Benzoin, Blume. SpICE Bush. A shrub, 5-15 ft. high, with smooth bark and slender twigs. Leaves oblong-obovate, acute at the base, pale and downy beneath, becoming smooth when old; petioles short. Flowers about as long as the pedicels, yellow, very fragrant. Ovary about as long as the style. Fruit an obovoid, red stone-fruit about $\frac{1}{3}$ in. long, on a slender pedicel. Banks of streams and damp woods. Twigs and leaves quite aromatic.*

\section{PAPAVERACE瓜. Poppy Family.}

Annual or perennial herbs, often with milky juice. Leaves sometimes all radical, stem-leaves usually alternate without 
stipules. Flowers perfect, regular or irregular. Sepals usually 2, shed as the flower opens. Petals 4-12, falling early. Stamens numerous or 6 (in 2 sets), 4, or 2. Carpels 2-16. Fruit a capsule.

\section{ESCHSHOLTZIA, Cham.}

Annual or perennial herbs. Leaves pale or bluish-green, usually cut into very narrow divisions. Sepals united into a pointed cap, which falls off in one piece as the flower opens. Petals 4, orange or yellow. Stamens many, with long anthers. Stigmas 2-6, spreading. Pods long and slender, grooved. Receptacle often surrounded by a rim on which the calyx rests.

1. E. californica, Cham. Annual or perennial, with rather succulent leafy stems. Flowers large and showy, yellow or orangeyellow. Receptacle top-shaped, with a broad rim. Cultivated from California.

\section{SANGUINARIA, Dill.}

Perennial. Rootstock thick, horizontal, joints and scars of previous growths persistent several years ; juice orangecolored. Leaves on long petioles, kidney-shaped. Scape 1-flowered. Sepals 2, falling off as the flower opens. Petals 8-12. Ovary 1, stigmas 2 ; capsule oblong, seeds crested.*

1. S. canadensis, L. BLоODRоoт. Leaves and scape with a bloom; leaves palmately 5-9-lobed, lobes rounded or toothed; scapes naked, nearly as long as the petioles. Flowers white, 1 in. or more wide. Petals oblong or obovate, quickly deciduous. Capsule 1-celled, 2-valved, the valves separating from the persistent placentæ at maturity. In rich, open woods.*

\section{CHELIDONIUM, $\mathrm{L}$.}

Erect, branched, perennial herbs with yellow juice. Leaves much divided. Flowers yellow. Sepals 2, falling as the flower opens. Petals 4. Ovary 1-celled; style dilated at the top, with 2 adnate stigmas. Capsule linear.

1. C. majus, L. Celandine. Stem 1-2 ft. high, brittle, slightly hairy, leafy. Leaves once or twice pinnate. Flowers small. A rather common weed in yards and along fences. Introduced from Europe. 


\section{PAPAVER.}

Annual or perennial herbs with milky juice. Stem erect, smooth, or rough-hairy, branching above. Leaves more or less lobed or dissected. Flower-buds nodding, flowers showy. Sepals commonly 2, falling off as the flower opens. Petals 4-6. Stamens many. Stigma disk-like, ovules many, borne on many inwardly projecting placentæ.*

1. P. somniferum, L. Opium Poppy. Annual; stem erect. branched above, smooth and with a bloom, 2-3 ft. high. Leaves oblong, irregularly lobed or cut, sessile, clasping. Flowers nearly white, with a purple center, large and showy, on long peduncles. Capsule globose, seeds minutely pitted. About old gardens and waste places. Cultivated in southern Asia, where the juice of the capsules is dried to make opium.*

2. P. dubium, L. Cons Poppy. Annual ; stem slender, branching, 1-2 ft. tall. Leaves pinnatifid, the lower petioled, the upper sessile. Flowers large and showy, usually red; capsule longobovoid, smooth. In cultivated ground. Both the species named are often cultivated in gardens and produce double flowers.*

3. P. orientale, L. Oriental Poppy. A large, rough-hairy perennial. Leaves large, deep green, almost pinnate. Flower very large, deep red. Cultivated from the eastern Mediterranean region.

4. P. nudicaule, L. ICelaxd Poppy. A delicate but roughhairy perennial plant. Leaves all radical, pale, pinnately cut. Flowers yellow-orange or white, borne singly on rather slender, hairy scapes. Cultivated from Europe.

\section{DICENTRA, Borkh.}

Smooth, delicate herbs with watery juice. Leaves compound in threes and finely cut. Flowers racemed, nodding. Sepals 2, small and scale-like. Petals 4, slightly united to form a heart-shaped or 2-spurred corolla (Fig. 12), the inner pair spoon-shaped, enclosing the stamens and pistil. Stamens 6 ; the filaments somewhat united into 2 sets, and the anthers in 2 sets close to the stigma. Stigma 2-crested. Pod 10-20seeded.

1. D. Cucullaria, DC. Detchman's Breeches, Breeches Flower. A low, stemless perennial, with a delicate scape and a cluster of root-leaves with linear divisions from a sort of bulb made 
of small, scaly grains. Flowers in a $4-10$-flowered simple raceme, not fragrant. Spurs of the corolla longer than the pedicels; corolla mostly white with a yellowish tip. Rich woods, common.

2. D. canadensis, DC. Squirrel Corn, Wild Hyacinth. A low, stemless perennial, with scape and leaves much as in No. 1, and with small yellow tubers looking like grains of corn scattered along the underground shoots. Corolla only heart-shaped at the base, whitish or flesh-colored, very fragrant. Rich woods.

3. D. spectabilis, DC. Bleeding Heart, Ear Drops. Stems branching, recurved. Leaves large, twice compound in threes, the divisions rather broad, like those of the common peony. Racemes long, drooping, many-flowered. Flowers large, heart-shaped, bright pink. Cultivated from China.

\section{ADLUMIA, Raf.}

A delicate climbing biennial. Leaves thrice-pinnate, cutlobed. Sepals 2, very small. Petals 4, all united into a corolla which is slightly heart-shaped or 2-knobbed at the base, remaining as a spongy covering over the small, few-seeded pod.
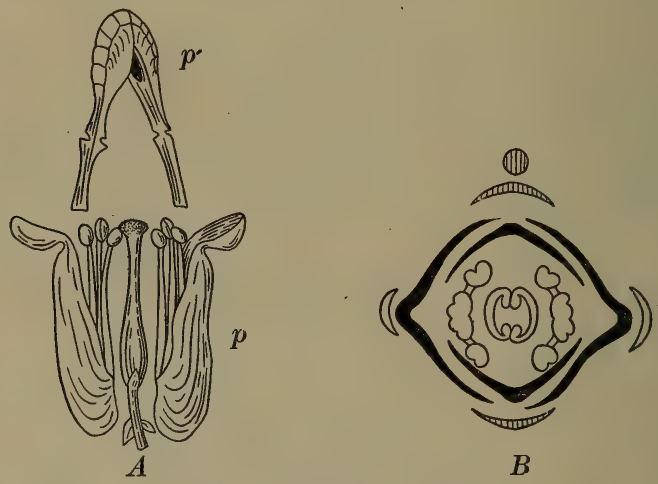

FIG. 12. - Flower of Dicentra.

$A$, view of flower partly dissected ; $p$, the larger outer petals ; $p^{\prime}$, the spoonshaped inner petals ; $B$, floral diagram.

1. A. cirrhosa, Raf. Mountain Fringe, Alleghany Vine. Climbing several feet high by the leaf-stalks. Flowers pinkishwhite. Rocky hillsides, often cultivated. 


\section{CORYDALIS, Vent.}

Leafy-stemmed biennial herbs (the American species). Leaves much divided, alternate or nearly opposite. Racemes terminal or opposite the leaves. Sepals 2, small. Petals 4; corolla with a single spur at the base, on the upper side. Capsule many-seeded.

1. C. glauca, Pursh. Pale Corydalis. Plant erect, covered with a bloom. Flowers pink-purple with yellow tips. Spur of the corolla very short and rounded. Rocky woods.

2. C. aurea, Willd. Golden Corydalis. A low, spreading plant, finally ascending. Corolla bright yellow, 1-2 in. long; the spur shorter than the pedicel, somewhat bent. Shaded, rocky banks.

\section{CRUCifera. Mustard Family.}

Herbs with pungent, watery juice and alternate leaves without stipules. Sepals 4 , often falling off early. Petals usually 4 , arranged in the form of a cross. Stamens 6 , the 2 outer ones shorter than the 4 inner ones. Fruit generally a pod, divided into two cells by a thin partition which stretches across from one to the other of the two placentæ. The flowers throughout the family are so much alike that the genera and species cannot usually be determined without examining the tolerably mature fruit.

\section{A.}

Pods short and flattened, contrary to the partition, splitting open when ripe. Pod roundish. Lepidium, I.

Pod triangular, inversely heart-shaped. Capsella, IX.

B.

Póds globular or cylindrical, splitting open when ripe.

(a) Pods globular. Flowers white. Petals much longer than the calyx.

Cochlearia, II.

(b) Pods cylindrical; seeds ellipsoid. Flowers very small, yellow.

Sisymbrium, III. 
(c) Pods cylindrical; seeds globular. Flowers of moderate size, yellow.

Brassica, IV.

(d) Pods cylindrical. Flowers white. Or pods ovoid or ellipsoid. Flower yellowish. Aquatic plants, or growing in wet soil.

Nasturtium, VI.

c.

Pods elongated, often jointed, tapering toward the tip, never splitting open. Raphanus, V.

D.

Pods flattened parallel to the partition, splitting open when ripe.

(a) Wild species leafy-stemmed; growing in or near water. Pods linear. Cardamine, VII.

(b) Wild species; stems naked below, bearing only 2 or 3 leaves. Pods lanceolate. Dentaria, VIII.

(c) Wild species ; leafy-stemmed; growing on dry ground or rocks. Pods linear; seeds usually winged or margined. Arabis, $\mathbf{X}$.

(d) Cultivated species. Pods round or roundish. Lobularia, XI.

(e) Cultivated species, covered with a grayish down of star-shaped hairs. Pods cylindrical.

Matthiola, XII.

\section{LEPIDIUM, Tourn.}

Annual; stem erect, or sometimes diffuse. Leaves entire, toothed, or pinnately divided. Flowers in a terminal raceme, small, white. Petals short, sometimes wanting. Stamens 2, 4 , or 6 . Pod rounded or obcordate, flattened contrary to the partition.*

1. L. virginicum, L. Peppergrass, Birds' Pepper, TongueGRAss. Stem erect, smooth, much branched, 1-2 ft. high. Lower leaves obovate in outline, pinnately cut with dentate lobes; upper leaves lanceolate, dentate, slightly downy. Flowers on slender pedicels, petals present, sometimes reduced in the later flowers. Stamens 2. Pod round. A weed growing in waste places.* 


\section{COCHLEARIA, Tourn.}

Perennial herbs. Leaves entire or pinnate. Flowers small, white. Sepals short. Petals with short claws. Pods globular or ellipsoid.

1. C. Armoracia, L. Horse-r A dish. A coarse herb with large leares from stout, long, cylindrical rootstocks filled with a very sharp, biting juice. Root-leaves long-petioled, linear-oblong, obtuse, regularly scalloped; stem-leaves sessile. Racemes in panicles. Pods obovoid, on long, slender pedicels. Seeds seldom or never ripening. Probably from Europe ; cultivated and often introduced in damp ground.

\section{SISYMBRIUM, Tourn.}

Annual or biennial herbs. Radical leaves spreading; stemleaves alternate, often eared at the base. Flowers in loose racemes, usually yellow, often bracted. Pods generally narrowly linear, cylindrical or 4-6-angled. Seeds many, ellipsoid, not margined.

1. S. canescens, Nutt. Tansy Mustard. Stem 1-2 ft. high. Leaves twice pinnately cut, usually covered with grayish down. Flowers very small, yellowish. Pods oblong, club-shaped, 4-angled, borne on pedicels projecting almost horizontally from the stem, in long racemes. Common westward.

2. S. officinale, Scop. Hedge Mustard. Stems branching, stiff. Leaves runcinate-toothed or lobed. Flowers very small, pale yellow. Pods somewhat 6-sided, awl-shaped, closely pressed against the stem. An unsightly weed in waste ground, introduced from Europe.

\section{BRASSICA, Tourn.}

Branching herbs. Leaves often pinnately cut. Flowers in racemes, rather large, yellow. Sepals spreading. Pods nearly cylindrical, sometimes tipped with a beak which does not open. Seeds globular.

1. B. arvensis, Boiss. ChArlock. Stem 1-2 ft. high; it and the leaves rongh-hairy. Lpper leaves rhombic-toothed or no. Flowers $\frac{1}{2}-\frac{3}{4}$ in. across, somewhat corymbed, bright yellow. Pods knotty, spreading, at least $\frac{1}{3}$ of each consisting of a 2 -edged, 1-seeded beak. A showy, troublesome weed in grain fields, introduced from Europe. 
2. B. juncea, Coss. Similar to the preceding, but nearly or quite smooth. Pedicels slender. Beak of the cylindric pod slender, conical, not containing a seed. Recently introduced from Asia and becoming very abundant eastward.

3. B. alba, Boiss. White Mustard. Stem 2-5 ft. high, with reflexed hairs. Upper leaves pinnately cut. Pods borne on spreading pedicels, bristly, with a sword-shaped, 1-seeded beak occupying more than half their length. Seeds pale. Cultivated from Europe and introduced to some extent.

4. B. nigra, Koch. Brack Mustard. Stem 3-6 ft. high, somewhat hairy. Lower leaves lyrate with the terminal lobe much the longest, stem-leaves linear-lanceolate, entire or toothed, smooth. Pods awl-shaped, 4-angled, smooth, lying against the stem. Seeds brownish, more biting than in No. 2. Cultivated from Europe and introduced.

\section{RAPHANUS, Tourn.}

Annual or biennial herbs. Root-leaves lyrate. Flowers in long racemes, white or yellow, purple-veined. Sepals erect. Pods rather long, slender-beaked, not splitting open but sometimes breaking across into 1 -seeded joints.

1. R. Raphanistrum, L. Wild Radish, Jointed Charlock. A stout, hairy annual 1-2 ft. high. Leaves cut into remote segments, which are coarsely toothed or serrate; terminal segment largest. Flowers yellow, turning whitish or purplish. Pods necklace-shaped, with a long beak. A common weed eastward, introduced from Europe.

\section{NASTURTIUM, R. Br.}

Annual or biennial, mostly aquatic plants. Stems erect or diffuse, often widely branching. Leaves simple, pinnately lobed. Flowers small, white or yellow. Sepals spreading. Stamens 1-6. Pod short and broad or nearly linear. Seeds numerous in 2 rows in each cell.*

1. N. officinale, R. Br. WAtercress. Aquatic herbs. Stems smooth, diffuse, rooting at the joints. Leaves with 3-9 rounded, pinnate lobes, the terminal lobe much the largest. Racemes elongating in fruit. Petals white, twice the length of the sepals. Pods linear, $\frac{1}{2}-\frac{3}{4}$ in. long, on slender, spreading pedicels. In ditches and slow streams. Often used for salad.*

2. N. palustre, DC. Yellow Watercress. Annual or biennial. Stem erect, branched, slightly downy. Leaves irregularly 
lrrate, the lower petioled, the upper sessile. Flowers small. Petals rellow. Pods linear, spreading, longer than the pedicels. In wet places.*

\section{CARDAMINE, Toum.}

Annual or perennial. Rootstock often scaly or bulb-bearing. Stem erect or ascending, usually smooth. Leaves more or less divided. Flowers in terminal racemes, white or purple. Petals rather large. Stamens 6. Fruit a linear flattened pod. Seeds several, in a single row in each cell.*

1. C. rhomboidea, DC. Brlbots Cress. Perennial. Root tuberous. Stem simple, erect, smooth, without runners, 9-18 in. tall. Lower leares long-petioled, orate, orbicular or heart-shaped, often angled or toothed, the upper short-petioled or sessile, lanceolate or oblong, toothed or entire. Pedicels $\frac{1}{2}-1$ in. long. Petals white, $\frac{1}{4}-\frac{1}{3}$ in. long. Pod erect, linear-lanceolate, tipped by the persistent style. Seeds round-oval. Cool, wet places.*

2. C. pennsylvanica, Muhl. Bitter Cress. Annual. Stem slender, erect, simple, or with a few slender branches, $6-15$ in. tall. Leaves. mostly in a cluster at the base of the stem, pinnately divided, the terminal lobe roundish, the lateral lobes narrower, somewhat hairy above, stem-leaves nearly linear. Flowers small. Petals white, longer than the sepals. Stamens 4. Pods linear, erect on erect pedicels, about 1 in. long. Seeds oval. In wet places.*

\section{DENTARIA, Tourn.}

Stems naked below, 2-3-leared above, from a thickish, more or less knotted or interrupted rootstock. Flowers rather large, in early spring. Pod lance-linear, flattish. Seeds in 1 row, wingless, seedstalks broad and flat.

1. D. diphylla, L. Two-leaved Toothwort, Pepper Root, Crixkle Root. Rootstock long, often branched, toothed, eatable, with a flavor like that of cress or radish. Stem-leaves 2, close together. each composed of 3 orate-diamond-shaped and toothed or crenate leaflets; the root-leaf like the stem-leaves. Flowers white. Damp woods.

2. D. laciniata, Muhl. Crow's Foот. Rootstock short, necklacelike. Stem-leares :-parted; root-leaf often absent. Flowers white or rose-color. Woods. 


\section{CAPSELLA, Medic.}

Annual. Stem erect, downy, with branched hairs. Racemes terminal, becoming elongated in fruit. Flowers small, white. Pod obcordate or triangular, flattened contrary to the partition, shorter than the spreading pedicel.*

1. C. Bursa-pastoris, Moench. Shepherd's Purse. Root long and straight. Stem branching above, downy below, smooth above. Lower leaves forming a rosette at the base of the stem, irregularly lobed or pinnately cut, stem-leaves lanceolate, clasping, toothed or entire. Sepals downy, about $\frac{1}{2}$ as long as the petals. Pod triangular, notched, or cordate at the apex. Seeds several in each cell. A common weed.*

\section{ARABIS, L.}

Annual or perennial herbs, smooth or with forked or starshaped hairs. Radical leaves spatulate; stem-leaves sessile. Flowers usually white. Petals entire, usually with claws. Pods linear, flattened. Seeds often margined or winged.

1. A. hirsuta, Scop. A rough-hairy, erect, leafy-stemmed biennial, 1-2 ft. high. Leaves simple ; stem-leaves oblong or lanceolate, entire or toothed, somewhat clasping, often with an arrow-shaped base. Flowers small, greenish-white, the petals somewhat longer than the sepals. Pods and pedicels upright. Style almost wanting. Seeds roundish, somewhat wing-margined. Rocks, N.

2. A. lævigata, Poir. A smooth, leafy-stemmed biennial 1-2 ft. high, covered with a bloom. Stem-leaves lance-linear, clasping. Flowers small and whitish, the petals hardly longer than the sepals. Pods 2-3 in. long, flattened, spreading, and recurved. Seeds broadly winged. Rocks.

3. A. canadensis, L. Sickle Pod. An upright, leafy-stemmed biennial, 2-3 ft. high, simple or slightly branching above, sometimes slightly hairy at the base. Stem-leaves sessile, oblonglanceolate, pointed at both ends, downy, the lower ones toothed. Flowers small, whitish, the petals twice as long as the sepals. Pods scythe-shaped, much flattened, hanging from hairy pedicels. Seeds broadly winged. Rocky hillsides.

\section{LOBULARIA, Desv. (ALYsSUM, L.)}

Perennial, though usually growing as an annual. Stems branching, diffuse; branches slender. Leaves small, entire, 
downy, with forked hairs. Flowers small, white, in numerous terminal racemes. Petals obovate, entire, twice as long as the sepals. Filaments enlarged below. Pod round, compressed. Seeds 1 in each cell.*

1. L. maritima, Desv. Sweet Alyssim. Stem weak, diffuse, ascending, minutely downy. Lower leares narrowed into a petiole, the upper sessile. Racemes erect, many-flowered. Flowers fragrant, pedicels ascending. Pod often pointed. Common in cultivation and often run wild.*

\section{MATTHIOLA, R. Br.}

Herbaceous or shrubby oriental plants, covered with a down composed of star-shaped hairs. Flowers in showy racemes of many colors, ranging from white to crimson. Stigmas large and spreading. Pods nearly cylindrical, except for a prominent midrib on each valve.

1. M. incana, Br. Commox Stock, Gillyflower. Biennial or perennial, with somewhat woody stems. Cultivated in greenhouses and gardens.

\section{CAPPARIDACE E. CAPER FAMily.}

Herbs (when growing in cool temperate regions), with bitter or nauseous juice. Leaves alternate, usually palmately compound. Flowers often irregular, usually perfect. Sepals 4-8. Petals 4 or wanting. Stamens 6 or more. Ovary and pod 1-celled, with 2 rows of ovules. Seeds kidney-shaped.

\section{POLANISIA, Raf.}

Ill-smelling annual plants covered with glandular or clammy hairs. Sepals distinct, spreading. Petals with claws, notched at the tip. Stamens 8-32, of various lengths. Receptacle not lengthened. Pod linear or oblong, rather large, many-seeded.

1. P. graveolens, Raf. A rery strong-scented, leafy, branching herb, $6-15$ in. high. Leaves with 3 oblong leaflets. Flowers small, pinkish and yellowish-white, in the axils of leafy bracts, in terminal racemes. Stamens $8-12$, not much longer than the petals. Pod about 2 in. long, slightly stalked. Gravelly banks. 


\section{CLEOME, L.}

Mostly annual herbs; stems branched. Leaves petioled, simple, or with 3-7 entire or serrate leaflets. Flowers in bracted racemes. Sepals 4, often persistent. Petals 4, often long-clawed, nearly equal, entire. Stamens 6, filaments thread-like, usually projecting much, but sometimes 1-3 much shorter than the others, inserted on the short receptacle. Ovary on a short stalk with a small gland at its base. Fruit a slender capsule on an elongated stalk.*

1. C. integrifolia, Torr. and Gr. Rocky Mountain Bee Plant. A smooth plant $2 \mathrm{ft}$. or more high. Leaves with 3 leaflets. Flowers pink, showy, in leafy-bracted racemes. Pod oblong to linear, 1-2 in. long. Cultivated as an ornamental plant and also for bees. Common in a wild condition $\mathrm{W}$.

\section{RESEdace瓜. Mignonette Family.}

Annual or perennial herbs, rarely shrubs. Leaves alternate, simple or pinnately cut. Flowers racemed or spiked, bracted. Calyx 4-7, parted, often irregular. Petals 4-7, hypogynous, often unequal and cleft or notched. Stamens usually many, borne on a large one-sided hypogynous disk. Ovary of 2-6 carpels, which are more or less united into a single 1-celled, many-seeded, several-lobed, or horned pistil, which opens at the top before the seeds ripen.

\section{RESEDA, Tourn.}

Annual; stems diffuse, widely branched. Leaves sessile, entire or lobed, smooth. Flowers in close racemes or spikes. Petals 4-7, toothed or cleft. Stamens 8-30, inserted at one side of the flower. Capsule 3-6-lobed.*

1. R. odorata, L. Mrgnonette. Stem widely diffuse, 6-12 in. high, smooth. Leaves wedge-shaped, entire or 3-lobed. Flowers small, greenish-yellow, very fragrant. Petals deeply 7-13-cleft. Often cultivated. From Egypt.* 


\section{SaRraceniace E. Pitcher-Plant Family.}

Perennial, stemless, marsh herbs. Leaves tubular or trumpet-shaped. Flowers single, nodding, on a naked or bracted scape. Sepals 4-5, colored, persistent. Petals 5, deciduous, or sometimes wanting. Stamens numerous. Pistil compound, 5-celled, many-ovuled; style terminal, nearly as broad as the flower, shield-shaped.*

\section{SARRACENIA, Tourn.}

Rootstock short, horizontal ; scape naked. Leaves trumpetshaped, with a wing extending nearly to the base and a broad blade at the apex (see Part II, Ch. XXVI); tube hairy within, with downward-pointing, stiff hairs. Calyx 3-bracted. Petals obovate, drooping or incurved. Style umbrella-shaped, 5 -angled; stigmas at the hooked angles of the style on the under surface. Capsule globose, rough. [The tubular leaves usually contain more or less water and dead insects, the latter having been attracted by a honey-like secretion near the opening. For a full account of the structure and peculiar action of the leaves, see Goodale's Physiological Botany, pp. 347-353.]*

1. S. purpurea, L. Side-SAddLE Flower. Leaves ascending, curred, broadly winged, purple-veined, 4-8 in. long; blade erect, round-cordate, hairy on the inner side. Scapes 12-18 in. tall ; flower deep purple, about 2 in. broad. Style yellowish. Mossy swamps.**

\section{SAXIFRAGACE民. Saxifrage Family.}

Herbs or shrubs. Leaves alternate or opposite, generally without stipules. Sepals 4 or 5, more or less coherent with each other and adnate to the ovary. Petals as many as the sepals and alternate with them. Stamens as many as the petals and alternate with them, or 2-10 times as many. Ovary usually of 2 carpels, united only at the base or more or less throughout. Fruit generally a 1-2-celled capsule, sometimes a berry. Seeds many, with endosperm. 


\section{SAXIFRAGA, L.}

Herbs with simple or palmately cut leaves and generally cymose or panicled flowers. Sepals 5 , more or less united. Petals 5, entire, inserted on the calyx-tube. Stamens 10. Capsule consisting of 2 (sometimes more) ovaries, united at the base, separate and diverging above.

1. S. virginiensis, Michx. Early Saxifrage, Mayflower. Perennial. Stemless, with a cluster of spatulate, obovate, or wedgeshaped root-leaves and a scape 3-9 in. high, which bears a dense cluster of small white flowers, becoming at length a panicled cyme. Petals white, oblong, much longer than the calyx. Rocks and dry hillsides $\mathrm{N}$.

2. S. pennsylvanica, L. Swamp Saxifrage. Perennial. Leaves 4-8 in. long, oblong-lanceolate and tapering to the base, slightly toothed.' Scape 1-2 ft. high, bearing an oblong cluster of small greenish flowers, at length diffusely panicled. Petals greenish-yellow (rarely crimson), linear-lanceolate, hardly longer than the calyx-lobes. Boggy ground.

\section{TIARELLA, L.}

Perennial. Flowers white, in racemes. Calyx white, 5 -parted, nearly free from the ovary. Corolla of 5 very narrow petals, with slender claws, alternating with the calyxlobes. Stamens 10, springing from the calyx-tube and extending outside the flower. Styles 2, long and slender. Ovary 1-celled, 2-beaked. In fruit one of the carpels grows to be much larger than the other, thus making up the main bulk of the thin, dry pod, which has a few seeds attached near the bottom.

1. T. cordifolia, L. False Mitre-wort. Stem 5-12 in. high, usually leafless, sometimes with 1 or 2 leaves. Rootstock bearing runners in summer. Leaves heart-shaped, sharply lobed, the lobes with acute or mucronate teeth, somewhat hairy above, downy beneath. Raceme short and simple. Rocky woods, especially N.

\section{MitellA, Tourn.}

Delicate perennial herbs. Flowers small, pretty, in a simple raceme or spike. Calyx 5-cleft, adnate to the base of the 
ovary. Petals 5, cut-fringed, inserted on the throat of the calyx-tube. Stamens 5 or 10 , not projecting from the calyxtube. Styles 2, very short. Ovary and pod 2-beaked, globular, 1-celled.

1. M. diphylla, L. Two-leaved Bishop's Cap, Fringe Cup, FAIRY CUP. Stemless, with long-petioled, roundish-cordate rootleares, and a scape about $1 \mathrm{ft}$. high, bearing 2 opposite, nearly sessile leaves. Flowers many, racemed, white. Woods.

\section{HEUCHERA, L.}

Perennials with a tall scape and roundish, heart-shaped radical leaves. Flowers rather small, greenish or purplish, in a long panicle. Calyx 5-cleft, the tube below adnate to the ovary. Petals 5 , small, spatulate, inserted with the 5 stamens on the margin of the calyx-tube. Capsule 1-celled, 2-beaked, splitting open between the beaks.

1. H. americana, L. Common Alum Root. Scapes 2-4 ft. high, rather slender, often several from the same root, hairy and glandular. Radical leaves large and long-petioled, abundant, somewhat 7-lobed. Flowers whitish with a tinge of purple, in a loose panicle. Stamens projecting considerably outside the flower, their stamens of a bright terra cotta color. The root is very astringent and is somewhat used as a home remedy. Shaded banks, fence rows, and thickets ; common W.

\section{PHILADELPHUS, L.}

Shrubs. Leaves simple, opposite, 3-5-ribbed, petioled, without stipules. Flowers solitary or in cymes, large, white. Calyx-tube top-shaped, adnate to the ovary, the limb 4-5parted, persistent. Petals $4-5$, rounded or obovate. Stamens $20-40$, shorter than the petals. Ovary 3-5-celled, manyseeded ; styles $3-\check{-}$, more or less united.*

1. P. grandiflorus, Willd. LARGE-FLowered SYRINGA. Shrub, 6-10 ft. high; branches downy. Leaves ovate or ovate-oblong, taper-pointed, sharply serrate, downy, 3-ribbed. Flowers solitary or 2-33 together, white, $1 \frac{1}{2}-2$ in. broad, not fragrant. Calyx-lobes ovate, taper-pointed, about twice as long as the tube. On low ground, S., and cultivated.*

2. P. coronarius, L. Gardex Syringa. Shrub, 8-10 ft. high. Leaves oval or ovate, obtuse at the base, acute at the apex, remotely 
toothed, smooth above, downy beneath. Flowers in terminal racemes, creamy white, $1-1 \frac{1}{2}$ in. wide, very fragrant. Calyx-lobes ovate, acute, longer than the tube. Common in cultivation.*

\section{DEUTZIA, Thunb.}

Shrubs with simple, opposite leaves, without stipules. Flowers all perfect and alike, racemed or panicled, showy. Calyx-lobes 5. Petals 5. Starnens 10, 5 long and 5 short; filaments flat and 3-pronged, the middle prong bearing an anther. Styles 3-5, slender. Pod 3-5-celled.

1. D. gracilis, Sieb. and Zucc. About $2 \mathrm{ft}$. high, loosely spreading. Leaves ovate-lanceolate, sharply serrate, smooth. Flowers white, very numerous. Cultivated from Japan, often in greenhouses.

\section{RIBES, $\mathbf{L}$.}

Shrubs. Leaves palmately veined and lobed, sometimes with stipules. Calyx-tube egg-shaped, adnate to the 1-celled ovary, its 5 lobes usually colored like the petals. Petals 5, small, generally inserted on the throat of the calyx-tube. Stamens 5, inserted with the petals. Styles 2. Ovary 1-celled, with 2 placentæ on its walls, becoming in fruit a pulpy (usually eatable) berry.

1. R. rotundifolium, Michx. Smooth WiLd GooseberRy. Spines few and short, prickles few or absent. Leaves roundish, lobed, with the lobes crenate-dentate, often downy. Peduncles slender ; flowers inconspicuous. Calyx-lobes reflexed. Styles and stamens projecting decidedly from the calyx-tube. Berries smooth.

2. R. Cynosbati, L. Prickly Wild Gooseberry. Spines in pairs. Leaves long-petioled, downy, heart-shaped, cut-dentate. The single style and the stamens not projecting from the calyx-tube. Berries generally prickly, brownish-purple, pleasant-flavored.

3. R. rubrum, L. ReD CuRRANT. Stems more or less reclining. Leaves somewhat heart-shaped, obtusely 3-5-lobed. Racemes drooping. Limb of the calyx wheel-shaped. Berries acid, eatable, red or light amber-colored. Cultivated from Europe, also a variety wild in the northern United States.

4. R. aureum, Pursh. Golden Currant, Flowering C., Missouri C., Clove C." A much taller shrub than the common red currant. Leaves 3-lobed, toothed. Racemes short and loose. Tube 
of the yellow calyx much longer than its limb. Flowers very fragrant. Fruit brownish-hlack, barely eatable.

44. Platanace $\mathbb{E}$. SyCAMore Family.

Trees; with simple, alternate, petioled leaves with stipules, the bases of the petioles covering the buds. Flowers monœcious, in axillary, long-peduncled, globose heads. Calyx and corolla very inconspicuous, each consisting of 3-8 minute scales, or wanting. Stamens as many as the sepals and opposite them. Pistils several, inversely conical, hairy at the base, styles long. Capsules 1-seeded.*

\section{PLATANUS, L.}

Characters of the family.

1. P. occidentalis, L. SycAmore, Buttonwood. A large tree, bark light-colored, smooth, peeling off in large, thin plates. Leaves large, round heart-shaped, angularly lobed and toothed, densely white-woolly when young, becoming smooth with age; stipules large, toothed. Fruit in a globular, drooping head, which remains on the tree through the winter, dropping the seeds very slowly. Common on river banks and in swampy woods.*

\section{ROSACE}

Herbs, shrubs, or trees. Leaves alternate or rarely opposite, simple or compound, with stipules. Calyx 5-lobed. Petals 5, rarely wanting, inserted with the stamens on the edge of a disk that lines the calyx-tuhe. Stamens many, rarely 1 or few. Carpels 1 or more, distinct or coherent, free or adnate to the calyx-tube. Fruit a pome, a stone-fruit or group of stone-fruits, or 1-several akenes or follicles, rarely a berry or capsule. The relation of the parts of the flower to each other and to the receptacle is shown in Fig. 13. 
A.

Ripe carpels not enclosed within the calyx-tube.

1. Fruit dry.

(a) Carpels 1-5, inflated.

Physocarpus, I.

(b) Pods 5-8, not inflated.

Spiræa, II.

(c) Akenes 2-6, styles not lengthening after flowering.

Waldsteinia, VIII.

(d) Akenes many, on a dry receptacle. Styles not lengthening.

Potentilla, X.

(e) Akenes many, on a dry receptacle. Styles lengthening after flowering, forming tails to the akenes.

2. Fruit fleshy.

Geum., XI.

(a) Akenes several-many, becoming little stone-fruits.

Rubus, VII.

(b) Akenes many, dry on ripening, on a fleshy, eatable receptacle.

Fragaria, IX.

(c) Pistil solitary, becoming a stone-fruit. Prunus, XIII.

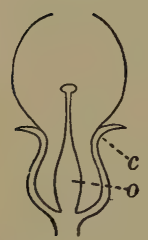

$A$

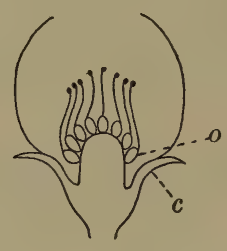

$B$

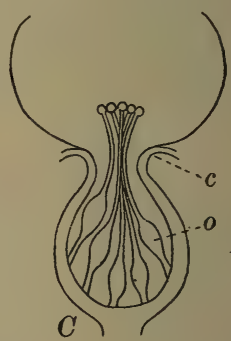

C

FIG. 13. - Pistils in the Rose Family.

$A$, Prunus-type ; $B$, Potentilla-type ; $C$, Rosa-type, $c$, calyx, $o$, ovary.

B.

Ripe carpels enclosed within the calyx-tube.

1. Fruit a pome.

(a) Carpels more than 2-seeded; seeds covered with a mucilaginous pulp. Fruit 5-celled.

Cydonia, III. 
(b) Carpels 2-seeded (except in some cultivated varieties); seeds without pulp. Fruit 5-celled.

Pyrus, IV.

(c) Carpels -2-seeded; fruit 10-celled.

Amelanchier, V.

2. Fruit not eridently a pome or not at all so.

(a) Trees or shrubs. Fruit appearing like a stone-fruit, with a stone usually of $2-5$ bony 1 -seeded carpels united.

Cratægus, VI.

(b) Herbs. Fruit consisting of numerous very small akenes collected on a fleshy, eatable receptacle. Fragaria, IX.

(c) Trees or shrubs. Fruit a simple stone-fruit (plum or cherry).

Prunus, XIII.

\section{PHYSOCARPUS, Maxim.}

Shrubs. Leaves simple, palmately veined and lobed, petioled. Flowers white, in terminal corymbs. Calyx spreading, 5-lobed. Petals 5. Stamens numerous. Pistils 1-5, shortstalked, stigma terminal; ovaries becoming inflated at maturity, 2-4-seeded, splitting open.*

1. P. opulifolius, Maxim. NiNebark. A spreading shrub 3-6 ft. high, the old bark separating into thin strips. Leaves petioled, broadly ovate or rounded, often heart-shaped, 3-lobed, the lobes doubly crenate-serrate : stipules deciduous. Corymbs terminal, peduncled, nearly globose, downy, many-flowered. Pedicels and calyx nearly smooth. Follicles 3-5, much longer than the calyx, smooth and shining, obliquely tipped by the persistent style. Banks of streams, and often cultivated.*

\section{SPIREA, L.}

Shrubs with simple leaves. Flowers perfect, in terminal or axillary racemes or panicles. Calyx 5-cleft, persistent. Petals 5. Stamens numerous. Pistils usually 5 , free from the calyx and alternate with its lobes. Follicles not inflated, 2-several-seeded.*

1. S. salicifolia, L. Willow-LEAfED SPIREA. Shrubs $2-5 \mathrm{ft}$. high, branches smooth; leaves lanceolate to oblong-ovate, smooth or nearly so, sharply serrate, base usually wedge-shaped, pale beneath ; stipules deciduous: flowers white or pink, panicle dense-flowered; follicles smooth. On low ground.* 
2. S. reevesiana, Gard. Bridal Wreath. Shrubs $2-4 \mathrm{ft}$. tall ; branches long, slender, and spreading; leaves lanceolate, serrate, sometimes 3-lobed or pinnatifid, with a bloom beneath; flowers white or pinkish, in axillary racemes or corymbs, often forming long wreaths ; follicles smooth. Cultivated from Europe.

3. s. tomentosa, L. HARDHAck. Erect shrubs; stems densely downy, usually simple; leaves simple, ovate or oblong, serrate, densely rusty downy below, smooth and dark green above; flowers small, pink or purple, in a close panicle; follicles 5, densely downy, several-seeded. On low ground S., and along fence-rows and in pastures $\mathrm{N}$., where it is a troublesome weed.*

\section{CYDONIA.}

Trees or shrubs. Leaves simple, toothed or lobed, stipules deciduous. Flowers usually solitary, white or pink. Calyxtube urn-shaped, adnate to the ovary, 5-lobed, lobes acute, spreading, persistent. Petals 5. Stamens numerous, inserted with the petals on the calyx-tube. Styles 2-5, mostly 5, united at the base. Ovary 5-celled, seeds many in each cell. Fruit a pome, globose, usually depressed or hollowed at the extremities, flesh without hard grains.*

1. C. vulgaris, Pers. Quince. Shrub 6-12 ft. high. Leaves oblong-ovate, acute at the apex, obtuse at the base, entire, downy below. Flowers large, white or pink. Fruit ovoid, downy. Cultivated.*

2. C. japonica, Pers. JAPAN Quince. A widely branching shrub, 3-6 ft. high, branches with numerous straight spines. Leaves ovate-lanceolate, acute at each end, smooth and shining, serrulate; stipules conspicuous, kidney-shaped. Flowers in nearly sessile axillary clusters, bright scarlet. Fruit globose. Common in cultivation.*

\section{PYRUS, L.}

Trees. Leaves simple, stipules small, deciduous. Flowers in cymes, large, white or pink. Calyx urn-shaped, adnate to the ovary, 5-cleft, its lobes acute. Petals rounded, shortclawed. Stamens numerous, borne with the petals on the calyx-tube. Styles 5, distinct or slightly united at the base. Fruit a pome, with about 2 seeds in each carpel.*

1. P. communis, L. PeAr. A tree, often very large, head usually pyramidal; branches often thorny. Leaves thick and leathery, 
ovate or oral, acute, finely serrate or entire, downy when young, becoming smooth with age ; petioles slender. Cymes few-severalflowered, terminal, and at the ends of "fruit spurs" grown the previous season. Flowers white. Strles not united. Fruit obovoid, with hard gritty grains near the core. A European and Asiatic tree common in cultivation.*

2. P. Malus. Apple. A tree with a rounded top and darkcolored bark. Leares oral or orate, obtuse or pointed, dentate or nearly entire, rounded at the base, smooth abore, downy beneath. Cymes few-mant-flowered. Flowers large, white or pink. Calyx downy. Fruit depressed-globose to oroid, hollowed at the base and usually at the apex. Cultirated from Europe and often running wild in old pastures, etc., E.**

3. P. coronaria, L. American Crab Apple. A small tree with smooth bark. Leares triangular or oral-lanceolate, acutish or rounded or a little heart-shaped at the base, cut-serrate and often somewhat 3-lobed, slender-petioled, soon smooth. Flowers large, few in a cluster, pale rose-color, very sweet-scented. Fruit bright green, turning rellowish, sometimes $1 \frac{1}{2}$ in. in diameter, flattened at right angles to the pedicels, very fragrant. Glades, W. N. Y., West and South.

4. P. angustifolia, Ait. NArrow-Leaved Crab Apple. A small tree with smooth, light gray bark. Leares lanceolate or oblong, serrate, downy when young, acute at the base, short-petioled. Corymbs few-flowered. Flowers pink, fragrant, about 1 in. broad. Styles smooth, distinct. Fruit nearly globose, about $\frac{3}{4}$ in. in diameter, very sour. In open woods, Penn., W. and S.*

5. P. arbutifolia, L. f. Chokeberry, Choke Pear, Dogberry. A shrub 5-8 ft. high. Leares oblong or oblanceolate, finely serrate, downy beneath, short-petioled. Flowers in a downy compound cyme, small, white or reddish. Fruit pear-shaped or nearly globular, not larger than a currant, very dark purple, dry and puckery. There is also a smooth-leared rariety with black fruit. Swamps and damp thickets, especially N. E.

6. P. americana, DC. American Mountain Ash. A tall shrub or small tree. Leares odd-pinnate. Leaflets oblong-lanceolate, taperpointed, sharply serrate, smooth, bright green. Flowers small, white, in large, flat, compound crmes. Fruit bright scarlet, not larger than currants. Common $\mathbf{Y}$. and often cultivated.

7. P. Aucuparia, Gaertn. Europeax Mountain Ash or Rowan TreE. Larger than No. 6. Leaflets paler, downy beneath. Fruit larger, about $\frac{1}{2}$ in. in diameter. Cultivated from Europe. 


\section{AMELANCHIER, Medic.}

Shrubs or small trees with smooth gray bark. Leaves simple, sharply serrate, petioled. Flowers white, in racemes. Calyx-tube 5-cleft, adnate to the ovary. Petals oblong. Styles 5, united below. Ovary 5-celled, 2 ovules in each cell, often only 1 maturing. Fruit small, berry-like.*

1. A. canadensis, Torr. and Gr. Service Berry, June Berry, Shad Bush, Sugar Plum, Sugar Pear, Wild Pear. A small tree, branches downy when young, soon becoming smooth. Leaves ovate to elliptical, finely and sharply serrate, acute at the apex, usually obtuse or cordate at the base. Racemes slender, manyflowered, appearing before or with the leaves. Flowers showy. Petals 4 or 5 times the length of the smooth sepals. Fruit globose, dark red, edible. In rich woods ; extremely variable in height, and in shape of leaves.*

\section{CRAT EGUS, L.}

Shrubs or small trees, mostly with numerous strong spines, wood very hard. Leaves serrate, lobed or deeply incised, petioled. Flowers white or pink, in terminal corymbs or sometimes solitary. Calyx-tube urn-shaped, 5-cleft, the limb persistent. Petals round. Stamens few or many. Styles 1-5, distinct; ovules 1 in each cell. Fruit a small pome with bony carpels.* [The species are hard to distinguish and are not very perfectly defined. At present the genus is undergoing a careful revision by Professor C. S. Sargent.]

1. C. coccinea, L. Scarlet-Fruited Thorn, Red Haw. A tall shrub or small tree, with smooth, reddish branches, but the young shoots downy. Leaves thin, roundish-ovate, cut-lobed or sharply toothed, slender-petioled. Flowers large, in a many-flowered corymb. Fruit bright red, nearly globular or obovoid, $\frac{1}{2} \mathrm{in}$. long.

Var. mollis, Torr. and Gr., has the young shoots densely covered with down and fruit twice the length of the preceding, sweet and edible. Common in the Mississippi valley.

2. C. tomentosa, L. Pear Thorn. A small tree, the young shoots, peduncles, and calyx downy or soft-hairy. Leaves large, thickish, ovate or ovate-oblong, downy beneath, doubly serrate or cut-lobed. Flowers later than No. 1, sometimes 1 in. in diameter. Fruit scarlet or orange, rather less than 1 in. long, edible.

3. C. Crus-Galli, L. Cockspur Thorn. Small trees with spreading branches; spines usually numerous, long and stout, but some- 
times few or wanting. Leares thick, oval or obovate, shining above, paler below, obtuse or acute, and sharply serrate at the apex, wedgeshaped and entire at the base. Corrmbs terminal, many-flowered, smooth ; flowers about $\frac{1}{2}$ in. wide; styles 1-3 ; fruit red, subglobose, $\frac{1}{2}$ in. in diameter. Common in open woods.*

4. C. spathulata, Michx. SMall-Fruited Haw. A small tree, young twig's densely downy; spines 1-2 in. long; leaves small, spatulate, crenate at the rounded apex, entire and wedge-shaped below, leathery, smooth; stipules crescent-shaped; corymbs compound, many-flowered; flowers small; calyx-lobes very short; styles 5; fruit red, about the size of a small pea. On river banks.*

5. C. flava, Ait. Yellow HAw. A small tree with rery numerous spines; leares oborate, glandular-serrate at the rounded apex, cuneate below, downy when young; petiole short; corymbs fewflowered, slightly downy; flowers $\frac{1}{2}-\frac{3}{4}$ in. wide; calyx-lobes entire or glandular-serrate ; styles $4-5$; fruit pear-shaped, $\frac{1}{2}$ in. or more in length, greenish-yellow. On sandy soil.*

\section{RUBUS, L.}

Mostly prickly shrubs, producing runners. Leaves alternate, simple or compound; stipules adnate to the petiole. Flowers in terminal and axillary clusters, rarely solitary, white (in one American species [No. 1] purple rose-color). Calyx free from the ovary, with a broad tube; its lobes 5, persistent. Petals 5. Stamens many. Carpels many, distinct, on a convex receptacle. Fruit a cluster of little 1-seeded stone-fruits on a dry or somewhat juicy receptacle.

\section{A. Raspberries.}

Grains of the fruit, when ripe, falling off from the receptacle and leaving the latter with the calyx.

1. Rubus odoratus, L. Flowerixg RAspberRy (often wrongly called Mulberry). Stems shrubby and rather stout, $3-5 \mathrm{ft}$. high, not prickly, the young shoots, peduncles, and calyx covered with sticky glandular hairs. Leaves large, simple, 3-5-5lobed. Flowers showy, rose-purple. 1-2 in. in diameter, on many-flowered peduncles. Fruit flattisli, eatable. Rather common E. and $\mathbf{N}$. and often cultivated.

2. R. triflorus, Richardson. I)wARF RAspberRY (also wrongly known as MCLBERY). A slender trailing plant, almost entirely herbaceous, not prickly but sometimes bristly. Leaves compound, 
usually of 3 but sometimes of 5 thin ovate-lanceolate, frequently unsymmetrical leaflets, which are coarsely doubly serrate and often cleft or lobed, with a shining upper surface. Flowers small, on 1-3flowered peduncles. Fruit of a few loosely cohering grains, eaten by children. Common, especially N., in hilly woods, often forming a dense carpet in the partial shade of pines.

3. R. occidentalis, L. Black RAspberry. Stems long and slender, often recurved and rooting at the tips, armed with weak, hooked prickles. Leaves petioled, 3-5 ovate leaflets, coarsely serrate, white-downy below. Flowers white, in compact terminal corymbs. Pedicels erect or ascending. Fruit black, hemispherical, separating easily from the receptacle. Common on borders of woods Mo. and N., widely cultivated.*

4. R. strigosus, Michx. Red RAspberRy. Stems widely branching, biennial, not rooting at the tips, armed with weak bristles and with a few hooked prickles. Leaves petioled, of 3-5 ovate leaflets which are sharply serrate and sometimes lobed, downy beneath. Flowers in terminal and axillary racemes and panicles, pedicels drooping. Fruit hemispherical or conical, red, separating easily from the receptacle. Common on mountains and burned clearings. Iowa and $\mathrm{N}$. and widely cultivated.*

\section{B. BLACKBERRIES.}

Grains of the ripe fruit falling from the calyx along with the soft, eatable receptacle.

5. R. nigrobaccus, Bailey. High Blackberry. Stem shrubby, erect or bending, 4-10 ft. high, glandular-downy above and with stout, hooked prickles below. Leaves pețioled, of 3-7 ovate leaflets which are acute, irregularly serrate, smooth or soft-hairy. Flowers in terminal, bracted panicles. Petals white, obovate, much longer than the taper-pointed sepals. Fruit large, black, oblong. Common in thickets.*

6. R. villosus, Ait. Low Blackberry, Dewberry. Stems shrubby, trailing widely, from 3-10 ft. long, somewhat prickly. Leaflets usually 3 , but sometimes 5 or 7 , ovate, acute, sharply (and doubly) cut-serrate, thin. Racemes upright on the short branches, 1-3-flowered. Fruit roundish, of fewer and larger grains than No. 5, very sweet when fully ripe. Common N., in stony or gravelly fields.

7. R. cuneifolius, Pursh. Sand Blackberry. Stem shrubby, erect or diffuse, 2-3 ft. high ; prickles straight or recurved. Leaves petioled, 3-5-foliate; leaflets obovate, serrate towards the apex, wedge-shaped towards the base, rough above, white downy-woolly beneath. Racemes mainly terminal, few-flowered. Petals white, 
longer than the sepals. Fruit oroid, black, smaller than the preceding. Common in old fields.*

8. R. hispidus, L. Stem trailing or prostrate, often several feet in length, armed with small, straight, or recurred prickles, and often thickly set with bristles. Leaves petioled, mostly of 3 leaflets ; leaflets obovate, obtuse, rather coarsely serrate. Flowering branches commonly erect, few-flowered, flowers white. Fruit black. Common on dry, sandy soil.*

\section{WALDSTEINIA, Willd.}

Stemless perennial herbs. Leaves 3-5-lobed or divided. Flowers several, rather small, yellow, on a bracted scape. Calyx-tube top-shaped; the limb spreading, with sometimes little bracts alternating with the lobes. Petals 5. Stamens many. Style 2-6. Akenes few, on a dry receptacle.

1. W. fragarioides, Tratt. Barren Strawberry. A low herb with much the appearance of a strawberry plant. Leaflets 3, broadly wedge-shaped, crenate-dentate. Scapes many-flowered ; the flowers rather pretty. Wooded hillsides.

\section{FRAGARIA, Toum.}

Perennial scape-bearing herbs, with runners. Leaves with 3 leaflets ; stipules adnate to the petiole. Flowers (of American species) white. Calyx free from the ovary, 5-parted, 5-bracted, persistent. Petals 5. Stamens many. Carpels many, on a convex receptacle. Akenes of the ripe strawberry many, very small, more or less imbedded in the large, sweet, pulpy receptacle.

1. F. virginiana, Mill. Wild Strawberry. Leaflets thick, oral to obovate, coarsely serrate, somewhat hairy. Scape usually shorter than the petioles, few-flowered. Fruit ovoid, akenes imbedded in deep pits. Common.*

2. F. vesca, L. Ecropean Strawberry. Leaflets ovate or hroadly oral, dentate above, wedge-shaped below, slightly hairy. Scape usually longer than the petioles. Fruit globular or oval, akenes adherent to the nearly eren surface of the receptacle. Common in cultivation. Many of the cultivated varieties of strawberry are hybrids between the two described above. The American form is less hairy than the European and is by some regarded as distinct.* 


\section{POtentilla, $\mathbf{L}$.}

Perennial herbs, rarely shrubs. Leaves compound; stipules adnate to the petiole. Flowers white or yellow, rarely red; solitary or in cymes. Calyx free from the ovary, 5 -cleft, with 5 little bracts alternating with its lobes. Petals 5. Stamens many. Carpels usually many, on a dry convex or concave receptacle; styles falling off from the akenes as they mature.

1. P. arguta, Pursh. Upright Cinquefoil. An erect, stout hairy plant, 1-4 ft. high. Root-leaves long-petioled, pinnate. Stemleaves few, each of 3-7 leaflets, the latter broadly ovate and cuttoothed or serrate, downy underneath. Flowers large, in dense terminal clusters; the petals whitish or cream-color. Rocky hills.

2. P. canadensis, L. Common Cinqueforl. Stems slender, procumbent, silky-hairy, sending out long runners. Leaflets obovate wedge-shaped, appearing like 5 from the divisions of the 2 lateral ones. Peduncles 1-flowered in the axils of the leaves. Flowers yellow. Common in dry pastures and a troublesome weed.

3. P. argentea, L. Silvery Cinquefoil. Stems prostrate or ascending and branching, woolly. Leaflets oblong, wedge-shaped, those of the upper leaves very narrow, with a few large, deeply cut teeth, smooth and green above, silvery beneath, with a dense coat of white wool. Flowers small and somewhat clustered, yellow. Dry fields and roadsides.

\section{GEUM, $\mathbf{L}$.}

Erect perennial herbs. Radical leaves crowded, pinnate, with a very large terminal leaflet. Flowers and fruit much as in Potentilla, but the akenes tailed with the remains of the styles.

1. G. album, Gmelin. White Avens. Stem erect, branching above, smooth or finely downy, 18-24 in. high. Radical leaves pinnate, or the earliest simple and rounded, long-petioled, serrate or dentate, terminal lobe larger than the lateral lobes; stem-leaves short-petioled, 2-5-lobed or parted. Flowers on slender peduncles. Petals white, not longer than the sepals. Styles jointed near the middle, the lower portion persistent and hooked. Ovaries and receptacle hairy, head of fruit globose. Rich woods.*

2. G. virginianum, L. Stem 2-3 ft. high, stout and bristly hairy.. Lower leaves and root-leaves pinnate, varying greatly; upper leaves mostly of 3 leaflets or 3-parted. Petals white or pale yellow, 
small, shorter than the calyx-lobes. Heads of fruit large, on stout, hairy peduncles; the receptacle nearly or quite smooth. Borders of woods and damp thickets.

3. G. rivale, L. Water Avexs, Perple Avens, Chocolate Rоот. Stem $1 \frac{1}{2}-2 \mathrm{ft}$. high, somewhat downy or hairy, simple or nearly so. Root-leares lyrate and somewhat pinmate, with the divisions irregular; stem-leaves few, of 3 leaflets or 3-lobed. Flowers rather large. Petals purplish-yellow, as long as the brownish-purple calyx-lobes. Styles long, purplish; stigmas thread-like, feathered with soft hairs, especially in fruit. Wet meadows.

\section{ROSA, Tourn.}

Erect, running or climbing prickly shrubs. Leaves pinnate, leaflets serrate, stipules adnate to the petiole. Calyx-tube urn-shaped, with a rather narrow mouth. Petals (in single roses) 5. Stamens many, inserted around the inside of the mouth of the calyx-tube. Ovaries many, hairy, ripening into bony akenes, enclosed in the rather fleshy and sometimes eatable calyx-tube.

1. R. blanda, Ait. EArly Wild Rose. Stems 1-3 ft. high, usually without prickles; stipules broad. Flowers generally large, corymbed or solitary; sepals after flowering closing over the mouth of the calyx-tube and persistent. Rocks and rocky shores.

2. R. carolina, L. SWAMP Rose. Stems 4-8 ft. high, with stout and generally recurved prickles. Stipules long and narrow; leaflets commonly downy beneath, finely serrate. Flowers several in a corymb, bright rose-color. Sepals spreading and falling off after flowering. Damp woods and borders of swamps.

3. R. lucida, Ehrh. DWARF WILD Rose. Stems varying in height from less than a foot to $6 \mathrm{ft}$., with stout, somewhat hooked prickles. Stipules rather broad; leaflets small, thickish and glossy above, coarsely toothed toward the tip. Flowers corymbed, or solitary, pale rose-color. Sepals spreading and falling off after flowering. Moist ground and swamps.

4. R. humilis, Marsh. PAstcre Rose. Stem erect, branched, usually armed with stout stipular prickles and with bristles, but sometimes nearly smooth, 1-3 ft. tall. Leaves mostly of 5 leaflets; stipules entire; leaflets oblong-lanceolate or oval, shining above, pale beneath, sharply serrate. Flowers solitary or 2-3 together, $2-3$ in. broad, pink. Peduncles and calyx glandular-downy. Calyxlobes leaf-like, spreading, finally deciduous. Styles distinct: Fruit globose, bristly hairy. On dry soil ; our most conmon wild rose. S.* 
5. R. rubiginosa, L. Sweetbrier. Stem erect or curving, armed with stout recurved prickles. Leaves with 5-7 leaflets, the latter broadly oval, coarsely serrate, glandular-bristly beneath, aromatic. Flowers white or pink. Sepals widely spreading, deciduous. Fruit obovate, slightly bristly. Common in cultivation and sometimes wild.*

\section{PRUNUS, Tourn.}

Trees or shrubs. Leaves simple, with stipules, which are often small or fall off early. Calyx with a bell-shaped or urn-shaped tube and 5-lobed spreading limb, falling off after flowering. Petals 5. Stamens 3-5 times as numerous, or indefinite, inserted on the throat of the calyx-tube. Pistil 1, long-styled, with 2 ovules, ripening into a single stone-fruit.

A. Stone oval, compressed; fruit smooth when ripe. Branches often spiny. (Plums.)

1. P. americana, Marsh. Wild Plum. A small tree, bark thick and rough, branches spiny. Leaves ovate or obovate, acuminate at the apex, rounded or cordate at the base, sharply serrate, rather thick, downy beneath; petioles glandular. Flowers in lateral, sessile umbels, appearing with or before the leaves; pedicels $\frac{1}{2}-\frac{3}{4}$ in. long, flowers $\frac{1}{2}-\frac{3}{4}$ in. in diameter. Calyx downy within; fruit globose, red or yellow, $\frac{1}{2}-1$ in. in diameter. Common in woods.*

2. P. angustifolia, Michx. Chickasaw Plum. A small tree with spiny branches. Leaves lanceolate or oblong-lanceolate, acute at the apex, usually obtuse at the base, finely and sharply serrate, rather thin, smooth. Flowers in lateral, sessile umbels, pedicels short. Calyx smooth. Fruit yellowish-red, subglobose, skin thin, stone only slightly compressed. In old fields, S.*

B. Stone deeply furrowed and pitted; fruit downy when ripe. Branches not spiny. (Peaches and almonds.)

3. P. persica, Sieb. and Zucc. Peach. A tree with a rounded top; bark nearly smooth. Leaves lanceolate, taper-pointed, finely serrate, smooth on both sides; petioles usually bearing 2 or 4 crescent-shaped or cup-shaped glands. Flowers pink, scaly-bracted. Fruit ovoid, with a seam along one side. Often escaped from cultivation.*

C. Stone more or less spherical; fruit smooth when ripe. Branches not spiny. (Cherries.) 
4. P. virginiana, L. Снокеcherry. A shrub or small tree, 5-20 ft. high. Leares thin, oval or obovate, pale, pointed, sharply serrate. Flowers small, white, in short racemes. Fruit bright red, turning at length to dark crimson, very puckery until fully ripe. River banks and thickets.

5. P. serotina, Ehrh. Wild Black Cherry. Often becoming a large tree; bark on old trees rough, nearly black. Leares rather thick, oval to lanceolate-ovate, acute or taper-pointed at the apex, finely serrate with calloused teeth, smooth above, downy on the veins beneath. Racemes terminal, long and spreading. Flowers white. Fruit globose, about $\frac{1}{4}$ in. in diameter, purplish-black. In rich woods. Wood much used in cabinet-making.*

6. P. Cerasus, L. Cherry. Often becoming a large tree. Leaves oral or ovate, acute or taper-pointed at the apex, rounded at the base, irregularly serrate-dentate, smooth on both sides, resinous when young. Flowers in lateral umbels, white; pedicels long and slender. Fruit globose, red or black. This is the European species from which most of our cultivated varieties have been developed.*

\section{6. leguminos $Æ$. Pulse Family.}

Herbs, shrubs, or trees. Leaves alternate, «sualiy com. pound (either pinnately or palmately), with stipules, the leaflets mostly entire. Calyx of 5 sepals, which are more or less united, often somewhat irregular. Corolla, of 5 petals, often

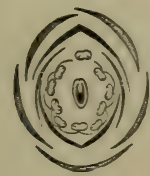

I

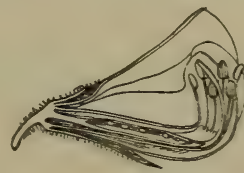

II

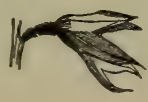

III

FIG. 14. - I, Diagram of Flower of Sweet Pea, Lathyrus odoratus. II, Vertical Section of Flower (magnified). III, Calyx (magnified).

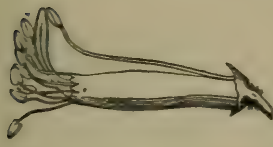

I

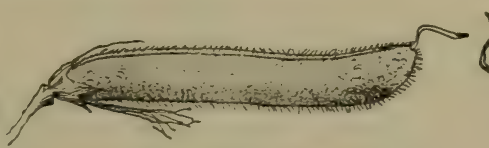

II

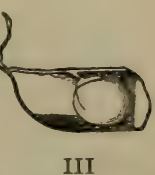

III

Frg. 15. - I, Stamens and Pistil of Sweet Pea (magnifled). II, Fruit. III, Part of Fruit, showing one seed. 
papilionaceous or somewhat regular, in No. XV much reduced. Stamens diadelphous (Fig. 15), monadelphous, or distinct. Ovary simple, free from the calyx. Fruit usually a 1-celled pod (Fig. 15). Seeds one or several, without endosperm.

\section{A.}

Flower regular, small. Stamens hypogynous. Leaves twice pinnate.

Petals not united to each other. Stamens 5 or 10 . Pod smooth.

Desmanthus, I.

Corolla gamopetalous, 5-cleft. Stamens 8 or $10 . \quad$ Pod minutely prickly or rough. Schrankia, II.

B.

Trees. Flowers somewhat or not at all papilionaceous; sometimes almost regular. The upper petal inside the others in the bud. Stamens 10 or less, usually not united to each other, borne on the calyx.

Flowers imperfectly papilionaceous. Leaves simple.

Cercis, III.

Flowers not papilionaceous. Thornless. Gymnocladus, IV.

Flowers not papilionaceous. Thorny. Gleditschia, V.

c.

Herbs or trees. Flowers decidedly papilionaceous. The upper petal external in bud and enclosing the others. Stamens 10, not united to each other.

Trees.

Cladrastis, VI.

Herbs.

Baptisia, VII.

D.

Shrubs with a corolla of one petal only.

Amorpha, XV.

E.

Herhs, shrubs, or trees. Flowers decidedly papilionaceous. Stamens monadelphous or diadelphous (in the latter case usually 9 and 1, as in Fig. 15). 
1. Stamens with anthers of two forms. Leaves palmately compound.

Herbs. Leaves with many leaflets.

Lupinus, VIII.

Trees.

Laburnum, IX.

Low shrubs.

Cytisus, $\mathrm{X}$.

2. Anthers all alike except in No. 14 .

Leares usually with 3 leaflets. Leaflets with fine teeth, except in No. 14.

(a) Pod coiled.

Medicago, XI.

(b) Pod not coiled. Flowers in racemes. Melilotus, XII.

(c) Pod not coiled. Flowers in heads. Trifolium, XIII.

(d) Leaflets entire.

Psoralea, XIV.

3. Leares odd-pinnate, with more than 3 leaflets.

(e) Low woody shrubs.

Amorpha, XV.

$(f)$ Tall twining shrubs.

Wistaria, XVI.

(g) Trees.

Robinia, XVII.

(h) Herbs.

Astragalus, XVIII.

4. Leares pinnate, the midrib prolonged into a tendril.

(i) Leaflets usually many pairs. Style slender, bearded only at the tip or all round the upper portion. Pod 2 -several-seeded.

Vicia, XIX.

(j) Leaflets few or several pairs. Style bearded along one face only. Pod several-seeded. Lathyrus, XX.

(k) Leaflets 1-3 pairs. Style enlarged above, grooved on the back. Pod sereral-seeded; seeds large, globular or nearly so.

Pisum, XXI.

\section{DESManthus, Willd.}

Shrubs or perennial herbs; stems erect or diffuse, smooth. Leaves abruptly twice-pinnate; stipules small. Flowers in heads or spikes, on axillary peduncles, the upper perfect, the lower often staminate or neutral. Calyx 5-toothed. Corolla of 5 distinct petals or 5-cleft. Stamens 5-10, distinct. Ovary nearly sessile, flat, several-seeded.* 
1. D. brachylobus, Benth. Desmanthus. Stem erect or ascending, smooth, 1-4 ft. high. Pinnæ 6-14 pairs, each with a minute gland at the base; leaflets 20-30 pairs, small, linear. Heads globose. Stamens 5. Pods several, on a peduncle 2-3 in. long, curved, flat, 2-valved, 3-6-seeded. Open, sandy fields.*

\section{SCHRANKIA, Willd.}

Perennial herbs ; stems reclining or prostrate, prickly, 2-5 ft. long. Leaves twice-pinnate; stipules bristly. Flowers perfect or somewhat monœecious, in axillary peduncled heads. Calyx minute. Corolla tubular, 5-cleft. Stamens 8-10, distinct. Pod long, prickly, 1-celled.*

1. S. uncinata, Willd. Sensitive Brier, Sensitive Rose, Shame Vine. Plant covered with hooked prickles. Leaflets elliptical, with a conspicuous network of veins beneath; leaves closing gradually after being touched. Flowers rose-colored. Pods nearly cylindrical, 2 in. long. Dry, sandy soil and rolling prairies, especially $\mathrm{S}$. and $\mathrm{W}$.

\section{CERCIS, $\mathrm{L}$.}

Trees. Leaves simple with stipules. Flowers in axillary clusters, papilionaceous. Calyx bell-shaped, 5-toothed. Stamens 10, distinct. Ovary short-stalked; ovules several. Fruit a flattened pod.

1. C. canadensis, L. REDBud. A small tree, 10-20 ft. high, wood hard but weak, bark smooth, dark-colored. Leaves broadly cordate, abruptly acute, rather thick, very smooth above, often slightly downy below. Flowers several in a cluster, appearing before the leaves, pinkish-purple. Pod oblong, compressed, many-seeded. Common on rich soil, especially S.*

\section{GYMNOCLADUS, Lam.}

A large, thornless tree, its twigs few and stout. Leaves very large, twice pinnately compound, without stipules. Flowers regular, whitish, diœcious or somewhat monœcious, in racemes at the ends of the branches. Calyx-tube rather long, its 5 lobes spreading. Petals oblong, all alike, inserted with the stamens on the throat of the calyx. - Stamens of the fertile flowers usually not pollen-bearing. Pod hard, flat, 
partly filled with a sweet substance, slow in opening. Seeds several, flattish, over $\frac{1}{2} \mathrm{in}$. in diameter, very hard and shining.

1. G. canadensis, Lam. Kextuckx Coffee Tree. Tree $50 \mathrm{ft}$. or more in height, with rough gray bark. Leares 2-3 ft. long, the leaflets vertical. Pods sometimes nearly $1 \mathrm{ft}$. long. Rich soil and river bottoms, especially S. and W.

\section{GLEDITSCHIA, L.}

Large trees; bark dark-colored, nearly smooth. Leaves usually pinnately twice compound; leaflets serrate. Flowers somewhat monœcious, in small spike-like racemes. Calyx spreading, 3-5-cleft. Petals as many as the sepals and inserted at the summit of the tube. Stamens 5-10, distinct, inserted with the petals. Ovary nearly sessile, ovoid or elongated. Fruit a 1 or many seeded, leathery pod.*

1. G. Triacanthos, L. Hovey Locust. A large tree, usually armed with stout, branched thorns, which are sometimes a foot or more in length. Leares petioled; leaflets short-stalked, lanceolate-oblong, base inequilateral, smooth above, often downy below. Racemes solitary or in small clusters, drooping. Flowers inconspicuous, greenish. Pod linear-oblong, often 12-15 in. long by 1 in. wide, twisted, manyseeded, smooth and shiny, pulpy within. In rich woods. [The thorns are plainly modified branches bearing dormant buds, and often partially developed leaves. The early spring leaves are usually only o.rce compound, while those of later growth are almost invariably twice compound. Often a single leaf will show both forms of compounding.]*

\section{CLADRASTIS, Raf.}

A moderate-sized tree with smooth dark gray bark and yellow wood. Leaves of 7-11 smooth oval or ovate leaflets. Flowers creamy-white, in long, drooping panicles. Calyx כ-toothed. Standard large, nearly round, reflexed; petals of the keel and wings separate and straight. Stamens 10 , unconnected with each other. Pod borne on a short stalk above the calyx. Seeds 4-6.

1. C. tinctoria, Raf. Yellow Wood. Tree $50 \mathrm{ft}$. or less in height, much branched, with a round, spreading top. Hillsides, in fertile soil, south central states. Also considerably planted as a shade tree. 


\section{BAPTISIA, Vent.}

Perennial herbs; stems erect, widely branched. Leaves simple or palmate, of 3 leaflets. Flowers in racemes. Calyx 4-5-lobed, persistent, the upper lobe usually longer and notched; standard rounded, its sides reflexed, wings about as long as the keel. Stamens 10, distinct. Pod stalked, long-pointed by the remains of the style. Plants usually becoming black in drying.*

1. B. tinctoria, R. Br. Wild Indigo. Stem smooth, slender, 2-4 ft. high; branches slender. Leaves of 3 leaflets, on short petioles, the upper nearly sessile ; stipules minute, quickly deciduous. Leaflets obovate to oblanceolate, obtuse at the apex, wedge-shaped at the base, entire. Racemes numerous, terminal. Flowers yellow, $\frac{1}{2}$ in. long. Pod globose, ovoid, on a stalk about the length of the calyx, point long and slender. Plant blackening in drying. Common on dry, sandy soil.**

2. B. leucophæa, Nutt. Low, hairy, and branching. Leaves nearly sessile, leaflets oblanceolate or obovate-spatulate. Stipules triangular-ovate, large, persistent ; bracts large and leaf-like. Racemes long. Flowers large, yellowish-white. Pod ovoid, swollen. Prairies and open woods, W. and S.

3. B. leucantha, Torr. and Gr. Stout, smooth, and covered with a bloom, $3 \mathrm{ft}$. or more high, with spreading branches. Petioles short; lanceolate stipules and bracts falling off early. Racemes erect. Flowers large, white. Pods ellipsoidal, 2 in. long, borne on a stalk twice as long as the calyx. Rich river bottoms and prairies.

4. B. alba, R. Br. White Wild Indigo. Stem smooth and with a bloom, often purple, $2-3 \mathrm{ft}$. high ; branches slender, spreading. Leaves petioled, with 3 leaflets; stipules minute, soon deciduous. Flowers white, mostly in a single raceme which is 1-3 ft. long, with occasionally lateral, few-flowered racemes. Pod linear-oblong, the point very slender and soon deciduous. Plant unchanged in drying. In damp soil.*

5. B. australis, R. Br. Blue False Indigo. Stem smooth, stout, 2-4 ft. high. Leaves of 3 leaflets, short-petioled; stipules lanceolate, persistent, longer than the petioles; leaflets oblong, wedge-shaped or narrowly obovate, entire. Flowers bright blue, 1 in. long, in terminal, erect, loosely flowered racemes; stalk about the length of the calyx. Pod oblong, with a slender, persistent point. Banks of rivers; often cultivated for ornament.* 


\section{LUPINUS, Tourn.}

Biennial or perennial herbs. Leaves simple or palmately compound. Flowers showy, in terminal racemes. Calyx 2-lipped, 5-toothed. Standard round, with the sides reflexed, keel scythe-shaped. Stamens monadelphous, anthers alternately oblong and roundish. Ovary sessile; matured pod oblong, several-seeded, often compressed between the seeds.*

1. L. perennis, L. Perennial ; stem erect, downr, 12-18 in. high. Leares palmately $7-9$ foliate; leaflets oborate or oblanceolate, obtuse and mucronate at the apex, slightly downy ; petiole slender ; stipules small. Racemes terminal, slender, loosely many-flowered. Flowers purple, blue, pink, or white. Pod oblong, densely downy, few-seeded. Dry, sandy soil.*

\section{LABURNUM, Benth.}

Trees or shrubs. Leaves of 3 leaflets, with very small stipules or none. Flowers golden-yellow, in slender, drooping racemes. Calyx 2-lipped, the upper lip 2-toothed, the lower 3 -toothed. Standard ovate, upright, of the same length as the straight wings. Stamens diadelphous (9 and 1). Ovary and pod somewhat stalked above the calyx, several-seeded.

1. L. vulgare, Gris. Labernum, Golden Chain. A small tree, with smooth, greenish bark. Leaves with slender petioles; leaflets oblong-orate, acute at the base, taper-pointed, dorrny beneath. Flowers showy, in graceful racemes. Cultivated from Europe.

\section{X. cytisus, $\mathbf{L}$.}

Shrubs, rarely spiny. Leaves of 1-3 leaflets or none ; stipules very smail. Calyx 2-lipped, the upper lip slightly 2 -toothed, the lower 3-toothed. Keel straight or a little curved, blunt, turned down after flowering. Stamens with their filaments all united; anthers every other one short and attached by its center, the alternate ones long and fastened by their bases. Style curved in, or, after the flower opens, coiled up. Pod flat, long, many-seeded.

1. C. canariensis, Steud. A shrub with many rather stiff, erect, slender branches. Leaves abundant, rery small, covered with soft 
gray hairs; leaflets 3 , obovate. Flowers rather small, yellow, in somewhat erect racemes. Cultivated in greenhouses. From the Canary Islands.

\section{MEDICAG0, Tourn.}

Annual or perennial herbs; leaves petioled, of 3 toothed leaflets. Flowers in terminal and axillary spikes or racemes. Calyx 5-toothed, the teeth short and slender. Standard oblong, much longer than the wings or keel. Stamens 10 , diadelphous. Ovary sessile. Pod 1-several-seeded, coiled, not splitting open, often spiny.*

1. M. sativa, L. Alfalfa. Perennial; stems erect, branching, downy when young, becoming smooth with age, 2-3 ft. high. Leaves short-petioled; leaflets obovate, sharply dentate towards the apex, obtuse or sometimes notched or mucronate; stipules lanceolate, entire. Flowers blue, small, in rather close spikes; pods downy, coiled, few-seeded. Introduced from Europe, and cultivated for hay and pasture.*

2. M. lupulina, L. Black Medick, Nonesuch. An annual or biennial, much branched, reclining herb, with stems from 6-20 in. long. Leaves very short-petioled; leaflets obovate, acute, $\frac{1}{4}-\frac{2}{3} \mathrm{in}$. long, toothed near the tip. Flowers small, yellow, in short spikes. Pods very small, 1-seeded, kidney-shaped, black. Roadsides and waste ground, introduced from Europe.

\section{MELILOTUS, Tourn.}

Annual or biennial herbs. Leaves petioled, of 3 leaflets. Flowers small, white or yellow, in $\dot{c}$ - se axillary and terminal racemes. Calyx 5 -toothed, the teetn nearly equal. Standard erect, wings and keel cohering. Stamens 10, diadelphous. Pod longer than the calyx, 1-4-seeded.*

1. M. alba, Lam. MeLrLotus. Biennial; stem erect, branching, smooth or the young branches slightly downy. Leaflets oblong or oblanceolate, rounded or truncate at the apex, serrate; stipules small. Racemes long, slender, erect. Flowers white. Standard longer than the wings and keel. Pod ovoid, wrinkled, drooping, mostly 1-seeded, scarcely opening. Common as a weed and widely cultivated.**

2. M. officinalis, Willd. Yellow Sweet Clover. A stout, upright, branching herb, 2-4 ft. high, looking much like the preceding species, but coarser. Flowers yellow. Waste ground and roadsides. Introduced from Europe. 


\section{TRIFOLIUM, Tourn.}

Annual, biennial, or perennial herbs. Stems more or less spreading. Leaves petioled, of 3 toothed or serrate leaflets; stipules adnate to the petioles. Flowers white, yellow, or red, in heads. Calyx 5-cleft, the teeth nearly equal and subulate. Petals withering-persistent, keel shorter than the wings. Stamens diadelphous. Pod smooth, 1-6-seeded, scarcely opening.*

1. T. procumbens, L. Low Hop-Clover. Annual; stem slender, erect, or spreading, downy, 6-10 in. long. Leaves short-petioled; leaflets oborate or obcordate, finely dentate, the middle one distinctly stalked; stipules lanceovate. Flowers yellow, reflexed in fruit. Pod 1 -seeded. Common on clay soil, in waste places.*

2. T. incarnatum, L. Crimson Clover. Annual ; stem erect, somewhat branched, downy, 1-2 ft. high. Lower leaves long-, the upper short-petioled; leaflets oborate or wedge-shaped, toothed at the apex. Flowers bright crimson, sessile, in terminal heads which finally become much elongated. Calyx silky, its lobes long and plumose. Introduced and cultivated for fodder.

3. T. pratense, L. RED Clover. Biennial or short-lived perennial ; stems spreading, branching, downy, 1-3 ft. long. Leaves longpetioled ; stipules large ; leaflets oval to obovate, finely toothed, often with a dark triangular spot near the center. Flowers red or purple, in globose heads, erect in fruit. Calyx-teeth bristle-shaped, hairy. Pod 1-3 seeded. Introduced and widely cultivated.*

4. T. carolinianum, Michx. Carolina Clover. Perennial; stems spreading or ascending, much-branched, downy, 6-10 in. long. Leaves short-petioled; leaflets small, obovate or obcordate, slightly toothed. Heads small, globose, on long peduncles. Flowers white, tinged with purple, reflexed in fruit. Pod 4-seeded. Common in waste places S.**

5. T. repens, L. White Clover. Perennial; stems widely branching at the base, prostrate and creeping, nearly smooth, 6-12 in. long. Leaves long-petioled; leaflets oval, obovate or obcordate, minutely toothed. Heads globose, long-peduncled. Flowers white, reflexed in fruit. Pod 3-4-seeded. Introduced; common about houses and in pastures.*

6. T. hybridum, L. Alsike Clover. Perennial, considerably resembling No. 5, but the stems more upright and stouter. Leaflets varying from broadly ovate to ovate-lanceolate, mucronate or slightly notched, the margins fringed with hairs; stipules prolonged into bristle-like points. Flowers rose-color and white, very fragrant. In fields and along roadsides. Introduced from Europe. 


\section{PSORALEA, L.}

Perennial herbs ; whole plant glandular-dotted. Leaves of $3-5$ leaflets ; stipules cohering with the petioles. Flowers in axillary or terminal spikes or racemes. Calyx 5-cleft, the lobes nearly equal. Standard ovate or orbicular, keel incurved, obtuse. Stamens monadelphous or diadelphous, 5 of the anthers often undeveloped. Ovary nearly sessile. Pod included in the calyx, often wrinkled, remaining closed, 1-seeded.*

1. P. melilotoides, Michx. SAMson's SNakeroot. Stem erect, slender, branching above, downy, 1-2 ft. high. Leaves of 3 leaflets; petioles shorter than the leaflets; stipules awl-shaped; leaflets elliptical or oblong-lanceolate, sparingly glandular-dotted, the terminal one stalked. Loosely flowered spikes axillary and terminal, on peduncles much longer than the leaves. Flowers blue or purple, about $\frac{1}{3}$ in. long. Pod compressed-globose, wrinkled transversely. Dry soil.*

2. P. tenuiflora, Pursh. Upright, slender, bushy and branching, 2-4 ft. high, covered when young with a fine grayish down. Leaves palmately compound, with 3-5 linear to obovate-oblong leaflets, covered with glandular dots. Flowers $\frac{1}{6}-\frac{1}{4}$ in. long, loosely racemed. Pod rough with glands. Prairies, W.

3. P. esculenta, Pursh. Pomme Blanche, Tipsin, Dakota TurNIP. Clothed with roughish hairs. Stem 5-15 in. high, erect and stout. Root turnip-shaped, starchy, eatable. Leaves palmately compound, with 5 lance-oblong leaflets. Flowers $\frac{1}{2}$ in. long, in a dense ellipsoidal spike. Pod hairy, with a pointed tip. High prairies or plains, especially N. W.

\section{AMORPHA, L.}

Small shrubs, glandular-dotted. Leaves odd-pinnate. Flowers purple, blue, or white, in slender spikes or racemes. Calyx 5-toothed, persistent. Standard obovate, concave, wings and keel none. Stamens monadelphous, projecting much. Ovary sessile. Pod curved, glandular-roughened, 1-2-seeded, never opening.*

1. A. fruticosa, L. False Indigo. A shrub 6-15 ft. high, with smooth, dark-brown bark. Leaves petioled; leaflets 15-21, shortstalked, oblong, obtuse or notched, sparingly punctate with clear dots. Slender flowering spikes, panicled or solitary, 4-6 in. long. 
Flowers blue or purple. Calyx-teeth short, nearly equal, downy. Pod glandular. River banks.*

\section{WISTARIA, Nutt.}

Tall, twining shrubs. Leaves odd-pinnate. Racemes terminal. Flowers large and showy. Calyx 2-lipped, the upper lip 2-cleft, short, the lower longer and 3-cleft. Standard large, round, with 2 calloused ridges at the base, wings eared at the base, keel scythe-shaped. Pod long, stalked, leathery, 2-valved, several-seeded.**

1. W. frutescens, Poir. Wistaria. Stem climbing 30-40 ft., often 2-3 in. in diameter at the base; branches and leaves downy when young, becoming smoother with age. Leaves short-petioled; stipules minute; leaflets $9-17$, orate-lanceolate, acute at the apex, rounded at the base. Racemes large, densely flowered. Calyx downy. Corolla lilac-purple, one wing with a short and one with a long appendage at the base. Pod 2-3 in. long, 2-4-seeded. River banks S. Often cultivated for ornament.*

2. W. chinensis, DC. Cirnese Irstaria. Larger and faster growing than No. 1. Racemes longer and more slender. Wingappendages equal. Seldom fruiting in this region. Cultivated from China or Japan.

\section{ROBINIA, L.}

Trees or shrubs. Leaves odd-pinnate ; stipules often spiny. Flowers showy, in axillary racemes. Calyx short, 5-toothed, the two upper teeth shorter and partially united. Standard large, orbicular, reflexed, keel obtuse. Stamens diadelphous. Style bearded on one side. Pod compressed, several-seeded.*

1. R. Pseudacacia, L. Black Locest. A tree of medium size; bark rough and nearly black; twigs and leaves smooth. Leaflets (3) 15 , ovate or oblong, obtuse and slightly mucronate at the apex; stipules forming persistent spines. Racemes loose, pendulous, 3-5 in. long. Flowers white, fragrant. Pod smooth, 4-8-seeded. Introduced and quite common; wood rery durable when exposed to the weather, and extensively used for posts.*

\section{ASTRAGALUS, Tourn.}

Mostly perennial herbs. Leaves odd-pinnate. Flowers in spikes or racemes. Calyx 5-toothed. Petals long, erect, with 
claws. Standard narrow. Stamens diadelphous (9 and 1). Pod usually swollen, sometimes fleshy and eatable, severalmany-seeded.

1. A. caryocarpus, Ker. Ground Plum, Buffalo Apple. Covered with pale, close-lying down. Leaflets narrow, oblong. Flowers violetpurple, in a short, narrow raceme. Fruit looking like a small, green, pointed plum, about $\frac{2}{3}$ in. in diameter, eatable. N. W., and S. to Texas.

2. A. mexicanus, A. DC. Prairie Apple. Smooth or with some loose hairs. Corolla cream-color, with the tip bluish. Fruit globular, not pointed, eatable. Prairies, Illinois and S. W.

3. A. canadensis, L. Erect, often tall (1-4 ft. high), more or less downy. Leaflets oblong, 21-27. Flowers pale greenish, in long spikes. Pod dry, 2-celled, sessile. River bottoms, prairies, and woods.

\section{VICIA, Tourn.}

Climbing or spreading herbs. Leaves odd-pinnate, usually ending in a tendril. Leaflets many, entire or toothed at the tip ; stipules half arrow-shaped. Flowers blue, purple, or yellow, in axillary racemes. Calyx-teeth nearly equal. Wings adnate to the keel. Stamens diadelphous (9 and 1); filaments thread-shaped, anthers all alike. Style bent, smooth or downy all round or bearded below the stigma; ovules usually many. Pod flattened, 2-several-seeded. Seeds globular.

1. V. americana, Muhl. Wild Vetch, Buffalo Pea. Perennial. Smooth, 1-3 ft. high. Leaflets 10-14, elliptical or ovateoblong, obtuse. Peduncles shorter than the leaves, 4-8-flowered. Flowers bluish-purple, $\frac{3}{4}$ in. long. Common $\mathrm{N}$. and W.

2. V. caroliniana, Walt. Perennial. Smooth or nearly so, 4-6 ft. high. Leaflets 8-24, narrowly oblong, blunt. Peduneles loosely flowered. Flowers smaller than in No. 1, whitish or tipped with pale purple. River banks.

3. v. sativa, L. Соммом Vетсн. Annual. Stem simple, smooth or downy, reclining, 1-3 ft. long. Leaves short-petioled; leaflets 5-7 pairs, obovate-oblong to linear, obtuse, notched and mucronate at the apex. Flowers in pairs, nearly sessile in the axils, pale purple, $\frac{3}{4}-1$ in. long. Pod linear, several-seeded. Introduced from Europe and common in cultivation.* 


\section{LATHYRUS, Tourn.}

Like Vicia excepting that the leaflets are fewer and the style is bearded on the side toward the standard.

1. L. venosus, Muhl. Veivy Vetch. Perennial. Stem stout, prominently angled, climbing or reclining, $2-5$ ft. long. Leaves short-petioled; stipules large, lanceolate; leaflets 5-7 pairs, broadly orate-obtuse, mucronate. Peduncles nearly as long as the leaves, many-flowered. Flowers purple, $\frac{3}{4}$ in. long. Calyx-teeth very unequal. Pod linear, veined, 4-6-seeded. Shady banks and moist prairies.*

2. L. maritimus, Bigelow. Beach Pea. Perennial. Stem stout, 1-2 ft. high. Stipules broadly ovate and heart or halberd shaped, nearly as large as the 6-12 leaflets, of which the lower pair is the largest; tendrils pretty large. Flowers large, blue or purple. Seashores and beaches of the Great Lakes.

3. L. palustris, L. Wild PeA. Stem frequently winged, slender, and climbing by delicate tendrils at the ends of the leaves. Stipules narrow and pointed; leaflets 4-8, narrowly oblong to linear, acute. Peduncles bearing 2-6 pretty large, drooping, blue, purple, and white flowers. Damp thickets and borders of swamps.

4. L. odoratus, L. Sweet Pea. Ánnual. Stem roughishhairy, it and the petioles winged. Leaflets only one pair, oral or oblong. Flowers large, 2 or 3 on the long peduncles, sweet-scented, white, rose-color, purple, or variegated. Cultivated from Europe.

\section{PISUM, L.}

Climbing or prostrate herbs. Style enlarged above, grooved on the back, soft-hairy down on the inner edge. Leaflets 1-3 pairs. Flowers and fruit much like those of Lathyrus.

1. P. sativum, L. Commox Pea. Annual. Smooth and covered with a bloom. Leaflets usually 2 pairs; tendrils branching; stipules large, orate, rather heart-shaped at the base. Peduncle severa!flowered. Flowers white, bluish, reddish, or variegated. Pods large; seeds globular or somewhat flattened and wrinkled. There are many varieties, differing greatly in size, of the plant and of the fruit. Cultivated from Europe (?).

\section{Geraniacese. Geranium Family.}

Herbs or small shrubs. Leaves simple, usually with glandular hairs which secrete an aromatic oil. Flowers perfect, 
axillary and solitary or clustered, regular or slightly irregular hypogynous, their parts in fives. Stamens 5 or 10 , monadelphous at the base. Carpels 5, each 2-ovuled, splitting away with their long styles when ripe from a central axis and thus scattering the seeds.

\section{GERANIUM, Tourn.}

Herbs, rarely shrubs. Leaves with stipules, opposite or alternate, usually cut or lobed. Flowers regular, on 1-2flowered axillary peduncles. Sepals and petals 5 . Stamens 10 , ripening in 2 sets. Ovary 5 -lobed, 5 -beaked; stigmas 5 .

1. G. maculatum, L. Wild Cranesbill, Wild Geranium. Perennial, with an erect, hairy stem, 12-18 in. high. Leaves about 5-parted, marked with pale blotches, the root-leaves long-petioled. Flowers large ( 1 in. or more in diameter), light purple, somewhat corymbed. Petals entire, twice as long as the calyx, the claw bearded. Open woods and thickets; common.

2. G. robertianum. Herb Robert. Annual or biennial. Stems somewhat hairy, weak and spreading, reddish. Leaves of 5 leaflets, the latter once or twice pinnately cut, long-petioled. Flowers light purple, about $\frac{1}{2}$ in. in diameter, streaked with dark and light ied. Claws of petals smooth. Damp woods and ravines $\mathbf{E}$.

\section{PELARGONIUIM, L'Her.}

Perennial herbs or shrubs. Leaves with stipules, scented. Flowers much as in the preceding genus, but one of the sepals hollowed out below into a nectar-bearing tube extehding down the pedicel. The 2 upper petals different in size or shape from the other 3. Cultivated from the Cape of Good Hope. [Most of the species are commonly, though not quite correctly, called "geraniums." Only a few of the commonest are here described.]

1. P. peltatum, Ait. Ivy Geranium. Stems somewhat prostrate and trailing. Leaves somewhat peltate, smooth or nearly so. Flowers pink or white.

2. P. zonale, Willd. Horseshoe Geranium. Stem erect, widely branched, woody below. Leaves alternate, opposite or sometimes in 3 's, round or kidney-shaped, palmately veined, crenate, 
downy, usually with a dark zone near the middle. Flowers in a long peduncled umbel, showy, red or white, often double. Numberless varieties in cultivation.

3. P. graveolens, Ait. Rose Geraxium. Stem erect or ascending, densely downy, 1-3 ft. high. Leaves alternate, palmately lobed or divided, the lobes often finely dissected, rolled under at the edges. Flowers umbelled, small, light purple with darker veins; whole plant rery fragrant. Common in cultivation.

4. P. odoratissimum, Ait. Netweg Geraxicm. Branches crooked and straggling from a rery short, moderately stout main stem. Leares small, roundish and scalloped, covered with velvety down, very fragrant. Flowers white, inconspicuous, on short pedicels, the petals hardly longer than the calyx.

\section{OXALIDACEA. WOOd-SorRel FaMily.}

Herbs or woody plants. Leaves compound. Flowers in fives, perfect, regular, hypogynous. Stamens 10, somewhat monadelphous at the base. Ovary with several ovules in each cell. Fruit a capsule.

\section{OXALIS, $\mathbf{L}$.}

Acid herbs. Leaves radical or alternate, with or without stipules, usually of 3 leaflets, which droop at night. Sepals 5. Petals 5. Stamens 10. Ovary 5-lobed, 5-celled; styles 5.

1. 0. Acetosella, L. Wood-sorrel. Stemless, from a creeping, scaly rootstock. Leaves all radical, long-petioled, of 3 inversely heart-shaped leaflets; scape slender, 2-5 in. high, 1-flowered. Flowers nearly 1 in. in diameter, white, reined with red or purple. Cold woods $\mathrm{N}$.

2. 0. violacea, L. Violet Wond-sorrel. Perennial from a bulbous root, stemless. Leaves long-petioled; leaflets inversely heart-shaped, sometimes slightly downy, often with a dark zone near the mirldle. Scajes usually longer than the petioles, umbellately 4-10-flowererl; pedicels slender. Flowers violet-purple, nodding. Petals obtuse, 2-;) times as long as the sepals; scapes and petioles $4-5$ in. long. Common in rich woorls.**

[The forms with small yellow flowers, hitherto referred to $O$. corniculata, belong to several nearly related species too difficult for the beginner.] 


\section{TROP}

Smooth and tender herbaceous plants, with biting juice, often climbing by the petioles of their simple leaves. Leaves alternate, without stipules. Peduncles axillary, 1 -flowered. Sepals $3-5$, the upper one with a long, distinct spur. Petals 1-5, hypogynous, not always all alike. Stamens $6-10$, perigynous, distinct. Ovary 1, 3-cornered, made up of 3-5 1-ovuled carpels; style 1 ; stigmas $3-5$. Fruit not opening.

\section{TROPAEOLUM, L.}

Characteristics of the genus those of the family above given, together with the following :

Petals usually 5, clawed, the 2 upper inserted at the mouth of the spur and unlike the 3 lower ones. Stamens 8, ripening unequally, the filaments curved. Fruit 3-celled, 3-seeded. Cultivated from S. A. for the very showy flowers and the sharp-flavored fruits, which are often pickled.

1. T. majus, L. Common Nasturtium. Climbing by the petioles $6-8 \mathrm{ft}$. (there is also a low variety which does not climb). Leaves roundish but more or less 6 -angled, peltate, with the petiole attached near the middle. Flowers varying from almost white to nearly black, but commonly crimson, scarlet, or flame-color.

\section{Linace五. Flax Family.}

Herbs, shrubs, or trees. Leaves usually alternate, simple, entire, sometimes with stipules. Flowers variously clustered. Sepals 5, distinct or coherent. Petals 5, hypogynous. Stamens 5, monadelphous below. Pod 8-10-seeded, with twice as many cells as there are styles.

\section{LINUIM, Tourn.}

Herbs or small shrubs, with tough, fibrous bark. Leaves sessile. Flowers in corymbs or panicles. Sepals 5, entire. Petals 5, distinct or coherent below, falling in a few hours after expanding. 
1. L. virginianum, L. WrLd FLAX. Stem rather slender, erect and cylindrical; branches cylindrical. Leaves small, varying from oblong to lanceolate or spatulate, the lower often opposite. Flowers small, yellow. Capsules flattened at right angles to the pedicels. Dry woods and pastures.

2. L. usitatissimum, L. Commox Flax. Stem erect, with corymbed branches at the top. Leaves narrowly lanceolate. Flowers handsome, large, blue. Cultivated for the fiber. From Europe; introduced here to some extent.

\section{RUtACE R. RUe Family.}

Shrubs or trees. Leaves alternate, compound, without stipules, marked with translucent dots. Flowers perfect or variously imperfect. Sepals and petals $3-5$ or none; petals hypogynous or perigynous when present. Stamens as many or twice as many as the sepals, inserted on the glandular disk. Pistils 2-5, often partially united. Fruit a capsule, a keyfruit, or in the important genus Citrus (orange, lemon, lime, etc., not here described) a leathery-skinned berry, the outer part of the skin containing many spherical oil-cavities.*

\section{XANTHOXYLUM, L.}

Trees or shrubs; bark, twigs, and petioles usually prickly; leaves odd-pinnate, marked with translucent dots. Flowers in axillary or terminal cymes or umbels, monœcious or rliøecious. Sepals and petals $3-5$ or none. Stamens $3-5$, hypogynous. Pistils 2-5, distinct. Carpels 2-valved, 1-2seeded. Seeds smooth and shining.*

1. X. americanum, Mill. Northern Prickly Ash, ToothacheTREE. A prickly shrub, 8-12 ft. high, with aromatic bark. Leaves pinnately compound; leaflets ovate-oblong. Flowers small and greenish, in axillary umbels, appearing before the leares. Petals 4-5. Pistils 3-5, the styles slender. Pods rather globose, somewhat more than $\frac{1}{8}$ in. in diameter, roughish, borne on a short stalk above the receptacle, with a strong scent of lemon and tasting at first aromatic, then burning. Rocky woods, ravines, and river banks. 


\section{PTELEA.}

Shrubs with smooth and bitter bark. Leaves with 3 leaflets. Flowers in terminal cymes, somewhat monœcious. Sepals $3-6$, deciduous, much shorter than the petals. Stamens 4-5, longer than the petals and alternate with them. Pistillate flowers producing imperfect stamens. Ovary compressed, 2-celled. Fruit a 2-celled, 2-seeded, broadly winged key.*

1. P. trifoliata, L. Hop-tree, WAfer Ash. A shrub 4-8 ft. high. Leaves long-petioled; leaflets oval or ovate, acute, obscurely serrate, the lateral ones oblique. Cymes compound. Flowers greenish. Stamens mostly 4, filaments bearded, key about 1 in. in diameter; wing notched, strongly netted-veined. Rocky banks; often cultivated.*

\section{POlygalace E. Polygala Family.}

Herbs or shrubs. Leaves alternate or nearly opposite, without stipules, simple. Flowers irregular. Sepals unequal, the 2 inner wing-shaped and petal-like. Petals $3-5$, hypogynous, the 2 lateral ones often united with the hooded lower one into a tube, split open at the base behind. Stamens 8, filaments united into a split sheath, which is usually adnate to the petals; anthers usually opening by pores. Ovary 2-celled, 2-ovuled. [A difficult family for the beginner.]

\section{POLYGALA, Tourn.}

Herbs or shrubs. Flowers racemed or spiked, some of them often cleistogamous. Petals adnate below to the stamensheath. Anthers opening by transverse pores.

1. P. paucifolia, Willd. Fringed Polygala, Babies' Toes, MaY Wings. A low perennial herb, with branches $3-4$ in. high from a slender, creeping rootstock. Lower leaves scattered, small and scale-like, the upper ones with petioles, crowded near the tips of the branches, ovate or nearly so. Flowers of two kinds, the cleistogamous whitish, fertile, borne underground along the rootstock, the terminal flowers large and showy (nearly an inch long), rose-purple, with a beautiful fringed crest. Woods, especially N. and E. 
2. P. Senega, L. Seneca Snakeroot. A perennial herb, with several erect stems arising from stout, hard, knotty rootstocks. Leares lanceolate, oblong or lance-ovate, sessile. Flowers all alike, small, white, in solitary close spikes. Rocky woods.

\section{EUPHORBIACE AE. SPYRGE FaMily.}

Herbs, shrubs, or trees, usually with a milky, more or less acrid and sometimes poisonous juice. Flowers mostly apetalous, monœcious or diœcious (Fig. 16). Ovary usually 3-celled, with 1 or 2 ovules in each cell; stigmas as many as the

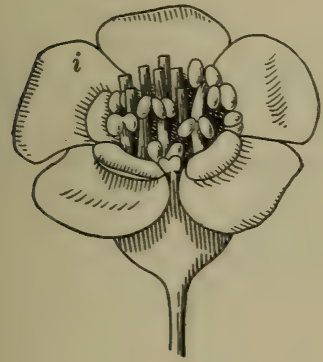

$A$

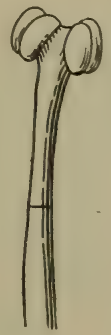

$\boldsymbol{B}$

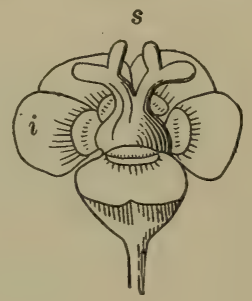

C

FIG. 16. - Euphorbia corollata.

$A$, flower-cluster with involucre, the whole appearing like a single flower; $B$, a single staminate flower; $C$, immature fertile flower, as seen after the removal of the sterile flowers; $i$, involucre; $s$, stigmas.

cells or twice as many. Fruit a 3-lobed capsule. Seeds containing fleshy or oily endosperm (Part I, Fig. 2). Most of the family are natives of hot regions, many of them of peculiar aspect from their adaptation to life in dry climates. [The family is too difficult for the beginner in botany to determine many of its genera and species with certainty, but a few are described below.] 


\section{EUPHORBIA, I.}

Herbs or shrubs, with milky juice, often poisonous. Flowers monœcious, enclosed in a 4 -5-lobed involucre, which is often showy and resembles a calyx or corolla, usually bearing large glands at its notches. Sterile flowers many, borne inside the involucre at its base (Fig. 16, A), each cousisting only of a single stamen attached by a joint to a pedicel which looks like a filament. Fertile flower standing alone at the center of the involucre (Fig.16,C) (soon pushed out by the growth of its pedicel), consisting only of a 3-lobed and 3 -celled ovary, 3 2-cleft styles, and 6 stigmas. Pod 3-celled and 3 -seeded.

\section{A. Cultivated shrubs.}

1. E. splendens, Bojer. Crown of Thorns. An extremely prickly shrub, with many erect, few-leaved branches. Leaves obovate or obovate-spatulate, mucronate, entire, each with two very sharp prickles (longer than the petiole) as stipules. Peduncles long, sticky, each bearing 2-4 objects, which appear to be showy scarlet flowers, but which are actually 2-bracted involucres containing the true flowers. Involucral scales somewhat kidney-shaped, mucronate. Flowering all the year round. Cultivated in greenhouses. From Mauritius.

B. Herbs with rather showy white flower-clusters.

2. E. corollata, L. Flowering Spurge. Perennial. Stem erect, umbellately branched above, smooth or downy, 1-3 ft. high. Leaves of the stem alternate, those of the branches usually opposite or whorled, rather thick, oval to narrowly oblong, pale beneath, usually slightly downy. Flowering branches repeatedly forked; involucres terminal and in the forks of the branches, peduncled; glands 4-5, oblong, green; appendages white and petal-like, showy. Capsule erect, seed smooth or faintly pitted. Common in dry, open woods.

C. Herbs: No. 3 a native species, No. 4 cultivated from Europe or escaping from gardens. Flower-clusters in umbels not white. Involucre 4 or 5 lobed, each lobe with a gland.

3. E. dictyosperma, Fischer and Mayer. Annual. Stem slender, 8-18 in. high, erect. Stem-leaves oblong-spatulate to obovate, serrate; floral ones roundish-ovate, somewhat heart-shaped. Flowercluster a compound umbel, the rays once or twice 3-forked, then 2 -forked. Seeds covered with a network. Prairies and roadsides. 
4. E. Cyparissias, L. Cypress Spurge, Cypress, Graveyard Moss. A perennial, in dense clusters 6-12 in. high from running rootstocks. Leaves much crowded, all sessile, the stem-leaves linear, floral ones broadly heart-shaped. Flower-chister a simple, manyrayed umbel. Glands crescent-shaped. Cemeteries, roadsides, etc., escaped from cultivation; also cultivated in old gardens. From Europe.

\section{JATROPHA, L.}

Shrubs or herbs. Leaves alternate. Flowers monœcious, staminate and pistillate intermixed in the cymes, apetalous. Calyx large, white, כ-lobed, corolla-like. Stamens numerous, usually monadelphous. Ovary usually 3-celled, 3-seeded ; styles 3 , united at the base, several-parted.*

1. J. stimulosa, Michx. Spurge Nettle. Perennial herbs armed with stinging hairs; stems erect, branched, bright green with white lines, 8-15 in. high. Leares long-petioled, deeply palmately 3-5lobed, the lobes irregularly cut and toothed, often mottled. Sepals white, spreading. Seeds oblong, smooth, mottled. In dry woods S.**

\section{ANACARDIACE无. SEMAC FAMILY.}

Trees or shrubs, with resinous, acrid, or milky sap. Leaves simple, of 3 leaflets or pinnately compound, alternate, without stipules. Flowers perfect or imperfect, small. Calyx 3-5-parted, persistent. Petals 3-5 or wanting. Stamens as many as the sepals or sometimes twice as many, inserted in the base of the calyx, distinct. Ovary free, 1-celled, styles 1-3. Fruit a 1-seeded stone-fruit.*

\section{RHUS, $\mathrm{L}$.}

Trees or shrubs. Leares of 3 leaflets or odd-pinnate. Flowers in spikes or panicles. Calyx mostly 5-parted. Petals and stamens 5. Pistil 1, sessile; styles 3, terminal. Fruit small, smooth or downy.*

1. R. glabra, L. Scuic. A shrub or small tree, sometimes 2.5-30 ft. high; branches downy. Leaves odd-pinnate, main midrib downy and wing-marwined; leaflets 9-21, ovate-lanceolate, acute at the apex, inequilateral, entire or slightly toothed, smooth and green 
above, pale and downy beneath. Panicle often large and spreading ; flowers somewhat monœcious. Fruit red, hairy, acid. Open woods.*

2. R. typhina, L. Staghorn Sumac. A small tree, 20-40 ft. high; branches and petioles closely velvety-hairy. Leaves odd-pinnate, leaflets 17-27, lanceolate-oblong, taper-pointed at the apex, very obtuse at the base, sharply serrate, smooth above, pale and downy beneath. Flowers somewhat monœcious, in dense terminal panicles. Fruit red, with crimson hairs. Dry hillsides N. and E.*

3. R. Toxicodendron, L. Poison Vine, Poison Ivy, Mercury, Black Mercury. Stem a woody vine climbing high by aerial rootlets, or sometimes short and erect. Leaves petioled, of 3 leaflets, downy; leaflets ovate or oval, taper-pointed, entire or somewhat dentate, often angled or lobed. Flowers diœcious, in loose axillary panicles. Fruit nearly white, smooth. Common in open woods and along fences. Plant poisonous to the touch.*

4. R. venenata, L. Poison Sumac, Poison Dogwood. A very smooth shrub with gray bark, 6-18 ft. high. Leaves large and glossy, with 7-13 obovate-oblong, entire leaflets. Flower-clusters loosely-flowered, axillary panicles. Fruit smooth, greenish-yellow. Swamps and wet openings in woods N. and E. Plant more poisonous than the preceding species.

\section{AQUifOliaceze. Holly Family.}

Trees or shrubs. Leaves simple, alternate, petioled; stipules small or wanting. Flowers small, greenish, clustered or solitary in the axils, usually diœcious. Calyx 4-9-parted. Petals 4-9, somewhat united at the base. Stamens inserted in the tube of the corolla and alternate with its lobes. Ovary free, 4-9-celled, with a single ovule in each cell. Fruit a berry-like stone-fruit, 4-9-seeded.*

\section{ILEX, L.}

Small trees or shrubs. Leaves usually leathery, often persistent and evergreen; stipules minute. Flowers axillary, 4-9-parted, the fertile often solitary and the staminate clustered. Fruit a stone-fruit with 4-9 nutlets. *

1. I. opaca, Ait. Holly. Trees with smooth, light-colored bark, and hard, very white wood; young twigs downy. Leaves leathery, oval or ovate, margin prickly-toothed, dark green and shining 
above, paler and sometimes slightly downy beneath. Peduncles short. bracted. Flowers 1-parted, staminate flowers in small cymes, the pistillate usually solitary. Fruit bright red. Damp, sandy soil E. and S.*

2. I. decidua, Walt. Decidror's Holly. Small trees; twigs smooth. Leares thin, obovate, obtuse or sometimes acute at the apex, scalloped, smooth, deciduous. Flowers in sessile clusters, 4-6 parted. Fruits rery numerous, bright red. On low ground S.*

3. I. verticillata, Gray. Black Alder, Winterberry. A muchbranched shrub 6-8 ft. high. Leaves thin, oval or obovate, taperpointed, serrate, $1 \frac{1}{2}-2$ in. long. Flowers greenish-white, on very short peduncles. Fruit bright red, 1, 2, or 3 in a leaf-axil, remaining long after the leaves have fallen. Swampy ground and damp woods and thickets.

\section{Celastrace AE. StafF-tree Family.}

Trees or shrubs, sometimes climbing. Leaves simple, opposite or alternate. Flowers small, in cymes. Calyx small, 4-5-lobed, persistent. Petals 4-6, short. Stamens 4-6, alternate with the petals and inserted with them on a disk. Ovary sessile, 3-5-celled; style entire or 3-5-cleft; ovules 2 in each cell. Seeds usually covered with an appendage (aril) growing from the hilum.

\section{CELASTRUS, L.}

A woody, twining shrub. Leaves alternate. Flowers diœcious or somewhat monœcious, small, greenish, clustered at the ends of the branches. Pod 3-celled, 3-valved, looking like an orange-colored berry, which on opening shows the scarlet arils of the seeds.

1. C. scandens, L. WAX-Work, Clmmixg Bittersweet. Climbing 10-15 ft. Leaves orate-oblong, 2-4 in. long, finely serrate, taper-pointed. In thickets and along fences, also planted for the showy scarlet seeds, which retain their color for many months.

\section{EUONYMUS, Tourn.}

Shrubs with 4-angled branches. Leaves opposite. Flowers in axillary, peduncled cymes, purplish or greenish, small. 
Sepals and petals $4-5$, spreading. Stamens as many as the petals, short. Ovary 3-5-celled, with 2 ovules in each cell. Seeds enclosed in a red, fleshy pulp.*

1. E. americanus, L. Strawberry Bush. A shrub 3-8 ft. high. Leaves short-petioled, ovate to ovate-lanceolate, acute or taper-pointed at the apex, finely serrulate, smooth or slightly hairy. Peduncles axillary, slender, 1-3-flowered. Flowers greenish. Capsule 3-5-angled, warty. In low, shady woods.

2. E. atropurpureus, Jacq. WAноo. A tree-like shrub 10-15 ft. high. Leaves oval to ovate, taper-pointed, finely serrulate, minutely downy petioles $\frac{1}{2}-\frac{3}{4}$ in. long. Peduncles slender, 3-forked, severalflowered. Flower purplish; capsule deeply 3-5-lobed, smooth. River banks.

\section{STAPHYLEACEÆ. Bladder-nut Family.}

Shrubs. Leaves pinnately compound, with stipules, and the leaflets with little individual stipules (stipels). Flowers regular and perfect. Calyx-lobes 5. Petals 5, inserted in or around a saucer-shaped disk. Stamens 5, alternate with the petals, perigynous. Ovary 2-3-celled, with the carpels more or less distinct; ovules several ; styles $2-3$, cohering somewhat below. Fruit usually 1 -few-seeded.

\section{STAPHYLEA, $\mathbf{L}$.}

Calyx deeply 5-parted, the lobes appearing like separate sepals, erect. Petals spatulate, borne on the rim of the thick disk. Pod large, papery, 3-celled, finally opening at the top. Seeds 1-4 in each cell, bony.

1. S. trifolia, L. American Bladder-nut. A shrub 6-12 ft. high, with smooth, slender, greenish striped, at length gray, branches. Leaves long-petioled, with 3 ovate, taper-pointed, finely serrate leaflets. Damp thickets.

\section{8. aCeracez. Maple Family.}

Trees or shrubs, with abundant, often sugary sap. Leaves opposite, simple and palmately lobed, or pinnate, without 
stipules. Flowers regular, mostly somewhat monœeious or diøcious, in axillary and terminal cymes or racemes. Calyx 4-9-parted. Petals as many as the lobes of the calyx or none. Stamens 4-12, hypogynous. Ovary 2-celled; styles 2. Fruit a double key.*

\section{ACER, Tourn.}

Characteristics of the genus as above given for the family.

1. A. saccharinum, L. (A. dasycarpum, Ehrh.). White Maple, River Maple. A tall tree with the main branches slender and rather erect. Leares rery deeply 5-lobed, with the notches rather acute, silvery-white, and when young downy on the lower surface, the dirisions narrow, coarsely cut and toothed. Flowers greenish, in umbel-like clusters, appearing long before the leaves. Petals absent. Fruit woully at first, then smooth, with diverging wings, the whole 2-3 in. long. Common on river banks $\mathrm{S}$. and W., also planted for a shade-tree, but not safe, as the branches are easily broken off by the wind.

2. A. rubrum, L. RED Maple. A small tree with red or purple twigs. Leaves simple, broadly ovate, palmately 3-5-lohed or sometimes merely serrate or cut-toothed, taper-pointed at the apex, rounded or heart-shaped at the base, smooth or downy, becoming bright red in autumn. Flowers appearing before the leaves on erect, clustered pedicels. Petals red or yellow, oblong or linear. Fruiting: pedicels elongated, and drooping. Key red, smooth, wings about an inch long. Swamps and river banks E.**

3. A. saccharum, Marsh (A. saccharinum, Wang.). Scgar Maple. A large tree. Leares simple, palmately lobed, truncate or heartshaped at the base, lobes sinuate-toothed and acuminate, pale and slightly downy beneath. Flowers appearing with the leaves, on clustered drooping pedicels. Calyx bell-shaped, fringed. Petals none. Keys smooth, wings about $1-1 \frac{1}{2}$ in. long. In. cold woods, more abundant northward. The sap of this tree is the principal source of maple sugar, and some forms of the tree produce the curled maple and hird's-ere maple used in cabinet-making.*

4. A. Pseudo-Platanus, L. SyCAMORE Maple. Easily recognized by its drooping clusters of rather large green flowers, which appear with the leaves. Cultivated from Europe.

5. A. platanoides, L. NorwaY Maple. A large tree, with milky sap. which exules from liroken shoots or leafstalks in the spring. Cultivaterl from Europe : a very desirable shade-tree.

6. A. Negundo, L. Box Fider. A small tree. Leaves opposite, 
pinnately 3-5-foliate; leaflets ovate, lobed, toothed or entire, downy when young. Flowers diøecious, appearing from lateral buds before or with the leaves; the staminate on long and drooping pedicels, the pistillate in drooping racemes. Keys smooth, 1-1 $\frac{1}{2}$ in. long. River banks. Often cultivated as a quick-growing shade-tree.*

\section{HippocastanACE 2 . Buckeye Family.}

Trees or shrubs. Leaves opposite, long-petioled, palmately compound. Flowers showy, somewhat monœeious, in terminal panicles. Calyx 5-lobed, oblique. Petals 4-5, unequal. Stamens 5-8, hypogynous. Pistil 1; ovary 3-celled, 2 ovules in each cell; style slender. Fruit a 1-3-celled, leathery capsule, 1-3-seeded. Seeds with a large scar.**

\section{ÆSCULUS, L.}

Characteristics of the genus as above given for the family.

1. A. Hippocastanum, L. Horse-Chestnut. A round-topped tree with frequently forking branches and stumpy twigs. Leaves very large, with 7 straight-veined leaflets. Flowers large and showy. Corolla open and spreading, of 5 white petals, spotted with purple and yellow. Stamens with long, curved filaments. Fruit large, covered with stout, soft prickles when young. Cultivated from Asia.

2. \&. glabra, Willd. Оніо Buckeye. A large tree, not unlike a horse-chestnut. Leaflets generally 5. Flowers small. Corolla of 4 upright, pale yellow petals. Stamens curved, about twice as long as the petals. Fruit prickly at first. River banks.

3. F. flava, Ait. SweEt BuckeYe. Varying in size from a low shrub to a tall tree. Leaves with 5-7 leaflets. Flowers in a short, dense panicle. Petals 4 , in 2 unlike pairs, bending inward, blades of the longer pair very small. Fruit not prickly. Woods W. and $\mathrm{S}$.

4. A. Pavia, L. Red Buckeye. Shrubs; stems erect, branched, 4-8 ft. high. Leaflets usually 5, lanceolate to narrowly oval, taperpointed at both ends, finely serrate, smooth or nearly so. Flowers in dense, erect panicles, bright red. Stamens rather longer than the petals. Fruit nearly smooth. Common in open woods.* 


\section{BALSAMINACE 2 . BALSAM FAMILY.}

Tender, fleshy-stemmed, annual herbs. Leaves simple, without stipules. Flowers perfect, irregular. Sepals usually 3 , the largest one with a spur. Petals 3. Stamens 5, distinct or nearly so. Ovary 5-celled, bursting when ripe into $\mathbf{5}$ valves.

\section{IMPATIENS, L.}

Characteristics of the genus those above given for the family. Fruit a capsule (very fleshy in our species), which when ripe bursts open with considerable force, throwing the seeds about.

1. I. aurea, Muhl. (I. pallida, Nutt.). Wild BAlsam. LAdy'sSLIPPER. Stem 3-5 ft. high, branching. Leaves oblong-ovate, 2-6 in. long, the lower often long-petioled, the upper neally sessile. Peduncles axillary, 1-3 in. long, slender, 2-5 flowered. Flowers pale yellow, slightly dotted with brownish-red. Sac of the large sepal broader than it is long, ending in a recurred spur about $\frac{1}{4}$ in. long. Damp, shaded ground, not very common.

2. I. biflora, Walt. (I. fulva, Nutt.). WILD BALSAM, LAdy'sslipper, Jewel Weed, Syap Weed, Kicking Colt. Stem 2-4 ft. high, branching. Leares rhombic-ovate, 1-4 in. long. Peduncles about 1 in. long, generally 2-3-flowered. Flowers orange-color, with many pretty, large, reddish-brown spots. Sac longer than it is broad, ending in a recurved spur about $\frac{1}{2}$ in. long. Damp, shaded ground, commoner than No. 1 and usually blossoming earlier.

\section{RHAMNACE EE. BuCKThORN FAMily.}

Trees or shrubs. Leaves simple, often 3-5-nerved ; stipules small. Flowers small, sometimes imperfect, green or yellow. Calyx 4-5-lobed. Petals 4, 5, or absent, inserted on a disk at the throat of the calyx, very small, hooded, usually with claws. Stamens 4-5, inserted with the petals and opposite them, often enclosed by the petals; filaments awl-shaped; anthers small, versatile. Ovary 3-celled, 3-ovuled. 


\section{BERCHEMIA, Necker.}

Shrubs ; stems twining or erect. Leaves alternate, prominently pinnate-veined, stipules minute. Flowers in axillary or terminal panicles, or rarely solitary. Calyx-tube hemispherical, 5-lobed. Petals 5, sessile, concave, as long as the calyx. Ovary 2-celled, half-inferior; stigmas 2. Fruit an oval, 2-seeded stone-fruit.*

1. B. volubilis, DC. Supple-Jack, Rattan-vine. Woody, often twining high; older bark yellowish, twigs purple, wood very tough. Leaves ovate or oval, acute or obtuse, cuspidate at the apex, rounded at the base, wavy on the margins, green above, pale beneath. Flowers in small panicles. Fruit purple. In moist woods and along streams S.**

\section{RHAMNUS, L.}

Leaves alternate, deciduous. Flowers in small, axillary cymes, often imperfect. Petals $4-5$ or wanting. Stamens 4 or 5, very short. Stone-fruit, 2-4-seeded.

1. R. lanceolata, Pursh. A tall shrub. Leaves with short petioles, taper-pointed or somewhat obtuse, very variable in size, smooth or nearly so above, more or less downy beneath, finely serrate. Flowers 2 or 3 together in the axils, greenish, about $\frac{1}{8}$ in. in diameter, usually diøcious, appearing at the same time as the leaves. Calyx 4-lobed. Petals 4. Stamens 4. Fruit black, about $\frac{1}{4}$ in. in diameter. Hills and river banks.

2. R. caroliniana, Walt. Carolina Buckthorn. A small tree with black bark and very hard wood ; twigs finely downy. Leaves alternate, prominently veined, elliptical to broadly oval, entire or obscurely serrate, smooth or sometimes downy below ; petioles slender, downy. Flowers in axillary, peduncled umbels; petals minute. Fruit globose, $\frac{1}{3}-\frac{1}{2}$ in. in diameter, 3 -seeded. Seeds smooth. On river banks.*

\section{CEANOTHUS, $\mathbf{L}$.}

Shrubs. Leaves alternate, petioled. Flowers perfect, in terminal panicles or corymbs formed of little umbel-like clusters. Calyx-tube top-shaped or hemispherical, with a 5-lobed border. Petals 5, with hoods, on slender claws. Stamens 5, filaments long and thread-like. Fruit dry, 3-lobed, splitting when ripe into 3 carpels. 
1. C. americanus, L. New Jersey TeA, Red Root. Shrub, with many branching stems, 1-3 ft. high, from a deep red root. Leares 1-3 in. long, ovate or nearly so, acute or taper-pointed at the tip, obtuse or somewhat heart-shaped at the base, downy beneath, serrate, 3-nerved. Flowers small, white.

\section{Vitace}

Shrubs, with the stem swollen at the insertion of the petioles and climbing by tendrils borne opposite the leaves. Leaves alternate, with stipules simple or compound. Flowers small, greenish, generally in clusters, borne in similar positions to the tendrils, hypogynous or nearly so. Sepals, petals, and stamens 4-5. Carpels 2, each 2-ovuled. Calyx very small. Corolla deciduous, the petals often hooded. Stamens opposite the petals. A disk inside the calyx bears nectar and its lobes alternate with the stamens. Fruit a berry.

\section{VITIS, Tourn.}

Climbing woody vines; stems with tumid joints, climbing by tendrils opposite some of the leaves. Leaves simple, palmately veined or lobed; stipules small, soon deciduous. Flowers mostly somewhat monœcious or diœcious. Petals often united at the apex and not expanding. Stamens inserted between the lobes of the disk. Ovary usually 2-celled, 4-ovuled. Fruit juicy, 1-4-seeded.*

1. V. labrusca, L. Fox Grape. Stems climbing high, often $1 \mathrm{ft}$. or more in diameter; bark shreddy, coming off in long strips, young branches woolly. Leares broadly heart-shaped, more or less deeply 3-5-lobed, mucronate-dentate, very woolly when young, becoming smooth above. Panicles of pistillate flowers compact, of staminate flowers looser. Fruit about $\frac{1}{2}$ in. in diameter, dark purple or sometimes nearly white. In rich woods E., S., and SW. Many of the cultivated varieties, Concord, Niagara, etc., have been developed from this species.*

2. V. æastivalis, Michx. Stmmer Grape. Stem climbing high; bark shreddy. Leares broadly heart-shaped, 3-5-lobed, the lobes dentate. notches rounder. white-woolly when young, often nearly smooth when old; tendrils or panicles opposite 2 out of every 3 
leaves, panicles long and slender. Fruit dark blue, small, very acid. In rich woods E. and S.*

3. V. cordifolia, Michx. Frost Grape, Chicken Grape. Leaves rather smooth, thin, and shining, either not lobed or somewhat 3-lobed, heart-shaped, with the notch at the base deep and acute, taper-pointed, with large, sharp teeth. Flower-clusters large and loose. Grapes shining black, very sour, not ripening until after frosts; seeds 1 or 2, rather large. Moist thickets and banks of streams S.

4. V. rotundifolia, Michx. Muscadine Grape. Stem climbing high; joints short; bark not shreddy; wood very hard, often producing long, aerial roots. Leaves orbicular, heart-shaped at the base, coarsely toothed, nearly or quite smooth. Panicle small. Grapes few in a cluster, large. The original form of the Scuppernong grape S.**

\section{AMPELOPSIS, Michx.}

Woody vines, climbing by tendrils and rootlets. Leaves palmately compound. Flowers in compound cymes, perfect or somewhat monœcious. Petals 5 , distinct, spreading; disk none. Stamens 5. Ovary 2-celled, 4-ovuled. Fruit a 1-4seeded berry, not edible.*

1. A. quinquefolia, Michx. Virginia Creeper. Woodbine. Stem usually climbing high, but sometimes short and prostrate, often producing many adventitious aerial roots which assist the vine in holding to a support; tendrils usually terminating in flat, adhesive disks. Leaves palmately compound, of 5 oval leaflets, coarsely and unevenly toothed above, usually entire below, smooth or slightly downy. Cymes large and spreading when mature; pedicels red. Berries small, dark blue. Common in rich woods.**

2. A. tricuspidata, Sieb. and Zucc. JAPANESE Ivy, Boston Ivy. A freely branching, hardy climber. Tendrils numerous, branching with closely adhesive disks. Leaves occasionally with 3 leaflets, but usually with only one, which is jointed with the main petiole and in autumn falls before the petiole; leaflet 3-lobed or only scalloped, roundish-ovate or heart-shaped, rather thick and shining. Cultivated from Japan.

\section{TILIACE E. Linden Family.}

Trees or shrubs, rarely herbs. Leaves alternate, with stipules. Flowers perfect in cymes, the latter usually in 
corymbs or panicles. Sepals 5. Petals 5 or fewer or wanting. Stamens many, inserted on a swollen disk. Ovary 2-10-celled, with 1 or more ovules in each cell. Fruit 1-12-celled, dry or berry-like.

\section{TILIA, Tourn.}

Trees with rough gray bark on the trunk; bark of the twigs smooth, lead-colored; wood white and soft. Leaves cordate, usually inequilateral. Cymes axillary or terminal, peduncles adnate to a large, prominently veined leaf-like bract. Flowers yellowish-white. Sepals 5. Petals 5. Stamens many, in 5 groups. Ovary 5-celled, with 2 ovules in each cell ; stigma 5-lobed. Capsule 1-celled, 1-2-seeded; peduncle and bract deciduous with the matured fruit, the bract forming a wing by which the fruit is often carried to a considerable distance.*

1. T. pubescens, Ait. BAsswood. A tree of medium size; leaves orate, acuminate at the apex, obtuse and oblique at the base, mucronate-serrate, woolly on both sides or smooth above when old; flowers fragrant, florai bract 2-3 in. long, usually rounded at the base. Fruit globose, about $\frac{1}{4}$ in. in diameter. In rich woods. Bees gather large quantities of nectar from the flowers.*

2. T. americana, L. Basswood, Whitewood. A large tree, sometimes $125 \mathrm{ft}$. high. Leaves larger than in No. 1 (2-5 in. wide), often unsymmetrical, heart-shaped or truncate at the base, sharply toothed. Floral bract often narrowed at the base. Fruit somewhat ovoid, $\frac{1}{3}$ in. or more in diameter. Common in rich woods; occurs farther N. than No. 1.

3. T. europæa, L. European Linden. A good-sized tree. Leaves roundish, obliquely heart-shaped, abruptly taper-pointed, finely toothed. Flowers differing from Nos. 1 and 2 in the absence of petal-like scales at the bases of the stamens. Cultivated from Europe.

\section{MaLVACE正. Mallow Family.}

Herbs or shrubs, with simple, alternate, palmately-veined leaves, with stipules. Flowers regular. Sepals 5, often surrounded by an involucre at the base. Petals 5 . Stamens numerous, monadelphous. Pistils several, more or less distinct. Fruit a several-celled capsule or a collection of 1 -seeded carpels. 


\section{MALVA, $\mathbf{L}$.}

Calyx 5-cleft, with a small, 3-leaved involucre. Petals obcordate or truncate. Styles many, slender, with stigmas running down the sides. Carpels many, 1-seeded, arranged in a circle and separating from each other, but not opening when ripe.

1. M. rotundifolia, L. Common Mallow, Cheeses (from appearance of the unripe fruit). A common biennial or perennial weed, with nearly prostrate stems. Leaves long-petioled, roundkidney-shaped, with crenate margins. Flowers small, whitish, on long peduncles.

2. M. sylvestris, L. High Mallow. Biennial or perennial. Stem erect, 2-3 ft. high. Leaves 5-7 lobed. Flowers purplish, larger than those of the preceding species.

\section{ABUTILON, Tourn.}

Calyx 5-cleft, the tube often angled. Styles 5-20, with knobbed stigmas. Carpels as many as the styles, arranged in a circle, each 1-celled, 3-6-seeded, and opening when ripe by 2 valves.

1. A. striatum, Dicks. Tassel Tree, Flowering Maple. A shrub 5-10 ft. high. Leaves maple-like. Flowers showy, solitary, nodding on slender peduncles. Corolla not opening widely, orange, striped with reddish-brown veins. Column of stamens projecting beyond the corolla like a tassel. Cultivated in hothouses. From Brazil.

\section{HYPERICACE}

Herbs, shrubs, or trees. Leaves opposite, often covered with translucent or dark dots, entire or with glandular teeth, without stipules. Flowers usually in terminal cymes. Sepals 5, rarely 4. Petals as many as the sepals, hypogynous. Stamens usually many, more or less grouped in bundles, anthers versatile. Pod 1-celled, with 2-5 parietal placentæ and the same number of styles, or else 3-7-celled, splitting along the partitions. 


\section{HYPERICUM, $\mathbf{L}$.}

Herbs, shrubs, or small trees. Leaves sessile, often dotted. Flowers yellow, perfect.

1. H. perforatum, L. Сомmon St. Johnswort. Perennial. Stem erect, 1-3 ft. high, 2-ridged, much branched. Leaves linear or oblong, obtuse, with translucent veins and dots. Cymes grouped in corymbs, many-flowered. Flowers 1 in. in diameter. Sepals acute. Petals much longer than the sepals, oblique at the tip and irregularly fringed. A common weed in meadows and pastures E. and N.

2. H. nudicaule, Walt. Orange-Grass, Pine-Weed. Low (4-9 in. high), slender annual, with erect, angled or almost winged wiry stem and branches. Leaves minute, awl-shaped scales. Corolla about $\frac{1}{4}$ in. in diameter, usually closing by or before midday. Sandy banks and roadsides.

66. Violace旡. Violet Family.

Herbs, with simple, alternate leaves, with stipules. Calyx of 5 persistent sepals. Corolla of 5 petals, somewhat irregular, one petal with a spur. Stamens 5 , short, the filaments often cohering around the pistil (Fig. 17). Style generally club-shaped, with a one-sided stigma, with an opening leading to its interior. Pod 1-celled, splitting into 3 valves, each bearing a placenta. The seeds are often dispersed by the splitting of the elastic valves (Fig. 17).

\section{VIOLA, Tourn.}

Sepals ear-like at the base. Petals somewhat irregular, some of them bearded within, thus affording a foothold for bees, the lowest one with a spur at the base. Stamens not cohering very much, the two lowermost with spurs which reach down into the spur of the lowest petal. Many species bear inconspicuous apetalous flowers later than the showy ordinary ones and produce most of their seed from these closed, self-fertilized flowers. (See Part I, Ch. XXVIII.) 


\section{§1. Stemless perennials.}

1. V. pedata, L. Bird-foot Violet, Horseshoe Violet, Sand VioLet. Rootstock stout, upright, not scaly. Leaves all palmately 5-9-parted into linear or linear-lanceolate divisions. Flowers showy, about 1 in. broad, pale violet to whitish; petals not bearded.

2. V. palmata, L. Coмmon Blue Violet. Rootstock stout and scaly. Earlier leaves roundish heart-shaped or kidney-form and crenate, with the sides rolled in at the base when young. The later ones variously cleft or parted. Flowers dark or light blue, sometimes whitish; the lateral petals bearded.

Variety cucullata, Gray. Common Blue Violet, Hood-Leaf Violet. Later leaves remaining nearly crenate, like the earlier ones, in rich soil becoming very luxuriant.

3. V. sagittata, Ait. Arrow-Leaved Violet, Spade-Leaf VioLET. Leaves very variable, ranging in shape from oblong-heart-
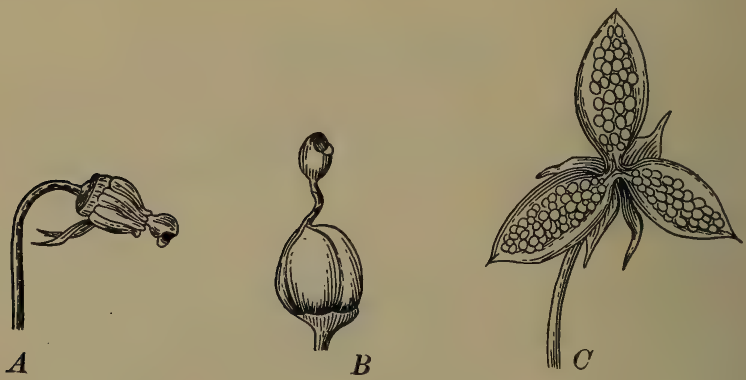

FIG. 17. - Viola tricolor.

$A$, stamens and pistil ; $B$, pistil with stamens removed ; $C$, pod split open.

shaped to triangular-halberd-shaped, very often with an arrowshaped base, the earlier ones on short, margined petioles, the later frequently long-petioled. Flowers rather large, otherwise much as in the preceding species. Variable and perhaps an aggregate of several distinct species.

4. V. blanda, Willd. Sweet White Violet. Rootstock long, slender, and creeping. Leaves roundish heart-shaped or kidneyshaped. Flowers rather small, whitish, sweet-scented, generally beardless, with the lowermost petal exquisitely veined with dark purple lines. In damp or marshy ground. 


\section{§2. Leafy-stemmed perennials.}

5. V. pubescens, Ait. Dowry Yellow Violet. Soft, downy, 6-12 in. high. Leaves broadly heart-shaped, toothed, with large stipules. Flowers yellow, with a short spur.

6. V. canadensis, L. CANAdA Violet. Stems very leafy, smooth, $1 \mathrm{ft}$. or more high. Leaves heart-shaped, taper-pointed, serrate. Flowers large and handsome; petals white, or nearly so, inside, the upper ones usually violet-tinged beneath, lateral petals bearded.

§3. Leafy-stemmerl, from an annual, biennial, or occasionally shortlived perennial root; stipules about as large as the leaves.

7. V. tricolor, L. Pansy, Heart's-ease. Stem branching, angular, hardly erect. Leaves variable, more or less ovate, crenate. Flowers large (often more than 1 in. across), flattish, short-spurred, exceedingly variable in color. Cultivated from Europe.

Variety arvensis. JoHNNY-JUMP-UP, LADY's-DELIGHT. A small flowered variety. Introduced in gardens and sometimes appearing like a native plant.

\section{PASSIFloRACEAe. Passion-flower Family.}

Shrubs or herbs, climbing by axillary tendrils. Leaves alternate, simple, mostly 3-lobed. Flowers axillary, on jointed peduncles, solitary or few together, perfect, regular, often showy. Calyx-tube 4-5-lobed, persistent. Petals usually 5, inserted on the throat of the calyx-tube, which is fringed with a crown of 1-3 rows of long and slender filaments. Stamens 5, their filaments united, and enclosing the stalk of the ovary. Styles 1-5; ovary with $3-5$ parietal placentæ. Seeds numerous, fruit fleshy.

\section{PASSIFLORA.}

Characters of the family.

1. P. incarnata, L. PAssion-flower. Perennial. Stem often 20-30 ft. long, somewhat angled or striate, smooth below, downy above. Leaves broadly heart-shaped, palmately 3-5-lobed, the lobes acute, finely serrate, usually heart-shaped at the base; petiole bearing 
2 oral glands near its summit. Flowers $2-3$ in. wide, solitary; peduncles 3-bracted, longer than the petioles; calyx-lobes with a small horn-like appendage on the back near the apex, white within. Petals and crown purple and white. Fruit yellow, about the size and shape of a hen's egg, edible. Seeds with a pulpy aril. Common along fence-rows and embankments S.*

2. P. lutea, L. Yellow Passion-flower. Perennial. Stem slender, smooth, 6-10 ft. long. Leaves broadly heart-shaped, 3-lobed at the summit, entire, often mucronate; stipules small; petioles without glands. Peduncles longer than the leaves, usually in pairs. Flowers greenish-yellow, $\frac{1}{2}-\frac{3}{4}$ in. wide. Fruit purple, oval, $\frac{1}{2} \mathrm{in}$. long. Woods and thickets S.*

\section{Begoniace $A$. Begonia Family.}

Chiefly perennial herbs or low shrubs, with fleshy or very juicy stems. Leaves alternate, generally heart-shaped at the base, often very unsymmetrical; stipules deciduous. Flowers monœcious, in cymes or other clusters, on axillary peduncles. Stamens many (Fig. 18). Pistillate flowers with the floral envelopes borne on the ovary; ovary 3-angled or 3-winged (Fig. 18), very many-seeded.

\section{BEGONIA, $\mathbf{L}$.}

Flowers with the calyx and corolla of the same color, staminate and pistillate ones both occurring in the same cluster. Sepals usually 2. Petals 2 or in the fertile flowers 3 or 4, sometimes wanting. Stamens many in a cluster, with short filaments. Styles of the fertile flowers 3, often with long, twisted stigmas (Fig. 18, $C$ ). The genus contains a great number of species and varieties, cultivated from tropical or subtropical regions, of which only a few of the commonest are here described.

1. B. Rex, Putz. Herb, stemless or nearly so, from a fleshy rootstock. Leaves large, taper-pointed, very unequally heart-shaped, the margin sinuous, often bristly fringed, upper surface wholly silvery or mottled silvery and dark green, lower surface green or reddish or of both colors. Flowers few, large ( $1 \frac{1}{2}$ to $1 \frac{3}{4}$ in. in diameter), varying from yellow to pinkish. Cultivated from the Himalayas; many varieties. 
2. B. manicata, Cels. Herb, with a short and fleshy stem. Leaves very unevenly heart-shaped, taper-pointed, the margins bristly fringed and sometimes with very remote teeth, upper surface dark green, lower surface and petioles partly corered with long fringed scales, stipules larger and fringed. Flowers flesh-colored, handsome, in a loose panicle borne on a long peduncle. Cultivated from Mexico.

3. B. coccinea, Hook. Tall, 3-10 ft. high, somewhat shrubby, often with many erect, smooth stems from the same root. Leaves

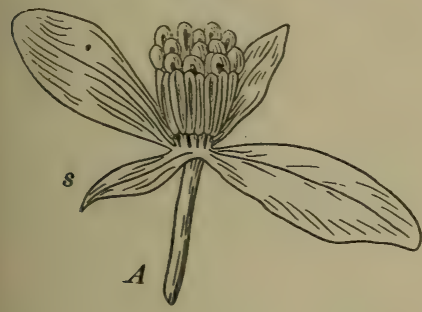

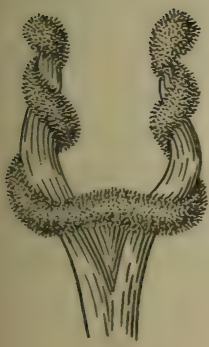

$C$

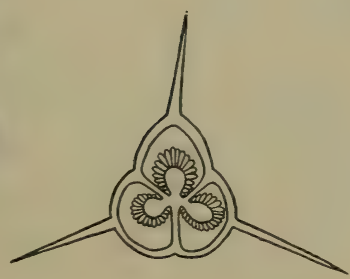

D
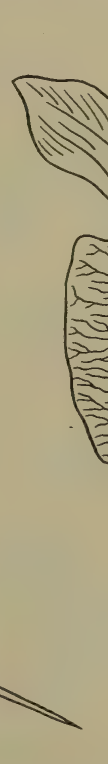

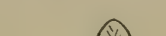

$\cdot$

FIG. 18. - Begonia Flowers.

$A$, staminate flower ; $B$, pistillate flower ; $C$, twisted stigmas, enlarged ; $D$, cross-section of ovary ; 0 , ovary ; $s$, sepals ; $p$, petals.

broadly and unevenly lanceolate or ovate-lanceolate, half-heart-shaped or broadly one-eared at the base, acute, nearly or quite entire, smooth, dull green above, sometimes tinged with reddish below. Peduncles several-many-flowered, reddish, slender, somewhat nodding. Flowers showy, medium sized, scarlet. Fruit showy, scarlet, very broadly winged. Cultivated from Peru. [Often called B. rubra.]

4. B. incarnata, Link and Otto. Herbaceous or mainly so, rather tall ( $2-4 \mathrm{ft}$.), stems clustered, slightly reclining, hairy when young, 
at length smoother. Leaves broadly and very unequally ovatelanceolate, tapering toward the tip but at the extremity somewhat blunt, half-heart-shaped at the base, somewhat lobed and sinuatetoothed, rough-hairy above and below and on the petioles, dark green above with coppery streaks along the veins. Flowers on short peduncles, few, of medium size, beautiful rose-pink in the bud, becoming almost white, thickly covered outside with soft, moss-like hairs. Cultivated from Mexico. [Often called B. metallica.]

5. B. semperflorens, Link and Otto. Stems smooth, herbaceous, rather fleshy, branching near the ground and reclining. Leaves obtuse or nearly so, broadly ovate, somewhat unevenly heart-shaped or tapering at the base, irregularly serrate, or scalloped and wavy, smooth, dark green, and very glossy above; stipules rather large, nearly ovate. Flowers in small, axillary clusters near the top of the stem, whitish to crimson, about $1 \frac{1}{4}$ in. in diameter. Ovary in fruit very broadly winged. An easily grown but homely species. Cultivated from S. Brazil.

\section{CaCtaceze. Cactus Family.}

Plants usually with very fleshy and much thickened, often globular or cylindrical stems (Fig. 49). Leaves usually wanting. Flowers sessile, solitary, often very showy. Perianth consisting of several rows of sepals and petals, adnate below to the ovary. Stamens many, with slender filaments, borne on the inside of the perianth-tube. Style 1 ; stigmas numerous; ovary 1-celled, many-ovuled. Fruit a manyseeded berry.

\section{OPUNTIA, Tourn.}

Stem composed of a series of flattened joints, which are usually leafless when full grown. Leaves very small, awlshaped, spirally arranged, appearing on the young joints, but soon dropping off, with barbed bristles and sometimes spines in their axils. Flowers yellow. Sepals and petals not much united into a tube. Fruit often eatable.

1. 0. vulgaris, Mill. Сommon Prickly Pear. Prostrate or nearly so, pale green. Leaves about $\frac{1}{6}$ in. long, rather scale-like; bristles many, with few or no spines. Flowers 2 in. or more in diameter, with about 8 petals. Fruit about 1 in. long, crimson 
when ripe, eatable. Dry rocks and sandy ground, from Massachusetts south along the coast.

2. 0. Rafinesquii, Engelm. Prostrate, green. Leaves $\frac{1}{4}-\frac{1}{3}$ in. long, awl-shaped, spreading; bristles often intermixed with a few small spines and a larger one $\frac{3}{4}-1$ in. long. Flowers larger than in No. 1 and with $10-12$ petals. Fruit about $1 \frac{1}{2}$ in. long, much tapered at the base. In poor soil.

3. 0. missouriensis, DC. Prostrate, light green. Leaves very small, with bristles and 5-10 spines in their axils. Flowers 2-3 in. in diameter. Fruit dry and spiny. Wisconsin, S. and W.

\section{PHYLLOCACTUS.}

Stems cylindrical when old, with long, flattened, fleshy but leaf-like, sinuate or serrate branches. Flowers nearly or quite regular, from the notches in the margins of the joints.

1. P. Ackermanni, L. Flowers very showy, bright red. Perianthtube shorter than the petals. Sepals scattered, small and bract-like. Petals many, 2-3 in. long, widely spreading, somewhat channeled, sharp-pointed. Cultivated fròm Mexico.

\section{CEREUS, DC.}

Stem more or less prismatic but strongly ridged, with bundles of spines borne on the ridges, sometimes prostrate or trailing, sometimes erect, columnar, and 50 or $60 \mathrm{ft}$. high. Flowers usually showy, borne on the sides of the stem, generally with a rather long perianth-tube, which is covered outside with scale-like sepals, usually with tufts of wool in their axils. Petals many, mostly long and spreading.

1. C. speciocissimus, DC. Stems $2-3 \mathrm{ft}$. high, with $3-4$ broadwinged and sinuate ridges. Flowers open in the daytime and lasting several days, red or crimson, very showy. Petals longer than the tube, stamens white, drooping, very numerous. Commonly cultivated from Mexico.

2. C. grandiflorus, Mill. Night-Bloomivg Cereus. Stems long, climbing by aerial roots, nearly cylindrical, but with 5 or more blunt angles. Flowers very showy, opening only for one night, wilting early in the morning, extremely fragrant. Sepals dull yellow. Petals pearly white, spreading, 6-8 in. long. Cultivated from Mexico. 
70. enotherace 瓜. Evening Primrose Family.

Herbs, rarely shrubs or trees. Leaves opposite or alternate, without stipules. Flowers regular. Calyx-tube adnate to the ovary, its margin 2-4-lobed. Petals $2-4$, rarely wanting, perigynous, quickly falling off. Stamens 1-8. Ovary usually 4-celled; style thread-like; stigma entire or 4-lobed; ovules 1 or more in the inner angle of each cell. Fruit a capsule, berry, or stone-fruit. Seeds 1 or more, smooth or hairy.

\section{ENOTHERA, $\mathbf{L}$.}

Herbs, rarely shrubby. Leaves alternate. Flowers large, yellow, red, or purple. Calyx-tube 4-angled. Petals 4 . Stamens 8. Capsule usually 4-celled, many-seeded.

1. E. fruticosa, L. Sundrops. Biennial or perennial. Stem erect, often rather stout, 1-3 ft. high, downy or sometimes smooth. Leaves lance-oblong, or in one variety linear or nearly so, usually minutely toothed. Racemes often corymbed. Flowers open in the daytime, showy, yellow, 1-2 in. in diameter. Pod nearly sessile, ellipsoidal, with prominent ribs and strong wings. Dry soil, common.

2. E. pumila, L. Small Sundrops. Much like the preceding, but smaller. Leaves oblanceolate or oblong, entire. Flowers $\frac{1}{3}-1$ in. in diameter. Pod club-shaped. In dry soil.

\section{FUCHSIA, L.}

Herbs, shrubs, or trees. Leaves opposite or 3 in a whorl. Flowers showy. Calyx colored, tubular-funnel-shaped, the tube extending much beyond the ovary, the margin 4-lobed. Petals 4, borne in the throat of the calyx. Stamens 8, projecting outside corolla. Capsule berry-like, ellipsoidal, 4-angled.

1. F. macrostemma, Ruiz and Pay. Common Fuchsia, Ladies' EARDROP. Smooth. Leaves slender-petioled, toothed. Flowers on long, drooping peduncles from the axils of the leaves. Calyx-tube oblong or a short cylinder, not as long as its spreading lobes. Petals obovate and notched, wrapped spirally around the projecting fila- 
ments and style. Found in many varieties, sometimes the calyx white or nearly so and the petals dark or with dark calyx and light petals. Cultivated from Chili.

\section{CIRCAEA, Tourn.}

Slender, erect herbs, with creeping rootstocks. Stem simple. Leares opposite, petioled. Flowers small, in terminal and lateral racemes. Calyx-tube ovoid, the limb 2-parted, reflexed, deciduous. Petals 2, inversely heart-shaped, inserted with the 2 stamens under a margin of a disk which is borne on the pistil. Ovary 1-2-celled; style thread-like ; stigma knobbed, 2-lobed ovules, 1 in each cell. Fruit ovoid, not splitting open, covered with hooked bristles.

1. C. lutetiana, L. Exchanter's Nightshade. Stem 1-2 ft. high, glandular-downy. Leares ovate, faintly toothed, long-petioled. Flowers $\frac{1}{8}$ in. in diameter, white or pink, on slender pedicels, jointed at the base. Damp, shaded places; very common.

\section{1. araliace}

Herbs, shrubs, or trees. Leaves alternate, simple or compound; stipules adnate to the petiole or wanting. Flowers regular, in umbels or heads. Limb of the calyx borne on top of the ovary, very short. Petals 5, very deciduous. Stamens 5, filaments bent inward, anthers versatile. Ovary 2-celled or several-celled; styles or stigmas as many as the cells; ovule 1 in each cell. Fruit a stone-fruit or berry. [The English ivy, an important member of the family, flowers too late for school study.]

\section{ARALIA, Tourn.}

Perennial plants with pungent or spicy roots, bark, and fruit. Leaves once or more compound. Flowers more or less monœcious, white or greenish, in umbels. Stone-fruit, berry-like.

1. A. hispida, Vent. Bristly Sarsaparilla, Wild Elder. Stem 1-2 ft. high, rather shrubby below, with prickly bristles. Leaves once or twice pinnate; leaflets ovate, acute, cut-serrate and 
often lobed. Peduncle bearing several umbels of cream-colored flowers, in a terminal corymb. Fruit blue-black. Dry fields and pastures E.

2. A. nudicaulis, L. SARsaparilla. Perennial herb; roots very long, somewhat fleshy, aromatic; stem very short or none. Leaf solitary, from a sheathing base, petioled, 6-12 in. long; compound in threes, each division 3-5-pinnate; leaflets oval or ovate, taper-pointed, finely and sharply serrate, smooth above, often downy below. Scape nearly as long as the petiole, usually bearing 3 short, peduncled umbels. Flowers greenish. Styles distinct. Fruit globose, black. In rich woods.

72. UMBEllifer 瓜. Parsley Family.

Herbs, usually with hollow, grooved stems. Flowers small, generally in umbels. Calyx-tube adnate to the ovary; limb of the calyx either wanting or present only as a 5-toothed rim or margin around the top of the ovary. Petals 5. Stamens 5, inserted on the disk, which is borne by the ovary (Fig. 19). Ovary 2-celled and 2-ovuled (Fig. 19), ripening into 2 akene-like carpels, which separate from each other. Each carpel bears 5 longitudinal ribs, in the furrows between which secondary ribs frequently occur. On a cross-section of the fruit, oil-tubes are seen, traversing the interspaces between the ribs, and near the surface of the fruit (Fig. 19). The seeds contain a small embryo, enclosed in considerable endosperm. [The family is a difficult one, since the flowers are so much alike that the species are distinguished from each other mainly by minute characteristics of the fruit.]

\section{ERYNGIUM, Tourn.}

Annual, biennial, or perennial herbs. Stems erect or creeping. Leaves simple, mostly linear and spiny-toothed. Flowers white or blue, in dense, bracted heads or spikes, flowers bracteolate. Calyx-teeth rigid, persistent. Petals erect, pointed. Styles slender. Fruit top-shaped, scaly or granular, ribs wanting, oil-tubes usually 5 , minute.* 
1. E. yuccæfolium, Michx. Button Sxakeroot, Rattlesvake Master. Perennial. Stem erect, branched above, striate, corered with a bloom, 2-3 ft. high. Leares linear, often $2 \mathrm{ft}$. or more in length, rigid, corered with a bloom, parallel-reined, fringed with white bristles. Bracts shorter than the heads, entire, bracteoles similar but smaller. Flower's white. Fruit scaly. In damp soil.*

\section{SANICULA, Tourn.}

Slender, erect, perennial herbs. Rootstock short, stout, creeping. Leaves palmately cut. Umbels small, somewhat globular, irregularly compound; bracts leafy ; bracteoles few ;
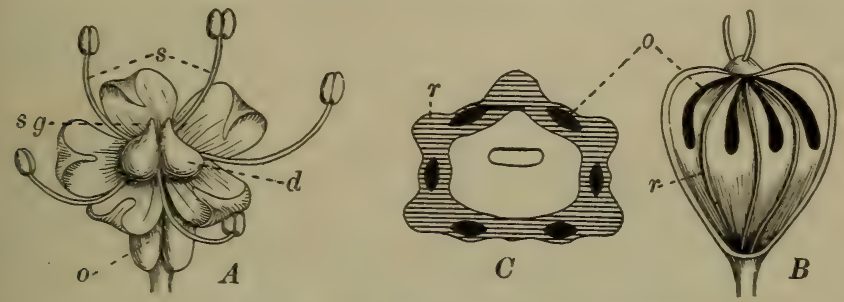

FIG. 19.-Flower and Fruit of 'Umbelliferæ.

$A$, flower of Faniculum; B, fruit of Heracleum; $C$, fruit of Heracleum, cross-section ; $o$ (in $A$ ), orary : $d$, disk ; $s g$, stigma ; $s$, stamens ; $o$ (in $B$, and $C$ ), oil-tubes ; $r$, ribs. $A, B$, and $C$ all enlarged.

flowers perfect or staminate, greenish or yellowish. Calyxteeth as long as the small petals, sharp-pointed. Fruit ovoid, covered with hooked prickles, ribless, each earpel with jo oiltubes.

1. S. marylandica, L. Saxicle, Black Sxakeroot. Stem rather stout. $1 \frac{1}{2}-4 \mathrm{ft}$. high. Leares $3-7$-parted, the dirisions irregularly serrate or dentate and often cut. Petals greenish-white, very small. Fruit with two slender, recurved styles at the apex. Rich woods.

\section{ERIGENIA, Nutt.}

A little smooth plant with a slender, unbranched stem, from a deep, nearly globular tuber. Leaves 1 or 2, twice or thrice compound in threes. Flowers few, small, in an imperfect leafy-bracted umbel. Calyx-teeth wanting. Petals obovate 
or spatulate. Fruit smooth, roundish, notched at both ends, the two carpels touching only at top and bottom, each with 5 slender ribs.

1. E. bulbosa, Nutt. Harbinger of Spring, Turkey Pea, Pepper-And-SALt. Stem scape-like, with a leaf which forms an involucre to the flower-cluster. Petals white, anthers brown-purple. A pretty, though inconspicuous plant; welcomed as one of the earliest spring flowers $\mathrm{S}$.

\section{OSMORRHIZA, Raf.}

Perennials, springing from stout, aromatic roots. Leaves compound in threes. Flowers white, in compound umbels. Calyx-teeth wanting. Fruit linear or nearly so, tapering at the base, with 5 equal bristly ribs, without oil-tubes.

1. 0. brevistylis, DC. Hairy Sweet Cicely. Rather stout and hairy, especially when young, $1 \frac{1}{2}-3 \mathrm{ft}$. high. Lower leaves on long petioles, large, twice compound in threes, the divisions ovate or oval, cut-toothed, upper leaves nearly sessile, less compound. Umbels with long peduncles and spreading rays. Style and its enlarged base somewhat conical. Root nauseous. Rich woods.

2. 0. longistylis, DC. Smooth-Leaved Sweet Cicely. Much like No. 1 in general appearance. Smooth or nearly so. Style rather thread-like. Root of a pleasant aromatic flavor (as is also the fruit). Woods.

Caution. So many plants of this family have actively poisonous roots and foliage that it is unsafe for any one but a botanist, who can distinguish the poisonous species from the harmless ones, to taste them.

\section{CARUIM, $\mathbf{L}$.}

Herbs, with slender, smooth stems. Leaves pinnately compound, smooth. Umbels compound. Flowers white or yellowish. Calyx-teeth minute. Fruit smooth, oblong or ovate, with thread-like ribs; oil-tube single in the intervals between the ribs; base of the styles thickened into a conical mass.

1. C. Carui, L. Caraway. Perennial. Leaves large, with the leaflets cut into numerous thread-like divisions. Flowers white. Fruit aromatic, used somewhat in this country and more in N. Europe for flavoring cookies, bread, etc. Introduced from Europe. 


\section{THASPIUM, Nutt.}

Perennial herbs. Stem erect. Leaves 1-2, compound in threes. Umbels compound, involucre and involucels usually wanting. Flowers yellow or purple. Calyx-teeth small, acute. Fruit ovoid or oblong, somewhat laterally compressed; carpels smooth, strongly ribbed, oil-tubes between the ribs.*

1. T. barbinode, Nutt. Hairy Meadow Parsitp. Stem erect, branching above, downy at the nodes, $2-7 \mathrm{ft}$. high. Leares petioled, slightly downy, leaflets mostly thin, ovate, toothed, incised or lobed toward the apex, entire toward the base. Umbels long-peduncled, few-rayed. Fruit oblong, lateral and central ribs strongly winged. Along streams.*

\section{ZIZIA, Koch.}

Smooth perennials. Leaves generally as in Thaspium. Involucre wanting; involucels of small bractlets. Umbels compound. Flowers yellow. Calyx-teeth prominent. Fruit more or less ovoid, smooth, with thread-like ribs, oil-tubes large and solitary between the ribs and a little one in each rib ; the central fruit of each umbellet sessile.

1. Z. aurea, Koch. Meadow Parswip, Golden Alexanders. Smooth, stem erect, 1-2 ft. high. Root-leares mostly heart-shaped and serrate, stem-leares usually once compound in threes. Flowers deep yellow. Fruit between globose and ovoid, about $\frac{1}{6}$ in. long, all the ribs generally winged. Woods and thickets.

\section{PASTINACA, L.}

A tall, smooth biennial with a stout, grooved stem. Leaves pinnate. Flowers yellow, in large umbels, with hardly any involucre. Calyx-teeth wanting. Fruit oval, very flat, with a thin wing, oil-tubes single, running the whole length.

1. P. sativa, L. Commox Parsxip. Cultivated from Europe for its large, conical, sweet, and edible roots. Also introduced in waste places.

\section{HERACLEUM, L.}

A stout perennial, with the very large leaves compound in threes. Umbels large, compound, with the involucels many- 
leaved. Petals white, inversely heart-shaped, the outer ones usually 2-cleft and larger. Calyx with 5 small teeth. Fruit tipped with a thick, conical enlargement of the style, with three blunt ribs on the outer surface of each carpel and a large oil-tube in each interval between the ribs. Seeds flat.

1. H. lanatum, Michx. Cow Parsnip. Stem grooved and woolly, 4-8 ft. high. Leaflets petioled, broad, deeply and irregularly toothed.

\section{DAUCUS, $\mathbf{L}$}

Annual or biennial, bristly-hairy herbs. Leaves pinnately twice or more compound, the divisions slender. Umbels compound, many-rayed. Flowers small, white. Calyx-teeth slender or wanting. Petals notched, the point bent inward, often unequal. Fruit ovoid or ellipsoid, with rows of spines.

1. D. Carota, L. Сомmon Carrot. Erect, 1-3 ft. high, with a conical, fleshy, orange-colored root. Lower and root-leaves 2-3 pinnate. Central flower of each umbel and sometimes of each umbellet larger and very dark purple, with the corolla irregular. Cultivated from Europe for the edible roots; also introduced in pastures and meadows and along roadsides E.

\section{CORNACE 2 . Dogwood Family.}

Shrubs or trees, rarely herbs. Leaves opposite or alternate, without stipules. Flowers small, regular, variously clustered. Calyx-tube adnate to the ovary ; limb of the calyx very short. Petals $4-5$, borne on the margin of a disk on top of the ovary. Stamens 4-5, inserted with the petals. Ovary 1-4-celled, with one ovule in each cell; style 1. Fruit (in our species) a 1-2-celled and 1-2-seeded stone-fruit.

\section{CORNUS, Tourn.}

Trees, shrubs, or herbs. Leaves usually opposite. Flowers in forking cymes, or in umbels or heads, each with an involucre, white or yellow. Calyx-teeth 4. Petals 4. Stamens 4 . Ovary 2-celled. Stone-fruit, ovoidal or ellipsoidal, the stone 2-celled. 
1. C. canadensis, L. Dwarf Corvel, Bunch-Berry, PuddingBERRY. Stem herbacegus, excepting at the base, low (3-9 in.), and unluranched. Rootstock rather woody, slender, and creeping. Leaves in what appears to be a whorl of 4 or 6 at the summit of the stem, sessile, orate, oval or nearly so, acute at each end, entire, smooth or very slightly downy. Flower-stalk slender, $\frac{1}{2}-1 \frac{1}{2}$ in. long, with a whorl of 4-6 large, white, petal-like bracts, forming an involucre round the small head of greenish flowers; the head with its involucre appearing to others than botanists like a single flower. Fruit nearly spherical, scarlet, about $\frac{1}{4}$ in. in diameter, in a close cluster, sweet and eatable, though rather insipid. Damp woods, especially N.

2. C. florida, L. Flowerixg Dogwood. Small trees; bark rough, black. Leares opposite, petioled, ovate to orate-lanceolate, entire, green and shining abore, paler and often downy beneath. Flowers small, greenish, in heads which are subtended by 4 large, white or pink, inversely heart-shaped bracts, thickened and greenish at the notch. Fruit oroid, bright red. In rich woods S. and E.*

3. C. circinata, L'Her. Round-Leaved Dogwood. A shrub 3-10 ft. high, with green, warty twigs. Leares petioled, roundishoral, contracted to an abrupt point, entire, usually rounded or truncate at the base, pale and soft-downy beneath. Flowers in flat crmes, $1 \frac{1}{2}-2 \frac{1}{2}$ in. in diameter. Fruit globose, light blue, $\frac{1}{4}$ in. or less in diameter. Thickets often in rocky soil $\mathbf{\Lambda}$. and along Alleghany Mountains.

4. C. sericea, L. Kiмхıкххік. A shrub, 6-10 ft. high; twigs purple, downy when young. Leares opposite, petioled, ovate or oblong, taper-pointed, smooth above, silky-downy below. Flowers white, in rather close cymes. Fruit blue, stone somewhat oblique. In low woods.*

5. C. asperifolia, Michx. Rough-Leaved Dogwood. A shrub 8-12 ft. high; twigs slender, reddish-brown, often warty, densely downy when young. Leares opposite, short-petioled, lance-ovate or oblong, acute or taper-pointed, with rough down above, downywoolly below. Cymes flat, spreading, the peduncle and branches corered with rough down. Flowers white. Fruit white or pale blue, stone depressed-globose. In dry woods.*

6. C. stolonifera, Michx. Red Osier Dogwood. A shrub 3-15 $\mathrm{ft}$. high, with smooth, reddish-purple bark on all the younger twigs, spreading by suckers from the base and therefore the stems usually clustered. Leares on rather slender petioles. acute or taper-pointed, rounded or tapered at the base, covered at least beneath by very fine, closely appressed hairs. Fruit white or nearly so, globose, $\frac{1}{4}$ in. or more in diameter. Common in wet ground, especially $\mathrm{N}$.

7. C. alternifolia, L. Alternate-leaved Dogwood. A shrub or small tree; twigs greenish, striped. Leaves alternate, often 
clustered at the ends of the twigs, long-petioled, oval, acute at the apex and often at the base, minutely toothed, pale and covered with fine, appressed hairs beneath; cymes loose and open. Flowers white. Fruit deep blue. Banks of streams.*

\section{NYSSA, $\mathbf{L}$.}

Trees or shrubs. Leaves alternate, petioled, entire or fewtoothed. Flowers somewhat monœcious or diœeious, the staminate in many-flowered heads or cymes, the pistillate in small clusters or solitary. Calyx-tube 5-toothed or truncate. Petals minute or wanting. Stamens 5-10. Ovary 1-celled, 1-ovuled; style long and recurved. Fruit a 1-seeded stonefruit.

1. N. sylvatica, Marsh. BLACK Gum. A tree with widely spreading branches and dark, rough bark, wood light-colored, very tough, base of trunk often enlarged. Leaves often clustered at the ends of the twigs, oval or obovate, taper-pointed or obtuse at the apex, entire, smooth and shining above, downy beneath, becoming bright red in autumn. Staminate flowers in heads. Pistillate 3-10 in a long-peduncled cluster. Fruit ovoid, dark blue or nearly black, $\frac{1}{2}$ in. long, stone slightly ridged. In rich, wet soil S. and E.*

2. N. uniflora, Wang. Tupelo. A large tree, similar to the preceding. Leaves long-petioled, oval or ovate, acute at each end, entire or coarsely toothed, the lower sometimes heart-shaped, smooth above, downy beneath, $4-8$ in. long. Staminate flowers in heads. Pistillate flowers on long peduncles, solitary. Fruit ovoid, dark blue, stone sharply ridged. In swamps $\mathrm{S}$. and E.*

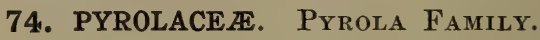

Perennial herbs, evergreen or else pale and without chlorophyll. Petals usually free from each other and falling off separately after flowering. Stamens hypogynous, the anthers without appendages and opening by pores or by a transverse slit. Fruit a capsule containing a great number of very small seeds.

\section{Chimaphila, Pursh.}

Low plants, nearly herbaceous, with reclining stems, from long, horizontal, underground shoots. Leaves opposite or 
whorled, leathery, shining, evergreen, on short petioles. Flowers fragrant, white or purplish, on a corymb or umbel which terminates the stem. Calyx 5-cleft or 5-parted, persistent. Petals 5, concave, roundish, spreading. Stamens 10 , the filaments enlarged and downy in the middle, the anthers somewhat 4-celled, opening when mature by pores at the outer end. Style top-shaped, nearly buried in the top of the globular ovary. Capsule erect, 5-celled.

1. C. umbellata, Nutt. Prince's Pive, Pipsissewa. Branches leafy, 4-12 in. high. Leares spatulate or wedge-oblanceolate, obtuse or nearly so, sharply serrate, very green and glossy. Flowers several, umbelled or somewhat corymbed, white or pinkish, the anthers violet. Dry woods, especially under pine trees.

2. C. maculata, Pursh. Spotted Wintergreen. Much resembles No. 1, but has only scattered teeth on the leares, which are mottled with white on the upper surface and are often broad or rounded at the base. Dry woods.

\section{PYROLA, Tourn.}

Biennial or perennial, almost woody herbs; rootstock slender and creeping. Leaves mostly radical, with broad petioles, evergreen. Flowers in racemes, nodding, on a bracted scape. Sepals 5. Corolla usually globose, of 5 free or nearly free, roundish petals. Stamens 10, in pairs opposite the petals, hypogynous; anthers as in Chimaphila. Capsule globose, 5 -celled, splitting into 5 valves, the latter usually with downy edges.

1. P. elliptica, Nutt. Shiv-Leaf. Scape 5-10 in. high. Leafblades oborate-oral or elliptical, rather thin, dark green, faintly scalloped, almost always longer than their margined petioles. Flowers greenish-white, very fragrant. Rich, usually dry woods, especially $\mathrm{N}$.

2. P. rotundifolia, L. Round-Leaved Wintergreen. Scape $6-20 \mathrm{in.} \mathrm{high.} \mathrm{Leaf-blades} \mathrm{roundish} \mathrm{or} \mathrm{oval,} \mathrm{leathery,} \mathrm{shining} \mathrm{above,}$ faintly scalloped, often rounded at the base or almost heart-shaped, usually shorter than the slightly margined petioles. Flowers white, very fragrant. Varies greatly. Usually in dry woods N. 


\section{MONOTROPA, $\mathbf{L}$.}

Leafless, simple, erect, white, brown, or red root-parasites or saprophytes or fed by slender fungus-threads which cluster on the roots. Stem scaly, the upper scales often passing into bracts. Flowers solitary or in spikes or racemes. Sepals or bracts $2-5$, erect, deciduous. Petals 4 or 5 , erect or spreading. Stamens 8 or 10 , hypogynous, the filaments awl-shaped, anthers kidney-shaped. Ovary 4-5-celled; style simple ; stigma disklike, with $4-5$ rays.

1. M. uniflora, L. Indian PiPe. Stem smooth, fleshy, 4-6 in. high. Bracts ovate or lanceolate. Flower single, tubular, $\frac{3}{4}-1$ in. long, inodorous. Stamens a little shorter than the petals. Capsule angled, $\frac{1}{2}-\frac{3}{4}$ in. long. Whole plant waxy-white, turning black in drying. In moist, shady woods $\mathrm{N}$. and E.*

2. M. Hypopitys, L. Pine-SAP. Stems single or clustered, white or reddish, 4-8 in. high. Bracts ovate-lanceolate. Flowers several, in a scaly raceme, fragrant, $\frac{1}{2}-\frac{3}{4} \mathrm{in}$. long. Capsule oval, $\frac{1}{4} \mathrm{in}$. long. In dry, shady woods, especially under oaks or pines.**

\section{ERICACE}

Usually shrubs or slightly shrubby plants. Leaves simple, generally alternate. Corolla commonly regular, 4-5-cleft, sometimes polypetalous. Stamens hypogynous, distinct, as many or twice as many as the petals, the anthers mostly opening by a hole at the end. Ovary usually with as many cells as there are corolla-lobes; style 1 . Seeds small, with endosperm.

\section{A.}

Shrubs or small trees. Calyx free from the ovary. Corolla hypogynous, usually gamopetalous.

Shrubs or small trees, with showy flowers. Anthers not held down in pockets in the corolla. Rhododendron, I.

Shrubs, with showy flowers. Anthers at first held in pocketlike depressions in the corolla. Kalmia, II. 
Shrubs, with small, mostly white, urn-shaped flowers.

Andromeda, III.

A prostrate plant, hardly at all shrubby. Leaves rather large, often $1 \frac{1}{2}$ in. wide, and veiny.

Epigæa, IV.

A trailing plant with small (about $\frac{1}{4}$ in. wide), thick, evergreen leaves. Arctostaphylos, V.

B.

Shrubs. Calyx-tube adnate to the ovary, on which the gamopetalous corolla and the stamens are borne. Fruit a true berry or resembling one.

Fruit a berry-like stone-fruit, with 10 nutlets which resemble seeds.

Gaylussacia, VI.

Fruit a berry with many small seeds.

Vaccinium, VII.

\section{RHODODENDRON, $\mathbf{L}$.}

Shrubs, often much branched. Leaves alternate, thin, deciduous. Flowers very showy, in terminal umbels, from scaly buds, which became well developed the previous season. Calyx very small, 5-parted. Corolla bell-shaped, the tube long and slender, the limb spreading and somewhat one-sided. Stamens 5 or 10, declined; anthers awnless. Style long and slender, declined; stigma knobbed. Capsule oblong or linear, 5-celled, many-seeded; seeds very small, scale-like.

1. R. nudiflorum, Torr. Wild Honeyseckle, Election Pink. A branching shrub, 4-6 ft. high; twigs smooth or' with a few coarse hairs. Leares oborate or oblong, ciliate-serrate, downy, becoming smooth abore; petioles short. Flowers appearing with or before the leares, pink or white, sometimes yellowish, fragrant, 1-2 in. wide, tube downy but not glandular. Capsule erect, linear-oblong, $\frac{2}{3}-\frac{3}{4}$ in. long. Swamps and banks of streams; flowers extremely variable in size and color.*

2. R. viscosum, Torr. Swamp Honeyseckle, Swamp Pink. A shrub, 4-6 ft. high; branches hairy. Leaves oborate, leathery, mucronate at the apex, mostly smooth above, downy on the veins beneath; petioles very short. Flowers appearing later than the leares, white, fragrant, $1 \frac{1}{2}-2$ in. long; tube long, glandular-riscid; capsule erect, $\frac{1}{2}-\frac{2}{3} \mathrm{in}$. long, bristly. In swamps.** 


\section{KALMIA, L.}

Erect and branching shrubs. Leaves alternate, opposite or in threes, entire, leathery, evergreen. Flowers showy, in corymbs or 1-3 in the axils. Calyx 5-parted. Corolla flatbell-shaped or wheel-shaped, 5-lobed. Stamens 10, the anthers placed in pouches in the corolla, filaments straightening elastically at maturity and so bringing the anthers in contact with any large insect-visitor. Style long and slender. Capsule globose, 5-celled, many-seeded.

1. K. angustifolia, L. Sheer Laurel. A shrub, 1-3 ft. high, with smooth, nearly erect branches. Leaves petioled, opposite or in threes, oblong, obtuse at both ends, dark green above, paler beneath. Corymbs lateral, glandular. Flowers purple or crimson, $\frac{1}{2}-\frac{1}{3}$ in broad; pedicels slender, recurved in fruit. Calyx downy, persistent. Style persistent; capsule depressed-globose. On hillsides ; abundant northward.*

2. K. latifolia, L. Calico Bush, Mountain Laurel. A shrub, 4-10 ft. high. Branches stout, smooth. Leaves mostly alternate, petioled, elliptical or oval, acute at each end, smooth and green on both sides. Corymbs terminal, compound. Flowers white to rosecolor, showy, 1 in. broad. Calyx and corolla glandular; pedicels long, slender, sticky-glandular, erect in fruit; calyx and style persistent. Shady banks on rocky or sandy soil.*

\section{ANDROMEDA, $\mathbf{L}$.}

A small shrub, with scaly buds. Leaves alternate. Flowers in nearly terminal umbels, white or pink. Sepals 4 . Corolla hypogynous, globose, with a 5-cleft, reflexed limb. Stamens 10, hypogynous, not projecting beyond the corolla; filaments bearded. Ovary 5-celled; style simple; stigma obtuse or enlarged. Capsule somewhat globose, 5-valved. Seeds small, smooth and hard.

1. A. polifolia, L. Wild Rosemary. Stems long, rooting at the base, with somewhat erect, twiggy, smooth branches, 6-18 in. high. Leaves elliptical-lanceolate, smooth and shining, thick and evergreen. Flowers small, purplish. Wet bogs, common N.

2. A. Mariana, L. StAGGer-BUSh. Usually smooth, $2-4 \mathrm{ft}$. high. Leaves moderately thin and deciduous, oblong or oval, 1-3 in. long. Flowers rather small, white or pinkish, nodding, in racemes on the 
naked shoots of the preceding year. Low grounds. Foliage said to be poisonous to young browsing animals.

IV. EPIGÆA, L.

Prostrate or trailing shrubs. Stems rusty-downy, 6-12 in. long. Leaves alternate, leathery, evergreen. Flowers in bracted, terminal close racemes or clusters. Calyx 5-parted, persistent. Corolla salver-shaped, 5-lobed. Stamens 10, about the length of the corolla-tube. Ovary 5-lobed; style columnar ; stigma 5-lobed. Fruit a globose, hairy, 5-celled, many-seeded capsule.*

1. E. repens, L. Ground Laurel, Trailing Arbutus, MayFLowER. Stems creeping, the young twigs ascending. Leaves oval or somewhat heart-shaped, entire, netted-veined, smooth above, rough-hairy beneath; petioles short, rough-hairy. Racemes shorter than the leaves. Flowers white to bright pink, $\frac{1}{2}$ in. broad, very fragrant. In dry woods, often covering considerable areas.*

\section{ARCTOSTAPHYLOS, Adans.}

Shrubs. Leaves alternate, evergreen. Flowers pinkish or nearly white, in terminal, bracted racemes. Calyx 4-5-parted, persistent. Corolla 4-5-lobed, the lobes recurved. Ovary 5-10-celled, each cell containing 1 ovule. Fruit a berry-like stone-fruit, with 5-10 nutlets.

1. A. Uva-ursi, Spreng. Bearberry. In trailing clumps, the branches 1-2 ft. high. Leaves evergreen, finely woolly, obovate or spatulate, entire, very leathery. Racemes few-flowered, very short. Corolla urn-shaped, the teeth hairy within. Berry red, $\frac{1}{4}$ in. in diameter. Rocks and dry hilltops, especially N.

\section{GAYLUSSACIA, HBK.}

Low, branching shrubs, mostly resinous-dotted. Leaves serrate or entire. Flowers small, white or pink, in lateral, bracted racemes, nodding; pedicels usually 2-bracteolate. Calyx-tube short, obconic, the lobes persistent. Corolla ovoid to bell-shaped, 5-lobed, the lobes erect or recurved. Stamens equal, usually included; anthers awnless. Fruit a 10-seeded, berry-like stone-fruit.* 
1. G. frondosa, Torr. and Gray. TANGLeberRy. An erect shruib, 1-3 ft. high; branches spreading, slender, gray, slightly downy. Leaves entire, oblong or obovate, obtuse, thin, smooth and green above, paler, downy, and with resinous dots beneath; petioles short. Racemes few-flowered. Corolla small, greenish-pink, short-bellshaped; bracts small, oblong, shorter than the pedicels. Berry depressed-globose, dark blue, with bloom, sweet, about $\frac{1}{3}$ in. in diameter. On low ground.*

2. G. resinosa, Torr. and Gray. HuckLeberRY. A muchbranched, stiff shrub, 1-3 ft. high, slightly downy when young. Leaves oval or oblong, rarely obovate, obtuse or nearly so, entire, covered when young with little resinous particles. Flowers in short, one-sided racemes. Corolla at first conical-ovoid, becoming afterward nearly cylindrical, pink or reddish. Fruit (in the typical form) black, with no bloom, sweet, the seed-like nutlets rather large. Woods and pastures in sandy soil.

\section{VACCINIUM, $\mathbf{L}$.}

Shrubs or small trees. Leaves entire or serrulate, often leathery and evergreen. Flowers terminal or lateral, clustered or solitary, nodding. Pedicels 2-bracteolate. Calyxtube globose or hemispherical, 4-5-lobed, persistent. Corolla urn-shaped, cylindrical or bell-shaped, 4-5-lobed. Stamens twice as many as the lobes of the corolla, anthers awned or awnless. Ovary 4-5-celled, each cell partially divided by a partition, which makes the ovary appear 8-10-celled; style slender; stigma simple. Fruit a many-seeded berry.*

1. V. corymbosum, L. High-Bush Blueberry. An erect shrub, 6-12 ft. high; branches stiff, young twigs minutely warty. Leaves deciduous, oval to ovate-lanceolate, acute, margins bristly, serrulate, smooth or downy, short-petioled. Racemes numerous, appearing with or before the leaves. Bracts oval or oblong, deciduous. Flowers white or pink. Corolla almost as long as the pedicel, cylindrical. Berry globose, blue or black, flavor slightly acid, pleasant. Common in woods and thickets, whole plant extremely variable.*

2. V. pennsylvanicum, Lam. Dwarf Blueberry, Low BlueBERRY. Low (usually 6-12 in. high, sometimes $2 \mathrm{ft}$. high) and smooth, with warty, green branches. Leaves oblong or oblonglanceolate, sharply serrate, with little bristle-pointed teeth, both sides smooth and shining except for down occasionally on the midrib and veins below, pointed at both ends. Flowers few in a cluster, longer than their minute pedicels. Corolla oblong, bell-shaped, 
a little narrowed at the throat, white or pinkish. Berry blue, with much bloom, ripening earlier than the other eatable species, sweeter than No. 1, but not so high-flarored. In dry or sandy soil, especially $\mathrm{N}$.

3. V. stamineum, L. Deerberry, Squaw Huckleberry. An erect shrub, 3-10 ft. high; hranches widely spreading, twigs smooth or minutely downy. Leaves deciduous, oval or oblong, acute or taper-pointed at the apex, obtuse or slightly heart-shaped at the base, firm, smooth, and green above, pale and slightly downy beneath, petioled. Racemes with leaf-like bracts. Flowers numerous, drooping, on jointed, slender pedicels. Corolla bell-shaped, purplish-green, 2-awned anthers and style projecting. Berry globose or pear-shaped, inedible. Dry woods.*

4. V. arboreum, Marsh. FARKLEBERry. Tree-like, sometimes $30 \mathrm{ft}$. high; bark gray ; twigs slender, smooth or downy. Leaves deciduous, orate or oval, mucronate, entire or glandular-dentate, leathery, green above, often slightly downy beneath. Racemes with leaf-like bracts; pedicels slender, drooping. Corolla campanulate, white. Anthers included; style projecting. Berry globose, black, mealy, ripening in winter. Common in dry, open woods.*

5. V. macrocarpon, Ait. Cravberry. Stems creeping, threadlike, 1-3 ft. or more in length, the branches not quite erect, sometimes 8 in. high. Leaves usually oval or oblong, obtuse, thickish, erergreen, the younger ones with the margins somewhat rolled under. Flowers nodding. Petals strongly reflexed, deep rose-red inside at the base, pale pinkish or almost white at the tips. Stamens with the filaments hardly $\frac{1}{3}$ as long as the anthers. Fruit red or reddish-purple, ellipsoidal or nearly globose, rery acid, much ralued for sauce, pies, and jellies. Common in peat-bogs and wet meadows $\mathrm{N}$.

\section{PRimulace e. Primrose Family.}

Herbs, with simple leaves, often most or all of them radical. Flowers perfect and regular, generally gamopetalous. Stamens commonly 5, inserted on the corolla, opposite its lobes. Pistil consisting of a single stigma and style and a (generally free) 1-celled ovary, with a free central placenta.

\section{DODECATHEON, L.}

A smooth, perennial herb, with a cluster of oblong or spatulate root-leaves, fibrous roots, and an unbranched scape, 
leafless except for an involucre of small bracts at the summit, with a large umbel of showy, nodding flowers. Calyx deeply 5-cleft, with reflexed, lanceolate divisions. Tube of the corolla very short, the divisions of the 5-parted limb strongly reflexed. Filaments short, somewhat united at the base; anthers long, acute, and combining to form a conspicuous cone.

1. D. meadia, L. Shooting Star, Indian Chief. Corolla varying from rose-color to white. In rich woods in most of the Middle and Southern States. Often cultivated.

\section{PRIMULA, $\mathbf{L}$.}

Low, perennial herbs, with much-veined root-leaves ; scapes, each bearing an umbel of flowers, which are often showy. Calyx tubular, decidedly angled, 5-cleft. Corolla more or less salver-shaped, with the tube widened above the insertion of the stamens; the 5 lobes of the limb often notched or cleft. Stamens 5, not protruding outside the corolla-tube. Capsule egg-shaped, splitting at the top into 5 valves, each of which may divide in halves.

1. P. grandiflora, Lam. True Primrose. Leaves spatulate or obovate-oblong. Flowers rising on separate slender pedicels from the leaf-axils. Corolla originally pale yellow, but varying to white, red, and many intermediate shades, with a broad, flat limb. Cultivated from Europe.

2. P. sinensis, Sabine. Chinese Primrose. A rather coarse, downy plant. Leaves round-heart-shaped, more or less lobed and cut, long-petioled. Flowers large, in umbels, usually rose-color or white. Calyx large, inflated and conical. Cultivated as a house plant.

\section{TRIENTALIS, $\mathbf{L}$.}

Low, smooth, perennial herbs, with slender, erect, unbranched stems. Leaves lanceolate, ovate, or oblong, mostly in a whorl at the summit of the stem. Flowers one or few, terminal, on slender peduncles, small, white or pink. Sepals narrow and spreading. Corolla wheel-shaped, with usually 7 taper-pointed segments. Ovary globose; style thread-like. Capsule globose, many-seeded. 
1. T. americana, Pursh. Star-flower, Chickiweed WinterGREEN. Spreading by long and slender rootstocks, branches erect, stem-like, 3-9 in. high. Leaves very thin, pale green, pointed at both ends. Flowers white. Capsules white, marked off into polygonal sections, each corresponding to 1 seed. Cold woods, common N.

\section{STEIRONEMA, Raf.}

Perennial herbs. Leaves opposite or whorled, simple, entire. Flowers yellow, axillary or racemose, on slender peduncles. Calyx-tube 5-parted, persistent. Corolla 5-parted, wheel-shaped, tube very short or none, the lobes denticulate at the apex, and in the bud each one enclosing a stamen. Stamens 5, distinct or slightly united at the base, sterile rudiments often alternating with them. Ovary globose; style slender. Fruit a globose, 5-valved, few or many-seeded capsule.*

1. S. ciliatum, Raf. Frixgen Loosestrife. Stems erect, slender, simple, or branched, 1-3 ft. high. Leaves opposite, ovate to orate-lanceolate, acute at the apex, rounded at the base, margins and petioles hairy-fringed; flowers solitary on axillary peduncles, $\frac{3}{4}-1$ in. broad; petals broadly ovate or roundish, denticulate; calyx shorter than the capsule. Woods and thickets.*

\section{LYSIMACHIA, Tourn.}

Perennials, with opposite or whorled entire leaves, which are often dotted. Calyx 5-6-parted. Corolla wheel-shaped, with its divisions commonly nearly separate. Stamens generally somewhat monadelphous at the base.

1. L. quadrifolia, L. Forr-Leaved Loosestrife. Stem erect and simple, 1-2 ft. high, hairy. Leaves whorled, most frequently in fours, broadly lanceolate. Flowers small, axillary, and solitary, on long and slender peduncles. Damp or sandy soil.

2. L. stricta, L. Belb-bearing Loosestrife. Stems 1-2 ft. high, finally branching, frequently producing hulblets in the leafaxils after flowering. Leares abundant, generally opposite, narrowly lanceolate. Flowers small, pediceled, in a long, terminal raceme. Low or swampy ground. 


\section{ANAGALLIS, Tourn.}

Annual or perennial herbs; stems erect or diffuse. Leaves opposite or whorled. Flowers axillary, peduncled. Calyxtube 5-parted, persistent. Corolla wheel-shaped, 5-parted, longer than the calyx. Stamens 5, inserted on the base of the corolla; filaments bearded. Ovary globose ; style slender ; stigma knobbed. Fruit a many-seeded capsule, the top coming off like a lid.*

1. A. arvensis, L. Poor Man's Weather-glass, Pimpernel. Annual; stem spreading, widely branched, 4-angled, smooth, 4-12 in. long. Leaves opposite, sessile, ovate, black-dotted beneath. Flowers on peduncles longer than the leaves, nodding in fruit, corolla fringed with glandular hairs, longer than the acute calyx-lobes, bright red, opening in sunshine. Capsule globose, tipped by the persistent style. Introduced, and common in fields and gardens.*

\section{EBenaCeж. Eвony Family.}

Trees or shrubs. Leaves alternate, entire, pinnately veined, without stipules. Flowers often diœcious. Calyx free from the ovary, persistent. Stamens 2-4 times as many as the divisions of the corolla. Ovary 3-12-celled; ovules 1 or 2 in each cell. Fruit a berry. Mostly tropical plants.

\section{DIOSPYROS, $\mathrm{L}$.}

Flowers diœcious or somewhat monœcious, the staminate ones in cymes, the pistillate ones axillary and solitary. Calyx 4-6-lobed. Corolla 4-6-lobed. Stamens in the staminate flowers usually 16 , in the pistillate ones 8 , imperfect. Fruit large, with the persistent calyx attached to its base, 4-8-seeded.

1. D. virginiana, L. Persimmon. Trees, with rough, black bark and very hard wood. Leaves oval or ovate-oblong, acute or acuminate at the apex, rounded or slightly cordate at the base, entire and dark green, smooth above, pale and often downy beneath, short-petioled, deciduous; flowers yellowish-white, the parts mostly in 4's; fruit globose, edible when ripe, very astringent when green; seeds large, compressed, often wanting. Fruit ripening late in the fall. Common in old fields and along roadsides S. and S.W.* 


\section{Oleaceze. Olive Family.}

Shrubs or trees. Leaves opposite, simple or odd-pinnate, without stipules. Flowers in forking cymes, small, white or greenish, perfect or imperfect. Calyx free from the ovary, 4-lobed or wanting. Corolla hypogynous, regular, 4-parted or of 4 separate petals, sometimes wanting. Stamens 2, borne on the petals-or hypogynous. Orary 2-celled. Fruit 1-2celled, each cell 1 -seeded, rarely 2 -seeded.

\section{FRAXINUS, Tourn.}

Deciduous trees. Flowers diœcious. Petals wanting (in our species). Stamens 2, hypogynous. Fruit a 1-2-celled key, each cell 1 -seeded.

1. F. americana, L. White Ash. A large tree; bark rough, gras; wood hard, strong, elastic ; twigs and petioles smooth. Leaflets usually 7 , orate to orate-lanceolate, taper-pointed at the apex, rounded or obtuse at the base, entire or slightly serrate, smooth above, often downy beneath, short-stalked. Flowers mostly dioecions. Calyx of the pistillate flowers persistent. Key $1 \frac{1}{2}-2$ in. long, winged only at the apex; wing spatulate or oblanceolate. In rich woods and swamps.*

2. F. pubescens, Lam. Ped Ash. A small tree; bark rough, dark gray; twigs and petioles densely relrety-downy. Leaflets 5-9, oblong-orate to orate-lanceolate, taper-pointed at the apex, narrowed into a short stalk at the base, finely serrate, smooth above, relvetydowny beneath. Calyx of the pistillate flowers persistent. Key $1 \frac{1}{2}-$ 2 in. long, the wing somewhat extended along the sides, oblanceolate or spatulate, often notched. Swamps and moist soil.*

3. F. platycarpa, Michx. Water Ash. A small tree; wood soft. light and weak; twigs smooth or downy. Leaflets $5-7$, ovate or elliptical, acute at the apex, acute or obtuse at the base, entire or slightly serrate, smooth or slightly downy, stalked. Flowers diœcious. Calyx persistent. Kiey often :3-angled or 3-winged, wings running nearly to the base, oblong or oral, pinnately veined. In swamps and wet soil.**

4. F. quadrangulata, Michx. Blce Asir. A large tree, with wood heary; but not as tough as No. 1; the most rigorous twigs usually square. Leaflets $7-9$, with short stalks, somewhat ovate or lanceolate, acute, sharply serrate. Fruit winged to the base, of nearly the same width throughout, narrowly oblong. Rich woods, especially W. 


\section{FORSYTHIA, Vahl.}

Shrubs. Leaves opposite or in threes, appearing later than the flowers, serrate. Calyx very short, deciduous. Corolla yellow, bell-shaped, its lobes long and slender. Stamens inserted on the base of the corolla-tube. Pod 2-celled, manyseeded.

1. F. viridissima, Lindl. A hardy shrub, with branches erect or nearly so. Leaves all simple, lance-oblong. Calyx-lobes half as long as the tube of the corolla. Lobes of the corolla spreading, narrowoblong, style equal in length to the tube of the corolla. Cultivated from Asia.

2. F. suspensa, Vahl. A hardy shrub, with drooping branches. Leaves broadly ovate, often some of them with 3 leaflets, the lateral leaflets small. Lobes of the corolla longer, broader, and more spreading than in No.1. Style shorter than the tube of the corolla. Cultivated from Asia, less common than No. 1, often trained over porches and arbors.

\section{SYRINGA, L.}

Tall shrubs, forking frequently, from the failure of the terminal buds on most branches. Leaves simple, entire. Flowers in close, compound panicles. Calyx 4-toothed. Corolla salver-shaped, the tube long, the limb 4-lobed. Pod dry, flattened at right angles to the partition, 4-seeded.

1. S. vulgaris, L. Соммоn Lilac. A strong-growing, hardy bush. Leaves ovate, somewhat heart-shaped. Flowers sweet-scented, in very close, large clusters, lilac or white. Corolla-lobes concave. Very commonly cultivated from Eastern Europe.

2. S. persica, L. Persian lilac. A more slender and less branched shrub than No. 1. Leaves lance-ovate, somewhat narrowed or tapering at the base. Flowers in rather loose clusters, not very sweet-scented, pale lilac or white. Corolla-lobes ovate, somewhat bent inward. Pods linear. Cultivated from Western Asia, less common than No. 1.

\section{CHIONANTHUS, L.}

Shrubs or small trees. Leaves simple, opposite, entire, petioled, deciduous. Flowers in panicles borne on wood of the previous season. Calyx small, 4-cleft, persistent. Corolla 
wheel-shaped, 4-parted, the lobes long and linear. Stamens $2-4$, included, inserted on the base of the corolla. Style short; stigma 2-lobed. Fruit a 1-seeded stone-fruit.*

1. C. virginica, L. Fringe-treE. A small tree, with smooth, light gray bark and spreading branches. Leaves oval to oblong, acute or obtuse at each end, smooth or slightly downy. Panicles large and loose, leafy-bracted, appearing with the leaves. Flowers on slender, drooping pedicels. Petals 1 in. or more in length. Fruit ovoid, purple, $\frac{1}{2}-\frac{2}{3}$ in. long. Along streams, usually on light soil.**

\section{LIGUSTRUM, Tourn.}

Shrubs. Leaves simple, opposite, entire, deciduous or sometimes persistent. Flowers in terminal panicles or similar clusters, white, small. Calyx minutely 4 -toothed or truncate. Corolla funnel-form, 4-lobed. Stamens 2, short, inserted in the tube of the corolla. Ovary free, 2-celled, 2 ovules in each cell, style short. Fruit a 1-4-seeded, globose berry.*

1. L. vulgare, L. Privet. A branching shrub, 4-10 ft. high; branches long and slender. Leaves somewhat leathery, lanceolate to obovate, short-petioled, tardily deciduous. Panicles dense, minutely downy. Flowers $\frac{1}{4}$ in. wide, fragrant. Stamens included. Berries black. Introduced from Europe and used largely for hedges.*

\section{9. gentianaceæ. Gentian Family.}

Annual or perennial herbs. Leaves entire, usually opposite, sometimes alternate, without stipules. Flowers regular, solitary or in cymes. Calyx free from the ovary, 4-8-toothed or lobed. Corolla hypogynous, wheel-, bell-, or funnel-shaped, 4-8-lobed. Stamens 4-8, inserted on the corolla-tube; filaments thread-shaped; anthers facing inwards. Ovary 1-2celled; ovules many, on 2 opposite placentas. Capsule 1-celled or partially 2-celled, 2-valved, many-seeded.

\section{OBOLARIA, L.}

A low, smooth, purplish-green perennial. Flowers axillary and terminal, Calyx of 2 distinct, spatulate, bract-like sepals. 
Corolla tubular-bell-shaped, 4-lobed. Stamens short, inserted at the notches of the corolla. Style short; stigma 2-lipped. Capsule ovoid, more or less 2-4-celled; seeds very minute and numerous.

1. 0. virginica, L. Pennywort. Stem $3-8$ in. high, often several from the same root. Leaves somewhat fleshy, wedge-obovate or somewhat diamond-shaped, often truncate, sessile. Flowers opposite or terminal in threes, nearly sessile. Corolla pale purple or nearly white. Rich woodlands, among dead leaves.

\section{MENYANTHES, Tourn.}

Perennial, scape-bearing marsh herbs. Rootstock creeping. Leaves of 3 leaflets. Flowers racemed. Calyx 5-parted. Corolla fleshy, funnel-shaped, the limb 5-parted. Stamens 5, inserted on the corolla-tube. Disk of 5 hypogynous glands. Ovary 1-celled; style thread-shaped; stigma 2-lobed. Capsule globose, many-seeded.

1. M. trifoliata, L. Buck-bean, Marsh Trefoll. Rootstocks stout and matted. Leaflets obtuse, entire. Flowers $\frac{2}{3}$ in. in diameter, white or pinkish. Bogs, especially $\mathbf{N}$.

\section{APOCynaCe 2 . Dogbane Family.}

Trees, shrubs, or herbs, with milky juice, often climbing. Leaves usually opposite, rarely whorled; entire, nearly or quite without stipules. Flowers regular, solitary, or in cymes. Calyx 4-5-cleft. Corolla hypogynous, funnel-, salver-, or bellshaped, sometimes with scales in the throat. Stamens, 4-5, borne on the corolla-tube or throat; filaments very short; anthers somewhat attached to the stigma. Ovary of 2 carpels, free or somewhat united; style short; stigma entire or 2-cleft. Fruit of 2 many-seeded pods (in the genera here described).

\section{AMSONIA, Walt.}

Perennial herbs; stem erect, branched. Leaves alternate. Flowers in terminal panicles. Calyx small, 5-parted. Corolla 
small, pale blue, funnel or salver form, downy within. Stamens inserted above the middle of the tube, included. Ovary of 2 carpels, united at the top by the slender style; stigma globose, surrounded by a cup-shaped appendage. Fruit 2 slender, erect, many-seeded follicles; seeds without tufts of hairs.*

1. A. tabernæmontana, Walt. Axsoxia. Stem smooth and glabrous, branched abore, -ㅡ $3 \mathrm{ft}$. high. Leaves lanceolate, entire, acuminate at the apex, acute at the base, smooth abore, with a bloom or slightly downy beneath, short-petioled. Flowers numerous, on bracted pedicels. Corolla-tube slender, smooth or sometimes downy abore, the lobes narrow, as long as the tube. Follicles slender, spreading, 4-6 in. long; seeds downy. Swamps and wet ground S.*

\section{VINCA, L.}

Perennial herbs or small, slender shrubs; juice not perceptibly milky. Leaves evergreen. Flowers solitary, white, blue, or purple. Calyx 5-parted, lobes taper-pointed, glandular inside at the base. Corolla salver-shaped, thickened at the throat, 5-lobed. Stamens 5, inserted on the upper or middle part of the corolla-tube. Ovary of 2 carpels. Pods 2, slender, cylindrical, many-seeded.

1. V. minor, L. Perrw ixkle. Stem slender, trailing, often rooting at the nodes, 1-3 ft. long. Leares orate, acute at the apex, short-petioled, bright green. Flowers axillary, solitary, 1 in. wide. Calyx with linear lobes nearly as long as the inflated tube of the blue corolla. Matured pods slender, slightly divergent. Introduced from Europe and common in gardens.*

\section{APOCYNUM, Tourn.}

Perennial herbs; stems with very tough bark, branched above. Leaves opposite, entire. Flowers in terminal and

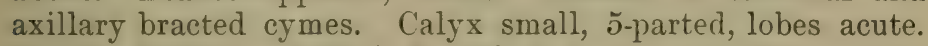
Corolla bell-shaped, 5-lobed, with a small, scale-like appendage at the base of each lobe. Stamens 5, distinct, inserted on the base of the corolla-tube. Ovaries 2, distinct, united by the styles; stigma obtuse, 2-lobed. Pods long, slender, many-seeded; seeds with a tuft of hairs.* 
1. A. cannabinum, L. Indran Hemp. Stem erect, smooth, with numerous erect or ascending branches. Leaves oval to oblong, mucronate at the apex, rounded at the base, downy beneath, shortpetioled. Cymes terminal, compact, shorter than the leaves. Flowers are on short, bracted pedicels, greenish-white, about $\frac{1}{4}$ in. broad. Calyx-lobes lanceolate, nearly as long as the tube of the corolla. Corolla-lobes erect. Pods very slender, tapering, 3-4 in. long. Along fences and in thickets.*

2. A. androsæmifolium, L. DogBane. Plant 2-3 ft. high, usually smooth, purplish, the branches spreading and forking. Leaves 2-3 in. long, acute, mucronate, petioles about $\frac{1}{4}$ in. long. Cymes mostly terminal, few-flowered. Calyx-teeth lance-ovate, about half as long as the corolla-tube. Corolla pale red or whitish, its lobes recurved. Pods stouter than in No. 1. Roadsides and clearings, common.

\section{NERIUM, $\mathbf{L}$.}

Shrubs. Leaves mostly whorled in threes. Flowers in terminal cymes. Calyx small, lobes acute. Corolla salver-form, the throat of the tube crowned with cleft or cut-fringed scales. Stamens 5, short, included; anthers tipped with a hairy bristle. Ovary of 2 carpels ; style short. Pods erect, seeds with a tuft of hairs.*

1. N. Oleander, L. OLEANDER. Stem erect, diffusely branched from below, 4-10 ft. high. Leaves narrowly elliptical, acute at each end, thick and leathery, short-petioled. Flowers showy, in large clusters, red or white, often double; scales of the crown 3-4-pointed unequal teeth; pods spindle-shaped, 3-4 in. long. Introduced from Palestine, common in cultivation.*

\section{ASClepiadaCEÆ. Milkweed Family.}

Shrubs or herbs, often twining; juice usually milky. Leaves generally opposite or whorled, entire, without stipules. Flowers regular. Calyx 5-parted. Corolla 5-parted. Stamens 5 ; the filaments usually cohering around the styles, often with hood-like appendages, each with an incurved horn borne on the stamen-tube and forming a crown around the stigma (Fig. 20,A); anthers pressing against the lobes of the stigma; the pollen clinging together in tough, waxy or fine- 
grained masses. Ovary free from the calyx-tube, of 2 carpels, more or less united below but unconnected above; styles 2 ; stigmas 5-angled; ovules several-many. Fruit consisting of 1 or 2 pods. The flowers are very highly specialized for pollination by insects (see below, under Asclepias).

\section{ASCLEPIAS, L.}

Perennial herbs. Flowers in simple (usually many-flowered) umbels. Calyx small, 5-parted, its lobes reflexed. Corolla deeply 5-parted, with reflexed lobes; crown of hoods and horns conspicuous (Fig. 20, $A, B$ ). Stamens with their filaments united into a tube around the pistil and anthers adnate to the stigma (Fig. 20,D,E); anther-cells 2 , each cell containing an elongated, pear-shaped, tough mass of pollen, a mass from one anther always paired with one from the adjoining anther and each two together suspended from one of the 5 split glands on the angles of the stigma (Fig. 20, D, E). Ovaries 2 ; styles very short. Pods 2 or sometimes 1 and the other undeveloped. Seeds flat, each with a tuft of long, silky hairs. The flowers are pollinated by insects, which get their feet entangled in the clefts of the glands (Fig. 20, g) and then carry off the pollen-masses. (See Müller, The Fertilization of Flowers, pp. 396-399 inclusive.)

1. A. purpurascens, L. Purple Mrlkweed. Stem 1-3 ft. high, somewhat branched above. Leaves 4-6 in. long, elliptical or nearly so, the upper ones taper-pointed, slightly velvety beneath, shortpetioled. Umbels terminal. Flowers $\frac{1}{2}$ in. long, dark purple; pedicels shorter than the peduncle; horn broadly scythe-shaped, with the point bent sharply inward. Dry soil.

2. A. Cornuti, Decaisne. Common Mrlkweed. Stem stout, $3-4 \mathrm{ft}$. high, finely downy. Leaves $4-8$ in. long, oblong or nearly so, downy beneath. Umbels terminal or nearly so. Flowers varying from purple or greenish-purple to whitish, numerous, with a strong, sweet, but sickening odor. Hoods with a tooth on each side of the stout horn. Common in rich soil.

3. A. phytolaccoides, Pursh. Poke-leaved Milkweed. Stem rather slender, $3-5 \mathrm{ft}$. high. Leaves 6-9 in. long, ovate or ovallanceolate, taper-pointed, short-petioled. Umbels several, mostly lateral; pedicels slender and drooping. Lobes of the corolla 
greenish; hoods white, with 2 teeth; horns with an awl-shaped point extending far out of the hoods. Damp thickets N. and E.

4. A. variegata, L. White Milkweed. Stem stout, leafless and smooth below, leafy and downy in lines above. Leaves opposite, the middle ones sometimes in fours, petioled, ovate to obovate,
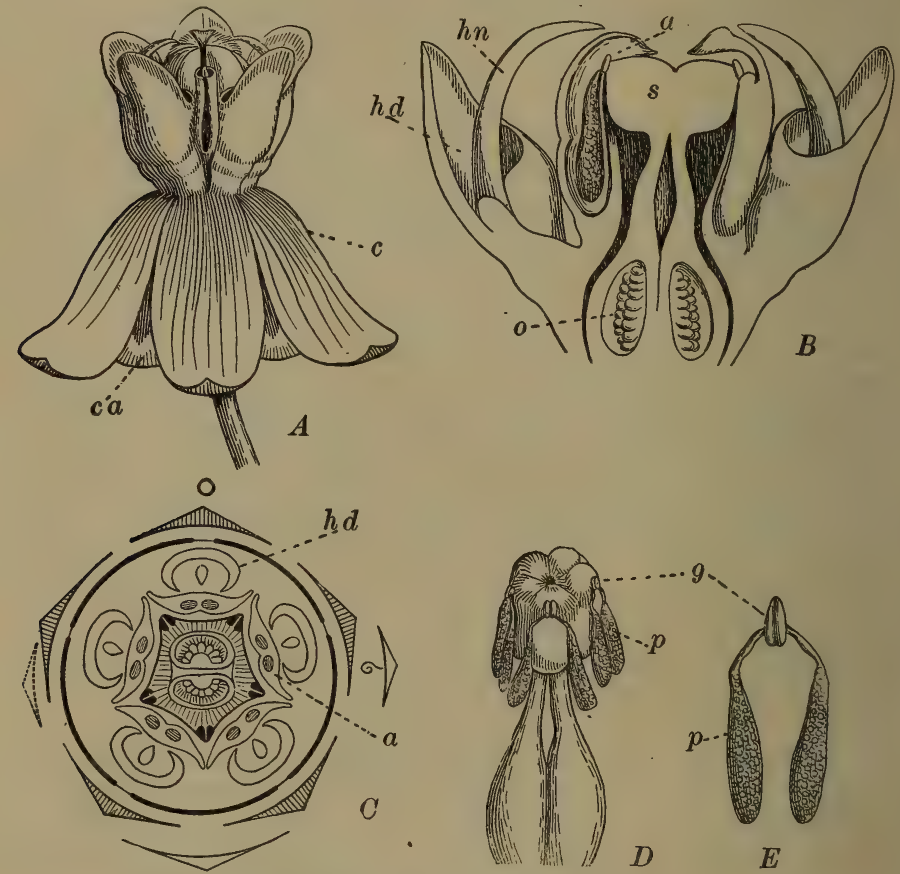

Fig. 20, - Flower of Asclepias Cornuti.

$A$, entire flower ; $B$, vertical section ; $C$, diagram ; $D$, details of pollen-masses and glands. $c a$, calyx ; $c$, corolla; $h d$, hood; $h n$, horn ; $a$, anther ; $s$, stigma $;$, ovary ; $g$, gland ; $p$, pollen-mass. (All considerably enlarged.)

cuspidate, smooth on both sides, pale beneath, edges slightly crenate. Umbels 1-5, compact, downy, 1-2 in. long ; pedicels erect, as long as the peduncles. Corolla white, often purple at the base; hoods roundish, spreading, a little longer than the thick, awl-pointed, incurved horn. Dry, open woods E. and S.*

5. A. quadrifolia, L. Four-leaved Milkweed. Stem slender, $1 \frac{1}{2}-2 \mathrm{ft}$. or more high, usually leafless below. Leaves in 1 or 2 
whorls of 4 each, near the middle of the stem, and a pair or two opposite, thin, slender-petioled, 2-t in. long, orate-lanceolate, taperpointed. Umbels usually 2, sometimes 1. with slender pedicels. Corolla-lohes rery pale pink or whitish ; hoods white; horn short, stout, and bent inward. Dry woods and fence-rows.

\section{HOYA, R. Br.}

Shrubby, more or less climbing, smooth, tropical plants. Leares fleshy. Calyx 5-cleft, corolla 5-lobed, wheel-shaped, its divisions thick and with a waxy look. Crown of 5 spreading segments. Pollen-masses fastened by the bases.

1. H. carnosa, R. Br. WAx Plaxt. Stems long and slender, rooting and trailing. Leares oral or nearly so, thick, dark green. Flowers in close umbels, pink or whitish, the corolla-lobes covered on the upper surface with minute projections. Cultirated from India as a house plant and in conservatories.

82. CONVOLVUlace Ae. Morning-Glory Family.

Usually twining herbs or shrubs, often with milky juice. Leaves alternate (wanting in Cuscuta), without stipules. Flowers variously clustered, rarely solitary, often large and showy. Sepals 5. Corolla hypogynous, regular, tubular, bellshaped or funnel-shaped; its limb more or less 5-lobed or angled. Stamens 5, inserted on the corolla-tube. Ovary usually 2-4-celled; style slender, 2-4-cleft; ovules 1 or 2 in each cell. Capsule 1-1-celled, 2-4-valved or bursting open across the base.

\section{CAlystegia, R. Br.}

Twining, trailing, or nearly erect perennials. Leaves heartshaped or arrow-shaped. Flowers peduncled, axillary and solitary. Calyx enclosed in 2 large, leaf-like, usually heartshaped bracts; sepals equal. Corolla bell-funnel-shaped, its border nearly or quite entire; style 1 ; stigmas 2. Pod 1-celled or partially 2-celled, 4-seeded.

1. C. sepium, R. Br. Crefepers, Rutlaxd Beauty. Stem twining or sometimes extensively trailing. Leaves heart-arrow- 
shaped or somewhat halberd-shaped, the lobes at the base truncate. Flowers numerous and showy, white or tinged with rose-color. Thickets and banks of streams, often cultivated.

2. C. spithamæa, Pursh. Downy, stem 6-12 in. high, erect or reclining. Leaves oblong, sometimes heart-shaped or eared at the base. Flowers white. In sandy soil.

\section{CONVOLVULUS, L.}

Herbs or shrubs, with stems twining or nearly erect. Calyx not bracted. Corolla broadly funnel-form or bell-shaped. Stamens not projecting from the corolla. Style 1; stigmas 2, thread-like ; ovary and pod 2-celled, 4-seeded.

1. C. arvensis, L. BindwEED. A perennial, prostrate or climbing herb, with many stems, from a long, slender rootstock. Leaves very variable, more or less arrow-shaped, 1-3 in. long. Peduncles mostly 1-flowered; flowers white or pinkish, about $\frac{3}{4}$ in. long. A weed in fields E.; introduced from Europe.

\section{QUAMOCLIT, Tourn.}

Twining annual herbs. Sepals 5, mostly mucronate or bristle-pointed. Corolla tubular, with a narrow, spreading border. Stamens projecting. Style 1; stigma knobbed, 2-lobed. Pod 4-celled, the cells 1-seeded.

1. Q. vulgaris, Choisy. Cypress Vine. Stem slender, smooth, twining high. Leaves dark green, pinnately cut, the divisions linear, smooth. Peduncles slender, as long as the leaves, 1-5-flowered; pedicels thickened upward. Sepals ovate or oblong, mucronate. Corolla bright scarlet, or sometimes yellowish-white, salver-form, the tube $1-1 \frac{1}{2}$ in. long, the limb flat and spreading, $\frac{1}{2}-\frac{3}{4}$ in. wide. Capsule ovoid, twice the length of the sepals. Common in gardens.*

\section{IMPOMGA, L.}

Annuals or perennials; stems often twining. Flowers showy. Calyx not bracted at the base, of 5 sepals. Corolla bell-shaped or funnel-shaped, twisted in the bud. Stamens not projecting from the corolla. Style slender; stigma knobbed, 2-lobed. Fruit a 2-3-celled capsule. [I. purpurea, the common morning-glory, blossoms too late for school study. I. Batatas, the sweet potato, seldom flowers.] 
1. I. hederacea, Jacq. Wild Morning-Glory. Stems hairy, twining. Leaves heart-shaped, 3-lobed. Peduncles 1-3-flowered. Calyx very hairy below. Corolla showy, bluish-purple or white. Pod usually 3-celled, with 2 seeds in each cell. A weed in fields and about dwellings; introduced from tropical America.

2. I. pandurata, Meyer. Wild Potato Vine. Perennial, from a very large, tuberous root; stem trailing or twining, smooth or slightly downy, $\tilde{5}-10 \mathrm{ft}$. long. Leaves broadly heart-shaped, with the apex slender and obtuse, sometimes fiddle-shaped or 3-lobed; petioles slender. Peduncles longer than the petioles, 1-o-flowered. Sepals oblong, obtuse, smooth, mucronate, the 2 outer ones shorter. Corolla white with a purple throat, $2-3$ in. wide, lobes pointed. Capsule globose, 2-3-seeded, the seeds woolly on the angles. On dry or damp, sandy soil, along fences, railroad embankments, etc., common S. and W.*

\section{Polemoniace e. Phlox Family.}

Annual or perennial herbs, rarely shrubs. Leaves alternate or the lower opposite, without stipules. Flowers in terminal, forking cymes. Calyx free from the ovary, 5-lobed. Corolla regular or nearly so, 5-parted. Stamens 5, inserted on the corolla-tube, usually unequal. Ovary 3-celled; style simple; stigmas 3 , linear; capsule 3 -celled, the cells 1 -manyseeded.

\section{PHLOX, $\mathbf{L}$.}

Perennial or rarely annual herbs; stems erect or diffuse. Leaves opposite, or the upper alternate, entire, without stipules. Flowers showy, white or purple, in terminal cymes or panicles. Calyx cylindrical or funnel-form, 5-cleft, the lobes acute. Corolla salver-form, the tube long and slender, the limb 5-parted, the lobes spreading, entire or obcordate. Stamens included, unequal. Ovary 3-celled, style slender. Capsule ovoid, 3-celled, 1-few-seeded; seeds wingless or narrow-winged.*

1. P. paniculata, L. Gardfen Phlox. Perennial; stems in clumps, stout, erect, simple or branched above, $2-4 \mathrm{ft}$. high. Leaves orate-lanceolate to oblong, taper-pointed at the apex, rounded or cordate at the base, thin, smooth, reins prominent beneath. Cymes numerous and compact, forming a pyramidal panicle; pedicels short. 
Calyx-teeth long, bristle-pointed. Corolla purple to white, lobes round-obovate, shorter than the tube. Capsule longer than the calyx-tube. In rich woods; often cultivated.*

2. P. maculata, L. Wild Sweet William. Stem erect, smooth or nearly so, rather slender, purple-spotted, 1-2 ft. high. Lower leaves lanceolate, the upper ones broader, taper-pointed, roundish or heart-shaped at the base. Panicle many-flowered, narrow, ellipsoidal. Calyx-teeth lanceolate, hardly acute. Flowers purple, occasionally white. Damp woods and fields.

3. P. pilosa, L. Downy Phlox. Perennial; stem erect, slender, simple or branched, 1-2 ft. high. Leaves linear-lanceolate to linear, distant, spreading, long, taper-pointed, sessile; stern and leaves downy. Cymes corymbose, loose. Flowers short-pediceled. Calyx glandular-viscid, the teeth shorter than the tube of the purple corolla, bristle-pointed. Corolla-tube downy, lobes obovate. Capsule twice the length of the calyx-tube. In dry, open woods.*

4. P. divaricata, L. Wrld Blue Phlox. Perennial; stems erect or ascending from a decumbent base, sticky-downy, $1 \mathrm{ft}$. high. Leaves distant, lanceolate to oblong, acute at the apex, rounded at the base, sessile, downy. Cymes corymbed, loosely flowered. Calyxteeth awl-shaped, longer than the tube. Corolla bluish-purple, $\frac{1}{2}-\frac{3}{4}$ in. long, lobes notched at the apex, as long as the tube. Capsule oval, shorter than the calyx-teeth. In moist, open woods.*

5. P. Drummondii, Hook. Drummond's Phlox. Annual; stem erect or ascending, slender, weak, branching, glandular-downy, 6-12 in. high. Leaves mostly alternate, lanceolate to oblong, downy, the upper clasping by a heart-shaped base. Corymbs loose. Flowers rather long-pediceled. Calyx-tube short, the teeth lanceolate, bristlepointed, soon recurved. Corolla purple to crimson or white, orifice of the tube usually with a white or yellowish star-like ring, lobes rounded at the apex. Ovary 3 -seeded, angles of the seeds winged. Introduced from Texas and common everywhere in gardens.*

6. P. subulata, L. Ground Pink, Moss Pink, Flowering Moss. Stems perennial, prostrate, 8-18 in. long, with many short, somewhat upright branches, 2-4 in. high. Leaves linear-awl-shaped, stiff, about $\frac{1}{2}$ in. long, crowded, with clusters of smaller ones in their axils. Flower-clusters 3-6-flowered. Corolla pink-purple, with a darker center, or sometimes white. Forms dense mats on rocky or sandy hillsides. S. and W. and often cultivated.

\section{POLEMONIUM, $\mathbf{L}$.}

Perennial herbs. Leaves alternate, pinnate. Flowers corymbed. Calyx bell-shaped, 5-lobed. Corolla wheel-shaped, the limb with 5 obovate lobes. Stamens borne on the throat of 
the corolla, the filaments enlarged and hairy below. Capsule ovoid, 3-celled, many-seeded.

1. P. reptans, L. Jacob's Ladder, Blee Valerian, BlueBELL. Stems smooth, branched, and leaning orer, 6-12 in. high. Leaflets usually 7 or 9 , about an inch long. Corolla blue, about 3 times as long as the calyx. Capsule 3 -seeded, borne on a short stalk in the persistent calyx. Damp, open woods, sometimes cultivated.

\section{HYDROPHYLLACE E. WATERLEAF FAMily.}

Herbs, usually hairy. Leares commonly alternate and alternate-lobed. Flowers with their parts in fives, in appearance not unlike those of the following family, in one-sided cymes, which are coiled up at first. Calyx free from the orary, usually with appendages at the notches. Corolla often with scales or nectar-bearing folds inside. Stamens borne by the corolla-tube. Style 2-cleft, or styles 2. Ovary entire and usually 1-celled. Fruit a capsule, 2-valved, 4-many-seeded.

\section{HYDROPHYLLUM, Tourn.}

Coarse perennials. Leaves large, petioled. Flowers white or pale blue, inconspicuous. Calyx כ̌-parted, sometimes appendaged at the notches. Corolla bell-shaped, 5-cleft, with 5 double, nectar-bearing folds inside. Stamens projecting, the filaments bearded. Style projecting; ovary covered with bristly hairs, the placentæ very broad and fleshy, enclosing the ovules. Capsule globular, 1-4-seeded.

1. H. macrophyllum, Nutt. A coarse, rough-hairy plant, about $1 \mathrm{ft}$. high, from scaly-toothed rootstocks. Leares oblong, pinnate and pinnately cut, the dirisions mucronate, obtuse, coarsely toothed. Flower-cluster dense, globular, long-peduncled. Flowers about $\frac{1}{2}$ in. long. Calyx little or not at all appendaged, its lobes broad at the base, but with slender, tapering points. Corolla white. Rich, rocky woods $\mathrm{W}$. and $\mathrm{S}$.

2. H. virginicum, L. Nearly smooth, 1-2 ft. high, stem often forking at the base. Leaves of the stem mostly near the top, pinnately cut into $5-7$ divisions; lobes oval-lanceolate, deeply serrate, the lowest 
ones distinct; petioles of the radical and lower leaves 4-8 in. long. Flower-clusters on peduncles longer than the petioles of the upper leaves, from the axils of which or opposite which they arise. Flowers about $\frac{1}{4}$ in. long. Calyx not appendaged, its lobes narrowly linear, bristly-margined. Corolla whitish, with purplish veins. Moist woods.

3. H. appendiculatum, Michx. Hairy, 1-1 $\frac{1}{2} \mathrm{ft}$. high. Stem-leaves palmately 5-lobed, the lobes acute, toothed, lowest ones pinnately divided. Flower-cluster rather loose. Calyx appendaged at the notches. Corolla blue. Stamens projecting from the corolla little or not at all. Moist woods.

\section{PHACELIA, $\mathbf{L}$.}

Herbs, mostly annual. Leaves alternate, sometimes simple, but in most species lobed or divided. Flowers in one-sided clusters, often showy. Calyx 5-parted, without appendages. Corolla with 5 spreading lobes. Ovary 1-celled, with narrow placentæ.

1. P. tanacetifolia, Benth. A tall, hairy annual. Leaves pinnately cut. Spikes long, densely flowered. Flowers showy, blue. Stamens projecting. Capsule 4-seeded. Cultivated from California.

2. P. Whitlavia, Gray. Whitlavia. A rather coarse, sticky annual. Leaves broad, ovate, coarsely toothed, petioled. Flowerclusters a loose raceme. Flowers showy, about 1 in. long, blue or sometimes white. Corollá bell-shaped. Stamens and style projecting. Capsule many-seeded. Cultivated from California.

3. P. Menziesii, Torr. EutocA. A much-branched, somewhat rough or rough-hairy plant, 3-12 in. high. Leaves linear, or lanceolate, entire or nearly so. Flowers showy, violet or white, loosely panicled. Capsule many-seeded. Cultivated from California.

\section{BORRAGINACE $\not E$. BORAGE FAMILy.}

Mostly herbs, with stems and foliage roughened with stiff hairs. Leaves alternate and entire, not aromatic. Flowers generally in a coiled inflorescence. Calyx 5-parted. Corolla hypogynous, generally 5-lobed and regular. Stamens 5, inserted on the corolla-tube. Style 1; ovary commonly 4-lobed, ripening into 41 -seeded nutlets. 


\section{HELIOTROPIUM, Tourn.}

Herbs or low shrubs. Leaves petioled. Flowers white, blue, or lilac, in one-sided, curved spikes. Calyx 5-parted. Corolla salver-shaped, the throat open. Anthers almost sessile. Style short; stigma conical or knobbed. Fruit separating into 2 or 4 nutlets.

1. H. peruvianum, L. Coмmox Helrotrope. Somewhat shrubby, much branched. Leaves lance-orate or somewhat oblong, veined and much wrinkled, short-petioled. Flowers numerous, in a cluster of terminal spikes, bluish-purple or lavender, rery sweet-scented, the odor not unlike that of ranilla. Cultivated from Peru.

\section{CYNOGLOSSUM, Tourn.}

Coarse, rough-hairy or silky biennials. Flowers small, bluish-purple or white, in forked and usually bractless cymes. Calyx 5-parted. Corolla funnel-shaped, the mouth closed by prominent scales, its lobes obtuse. Stamens not projecting. Styles stiff, persistent. Nutlets 4, covered with hooked or barbed bristles, attached to a thickened, conical receptacle.

1. C. officinale, L. Hound's-tongue, Sheep-lice, Dog-Bur, Stick-тights. Stem 1-2 ft. high, soft-downy, panicled above. Root-leaves 8-10 in. long, long-petioled, oblong or oblong-lanceolate; stem-leares sessile, linear-oblong or lanceolate, rounded or heart-shaped at the base. Corolla $\frac{1}{2}$ in. in diameter, reddish-purple. Nutlets $\frac{1}{4}$ in. long, with a thickened border. Whole plant with a strong smell like that of mice. A troublesome weed, along roadsides and in pastures, introduced from Europe.

2. C. virginicum, L. Wild Comfrey. Perennial. Stem stout, simple, erect, leafless above, 2-3 ft. high. Leaves oval or oblong, the upper clasping by a heart-shaped base. Racemes bractless. Flowers pale blue, on short pedicels, which are recurved in fruit. Nutlets not margined, separating and falling away at maturity. On dry soil.

\section{ECHINOSPERMUM, Lehm.}

Annual or biennial herbs, grayish, with rough hairs. Flowers small, blue or whitish, racemed or spiked. Corolla salver-shaped, its throat closed with 5 concave scales. Nutlets 
more or less covered with prickles, which are barbed at the tip, attached by their sides to the base of the style.

1. E. virginicum, Lehm. BEGGAR's Lice. A coarse biennial, 2-4 ft. high, the stem much branched above. Root-leaves roundishovate or heart-shaped, on slender petioles ; stem-leaves $3-4 \mathrm{in}$. long; pointed at both ends. Racemes 1-3 in. long, terminating the slender, spreading branches. Flowers small, bluish-white. Fruit forming a troublesome bur. Fence-rows and thickets.

\section{MERTENSIA, Roth.}

Perennial herbs̀. Leaves generally pale, smooth, and entire. Calyx short, deeply 5-cleft or 5-parted. Corolla somewhat trumpet-shaped or funnel-shaped, often with 5 small folds or ridges in the throat, between the points of insertion of the stamens. Style long and slender. Nutlets smooth, or at length becoming wrinkled.

1. M. virginica, DC. Lungwort, Bluebells. Smooth, nearly erect, $1-1 \frac{1}{2} \mathrm{ft}$. high. Root-leaves large, obovate, or nearly so, and petioled; stem-leaves smaller, sessile. Flowers clustered. Corolla nearly trumpet-shaped, varying with age from lilac to blue (or occasionally white). Stamens with slender filaments projecting beyond the corolla-tube. Damp, open woods and banks of streams, sometimes cultivated.

\section{MYOSOTIS, Dill.}

Low, annual, biennial, or perennial herbs ; stems branching, erect or diffuse. Leaves alternate, entire. Flowers small, blue, pink, or white, in elongated, bractless racemes. Calyx 5-cleft, the lobes erect or spreading in fruit. Corolla salverform, 5-lobed, the tube as long as the calyx, the throat with 5 small appendages. Stamens 5 , inserted in the tube of the corolla, included. Ovary 4-parted; style slender. Nutlets smooth or downy, elliptical, compressed.*

1. M. palustris, Withering. ForGet-ME-мот. Perennial, from slender rootstocks. Stems slender, downy, rooting at the nodes, $6-15$ in. long; leaves oblong to oblong-lanceolate, obtuse, narrowed to the sessile base, appressed-downy. Racemes many-flowered; pedicels becoming elongated in fruit. Lobes of the calyx shorter than the tube, spreading in fruit. Corolla blue with a yellow eye; nut lets angled, smooth. Common in gardens and often naturalized.* 
2. M. laxa, Lehm. Syall Forget-me-xot. Annual or perennial; whole plant downy; stem slender, weak, decumbent and rooting at the base, $1-2 \mathrm{ft}$. long. Lower leaves spatulate, the upper lanceolate. Racemes loosely towered, becoming elongated in fruit. Pedicels spreading. Calyx rough-hairy, the lobes as long as the tube. Corolla pale blue, with a yellow eye. Nutlets convex on all sides. On low ground and in brooks and ponds.*

\section{LITHOSPERMUM, Tourn.}

Herbs, with stout, usually reddish roots. Flowers appearing axillary and solitary or else in leafy-bracted spikes. Corolla funnel-shaped or salver-shaped, with or without folds or appendages at the mouth of the tube ; the limb 5-cleft, its divisions rounded. Stamens included in the corolla-tube, the anthers nearly sessile. Nutlets either smooth or wrinkled, generally very hard and bony.

1. L. arvense, L. Corx Gromwell. A rough weed, about $1 \mathrm{ft}$. high. Leares narrowly lanceolate. Flowers inconspicuous, whitish in the upper leaf axils. Corolla hardly extending beyond the calyx, without appendages in the throat. Nitlets rough or wrinkled and dull. Sandy banks and roadsides: introduced from Europe.

2. L. hirtum, Lehm. Hairy Puccoox. Rough-hairy, perennial, 1-2 ft. high. Corolla deep orange-vellow, with appendages in the throat and clad with wool within at the bottom; flowers handsome, peduncled, in a crowded cluster. Drv, open pine woods, in sandy soil.

3. L. canescens, Lehm. Prccoox, Inprax Paint. Perennial. Clothed with soft hairs, 8-12 in. high. Flowers axillary and sessile. Corolla appendaged, not woolly within, showy, orange-yellow. Banks and open woods.

\section{ECHIUM, Tourn.}

Herbs or sometimes shrubs, usually stout, coarse, and hairy. Leaves entire. Flowers white, reddish-purple or blue, in spiked or panicled racemes. Calyx 5-parted. Corolla-tube cylindrical or funnel-shaped; the throat dilated; the limb with 5 unequal lobes. Filaments unequal, adnate to the corolla below, projecting from the corolla. Style thread-like, stigma 2-lobed. Nutlets 4, ovoid or top-shaped, wrinkled.

1. E. vulgare, L. Blue Thistle, Blee Weed, Bite Devils. Stems 1-3 ft. high, more or less erect, leafy, corered with stinging 
hairs. Root-leaves lanceolate or oblong, petioled, 4-8 in. long; stem-leaves sessile, acute, rounded at the base. Flowers showy, reddish-purple in the bud, changing to bright blue. A very troublesome weed, especially in fallow fields. Introduced from Europe.

\section{VERBENACE AE. Verbena FAMILY.}

Herbs, shrubs, or trees. Leaves opposite or whorled, without stipules. Flowers irregular, in bracted cymes. Calyx free from the ovary, cleft or toothed. Corolla free from the ovary, tubular, usually more or less 2-lipped. Stamens usually 4, 2 long and 2 short, inserted on the corolla-tube. Ovary usually 2-4-celled (in Phryma 1-celled), with the style springing from its summit.

\section{VERBENA, Tourn.}

Annual or perennial herbs. Leaves simple, opposite, serrate or pinnately lobed. Flowers in terminal spikes which become much elongated in fruit. Calyx tubular, 5-ribbed, 5-toothed. Corolla salver-form or funnel-form, the tube often curved, bearded in the throat, limb spreading, 5-lobed, often somewhat 2-lipped. Stamens 4, 2 long and 2 short, rarely only 2, included. Ovary 2-4-celled, 2-4-ovuled; style slender, 2-lobed. Fruit 2-4 smooth or roughened, 1-seeded nutlets. [Several of the commonest species are tall, coarse herbs which blossom too late for school study.]

1. V. officinalis, L. European Vervain. Annual ; stem erect, slender, nearly or quite smooth, branching, 1-3 ft. high. Leaves ovate to obovate in outline, pinnately lobed or divided, narrowed and entire toward the base, downy beneath; petioles margined. Spikes several, very slender; flowers small, purple, bracts shorter than the calyx. In fields and waste places; introduced from Europe.*

2. V. angustifolia, Michx. Narrow-Leaved Vervain. Perennial, rough-hairy ; stem simple, or branched below, from a creeping base, 1-2 ft. high. Leaves lanceolate to spatulate, obtuse and toothed at the apex, tapering to a sessile base. Spike peduncled, slender, close-flowered; bracts about the length of the calyx. Corolla.purple, tube slightly curved, $\frac{1}{4}$ in. long. In dry, open woods.* 
3. V. Aubletia, L. Terbera. A slender-stemmed, somewhat reclining annual, $1 \mathrm{ft}$. or less in height. Leaves ovate or nearly so, wedge-shaped at the base, lobed and toothed or 3-cleft. Flowers showy, reddish-purple or lilac (seldom white), in a peduncled spike. Calyx-teeth as long as or longer than the bracts. Corolla very slightly bearded in the throat. In dry prairie soil and open woods, also cultivated. [Other somewhat similar cultivated species are from Brazil.]

\section{CALLICARPA, $\mathbf{L}$.}

Shrubs. Leaves simple, petioled, opposite or whorled, glandular-dotted. Flowers in axillary cymes. Calyx 4-toothed or entire. Corolla funnel-form, 4-cleft, regular; stamens 4, equal, projecting. Ovary 4-ovuled; style slender; stigma knobbed. Fruit a 1-4-seeded berry.*

1. C. americana, L. French Mulberry, Mexican Mulberry. Shrubs, with star-shaped, glandular or scurfy down, widely branched, 3-8 ft. high. Leares ovate to oblong, acute at each end, crenateserrate, rough above, downy beneath, glandular-dotted; petioles slender. Cymes many-flowered, the peduncle as long as the petiole, pedicels short. Calyx cup-shaped, the teeth short. Corolla double the length of the calyx, blue. Fruit violet-purple, very conspicuous in autumn. Common in fields and thickets S.**

\section{LABIAT Æ. Mint FAMily.}

Mostly herbs, with square stems and opposite, more or less aromatic leaves, without stipules. Flowers generally in cyme-like axillary clusters, which are often grouped into terminal spikes or racemes. Calyx tubular, usually 2-lipped, persistent. Corolla usually 2-lipped (Fig. 148). Stamens 4 (2 long and 2 short) or only 2 . Ovary free, with 4 deep lobes, which surround the base of the style. Fruit consisting of 4 nutlets, ripening inside the base of the calyx.

Stamens 4.

A.

(a) Calyx 2-lipped.

Lips entire.

Scutellaria, I.

Lips toothed and cleft. Plants not aromatic.

Brunella, IV. 
Lips toothed and cleft. Plants aromatic. Leaves extremely small.

Thymus, IX.

(b) Calyx not 2-lipped, or not much so.

Calyx tubular, 5-10-toothed. Stamens not projecting from tube of corolla. Marrubium, II.

Calyx tubular, with 5 equal teeth. Stamens under upper lip of corolla.

Nepeta, III.

Calyx tubular, bell-shaped, with 5 awl-shaped teeth. Stamens not turned down after maturing.

Lamium, V.

Calyx top-shaped, with spreading spiny teeth.

Leonurus, VI.

Calyx as in No. 5. Stamens turned down after maturing.

Stachys, VII.

B.

Stamens 2.

Salvia, VIII.

\section{SCUTELLARIA, $\boldsymbol{L}$.}

Mostly slender herbs, not aromatic. Flowers solitary or in pairs, axillary or in terminal spikes or racemes. Calyx bellshaped, 2-lipped, the upper part swollen into a helmet-shaped pouch; mouth of the calyx closed after flowering. Corollatube long, naked inside. Stamens 4, the anthers meeting in pairs, hairy-fringed. Style with a very short upper lobe. [The species here described are not the commonest ones, but most of the others grow in damp soil and bloom later.]

1. S. serrata, Andrews. Skullcap. Stem not much branched, 1-3 ft. high. Stem-leaves serrate, taper-pointed at both ends, ovate or nearly so. Racernes single, loose. Calyx rather hairy. Corolla $1 \mathrm{in}$. long, the lips of equal length. Woods.

2. S. pilosa, Michx. Hainy Skuldcap. Stem more or less hairy, not much if at all branched, 1-3 ft. high. Leaves a few distant pairs, diamond-ovate, oblong-ovate, or roundish-ovate, scalloped, obtuse, the lower heart-shaped or nearly truncate at the base, with long petioles. Racemes short, few-flowered. Corolla $\frac{1}{2}$ in. long, 
tube whitish, lips blue, the lower one rather shorter. Open woodlands and dry soil.

3. S. integrifolia, L. LARge-Flowered Skullcap. Stem covered with fine, grayish down, usually umbranched, 1-2 ft. high. Leaves lance-oblong or nearly linear, mostly entire, obtuse, with very short petioles. Corolla $1 \mathrm{in}$. long, tube pale, lips large and spreading, blue. Dry ground.

\section{MARRUBIUM, Tourn.}

Perennial, downy, or woolly herbs. Whorls of flowers axillary; flowers small; bracts leaf-like. Calyx tubular, 5-10toothed, teeth somewhat spiny. Corolla short; upper lip erect, lower spreading, 3-cleft, the middle lobe broadest. Stamens 4, not projecting. Lobes of the stigma short and blunt.

1. M. vulgare, L. Horehocxd. Stems somewhat reclining, stout, branching, leafy, 1-1 $\frac{1}{2} \mathrm{ft}$. high. Leaves broadly ovate, heartshaped or wedge-shaped at the base, scalloped, leathery and wrinkled. Whorls of flowers dense. Calyx-teeth hooked at the tip. Corolla $\frac{1}{2}$ in. long, white. Cultivated from Europe as an herb (used in preparation of horehound candy) and somewhat naturalized.

\section{NEPETA, L.}

Erect or prostrate herbs. Whorls of flowers axillary or terminal; flowers blue or white. C'alyx tubular, 10ั-ribbed, 5-toothed. Corolla-tube slender below, dilated at the throat, naked; upper lip notched or 2-cleft; lower lip 3-cleft, middle lobe large. Stamens 4, ascending under the upper lip, the upper pair longer. Lobes of the stigma awl-shaped.

1. N. Cataria, L. Catxip. Stem grayish, downy, 2-3 ft. high, branched, very leafy. Leares large, ovate-heart-shaped, deeply scalloped, serrate, white and downy beneath. .Corolla about $\frac{1}{2}$ in. long, whitish with purple dots. Introduced from Europe; a common weed about dooryards.

2. N. Glechoma, Benth. Grouxd Ivy, Gill-over-The-Ground, Crefpisg Charley, Crow-victuals, Robin-Runaifay. Creeping. Leares roundish, kidney-shaped, and crenate. Corolla bluishpurple, three times as long as the calyx. Introduced from Europe, common in damp places about houses and gardens. 


\section{BRUNELLA, Tourn.}

Perennials, with stems simple or nearly so, and sessile, 3 -flowered flower-clusters in the axils of kidney-shaped bracts, the whole forming a spike or head. Calyx tubularbell-shaped, somewhat 10-ribbed, upper lip broad, 3-toothed, the teeth short, lower lip with 2 longer teeth. Upper lip of the corolla upright, arched, and entire, the lower spreading, reflexed, fringed, and 3-cleft. Stamens 4, reaching up under the upper lip, with the tips of the filaments 2-toothed, only one tooth anther-bearing.

1. B. vulgaris, L. Self-heal, Heal-all, Carpenter-Weed. Leaves with petioles, ovate-oblong, either entire or toothed, often somewhat hairy. Corolla usually blue or bluish, somewhat longer than the brown-purple calyx. Open woods and fields everywhere.

\section{LAMIUM, L.}

Annual or perennial hairy herbs. Calyx tubular-bellshaped, 5-veined, with 5 awl-pointed teeth of nearly equal length. Corolla with dilated throat, upper lip arched, middle lobe of the lower lip notched, the lateral lobes small, close to the throat of the corolla. Stamens 4, rising beneath the upper lip.

1. L. amplexicaule, L. Hen-bit, Dead Nettle. An annual or biennial weed. Leaves roundish, deeply scalloped, the lower ones petioled, the upper sessile and clasping. Corolla sometimes $\frac{3}{4}$ in. long, downy, rose-colored or purplish. Introduced from Europe; not uncommon about gardens and dooryards.

2. L. purpureum, L. Stem 6-18 in. high, silky-hairy or nearly smooth, reclining below, branched from the base. Leaves long-petioled, obtuse, heart-shaped, scalloped. Whorls of flowers mostly terminal, crowded. Corolla $\frac{1}{2}-\frac{3}{4}$ in. long, purple (rarely white). Introduced from Europe.

\section{LEONURUS, $\mathbf{L}$.}

Erect herbs. Leaves lobed. Whorls of flowers axillary, densely flowered, scattered; bractlets awl-shaped; flowers small, pink or white. Calyx 5-nerved, top-shaped, with 5 rather spiny, spreading teeth. Corolla with upper lip erect 
and entire, lower 3-cleft. Stamens 4 ; anthers joined in pairs. Nutlets with 3 projecting angles, their sides channeled.

1. L. cardiaca, L. Mотнекшовт. Stem 2-4 ft. high, prominently angled, stiff, stout, upright, rery leafy. Leares palmately lobed or cleft; radical ones long-petioled; lower stem-leares many-cleft, the upper ones 3-cleft, prominently nerred, the dirisions acute. Corolla $\frac{1}{2}$ in. long, pale rose-color, the upper lip and outside of the tube densely soft-bearded. Common about dooryards and fence-rows. Introduced from Europe.

\section{STACHYS, Tourn.}

Herbs, rarely shrubs. Leaves scalloped or serrate. Whorls of flowers 2 or more flowered, usually in terminal racemes. Calyx nearly bell-shaped, 5-toothed. Corolla-tube cylindrical, usually with a ring of hairs inside, not dilated at the throat; upper lip erect or spreading; lower spreading, 3-lobed, the middle lobe largest. Stamens 4, the 2 lower longest.

1. S. palustris, L. Perennial; stem erect, 4-angled, $2-3 \mathrm{ft}$. high, hairy, especially on the angles, with projecting or reflexed hairs, leafy. Stem-leares short-petioled or sessile, orate-lanceolate or oblong-lanceolate, scalloped-serrate, coarsely or finely downy, roundish at the base, rather obtuse at the tip. Calyx bristly, the lanceawl-shaped teeth rather spiny. Upper lip of the corolla downy. In wet soil, especially $\mathbf{N}$.

2. S. aspera, Michx. Taller than No. 1; angles of the stem corered with stiff reflexed bristles, but the sides often smooth. Leaves serrate, nearly all with distinct petioles. Calyx usually smooth. Corolla smooth throughout. Damp thickets and along streams.

\section{SALVIA, $\mathbf{L}$.}

Annual, biennial, or perennial herbs, or sometimes shrubby. Flowers in spikes, racemes, or panicles, usually showy. Calyx tubular or bell shaped, not bearded in the throat, 2-lipped, the upper lip entire or 3-toothed, the lower 2-cleft. Corolla 2-lipped, the upper lip entire or notched, the lower spreading, 3-lobed, with the middle lobe longer. Stamens 2, short, anthers 2-celled, the upper cell fertile, the lower imperfect. Style 2-cleft. Nutlets smooth.* 
1. S. lyrata, L. Lxre-Leaved Salvia, Biennial or perennial; stem erect, sparingly branched above, rough-hairy, 1-2 ft. high. Leaves mostly basal, spreading, lyrate-pinnatifid, usually purple, stem-leaves small, sessile or short-petioled. Racemes many-flowered, whorls about 6-flowered. Calyx-teeth short on the upper lip, long and awl-shaped on the lower. Corolla blue or purple, the tube about 1 in. long, dilated upward. On dry soil.**

2. S. officinalis, L. GARden SAGE. Stem shrubby, slender, much branched below, $1 \mathrm{ft}$. high. Leaves grayish-green, lance-oblong, crenate, wrinkled. Flowers in terminal spikes, whorls several-flowered. Corolla blue, upper lip strongly arched, about equaling the lower. Introduced from Europe and a common garden herb.**

\section{THYMUS, $\mathbf{L}$.}

Small, much-branched shrubs, very aromatic. Leaves small, entire, margins often rolled under. Whorls of flowers fewflowered, in loose or close spikes; bracts very small; flowers usually purple. Calyx ovoid, 2-lipped, upper lip 3-toothed, lower 2-cleft, woolly in the throat. Corolla slightly 2-lipped. Stamens 4, usually projecting from the flower, straight, lower pair longer.

1. T. Serpyllum, L. Creeping Thyme. Smooth or hairy, stem prostrate, the flowering branches somewhat ascending. Leaves $\frac{1}{8}-\frac{1}{4}$ in. long, flat, ovate or obovate-lanceolate, obtuse. Flowers crowded in spikes at the end of the branches. Corolla rose-purple, $\frac{1}{4}-\frac{3}{4} \mathrm{in}$. long. Becoming introduced from Europe.

2. T. vulgaris, L. Garden Thyme. More erect than No. 1. Leaves somewhat curled under at the edges. Flower-clusters shorter and not all terminal. Corolla pale purple. Cultivated from Europe as an herb.

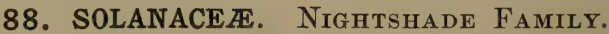

Mostly tropical herbs or shrubs (rarely trees). Leaves usually alternate, without stipules. Flowers regular, borne on bractless pedicels at or above the leaf axils, or in cymes. Calyx free from the ovary, 5-cleft, usually persistent. Corolla hypogynous, wheel-shaped, bell-shaped, or. salver-shaped, 5lobed. Stamens 5, short, inserted on the corolla-tube. Ovary 2-celled or imperfectly 4-celled; style simple; stigma simple or lobed. 'Fruit a many-seeded capsule or berry. 


\section{LYCIUM, L.}

Shrubs or woody vines, often spiny. Leaves entire, alternate, often fascicled. Flowers solitary or clustered, terminal or axillary. Calyx persistent, $4-5$-lobed or toothed, not enlarged in fruit. Corolla funnel-form or bell-shaped, the limb 4-כ-lobed, the lobes obtuse. Stamens 4-5, projecting. Ovary 2-celled; style single; stigma obtuse. Fruit a many-seeded berry.*

1. L. vulgare, Dunal. Matrimoxy Vine. Stem slender, branching, twining or trailing, 6-15 ft: long; branches angled, spiny. Leaves elliptical, smooth, entire, sessile, or short-petioled. Flowers solitary or few in the axils; peduncles long and slender. Corolla spreading, greenish-purple, $\frac{1}{3}-\frac{1}{2}$ in. wide. Berry oval, orange-red. Introduced from Africa, and often planted for covering trellises.*

\section{SOLANUM, Tourn.}

Herbs or shrubs: stems often prickly, sometimes climbing. Leaves alternate, often nearly or quite opposite. Flowers clustered, the peduncles often opposite or above the axils. Calyx spreading, כॅ-toothed or $\check{5}$-cleft, persistent. Corolla

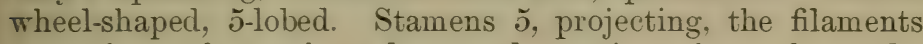
rery short, the anthers long and meeting about the style. Orary 2-celled; style slender. Fruit a many-seeded, juicy berry.*

1. S. Dulcamara, L. Bittersweet. Perennial. Stems rather shrubby, long, and climbing. Leares heart-shaped, or some of them with irregular lobes, or ear-like leaflets at the base. Flowers blue or purple, somewhat crmose. Berries showy, of many shades of orange and red in the same cluster, according to their maturity.

2. S. nigrum, L. Nightshade. Annual; stem smooth, or downy with simple hairs, erect, diffusely branched; branches wingangled. 1-3 ft. high. Leares ovate, irregularly toothed or entire, somewhat inequilateral. petioled. Flowers in lateral, peduncled umbels, small. white, drooping. Calyx-lohes obtuse: corolla $\frac{1}{3}-\frac{1}{2}$ in. wide; filaments downy: herries glohose, smooth, black when ripe. Common in cultivated fields and waste places.*

3. S. carolinense, L. Horse Nettle. Perennial; stem erect, branched, downy with star-shaped hairs, armed with straight, yellow prickles, 1-3 ft. high. Leaves ovate-oblong, deeply toothed or lobed, 
acute at the apex, abruptly contracted to the short petiole, prickly on the veins. Racemes lateral, few-flowered; pedicels recurved in fruit. Calyx-lobes taper-pointed. Corolla deeply angular-lobed, blue or white; berry globose, smooth, yellow. A common weed.*

4. S. rostratum, Dunal. Sand Bur, Buffalo Bur. Annual; the whole plant beset with yellow prickles; stem erect, diffusely branched, 1-2 ft. high. Leaves broadly oval or ovate in outline, deeply pinnately lobed or parted, petioled, downy, with star-shaped hairs. Racemes few-flowered; pedicels erect in fruit. Calyx very prickly, becoming enlarged and enclosing the fruit. Corolla bright yellow, 5-angled, about 1 in. broad. Introduced from the West, and becoming a troublesome weed in some places.*

5. S. tuberosum, L. Irish Ротато. Annual; stem diffusely branched, downy, underground branches numerous and tuber-bearing. Leaves irregularly pinnatifid and divided. Flowers in cymose clusters, white or purple, with prominent yellow anthers; pedicels jointed. Corolla 5-angled, $\frac{3}{4}-1$ in. broad. Fruit a globose, greenishyellow, many-seeded berry, about $\frac{1}{2}$ in. in diameter. Cultivated from Chili.*

\section{LYCOPERSICUM, Tourn.}

Annual ; stem diffusely branched. Leaves pinnately divided. Flowers in raceme-like clusters on peduncles opposite the leaves. Calyx 5-many-parted, persistent. Corolla wheelshaped, 5-6-parted. Stamens 5-6, inserted in the short tube of the corolla, filaments short, anthers elongated. Ovary 2 -several-celled, style and stigma simple. Fruit a manyseeded berry.*

1. L. esculentum, Mill. Tomato. Stem diffusely branched, at length leaning over, furrowed and angled below, sticky-hairy, 3-5 ft. long. Leaves irregularly lobed and pinnatifid, petioled. Calyxlobes linear, about as long as the yellow corolla. Fruit (in the wild state) globose or ovoid, red or yellow, $\frac{1}{4}-\frac{1}{2}$ in. in diameter, but greatly enlarged in cultivation. Common in cultivation from tropical America.*

\section{DATURA, L.}

Annual or perennial, strong-scented herbs; stems tall and branching. Leaves petioled, entire or lobed. Flowers large, solitary in the forks of the branches. Calyx tubular, 5-toothed or lobed, the upper part deciduous and the lower persistent. Corolla funnel-form, 5-angled. Stamens 5, inserted in the 
corolla-tube. Ovary 2-celled or imperfectly 4-celled; style filiform ; stigma 2-lobed. Fruit a spiny, 4-valved, many-seeded capsule.*

1. D. Stramonium, L. Jimsox-WeED. Annual; stem smooth, green, stout, forking abore, 1-4 ft. high. Leaves ovate to oblongorate, acute at the apex, narrowed at the base, sinuate-toothed, petioled. Calyx 5-angled. Corolla white, about 4 in. long. Capsule oroid, erect, 2 in. long. A common weed ; poisonous. Introduced from Asia.*

2. D. Tatula, L. Taller, with a purple stem. Flowers rather later than No. 1; corolla violet-tinged.

\section{PETUNIA, Juss.}

Herbs; leaves alternate and entire. Divisions of the calyx oblong-spatulate. Corolla showy, spreading funnel-shaped, not perfectly regular. Stamens 5, somewhat unequal in length, inserted in the middle of the corolla-tube and not projecting beyond it. Capsule 2-celled, containing many very small seeds.

1. P. violacea, Lindl. Comion Petuxia. Stems rather weak and reclining. Leaves corered with clammy down. Corolla varying from pale pink to bright purplish-red, often rariegated, with a broad, inflated tube, which is hardly twice as long as the calyx. Cultivated annual from South America.

2. P. nyctaginiflora, Juss. White Petcria. Leaves somewhat petioled. Tube of corolla long and slender. Flowers white. Cultivated from South America. This and the preceding species much mixed by hybridization.

\section{SCROPHULARIACE 2 . FigWORt Family.}

Mostly herbs, with irregular flowers. Calyx free from the ovary and persistent. Corolla 2-lipped or otherwise more or less irregular. Stamens usually 2 long and 2 short, or only 2 in all, inserted on the corolla-tube, often 1 or 3 of them imperfectly developed. Pistil consisting of a 2-celled and usually many-ovuled ovary, with a single style and an entire or 2-lobed stigma. 
Corolla wheel-shaped, stamens 5 .

Verbascum, I.

Corolla wheel-shaped or salver-shaped, nearly regular, stamens 2.

Veronica, VI.

Corolla 2-lipped, the mouth closed by a palate, tubular below, a spur at the base.

Linaria, II.

Corolla 2-lipped, the mouth closed by a palate, tubular below, a short, broad pouch at the base.

Antirrhinum, III.

Corolla decidedly 2-lipped.

Stamens with anthers 2.

Gratiola, V.

Stamens 4, with a fifth antherless filament.

Pentstemon, IV.

Stamens 4, the anther-cells unequal.

Stamens 4, the anther-cells equal.

Castilleia, VII.

Pedicularis, VIII.

\section{VERBASCUM, $\mathrm{L}$.}

Biennial ; stem tall, erect. Leaves alternate. Flowers in spikes, racemes or panicles. Calyx deeply 5-cleft. Corolla wheel-shaped, 5-lobed, the lobes nearly equal. Stamens 5, unequal, declined, some or all of the filaments bearded. Style flattened at the apex. Fruit a globose capsule; seeds roughened.*

1. V. Blattaria, L. Mотн Mullein. Stem erect, slender, simple or sparingly branched, smooth below, downy above, $2-4 \mathrm{ft}$. high. Leaves oblong to lanceolate, acute at the apex, obtuse or truncate at the base, dentate to pinnately lobed, the lower petioled, the upper sessile and clasping. Raceme long and loose, glandular-downy, pedicels bracted. Corolla white or yellow, marked with brown on the back, about 1 in. wide. Filaments all bearded with purple hairs. Capsule longer than the calyx. Common in fields and waste places ; introduced from Europe.*

\section{LINARIA, Tourn.}

Herbs, rarely shrubby. Lower leaves opposite, whorled or alternate. Flowers in bracted racemes or spikes or axillary and solitary. Calyx 5-parted. Corolla 2-lipped, the tube spurred. Stamens 4, with sometimes a rudiment of a fifth. Stigma notched or 2-lobed. Capsule ovoid or globose; cells nearly equal. 
1. L. vulgaris, Miller. Butter-AND-EGGS, JACOB'S LADDER, Wild Flax. A peremnial, erect, smooth herb, with a bloom, stem 1-2 ft. high. Leaves linear or lanceolate, 1-3 in. long, often whorled. Racemes densely flowered. Sepals shorter than the spur. Corolla yellow, $\frac{3}{4}-1$ in. long; spur parallel to and as long as the tube; throat closed by a palate-like fold. Common in dry fields and pastures and along roadsides; introduced from Europe.

2. L. canadensis, Dumont. ToAD-FLAX. Biennial; flowering stems erect, slender, rarely branched, smooth, 1-2 ft. high, sterile stems prostrate, with opposite or whorled leaves, 2-6 in. long. Leares linear, entire, sessile. Racemes erect, slender; pedicels erect, as long as the calyx. Corolla small, blue and white, the spur thread-like, curved, longer than the pedicels. Capsule 2-valved, the valves 3 -toothed. On dry or cultivated ground E.

\section{ANTIRRHINUM, Toum.}

Annual or perennial herbs. Leaves entire, rarely lobed, the lower ones opposite, the upper alternate. Flowers axillary and solitary or racemed and bracted. Calyx 5-parted. Corolla 2-lipped. The tube with a sac, the broad bearded palate closing the throat. Stamens 4. Stigma with 2 short lobes. Capsule 2-celled, the upper cell opening by 1 pore, the lower by 2 .

1. A. majus, L. Snapdragon. Perennial; stem erect, smooth below, glandular-downy above, 1-2 ft. high. Leares linear to oblong-lanceolate, entire, smooth, sometimes fleshy, sessile or shortpetioled. Flowers in a terminal raceme; pedicels short, stout, erect in fruit. Corolla $1 \frac{1}{2}-2$ in. long, of many colors. Capsule oblique, the persistent base of the style bent forward. Common in gardens, cultirated from Europe, and often escaped.*

\section{PENTSTEMON, Mitchell.}

Perennials, the stems branching from the base, unbranched above. Leaves opposite. Flowers usually showy in a terminal panicle. Calyx of $\tilde{5}$ nearly distinct sepals. Corolla tubular, the tube wide above and narrowed below; 2-lipped. Stamens 4, 2 long and 2 short, with a fifth antherless filament as long as the others, its upper half bearded. Capsule ovoid, acute.

1. P. pubescens, Solander. Stem somewhat sticky-downy, 1-2 ft. high. Leaves varying from oblong to lanceolate, $2-4$ in. long, 
usually with small teeth. Flower-cluster narrow. Corolla dingy violet, purplish, or whitish, the tube not much widened above, its throat nearly closed by a hairy palate. Sterile filament much bearded. Dry hillsides or stony ground.

2. P. lævigatus, Solander. Stem usually smooth except the flower-cluster, 2-4 ft. high. Leaves shining, those of the stem ovate-lanceolate or broadly lanceolate, $2-5$ in. long, with a somewhat heart-shaped clasping base. Flower-cluster broader than in No. 1. Corolla white or oftener purplish, suddenly widened above, the throat not closed. Sterile filament slightly bearded toward the top. In rich soil.

3. P. barbatus, Nutt. Stems slender and rod-like, $3-4 \mathrm{ft}$. high. Leaves lanceolate, entire. Flower-cluster long and loosely flowered. Flowers showy, drooping. Corolla-tube slender, scarlet, somewhat bearded in the throat. Sterile filament beardless. Cultivated from Mexico.

\section{GRATIOLA, L.}

Low herbs growing in wet or damp ground. Leaves opposite, sessile. Flowers axillary and solitary, peduncled. Calyx 5 -parted, usually with 2 bractlets at the base. Corolla somewhat 2-lipped. Perfect stamens 2. Stigma enlarged or 2-lipped. Pod 4-valved, many-seeded.

1. G. virginiana, L. Stem cylindrical, 4-10 in. long, branching from the base. Leaves $\frac{3}{4}-1 \frac{1}{2}$ in. long, varying from lance-oblong to spatulate. Corolla pale yellow, tinged with red. Common in muddy soil, along brooksides, etc.

\section{VERONICA, Tourn.}

Herbs or shrubs. Lower leaves or all the leaves opposite, rarely whorled. Flowers in axillary or terminal racemes, rarely solitary. Calyx usually 4-parted. Corolla wheelshaped or somewhat bell-shaped; limb usually 4-cleft, spreading, the side lobes commonly narrower. Stamens 2, inserted on the corolla-tube at the sides of the upper lobe, projecting. Stigma somewhat knobbed. Capsule generally flattened, often notched at the apex, 2-celled, few-many-seeded.

1. V. americana, Schweinitz. Brooklime. A perennial smooth herb, somewhat prostrate below, but the upper parts of the stem erect, 8-15 in. high. Leaves 1-2 in. long, lance-ovate or oblong, 
serrate, short-petioled. Racemes 2-t in. long, axillary and opposite. Corolla wheel-shaped, blue. Capsule swollen, roundish. Muddy soil about springs and brooks.

2. V. officinalis, L. Common Speedweld, Grysy Weed. Perennial. Roughish-downy, with the prostrate stems spreading and rooting. Leares wedge-oblong or nearly so, obtuse, serrate, somewhat petioled. Racemes dense, of many pale bluish flowers. Capsule rather large, inversely heart-shaped and somewhat triangular. Dry hillsides, open woods and fields.

3. V. serpyllifolia, L. Thyme-Leaved Spennfeld. Perennial. Smooth or nearly so; branching and creeping below, but with nearly simple ascending shoots, $2-4$ in. high. Leaves slightly crenate, the lowest ones petioled and roundish, those farther up ovate or oblong, the uppermost ones mere bracts. Raceme loosely flowered. Corolla nearly white or pale blue, beautifully striped with darker lines; capsule inversely heart-shaped, its width greater than its length. Damp grassy ground; a common weed in lawns.

4. V. peregrina, L. Purslaxe Speedwell. A homely, rather fleshy, somewhat erect-branched annual weed, 4-9 in. high. Lowest leares petioled, oblong, somewhat toothed, those above them sessile, the uppermost ones broadly linear and entire. Flowers solitary, inconspicuous, whitish, barely pediceled, appearing to spring from the axils of the small floral leares. Corolla shorter than the calyx. Roundish, barely notched, many-seeded. Common in damp ground, in fields and gardens.

\section{CASTILleIA, Mutis.}

Herbs parasitic on the roots of other plants. Leaves alternate; the floral ones usually colored at the tip and more showy than the flowers. Flowers yellow or purplish in terminal leafy spikes. Calyx tubular, flattened, 2-4-cleft. Corolla-tube included within the calyx; upper lip of the corolla very long, linear, arched, and enclosing the stamens, 2 of which are long and 2 short. Ovary many-ovuled.

1. C. coccinea, Sprengel. Scarlet Painted Cup, Paint-brush, Indan Pink, Prairie Fire, Wickakee. A hairy, simple-stemmed herb. Annual or hiennial. Root-leaves clustered obovate or oblong. Stem-leaves cut ; floral leaves :3-; cleft and bright scarlet (occasionally yellow) toward the tips, as though dipped in a scarlet dye. Calyx nearly as long as the pale yellow corolla, 2-cleft. The spikes are often very broad, making this one of the most conspicuous of our native flowers. Damp, sandy ground, or on bluffs near streams; sometimes in marshes. 


\section{PEDICULARIS, Tourn.}

Perennial herbs, with the lower leaves pinnately cut and the floral ones reduced to bracts. Flowers spiked. Corolla markedly 2-lipped; the upper lip much flattened laterally and arched, the lower lip spreading, 3-lobed. Stamens 4, beneath the upper lip. Capsule 2-celled, tipped with an abrupt point, several-seeded.

1. P. canadensis, L. Common Lousewort. Hairy, with clustered simple stems, $1 \mathrm{ft}$. high or less. Leaves petioled, the lowermost ones pinnately parted, the others somewhat pinnately cut; spike short, closely flowered and leafy-bracted; calyx split down the front; corolla greenish-yellow and purplish, with its upper lip hood-like, curved under, and with 2 awl-like teeth near the end; capsule flat, broadly sword-shaped. Knolls and openings among thickets.

\section{Bignoniace 2 . Bignonia Family.}

Trees or shrubs, often twining or climbing, rarely herbs. Leaves usually opposite, without stipules. Flowers showy, irregular. Corolla tubular, with a widened throat and a 5 -lobed limb. Stamens usually 2 long and 2 short, or only 2 . Ovary free from the calyx, 2-celled or rarely 1-celled, with many ovules. Fruit a capsule; seeds large, winged.

\section{BIGNONIA, Tourn.}

Woody vines. Leaves opposite, compound, usually tendril-bearing. Flowers large, in axillary clusters. Calyx cup-shaped, truncate, or undulate-toothed. Corolla spreadingtubular, somewhat 2-lipped, the lobes rounded. Stamens 4, 2 long and 2 short. Capsule linear, flattened parallel with the partition, the two valves separating from the partition at maturity. Seeds flat, broadly winged.*

1. B. capreolata, L. Cross-vine. Stem climbing high, a transverse section of the older stems showing a conspicuous cross formed by the 4 medullary rays; branches smooth. Leaves evergreen, petioled; leaflets 2, ovate, taper-pointed with a blunt apex, heartshaped at the base, entire, stalked, upper leaflets transformed into 
branching tendrils. Flowers numerous, short-peduncled. Corolla 2 in. long, reddish-brown without, yellow within. Capsule 6 in. long, flat, the ralves with a prominent central nerve. Seeds broadly winged on the sides, short-winged on the ends. Common in woods S.*

\section{TECOMA, Juss.}

Woody vines, climbing by aerial rootlets. Leaves compound, odd-pinnate. Flowers large, in terminal clusters. Calyx bell-shaped, unequally 5-toothed. Corolla funnel-form, enlarged above the calyx, 5-lobed, slightly 2-lipped. Stamens 4, 2 long and 2 short. Capsule slender, spindle-shaped, slightly compressed contrary to the partition, 2-valved, dehiscent. Seeds winged.*

1. T. radicans, Juss. Trumpet Flower, Trumpet Creeper. Stems climbing high by numerous rootlets, bark shreddy. Leares deciduous, petioled; leaflets $9-11$, orate tr orate-lanceolate, serrate, short-stalked, smooth or slightly downy. Flowers in short, terminal racemes or corymbs. Calyx tubular, $\frac{3}{4}$ in. long. Corolla $2-3$ in. long, scarlet without, yellow within, the lobes spreading. Capsule $5-6$ in. long, curred, often persistent through the winter. Seeds broadly winged. On borders of fields and in woods S.; often cultivated.*

\section{CATALPA, Scop., Walt.}

Small trees. Leares large, opposite, simple, petioled, deciduous. Flowers large and showy, in terminal panicles. Calyx irregularly 2-lipped. Corolla tubular-bell-shaped, oblique, 5-lobed, 2-lipped. Fertile stamens 2, sterile stamens 3, short. Fruit a linear, 2-valved, many-seeded capsule. Seeds winged.*

1. C. bignonioides, Walt. CATALPA. A small tree with thin, rough, gray bark and light, soft, but exceedingly durable wood. Leares long-petioled, heart-shaped, entire or palmately 3-lobed, taperpointed at the apex, palmately reined, downy. Branches of the panicle in threes; flowers large, $1-1 \frac{1}{2}$ in. long, white, variegated with yellow and purple. Corolla lobes undulate or crisped. Capsule rery slender, $1 \mathrm{ft}$. or more in length, pendulous. Seeds with long, fringed wings. On margins of rivers and swamps S., often cultivated.*

2. C. speciosa, Warder. CATALPA. A tall tree with very durable wood. Leares large, heart-shaped, taper-pointed. Corolla about 2 in. long, almost white, but slightly spotted ; tube inversely conical ; 
limb somewhat oblique, its lower lobe notched. Pod rather stout. Rich, damp woods, especially S. W. ; often cultivated.

\section{OROBANCHACE无. BROOM-RAPE FAMILY.}

Leafless brownish root-parasites. Rootstock often tuberous, naked or scaly. Stem usually stout, solitary, scaly. Flowers spiked or racemed. Sepals 4-5, free from the ovary. Corolla hypogynous, irregular, the tube curved; the limb 2-lipped. Stamens 4, 2 long and 2 short, inserted on the corolla-tube; anthers 2-celled, the cells spurred at the base. Ovary 1-celled, of 2 carpels, style simple, stigma 2-lobed; ovules many. Capsule 1-celled, 2-valved, few-many-seeded; seeds very small.

\section{CONOPHOLIS, Wallroth.}

Stems often clustered, stout, covered with scales which overlap, the uppermost ones each with an axillary flower, thus forming a spike. Calyx irregularly 4-5 cleft, split down the lower side. Corolla swollen below, decidedly 2-lipped, the upper lip arched. Stamens projecting.

1. C. americana, Wallroth. SquAW-Root, CANCER-Root. Stems 3-6 in. high, yellowish or yellowish-brown. Flowers numerous, inconspicuous. Corolla dirty white or pale brown. In oak woods, not very common.

\section{APHYLLON, Mitchell.}

Brownish or whitish plants with naked scapes borne on scaly, mostly underground stems. Calyx regular, 5-cleft. Corolla 5-lobed, slightly irregular. Stamens not projecting from the corolla-tube.

1. Aphyllon uniflorum, Gray. One-Flowered CANCER-Root. Slightly covered with clammy down. Stems very short-branched, each with 1-3 1-flowered scapes 3-5 in. high. Calyx-lobes lanceawl-shaped, half as long as the corolla. Corolla yellowish-white, veiny, purple-tinged, palate with 2 yellow bearded ridges. Damp woods.

2. A. fasciculatum, Gray. Stem scaly, upright, 3-4 in. high above ground and generally longer than the numerous 1-flowered peduncles. Calyx-lobes short, triangular. Parasitic on wild species of Artemisia, etc., in sandy and loamy soil N. W. and W. 


\section{LENTIBULARIACEÆ. BLAdDERWORT Family.}

Scape-bearing herbs, chiefly aquatic or living in marshes. Leaves are often thread-like and floating, without stipules. Flowers irregular. Calyx free from the ovary, persistent. Corolla hypogynous, 2-lipped, the tube short, spurred at the base. Stamens 2, opposite the lateral sepals, hypogynous or inserted on the corolla-tube. Ovary free, 1-celled; style short, thick, stigma 2-lipped, ovules many. Capsule 2-valved or bursting irregularly, many-seeded.

\section{UTRICULARIA, $\mathbf{L}$.}

Aquatic or terrestrial herbs, often floating and propagated by buds which break loose from the plant and sink to the bottom of the pond or stream during the winter. Leaves of the aquatic species floating, thread-like, furnished with little bladders in which animalcules are caught. Flowers often rather showy, solitary, spiked or racemed. Corolla with its throat nearly closed by the palate. Capsule globose, bursting irregularly.

1. U. cornuta, Michx. Horved Bladderwort. Stemless. Leaves linear and entire or none; air bladders few or none. Scape erect, stout, 2-5̆-flowered, 8-12 in. high. Flowers yellow, fragrant, $\frac{3}{4} \mathrm{in}$. wide. Pedicel as long as the calyx. Lips of the corolla obovate, unequal, the lower longer, abruptly pointed, the sides reflexed, as long as the horn-shaperl, curved spur, throat bearded. Seeds minutely pitted. In swamps and muddy places.*

2. U. subulata, L. Sirall Bladderwort. Scape thread-like, 2-6 in. high. Leares few and awl-shaped or none; air bladders few or none. Racemes zigzag, 1-6-flowered; pedicels much longer than the calyx. Corolla yellow, $\frac{1}{4}$ in. wide, the lower lip 3-lobed, longer than the appressed, conical, green-pointed spur. Wet, sandy soil.*

3. U. inflata, Walt. Swollex Bladderwort. Perennial; stem very slender, floating. Leares finely dissected, the lower ones scattered, the upper ones whorled; the petioles dilated upward and inflated, air bladders very numerous. Scape stout, 6-12 in. high, $3-10$-flowered. Corolla yellow, about $\frac{3}{4}$ in. wide, upper lip ovate, slightly lobed, lower lip 3-lobed, twice the length of the curved, emarginate spur. Fruit nodding. In ponds and still water.* 
4. U. vulgaris, L. Greater Bladderwort. Stems submerged, leafy, 1-3 ft. long. Leaves spreading, pinnately cut into very many thread-like segments which bear many bladders. Scapes 6-12 in. long, 5-12-flowered, pedicels bent down after flowering. Corolla $\frac{1}{2}-\frac{3}{4}$ in. long, yellow, upper lip broad and short, palate prominent; spur conical, pressed close to the under lip. Ponds and slowly flowing streams.

\section{ACANThaCe}

Herbs or shrubs. Leaves opposite or whorled, without stipules. Flowers irregular, usually with large bracts. Calyx of 4 or 5 unequal segments which considerably overlap each other. Corolla 4-5-parted and usually more or less 2-lipped. Stamens usually 2 long and 2 short, sometimes only 2. Ovary free from the calyx. Fruit usually a capsule. Seeds not winged. A large family, mostly tropical, with only a few insignificant wild species in the northern United States.

\section{RUELLIA, Plumier.}

Perennial herbs; stems swollen at the joints and often between them, somewhat 4-angled. Leaves sessile or shortpetioled, mostly entire. Flowers axillary, solitary or clustered, showy, white, blue, or purple. Calyx 2-bracted, 5-parted, the divisions linear and awl-shaped. Corolla-tube slender, often much elongated, the limb spreading, nearly equally 5-lobed. Stamens 4, 2 long and 2 short, included or slightly projecting. Style slender. Capsule slender, narrowed below, 4-12-seeded.*

1. R. strepens, L. Sмоотн Ruellia. Stem erect, slender, usually simple, smooth or hairy, 1-3 ft. high. Leaves ovate to oblong, acute at the apex, narrowed below into a short petiole. Flowers solitary or in small clusters, sessile or short-peduncled. Calyx-lobes shorter than the tube of the corolla, downy or fringed. Corolla blue, the tube $1 \frac{1}{2}-2$ in. long, the limb $1-1 \frac{1}{2}$ in. wide. Capsule usually longer than the calyx, smooth, 8-12-seeded. The later flowers often without a corolla. On rich, dry soil.*

2. R. ciliosa, Pursh. HaIry Ruellia. Stem erect, rather stout, often few-branched above, covered with white hairs, 4-30 in. high. Leaves oblong to ovate, acute or obtuse at the apex, narrowed and 
mostly sessile at the base, hairy-fringed. Flowers pale blue, solitary or 2-3 together. Calyx-lobes bristle-shaped, half the length of the corolla-tube. Tube of the corolla 2 in. long. Capsule shorter than the calyx, smooth, 8-12-seeded. A very variable species, the flowers often without a corolla. In dry woods and fields S.**

\section{DIANTHERA, Gronov.}

Perennial herbs; stem smooth. Leaves opposite, entire or toothed. Flowers axillary, solitary or clustered, irregular. Calyx 5-parted. Corolla 2-lipped, upper lip erect, concave, entire or notched, the lower prominently veined, spreading, 3-lobed. Stamens 2, inserted in the throat of the corolla. Ovary 2-celled, 4-ovuled, style simple, acute. Capsule flattened, narrowed below into a little stalk.*

1. D. americana, L. WATER WirLow. Stem erect, slender, 2-3 ft. high. Leares lanceolate to linear-lanceolate, taper-pointed at the apex. narrowed below to the sessile or short-petioled base. Flowers bracted, in short spikes, on peduncles as long as the leares. Corolla pale blue or purple, the tube as long as the lips, lower lip wrinkled. Capsule about the length of the calyx. In water S.*

\section{Plantaginace丑. Plantain Family.}

Annual or perennial scape-bearing herbs. Leaves usually all radical, with parallel ribs. Flowers small, green, usually spiked, regular and perfect (Fig. 21). Sepals 4, persistent. Corolla hypogynous, salver-shaped, thin and dry; lobes 4, spreading. Stamens 4, usually inserted on the corolla-tube, filaments thread-like, anthers large and versatile. Ovary free, usually 2-4-celled; style thread-like. Fruit a 1-4-celled, 1 or more seeded membranous capsule, which splits open transversely, the top coming off like a lid.

\section{PLANTAGO, L.}

Characteristics of the genus as given above for the family.

1. P. major, L. Plantaix. Perennial, from a very short rootstock. Leaves ovate to oral, strongly $\tilde{5}-9$-ribbed, acute or obtuse at 
the apex, rounded at the base into a long, concave petiole, entire or toothed, smooth or slightly downy. Scape taller than the leaves, downy, spike densely flowered; bracts short, ovate. Flowers perfect. Stamens 4, projecting. Capsule ovoid, about twice the length of the calyx. Common in dooryards.*

2. P. lanceolata, L. RiBGRAss. Biennial or perennial; softhairy or nearly smooth. Leaves numerous, lanceolate to elliptical,

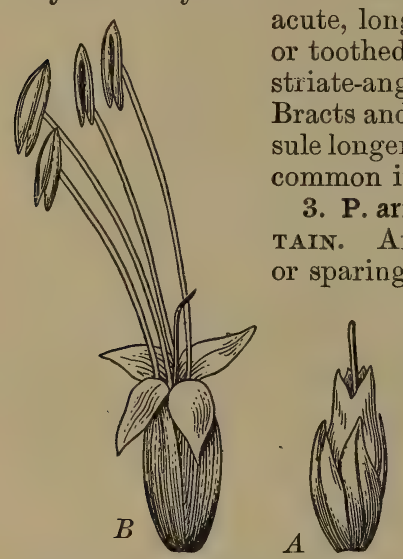

Frg. 21. - Flowers of Plantain

(Plantago), enlarged.

$A$, earlier stage, pistil mature, stamens not yet appearing outside the corolla. $B$, later stage, pistil withered, stamens mature.

twice the length of the calyx, many-seeded. Common in cultivated ground, especially S.*.

\section{RUBIACE E. MAdDER FAMily.}

Herbs, shrubs, or trees. Leaves opposite and entire, with stipules between them, or appearing whorled since the stipules resemble the leaves. Flowers always perfect, frequently dimorphous (as in Houstonia, Mitchella, and Bouvardia). Calyx-tube adnate to the ovary; limb 3-6-toothed. Corolla regular, inserted on the calyx-tube, as many-lobed as the calyx. Stamens equal in number to the divisions of the corolla. Ovary 2 or more celled. A very large and important 
family, of which many of the important species, for instance, the coffee shrub and the cinchona tree, are natives of warm or tropical climates.

\section{HOUSTONIA, L.}

Annual, biemnial, or perennial herbs; stems erect or diffuse. Leaves entire, stipules often only a line connecting the bases of opposite leaves. Flowers small, solitary, or clustered. Calyx 4-toothed, persistent. Corolla wheel-shaped to funnelform, 4-lobed. Stamens 4. Ovary 2-celled, style slender, stigmas 2. Fruit a 2-celled, few-many-seeded capsule, opening at the apex, free from the calyx.*

1. H. cœrulea, L. Bluets, Ixyocence, Quaker Ladies, ExeBRIGHT. Perennial, from very slender rootstocks; stems tufted, erect, smooth, forking, 3-6 in. high. Leares sessile, often hairyfringed, the lower spatulate, the upper lanceolate. Flowers solitary, on slender axillary peduncles. Calyx small. Corolla salver-form, blue or white, yellow in the throat, smooth, of two forms, the stamens projecting and the style short in one form, while in the other the stamens are short and the style projecting. Capsule laterally compressed, 2-lobed, shorter than the calyx. Common on open ground.*

2. H. patens, Ell. Syall Blcets. Annual. Stem erect, branched at the base, forking above, smooth, $2-4 \mathrm{in}$. high. Lower leaves oval to ovate, petioled, the upper narrower and sessile. Flowers solitary, on slender, axillary peduncles, blue or white. Calyx small. Lobes of the corolla about as long as the tube ; stamens and style projecting or included. Capsule compressed, as long as the calyx. Common on dry, open ground.*

3. H. purpurea, L. Large Blcets. Perennial; stem stout, erect, simple or branched, smooth or downy, 4-angled, 6-12 in. high. Leaves orate to orate-lanceolate, sessile or short-petioled, 3-5-nerved, often hairy-fringed on the margins. Flowers in terminal cymes, purple to nearly white. Corolla funnel-form, the tube longer than the limb, hairy within. Stamens and style projecting or included. Capsule compressed-globose, much shorter than the calyx. In dry, open woods.**

Var. longifolia, Gray. Loxg-Leaved Bluets. Peremial. Stem erect, brancher, smooth, 4-angled, 8-12 in. high. Leaves sessile, the lower oblanceolate or spatulate, the upper linear, 1-nerved. Corymbs terminal, few-flowered. Corolla light purple to white, the lobes much shorter than the tube. Capsule compressed-globose, nearly as long as the calyx. In dry, open woods.* 


\section{BOUVARDIA, Salisb.}

Smooth perennials. Leaves lanceolate, thickish. Calyx 4-lobed, the divisions slender. Corolla with a long and narrow or rather trumpet-shaped tube and spreading 4-lobed limb. Anthers 4, inserted in the throat of the corolla, almost sessile. Stigmas 2, flat. Capsule globular, 2-celled, many-seeded. Flowers dimorphous.

1. B. triphylla, Salisb. Three-Leaved Bouvardia. Somewhat shrubby. Leaves nearly smooth, ovate or oblong-ovate, the lower ones in threes, the upper ones sometimes in pairs. Corolla scarlet and slightly downy outside.

2. B. leiantha, Benth. Downy-Leaved Bouvardia. Leaves rather downy. Corolla deep scarlet, smooth outside.

Both species cultivated from Mexico; in greenhouses.

\section{MITCHELLA, L.}

A pretty trailing evergreen herb. Leaves roundish-ovate, petioled. Flowers fragrant, white or pinkish, dimorphous, growing in pairs, joined by their ovaries. Calyx 4-toothed. Corolla funnel-shaped, with the lobes bearded within. Stamens 4, short. Style 1, stigmas 4, slender. Fruit double, composed of the united ovaries, really a stone-fruit containing 8 seed-like bony nutlets, ripening into tasteless scarlet berries which cling to the plant through the winter.

1. M. repens, L. Partridge Berry, Squaw Vine, Two-eye BERRY. Common in dry woods, especially under evergreen coniferous trees.

\section{GALIUIM, L.}

Annual or perennial herbs ; stems slender, 4-angled. Leaves appearing whorled. Flowers small, in axillary or terminal cymes or panicles, perfect or rarely diœcious. Calyx-tube short, the teeth minute or wanting. Corolla wheel-shaped, 3-4-lobed. Stamens 3-4, short. Ovary 2-celled, styles 2, short, united below. Fruit 2, united, sometimes fleshy, 1-seeded carpels which do not split open.*

1. G. Aparine, L. Goosegrass. Annual; stem weak, decumbent, sharply 4 -angled and with backward pointing prickly hairs, 
widely branched, 2-4 ft. long. Leares $6-8$ in a whorl, oblanceolate, prickly-hairy on the margins and midrib. Peduncles axillary, longer than the leaves, 1-3-flowered; flowers white. Fruiting pedicels erect; fruit dry, covered with hooked bristles. In waste places.*

2. G. circæzans, Michx. Wild Licorice. Perennial; stems sereral, erect, smooth or downy, 12-18 in. high. Leaves 4 in a whorl, oral to orate, obtuse at the apex, strongly 3-nerved, downy. Cymes long-peduncled, repeatedly branched. Flowers nearly sessile, greenish-purple; pedicels at length recurred. Fruit with hooked bristles. In dry, open woods S. Easily recognized by the sweet, licorice-like taste of the leaves.*

3. G. hispidulum, Michx. Bedstraw. Perennial, from yellow roots; stems diffusely branched, smooth or slightly roughened, downy at the joints, erect or decumbent, 1-2 ft. long. Leaves 4 in a whorl, narrowly oral, acute, rough on the margins and mid-vein. Peduncles 1-3-flowered; flowers white. Pedicels becoming reflexed; fruit a bluish-black, roughened berry. On dry, sandy soil.*

4. G. triflorum, Michx. Perennial; stems reclining or prostrate, angles rough-bristly. Leaves mostly in sixes, lance-oblong, mucronate. Flowers usually in threes, on slender peduncles. Woodlands, especially $\mathrm{N}$.

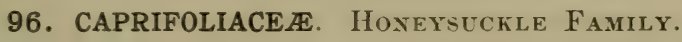

Mostly shrubs. Leares opposite, without true stipules. Flowers often irregular. Calyx-tube adnate to the ovary. Corolla tubular or wheel-shaped. Stamens usually as many as the corolla-lobes and inserted on the corolla-tube. Fruit a berry, stone-fruit, or capsule.

\section{SAMBUCUS, Tourn.}

Shrubs with odd-pinnate leaves. Calyx-limb minute or wanting. Flowers very many, small, white, in compound cymes. Corolla with a small, somewhat urn-shaped tube and a flattish, spreading, 5-cleft limb. Stamens 5. Stigmas 3, sessile. Fruit a globular, pulpy stone-fruit, 3 -seeded, appearing like a berry.

1. S. canadensis, L. Coмmon Elder. Stems 5-10 ft. high, with a thin cylinder of wood surrounding abundant white pith. 
Leaflets 5-11, oblong, taper-pointed, smooth. Cymes flat and often very large. Fruit purplish-black, insipid or almost nauseous, but somewhat used in cookery.

2. S. racemosa, L. ReD-BerRied Elder. More woody, with brown pith. Leaflets fewer, downy beneath, especially when young. Cymes panicled and somewhat pyramidal. Fruit scarlet.

\section{VIBURNUIM, $\mathbf{L}$.}

Shrubs or small trees. Leaves simple, entire, dentate or lobed, with or without stipules. Flowers small, white, in terminal cymes, the outer flowers of the cyme sometimes greatly enlarged and sterile. Calyx-tube very small, 5-toothed. Corolla wheel-shaped or bell-shaped, 5-lobed. Stamens 5, inserted in the tube of the corolla. Ovary 1-3-celled, 1-3ovuled, but only 1 ovule maturing; style short, 3-lobed. Fruit a 1 -seeded stone-fruit.*

A.

Flowers around the margin of the cyme without stamens or pistils, large and showy.

1. V. lantanoides, Michx. Hobble-bush, Witch-новвle. A shrub about $5 \mathrm{ft}$. high, with the branches reclining and often rooting and forming loops (whence the popular names). Leaves very large, roundish, abruptly taper-pointed, serrate, with a rusty down on the petioles and veinlets. Cymes very broad and showy. Fruit red, not eatable.

2. V. Opulus, L. Cranberry Tree, High-bush Cranberry. A handsome, upright shrub. Leaves 3-5-ribbed and 3-lobed. Fruit bright red, juicy, very acid, and used as a substitute for cranberries. Common N. The form known as "Snowball" with all the flowers showy and sterile is cultivated from Europe.

B.

Flowers all small and perfect.

3. V. acerifolium, L. Maple-Leaved Arrowwood. A slender shrub 3-6 ft. high. Leaves broadly ovate to heart-shaped, palmately veined and 3-lobed, serrate or nearly entire, petioled, downy, becoming smooth above. Cymes peduncled, about 7-rayed, 2-3 in. wide; sterile flowers none. Fruit oval, black, stone flat, 2-ridged on the edges. In dry, open woods.* 
4. V. dentatum, L. ARrowwood. A shrub $8-15 \mathrm{ft}$. high. Leares broadly orate to oral, acute at the apex, rounded or heartshaped at the base, coarsely dentate, smooth above, hairy in the axils of the reins beneath, short-petioled. Cymes long-peduncled, 7 -rayed, 2-3 in. wide; sterile flowers none. Calyx smooth. Fruit globose, dark blue, stone compressed, grooved on one side. In rich, damp soil.*

5. V. nudum, L. Withe-RoD. A shrub 8-12 ft. high. Leaves orate to lanceolate, entire or slightly toothed, acute at both ends, thick, smooth above, the reins prominent beneath; petiole short. Cymes short-peduncled, 5-rayed; sterile flowers none. Fruit ovoid, blue. Common in swamps.*

6. V. prunifolium, L. BLACK HAw. A small tree, 15-20 ft. high. Leares oval to ovate, acute or obtuse at each end, finely and sharply serrate, smooth and shining above, often slightly downy beneath; petioles dilated and-rusty-downy. Cymes sessile, large, 4-5-rayed; sterile flowers none. Fruit oval, bluish-black, eatable. In rich, moist woods.*

\section{SYMPHORICARPOS, Dill.}

Shrubs. Leaves short-petioled, deciduous. Flowers in axillary clusters. Calyx-tube globose, 4-5-toothed. Corolla bell-shaped, 4-5-lobed, sometimes knobbed at the base, smooth or hairy within. Stamens 4-5. Ovary 4-celled, 2 of the cells with a single fertile ovule in each, the other cells with several abortive ovules; style slender, stigma knobbed or 2-lobed. Fruit a 4-celled, 2-seeded berry.*

1. S. racemosus, Michx. Sxowberry. An ornamental shrub, $2-3 \mathrm{ft}$. high. Flowers in loose terminal racemes, which are often leafy. Corolla bell-shaped, much bearded inside, pinkish-white. Stamens and style not projecting. Berries rather large, snow-white, remaining long on the branches. Rocky banks, often cultivated.

\section{LINN ÆA, Gronov.}

A very small, slender, creeping evergreen shrub; branches inclined, ending in a slender, erect, 2-flowered peduncle. Leaves opposite, without stipules. Flowers nodding, on slender pedicels, with 2 bractlets. Calyx-tube ovoid; limb 5-lobed. Corolla nearly bell-shaped, כ-lobed. Stamens 4, inserted near the base of the corolla, 2 of them longer than the other 2 . 
Ovary 3-celled; style thread-like, stigma knobbed; ovules many in 1 cell, solitary in the 2 others. Fruit nearly globose, 1-seeded.

1. L. borealis, L. Twin-Frower. A beautiful, delicate plant. Corolla pale pink, very fragrant. Moist woods, in moss, and cold bogs $\mathbf{N}$.

\section{TRIOSTEUM, L.}

Coarse, hairy, perennial herbs. Leaves large, those of each pair somewhat joined at the base, so that the stem appears to rise through them. Calyx-tube ovoid; divisions of the limb leaf-like, lance-linear, persistent. Corolla knobbed at the base, nearly equally 5-lobed. Ovary usually 3-celled, ripening into a stone-fruit with 3 nutlets.

1. T. perfoliatum, L. Tinker-weed, Wild Coffee, Feverwort, Horse-Gentian. Stem unbranched, soft-hairy, $2-4 \mathrm{ft}$. high. Leaves spatulate-ovate, abruptly narrowed at the base, 4-7 in. long and 2-4 in. wide, bordered with a fringe of hairs. Flowers dark brownish-purple. Corolla about $\frac{1}{2}$ in. long, sticky-downy. Fruit ellipsoidal, orange-colored when ripe. Common along fence-rows and in rocky woods.

\section{LONICERA, $\mathbf{L}$.}

Shrubs or woody vines. Leaves simple, usually entire, those of a pair often appearing as if joined together at the base, so that the stem seems to rise through them. Calyxtube ovoid, 5-toothed. Corolla tubular to bell-shaped, often knobbed at the base or 2-lipped. Stamens 5. Ovary 2-3celled, ovules several in each cell; style slender, stigma knobbed. Fruit a 1-3-celled, 1-few-seeded berry.*

\section{A.}

Stems twining.

1. L. Sullivantii, Gray. Yellow Honeysuckle. Stem somewhat twining. Leaves oval to obovate, obtuse, entire, green above, with a bloom beneath, the lower short-petioled, the upper sessile or joined at the base. Flowers in crowded, terminal whorls, bright yellow, fragrant. Corolla-tube slender, 1-1 $\frac{1}{2}$ in. long, bilabiate, 4-lobed, pubescent within. Stamens and style projecting. On river banks and hillsides; often cultivated.* 
2. L. sempervirens, L. Coral Honeysuckle, Trumpet HoneysuckLE. Stem twining high. Leares evergreen (in the South), oral to oblong, obtuse, entire, smooth above, pale and often downy beneath, the lower petioled, the upper pair nearly semi-orbicular and joined at the base. Flowering spikes terminal, bearing several whorls. Corolla about 2 in. long, slender, smooth, the limb short, nearly equally 5-lobed, scarlet without, bright yellow within. Stamens slightly projecting; fruit red. On low ground; often cultivated.*

3. L. japonica, Thunb. Japax Honeysuckle. Stem twining high; young branches downy. Leaves ovate to oblong, entire, smooth above, pale and downy beneath, all short-petioled; peduncles axillary, 2-bracted, 2-flowered ; flowers white or pink, fading to yellow, 2-lipped, the lips nearly as long as the downy tube. Stamens and style projecting. Fruit black. Introduced from Japan ; common in cultivation.*

4. L. Caprifolium, L. European Honeysuckle. A moderately high-climbing shrub. Leares smooth and deciduous, several of the upper pairs united at their bases to form a flattish disk or somewhat cup-shaped leaf. Flowers in a single terminal whor], very sweet-scented. Corolla whitish, red, or yellow, 2-lipped, with the lips recurved. Cultivated from Europe.

B.

More or less upright bushes, not climbing.

5. L. tatarica, L. Tartariax Honeyscckle. A branching shrub, 5-8 ft. high. Leaves oval or ovate, heart-shaped, shining. Flowers many, showy, rose-colored. Fruit consisting of 2 red berries; somewhat united below at maturity. Cultivated from Asia.

6. L. ciliata, Muhl. Early Fly Honeyseckle. A straggling: bush, 3-5 ft. high. Leaves ovate or oval, slightly heart-shaped, thin, at first downy beneath. Flowers straw-yellow, on short, slender peduncles. Corolla-lobes nearly equal; tube pouched at the base. Fruit, 2 separate red berries.

\section{DIERVILLA, Tourn.}

Low, upright shrubs. Leaves taper-pointed, serrate. Flowers in loose terminal or axillary clusters or cymes. Calyx with a limb of 5 linear divisions. Corolla funnel-shaped, almost regularly 5-lobed. Stamens 5. Ovary slender, 2-celled, ripening into a 2-valved, many-seeded pod. 
1. D. trifida, Moench. Common Bush Honfysuckle. Bushy, 1-4 ft. high. Leaves ovate or oblong-ovate, petioled. Peduncles 1-3-flowered. Pods tapering to a slender point. Rocks, especially $\mathrm{N}$.

2. D. japonica, Thunb. WeIGELA. A stout, branching shrub, 3-6 ft. high. Leaves broadly oval, acute at the apex, rounded at the base, coarsely serrate, rough above, downy beneath, short-petioled. Flowers spreading, funnel-form, rose-color, $1-1 \frac{1}{2}$ in. long. Calyx-lobes deciduous. Corolla downy without, the lobes spreading. Capsule oblong or spindle-shaped. Seeds with netted wings. Introduced from Japan ; common in cultivation.*

\section{VALERIANACE}

Herbs, rarely shrubs. Leaves opposite, without stipules. Flowers small, usually irregular, in forking cymes. Calyxtube adnate to the ovary. Corolla funnel-shaped, the base often with a sac or spur. Stamens 1-3 or 5, inserted at the base of the corolla-tube; filaments slender, anthers versatile. Ovary cells 3, two of thern not ovule-bearing, the third with a single ovule hanging from the top; style thread-like, stigma blunt or 2-3-lobed. Fruit small, not splitting open.

\section{VALERIANA, $\mathbf{L}$.}

Perennial, rarely annual, herbs. Root-leaves crowded; stem-leaves opposite or whorled, entire or pinnately cut. Flowers in corymbed, headed, or panicled cymes. Limb of the calyx consisting of several plumy bristles. Lobes of the corolla 5 or rarely $3-4$, unequal. Stamens 3 . Stigma knobbed. Fruit flattened, ribbed, 1-celled, 1-seeded.

1. V. edulis, Nutt. An upright, straight-stemmed plant, 1-4 ft. high. Leaves all thickish and closely fringed with short hairs; root-leaves linear-spatulate or lanceolate-spatulate, entire ; stem-leaves pinnately parted, the 3-7 divisions long and narrow. Flowers almost diœcious, in a long, interrupted panicle. Corolla whitish. Root long and stout, eaten by Indians. Low ground and wet prairies, especially N. W.

2. V. officinalis, L. Garden Valerian. Plant smooth or hairy below, strong-smelling. Rootstock short. Leaves all pinnate ; root- 
leaves long-petioled, soon withering; stem-leaves 2-5 in. long, sessile, the leaflets lanceolate, entire or serrate. Corolla pale pink. Rootstocks strong-scented, used in medicine. Cultivated from Europe.

\section{VALERIANELLA, Toum.}

Annual herbs; stem forking regularly. Leaves opposite, entire or dentate. Flowers in crowded, terminal, bracted cymes. Calyx-limb toothed or wanting. Corolla white or purplish, funnel-form, 5-lobed. Stamens 3. Style 3-lobed. Fruit 3-celled, 1-seeded.*

1. V. olitoria, Poll. LAmB Letruce. Stem erect, smooth, or downy at the nodes, many times forked, 9-12 in. high: Basal leaves tufted, spatulate to oborate, entire, the upper lanceolate, dentate, sessile. Cymes short-peduncled, bracts linear. Flowers pale blue. Fruit compressed, oblique. On rich soil in waste places.*

2. V. radiata, Dufr. Corr SALAD. Stem erect, smooth above, downy below, 2-4 times forked, 8-12 in. high. Lower leaves spatulate, entire, the upper lanceolate, clasping at the base, dentate. Cymes compact; bracts lanceolate. Flowers white. Fruit ovoid, downy, furrowed. On damp soil.*.

\section{CUCURBItACE无. Gourd Family.}

Somewhat succulent, tendril-bearing, prostrate or climbing, herbaceous plants. Leaves alternate, with stipules. Flowers diœcious or monœcious, often gamopetalous. Calyx-tube adnate to the ovary; calyx-limb (if present) 5-lobed. Corolla usually 5-lobed and with its tube more or less united with the calyx-tube. Stamens perigynous or borne upon the corolla, the anthers usually joined in long, serpentine ridges. Ovary 3-celled; stigmas 2 or 3 . Fruit generally a pepo (like the melon, squash, and pumpkin), but sometimes dry. Seeds commonly large and flat. A large family, mostly of tropical plants, many with eatable fruit, but some species poisonous. 


\section{CUCURBITA, $\mathbf{L}$.}

Annual or perennial herbs ; stem trailing or climbing, 2-20 ft. long. Leaves angular-lobed; tendrils branching. Flowers monœcious, solitary or in small clusters. Calyx 5-toothed, the limb deciduous. Corolla bell-shaped, 5-lobed. Staminate flowers with 3 stamens and no pistil; pistillate flowers with 1 pistil and 3 imperfect stamens. Style short; stigmas $3-5$, each 2-lobed. Fruit 1-celled, with numerous seeds on the 3 parietal placentæ.*

1. C. Melopepo, L. Summer Squash. Stem rough-hairy, angled, $2-5$ ft. long. Leaves broadly heart-shaped, angularly 3-5-lobed, rough. Flowers yellow, short-peduncled. Fruit roundish, longitudinally compressed, the margin smooth, wavy, or tubercular. Common in cultivation.*

2. C. verrucosa, L. CRоoкNeck SQUash. Stem rough-hairy, angled and striate, 5-10 ft. long. Leaves cordate, deeply 5-lobed, very rough, long-petioled. „Flowers light yellow, long-peduncled. Fruit clavate, the base often slender and curved, smooth or tuberculate, very variable. Common in cultivation.*

\section{CUCUMIS, $\mathbf{L}$.}

Annual herbs; stems trailing, usually shorter and more slender than in the preceding genus. Tendrils not forked. Leaves varying from entire or nearly so to deeply cut. Sterile flowers in clusters, fertile ones solitary in the leaf-axils. Corolla of 5 acute petals, which are but little joined at the base. Stamens not evidently united. Style short; stigmas 3, each 2-lobed. Fruit rather long. Seeds not large, lanceoblong, not margined.

1. C. sativus, L. Cucumber. Leaves, somewhat lobed, the middle lobe largest. Fruit more or less covered when young with rather brittle, blackish prickles, which fall off as it ripens. Cultivated from S. Asia. [Other varieties of the genus Cucumis are the muskmelon, cantaloupe, and nutmeg melon. Other commonly cultivated genera are Citrullus, the watermelon, and Lagenaria, the bottle-gourd. Two wild genera, Echinocystis, the wild cucumber, and Sicyos, the star cucumber, which blossom through the summer and autumn, are common in the Northern States and the Middle West.] 


\section{CAMPANULACER. CAMPANULA FAMily.}

Herbs, with milky juice. Leaves alternate, without stipules. Flowers regular, not clustered. Calyx 5-lobed, adnate to the ovary. Corolla regular, bell-shaped, 5-lobed. Stamens 5, usually free from the corolla and not coherent. Style 1, usually hairy above; stigmas 2 or more. Fruit a capsule, 2 or more celled, many-seeded.

\section{CAMPANULA, Tourn.}

Annual, biennial, or perennial herbs. Flowers solitary, racemed or spiked, regular, blue or white. Calyx 5-lobed or parted. Corolla wheel-shaped to bell-shaped, 5-lobed. Stamens 5, free from the corolla, distinct, filaments dilated at the base. Ovary 3-5-celled, many-ovuled; style 3-parted. Capsule short, bearing the persistent calyx-lobes at its apex, many-seeded, splitting open on the sides.*

1. C. rotundifolia, L. Harebell. A slender, smooth, branching perennial, 5-12 in. high. Root-leaves broadly ovate-heart-shaped, generally somewhat crenate, soon withering. Stem-leaves varying from linear to narrowly lanceolate, entire. Pedicels slender, flowers solitary or somewhat racemed, the buds erect but the fully opened flower drooping. Calyx-teeth erect, awl-shaped. Corolla bell-shaped, $\frac{1}{3}-1$ in. long, its lobes short and recurved. Rocky hillsides, especially $\mathrm{N}$.

2. C. aparinoides, Pursh. Marsh Bell-Flower. Stem angular, unbranched, slender, weak and leaning on the grass among which it usually grows, the angles clothed with minute, backward-pointing prickles. Leares lance-linear, nearly entire. Flowers terminal, about $\frac{1}{3}$ in. long, white. Corolla bell-shaped. Wet meadows, in tall grass.

\section{SPECULARIA, Heister.}

Annual; stems slender, angled. Leaves entire or toothed. Flowers axillary, regular, solitary or in small clusters, sessile, bracted. Calyx-tube slender, 3-5-parted. Corolla wheelshaped, 5-lobed. Stamens with the filaments flattened and shorter than the anthers. Ovary 3-celled, many-ovuled; stigmas 3. Fruit a prismatic, 3-celled, many-seeded capsule.* 
1. S. perfoliata, A. DC. Specularia. Stem erect, simple or branched from the base, angles roughened, 10-20 in. high. Leares ovate to lanceolate, acute at the apex, sessile, crenate or entire, the upper bract-like. Flowers solitary or in pairs. Corolla blue, often wanting. Capsule cylindrical, smaller above. In waste places.*

100. COMPOSIT E. Composite Family.

Flowers in a dense head, on a common receptacle, surrounded by an involucre composed of many bracts (Fig. 22),

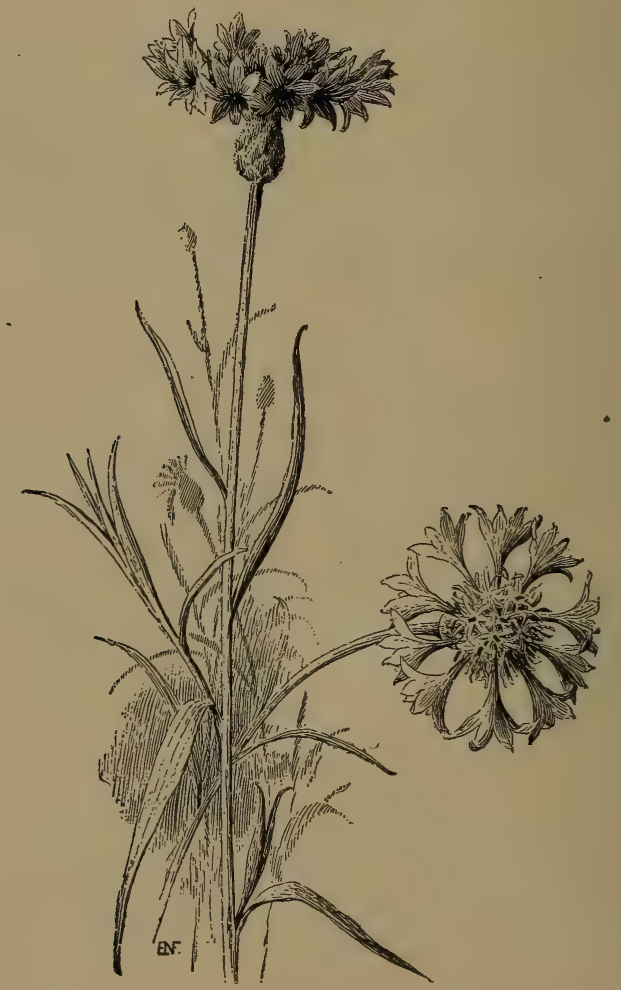

FIG. 22. - Flower-cluster of Bachelor's Button (Centaurea Cyanus). 
with usually 5 stamens inserted on the corolla, the anthers united into a tube which surrounds the style (Fig. 23, V). Calyx with its tube adnate to the ovary, the limb sometimes wanting, when present taking the form of scales, bristles, etc., known as pappus (Fig. 24, II, III). Corolla either strapshaped (Fig. 25, r) or tubular (Fig. 23, V), in the former case

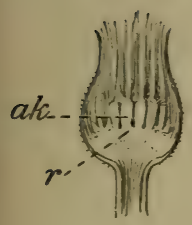

I

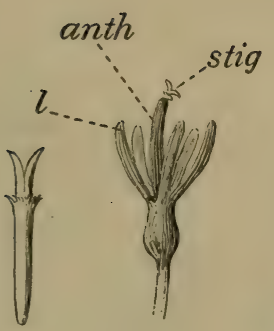

II

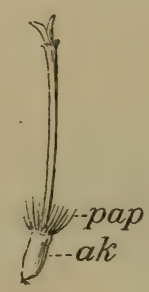

IV

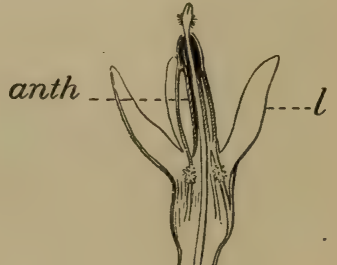

Frg. 23. - Bachelor's Button.

I, vertical section of the receptacle; II, style and forked stigma (magnified); III, corolla, united anthers and stigma (magnified); IV, pistil (magnified); prop, pappus; $a k$, akene ; $\mathrm{V}$, tubular flower cut vertically (magnified), showing anther-tube, traversed by the style; $l$, lobe of corolla.

often 5-toothed, in the latter usually 5-lobed. Style 2-cleft above. Fruit an akene, often provided with means of transportation (Part II, Ch. XXIX). The largest family of flowering plants and among the most specialized for insect pollination. The genera of the northern United States are divided into two suborders: I. TUBULIFLORæ, corolla of the perfect flowers tubular and 5-lobed; II. LIGULIFLORE, corollas all strap-shaped and flowers all perfect. 

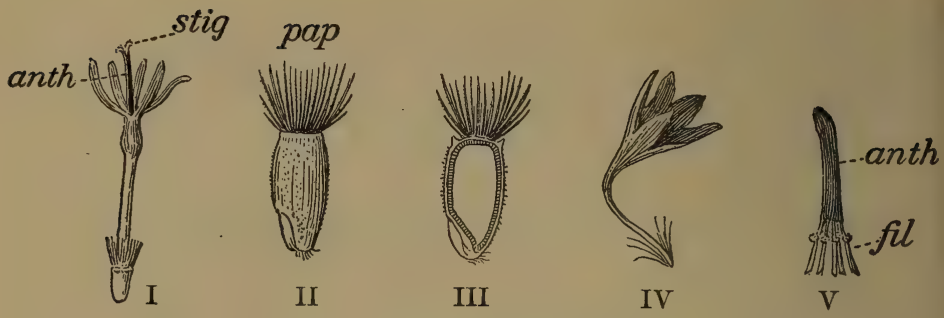

Frg. 24. - Bachelor's Button.

I, a tubular flower (magnified) ; anth, the united anthers ; II, fruit (magnified) ; III, fruit, vertical section (magnified); IV, a neutral ray-flower ${ }^{1} \mathrm{~V}$, ring of anthers.
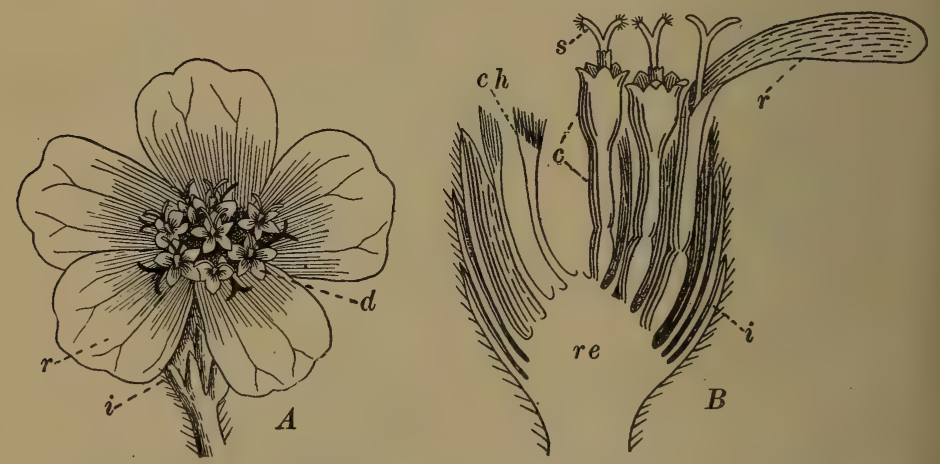

FIG. 25. - Flower-cluster of Yarrow (Achillea Millefolium), enlarged.

$A$, head seen from above ; $B$, longitudinal section ; re, receptacle ; $c h$, chaff ; $i$, involucre ; $r$, ray-flowers ; $d$, disk-flowers ; $c$, corolla ; $s$, stigma.

1 This is not precisely homologous with the ray-flowers of Helianthus and most rayed Compositæ, but is an enlarged and conspicuous tubular flower. 


\section{TUBULIFLORÆ.}

\section{A. 1}

Corollas some or all of them tubular.

Rays white, pink, or purplish.

Rays many; akenes flat; pappus wanting; low herbs. Bellis, I.

Rays many; akenes cylindrical or winged, grooved; pappus wanting; tall herbs or shrubby. Chrysanthemum, VIII.

Rays many; akenes flat; pappus of an outer row of minute scales and an inner row of delicate bristles. Erigeron, II.

Rays many; akenes cylindrical or ribbed; pappus wanting; strong-scented branching herbs. Anthemis, VI.

Rays few.

Achillea, VII.

Rays yellow.

Disk purplish-brown.

Rudbeckia, IV.

Disk yellow.

Involucre of 2 rows of bracts, the outer rather leaf-like.

Coreopsis, III.

Involucre of reflexed scales; pappus of 5-8 scales.

Helenium, V.

Involucre of erect scales ; pappus of abundant soft hairs.

Senecio, IX.

Rays none, but the marginal flowers sterile and their tubular corollas partly flattened like rays (Fig. 24). Centaurea, X.

Rays none and marginal flowers like the others; scales of the involucre overlapping in many rows, prickly-pointed.

Cirsium, XI.

\section{B.}

Corollas all strap-shaped.

Corollas blue (rarely pinkish); akenes not beaked.

Cichorium, XIII.

Corollas blue; akenes beaked. Lactuca, XVIII.

1 The characters in this key are not necessarily true of all species in the genera referred to, but only of those described below. 
Corollas yellow.

Akenes truncate; pappus double, of chaff and bristles.

Krigia, XII.

Akenes columnar; pappus of tawny, rough bristles ; stem scape-like.

Hieracium, XIV.

Akenes spindle-shaped, not beaked; pappus of plumed bristles. Leontodon, $\mathrm{XV}$.

Akenes ovoid to spindle-shaped, long-beaked; pappus white, soft, and abundant.

Taraxacum, XVI.

Akenes nearly as in XVI; pappus tawny.

Pyrrhopappus, XVII.

Akenes flattened, beaked; pappus soft, white, the hairs soon falling off separately; leafy-stemmed herbs.

Lactuca, XVIII.

Akenes flattened, not beaked ; pappus abundant, soft, white; leafy-stemmed, spiny-leaved herbs.

Sonchus, XIX.

\section{BELLIS, $\mathbf{L}$.}

Small herbs. Leaves usually all radical, petioled. Heads solitary, disk yellow, ray-flowers white or pink; involucre bell-shaped, bracts in 1 or 2 rows, green; receptacle conical. Ray-flowers many, in a single row, pistillate. Disk-flowers tubular, perfect, 4-5-toothed; forks of the style short, thick, tipped by roughened cones. Fruit flattened, obovate; pappus wanting.

1. B. integrifolia, Michx. American DaIsy. A branching annual or biennial herb, 4-12 in. high. Upper leaves lanceolate or oblong, the lower unes obovate-spatulate. Heads borne on slender peduncles; rays violet-purple. Prairies, especially S.W.

2. B. perennis, L. Engrish Daisy, Scotch Daisy. A stemless perennial. Leaves obovate-spatulate, smooth or hairy. Heads $\frac{3}{4}-1$ in. in diameter, very pretty, the rays delicate. Cultivated from Europe.

\section{ERIGERON, $\mathbf{L}$.}

Herbs. Leaves usually sessile. Heads many-flowered, flat or nearly hemispherical, the rays numerous, narrow, pistillate. Scales of the involucre narrow and overlapping but little. 
Akenes flattish, crowned with a single row of hair-like bristles, or sometimes with shorter bristles or scales outside these. Disk yellow, rays white, pinkish, or purple.

1. E. annuus, Pers. Common Fleabane. Anuual or biennial. Stem grooved and stout, branching, 2-5 ft. high, with scattered hairs; lowest leaves petioled, ovate, coarsely toothed, those higher up the stem successively narrower, sessile; heads in a large loose corymb ; rays short, white or purplish. Fields and waste ground.

2. E. strigosus, Muhl. Daisy Fleabane. Annual or biennial. Considerably resembling the preceding species, but with entire leaves, smaller and less branched stem, smaller heads, and longer rays. Fields and pastures.

3. E. bellidifolius, Muhl. Robix's Plantain. Perennial. Softhairy; stems sometimes throwing out offsets from the base; simple, erect, 1-2 ft. high; root-leares, oborate-obtuse, somewhat serrate; stem-leaves few, lance-oblong, acute, clasping; heads rather large, $1-9$, on long peduncles, with 50-60 long, rather broad, bluish-purple or reddish-purple rays. Thickets and moist banks.

4. E. philadelphicus, L. Perennial. Rather hairy; stems slender, about $2 \mathrm{ft}$. high; root-leaves spatulate and toothed; stem-leaves usually entire and strongly clasping, sometimes with a heart-shaped or eared base; heads several, small, long-petioled ; rays exceedingly numerous, thread-like, reddish-purple or flesh-color. In damp soil.

\section{COREOPSIS, L.}

Annual or perennial herbs. Leaves opposite or the upper alternate, entire or pinnately divided. Heads radiate, solitary or corymbed, many-flowered; bracts in 2 rows of about 8 each, the inner membranaceous and appressed, the outer narrower and spreading; receptacle chaffy. Ray-flowers neutral; diskflowers tubular, perfect. Akenes compressed, oval to oblong, often winged. Pappus of 2 scales or bristles, or wanting.**

1. C. tinctoria, Nutt. Garden Coreopsis. Annual. Stem erect, smooth, branched, 2-3 ft. high. Leaves 2-3 times pinnately divided, the divisions linear, lower leares petioled, the upper often sessile and entire. Heads $1-1 \frac{1}{2}$ in. wide, on slender peduncles; inner bracts brown with scarious margins, outer bracts very short. Ray-flowers about 8, yellow with a brown base, 3-lobed at the apex. Akenes linear. Pappus minute or none. Common in gardens.*

2. C. lanceolata, L. Tickseed. Perennial; stem slender, erect or ascending, smooth or slightly downy below, simple, 9-15 in. high. Leaves opposite, the lower spatulate to elliptical, sometimes lobed, 
on long, hairy-fringed petioles, the upper lanceolate, sessile. Heads few, on long peduncles; bracts ovate-lanceolate, the outer narrower. Ray-flowers 6-10, rays 3-5-lobed, bright yellow. Akenes oval, broadly winged, warty. Pappus of 2 teeth. On rich, dry soil S. and E.*

3. C. auriculata, L. Running Tickseed. Perennial; stem ascending or decumbent, weak, smooth, nearly simple, 6-15 in. long. Leaves ovate to oval, entire or with $2-4$ small and rounded lobes at the base, downy, long-petioled. Heads $1-1 \frac{1}{2}$ in. wide, few or single; outer bracts narrower than the inner. Rays 6-10, mostly 4-toothed at the apex ; chaff as long as the flowers. Akenes oblong, the wings narrow and thickened. Pappus of 2 minute teeth. In rich woods.*

\section{RUDBECKIA, L.}

Perennial or biennial. Leaves alternate, entire or lobed. Heads radiate, long-peduncled, many-flowered; bracts imbricated in 2-3 series, spreading; receptacle convex or long-conical, with concave, chaffy scales. Ray-flowers yellow, neutral; disk-flowers purple to brown, perfect. Akenes smooth, 4-angled, truncate. Pappus a few short teeth or wanting.*

1. R. hirta, L. CONE-FLower. Annual or biennial; stem erect, rough-hairy, simple or branched, 2-3 ft. high. Leaves lanceolate to oblong, thick, obscurely serrate, rough-hairy, 3-ribbed, the lower petioled, the upper sessile. Heads few, long-peduncled; bracts rough-hairy, spreading. Ray-flowers $10-20$, orange-yellow; diskflowers purplish brown. Chaff acute, hairy at the apex. Pappus none. On dry, open ground.

\section{HELENIUM, $\mathbf{L}$.}

Annual or perennial. Leaves alternate, forming wings on the stem. Heads radiate, peduncled, many-flowered; bracts in 2 series, the outer linear and spreading, the inner few and scale-like; receptacle naked, convex or oblong. Ray-flowers pistillate and fertile, or neutral, the rays wedge-shaped, 3-5lobed; disk-flowers perfect, tubular, 4-5-lobed. Akenes topshaped, hairy, ribbed. Pappus of 4-5 entire, toothed or awned scales.*

1. H. nudiflorum, Nutt. SNeezeweed. Perennial; ; stem slender, erect, downy, branched above, 1-2 ft. high. Leaves lanceolate, entire or slightly toothed, the lower petioled, the upper sessile. 
Heads numerous. Ray-flowers 10-15, neutral, yellow or yellow and brown; disk-flowers purple. Akenes hairy on the ribs; pappus of ovate, minutely toothed, awned scales. Common on river banks S.*

\section{ANTHEMIS, $\mathrm{L}$.}

Aromatic or ill-scented herbs. Leares finely pinnately divided. Heads many-flowered, with ray-flowers. Rays pistillate or neutral. Involucre of many small, dry, close-pressed scales. Akenes nearly cylindrical, generally ribbed; barely crowned or naked at the summit.

1. A. Cotula, DC. Mariteed, Dog-Fenvel. Leares irregularly cut into verr many narrow segments. Heads small, produced all summer. Disk rellow. Rays rather short, white, neutral. A low, offensire-smelling annual weed, by roadsides and in barnyards.

\section{ACHILLEA, L.}

Perennial; leaves alternate, pinnately divided. Heads with ray-flowers in a terminal corymb; involucral bracts imbricated in sereral series. the outer shorter; receptacle chaffy. Rayflowers white or pink, pistillate and fertile; disk-flowers perfect, tubular, כ̃-lobed. Akenes oblong, compressed, slightly margined. Pappus none.*

1. A. Millefolium, L. YARrow. Stemis often clustered, erect from a creeping rootstock, simple, downy or woolly, 1-2 ft. high. Leares lanceolate or oblong, the segments finely cut and divided, smooth or downy, the lower petioled, the upper sessile. Heads small, numerous, in flat-topped corymbs; bracts downy. Ray-flowers 4-5, white or pink, rays 3-lobed at the apex. Common in old fields.*

\section{CHRYSANTHEMUM, Tourn.}

Perennials, with toothed, pinnately cut or divided leaves. Heads nearly as in the Anthemis, except that the ray-flowers are pistillate.

1. C. Leucanthemum, L. Oxeye Daisy, Whiteweed, Bull'sexe, Sheriff Pixk. Stem erect, unbranched or nearly so, 1-2 ft. high; root-leares oblong-spatulate, petioled, deeply and irregularly toothed ; stem-leares sessile and clasping, toothed and cut, the uppermost ones shading off into bracts. Heads terminal and solitary, 
large and showy, with a yellow disk and many white rays. A troublesome but handsome perennial weed. Introduced from Europe, chiefly E.

2. C. frutescens, L. MARGUERIte. Erect, branching, perennial, woody below, smooth, and with a pale bloom. Divisions of the leaves linear, with the uppermost leaves often merely 3 -cleft bracts. Heads long-peduncled, showy, with a yellow disk and large, spreading white rays. Cultivated in greenhouses; from the Canary Islands.

\section{SENECIO, Tourn.}

Annual or perennial; stems often hollow. Leaves alternate, entire or pinnately divided. Heads with or without rays, in terminal corymbs; bracts mostly in a single row, often with a few shorter ones at the base; receptacle naked or pitted. Rayflowers yellow or orange, pistillate and fertile when present; disk-flowers tubular, perfect. Akenes cylindrical or compressed, not beaked or winged, 5-10-ribbed, downy. Pappus of numerous, slender, white hairs.*

1. S. tomentosus, Michx. Woolly Ragweed. Perennial; woolly throughout; stem stout, erect, mostly simple, 2-3 ft. high. Lower leaves ovate to oblong, crenate or entire, obtuse, long-petioled; stemleaves few, elliptical to oblanceolate, serrate or toothed, acute, sessile. Heads radiate, $\frac{3}{4}$ in. wide, on slender peduncles; bracts narrow, becoming smooth. Ray-flowers 12-15, yellow. Akenes hairy. On damp soil.*

2. S. aureus, L. Golden RAGWEed. Perennial; stems often tufted, erect, slender, woolly when young, branched above, 18-30 in. high. Lower leaves broadly ovate, obtuse at the apex, heart-shaped at the base, crenate, long-petioled; stem-leaves lanceolate and often pinnatifid, the upper small and sessile. Heads radiate, corymbed, on slender peduncles; ray-flowers 8-12, bright yellow. Akenes smooth. On wet soil; very variable.*

3. S. lobatus, Pers. Butterweed. Annual ; stem erect, ridged, hollow, often woolly when young, and becoming smooth with age, branched above, 1-3 ft. high. Leaves lyrate-pinnatifid, thin, the lower petioled, the upper sessile. Heads radiate in a terminal corymb; bracts linear, acute. Ray-flowers about 12, yellow. Akenes slightly rough-hairy on the angles. Pappus rough, longer than the involucre. Common on low ground.* 


\section{Centaurea, $\mathbf{L}$.}

Herbs. Leaves entire or cut, often spiny-toothed. Heads single; involucre ovoid or globose (Fig. 22); bracts closely overlapping, entire, dry and membranaceous. Corollas all tubular, oblique or 2-lipped, inflated above; the outer ones usually larger and neutral, the inner flowers perfect; lobes 5, slender. Akenes flattened. Pappus hairs short, slender, rough.

1. C. Cyanus, L. Bachelor's Button. Stem erect, slender, grooved, 1-2 ft. high, somewhat branched. Leaves acute, sessile, narrow, entire or few-lobed. Peduncles covered with cottony wool. Heads $\frac{1}{2}-1$ in. in diameter, cobwebby. Ray-like flowers few, large, bright blue or pink; those of the disk smaller. Cultivated from Europe and escaped from gardens.

\section{CIRSIUM, Tourn.}

Biennial or perennial; stem erect; simple or branched. Leares alternate, prickly, often forming wings on the stem. Heads discoid, terminal and solitary or corymbed, many-flowered; bracts overlapping in many series, the outer shorter, usually spine-pointed; receptacle bristly. Corollas purplish or nearly white, the tube slender, deeply 5-cleft. Akenes oblong, 4-angled, smooth or ribbed. Pappus of numerous simple or plumose bristles.*

1. C. altissimum, Spreng. Tall Thistle. Perennial or biennial; stem stout, very leafy, downy or woolly, branched 4-10 ft. high; leares rough-downy abore, hoary beneath, fringed with fine prickles, not forming wings on the stem, the lower petioled and often pinnately cut, the upper sessile and entire. Heads ovoid, 1 in. in diameter; bracts riscid, webby when young, all except the inner ones tipped with weak and spreading bristles. Flowers light purple. Common in fields, woods, and waste places.*

2. C. horridulum, Michx. Yellow Thistle. Biennial or perennial ; stem erect, stout, woolly when young, becoming smooth, often purple, branched $1-3 \mathrm{ft}$. high. Leares pinnately cut, with very spiny teeth, mostly sessile and clasping, smooth and green on both sides. Heads large, surrounded by a whorl of linear-oblong, comblike leaves; involucral bracts linear, ciliate, not spine-tipped. Flowers purple or yellowish. On sandy soil E. and S.** 


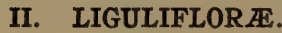

\section{KRIGIA, Schreber.}

Small, annual or perennial herb. Leaves mostly radical, toothed or lyrate. Heads several-many-flowered; scales of the involucre about 2-rowed, thin. Akenes short, truncate. Pappus in 2 rows, the outer one of thin, blunt, chaffy scales, the inner one of slender bristles. Corollas yellow.

1. K. virginica, willd. Annual ; scapes usually 2-5 from one root, slender. Leaves mostly lyrate, smooth and with a bloom, the earlier ones rounded or spatulate. Scales of the involucre linearlanceolate, nearly equal, spreading. Akenes top-shaped, reddishbrown, crowned with 5 wedge-obovate scales and 5 rough white bristles.

2. K. Dandelion, Nutt. Perennial, from slender tuber-bearing roots. Scapes leafless, 6-18 in. high. Leaves entire or nearly so, varying from spatulate-oblong to linear-lanceolate. Akenes more slender than in No. 1. Pappus consisting of 10-15 small, oblong, chaffy scales and 15-20 bristles. In moist ground, especially S.

3. K. amplexicaulis, Nutt. Stem $12-18$ in. high, often 2-3 from the same root, mostly 2 -forked or 3 -forked at the summit. Rootleaves 3-6 in. long, lanceolate, entire, toothed or rarely pinnately cut, clasping at the base; stem-leaves 1-3. Akenes and pappus about as in No. 2. Moist banks.

\section{CICHORIUM, $\mathbf{L}$.}

Perennial herbs with spreading branches; juice milky. Leaves radical and alternate, toothed or pinnately cut. Heads axillary; involucre cylindrical, bracts in 2 rows, the inner row erect, coherent at the base, the outer shorter; receptacle flattish. Corollas blue, pale pink, or yellow. Upper part of the style and its slender arms hairy. Akenes crowded on the hardened receptacle, firmly covered by the stiff involucre, obovoid or top-shaped, not beaked. Pappus 1 or 2 rows of short scales.

1. C. Intybus, L. Chicory, Blue Dandelion, Blue Sailors. Root very long, stout, and fleshy. Stem 1-3 ft. high, angled and grooved ; branches straight and stiff. Root-leaves and lower stemleaves runcinate; upper stem-leaves oblong or lanceolate, clasping, 
those of the branches reduced to bracts. Flowers rery showy, usually bright blue, rarely pinkish-white. Introduced from Europe; a troublesome weed in grass-lands and common in waste places, particularly in New England.

\section{HIERACIUM, L.}

Perennial herbs, often corered with glandular or star-shaped hairs; juice milky. Leares alternate. Heads solitary, or in corymbs or panicles; bracts of the inrolucre many, overlapping, unequal; receptacle flattish, naked, pitted. Corollas yellow, rarely orange; arms of the style slender and upper part of the style hairy. Akenes angled or grooved, not beaked. Pappus hairs in a single row, simple, stiff, tawny, or brownish, brittle.

1. H. venosum, L. Rattlessake Weed. Stem scape-like, usually leafless or nearly so, smooth, 1-2 ft. high. Root-leaves 2-5 in. long, obovate or ovate-oblong, generally purple-veined. Heads rather large, Jellow, in a loose panicled corymb. Dry hills and roadsides, and in pine woods $\mathrm{E}$.

\section{LEONTODON, L.}

Perennial, scape-bearing herbs; juice milky. Leaves all radical, toothed or pinnatifid, often runcinate. Heads on simple or branched scapes, yellow; bracts of the involucre many, in several rows, the anther smaller; receptacle flat, naked. Arms of the style linear, obtuse, hairy. Akenes cylindrical, grooved, transversely wrinkled; beak short; pappus hairs stiff, in 1 or 2 rows.

1. L. autumnalis, L. Scape usually branching, $5-15$ in. high, bracted: peduncles eninged above. Rootstock truncate. Heads $1 \frac{1}{2}-1$ in. or more in diameter; inrolucre top-shaped or bell-shaped. Pappus of a single row of tawny hairs. Fields and roadsides, especially N. E. Introduced from Europe.

XVI. TARAXACUM, Haller.

Stemless, perennial or biennial herbs. Leaves in a flattish tuft, pinnately cut or runcinate (Fig. 38). Head manyflowered, large, solitary, yellow, borne on a hollow scape, which 
is short at first but lengthens after flowering. Involucre composed of a single row of long, erect, inner scales and a set of much shorter ones outside and at the base of the former ones. Akenes cylindrical or spindle-shaped, with 4-5 rough ribs, the apex tapering into a bristle-like beak which bears a short, broadly conical tuft of soft white hairs.

1. T. officinale, Weber. Dandelion. Outer involucre reflexed; inner involucre closing over the head, after the flowers are withered, and remaining shut for some days, then opening and allowing the akenes to form a globular head. Root stout, bitter, medicinal. Young leaves eaten as a pot-herb ("greens") in spring - the plant often cultivated for the leaves by market-gardeners.

\section{PYRRHOPAPPUS, DC.}

Annual or biennial; stem erect, leafy below, nearly naked above, smooth. Leaves oblong, toothed or pinnatifid. Heads large, long-peduncled; involucre cylindrical or spreading, the inner row of bracts erect, united at the base, the outer rows shorter and spreading; receptacle naked. Flowers yellow; rays truncate, 5 -toothed at the apex. Akenes oblong, 5-ribbed, narrowed above into a long and slender beak; pappus soft, tawny, with a short, soft-hairy ring at the base.*

1. P. carolinianus, DC. FAlse DANdelion. Annual or biennial; stem glabrous, furrowed, branched above, 2-3 ft. high. Lower leaves lanceolate to oblong, entire, toothed or pinnatifid, narrowed into a margined petiole, the upper sessile, bract-like, entire. Heads few, long-peduncled, peduncles and involucre sometimes finely downy; inner bracts calloused at the apex, the outer awl-shaped and spreading. Akenes much shorter than the thread-like beak. Common in fields.*

\section{LACTUCA, Tourn.}

Annual, biennial, or perennial ; stems leafy. Leaves entire to pinnately cut. Heads panicled; involucre cylindrical, bracts unequal, overlapping in 2 or more rows, the outer shorter; receptacle naked. Flowers blue, yellow, or white; rays truncate, 5-toothed at the apex. Akenes compressed, ribbed, the apex contracted into a slender beak, which is enlarged into a disk bearing the soft, hairy, white or tawny pappus.* 
1. L. canadensis, L. Wrld Lettuce. Biennial ; stem erect, smooth, hollow, branched above, 3-10 ft. high. Leaves lanceolate to spatulate, pale beneath, the lower petioled and pinnately cut, the upper sessile, clasping, and nearly entire. Heads numerous, about 20-flowered. Flowers yellow; akenes oval, flat, 1-ribbed on each side, minutely roughened, about as long as the beak. Pappus white. In waste places.*

2. L. acuminata, Gray. Blue Letruce. Stem very leafy, smooth, paniculately branched above, 3-6 ft. high. Leaves ovate to lanceolate, taper-pointed, often hairy beneath, the lower on winged petioles and often sinuate-lobed, the upper sessile. Heads racemed, on divergent and bracted peduncles. Flowers blue. Akenes slightly compressed, beak very short. Pappus white. In waste places.*

\section{SONCHUS, L.}

Annual or perennial. Leaves mostly toothed or pinnately cut, prickly margined. Heads in corymbs or panicles; bracts in several series, the outer shorter; receptacle naked. Flowers yellow, rays truncate, 5-toothed at the apex. Akenes oval to oblong, compressed, ribbed, truncate at the apex. Pappus of numerous soft white hairs.*

1. S. oleraceus, L. Sow Thistle. Annual; stem erect, branched, smooth, 2-6 ft. high. Leaves spiny-toothed, the lower long-petioled, very irregularly cut or pinnatifid, the upper clasping by an eared base. Involucre downy when young. Akenes channeled and transversely wrinkled. In waste places on very rich soil.*

2. S. asper, Vill. Spiny Sow Thistle. Annual; stem erect, smooth, branched but little, 2-6 ft. high. Leaves undivided, spatulate to oblanceolate, fringed with spiny teeth, the lower narrowed into a petiole, the upper clasping by an eared base, the ears rounded. Heads numerous ; involucre glabrous. Akenes flattened, margined, 3 -nerved on each side, smooth. In waste places.* 



\section{GLOSSARY}

\section{OF TECHNICAL TERMS USED ONLY IN THE FLORA}

Abortive, imperfectly developed.

Appressed, lying flat throughout its length, used of such parts as bracts.

Awl-shaped, narrow and tapering to a point.

Awned, having a bristle-like appendage.

Awnless, not awned.

Capitate, (1) having a round head like the stigma of a primrose; (2) growing in heads.

Carpellary, relating to a carpel. Chaff, small membranous scales, such as are found on disks of Compositoe.

Clasping, partly surrounding the stem, said of the bases of leaves. Claw, the narrowed base of a petal. Cleft, cut halfway down.

Coated (bulbs), those with scales which completely cover them, as in the onion.

Cone, the fruit of pines, etc., with ovule-bearing scales.

Connate, united, said of opposite leaves which appear as if grown together at their bases.

Cordate, heart-shaped.

Corm, a bulb-like, fleshy stem or base of a stem.
Crown, an inner appendage to a petal or to the throat of the corolla.

Deciduous, falling as petals do after blossoming, or as leaves of most trees except evergreens do.

Declined, directed obliquely.

Decumbent, reclining, but with the summit somewhat erect.

Dehiscent, splitting into definite parts.

Diffuse, spreading widely or loosely.

Disk, (1) an outgrowth of the receptacle within the calyx or within the corolla and stamens; (2) the central part of the head (all but the rays) in Compositce.

Dissected, deeply divided or cut into many segments.

Drupe, a stone-fruit such as a peach or a plum.

Equitant, leaves astride of those within them, thus appearing in a cross-section like the diagram, $<<$.

Even-pinnate,abruptly pinnate,i.e., with no leaflet at the end.

Fascicle, a close cluster or bundle of flowers, leaves, stems, or roots. 
Fertile, capable of producing fruit ; fertile flowers, those which have pistils.

Filiform, thread-shaped.

Fleshy, succulent, thick and full of sap.

Funiculus, the little stalk which connects a seed or ovule with the placenta.

Gland, (1) a structure which secretes something, as the knobs on the hairs of sundew ; (2) any knob or swelling.

Herbaceous, with no stem aboveground which lives through the winter, not woody or shrubby.

Indefinite, too many to be easily counted.

Indehiscent, not splitting open regularly.

Involucrate, provided with an involucre.

Keel, the two anterior and united petals of a papilionaceous corolla.

Key, a winged fruit like that of the ash or maple.

Limb, the border or spreading part of a gamopetalous calyx or corolla.

Lobed, having divisions, especially rounded ones.

Nerved, having simple or unbranched veins or slender ribs.

$\mathrm{Ob}$, in composition, signifies inversely, as obcordate, inversely heart-shaped.
Odd-pinnate, pinnate with a single leaflet at the end of the midrib.

Palate, a projection in the throat of a corolla.

Papilionaceous, butterfiy - shaped, like the corolla of the sweet pea. Papillose, cevered with papillæ or minute projections, like the human tongue.

Pappus, tufts of hair or other objects, representing the limb of the calyx in Compositce.

Perfoliate, with the stem apparently growing up through a leaf, as in some honeysuckles.

Persistent, not deciduous.

Pinnatifid, pinnately cleft.

Pistillate, having pistils but not stamens.

Pubescent, clothed with soft hair, downy.

Punctate, marked with dots, depressions, or translucent glands.

Radical, arising from the root or a very short stem at its summit, as the leaves of the dandelion.

Reflexed, bent or turned abruptly downward or backward.

Root-parasite, a plant parasitic on the roots of another.

Sagittate, arrow-shaped.

Scape, a leafless flower-stalk arising from the ground, as in the dandelion and cyclamen.

Scarious, thin, dry, and membranous, not green.

Sessile, without a stalk.

Simple (stem), unbranched. 
Spadix, a spike with a fleshy axis, like that of the Indian turnip or the "calla."

Spathe, a large bract which encloses a flower-cluster, often a spadix. Staminate, having stamens only. Standard, the posterior petal of a papilionaceous corolla.

Sterile, (1) barren, as a flower without a pistil or an antherless stamen; (2) staminate or male, said of flowers.

Striate, marked with fine longitudinal parallel lines.

Sub- (in composition), somewhat, as subglobose.

Subtend, to extend beneath, as a bract in the axil of which a flower is borne.

Succulent, fleshy or juicy.

Three-ranked, with three vertical rows on a stem or axis.
Throat, the top of the tubular part of a gamopetalous corolla. Truncate, appearing as if cut squarely off, as the leaves of the tulip-tree.

'Tubercled, covered with warty growths.

Tubercular, having tubercles, or like a tubercle.

Two-ranked, with three vertical rows on a stem or axis.

Utricle, a small bladdery ovarywall.

Versatile, turning freely on its support, as an anther on its filament.

Whorled, arranged in a circle around an axis, as the leaves of some lilies.

Wings, the side-petals of a papilionaceous flower. 



\section{N D E X}

Abies, 17.

Abutilon, 148.

Acanthaceæ, 210.

Acanthus Family, 210.

Acer, 141.

Aceraceæ, 140, 141.

Achillea, 231.

Aconitum, 80.

Acorus, 25.

Actæa, 79.

Adder's-tongue, 36 .

Adlumia, 92.

Esculus, 142.

Agrostemma, 73.

Aizoaceæ, 69.

Alder, 55, 139.

Alfalfa, 124.

Alisma, 21.

Alismaceæ, 21.

Alleghany Vine, 92.

Allium, 34.

Alnus, 54, 55 .

Alum Root, 103.

Alyssum, 98, 99.

Amaryllidaceæ, 42.

Amaryllis Family, 42.

Amelanchier, 110.

American Aspen, 47.

Amianthium, 32, 33.

Amorpha, 126.

Ampelopsis, 146.

Amsonia, 178, 179.

Anagallis, 174 .

Anarcardiaceæ, 137.
Andromeda, 168.

Anemone, 80, 81 .

Anemone, Rue, 82.

Anemonella, 82 .

Angiosperms, 20.

Anonaceæ, 88.

Anthemis, 231.

Antirrhinum, 203.

Apetalous Division, 6.

Aphyllon, 208.

A pocynaceæ, 178.

Apocynum, 179, 180.

Apple, 109.

Aquifoliaceæ, 138.

Aquilegia, 79 .

Arabis, 98.

Araceæ, 23.

Aralia, 157, 158.

Araliaceæ, 157.

Arbor Vitæ, 18.

Arbutus, Trailing, 169.

Aretostaphylos, 169.

Arisæma, 24, 25.

Aristolochia, 65.

Aristolochiaceæ, 64, 65 .

Arrowhead, 22.

Arrowwood, 216, 217.

Arum Family, 23.

Asarum, 65.

Asclepiadaceæ, 180, 181.

Asclepias, 181, 182.

Ash, 134, 175.

Ash, Mountain, 109.

Asimina, 88. 
Asparagus, 38.

Asp, Quaking, 47.

Aspen, American, 47.

Astragalus, 127, 128.

Atamasco Lily, 43.

Avens, 114, 115.

Babies' Toes, 134.

Bachelor's Button, 233.

Bald Cypress, 18.

Balsam, 143.

Balsam Family, 143.

Balsam Fir, 17.

Balsaminaceæ, 143.

Bamboo-vine, 42.

Baneberry, 79.

Baptisia, 122.

Barberry, 84.

Barberry Family, 84 .

Barren Strawberry, 113.

Basswood, 147.

Bastard Toad-flax, 64 .

Bayberry, 49.

Bayberry Family, 49.

Beaked Hazelnut, 53.

Bearberry, 169.

Bedstraw, 215.

Beech, 56.

Beech Family, 55.

Beggar's Lice, 190.

Begonia, 152, 153, 154.

Begoniaceæ, 152.

Begonia Family, 152.

Bell Flower, 223.

Bell Flower Family, 223.

Bellis, 228.

Bellwort, 33.

Benjamin, 41.

Berberidaceæ, 84 .

Berberis, 84, 85.

Berchemia, 144.
Betula, 53, 54.

Betulaceæ, 51 .

Bignonia, 206.

Bignoniaceæ, 206.

Bignonia Family, 206.

Bindweed, 184.

Birch, 53, 54.

Birch Family, 51 .

Bird's Pepper, 94.

Bishop's Cap, 103.

Bitter Cress, 97.

Bittersweet, 139, 199.

Black Alder, 139.

Blackberry, 112.

Black Gum, 164 .

Black Haw, 217.

Black Walnut, 50 .

Bladder-nut, 140.

Bladder-nut Family, 140.

Bladderwort, 209, 210.

Bladderwort Family, 209.

Bleeding Heart, 92.

Bloodroot, 90.

Blue Beech, 52.

Bluebell, 187.

Bluebells, 190.

Blueberry, 170.

Blue Cohosh, 85.

Blue Dandelion, 234.

Blue Devils, 191.

Blue Flag, 45.

Blue Sailors, 234.

Blue Thistle, 191.

Bluets, 213.

Blue Valerian, 187.

Blueweed, 191.

Borage Family, 188.

Borraginaceæ, 188.

Boston Ivy, 146.

Bouvardia, 214.

Box Elder, 141. 
Brassica, 95, 96.

Breeches Flower, 91.

Bridal Wreath, 108.

Brooklime, 204.

Broom-rape Family, 208.

Broussonetia, 62.

Brunella, 196.

Buck-bean, 178.

Buckeye, 142.

Buckeye Family, 142.

Buckthorn, 144.

Buckthorn Family, 143.

Buckwheat, 67 .

Buckwheat Family, 66 .

Buffalo Apple, 128.

Buffalo Pea, 128.

Bull Nut, 51.

Bull's-eye, 231.

Bulrush, 24.

Bunch-berry, 163.

Bur, Buffalo, 200.

Bur, Sand, 200.

Butter and Eggs, 203.

Buttercup, 83.

Buttercup Family, 77, 78 .

Butternut, 50.

Butterweed, 232.

Button Snakeroot, 159.

Buttonwood, 105.

Cactaceæ, 154.

Cactus Family, 154.

Calamus, 25.

Calico Bush, 168.

Callicarpa, 193.

Caltha, 78.

Calycanthaceæ, 87.

Calycanthus, $87,88$.

Calycanthus Family, 87 .

Calystegia, 183, 184.

Camassia, 36, 37.
Campanula, 223.

Campanulaceæ, 223.

Campanula Family, 223.

Cancer Root, 208.

Cannabis, 62.

Cantaloupe, 222.

Caper Family, 99.

Capparidaceæ, 99.

Caprifoliaceæ, 215.

Capsella, 98.

Caraway, 160.

Cardamine, 97.

Carnation, 75.

Carpenter-weed, 196.

Carpet-weed, 70.

Carpinus, 51, 52.

Carrion Flower, 41.

Carrot, 162.

Carum, 160.

Carya, 50, 51.

Caryophyllaceæ, 71, 72.

Castanea, 56.

Castilleia, 205.

Catalpa, 207.

Cat-brier, 42.

Catchfly, 74.

Catnip, 195.

Cat-tail, 20.

Cat-tail Family, 20.

Caulophyllum, 85.

Ceanothus, 144, 145.

Cedar, 18, 19.

Celandine, 90.

Celastraceæ, 139.

Celastrus, 139.

Celtis, 60 .

Centaurea, 233.

Cerastium, 72.

Cercis, 120.

Cereus, 155.

Chamælirium, 32. 
Charlock, 95, 96.

Cheeses, 148.

Chelidonium, 90.

Chenopodiaceæ, 68.

Chenopodium, 68, 69.

Cherry, 117.

Chestnut, 56.

Chickweed, 72.

Chickweed Wintergreen, 173.

Chicory, 234.

Chimaphila, 164, 165.

Chinese Sacred Lily, 43.

Chinquapin, 56.

Chinquapin, Water, 76.

Chionanthus, 176, 177.

Chocolate Root, 115.

Chokeberry, 109.

Chokecherry, 117.

Chokepear, 109.

Chrysanthemum, 231, 232.

Cichorium, 234.

Cinquefoil, 114.

Circæa, 157.

Cirsium, 233.

Citrullus, 222.

Citrus, 133.

Cladrastis, 121.

Claytonia, 70.

Clematis, 82.

Cleome, 100.

Clove Pink, 75.

Clover, 124, 125.

Cochlearia, 95.

Coffee Tree, 121.

Cohosh, 85.

Columbine, 79 .

Comandra, 64 .

Comfrey, 189.

Commelina, 27.

Commelinaceæ, 26.

Compositæ, 224-228.
Composite Family, 224-228.

Cone-flower, 230.

Coniferæ, 13.

Conopholis, 208.

Convallaria, 40.

Convolvulaceæ, 183.

Convolvulus, 184.

Convolvulus Family, 183.

Coptis, 79.

Coreopsis, 229, 230.

Cornaceæ, 162.

Corn Cockle, 73.

Cornel, 163.

Corn Gromwell, 191.

Corn Salad, 221.

Cornus, 162, 163.

Corydalis, 93.

Corylus, 52, 53.

Cotton wood, 48.

Cow Lily, 77.

Cow Parsnip, 162.

Cowslip, 78.

Crab Apple, 109.

Cranberry, 171.

Cranberry Tree, 216.

Cranesbill, 130.

Cratægus, 110, 111.

Creepers, 183.

Creeping Charley, 195.

Cress, 97.

Crinkle Root, 97.

Crocus, 45.

Cross-vine, 206.

Crowfoot, 83.

Crowfoot Family, 77, 78.

Crown Imperial, 35.

Crown of Thorns, 136.

Crow's Foot, 97.

Crow-victuals, 195.

Cruciferæ, 93, 94.

Cucumber, 222. 
Cucumis, 222.

Cucurbita, 222.

Cucurbitaceæ, 221.

Currant, 104.

Cuscuta, 183.

Cydouia, 108.

Cynoglossum, 189.

Cyperaceæ, 23.

Cypress, 18, 137.

Cypress Vine, 184.

Cypripedium, 46.

Cytisus, 123.

Daffodil, 43.

Daffy, 43.

Daisy, 228, 231.

Dakota Turnip, 126.

Dandelion, 236.

Datura, 200, 201.

Daucus, 162.

Dayflower, Virginia, 27.

Day-lily, 34.

Dead Nettle, 196.

Deerberry, 171.

Delphinium, 80.

Dentaria, 97.

Deptford Pink, 75.

Desmanthus, 119, 120.

Deutzia, 104.

Devil's Bit, 32.

Dewberry, 112.

Dianthera, 211.

Dianthus, 75 .

Dicentra, 91, 92.

Dicotyledonous Plants, 47.

Diervilla, 219, 220.

Diospyros, 174.

Dock, 66, 67 .

Dodecatheon, 171, 172.

Dogbane, 180.

Dogbane Family, 178.
Dogberry, 109.

Dog-brier, 42.

Dog-bur, 189.

Dog-fennel, 231.

Dog's-tooth Violet, 36.

Dogwood, 163.

Dogwood Family, 162.

Dogwood, Poison, 138.

Dragon Root, 25.

Dutchman's Breeches, 91.

Dutchman's Pipe, 65.

Dutchman's Pipe Family, 64, 65.

Ear Drops, 92.

Easter-flower, 43.

Ebenaceæ, 174.

Ebony Family, 174.

Echinocystis, 222.

Echinospermum, 189, 190.

Echium, 191.

Elder, 215, 216.

Elder, Wild, 157.

Elm, 60 .

Elm Family, 59.

Enchanter's Nightshade, 157.

English Ivy, 157.

English Walnut, 50.

Epigæa, 169.

Ericaceæ, 166, 167.

Erigenia, 159, 160.

Erigeron, 228, 229.

Eryngium, 158, 159.

Erythronium, 36.

Eschscholtzia, 90.

Euonymus, 139, 140.

Euphorbia, 136, 137.

Euphorbiaceæ, 135.

Eutoca, 188.

Evening Primrose Family, 156.

Eyebright, 213. 
Fagaceæ, 55 .

Fagus, 55, 56.

Fairycup, 103.

False.Buckwheat, 67.

False Dandelion, 236.

False Indigo, 126.

False Mitre-wort, 102.

False Spikenard, 38.

Farkleberry, 171.

Feverwort, 218.

Field Garlic, 34.

Figwort Family, 201, 202.

Fir, 17.

Fire Pink, 74 .

Flag, 45, 46.

Flax, 133.

Flax Family, 132 .

Fleabane, 229.

Fleur-de-lis, 45, 46.

Flowering Maple, 148.

Flowering Moss, 186.

Fly Poison, 33.

Forget-me-not, 190, 191.

Forsythia, 176.

Fragaria, 113.

Fraxinus, 175.

French Mulberry, 193.

Fringe Cap, 103.

Fringe Tree, 177.

Fritillaria, 35.

Fuchsia, 156.

Galium, 214, 215.

Garden Columbine, 79.

Garden Sage, 198.

Garget Root, 69.

Garlic, 34.

Gaylussacia, 169, 170.

Gentianaceæ, 177.

Gentian Family, 177.

Geraniaceæ, 129, 130.
Geranium, 130, 131.

Geranium Family, 129, 130.

Geum, 114, 115.

Gill-over-the-ground, 195.

Gillyflower, 99.

Ginseng Family, 157.

Gleditschia, 121.

Golden Alexanders, 161.

Golden Chain, 123.

Gold Thread, 79.

Gooseberry, 104.

Goosefoot, 69.

Goosefoot Family, 68.

Goose Grass, 214.

Gourd Family, 221.

Gramineæ, 23.

Grape, 145, 146.

Grape Family, 145.

Grass Family, 23.

Grass Pink, 75.

Gratiola, 204.

Grāveyard Moss, 137.

Green-brier, 42.

Green Dragon, 25.

Gromwell, Corn, 191.

Ground Ivy, 195.

Ground Pink, 186.

Ground Plum, 128.

Guinea-hen Flower, 35.

Gum, Black, 164.

Gymnocladus, 120, 121.

Gymnosperms, 13.

Gypsy Weed, 205.

Hackberry, 60.

Hackmatack, 18.

Harbinger of Spring, 160.

Hardhack, 108.

Harebell, 223.

Haw, 110, 111, 217.

Hazelnut, 52, 53. 
Heal-all, 196.

Heart's-ease, 151.

Heath Family, 166, 167.

Hedge Mustard, 95.

Helenium, 230.

Heliotrope, 189.

Heliotropium, 189.

Hellebore, White, 32.

Hemerocallis, 33, 34 .

Hemlock, 17.

Hemp, 62,

Hen-bit, 196.

Hepatica, 81.

Heracleum, 161, 162.

Herb Robert, 130.

Heuchera, 103.

Hickory, 51.

Hieracium, 235.

High-bush Cranberry, 216.

Hippocastanaceæ, 142.

Hobble-bush, 216.

Holly, 138, 139.

Holly Family, 138.

Honey Locust, 121.

Honeysuckle, 167, 218-220.

Honeysuckle Family, 215.

Hop Clover, 125.

Hop-tree, 134.

Horehound, 195.

Hornbeam, 52.

Horse-brier, 42.

Horse-chestnut, 142.

Horse-gentian, 218.

Horse Nettle, 199.

Horse-radish, 95.

Hound's-tongue, 189.

Houstonia, 213.

Hoya, 18 .

Huckleberry, 170, 171.

Hyacinth, 37.

Hyacinthus, 37 .
Hydrophyllaceæ, 187.

Hydrophyllum, 187, 188.

Hypericaceæ, 148.

Hypericum, 149.

Hypoxis, 43.

Ice Plant, 69.

Ice-plant Family, 69 .

กlex, 138, 139.

Impatiens, 143.

Indian Chief, 172.

Indian Cress Family, 132.

Indian Hemp, 180.

Indian Paint, 191.

Indian Pink, 205.

Indian Pipe, 166.

Indian Poke, 32.

Indian Turnip, 25.

Indigo, 122.

Indigo, False, 126.

Innocence, 213.

Ipomœa, 184, 185.

Iridaceæ, 45.

Iris, 45, 46.

Iris Family, 45.

Irish Potato, 200.

Iron Wood, 52.

Isopyrum, 78 .

Ivy, 138.

Jack-in-the-pulpit, 25.

Jacob's Ladder, 39, 187, 203.

Japanese Ivy, 146.

Jatropha, 137.

Jerusalem Oak, 69.

Jewel Weed, 143.

Jimson Weed, 201.

Johnny-jump-up, 151.

Jointed Charlock, 96.

Juglandaceæ, 49, 50.

Juglans, 50. 
Juncaceæ, 29.

Juneberry, 110.

Juniper, 19.

Juniperus, 19.

Kalmia, 168.

Kicking Colt, 143.

King Nut, 51.

Kinnikinnik, 163.

Knawel, 73.

Knot-grass, 67.

Krigia, 234.

Labiatæ, 193, 194.

Laburnum, 123.

Lactuca, 236, 237.

Ladies' Eardrop, 156.

Lady's-delight, 151.

Lady's-slipper, 46, 143.

Lady's Tresses, 46.

Lagenaria, 222.

Lamb Lettuce, 221.

Lamium, 196.

Larch, 18.

Larix, 17, 18.

Larkspur, 80.

Lathyrus, 129.

Lauraceæ, 88, 89.

Laurel, 168, 169.

Laurel Family, 88, 89.

Leather Flower, 82.

Leguminosæ, 117-119.

Lemon, 133.

Lentibulariaceæ, 209.

Leontodon, 235.

Leonurus, 196, 197.

Lepidium, 94.

Lettuce, 237.

Lever-wood, 52.

Ligulifloræ, 234.

Ligustrum, 177.
Lilac, 176.

Liliaceæ, 29.

Lilium, 35.

Lily, 34, 35.

Lily Family, 29.

Lily-of-the-valley, 40.

Lime, 133.

Linaceæ, 132.

Linaria, 202, 203.

Linden, 147.

Linden Family, 146, 147.

Lindera, 89.

Linnæa, 217, 218.

Linum, 132, 133.

Liriodendron, 87.

Lithospermum, 191.

Live Oak, 58.

Liver-berry, 39.

Liverleaf, 81.

Liverwort, 81.

Lobularia, 98, 99.

Locust, 121, 127.

London Pride, 74.

Lonicera, 218, 219.

Loosestrife, 173.

Loranthaceæ, 63.

Lotus, 76.

Lousewort, 206.

Lungwort, 190.

Lupinus, 123.

Lychnis, 74 .

Lycium, 199.

Lycopersicum, 200.

Lysimachia, 173.

Maclura, 61, 62.

Madder Family, 212, 213.

Magnolia, 86.

Magnoliaceæ, 85, 86.

Magnolia Family, 85, 86.

Maianthemum, 39. 
Mallow, 148.

Mallow Family, 147, 148.

Malva, 148.

Malvaceæ, 147, 148.

Maple, 141.

Maple Family, 140, 141.

Marguerite, 232.

Marigold, Marsh, 78.

Marrubium, 195.

Marsh Bell-flower, 22:3.

Marsh Marigold, 78.

Marsh 'Trefoil, 178.

Matrinony Vine, 199.

Matthiola, 99.

May-apple, 85.

Mayflower, 102, 169.

Mayweed, 231.

May Wings, 134.

Meadow Buttercup, 78 .

Meadow Garlic, 34.

Meadow Lily, 35.

Meadow Parsnip, 161.

Meadow Rue, 84.

Medicago, 124.

Medick, 124.

Melilotus, 124.

Melon, 221.

Menyanthes, 178.

Mercury, 138.

Mertensia, 190.

Mignonette, 100.

Mignonette Family, $10 \mathrm{~s}$.

Milkweed, 181, 182.

Milkweed Family, 180, is

Mint Family, 193, 194.

Mistletoe, 64 .

Mistletoe Family, 63.

Mitchella, 214.

Mitella, 102.

Mitre-wort, 102.

Mollugo, 70.
Monkshood, 80.

Monocotyledonous Plants, 20.

Monotropa, 166.

Moraceæ, 61.

Morning-glory, 184, 185.

Morning-glory Family, 183.

Morus, 61.

Moss Pink, 186.

Motherwort, 197.

Mountain Ash, 109.

Mountain Fringe, 92.

Mouse-ear Chickweed, 72.

Mulberry, 61, 62, 111.

Mulberry Faniily, 61.

Mulberry, French, 193.

Mulberry, Mexican, 193.

Mullein, Moth, 202.

Mullein Pink, 74.

Muskmelon, 222.

Mustard, 95, 96.

Mustard Family, 93, 94.

Myosotis, 190, 191.

Myrica, 49.

Myricaceæ, 49.

Narcissus, 43.

Nasturtium, 96, 132.

Nelumbo, 76.

Nepeta, 195.

Nerium, 180.

Nettle, 63.

Nettle Family, 62, 63.

New Jersey Tea, 145.

Nightshade, 199.

Nightshade Family, 198.

Ninebark, 107.

Noble Liverwort, 81.

None-so-pretty, 74.

Nonesuch, 124.

Nuphar, 76, 77.

Nutmeg Melon, 222. 
Nymphæa, 76.

Nymphæaceæ, 75.

Nyssa, 164.

Oak, 57, 58, 59 .

Oakesia, 33.

Obolaria, 177, 178.

Enothera, 156.

Enotheraceæ, 156.

Oleaceæ, 175.

Oleander, 180.

Olive Family, 175.

Onion, 34.

Opuntia, 154, 155.

Orange, 133.

Orange Grass, 149.

Orange, Osage, 62.

Orchidaceæ, 46.

Orchis Family, 46.

Ornithogalum, 37.

Orobanchaceæ, 208.

Osage Orange, 62.

Osmorrhiza, 160.

Ostrya, 52.

Oxalidaceæ, 131.

Oxalis, 131.

Pæonia, 78.

Pæony, 78.

Paint-brush, 205.

Painted Cup, 205.

Pansy, 151.

Papaver, 91.

Papaveraceæ, 89, 90.

Paper Mulberry, 62.

Pappoose Root, 85.

Parsley Family, 158.

Parsnip, 161.

Partridge Berry, 214.

Pasque Flower, 80.

Passiflora, 151, 152.
Passifloraceæ, 151.

Passion-flower, 151, 152.

Passion-flower Family, 151.

Pastinaca, 161.

Pawpaw, 88.

Pawpaw Family, 88.

Pea, 129.

Pea Family, 117-119.

Peach, 116.

Pear, 108.

Pecan, 50.

Pedicularis, 206.

Pelargonium, 130, 131.

Pennywort, 178.

Pentstemon, 203, 204.

Peony, 78.

Pepper-and-salt, 160.

Peppergrass, 94.

Pepper Root, 97.

Periwinkle, 179.

Persimmon, 174.

Petunia, 201.

Phacelia, 188.

Philadelphus, 103.

Phlox, 185, 186.

Phlox Family, 185.

Phoradendron, 63, 64.

Phyllocactus, 155.

Physocarpus, 107.

Phytolacca, 69.

Phytolaccaceæ, 69.

Picea, 16.

Pickerel Weed, 28, 29.

Pickerel-weed Family, 28.

Pignut, 51.

Pimpernel, 174.

Pine, 14, 15, 16.

Pine Family, 13.

Pine-sap, 166.

Pine-weed, 149.

Pink, 74, 75, 167. 
Pink Family, 71, 72.

Pinus, 14.

Pipe Vine, 65.

Pipsissewa, 165.

Pisum, 129.

Pitcher-plant Family, 101.

Plantaginaceæ, 211.

Plantago, 211, 212.

Plantain, 211, 212.

Plantain Family, 211.

Plantain, Water, 21.

Platanaceæ, 105.

Platanus, 105.

Plum, 116.

Podophyllum, 85.

Poet's Narcissus, 43.

Poison Ivy, 138.

Poison Vine, 138.

Pokeberry, 69.

Pokeberry Family, 69.

Poke, Indian, 32.

Pokeweed, 69.

Pokeweed Family, 69.

Polanisia, 99.

Polemoniaceæ, 185.

Polemonium, 186, 187.

Polygala, 134, 135.

Polygalaceæ, 134.

Polygala Family, 134.

Polygonaceæ, 66.

Polygonatum, 39, 40.

Polygonum, 67.

Pomme Blanche, 126.

Pontederia, 28.

Pontederiaceæ, 28.

Poor Man's Weather-glass, 174.

Poplar, 47.

Poplar, White, 87.

Poppy, 91.

Poppy Family, 89, 90.

Populus, 47, 48.
Portulaca, 71.

Portulacaceæ, 70.

Portulaca Family, 70.

Potato, 200.

Potentilla, 114.

Prairie Apple, 128.

Prairie Fire, 205.

Prickly Ash, 133.

Prickly Pear, 154.

Primrose, 172.

Primrose Family, 171.

Primula, 172.

Primulaceæ, 171.

Prince's Pine, 165.

Privet, 177.

Prunus, 116, 117.

Psoralea, 126.

Ptelea, 134.

Puccoon, 191.

Pudding-berry, 163.

Pulse Family, 117-119.

Purslane, 71.

Purslane Family, 70.

Pyrola, 165.

Pyrolaceæ, 164.

Pyrola Family, 164.

Pyrrhopappus, 236.

Pyrus, 108, 109.

Quaker Ladies, 213.

Quaking Asp, 47.

Quamoclit, 184.

Quercus, 56-59.

Quince, 108.

Radish, Wild, 96.

Ragweed, 232.

Ranunculaceæ, 77, 78.

Ranunculus, 82, 83.

Raphanus, 96.

Raspberry, 111, 112. 
Rattan-vine, 144.

Rattlebox, 74.

Rattlesnake Master, 159.

Rattlesnake Weed, 235.

Redbud, 120.

Red Cedar, 19.

Red Root, 145.

Reseda, 100.

Resedaceæ, 100.

Rhamnaceæ, 143.

Rhamnus, 144.

Rhododendron, 167.

Rhus, 137, 138.

Ribes, 104.

Ribgrass, 212.

Robinia, 127.

Robin-runaway, 195.

Robin's Plantain, 229.

Rocky Mountain Bee Plant, 100.

Rosa, 115, 116.

Rosaceæ, 105-107.

Rose, 115.

Rose Family, 105-107.

Rosemary, 168.

Rowan Tree, 109.

Rubiaceæ, 212, 213.

Rubus, 111-113.

Rudbeckia, 230.

Rue Anemone, 82.

Rue Family, 133.

Ruellia, 210.

Rumex, 66, 67.

Rush Family, 29.

Rutaceæ, 133.

Rutland Beauty, 183.

Sage, 198.

Sagittaria, 21, 22.

Salicaceæ, 47.

Salix, 48.

Salsify,
Salvia, 197, 198.

Sambucus, 215, 216.

Sandalwood Family, 64 .

Sand Bur, 200.

Sanguinaria, 90.

Sanicle, 159.

Sanicula, 159.

Santalaceæ, 64 .

Sarracenia, 101.

Sarraceniaceæ, 101.

Sarsaparilla, 157, 158.

Sassafras, 89.

Savin, 19.

Saxifraga, 102.

Saxifragaceæ, 101.

Saxifrage, 102.

Saxifrage Family, 101.

Schrankia, 120.

Scilla, 36 .

Scleranthus, 73.

Scrophulāriaceæ, 201, 202.

Scutellaria, 194, 195.

Sedge Family, 23.

Self-heal, 196.

Senecio, 232.

Sensitive Brier, 120.

Sensitive Rose, 120.

Service Berry, 110.

Shad Bush, 110.

Shame Vine, 120.

Sheep-lice, 189.

Sheep Sorrel, 66.

Shellbark, 51.

Shepherd's Purse, 98.

Sheriff Pink, 231.

Shin-leaf, 165.

Shooting Star, 172.

Shrub, 88.

Sickle Pod, 98.

Sicyos, 222.

Side-saddle Flower, 101. 
Silene, 73, 74 .

Sisy mbrium, 95.

Sisy rinchium, 46.

Skullcap, 194, 195.

Skunk Cabbage, 25.

Smilacere, 31.

Smilacina, 38.

Smilax, 41, 42.

Suakeroot, 135.

Snakeroot, Black, 159.

Snakeroot, Samson's, 126.

Snapdragon, 203.

Snappers, 74 .

Snapweed, 143.

Sneezeweed, 230.

Snowball, 216.

Snowberry, 217.

Solanaceæ, 198.

Solanum, 199, 200.

Solomon's Seal, 39, 40.

Sonchus, 237.

Sorrel, Sheep, 66.

Spanish Dagger, 38.

Spatter-dock, 77.

Spearwort, 83.

Specularia, 223, 224.

Speed well, 205.

Spice Bush, 88, 89.

Spiderwort, 27.

Spiderwort Family, 26.

Spikenard, False, 38.

Spinach, 68.

Spinacia, 68.

Spiranthes, 46.

Spirea, 107, 108.

Spring Beauty, 70, 81.

Spruce, 16, 17.

Spurge, 136, 137.

Spurge Family, 135.

Spurge Nettle, 137.

Squash, 222.
Squawroot, 41, 208.

Squaw Vine, 214.

Squill, 36.

Squirrel Corn, 92.

Stachys, 197.

Staff-tree Family, 139.

Stagger-bush, 168.

Staphylea, 140.

Staphyleaceæ, 140.

Star-flower, 173.

Star-grass, 43.

Star of Bethlehem, 37.

Steironema, 173.

Stellaria, 72.

Stick-tights, 189.

Stitchwort, 72.

St. Johnswort, 149.

St. Johnswort Family, 148.

Stock, 99.

Strawberry, 113.

Strawberry Buslı, 88, 140.

Straw Lilies, 33.

Streptopus, 39.

Sugar Pear, 110.

Sugar Plum, 110.

Sumach, 137, 138.

Sumach Family, 137.

Sundrops, 156.

Supple Jack, 144.

Sweet Alyssum, 99.

Sweet Bay, 86.

Sweetbrier, 116.

Sweet Cicely, 160.

Sweet Clover, 124.

Sweet Fern, 49.

Sweet Flag, 25.

Sweet Potato, 184.

Sweet-scented Shrub, 88.

Sweet William, 75.

Sycamore, 105.

Sycamore Family, 105. 
Symphoricarpus, 217.

Symplocarpus, 25.

Syringa, 103, 176.

Tamarack, 18.

Tangleberry, 170.

'Tansy Mustard, 95.

Taraxacum, 235, 236.

Tassel Tree, 148.

Taxodium, 18.

Tecoma, 207.

Thalictrum, 84.

Thaspium, 161.

Thistle, 233, 237.

Thorn, 110.

Thuya, 18, 19.

Thyme, 198.

Thymus, 198.

Tiarella, 102.

Tickseed, 229, 230.

Tilia, 147.

Tiliaceæ, 146, 147.

Tinker-weed, 218.

Tipsin, 126.

Toad-flax, 64 .

Toad-flax, Wild, 203.

Tomato, 200.

Tongue-grass, 94.

Toothache-tree, 133.

Toothwort, 97.

Tradescantia, 27.

Trailing Arbutus, 169.

Trefoil, Marsh, 178.

Trientalis, 172, 173.

Trifolium, 125.

Trillium, 40, 41.

Triosteum, 218.

Tropaeolaceæ, 132.

Tropæolum, 132.

Tropæolum Family, 132.

Trumpet Creeper, 207.
Trumpet Flower, 207.

Tsuga, 17.

Tubulifloræ, 227, 228.

Tulip, 36.

Tulipa, 36.

Tulip Tree, 87.

Tupelo, 164.

Turkey Pea, 160.

Twin-flower, 218.

Two-eye Berry, 214.

Typha, 20.

Typhaceæ, 20.

Ulmaceæ, 59 .

Ulmus, 59, 60 .

Umbelliferæ, 158.

Umbrella 'Tree, 86 .

Unicorn-root, 32.

Urtica, 63.

Urticaceæ, 62, 63.

Utricularia, 209, 210.

Uvularia, 33.

V-accinium, 170, 171.

Valerian, 220.

Valeriana, 220.

Valerianaceæ, 220.

Valerianella, 221.

Valerian Family, 220.

Veratrum, 32.

Verbascum, 202.

Verbena, 192, 193.

Verbenaceæ, 192.

Verbena Family, 192.

Veronica, 204, 205.

Vervain, 192.

Vetch, 128, 129.

Viburnum, 216, 217.

Vicia, 128.

Vinca, 179.

Vine Family, 145. 
Viola, 149, 150, 151.

Violaceæ, 149.

Violet, 150, 151.

Violet Family, 149.

Virginia Creeper, 146.

Virginia Dayflower, 27.

Vitacere, 145.

Vitis, 145, 146.

Wafer Ash, 134.

Wahoo, 140.

Wait-a-bit, 42.

Wake-robin, 40, 41.

Waldsteinia, 113.

Walnut, 50.

Walnut Family, 49, 50.

Wandering Jew, 28.

Water Chinquapin, 76.

Watercress, 96.

Waterleaf Family, 187.

Water-lily, 76.

Water-lily Family, 75 .

Water Plantain, 21.

Water-plantain Family, 21.

Water Willow, 211.

Waxberry, 49.

Wax Plant, 183.

Wax-work, 139.

Weigela, 220.

White Hellebore, 32 .

White Poplar, 87.

White Water-lily, 76.

Whiteweed, 231.

Whitewood, 87, 147.

Whitlavia, 188.

Wickakee, 205.
Wild Coffee, 218.

Wild Flax, 203.

Wild Ginger, 65.

Wild Hyacinth, 37, 92.

Wild Licorice, 215.

Wild Lily-of-the-valley, 39.

Wild Oats, 33.

Wild Pear, 110.

Wild Pink, 74.

Wild Potato Vine, 185.

Wild Raddish, 96.

Wild Sweet William, 186.

Willow, 48.

Willow Family, 47.

Wind-flower, 81.

Winterberry, 139.

Wintergreen, 165, 173.

Wistaria, 127.

Witch-hobble, 216.

Withe-rod, 217.

Woodbine, 146.

Wood-sorrel, 131.

Wood-sorrel Family, 131.

Yarrow, 231.

Yellow Flag, 46.

Yellow Pond Lily, 77.

Yellow Sweet Clover, 124.

Yellowwood, 121.

Yucca, 37, 38.

Xanthoxylum, 133.

Zebrina, 28.

Zephyranthes, 42, 43.

Zizia, 161. 


$$
\text { Let"ll } \quad 49464
$$




\section{.}





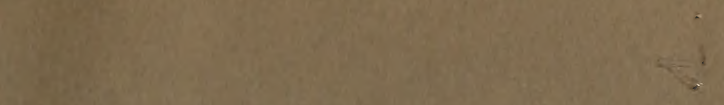

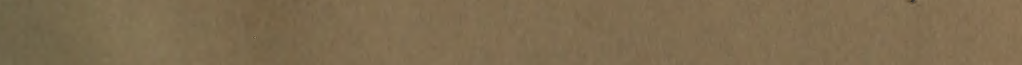
西

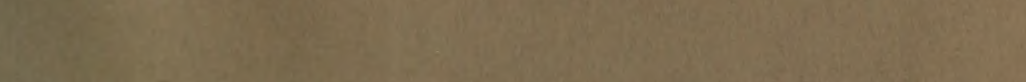

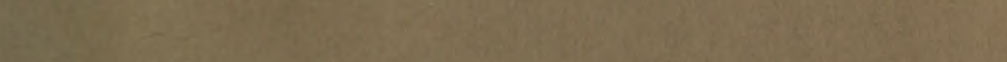

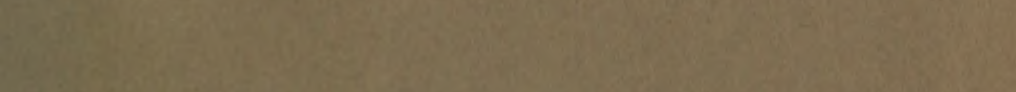

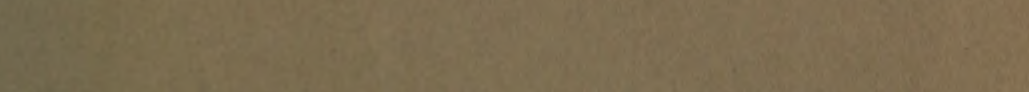
6.

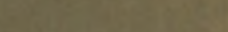

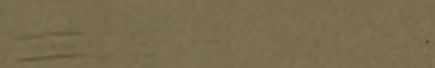

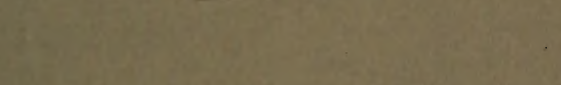

(6)

(4)

(e)

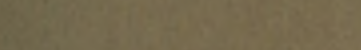

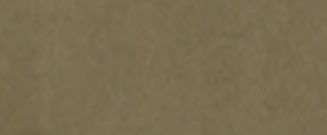

6.

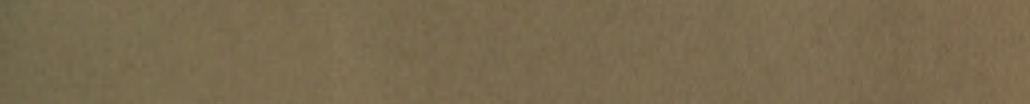

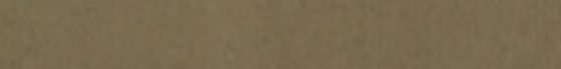
2.

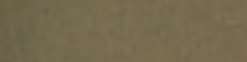

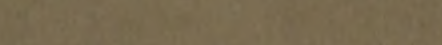
thing in 12

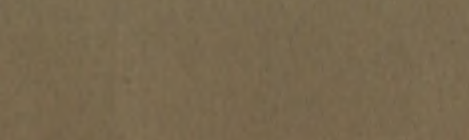





$$
\text { se }
$$


LIBRARY OF CONGRESS

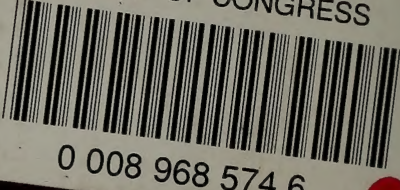

